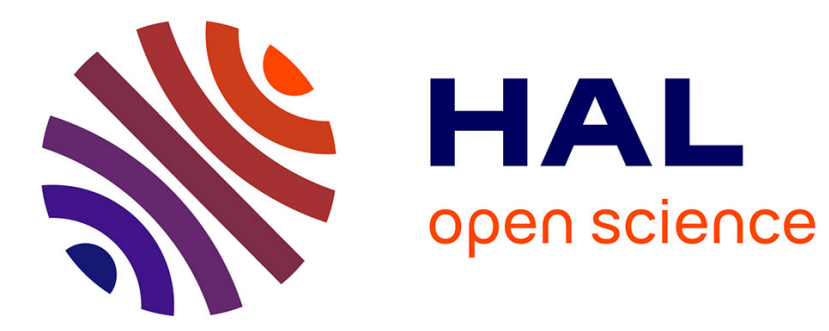

\title{
Les Bandits. Un historien au Mozambique, 1994
}

Michel Cahen

\section{To cite this version:}

Michel Cahen. Les Bandits. Un historien au Mozambique, 1994. 2002. halshs-02971098

\section{HAL Id: halshs-02971098 \\ https://shs.hal.science/halshs-02971098}

Preprint submitted on 19 Oct 2020

HAL is a multi-disciplinary open access archive for the deposit and dissemination of scientific research documents, whether they are published or not. The documents may come from teaching and research institutions in France or abroad, or from public or private research centers.
L'archive ouverte pluridisciplinaire HAL, est destinée au dépôt et à la diffusion de documents scientifiques de niveau recherche, publiés ou non, émanant des établissements d'enseignement et de recherche français ou étrangers, des laboratoires publics ou privés. 
Ce document est le manuscrit français de l'ouvrage de Michel Cahen Les Bandits. Un historien au Mozambique, 1994, Paris, Publications du Centre culturel Calouste Gulbenkian, juillet 2002, 354 p., ISBN : 972-8462-28-X, cartes, index des noms de personnes, de lieux, des dates et thématique.

Une version en portugais a également été publiée sous un titre différent : Os outros. Um historiador em Moçambique, 1994, Bâle (Suisse), P. Schlettwein Publishing Foundation, 2003, 230 p., cartes, 3 index, ISBN : 3-908193-13-3, traduction de Fátima Mendonça [la légère différence dans le titre vise à éviter qu'il ne soit pris au premier degré par un lectorat mozambicain pour qui l'appellation « bandits » reste passionnelle]. 


\section{Michel Cahen}

\section{Les Bandits \\ Un historien au Mozambique, 1994}

Manuscrit pour l'édition en langue française

CENTRE D'ETUDE D'AFRIQUE NOIRE

Institut d'études politiques de Bordeaux

Bordeaux, janvier 2002 


\title{
Introduction Le chercheur et les « Bandits »
}

\begin{abstract}
À l'automne 1994, dans le cadre du Groupement de recherche «Afrique australe » du Centre national de la recherche scientifique (France), je partis au Mozambique pour y étudier, du côté de la Renamo (Resistência nacional de Moçambique), la campagne électorale et la transformation de ce groupe guerrier en parti politique. De par l'Accord général de paix, signé à Rome le 4 octobre 1992 entre le gouvernement et les rebelles sous les auspices de la confrérie catholique de Santo Egidio, le Mozambique sortait d'une guerre d'agression sudafricaine - l'Afrique du Sud de l'apartheid -, devenue une terrible guerre civile qui, de 1977 à 1992, avait provoqué probablement un million de morts (sur environ quinze millions d'habitants), directement (massacres et dans une moindre mesure, combats) et indirectement (désorganisation presque complète de la société, incapable dès lors de résister aux sécheresses et aux crues).
\end{abstract}

Je m'y rendis en un séjour relativement court, du 19 septembre au 21 novembre, mais à un moment tout à fait privilégié pour l'observation: les premières élections libres et pluripartisanes de toute l'histoire du pays, coloniale et post-coloniale. Mon propre thème de recherche devait porter sur: «La Renamo, de l'armée sauvage au parti politique ? Une guérilla atypique dans la transition libérale au Mozambique ». Par «armée sauvage », j'entendais la formation progressive d'un corps social guerrier, d'une armée presque «professionnelle » parce que devenant elle-même société même si formée de va-nu-pieds, mais, à la différence des armées ordinaires, d'une armée sans État. Ce n'était pas un groupe de guérilla classique, son origine, au moins partiellement externe, ne faisait aucun doute, et elle n'avait pas vraiment de programme politique. Est-ce à dire qu'elle n'avait pas réussi à acquérir une base sociale interne au pays ? Est-ce à dire que, même de manière confuse, elle ne véhiculait pas certaines valeurs politiques ? Cela était un terrain d'étude complexe, mais surtout, passionnel.

N'oublions pas que nous autres, universitaires de gauche de la génération post-Mai 1968, plus ou moins formés ou acquis au(x) marxisme(s), étions très concernés par la lutte contre l'apartheid et la solidarité envers les pays agressés par la déstabilisation organisée depuis Prétoria. Il était très tentant de ne voir dans la Renamo que le bras régional des racistes blancs, ce qui permettait de maintenir une solidarité sans faille envers le Frelimo (Frente de libertação de Moçambique) qui avait pris le pouvoir en 1975 après onze ans de guérilla anticoloniale et était devenu, en 1977, un «parti marxiste-léniniste de l'alliance ouvrierspaysans ». Plus exactement, certains inversaient, sans même y penser, le raisonnement : des impératifs de solidarité envers le Mozambique (qu'ils confondaient avec l'État du Frelimo), ils déduisaient que la Renamo n'était que l'expression régionale de l'apartheid. C'est-à-dire que le devoir de connaissance, ce b-a-ba du chercheur ou de l'universitaire, était à l'avance refusé pour la Renamo : on la dénonçait, il ne s'agissait pas de faire de la recherche sur elle ou alors on faisait une recherche exclusivement pour prouver ses liens avec les services secrets racistes. La guerre secrète fut ainsi mieux connue que la guerre réelle.

\section{De la guerre d'agression...}

Mais il est parfaitement juste de rappeler que le Mozambique, en 1975, était encore frontalier de la Rhodésie (le Zimbabwe ne sera indépendant qu'en 1980) et de l'Afrique du Sud en plein apartheid. Les services secrets de ces pays soutenaient, face au parti « marxisteléniniste » mozambicain, un petit groupe militaire, qui avait commencé ses exactions dans le centre du pays à la fin 1976, en élargissant peu à peu les zones d'incidence. Le gouvernement « communiste », soutenu non seulement par les pays de l'Est mais pratiquement par toute la communauté internationale - en particulier le gouvernement anglais de Margaret Thatcher cherchait non seulement à riposter militairement et socialement (regroupant autoritairement les paysans dans des «villages communaux »), mais aussi à délégitimer complètement la guérilla. Les rebelles étaient systématiquement dénommés "os bandidos armados » (les « bandits armés ») et une prose macabre se développait afin de décrire par le menu, semaine après semaine, leurs massacres «apolitiques », leurs destructions d'écoles, d'infirmeries, 
leurs assassinats de femmes et d'enfants, ces pères obligés de réduire en bouillie le crâne de leurs bébés au pilon à farine, de ces enfants obligés de tuer leurs parents devant la communauté villageoise assemblée, et ne pouvant de ce fait plus jamais revenir chez eux, recrutés en toute sécurité. Cette prose se développait d'autant mieux que, non seulement les victimes étaient bien réelles et les atrocités parfois exactes, mais que la Renamo était appuyée par les courants politiques les plus réactionnaires et antidémocratiques (Rhodésie, Afrique du Sud, courants chrétiens d'extrême droite) ainsi que par la fort droitière démocratie-chrétienne bavaroise. Enfin, les correspondants de la presse internationale, supposés produire des analyses indépendantes, étaient en fait tous des sympathisants actifs du Frelimo - en particulier celui, communiste britannique, de l'Agence France Presse.

Mais le plus important était surtout que, face à une Renamo où un titulaire de la $4^{a}$ classe (le CM2 français) était un cadre supérieur, tous ces gens - nationaux ou étrangers producteurs de l'écrit relevaient de la sphère de l'État moderne : sympathisants du Frelimo ou vivant tout simplement dans son monde, ils ignoraient, parfois pathétiquement, la totalité de ce qui se passaient à vingt kilomètres en brousse. Les «bandits armés »n'avaient selon eux aucune base sociale, n'exprimaient que les intérêts régionaux de l'apartheid, leurs soldats étaient seulement des enfants enlevés. Bien sûr le régime avaient fait des « erreurs »- dont il dressait d'ailleurs lui-même la liste en recevant les donateurs de la communauté internationale - mais lui seul représentait la légitimité. Des enquêtes opportunes renforcèrent cette impression, comme le fameux Rapport Gersony commandité par le département d'État américain dans lequel les paysans avaient toujours vu les tueurs de la Renamo mais jamais les avions zimbabwéens bombardant les villages au napalm, ou encore ces études « universitaires » d'enquêteurs n'interrogeant que des repentis de la Renamo ou d'autres visitant le pays dans des voitures du gouvernement (voir note 9 , infra).

Mais à partir d'un certain moment, tout chercheur mu par le seul désir de comprendre, ne comprenait plus rien. Comment un groupe de mercenaires, ayant pour seule activité de tuer femmes et enfants, de dynamiter ponts et écoles, de piller les rares ressources, pouvait-il se développer au point d'être actif, autour de 1986, dans $80 \%$ du territoire du pays ? Comment comprendre l'incapacité complète de l'armée à réagir ? Pourquoi la paysannerie ne développait-elle pas elle-même des mouvements de contre-guérilla populaire ?

Et surtout, surtout - mais on ne le vit qu'en 1994 - comment comprendre que près de $40 \%$ des Mozambicains aient finalement voté pour les «bandits massacreurs » au cours d'élections libres étroitement organisées par l'Onu, y compris dans des zones toujours restées sous contrôle gouvernemental?

Il fallait tout reconsidérer, dans des conditions éthiques d'autant plus difficiles qu'effectivement il était hors de question de faire le jeu de l'apartheid.

\section{... à la guerre civile}

La première étape fut d'admettre qu'il s'agissait bien d'une guerre civile, c'est-à-dire de comprendre les ressorts qui avaient poussé certains segments de la société à l'accueil (parfois avec joie) d'une structure de guérilla venue de l'extérieur. En réalité, c'est tout le rapport à l'État moderne qu'il fallait analyser : comment certains corps sociaux, marginalisés depuis l'époque coloniale, l'étaient devenus encore plus sous le nouveau régime et à l'inverse comment les segments déjà les plus liés à l'appareil d'État colonial avaient bien rapidement monopolisé les rapports avec l'État indépendant. Comprendre comment la nouvelle administration, mue par un paradigme de modernisation autoritaire, parlant un langage incompréhensible (« À bas le féodalisme ! À bas le tribalisme !»), réprimant les religions et rites animistes, obligeant les paysans à se regrouper en villages communaux pour créer l'homme nouveau, pratiquant une politique des prix favorable aux villes, interdisant toute expression des ethnicités locales, humiliant les chefferies traditionnelles, fut rapidement ressentie comme d'essence étrangère, et d'autant plus agressive dans ses « diktats modernes » que n'apportant en échange aucun progrès social. Le tout, dans un contexte de parti unique où aucune structure n'existait pour corriger vraiment les erreurs ou se plaindre du comportement de satrape de tel ou tel administrateur local vous ayant volé votre femme ou vos biens, où des gens étaient envoyés parfois pour cette raison même en camp de rééducation, ou parfois sans motif connu et toujours sans procès. 
Aujourd'hui, certains anciens sympathisants analysent tout cela comme des «erreurs gauchistes », sans voir qu'il s'agissait d'une politique d'hostilité envers la population, sa culture, ses relations sociales organisées, une population supposée ressembler très vite à cette petite élite créole européanisée qui, depuis les quartiers du ciment de la capitale, là-bas, dans la «nation », dirigeait le pays. Quand le libéralisme économique s'implanta, vers 1985, les différenciations sociales s'accélérèrent et les « communistes » directeurs d'usine en devinrent bien souvent les patrons privés: le même groupe social de pouvoir restait en place, nourrissant ainsi la rébellion "anticommuniste». L'aide humanitaire des ONG, devant au minimum transiter par les zones gouvernementales quand elles ne leur étaient pas explicitement favorables, profitait avant tout à celles-ci et aggravaient ainsi les contrastes entre la sphère de l'État moderne et le reste. L'Afrique du Sud raciste ? Mais c'était le paradis, où chacun essayait d'émigrer clandestinement, c'était loin ! Les exactions de l'armée - souvent appelée «Renamo $\mathrm{n}^{\circ} 2$ » par la population - et les bombardements zimbabwéens étaient proches. En effet, dans une situation où, depuis des années, tout se réglait par la violence, où l'interdit social de tuer était depuis longtemps oublié, de plus en plus de gens constataient que l'on vivait mieux avec un kalachnikov que sans. Combien de villages en bordure de casernes, attaqués seulement la nuit par des «guérilleros » jamais poursuivis à l'aube et auteurs d'exactions d'autant plus sordides qu'ils étaient conscients de franchir tous les interdits? Il n'y eut cependant pas, ou très peu, de phénomènes de type «seigneurs de guerre », ou «grandes compagnies » pillant pour leur propre compte. Le régime tenta de le faire croire, présentant la Renamo comme une constellation de groupes de bandits locaux peu contrôlés par le commandement central. On sait aujourd'hui que c'était totalement faux, la rébellion étant extrêmement centralisée, y compris pour la moindre décision d'attaque d'une localité. L'espace pour l'existence de «seigneurs de guerre » était fortement limité par l'affrontement entre les deux blocs, prompts à éliminer ce qui les gênait vraiment, dans une société paysanne déjà épuisée, sans ressources céréalières disponibles et à l'inverse de l'Angola (ou de l'Algérie), sans richesses minérales (pétrole, diamants) qui auraient pu permettre aux deux camps de vivre sans aucun soutien populaire.

\section{Un corps social guerrier}

La deuxième étape fut de comprendre la nature de la Renamo. Son « origine indigne » ne souffrait guère de contestation, mais l'important était de saisir comment elle fonctionnait, s'étendait, se renforçait. On comprit qu'il s'agissait d'un authentique corps social guerrier qui, bien que créé par la Rhodésie, avait réussi à à devenir un acteur dans la profonde crise sociale mozambicaine provoquée par la politique de modernisation agressive des élites européanisées au pouvoir, et donc, d'une certaine manière, était parvenu à exprimer cette crise : en redonnant le pouvoir aux chefs traditionnels considérés comme légitimes par la population, en brûlant les villages communaux et en tuant leurs présidents (et familles...), en permettant à la population de rejoindre les terres d'habitat dispersé liées aux structures claniques et religieuses, en organisant des milices locales veillant à dénoncer toute incursion de l'État. Certains segments de la population crurent ainsi qu'ils pourraient utiliser la structure de guérilla pour se protéger de l'État, organiser leur autarcie et - désir réactionnaire au sens littéral - revenir à la situation ante, c'est-à-dire non seulement d'avant le Frelimo mais d'avant les Portugais, d'avant l'État moderne, ces temps que les Anciens avaient vécus et dont ils parlaient encore. La Renamo n'était ni un groupe mercenaire ni un parti politique, c'était un corps social guerrier désormais auto-reproduit par la guerre en cours ${ }^{1}$.

Troisième étape de la compréhension, on vit qu'il n'y avait pas contradiction entre affirmer qu'il s'agissait d'une guerre civile, et que le conflit était, militairement parlant, souvent ressenti comme une guerre privée entre Frelimo et Renamo. Car il ne s'agissait effectivement pas d'une rébellion paysanne spontanée, mais d'un accueil, dans un contexte particulier, d'une guérilla extérieure par certaines populations souhaitant se soustraire de la sphère de l'État moderne. De ce fait, la guerre prit non point un caractère ethnique, mais un aspect communautaire atroce : elle devint une guerre pour le contrôle des « deux populations » (celle

${ }^{1}$ Sur le corps social guerrier, voir Christian GEFFRAY, La cause des armes au Mozambique. Anthropologie d'une guerre civile, Paris, Karthala, 1990 ; et Michel CAHEN, Mozambique, analyse politique de conjoncture 1990, Paris, Indigo Publications, 1990. 
de l'État, celle de l'autarcie). Lutter contre l'État était synonyme de lutter contre ceux qui continuaient à vivre dans sa sphère : cette femme et ses enfants massacrés ne roulaient-ils pas, en voiture, sur la route nationale $n^{\circ} 1$ ? Ces familles paysannes qui n'avaient pas quitté le village communal n'étaient-ils pas des «éléments de l'ennemi »? Et ces soldats du Frelimo, prenant d'assaut une base de la Renamo (en général déjà évacuée par ses guérilleros) et y rencontrant des civils de sexe masculin, n'étaient-ils pas fondés à les tuer tous ? Non, les violences horribles que l'on décrit en Algérie ne sont en rien historiquement exceptionnelles : le Mozambique a connu les mêmes, et, plus généralement, elles se produisent quand se déchaînent des guerres contemporaines faites, suivant Ernst Bloch, par des «forces non contemporaines ».

\section{L'implosion postcoloniale}

Enfin, dernière étape, comprendre que cette guerre de guérilla ne constituait pas de vastes « zones libérées », comme l'avait fait celle du Frelimo en 1964-1974, mais seulement des poches, en «peau de léopard», avec des poches favorables à la guérilla éparpillées sur le territoire, pour des raisons tenant largement à l'histoire très locale des lignages, des élites de l'endroit, des trajectoires sub-ethniques. En effet, il ne s'agissait plus d'une guerre d'explosion anticoloniale, mais d'implosion et pulvérisation post-coloniale.

Au départ, il y avait sans doute les manipulations des experts des services rhodésiens, mais leur travail avait produit un «monstre » qui, au grand étonnement du chef desdits services proposant en 1979, à lui et à ses compagnons, de les mettre au vert à l'approche de l'indépendance du Zimbabwe, choisissait, de continuer la «lutte ». La «nouvelle Renamo» était bel et bien un produit du parti unique, de cet État agressivement modernisateur sans contrepartie de progrès social. Arrivé à ce stade de la réflexion, on comprenait alors que le combat n'était pas entre la civilisation et la sauvagerie, que l'issue ne pouvait être que politique, qu'il fallait rouvrir, et peu à peu rebâtir, le champ du politique : élections libres pour tous les partis, pluralisme, liberté associative et de la presse. Un abîme de haine et de méfiance séparaient les deux camps. Le camp gouvernemental découvrit cependant à Rome que les envoyés de la Renamo n'étaient pas des hordes sauvages. La rébellion comprit que sa survie ne pouvait être que politique et cela passait par des élections de légitimation ${ }^{2}$.

\section{Le chercheur dans l'histoire immédiate}

Tel était le cadre de mon étude. Elle devait néanmoins être «équilibrée » par des recherches de deux autres membres, mozambicains, de notre équipe du Groupement de recherche (GDR) «Afrique australe ». Luis de Brito, professeur à l'Université Mondlane, devait faire une recherche sur la genèse du pluralisme au Mozambique et notamment ses racines sociales. Mais, ayant été chargé de l'organisation de l'Institut de formation et de recherche en sciences sociales (UFICS) de l'Université Mondlane, il fut submergé par ses tâches pédagogiques et bureaucratiques et ne put se livrer à l'analyse approfondie qu'il aurait souhaitée. Rafael da Conceição, directeur au ministère mozambicain de la Culture, devait effectuer quant à lui une recherche sur l'évolution des rapports interethniques dans la province de Cabo Delgado dans le cadre des changements politiques : nettement minoritaire sur le plan numérique, l'ethnie maconde avait en effet acquis une importance disproportionnée à tous les échelons de pouvoir de la province en raison de son passé dans la lutte armée de libération et de son identification au parti unique au pouvoir. Cela avait produit une certaine « macondisation» de la province, mais aussi des ressentiments certains parmi les Macuas, les Muanes, et les Suaílis auxquels le tournant pluraliste permettait de s'exprimer plus ouvertement (même si la loi interdisait les partis ethniques). Mais Rafael da Conceição fut nommé à la direction de la Commission nationale électorale (au titre des indépendants), et se trouva dans l'impossibilité totale de mener à bien cette recherche.

Le problème que notre GDR eut avec ses deux membres correspondants mozambicains est très classique : les rares cadres formés à la recherche sont immédiatement aspirés vers des tâches administratives car si la recherche prépare le futur, l'État doit impérativement assurer l'immédiat.

\footnotetext{
${ }^{2}$ Ces paragraphes sont largement repris de mon article «Algérie, les leçons du Mozambique », in Politique africaine (Paris, Karthala), juin 1998, 70 : 129-137.
} 
La mission que j'effectuai se trouva donc, dans le cadre du projet du GDR, être la seule à aborder la transition politique, de surcroît sous l'angle particulier de l'étude de l'évolution de la Renamo. Ne risquais-je pas, dès lors, de développer une vision trop orientée, non point tant à cause de mes opinions personnelles, que de la place que j'occupais pendant l'observation? Ma culture historique et politique sur le Mozambique limitait le danger, mais il restait présent.

Heureusement, un autre membre français du GDR, Christine Messiant, chercheur du Centre d'études africaines de l'École des hautes études en sciences sociales, avait effectué une mission au Mozambique (juillet 1994) dans le cadre d'un autre projet de recherche ${ }^{3}$, qui put être complété par un bref séjour dans le cadre de l'observation internationale des élections (fin octobre 1994). Son travail portait sur le processus de démobilisation au Mozambique, côté Renamo comme côté gouvernemental. Sa mission, antérieure à la mienne, me fut extrêmement utile, sur le plan de l'analyse politique et pour les contacts qu'elle avait déjà établis auprès de l'Onumoz (Opération des nations unies au Mozambique). L'étude de la démobilisation côté Renamo m'était évidemment précieuse pour celle que je comptais mener sur la civilisation de la Renamo, de groupe guerrier en organisation civile.

Le processus de transition avait duré plus longtemps qu'initialement prévu par l'Accord général de paix de Rome (4 octobre 1992), les élections avaient été repoussées aux 27-28 octobre 1994. Ce retard eut des conséquences importantes sur la Renamo : au moment des élections, elle avait réellement perdu ses caractéristiques militaires et se présentait comme une organisation dont la structure était entièrement civile. C'est pourquoi mon étude ne pouvait plus porter spécifiquement sur la transformation d'une armée, mais déjà, d'une ex-guérilla, en parti. Mon point de départ était, on l'a vu, l'idée d' « armée sauvage », de corps social guerrier, de l'armée professionnelle sans État - alors que l'armée est en général le cœur même de l'appareil d'Etat, son essence en dernière analyse. Mon travail sur le terrain ne me permettrait plus de saisir directement cette réalité, dont Christine Messiant, trois mois auparavant, avait pu voir la décomposition rapide.

C'est pourquoi mon étude porta en pratique sur un moment privilégié de l'évolution de la Renamo, à savoir sa campagne électorale. Je complétai ce travail général à l'échelle du pays par une recherche de terrain dans l'estuaire du fleuve Save, qui me permit de poursuivre un travail d'archives mené antérieurement sur des événements de 1930 à 1965 et d'en comprendre la continuité politique avec la Renamo. Cette zone, bien que toujours restée sous l'administration de l'Etat et du Frelimo, allait en effet massivement voter Renamo - et jcela était prévisible.

Le moment politique de mon arrivée au Mozambique fut celui de l'achèvement de la démobilisation, avec la fin de la période intense d'incidents de type revendicatif des soldats des deux camps exigeant d'être démobilisés et de toucher les indemnités de l'Onu.

À ce moment, à l'exception de sa sécurité rapprochée, Afonso Dhlakama, le président de la Renamo, n'avait plus à sa disposition d'appareil militaire. Je demandai alors mon intégration à l'équipe de campagne. J'avais déjà rencontré l'ancien chef de guerre en juin 1992 à Paris, lors de ses premiers contacts, encore informels, avec le gouvernement français. Par ailleurs, Jorge Correia, l'un de ses conseillers, connaissait certains de mes travaux. Le contact, par l'intermédiaire d'Éric Lubin, proche collaborateur d'Aldo Ajello (envoyé spécial du Secrétaire général de l'Onu au Mozambique), put être rapidement pris.

\section{La position de vue et le point de vue}

Le premier problème méthodologique, déjà évoqué, était un problème classique en histoire immédiate, une histoire qui ne permet pas le recul : je ne pouvais pas, physiquement, suivre à la fois la campagne du Frelimo et de la Renamo et je risquais donc, du fait de cette position de vue partielle, de produire un point de vue partial.

Ce problème fut, de loin le plus sérieux, car le seul scientifique : il se trouva réellement un moment de la campagne où j'étais tellement impressionné par les capacités de mobilisation de

\footnotetext{
${ }^{3}$ Appel d'offre du département des Affaires stratégiques du ministère de la Défense (France), projet de recherche du Centre d'études et recherches internationales sur «Les démobilisations à l'issue des guerres civiles ». Ses travaux ont été publiés notamment dans Roland MARCHAL \& Christine MESSIANT, Les chemins de la paix et de la guerre : les fins de conflits en Afrique orientale et australe, Paris, Karthala, 1997, 254 p. (« Les Afriques ») [aborde l'Éthiopie, la Somalie, le Mozambique et l'Angola].
} 
la Renamo que j'émis l'hypothèse d'une possibilité de sa victoire. Contrairement à ce qu'en déduisit un journal portugais titrant: "Michel Cahen [...]: pourquoi Dhlakama peut gagner $»^{4}$, je n'ai jamais eu une position aussi tranchée. Mais ce qui était réellement nouveau pour moi à ce moment de la campagne (15-20 octobre) était que, venu de France avec la certitude que le Frelimo allait gagner, je ne savais plus si cette certitude était fondée. Donc, théoriquement, Dhlakama pouvait gagner. De là à l'affirmer en titre d'un article..., ce fut un pas que la rédaction du Público franchit - ce qui me valut l'étonnement de certains collègues portugais. En fait la situation était la suivante : la Renamo vivait de la construction d'une « coalition des marginalités $»^{5}$ et une des composantes de cette coalition pouvait être le vote massif de groupes ethniques longtemps marginalisés par l'État portugais, puis l'État du Frelimo. Les groupes sudistes étant acquis au Frelimo et ceux du Centre à la Renamo, l'issue du scrutin dépendait énormément de l'attitude du grand groupe macua-lómuè présent sur quatre provinces du Centre-Nord et du Nord. Or mon équipée dans ces régions m'avait persuadé de la grande importance d'une question ethnique dans le vote, c'est-à-dire que l'affirmation de l'identité ethnique macua serait un critère important du vote des habitants de ces régions. Mais je n'avais pas confondu question ethnique dans le vote et vote ethnique, de bloc. Ce qui finalement «perdit» la Renamo, lui assurant cependant une éclatante victoire de légitimation (près de $40 \%$ des voix à l'échelle nationale) fut qu'il n'y eut pas un vote ethnique homogène des Macuas : l'histoire locale de la guerre et les niveaux intra-ethniques clanique et lignager, pesèrent de tout leur poids. La majorité des Macuas votèrent Renamo en Zambézia et Nampula, mais Frelimo au Cabo Delgado et Niassa.

Vers le milieu de la campagne, du fait de ma position de vue, je fus donc amené à surestimer le vote ethnique, qui se manifesta en force dans le Sud - le Frelimo y bénéficia d'un écrasant réflexe identitaire ${ }^{6}$ - et le Centre, mais non point dans le Nord : c'est ce qui transparut dans le premier article publié, pendant ma mission, dans un hebdomadaire indépendant de Maputo, Savana ${ }^{7}$.

\section{Faut-il fréquenter Satan?}

Deuxième problème méthodologique: si la Renamo acceptait de m'intégrer comme observateur à son équipe électorale, c'est évidemment qu'elle y trouvait son intérêt. Sans surestimer l'importance de ma personne, mon passé et présent d'historien aux idées de gauche affirmées, mais toujours ouvertement hostile au parti unique et donc très critique envers le Frelimo, pouvait faire de moi une espèce de caution légitimante pour la Renamo : elle attirait ainsi non seulement d'anciens sympathisants issus de milieux les plus conservateurs (comme le Britannique David Hoile ${ }^{8}$ ), voire associés à l'ex-régime sud-africain d'apartheid, mais un « marxiste français ».

Ce deuxième problème me valut de grands désagréments sur le moment, mais cela est assez dérisoire. À Tete, mon ami portugais João Gomes Cravinho, observateur de la Communauté européenne, me demanda :

- Michel, cela ne te pose pas de problème de pousser tes positions logiques jusqu'à leurs conséquences illogiques?

4 «Michel Cahen, historiador e investigador: porque pode Dhlakama ganhar», Público, Lisbonne, 27 octobre 1994: 4, propos recueillis par Luis Pedro Nunes. Il ne s'agit pas de la transcription enregistrée d'une entrevue, mais d'un article reconstruit par L. P. Nunes. Le titre, bien sûr de la rédaction, inutilement provocateur, ne correspondait du reste pas au contenu de l'article du journaliste qui avait bien plus fidèlement reproduit la teneur de mes propos.

${ }^{5}$ Dès mon retour, je publiai un article développant cette idée : " "Dhlakama é maningue nice!" Une guérilla atypique dans la campagne électorale au Mozambique », L'Année africaine 1995, Bordeaux, CEAN /Paris, Karthala, mars $1995: 119-161$.

${ }^{6}$ Sur le vote ethnique en faveur du Frelimo, voir mon étude « Nationalisms and Ethnicities. Lessons from Mozambique », pp. 163-187 in Einar BRAATHEN, Morten BøÅs \& Gjermund SÆTHER, Ethnicity Kills ? The Politics of War, Peace and Ethnicity in Subsaharian Africa, Londres, Macmillan / New York, St.Martin's Press, 223 p., bibl., index, ISBN : 0-333-77381-0 et 0-312-22988-7.

7 «Renamo, o grande partido conservador-populista », Savana, Maputo, 4 novembre 1994 : 7.

${ }^{8}$ David Hoile, activiste du lobby britannique pro-Renamo avait à plusieurs reprises utilisé mes critiques du Frelimo dans ses arguments pro-Renamo. 
$-\ldots ?$

- ... par hostilité au Frelimo, d'avoir accepté d'être un conseiller rémunéré d'Afonso Dhlakama?»

Dans le milieu des journalistes occidentaux sympathisants du Frelimo à Maputo, on lui avait dit cela et il l'avait sincèrement cru. Le bruit a continué à courir et court encore peutêtre. Faut-il répondre à ce genre de rumeur? Non, mais il n'en reste pas moins qu'il décrédibilise l'analyse de celui qui en est la victime.

Mais sur le fond, on en revenait à la situation de l'historiographie mozambicaine contemporaine : en effet, cette guerre a durant très longtemps vu sa caractéristique de guerre civile niée par de nombreux analystes. Ce devait être seulement une guerre d'agression sudafricaine, il fallait enquêter seulement sur le soutien sud-africain (bien réel au demeurant). Quant aux massacres (bien réels eux aussi), ils furent systématiquement mis sur le compte de la Renamo, sans le minimum de méthodologie critique 9 .

Durant les quinze années qu'a duré la guerre, aucun intellectuel indépendant ne se rendit en zone Renamo. Moi-même, je ne l'ai pas fait. Jusque vers 1990, je n'y étais pas prêt moralement («aller voir les alliés de l'apartheid»). Je commençai néanmoins à établir des relations de travail, et donc des relations cordiales, avec la Renamo à Lisbonne et Londres. Mais mon premier contact direct avec le Président de la Renamo fut seulement à Paris en juin 1992, peu de mois avant le cessez-le-feu.

Il est du reste significatif que ce qui provoqua la colère d'un Paul Fauvet - très représentatif des milieux occidentaux sympathisants du Frelimo - à mon égard ne fut pas tant l'exposé dans la presse mozambicaine de mon analyse de la Renamo comme «parti conservateur-populiste »-qualificatif qui aurait dû suffire à montrer que je n'avais pas de sympathie politique pour ce mouvement-, mais le simple fait que je sois allé en zones Renamo et aie accompagné ses équipes ${ }^{10}$. Le contact direct avec Satan restait condamné, il ne devait être étudié que de l'extérieur.

Tout cela paraît bien anodin. Mais au-delà de mon cas personnel, on aurait tort de sousestimer ce que fut vraiment, des années durant, le contexte moral de la recherche sur la guerre civile mozambicaine ${ }^{11}$.

\section{La campagne}

Quelles ont été les conditions concrètes de l'enquête ? Je fus intégré à l'équipe de campagne du Président de la Renamo, en pratique : les démineurs et gardes du corps, quelques responsables politiques nationaux, des responsables régionaux aux différentes étapes, quelques généraux ayant maintenant des tâches politiques, et des journalistes de la Renamo, ainsi que des journalistes de la presse, de la radio et de la TV mozambicaine (seule l'équipe de télévision étant présente en permanence). À signaler qu'aucun correspondant de presse étrangère ne resta durablement avec cette équipe, certains (souvent correspondants mozambicains de médias étrangers, surtout portugais) apparaissant dans les grandes villes et

\footnotetext{
${ }^{9}$ Le summum fut atteint par le "rapport Gersony" commandité par le Département d’État américain. Ce rapport était nul du simple point de vue de l'usage mathématique des quotas (comptabilisant plusieurs fois les mêmes personnes !) et sans la moindre méthodologie critique : il était fondé sur des entrevues de paysans mozambicains réfugiés dans des camps des institutions internationales (relevant donc, pour la population, de l'État moderne), interrogés sous double traduction (langue bantoue/portugais/anglais). L'enquêteur ne se rendit même pas compte d'invraisemblances majeures : ainsi, alors que les personnes interrogées affirmaient avoir toujours bien reconnu l'auteur des attaques et des massacres, aucun n'avait vu de Zimbabwéens ; ainsi l'enquêteur ne s'aperçut pas que la grande vague de réfugiés au Malawi n'était pas consécutive à l'offensive de la Renamo en Zambézia en 1986, mais à la contre-offensive de l'armée du Frelimo et des Zimbabwéens en 1987-88... Un autre rapport du même genre, celui de l'universitaire américain William Minter, fut exclusivement fondé sur des entrevues d'ex-membres de la Renamo en prison sous surveillance du Snasp (police politique) ou « amnistiés »... Ces deux rapports restent cependant, inexplicablement, encore souvent cités par de nombreux analystes.

${ }^{10}$ Voir la note 9 du chapitre « Retour à la nation ».

${ }^{11}$ Avant même cette mission, je m'en étais expliqué dans mon article: «Le contexte politico-documentaire de la recherche en histoire contemporaine et immédiate sur l'Afrique lusophone », Cahiers d'histoire immédiate, Toulouse, 6, automne $1994: 65-100$.
} 
s'en retournant. Je fus donc le seul observateur indépendant étranger à suivre la totalité de la campagne du côté de la Renamo - ce qui ne manqua pas de m'étonner.

Il s'agit donc classiquement d'une vie commune de plusieurs semaines, qui provoque la camaraderie propice, par exemple, à l'établissement d'histoires de vie, à des conversations politiques approfondies, etc.

Je dois cependant signaler des limites : certaines entrevues furent très décevantes (comme celle avec le général Frank qui me tint un discours en bois massif : "La guérilla est appuyée par le peuple, donc elle est invincible, etc.»), d'autres n'eurent pas lieu parce que nous n'avons pas trouvé le temps, problème qui peut aussi être une forme d'esquive (général Issufo Momade, colonel Bute). D'une manière générale, après plusieurs jours de camaraderie, l'accueil fut tout à fait fécond. Le temps manqua aussi pour que je puisse aller à Maringué (l'ex-quartier général de la Renamo), qui n'avait plus d'importance politique à ce moment mais où demeuraient encore des archives.

En revanche, je pus ainsi visiter environ soixante-dix localités de Zambézia, Nampula, Cabo Delgado, Niassa, Tete, Manica et Sofala ${ }^{12}$, en d'incessants trajets d'hélicoptères prévus pour quinze personnes et où nous entrions jusqu'à trente-deux, sans compter les animaux offerts, les armes, les hauts-parleurs, etc. (trajets complétés d'étapes en voitures ou à pieds). Cela permit non seulement l'observation minutieuse de nombreux mitins (nombre de participants, structure de la réunion, place des hiérarchies locales, type de réponses des gens aux vivas, réceptivité aux thèmes ethniques, maintien ou non de l'assistance jusqu'à la fin, nuances dans le discours de Dhlakama, etc.), mais aussi d'un nombre important de minienquêtes auprès des directions locales de la Renamo.

En effet, nous - c'est-à-dire l'équipe de protection et les journalistes - arrivions toujours quelques heures avant Afonso Dhlakama sur le lieu de la réunion : les démineurs et gardes du corps devaient assurer la sécurité du site. Cela me laissait le temps d'enquêtes certes courtes, mais qui, répétées des dizaines de fois, acquirent à mon avis un fondement assez solide. C'est ainsi que je me rendis compte de l'existence, bien plus importante que je le soupçonnais, de l'ancienne composante civile de la Renamo du temps de la lutte (les administrateurs, les infirmiers et instituteurs, les agents de renseignement civil) qui surgissait maintenant comme colonne vertébrale de la construction du parti civil, qui agglutinait autour d'elle les deux autres composantes civiles, à savoir les clandestins des villes et les nouvelles recrues. Sur ce point, je me heurtai et me heurte encore à un certain scepticisme d'autres observateurs mettant en doute l'importance numérique et la prégnance politique de ces civils. On peut toujours discuter du caractère politique de certains militants (quelques-uns vinrent à la Renamo comme on trouve un travail), mais pour d'autres, des centaines, l'engagement civil, pour des raisons fort claires, en faveur de la Renamo, parfois depuis 1977, ne faisait aucun doute. Il faut signaler qu'un observateur privilégié comme Eric Lubin, qui eut à «traiter » la Renamo pour le compte de l'Onumoz pendant trois ans, partagea tout à fait cette analyse.

Corollaire de la civilisation de la Renamo, je constatai la disparition des militaires, y compris de simples soldats, de toutes les directions locales du parti. Mais il faut signaler que les soldats que je pus interroger (y compris des gardes du corps) n'avaient aucun problème avec leur « rapt ». Non seulement ils ne le cachaient pas, mais ils en parlaient sans même qu'on le leur demandât, comme d'un acte social certes pénible mais parfaitement normal : «la Renamo est arrivée, ils sont restés quelques jours, ils ont parlé dans le village aux jeunes et ils m'ont emmené », ou, plus violent et plus triste : «Je n'ai pas pu dire au revoir à mes parents, j'ai été emmené, maintenant je suis entre leurs mains », etc. Le rapt en temps de guerre est vu par les intéressés comme un acte absolument ordinaire : le chef est aussi celui qui recrute. Cet aspect socialement acceptable du rapt, venu de la tradition des captifs, explique en grande partie le fait que les désertions aient été si peu nombreuses - la dureté de la discipline et de la répression ne peut expliquer cette rareté des fuites. Côté Frelimo, le scénario fut le même, souvent plus urbain (rafles des miliciens à la sortie des écoles, etc.). Mais le rapt ne doit pas mener à sous-estimer les engagements parfaitement volontaires et très clairement motivés, dont je recueillis de nombreux témoignages.

Autant le dire : j'estimai à mon retour avoir fait une mission d'une exceptionnelle richesse, en tant qu'observateur privilégié - le seul observateur indépendant à suivre la campagne de Dhlakama-, mais j'avais paradoxalement le sentiment que la Renamo demeurait-et

\footnotetext{
${ }^{12}$ Le Sud fut totalement sacrifié par Dhlakama (voir infra et l'article in L'Afrique politique, op. cit.).
} 
demeure - essentiellement une... inconnue. Il faudra des années, et gagner la confiance de dizaines de cadres pour que les entrevues parviennent au niveau nécessaire d'intimité, de détails, de comportement, pour permettre de comprendre le corps social guerrier et la coalition des marginalités.

Cette enquête sera d'autant plus difficile qu'à l'exception du petit noyau dirigeant qui est resté stable, la nouvelle situation de paix et de parlementarisme disperse les anciens acteurs de la guerre. Et naturellement, ni le Frelimo ni la Renamo ne seront favorables à une politique systématique de recherche historique sur le conflit. Sous couvert de réconciliation, l'heure sera à l'amnésie-amnistie pour le plus grand soulagement des chefs de guerre des deux camps.

\section{Mambone et Machanga}

Conformément à mon projet de recherche, je voulus compléter l'enquête nationale par une étude de terrain dans une zone de vieille implantation Renamo.

J'avais le choix entre deux types bien différents de région: soit une ancienne «zone libérée » de la Renamo, où le contrôle militaire des rebelles avait été permanent ou quasipermanent pendant une dizaine d'années ; soit une zone qui n'avait jamais été sous contrôle militaire de la Renamo, mais où, avant même le scrutin, j'avais senti (au cours de l'enquête nationale) que la Renamo obtiendrait un score écrasant.

C'est ce deuxième type de région que je choisis, pour deux raisons : premièrement je désirais pouvoir analyser une implantation de type uniquement politique de la Renamo, sortant donc du cliché de l'imposition militaire et de l'électorat captif ; deuxièmement j'avais déjà fait un travail de recherche historique et d'archives sur une de ces régions aujourd'hui politiquement favorables à la Renamo, sur des événements des années trente aux années soixante ${ }^{13}$.

J'ai donc choisi d'enquêter dans la zone de l'estuaire du Save, région de contact entre les ethnies ndau (du groupe chona) et tsua (l'un des grands groupes du Sud, très proches des Changanes et Ronga). Plus précisément dans les villages de Mambone (province de Sofala) et de la Machanga (province d'Inhambane), de part et d'autre du fleuve.

Cette région avait connu un proto-nationalisme précoce lié, d'une part aux effets de l'émigration massive vers l'Afrique du Sud et la Rhodésie et de ses retours nourrissant d'autres horizons, et, d'autre part, à une intense activité religieuse, surtout congrégationnaliste américaine, mais aussi baptiste, presbytérienne, méthodiste et catholique (italienne) - sans parler des plus récentes et nombreuses petites Églises éthiopiennes et zionistes. Ce fut de 1939 à 1953 la zone d'influence du Núcleo Negrófilo de Manica e Sofala (Noyau négrophile du Manica e Sofala), organisation si prégnante que certains de mes interlocuteurs de 1994 la qualifiaient encore à ce moment de «governo » (gouvernement), dont la direction était formée par des assimilados ${ }^{14}$ issu du groupe ethnique ndau de Beira, avec des adhérents dans cette ville et dans de nombreuses localités de Búzi, Mambone, Machanga..., ainsi qu'en Afrique du Sud et à Salisbury. Cette organisation prit une part active à la lutte contre les mauvais traitements et contre les détournements des secours de l'État lors du cyclône de 1953, et fut finalement interdite en 1956. Le souvenir en resta si vif que tous mes interlocuteurs, comprenant parfaitement l'enjeu de l'enquête historique, me dirent: "La révolte n'a pas commencé à Mueda, en 1960, mais ici, en 1953 », manière de remettre en cause le mythe fondateur du nationalisme du Frelimo qui fait de l'émeute de Mueda, au Cabo Delgado, et de sa répression, la justification première de la lutte armée.

\footnotetext{
${ }^{13}$ Le rapport provisoire de cette recherche a été présenté lors de la Deuxième rencontre internationale de spécialistes en sciences sociales sur l'Afrique lusophone, Bissau, 1991: Les "mutineries" de la Machanga et de Mambone (1953) : conflits sociaux, activisme associatif et tension religieuse dans la partie orientale de la "zone vandau", Bordeaux, CEAN, janvier 1991, 55 p.multigr. Cette version préliminaire devra être fortement remaniée sur la base de nombreux éléments nouveaux recueillis tant au Mozambique en 1994 qu'ultérieurement aux Archives nationales de la Torre do Tombo et aux Archives historiques diplomatiques du ministère des Affaires étrangères (Lisbonne).

${ }^{14}$ Assimilados : les «assimilés » étaient les Noirs qui, à l'inverse des indígenas («indigènes »), avaient réussi à obtenir la citoyenneté portugaise et, plus ou moins, le statut social correspondant.
} 
Protonationalisme précoce, mais pour cela même précocement réprimé, avec des conséquences considérables pour la suite : l'élite nationaliste en formation dans le Sofala dès la fin des années trente fut dispersée, au milieu des années cinquante, précisément au moment où se cristallisaient les noyaux qui formeront ensuite le Frelimo. Les cadres issus du Centre furent ainsi peu nombreux à s'intégrer au Frelimo et, s'y sentant mal à l'aise en ressortirent souvent ou furent expulsés, voire violemment réprimés.

Mon enquête porta ainsi de façon indissociable tant sur le passé historique que sur la situation présente, les mêmes entrevues portant souvent sur cinquante années d'histoire! En effet, à une importante exception près, la totalité des anciens cadres du Núcleo que je retrouvai (et que j'avais repérés auparavant dans mon travail d'archives) étaient maintenant sympathisants, militants ou dirigeants locaux de la Renamo. La Renamo remporta une écrasante victoire électorale dans cette région toujours restée sous administration de l'État. Mes interlocuteurs l'exprimaient très simplement : «La Renamo et le Núcleo, c'est la même politique. Le Frelimo a seulement accompagné l'Associação Africana » - faisant référence à l'organisation des métis et des quelques Noirs assimilados de Maputo.

De façon frappante, c'est évidemment le fait identitaire qui s'exprimait ici dans sa continuité : d'aucuns diront ethnique - et je n'y vois aucun inconvénient si l'on ne donne pas à ce mot un sens péjoratif. Le Frelimo y fut très vite ressenti comme un corps étranger, d'autant plus que, de 1975 à aujourd'hui, la totalité ou la très grande majorité des membres de l'administration locale étaient originaires du Sud (surtout des Vatsua). Privilèges nomenklaturistes et ressentiments ethniques s'accumulèrent classiquement.

À la Machanga et à Mambone, je vis tous les responsables locaux de la Renamo (dont certains militants clandestins depuis 1977); le seul (et très important) acteur de l'époque protonationaliste à être resté fidèle au Frelimo; le missionnaire catholique (présent depuis quarante ans...) ; des responsables locaux de l'Église congrégationaliste américaine ; et de nombreux anciens membres du Núcleo ainsi qu'un ancien cipaye de l'administration coloniale (fervent partisan de la Renamo...). Je pus étudier les résultats électoraux bureau par bureau et constater le brutal changement de majorité quand on passe d'une terre mandau à une terre matsua. J'ai presque toujours pu parler en portugais. Une seule fois, j'ai dû recourir à un traducteur: la grande majorité des anciens du Núcleo et des actuels responsables de la Renamo sont des gens qui ont été réellement scolarisés dans les missions.

L'exemple de la Machanga et de Mambone illustre la nécessité de l'histoire locale pour comprendre la guerre civile : on ne peut saisir les raisons pour lesquelles une population a exprimé une sympathie massive envers la Renamo ou, à l'inverse, est demeurée fidèle à l'État du Frelimo, uniquement par l'analyse des politiques. L'histoire des trajectoires locales, des phénomènes identitaires (non seulement ethniques mais aussi régionaux, religieux, migratoires) est fondamentale.

\section{Carnets de route d'un historien}

Ce qui va suivre est la transcription des notes de mes carnets de route. Il ne s'agit donc pas d'écrits achevés de recherche. Par ailleurs, je ne savais pas trop ce qui m'attendait et n'avais pas pensé, au départ, écrire en vue de publication «non scientifique ». Cela vint peu à peu, au jour le jour, d'où plus de détails ou de réflexions au fur et à mesure que l'on avance dans les «carnets". Mais s'il ne s'agit en aucun cas d'articles de recherche - ceux-là ont déjà été signalés ${ }^{15}-$, il y a des détails, des impressions, des réflexions momentanées, que l'on ne pourra jamais intégrer à un article «scientifique » et qui ont pourtant leur intérêt du point de vue des sciences sociales.

Je n'enregistre presque jamais mes entrevues : mes seules armes sont un crayon et de petits carnets (qui n'attirent pas la convoitise des voleurs). Je prends des notes très rapidement pendant que l'interlocuteur parle, lequel, voyant mon effort, ralentit son rythme, réfléchit mieux à ce qu'il va dire, classe ses propos. Mais cela ne nuit pas à sa spontanéité, au

\footnotetext{
${ }^{15}$ Outre les articles déjà cités en rapport avec cette mission, j'ai également publié un peu plus tard, une étude sur le discours politique de la Renamo: «Entrons dans la nation. Notes pour une étude du discours politique de la marginalité. Le cas de la Renamo du Mozambique », Politique africaine (Paris, Karthala), octobre $1997,67: 70-88$.
} 
contraire : il sait que je suis le seul responsable de ce que j'écris, puisqu'il n'y a pas de «preuve » enregistrée. Je pose très peu de questions, mais j'ai, en général, la culture historique suffisante pour, de temps à autres, faire la petite remarque pertinente qui rappelle à mon interlocuteur un fait, une situation, etc., et lui permet de repartir ou de réfléchir lui-même à son expérience. En général, mes questions ne sont pas reproduites ici, pour la simple raison que je ne les ai pas moi-même notées.

La plupart des notes d'entretien ont été prises directement en portugais, et j'ai respecté le plus possible la manière mozambicaine et populaire de parler portugais ${ }^{16}$. De même, de mes notes en français, j'ai reproduit sans pratiquement aucun changement le contenu, à d'infimes corrections près, alors de stricte grammaire. Quand un ajout a été indispensable, il apparaît clairement entre crochet et en italiques (les ajouts entre crochets en caractères romains sont des indications portées par moi-même sur mes carnets au cours d'entretiens). En revanche, un assez important appareil de notes de bas de page a été ajouté : elles sont donc toutes postérieures ${ }^{17}$.

Ces carnets datent de 1994. Seule la surcharge de travail à l'Institut d'études politiques de Bordeaux et à la revue Lusotopie m'a empêché de mener à bien le projet de les transcrire (je n'avais pas d'ordinateur portable !), ce qui explique qu'ils paraissent seulement à présent. Mais, au moment où le Mozambique vit ses deuxièmes élections générales, et où la démocratie devrait donc entrer dans la banalité, il n'est pas sans intérêt de revenir à celles, historiques, de 1994.

Il n'est pas inutile non plus que paraisse un livre, non point en faveur de la Renamo, mais sur la Renamo, et plus encore sur le monde de la Renamo et de ses marginalités. En effet, même si le pluralisme semble, malgré les soubresauts, durablement implanté au Mozambique, on ne peut que constater, dans la sphère de l'écrit, le maintien d'un écrasant déséquilibre éditorial. De 1990 (constitution pluraliste) ou même 1992 (cessez-le-feu, légalisation de la Renamo) à nos jours, aucun livre n'a été publié par la Renamo, sur la Renamo, sur le monde de la Renamo, aucune œuvre littéraire ou poétique n'a été produite à partir de ce monde et publiée. La totalité de la production reste le fait du monde du Frelimo, de la sphère de l'État moderne. Il s'agit bien entendu d'une conséquence des déséquilibres sociaux, scolaires, ethniques hérités de la colonisation, maintenus par le Frelimo pendant la phase radicale et à nouveau aggravés aujourd'hui par le néolibéralisme. Mais il s'agit aussi d'un problème symbolique : la légitimité reste l'apanage d'un seul côté. Par exemple, on compte sur les doigts d'une seule main le nombre d'étudiants mozambicains qui ont choisi de faire leurs mémoires de licenciatura (maîtrise) ou leurs thèses de mestrado (DEA), en histoire, sociologie, linguistique, etc., sur le monde de la Renamo.

Écrire un livre sur ce monde-là fut donc un objectif en soi, même si je suis un étranger : pour banaliser la Renamo comme objet d'études, pour la faire «entrer dans la nation ${ }^{18}$. Cette « entrée » est encore loin d'être assurée, ce qui explique également la légère différence de titre entre la version française originale et la version portugaise : d'une part Les Bandits. Un historien au Mozambique, 1994, d'autre part Os Outros. Um historiador em Moçambique, 1994. Il est bien évident que la référence aux «Bandits »(Bandidos) relève du vocabulaire politique du Frelimo pendant la guerre civile, introduite ici au «deuxième degré ». Cela est aisément compréhensible par qui est loin des passions. Mais s'agissant d'un public lusophone

\footnotetext{
${ }^{16}$ La traduction en français de cette manière populaire n'a pas toujours été facile, car d'un côté il n'y a aucune raison de considérer « incorrectes », à la seule aune du portugais lisboète, les spécificités du portugais mozambicain, menant immanquablement à faire comme s'il s'agissait d'un «petit-nègre » (pretoguês); mais de l'autre, dans le cadre même de la spécificité mozambicaine, il y a des interlocuteurs qui évidemment savent plus ou moins bien le portugais. La traduction est toujours quelque peu une trahison : c'est la raison pour laquelle, dans cette édition française, une partie des dialogues sont reproduits dans les deux langues, le français suivant le portugais. Certaines expressions isolées, qui étaient en portugais dans mes commentaires personnels généralement rédigés en français, sont reproduites en portugais avec la traduction en notes.

${ }^{17}$ L'appareil de notes est un peu plus important pour la version française que pour la version portugaise : il s'agit d'explications de certaines traductions, et diverses mentions de faits historiques ou politiques inutiles pour le public lusophone.

${ }^{18}$ Voir note 15.
} 
et, notamment, mozambicain - y compris, je l'espère beaucoup, celui du «monde de la Renamo », ces Autres, ces Outros -, j'ai crains que la référence aux Bandidos ne soit prise pour ce qu'elle fut au premier degré de la réalité vécue, le stigmate de l'expulsion et de la marginalisation de qui n'était pas intégré au monde du Frelimo.

Tous les lieux, tous les noms de personne, tous les faits sont réels. Mais je reste le seul responsable de la manière dont les épisodes sont contés. Si ma plongée auprès des anciens Bandidos armados donne au lecteur - y compris mozambicain - une vision différente du Mozambique, ce pays infiniment complexe et attachant, mon objectif aura été atteint.

Bordeaux, le 9 avril 1999

\section{Addendum du 10 janvier 2001}

Lors des deuxièmes élections générales (législatives et présidentielles), les 3 , 4 et 5 décembre 1999, alors que le Frelimo s'attendait à une victoire facile du fait de l'éloignement de la «peur que la Renamo ne retourne à la guerre si on ne vote pas pour elle », cette dernière, désormais pourtant dépourvue de l'argent de l'Onu, a fortement accru son score, malgré son insigne faiblesse politique et ses erreurs (comme le boycott des élections municpales en 1998).

Elle a obtenu 38,81\% des voix contre $48,54 \%$ au parti Frelimo, mais, surtout, le candidat présidentiel, Afonso Dhlakama, a recueilli $47,71 \%$ des suffrages exprimés (soit près de $15 \%$ de plus qu'en 1994) contre 52,29\% à Joaquim Chissano, le Président en poste. Ce dernier n'a été réélu qu'avec 224678 suffrages d'avance (sur 7099105 inscrits). Mais environ 550 procès-verbaux (environ $6 \%$ du total), totalisant 377773 bulletins furent écartés par la Commission nationale électorale... Ce faible écart en voix, inférieur au nombre de bulletins annulés ou « perdus » a nourri les accusations de fraude de la part de la Renamo, d'autant que le gouvernement a systématiquement refusé le recomptage des voix. La Renamo a donc refusé de reconnaître la légitimité du nouveau gouvernement et de l'administration, même si elle s'est enlisée dans des « discussions » non officielles avec le gouvernement, de toute manière rompues dès juillet 2000. Depuis, la tension a été grave, permanente et croissante.

Le 5 mai 2000, un banal incident, à Aube, une petite localité près d'Angoche dans le sud côtier de la province septentrionale de Nampula, se termina par la mort de quatre à huit personnes (d'autres sources disent seize), toutes de la Renamo et tuées par la police. Aucune enquête indépendante ne fut diligentée par le gouvernement. Le 11 octobre, la police encercla, avec des blindés, le siège de la Renamo à Beira, pour des perquisitions qui furent poursuivies aux domiciles de dirigeants locaux, y compris la résidence de Dhlakama. Le 9 novembre, la Renamo, qui sortait d'une grave crise interne, appela à nouveau à manifester contre les résultats officiels des élections : ces manifestations furent réprimées avec la plus extrême violence, souvent à balles réelles, même là où les manifestants étaient totalement pacifiques, voire n'avaient même pas encore eu le temps de se former en cortège : environ quarante morts selon le gouvernement. Le 22 novembre, la voiture de Carlos Cardoso, journaliste respecté, éditeur du journal par fax Metical, fut bloquée par deux véhicules au sortir de son bureau, en plein cœur de Polana, le quartier luxueux de Maputo : leurs occupants le tuèrent de dix balles d'AKM, blessèrent grièvement son chauffeur, et disparurent sans problème ${ }^{19}$. Le soir, Rafael Custódio le journaliste de la télévision qui avait très vite été sur les lieux et avait diffusé son reportage, fut attaqué par des inconnus qui, tout en lui disant : «Tu as beaucoup parlé », lui tailladèrent la langue au couteau et le battirent jusqu'à l'inconscience. Le lendemain matin on apprit que, la veille, avaient été retrouvés les corps sans vie de quatre-vingt trois prisonniers (tous de la Renamo) dans la prison de Montepuez, une bourgade de la province de CaboDelgado (frontalière de la Tanzanie, à $1650 \mathrm{~km}$ de Maputo) où avaient eu lieu les plus graves

${ }^{19}$ Les éditions spéciales du journal Metical sur l'assassinat de son directeur peuvent être consultées sur internet : <http://www.ccardoso.tropical.co.mz/>. 
incidents le 9 novembre. Laissés de trois à neuf jours (selon les sources) sans eau ni alimentation, entassés à près de cent dans une cellule de $21 \mathrm{~m}^{2}$ prévue pour dix pesonne, les détenus - sans inculpation - sont morts de soif, de faim, d'épuisement et d'asphyxie. Le Premier ministre, Pascoal Mocumbi, déclara que des «choses étranges » se passaient dans le pays mais, il est vrai, envoya aussitôt une mission médicale internationale d'enquête sur place. Le président Joaquim Chissano, depuis l'étranger où il effectuait un voyage officiel, déclara que désormais, il acceptait la demande de rendez-vous réclamée depuis longtemps par Afonso Dhlakama, sans pour autant accepter l'ordre du jour proposé par ce dernier. Lors de la minute de silence pour C. Cardoso à l'Assemblée, le groupe parlementaire Renamo se leva d'un bloc, pendant que celui du Frelimo, y compris le dirigeant de premier plan, Armando Guebuza, resta de longues secondes assis.

Tel est le pays invariablement décrit comme une success story par la Banque mondiale et le FMI, soutenu par toute la communauté internationale, et dont $34 \%$ des habitants ont accès à l'eau potable. Les ambassades étrangères semblent ne voir le pays qu'à partir de la capitale - ce qui est assez classique -, mais, rappelons-le, d'une capitale complètement excentrée, située au sud (comme si Perpignan était la capitale française ou Vila Real de Santo António la capitale portugaise), branchée totalement sur l'économie sud-africaine, concentrant $80 \%$ des investissements étrangers, socialement, ethniquement voire religieusement étrangère aux régions les plus peuplées du pays.

L'aggravation des déséquilibres régionaux, issus de l'héritage colonial mais « redynamisés » par le néolibéralisme actuel, pose avec plus d'acuité que jamais la question de la base sociale, hétérogène mais massive, que peut bâtir un mouvement fondamentalement marginal au regard des milieux sociaux qui tiennent l'État et la " nation ». Mais le résultat des élections de fin 1999 montre que tout se passe comme si, quelle que soit la faiblesse politique de la Renamo, de vastes secteurs de la population se servaient d'elle et de son leader pour exprimer leur exaspération face au régime de Maputo.

La Renamo est portée par un mouvement qui la dépasse, une très forte attente sociale. Le paysage politique du pays est bouleversé, l'ancien parti «marxiste » Frelimo étant le représentant naturel des secteurs les plus modernes du capitalisme mozambicain et la «procapitaliste» Renamo devant répondre à la forte demande sociale - demande « de gauche » est-on tenté de dire... - des va-nu-pieds.

Tout se passe comme s'il y avait une espèce d'imperméabilité, sociale plus encore que politique, empêchant le Frelimo - au détriment de ses intérêts à long terme - de comprendre son extériorité dans de vastes zones du pays, de saisir la pertinence des aspirations de ceux qui ne se reconnaissent pas en lui. Repousser la Renamo dans la marginalité, pour qu'elle y étouffe, semble la seule stratégie du pouvoir: si l'on pouvait s'en tenir à la seule Renamo comme appareil partisan, on pourrait penser que cette attitude a des chances de succès.

Mais c'est précisément ne pas comprendre que l'important n'est pas la Renamo, mais le monde de la Renamo, cette énorme base sociale qui s'est dressée en 1994 et renforcée, contre toute attente, fin 1999. L'hypothèse d'une victoire de la Renamo lors des troisièmes élections générales, en 2004, ne peut plus être écartée.

Cela souligne l'impérieuse nécessité de s'occuper sérieusement, au-delà de la société de la ville de ciment et du Sud, de ce monde des Autres et des Bandits dans le Centre et dans le Nord et plus généralement partout où des gens sont délaissés depuis trop longtemps ${ }^{20}$.

\footnotetext{
${ }^{20}$ Sur la situation politique au Mozambique à la fin 2000, voir mon article : «Mozambique : l'instabilité comme gouvernance ? », Politique Africaine (Paris, Karthala), nº 80, déc. 2000 : 111-135.
} 


\section{Chapitre 1}

\section{Madjermane}

Maputo, 23 septembre 1994

Raúl Nequice Junior est né le 24 juillet 1964 à Beira, la deuxième ville du pays, capitale de la région centrale. Son père, Raúl Gonçalves Nequice, était de Vilanculos, bourgade de la province d'Inhambane, plus au sud, et travaillait comme secrétaire à l'Administration civile ${ }^{21}$ de Vilanculos. Au cours des années cinquante, il avait émigré à Beira ${ }^{22}$, employé dans l'étude notariale d'un Portugais, le Dr Palhinhas, jusqu'en 1974. Ensuite, l'étude fut intégrée au ministère de la Justice, et il passa aux services d'état civil (Conservatória do registo civil) de Beira, où il est encore. En 1981, il suivit le cours de formation des juges de district, mais refusa ensuite une nomination à Chibabava ${ }^{23}$, vu les grandes difficultés à y emmener sa famille.

Il n'adhéra jamais à aucun parti, se définissant uniquement ainsi : - Sou de Vilanculos (« Je suis de Vilanculos »), désirant y passer sa retraite. Il savait le xitsua [la langue de l'ethnie Tsua] mais ne le parlait qu'avec les personnes qui ne savait pas le portugais, s'exprimant toujours en portugais devant ses enfants. C'était un assimilado qui avait participé aux activités du Centro Africano ${ }^{24}$, un notable respecté dans la société coloniale métisse et assimilée, et même parmi les Blancs. Son mariage, quelques mois avant le coup d'État d'avril 1974, lui avait valu un article dans le Notícias da Beira ${ }^{25}$. Il lisait beaucoup et était abonné à des services de livres en portugais. À l'indépendance, il avait eu quelques velléités de participer aux $\mathrm{GDs}^{26}$, mais s'en était vite écarté, se repliant sur son travail.

C'est pourquoi Raúl (Junior) apprit le xitsua avec ses grands-parents, qui étaient domestiques. Il sait aussi le cindau et le xisena, les deux langues de Beira ${ }^{27}$.

Son grand-père maternel était un Chinois de Canton qui avait fui la révolution. Au Mozambique, il s'était installé à Macovane, non loin de Nova Mambone ${ }^{28}$. Il s'y était marié et avait racheté une cantina ${ }^{29}$ à Joaquim Alvès, un grand commerçant portugais de Vilanculos. Sa

\footnotetext{
* L'ordre originel de la conversation a été scrupuleusement respecté, d'où un aspect parfois décousu des thèmes abordés. Merci à Henri Valot pour avoir facilité le contact. Le madjermane est l'homme qui a travaillé en Allemagne de l'Est (« Ma-German », ma- étant la mention du singulier).

${ }^{21} \mathrm{~L}$ '« Administration civile » gérait toutes les affaires relatives aux Européens, métis, indiens et assimilados. Le reste de la population relevait des Negócios indígenas («Affaires indigènes »).

${ }^{22}$ Bien que faisant partie du grand ensemble du Sul do Save (régions du pays situées au sud du fleuve Save), toute la partie centrale et nord du district d'Inhambane subissait l'influence de Beira.

${ }^{23}$ Petite localité au sud de Beira, au cœur d'une zone hostile au Frelimo.

${ }^{24}$ Association légale (et contrôlée) qui regroupait principalement les métis et quelques assimilés (les indigènes n'avaient pas le droit d'association).

${ }^{25}$ Quotidien contrôlé par Jorge Jardim, une espèce de Lawrence d'Arabie luso-mozambicain qui avait été intime de Salazar, mais avait évolué vers des positions d'indépendance contrôlée, et qui cherchait à valoriser les cadres africains acceptables.

${ }^{26}$ Les Grupos dinamizadores, ou GDs (Groupes dynamiseurs), étaient à la fois des structures de sympathisants du parti unique (pré-cellules) et des organismes de base de gestion municipale. Ils furent un outil capital d'encadrement de la population.

${ }^{27}$ Respectivement langue des ethnies Ndau et Sena.

${ }^{28}$ Bourgade de la rive droite de l'estuaire du fleuve Save, à la limite nord du district d'Inhambane en face de celui du Manica e Sofala, seule poche ethnique ndau au sud du fleuve.

${ }^{29}$ Petite boutique (en brousse ou à la périphérie des villes).
} 
femme était de Mambone. Ils eurent quatre enfants, deux filles et deux garçons, dont l'un, Pinto Fi-Yen Chim-Jin, devait plus tard être rapté par la Renamo et disparut. Quand son grand-père devint un peu plus riche, sa famille et des amis chinois lui reprochèrent de s'être marié avec une Mozambicaine. Il finit par se séparer d'elle, mais l'emmena, avec les enfants, à Maimelane (près $\mathrm{d}^{\prime}$ Inhassoro ${ }^{30}$ ) sans les abandonner. Il se maria alors avec une «Chinoise pure », mais reprit les enfants.

L'histoire allait se répéter. Une de ses filles, métisse, la mère de Raúl (Junior), s'était mariée avec Raúl Gonçalves Nequice mais, sur la pression de ses sœurs, s'en sépara. Une métisse ne se mariait pas sans déchoir avec un Noir, même assimilé. Elle se remaria avec un métis indienafricain et, avec leur cinq enfants, ils vécurent à Massinga, près de Maxixe ${ }^{31}$, localité qui allait devenir une forte zone d'action de la Renamo.

Dans cette région, la population a toujours été plutôt légitimiste et favorable au Frelimo. Mais elle savait bien que outre les attaques de la «Renamo 1 », il y avait beaucoup d'attaques de la «Renamo 2 », c'est-à-dire de soldats du Frelimo venant se nourrir. Les gens demandaient : «Comment est-ce possible, une Renamo qui existe seulement la nuit alors que le jour tout est calme ?».

La « Renamo 1 », celle de la grande base de Neves, vint deux fois dans sa maison. Ils parlaient cindau. La première fois, un soldat avait surpris sa mère en train de cuisiner. Elle ne dit rien, ne tenta pas de fuir. Un commandant parlait portugais. Son mari lui dit de les servir. Ça se termina bien.

Une deuxième fois, un autre groupe de la Renamo arriva, mais cette fois, un de ses membres avait été dans la cantina du grand-père. Bien sûr il ne fallait pas le montrer - signifiant un risque de dénonciation. Ainsi, des deux côtés, rien ne fut dit. Ce second groupe était plus nerveux. Ils voulaient des piles, des xiricos ${ }^{32}$. L'homme de l'ex-cantine lui faisait des clins d'œil. Ils prirent tout le manioc du champ. Le commandant demanda au mari :

- Pourquoi n'êtes-vous pas membre du Frelimo ? », et il répondit

- Nunca gostei de estar disto e daquilo, bastou a tropa colonial» («Je n'ai jamais aimé m'affilier à tel ou tel groupe, l'armée coloniale m'a suffi »).

Cette fois encore, ça se termina bien.

Mais la disparition d'un oncle provoqua plus de consternation que de haine. Pinto Fi-Yen restait pratiquement seul dans sa boutique à Macovane, que la population avait abandonné. Il avait été comando ${ }^{33}$, et s'en sortait toujours. La Renamo tenta trois fois de le kidnapper. À l'époque où se produisit le troisième assaut, il avait organisé une espèce de milice locale avec arcs et flèches, qui avait réussi à tuer quelques soldats de la Renamo. Mais ils réussirent finalement à le prendre au début de 1987.

Raúl (Junior) a étudié à Beira. Lors de la 9e classe (la « seconde » française), il apprit, fin 1986, que la décision avait été prise, sans qu'il ait été consulté, de le placer au ministère de la Défense. Le directeur du lycée était Gulamo Tajú, il était porreiro ${ }^{34}$ mais ne put rien faire pour éviter ce placement. Aussi décida-t-il de tout abandonner (études, etc.) pour ne pas aller à la Défense. Le contrôle n'était pas si efficace. Du reste, il ne fit jamais son service militaire, bien qu'appelé trois fois, il suivit juste l'entraînement d'autodéfense quand Marcelino dos Santos ${ }^{35}$ était gouverneur de Beira en 1984-1985. L'entraînement était obligatoire pour tous ceux de plus de

${ }^{30}$ Bourgade entre Vilanculos et Mambone.

${ }^{31}$ Bourgade située dans la baie d'Inhambane du côté opposé à la presqu'île de la ville d'Inhambane.

${ }^{32}$ Radios transistors produites au Mozambique.

${ }^{33}$ Troupe d'élite, fortement africanisée, de l'armée coloniale portugaise.

${ }^{34}$ « Sympa », « chouette $» .$.

${ }^{35}$ Ancien représentant à Rabat de l'Udenamo (União democrática nacional de Moçambique), puis dirigeant du Frelimo, un des rares dirigeant nationaliste à avoir été «marxiste » dès le début. 
seize ans qui continuaient leurs études. Mais lui, absolument pas intéressé par le «militarisme », ne demanda pas même le cartão (certificat).

Ne voulant aller ni au SNASP ${ }^{36}$ ni à la défense, il décida d'aller à Maputo pour voir s'il pourrait s'y réinscrire dans une autre école. Il y avait déjà de la famille, côté paternel. Mais il n'y parvint pas. Or, une cousine qui travaillait au ministère du Travail lui proposa une « option »partir en Allemagne de l'Est pour «formation professionnelle » en électricité. Il y avait déjà là seize mille Mozambicains, dont une grande majorité d'hommes. Il partit.

En fait de formation, ce fut surtout du travail. Après six mois d'apprentissage intensif de l'allemand, il fut placé dans une entreprise minière où son activité consista à suivre des aulas práticas (cours pratiques), en fait un travail salarié à faible composante de formation. Il resta en RDA, puis dans l'Allemagne unifiée jusqu'en 1991, hésitant entre rester (il le pouvait) ou rentrer. Il espérait pouvoir recommencer à étudier vraiment, avec le changement. Il parlait couramment allemand et voulait étudier l'informatique. Mais il n'y parvint pas et rentra à Maputo.

Malgré la guerre qui continuait ${ }^{37}$, il se rendit à Massinga dans un camion de Médecins sans Frontières/Hollande, puis emprunta d'autres $\operatorname{chapas}^{38}$. Il y resta six mois. La vila (bourgade) était alors sujette à de nombreuses attaques, mais surtout dans les environs. Il ne voulait pas y demeurer si longtemps, mais comment sortir? Tous les deux jours, on retrouvait des morts sans sexe. Finalement il partit avec la coluna do Salema. On appelait ainsi le convoi (« colonne ») de l'armée qui, dès le début, avait avant tout protégé les biens du gros commerçant Salema. Sa « colonne » était mieux équipée que les garnisons devant défendre un district entier. Elle était liée au pouvoir et facilitait les passages des Gazenses et des Machungos ${ }^{39}$. La Renamo tirait mais la colonne ne s'arrêtait jamais et continua toujours à assurer la liaison Maputo-Save. Quand luimême l'emprunta, elle ne fut pas attaquée.

Il fut de retour en juin 1992 à Maputo, travailla dans un restaurant, puis avec un oncle dans une petite entreprise de réparations immobilières. Mais l'oncle dépensait illico les bénéfices et l'entreprise fit faillite. Depuis deux ans il n'a pas de travail et rêve d'un cours d'informatique.

Il a de la sympathie pour le $\mathrm{PCN}^{40}$. Mais relativement à la Renamo, il ne se fait pas un jugement simplement «à partir de la manière » dont la guerre a été menée. Il sait tout de la guerre, mais pense qu'il n'y a pas eu d'autres manières possibles. Il veut voir dans ce «mal nécessaire » ce que la Renamo pouvait être. Face à un Frelimo très fort, malin, astucieux, manipulateur, le seul moyen d'obliger le Frelimo à « ouvrir » était la guerre.

Mais cette guerre si cruelle, qui tue des enfants et des femmes ? Il pense que sans cet aspect horrible le Frelimo n'aurait pas « ouvert». Pourquoi ces femmes et ces enfants allaient-ils dans ces colonnes, sachant qu'elles seraient attaquées puisque organisées par le gouvernement ? Les voitures civiles ne pouvaient-elles pas servir à cacher du matériel militaire ?

- Sei que eles fizeram muito mal, mas no fundo de tudo, tiveram razões de existir...» (« Je sais bien qu'ils ont fait beaucoup de mal, mais, au fond, ils avaient quand même des raisons d'exister »).

\footnotetext{
${ }^{36}$ SNASP, Serviço nacional de segurança popular, police politique du parti unique.

${ }^{37}$ Les accords de paix sont signés à Rome le 4 octobre 1992.

${ }^{38}$ Camions normalement destinés à transporter les marchandises mais utilisés au transport des personnes.

${ }^{39}$ Également habitants de la région de Gaza. En fait il s'agit de clans d'ethnie changane, proches du pouvoir. La Renamo a toujours dénoncé dans le Frelimo la reconstitution de l'« Empire de Gaza » du début du siècle.

${ }^{40}$ PCN (Partido da Convenção nacional), petite formation sans représentation parlementaire mais dotée de cadres intellectuels, influencée par le christianisme protestant et dont certains dirigeants sont d'ethnie ndau, comme Afonso Dhlakama, chef de la Renamo. Le PCN est ainsi parfois présenté comme proche de la Renamo.
} 
Sa sympathie pour la Renamo n'est pas une sympathie d'adhésion, peut-être même pas de vote $^{41}$, mais il la voit de bons olhos (favorablement), comme facteur d'équilibre.

- É bom lembrar que a Frelimo matou, matou de outras maneiras, fuzilamentos em público em nome do povo...» («Il faut quand même rappeler que le Frelimo a tué, a tué d'autres manières, avec des exécutions en public au nom du peuple...»).

Il pense que la Renamo a peu d'appuis politiques mais une forte position venant de gens qui en ont assez du gouvernement de l'«Empire de Gaza». Maintenant les gens vont voter pour les dirigeants qui sont de la même origine qu'eux. Mais cela peut être plus régional, tout le Centre et le Nord contre le Sud, qu'à proprement parler ethnique. Ainsi les Senas n'aiment pas les Ndaus mais voteront contre le Frelimo ${ }^{42}$ À Maputo forcément le vote Renamo sera plus restreint, fondé sur des ressentiments personnels, pour se venger du Frelimo. Inversement beaucoup de gens ayant vécu en zones Renamo ne vont pas voter pour elle ${ }^{43}$. Le Frelimo va gagner ces élections, et même les suivantes, parce que quand une mère bat son enfant, celui-ci se blottit contre elle.

Mais pourquoi aucun parti ne demande-t-il le changement de capitale $^{44}$ ? Il y a eu des propositions même au sein du Frelimo et la réponse a été : Maputo capitale politique, Beira capitale économique. Só discurso! (Rien que des mots !). L'opposition attend peut-être d'être au pouvoir pour le dire? Mais cela coûte cher et ils imitent le Frelimo.

Si l'opposition civile avait fait bloc, elle aurait pu faire un bon résultat et gagner aux élections suivantes. Son erreur majeure est l'ambition personnelle. La peur augmente car il n'y a que deux partis armés. Comment la Renamo, et pas seulement le dirigeant Dhlakama, va-t-elle accepter sa défaite?

${ }^{41}$ Les premières élections pluralistes allaient avoir lieu environ un mois plus tard.

${ }^{42}$ C'est effectivement ce qui s'est passé.

${ }^{43}$ Cela ne semble pas s'être produit.

${ }^{44}$ Maputo est située à l'extrémité sud du pays et fait souvent figure d'annexe sud-africaine. 


\section{Chapitre 2}

\section{Zambézia}

[À Maputo, le contact avec la Renamo se fit avec une facilité déconcertante. Je pensais utiliser le fait que j'avais déjà parlé avec Afonso Dhlakama lors de son premier voyage à Paris, en juin 1992: comme démarche d'approche, j'avais alors simplement téléphoné, depuis Bordeaux, à l'hôtel Lutétia où j'avais appris qu'il était descendu. En trois secondes, je l'avais au téléphone et immédiatement il me fixait un rendez-vous, deux jours plus tard. Cette facilité m'apparut ensuite aisément explicable : j'étais le seul universitaire à lui avoir demandé une entrevue... Or il était très préoccupé par la déplorable image de la Renamo dans les milieux académiques. Nous avions parlé trois heures, du "communisme », de la guerre et de beaucoup d'autres choses, et à la fin, il m'avait demandé "comment faire pour pénétrer les milieux intellectuels ». Un peu gêné de la frontalité de la question, je lui avais prudemment répondu que, plus vite la Renamo résoudrait les questions dont on l'accusait, et plus son image s'améliorerait...

Ensuite, en décembre de la même année, lors d'un bref séjour à Maputo pour un colloque de l'ISRI (Instituto superior de relações internacionais), j'avais également parlé avec José de Castro, qui venait juste d'ouvrir le premier bureau de la Renamo dans la capitale, suite à la signature des accords de Rome (4 octobre).

Mais, début septembre 1994, les choses étaient plus compliquées, la campagne électorale avait en pratique déjà commencé, Dhlakama était toujours en déplacement. Par ailleurs je ne voulais pas seulement une entrevue, je voulais pendant toute cette période suivre pas à pas la direction de campagne de la Renamo.

Tout fut facilité par la présence de l'Onumoz ${ }^{45}$, cet État dans l'État qui occupait tout l'énorme hôtel Rovuma, loué au Comité central du Frelimo. Christine Messiant était venue à Maputo quelques mois auparavant pour étudier le processus de démobilisation contrôlé par les Nations unies, et je pus ainsi intensément utiliser les contacts qu'elle y avait établis. Éric Lubin, un Français proche collaborateur d'Aldo Ajello ${ }^{46}$, avait été responsable des démarches d'approche et $d$ '" apprivoisement» des dirigeants de la Renamo. Sans être directement responsable des questions militaires, il intervenait dans tous les aspects politiques des relations avec les rebelles. C'est lui qui avait conseillé à Dhlakama, en partance pour les États-Unis et très inquiet de la campagne hostile qu'il s'attendait à y affronter sur la question des enfants soldats, de la "défaire » en reconnaissant tout simplement que... c'était vrai, que la guérilla africaine s'était faite ainsi et que la question était maintenant de trouver les moyens de réunifier les familles. Ça avait marché et deux ou trois autres conseils politiques de cette sorte, couronnés de succès, avaient valu à Éric Lubin la confiance de la direction de la Renamo. Il avait lu certains des travaux de Christine Messiant, de Christian Geffray ou de moi-même, était intimement persuadé que les " analyses françaises», rompant avec le paradigme du "banditisme armé », étaient les meilleures. Bref, en deux jours, il avait convaincu Jorge Correia, un conseiller du "Président » (de la Renamo) de m'intégrer à l'équipe de campagne, comme observateur indépendant. Finalement, mes éventuelles remarques de terrain pourraient toujours être utiles, dans l'Onumoz ou même ailleurs. J'allais faire la connaissance de cet atypique Blanc de Beira, militant du MES (Movimento da esquerda socialista, un groupe d'extrême-gauche en 1974-77) au Portugal, et qui y avait soudainement rejoint la Renamo suite à un réunion discrète que Dhlakama avait tenue en Allemagne au début des années quatre-vingt...

Bref, je devais être à l'aéroport de Maputo le 27 septembre, à 8h45.]

\footnotetext{
${ }^{45}$ Onumoz, Opération des Nations Unies au Mozambique.

${ }^{46}$ Représentant spécial au Mozambique de Boutros Boutros-Ghali, secrétaire général de l'Onu.
} 


\section{7 septembre 1994}

\section{Aéroport de Maputo}

$8 \mathrm{~h} 45$. Il n'y a personne. J'apprends qu'un Antonov ${ }^{47}$ qui doit venir nous chercher n'a pas encore quitté Beira. J'attends avec une équipe de la TVM.

12h45. On s'apprête enfin à partir dans l'Antonov loué à la SAM, une société française de Beira. Discussions à bâtons rompus avec Jorge Correia et José Pinto de Sá, correspondant à Maputo du quotidien lisboète Público.

13h10. On est toujours là. Chargement d'assiettes en plastique et de cahiers d'écolier, tous objets à l'effigie de Dhlakama. Jorge Correia annonce que l'aéroport traîne à envoyer le camion de ravitaillement en kérosène.

14h05. Décollage. On doit arriver à Mocuba $^{48}$ vers $17 \mathrm{~h} 30$, bien après le « Président », parti avant dans un petit appareil avec quelques dirigeants. Dans notre avion, il y a les hauts parleurs, qui arriveront donc après le meeting... A mes côtés, le « Colonel Butre ». Le bruit est tel qu'on ne peut absolument pas se parler. Tout le monde reste silencieux.

\section{Mocuba}

17h. Après que l'avion a cherché la piste une demi-heure (pas de tour de contrôle), atterrissage sur la piste de terre de Mocuba. Il y a encore énormément de monde, le meeting venant de se disperser. Dans la lumière du soir, des centaines d'yeux d'enfants regardent l'Antonov immobile.

18h. Samuje, assesseur Renamo pour la province de Zambézia, nous emmène en ville, à la pension Cruzeiro.

20h. On dîne à la pension São Cristovão. Discussion avec André Jonas, attaché de presse de Dhlakama, militant clandestin depuis 1984 alors qu'il était journaliste au Notícias de Maputo. Son père, ancien administrateur colonial, représente la Renamo au Malawi.

J'ai récupéré un morceau d'enregistrement du discours de Dhlakama lors du meeting :

«...C'est la première fois dans notre vie que le peuple du Mozambique a le droit de choisir librement son président, de choisir ses représentants...

Mon message est clair : les líders des autres partis [...] vont aussi passer par ici, ils veulent être présidents, y compris ceux qui n'ont jamais été élus mais ont toujours gouverné sous la dictature [...]. Pour la première fois, ils vont dire: "Votez pour moi". C'est très intéressant pour le peuple du Mozambique de voir ça. C'est très bien. C'est notre chance. Choisissez librement, sans intimidation. Choisissez bien [...] pour changer de système dans le pays, nous voulons des changements profonds, non une démocratie en parole mais une vraie démocratie qui serve à résoudre nos difficultés [cris, sifflets, Vivas]. Vive la démocratie !

- La foule : Viva!

- Vive la liberté!

- La foule : Viva!

- Vive la justice!

- La foule : Viva!

- Vive les habitants de Mocuba!

- La foule : Viva!»

Puis il répète le discours en echuabo :

«Je ne suis pas ici pour vous tromper, pour promettre ce que la Renamo ne fera pas. Nous ferions les mêmes erreurs que celles que le Frelimo a commises. Voter Renamo, c'est voter pour la garantie d'être des humains [...]

Mais bien sûr, vous pouvez tous vous demander, va-t-il devenir Président, ce gamin qui courait la brousse, il va gouverner quoi ? Je vais réussir, tout comme j'ai réussi à nous libérer du communisme [applaudissements] [...]

\footnotetext{
${ }^{47}$ Avion militaire russe d'âge respectable.

${ }^{48}$ Bourgade du centre de la Zambézie.
} 
La Renamo, vous connaissez, ce n'est pas une nouveauté ici, tout le monde connaît, elle a vécu en brousse luttant pour les élections, pour la justice, pour la liberté [applaudissements] $[\ldots]$

Le plus important, c'est votre liberté de voter [...]. Nous allons assurer votre liberté de faire les cultures que vous voulez pour produire plus de nourriture. [...]. Nous savons que ce n'est pas facile dans les petites fermes : il faut des semences, il faut des coupe-coupe [...]. Le gouvernement de la Renamo donnera la priorité à l'agriculture [...] Le gouvernement de la Renamo va créer les conditions de commercialisation, des routes... Il faudra que le gouvernement de la Renamo protège l'initiative privée [...] »

\section{8 septembre}

Le «Président» est au Malawi. Tour de la vila ${ }^{49}$ jusqu'au fleuve Licungo. Il y a une petite élite métisse, indienne et afro-indienne, ce qui ne saurait étonner en Zambézia. Atmosphère calme. Vers dix heures passe en chantant une brigade de la Renamo. Mais il paraît que durant les trois jours antérieurs à l'arrivée de Dhlakama, les camions de l'administration munis de hautparleurs, ont appelé les gens à aller au champs le jour du meeting de la Renamo. On pouvait penser, selon un assesseur de Dhlakama, que le Frelimo contrôlait la ville. Mais, hier, jour de son arrivée, il y a vraiment eu beaucoup de monde, six mille me disent des journalistes. Joaquim Chissano doit d'ailleurs venir samedi $1^{\text {er }}$ octobre. On ne voit encore aussi signe apparent de préparation.

17h. Conférence de presse de Dhlakama (je m'aperçois que je suis le seul observateur international à suivre la tournée du chef de la Renamo dans le Nord). Il avait prévu de se rendre du Malawi au Zimbabwe, mais il y a eu un contretemps. C'est lui qui a demandé un rendez-vous à Mugabe, afin de discuter de la « vieille amitié Frelimo-Zanu ${ }^{50}$ » et de ses effets possibles sur les élections mozambicaines. Il veut éclaircir devant nous trois points : - Que signifie la réconciliation nationale ? - La sécurité après la guerre. - Réfuter les promesses que le Chef de l'État a faites dans la campagne.

«1. Après seize années de guerre, il faut rconstruire la dignité, notre dignitié, nous concentrer sur ce qui nous unit. Travailler ensemble n'est pas accepter l'idéologie de l'autre. Si le Frelimo travaille avec la Renamo, cela ne veut pas dire qu'il adhère à la Renamo. Aujourd'hui le PR [Président de la République ${ }^{51}$ ] dit: "Dhlakama veut le GUN ${ }^{52}$. Comment est-il possible pour nous de travailler avec l'opposition? Si la Renamo gagne, voudra-t-elle travailler avec le Frelimo, ses hommes voudront-ils adhérer au Frelimo ?". Ceci n'est pas parole d'un démocrate ! La réconciliation, c'est garantir la stabilité sociale du pays. Ni moi ni Chissano ne pouvons faire cela tout seuls. Même Bill Clinton a gardé beaucoup de cadres de Bush. Mais nous [allons] encore à essayer. Je n'ai jamais posé de conditions. Je ne suis pas en train de demander une belle maison ${ }^{53}$, un bon salaire, je peux retourner à Maringue ${ }^{54}$. Il ne peut y avoir de démocratie dans ce pays sans ma participation. Je suis un líder très valable, des milliers et des milliers de Mozambicains croient en moi.

2. Je suis très inquiet. Les $\mathrm{FADM}^{55}$, n'existent pas, mes généraux ont été cantonnés, et aujourd'hui ils vivent à l'hôtel, ils vivent comme des touristes, sans protection. Mais les

${ }^{49}$ Dans la tradition portugaise, la vila (bourgade ) est bien distinguée de la cidade (ville).

${ }^{50}$ Zanu, Zimbabwe African National Union, principal mouvement nationaliste du Zimbabwe, aujourd'hui au pouvoir, et que le Frelimo avait aidé non seulement contre les Rhodésiens mais aussi contre la concurrence de la Zapu (Zimbabwe African People's Union) très liée à l'URSS.

${ }^{51}$ La langue portugaise adore les sigles, et on les prononce tels quels : ici, Dhlakama prononce donc «pé-erre ».

${ }^{52}$ GUN, Gouvernement d'unité nationale. La formation d'un tel gouvernement était souhaitée par la communauté internationale, par l'Onumoz et par Nelson Mandela, à l'image de ce qui s'était passé en Afrique du Sud, afin de garantir la stabilité post-électorale.

${ }^{53}$ L'octroi d'une maison offrant à la fois dignité et sécurité avait été pour Dhlakama un feuilleton à épisodes nombreux les mois précédents...

${ }^{54}$ Quartier général de la Renamo pendant la guerre.

${ }^{55}$ Forças armadas de defesa de Moçambique, l'armée unifiée prévue par les accords de Rome. 
généraux du Frelimo ont leurs maisons. Ça risque d'être comme en Angola, où on a armé la police et délaissé l'armée unifiée. Le Frelimo entraîne unilatéralement ses policiers à se préparer à tuer la Renamo. Sans aucun doute, ces policiers vont être utilisés contre la Renamo tout comme en Angola [...]. J'ai un problème avec ces généraux, ils veulent retourner en brousse et pas rester à l'hôtel. Dans tous les immeubles et les quartiers, il y a les FPLM ${ }^{56}$ avec des bazookas. Quand la $\mathrm{Civpo}^{57}$ et l'Onumoz essayent [de saisir ces armements], ils disent que l'on rompt la dignigité nationale [et elles ne réussisent pas]. Nous, nous sommes déjà désarmés, nous sommes des politiques. Eux non. Je suis extrêmement préoccupé.

3. Les promesses du Frelimo sont fausses. Pourquoi ne font-ils pas les choses tout de suite ? Ils ne sont pas dans l'opposition ! Le PR admet qu'il va travailler avec des gens bien. Je ne le crois pas. Un chef d'Etat ne peut pas parler comme s'il était chef de l'opposition.. Pourquoi n'y a-t-il pas eu avant de futur meilleur ${ }^{58}$ ? Mais je me sens bien content parce qu'ainsi il admet travailler avec des gens pas bien, grâce à ce gamin Dhlakama. J'ai peur qu'il arrive ce qui est arrivé en Angola, où un jour les militants de l'Unita ont tous été tués ${ }^{59}$. Déjà le 19 novembre 1993 à Nampula ${ }^{60}$, il y avait un plan de la police pour me liquider. Mais mes gars ont découvert les armes ».

Je pose trois questions, sur le GUN, sur la capitale et sur la description qu'il fait de lui-même comme «gamin » (miudo). En fait, s'il dénonce le refus par le Frelimo du GUN il ne reprend plus cette exigence, il parle de réconciliation. Donc il préfère mettre en avant la revendication de la reconnaissance d'un statut de chef de l'opposition : "Nous voulons que le chef de l'opposition soit protégé, qu'il y ait un budget pour les partis après l'Onumoz ». Concernant la capitale, la Renamo n'a jamais condamné sa présence à Maputo. Ce sera plus tard, au parlement, de faire cela : - Não sou eu, que sou da Beira, que vou pedir que a capital seja na Beira » (Ce n'est pas moi, qui suis de Beira, qui vais demander que la capitale soit à Beira »). À ma question sur le « miudo », si cela dévoile qu'il ressent un certain mépris des autres pour lui, il ne répond pas vraiment : - Sou um miúdo relativamente ao Chissano, sou um rapaz, com muita energia », « Je suis un gamin par rapport à Chissano, je suis un garçon, mais plein d'énergie ».

Interrogé sur le malaise de ses généraux, il ajoute : "Dans les FADM, tout a été retiré des maisons [qu'on leur propose], les assiettes, la climatisation, tout... Mes généraux trouvent que c'est trop ». Interrogé sur l'idée de racheter les armes pour diminuer la libre circulation des kalachnikovs dans le pays, il répond simplement qu'il faut d'abord réussir et finir la démobilisation, sans quoi les hommes vont garder et cacher les armes pour les vendre ensuite.

\section{9 septembre}

8h. Je discute avec l'assesseur provincial Samuje. Il a été sympathisant de la Renamo depuis 1989 et militant clandestin depuis 1991. Il travaillait par le biais du Programme alimentaire mondial, distribuant de la nourriture là où la $\mathrm{DPCCN}^{61}$ n'allait pas. Le grand vecteur de

\footnotetext{
${ }^{56}$ Forças populares de libertação de Moçambique, l'armée du Frelimo.

${ }^{57}$ Civpol, Civilian Police, police de l'Onumoz, dont la création n'était pas prévue pas les accords de Rome, mais que la Renamo a exigé pour contrebalancer le renforcement de la police du Frelimo, en particulier les «ninjas » (police de choc militarisée).

${ }^{58}$ Le slogan central de la campagne du Frelimo était «Futuro melhor » («Futur meilleur »).

${ }^{59}$ Quelque temps après les élections multipartisanes de 1992 en Angola, dont les résultats furent refusés, sous l'allégation de fraudes massives, par l'Unita (Union nationale pour l'indépendance totale de l'Angola), le MPLA (Mouvement populaire de libération de l'Angola, au pouvoir et de la même génération politique que le Frelimo mozambicain) organisa une véritable chasse à l'homme à Luanda, massacrant des centaines de ses militants, et aussi de simples citoyens d'ethnie ovimbundu. Ce fut la « Toussaint sanglante ».

${ }^{60}$ Capitale du nord du pays.

${ }^{61}$ Departamento provincial de combate às calamidades naturais : le service de lutte contre les catastrophes naturelles, cité ici à son échelon provincial, avait d'abord été mis en place pour lutter contre les effets de famines consécutives à des sécheresses ou crues catastrophiques. Il servit ensuite à acheminer des secours aux victimes de la guerre en zones gouvernementales. Disposant d'une partie de l'aide internationale, il fut largement utilisé pour
} 
l'implantation urbaine de la Renamo à Nampula, Nacala, Angoche, a été au départ le transfert de travailleurs de la TextÁfrica du Manica pour la Texmoque ${ }^{62}$ de Nampula. Les travailleurs du Manica vinrent avec leurs sympathies pour la Renamo. Mateus Damião ${ }^{63}$ apparaît dans ce contexte. Membre du Service des eaux et constructions (Direcção das Aguas e Construções), il recrute presque toute la direction de l'entreprise de Nampula, sauf le directeur, puis celle de Nacala, et des gens à Angoche. Ainsi le Service des eaux fut un vecteur important de construction de la Renamo. À Angoche, le directeur des Eaux, Madeira, en était. Juste après le cessez-le feu, quand les guérilleros, qui étaient à $6 \mathrm{~km}$ de la ville, y pénétrèrent ${ }^{64}$, ils le contactèrent. Mais alors Gamito, le gouverneur de la province de Nampula, le démit, ainsi qu'une bonne partie du Service des eaux.

9h. Départ en hélicoptère pour Lugela.

\section{Lugela}

9h25. Arrivée sur la petite piste de terre battue. Quelques centaines de personnes sont déjà là. Chants, sifflets, portraits de Dhlakama. Très ordonné. Groupe de femmes en chorale, avec capulanas $^{65}$ à l'effigie du Président. Les gens sont en longues rangées, presque au garde-à-vous, nombreux sont les costumes cravates à l'avant! Deux jeunes arborant des T-shirts du Frelimo portent des banderoles Renamo... L'équipe installe le podium. Le petit groupe plus en avant est certainement la direction locale. L'agitateur en uniforme militaire crie les slogans, repris par les femmes :

- Abaixo a aldeia comunal! » « À bas le village communal!»

- Abaixo a cooperativa!», « Å bas la coopérative!»

- Abaixo a machamba do povo! », « À bas le champ collectif!»

- Viva a paz, Viva a democracia!", «Vive la paix, Vive la démocratie!»

Le reste de la foule, pour l'instant, est silencieux. Des gens arrivent en courant des alentours, la petite foule grossit. Un camion bourré de personnes arrive. Un Civpol, béret blanc, regarde la scène.

Je m'approche du premier rang : c'est bien la cupula distrital (direction de district) : Baptista Janela Inteta, le délégué, est tailleur, entouré des delegados de povoação (délégués des villages) :

- Vou fazer-lhe o serviço da Renamo », « Je vais vous présenter la Renamo ».

Anselmo Ramalho Francisco, l'administrateur civil de la Renamo, espère la réintégration dans l'administration étatique. Il a été élève jusqu'à la $7^{\mathrm{a}}$ classe ${ }^{66}$, puis mobilisateur en 1985, puis administrateur de la Renamo à Tacuane (zone sous contrôle de la rébellion) à partir de 1987. Il a toujours été civil, jamais soldat. António Meniço Mativale a fait la $6^{\mathrm{a}}$ classe de la Mission catholique et a été administrateur Renamo à Munhamade à partir de 1992. João Samuva (?) Armazem a fait la $4^{\text {a }}$ classe, il est oficial de administração (employé administratif) à Tacuane. Pedro Daniel Tomas Jambo est le délégué à l'organisation du district de Munhamade, il a fait la

concentrer les populations dans les zones contrôlées par le gouvernement. Sa gestion a été entachée de graves affaires de détournement et corruption.

${ }^{62}$ Deux entreprises textiles.

${ }^{63}$ Cadre de la Renamo qui était, à ce moment, membre de la CNE, la Commission nationale électorale, pour la Renamo.

${ }^{64}$ La signature du cessez-le-feu à Rome le 4 octobre 1994 fut respectée immédiatement à peu près partout (prouvant du reste que la Renamo était centralisée et bien organisée). Il était prévu que les zones de chaque camp resteraient à leur «propriétaire » respectif. Parmi les incidents les plus graves, l'occupation d'Angoche : la ville était restée aux mains du gouvernement même si la brousse était à la Renamo. L'occupation, quelques jours, de la ville, fut sans doute due à un problème interne à la Renamo, dont le commandant provincial aurait fait croire à sa direction qu'il occupait la ville. Il se devait donc de la réaliser très vite au moment du cessez-le-feu pour rendre « vraie » la situation.

${ }^{65}$ Pagnes de coton.

${ }^{66}$ Équivalent de la troisième dans le système scolaire français. 
$5^{\text {a }}$ classe au séminaire de Zobué, à Tete. Alberto Monda Maurito a été chef de l'intelligence à Tacuane dès 1984, puis à Namarroï et autres lieux. Koluve Malhanga est aussi ofical de administração. Laurinho Fernando Mutumba est chef de bureau au département de l'information à Lugela. Francisco Ossenha Mussivana est responsable de l'éducation, il a la $5^{\text {a }}$ classe, est à la Renamo depuis 1985 et c'est un ancien guérillero. António dos Santos Diwarimba est du département d'organisation, 4a classe. Paulo Nalimata, né à Ile, 5 classe à Alfazema, est délégué à la santé et est «infirmier ». Il est à la Renamo depuis 1986, toujours civil et toujours en zone Renamo de Tacuane. Armo (?) Armando est délégué de district à l'éducation depuis 1984, il a toujours été civil en zone Renamo et organisait les écoles. (Ils veulent tous me donner leur nom et leurs états de service !) Tito Morais, chef du parti à Munhamade, Renamo depuis 1985, militaire jusqu'en 1993. Nino Nikobara chef de zone du parti de Munhacala-Tacuane, Renamo depuis 1984, jamais militaire mais mobilisateur, a été jusqu'à la $2^{\text {a }}$ classe. Jordal Ilário Jackson, chef du parti à Mute-Derre à partir de 1985, mobilisateur, $4^{\mathrm{a}}$ classe. Daniel Maia, chef du parti à LimbeTacuane depuis 1985, jamais militaire, mobilisateur. Il est adventiste (ici, il n'y a que des catholiques et des adventistes). Abílio Candjeta, major de la Renamo depuis 1979 à la base de Tacuane et d'autres bases du côté de Pebane, Maganja da Costa, démobilisé en 1994. Catholique, n'a fait aucune étude (c'est le seul gradé militaire ayant une fonction politique de tous les gens rencontrés ici ; tous les autres sont des civils, l'un ou l'autre ayant été simple soldat.

- Não sou orgulhoso porque sou político », «Je ne suis pas orgueilleux, parce que je suis un politique », me dit l'un.

Au deuxième rang, ce sont les regedores ${ }^{67}$, tous de la Renamo : Corrio, Marusso, Matewe, Mudedeiria, Matewe Junior, Muroma, M'Bwaname, Russia, Mukamula, Muúra, Malubanha, Mugawanhe, Mbawa, Nangoura, Nimede... Tous ces chefs donnent une impression de grande pauvreté et, même, d'humilité.

Du troisième rang, je ne pensais pas noter les noms des vingt-huit autres, simples delegados de povoação [délégués de hameaux], mais la plupart viennent me voir. Alors je continue ! Armindo Caminho, délégué de la zone Marussia est né ici. Il est à la Renamo depuis 1987, n'a jamais été militaire. C'est un activiste adventiste du Septième Jour. Pendant la guerre, il n'a eu aucun contact avec les adventistes en zone Frelimo. Junquenha Abreu est né ici, infirmier militaire, à la Renamo depuis 1990. Sambone Gruveta est infirmier civil Renamo depuis 1984, né à Napone et travaille dans la zone de Tacuane. Matario Maïnato, professeur ${ }^{68}$, a la $4^{\text {a }}$ classe. Sa fonction provient de la réunion civile de la Renamo, à Morrumbala, en 1985, qui avait regroupé tous ceux qui avaient la $4^{\mathrm{a}}$, la $5^{\mathrm{a}}$ ou la $6^{\mathrm{a}}$ classe. Les uns avaient été désignés pour un entraînement de professeur, les autres d'infirmier. Venturas Julias Chafoor, né à Lugela, enlevé le 4 novembre 1986, 4a classe, secrétaire à Mandjavira-Mocuba. Il dit tranquillement devant les autres : - Fui raptado », «J'ai été rapté » ${ }^{69}$. Manuel Rui Sabonete n'a pas été militaire mais est Segurança civil (sécurité), il est à la Renamo depuis 1986, à Munhamade, et dans divers autres endroits, a la 4a classe (- A Renamo chegou, estabeleceu uma base. Engagei-me », "La Renamo est arrivée, a établi une base, je me suis engagé »). Bernardo Mainate est chef du parti à Munhamade, à la Renamo depuis 1983, n'a jamais été soldat, a la 4a classe. Rogério Benjamin a la $7^{\mathrm{a}}$ classe. António Marso, $7^{\mathrm{a}}$ classe, né à Mutulono (?), Mocuba, à la Renamo depuis 1984, jamais soldat. Mario Sentinela, chef du parti à Mbwnawe, à la Renamo depuis 1983 (- fui conversando com eles », «Ce fut en leur parlant»), $3^{\text {a }}$ classe, jamais soldat. Felizardo Arturo Bedissone, administrateur de Maharbaname (?), 6 $6^{\text {a }}$ classe, Renamo depuis 1989 (-Fui recrutado voluntariamente », "J'ai été recruté volontairement»). Carlos Jafoma, chef à l'organisation de Matia depuis 1985, a été désigné lors d'une réunion de la population pour intégrer la Renamo.

\footnotetext{
${ }^{67}$ Chefs (plus ou moins) traditionnels.

${ }^{68}$ C'est-à-dire instituteur.

${ }^{69} \mathrm{Je}$ devais rencontrer d'innombrables fois ensuite cette manière toute simple de parler du rapt. ÊEtre un « rapté » est un fait social qui n'a pas lieu d'être caché. Cela ne diminue en rien le drame personnel, ou, comme on voudra, le scandale (surtout quand il s'agit d'enfants), mais si l'on cherche à comprendre, il faut l'aborder d'abord comme fait social.
} 
Jamais soldat. Estelino Luntia, chef de la santé dans une des sections de Munhamade, à la Renamo depuis 1988, 4ª classe, n'a jamais été soldat mais «le village était près d'une base ». João Cavate Manguira a la $4^{\mathrm{a}}$ classe, a été rapté le 21 juin 1985 à Mungala, district de Morrumbala (- Muita gente foram apanhados », «Beaucoup de gens ont été pris »). Il n'a jamais été soldat ${ }^{70}$ et fut secrétaire du département d'administration interne, à l'extérieur de la base. Il veut rentrer à Mungala mais comme il est toujours secrétaire, sa famille est venue ici. Afonso Piambecambra, est « oficial » [responsable] du parti à Tacuane. Il a la $6^{\text {a }}$ classe. Il est né en 1963, est à la Renamo depuis le 30 décembre 1982. "Quand la Renamo est arrivée, je me suis engagé », dit-il en niant tout rapt ce qui est très vraisemblable puisqu'il n'a jamais été soldat mais est mudjiba ${ }^{71}$.

Il y a aussi Carlos Virgem, pasteur adventiste.

La Renamo de Lugela fournit deux candidats dans la liste des candidats de Zambézia pour l'élection de l'Assemblée: Felizberto da Costa et Ricardo Armando. Ont-ils été élus par les militants?

- Foi uma orientação », « On a reçu la directive ».

10h45. Arrivée de Dhlakama dans un petit hélicoptère. Tout le monde se remet en rang. Dhlakama sort seul, V de la victoire, les femmes s'approchent, il les congratule une à une. Les enfants s'approchent avec une couronne de fleurs : «Dhlakama yé ! yé ! ». Il y a environ mille personnes. Les délégués locaux lisent péniblement des discours en portugais. L'un d'eux demandent :

- São entendidos? », « Nous comprenez-vous?».

— La foule répond : «Não!».

- L'orateur dit alors : "É preciso traduzir », «Il faut traduire».

Alors Dhlakama demande en echuabo si ça va bien. Rires. Puis il fait son discours en portugais, avec une diction très lente :

"O Presidente da Renamo, o vosso filho, trouxe a democracia! Já não vão ter presidente ditador que governa com armas. Já acabou! », " Le Président de la Renamo, votre enfant, a amené la démocratie! Vous n'aurez plus de président dictateur qui gouverne avec les armes ! C'est fini !»

Il parle ensuite de l'autorité de la famille, du respect de la religion :

«Ils vont jusqu'à dire que Dieu n'existe pas. Moi, comme catholique, je ne vais pas donner la priorité à l'Église catholique. Mais nous avons toujours reconnu la différence entre la religion et la politique. »

Les autres thèmes classiques suivent :

«La Renamo reconnaît vos difficultés. La Renamo va donner de bons prix pour vos cultures. [...] Il faut réimplanter nos traditions. Avenue Karl Marx, Nyerere, Mao-TséToung ? Qu'est-ce que c'est que ça ? N'avons-nous pas d'ancêtres, n'avons-nous pas de regulos $^{72}$ [pour les noms de rue] ? Après la $4^{\mathrm{a}}$ classe, nos fils sont obligés d'aller jusqu'à Quelimane, et quand ils reviennent, c'est déjà avec d'autres valeurs, ils divorcent déjà des parents. Nous allons en finir avec ça, il faut qu'ils aillent jusqu'à la $7^{\mathrm{a}}$ classe auprès de leurs parents. [...] Retenez bien ma figure, repérez bien où se situe la photo [...]»,

dit-il, brandissant un modèle de bulletin de vote.

${ }^{70} \mathrm{Il}$ est à remarquer que la pratique du rapt par la Renamo ne vise pas forcément au recrutement de soldats. Il s'agit en tout premier lieu d'un rapt de population, pour la soustraire à la sphère de l'État moderne et l'emmener dans ses zones d'autarcie. Naturellement, le statut social du rapté, sauf s'il a une fonction dans la Renamo, se rapproche de celui, ancien, du captif.

${ }^{71}$ Les mudjiba sont une espèce de milice en zone Renamo qui ne dépend pas directement de la base militaire mais du regedor (chef traditionnel).

${ }^{72}$ Autre désignation pour regedor, chef traditionnel. 
12h15. Départ pour Ile. L'hélicoptère cherche un moment la piste, après avoir survolé les inselbergs ${ }^{73}$. Terre rouge partout. Y a-t-il deux mille personnes? Pas plus, o sol não ajuda! [le soleil n'aide pas] La foule est moins organisée, pas de files et de rangées, même si des groupes d'agitateurs lancent des «Viva a democracia! ».

Quand Dhlakama arrive, la foule s'organise un peu et il serre les mains à l'intérieur d'un grand cercle.

J'engage la conversation avec le Padre Giovanni Bonalumi, un père catholique italien qui est au Mozambique depuis quarante-cinq ans. Il a maintenu son école missionnaire en fonctionnement, en zone Renamo, du 4 novembre 1986 à 1991. Cette année-là, poursuivis par les Naparramas ${ }^{74}$ qui voulaient les capturer, lui et ses élèves restèrent cachés sept mois en brousse dans le district de Lugela. Ne tenant plus, il demanda l'autorisation à Dhlakama de passer au Malawi. Lui-même retourna ensuite en Italie, avant de revenir ici lors du cessez-le-feu. Très hostile au Frelimo [, il dit] :

«Il y a eu beaucoup d'atrocités, mais je ne peux pas parler. Du côté de la Renamo aussi, mais pas à cause de Dhlakama. Nous avons été les seuls pères catholiques à être restés. Nous avons décidé de rester. Dhlakama a aimé notre attitude. A Rome, on a parlé de nous comme de l' "Église perdue", mais nous étions ici. Je n'ai pas dormi dans mon lit pendant quatre ans. Ils nous ont bombardé sept fois, des Migs et des hélicoptères. Au début, c'était pour nous tuer, ensuite pour nous rapter. »

Il trouve que Dhlakama est un «homme très sincère ». Contrairement au Lugela, ici la foule colle à l'estrade, l'entoure de tous les côtés. Le manque d'organisation m'empêche de faire la même enquête rapide qu'à Lugela. Le discours de Dhlakama est pratiquement identique :

«Le Président Dhlakama n'est pas un président de palais, de Mercedes Benz, c'est un

Président du peuple. Les administrateurs seront d'ici. »

Et tout le monde comprend qu'ils ne seront plus du Sud. Mais sur la route qui longe la piste, quelques personnes, à pieds, passent sans s'arrêter pour écouter ou regarder le meeting.

15h. Départ pour Gurué.

15h20. Arrivée à Gurué. le temps est plus frais, très beau paysage d'inselbergs. Les cultures de thé sont partout, en bon état. Les gens attendent depuis sept heures du matin ! Respecter mieux les horaires ne serait-il pas respecter mieux l'électorat ? Un millier ? Des camions amènent d'autres personnes. Les groupes de femmes chantent à côté de la direction locale. Des enfants mangent de la canne à sucre, d'autres groupes de femmes et d'hommes dansent au son du djembé.

16h20. Le Président n'est toujours pas là. Dans dix minutes, on doit partir pour retourner à Mocuba avant la nuit qui tombe vers $17 \mathrm{~h} 30$. Selon un observateur du STAE-Onumoz ${ }^{75}$, here it's fifty-fifty.

\footnotetext{
${ }^{73}$ Formations rocheuses très impressionnantes (type «pain de sucre ») produites par des zones particulièrement dures du socle précambrien (alors que le sol autour a été dégagé par l'érosion).

${ }^{74}$ Les Naparramas (autres orthographes possibles) furent le principal exemple de «contre-guérilla populaire » de la guerre civile mozambicaine. Peut-être spontané mais observé de près dès son origine par le Snasp, ce mouvement armé d'arcs et de flèches vaccinait, très classiquement, ses soldats contre les balles. Il infligea ainsi de sérieuses défaites à la Renamo dans les provinces de Nampula et Zambézia, dont les soldats prenaient peur, jusqu'à ce que Dhlakama envoie dans la région quelques troupes d'élite qui prouvèrent à ses propres soldats que le vaccin ne fonctionnait pas toujours. Suite à la mort de leur chef, les Naparramas se divisèrent, certains allant parfois vers le banditisme et d'autres, dit-on, furent dans certains cas récupérés par la Renamo.

${ }^{75}$ STAE, Secrétariat technique d'administration électorale.
} 
16h35. Il arrive. Le GPS de son hélicoptère est tombé en panne, le pilote a cherché une heure. Dhlakama demande : - Quem são os que foram recenseados? ", "Quels sont ceux qui ont été recensés ? » La foule répond : - Todos », «Tous ».

\section{0 septembre}

\section{0h15. Départ pour Gilé.}

11h30. Arrivée à Gilé, après avoir traversé une région peu peuplée. Mille personnes selon moi (sept-cents selon les Onumoz locaux), en bon ordre avec la cupula [direction] du parti au premier rang et les chefs traditionnels au deuxième. Mais ils n'ont eu la nouvelle du meeting qu'hier, et encore transmise par l'administrateur du district (gouvernemental), le seul à avoir le téléphone. Aussi les activistes n'ont-ils pu couvrir toute la région. Dhlakama devait arriver à huit heures et le Frelimo a organisé un meeting à ce moment-là, par provocation ${ }^{76}$. Des hommes et des enfants y sont allés, pour voir Dhlakama ensuite. Daniel Pedro Trinta est candidat aux élections. Membre de la Renamo depuis décembre 1992, n'a jamais été soldat. Il a la 7a classe.

Quand Dhlakama arrive, c'est le délire, on s'arrache les portraits jetés à la volée. Le bon ordre explose, tout le monde s'avance. Les observateurs Onumoz disent qu'il y a plus d'enthousiasme que pour le meting du Frelimo, pour autant de gens selon eux (sept cents), mais l'orateur n'était que le secrétaire local.

Gilé a été occupé par la Renamo pendant trois ans. Je me promène un peu en m'éloignant, je parle avec des jeunes qui ont le T-shirt de Chissano: - O ! isso é propaganda! Posso ouvir qualquer!», «Oh! ça, c'est de la propagande, je peux écouter n'importe lequel! ». Les gens attendent pour voir, semblent indécis.

Grappes d'enfants accrochés aux arbres. Pas d'estrade, une simple table sous un anacardier. Dhlakama danse avec le groupe de femmes. Délire. Un policier frappe pour faire reculer la foule. Le responsable local lance les vivas d'usage et aussi : - Abaixo intimidações! ", " À bas les intimidations! » et : - Abaixo o marequecismo!», «À bas le marequecisme ${ }^{77}$ ! ». Dhlakama monte, après hésitation, sur les chaises.

Le discours, en diction lente, a toujours la même structure. Salutations. Remerciements pour l'appui pendant la lutte armée. Dhlakama seul ne pourrait rien. La Renamo est le parti du peuple en lutte contre le communisme. Les autres ont déjà promis. La Renamo va respecter nos traditions. Défense de l'autorité familiale. Défense de la religion. Défense de la démocratie, la majorité ne peut dominer les groupes plus petits. Ici l'ethnicité pourtant sera abordée avec une grande netteté :

«Nous allons reconnaître les groupes ethniques. Ici, vous êtes lómuès [approbations]. Dire cela, c'est du tribalisme ? Non ! Vous avez votre tradition, nous n'allons pas dire :"Ah ! ce groupe n'est pas civilisé, nous allons vous obliger à apprendre ceci et cela". Les Macuas ${ }^{78}$ dans ce pays n'ont jamais été bien respectés. Mais avec le gouvernement de la Renamo, les Macuas seront bien protégés ».

Il parle ensuite en етасиа. Il ne parle pas beaucoup de la région de Zambézia comme à Mocuba, Ile ou Gurué, mais surtout du groupe ethnique macua-lómuè, sauf quand il aborde l'administration :

${ }^{76}$ L'attitude des administrateurs de l'État, bien que membres du Frelimo le plus souvent, n'a pas toujours été identique à celle des secrétaires du parti lui-même. Certains ont fait ouvertement la campagne du parti, d'autres ont tenu à garder une position plus neutre.

77 «Marequecismo », c'est-à-dire le marxisme (marxismo), mot dont les conjonctions de consonnes sont difficiles à prononcer en emacua.

${ }^{78}$ Macuas et Lómuès sont deux groupes ethniques proches et on parle souvent des Macuas-Lómuès comme d'un seul grand groupe. 
«Je veux gagner les élections, nous allons changer les choses, le peuple doit sentir qu'il y a eu des changements. Le gouverneur de la Zambézia va être un Zambézien. Il ne passera pas pour un étranger. Dans les entreprises publiques, il n'y a pas de Zambéziens. Ce n'est pas du tribalisme, ça? 11 faut que les gens pratiquent une bonne distribution des pouvoirs ».

Sur l'éducation, reprise du même thème : les enfants doivent rester avec les parents jusqu'à la 9a classe, car les parents sont déjà vieux, les enfants doivent les aider. Mais il faut une spécialisation plus tôt dans l'école, apprendre vite un métier.

Il insiste. fortement sur l'image de la perdrix et sur sa photo : - Não podem confundir com o milho da Frelimo », " Vous ne devez pas confondre avec le maïs [des affiches] du Frelimo ».

\section{3h15. Départ pour Pebane.}

13h45. Arrivée après avoir survolé de grandes forêts, souffrant visiblement de la sécheresse, puis, en arrivant sur la côte, la zone des historiques cocoteraies ${ }^{79}$ ! Moins de mille personnes chantent au son du djembé frappé par des femmes. Le meeting a été convoqué seulement la veille au soir. En plus, c'est vendredi, dans cette zone musulmane. Pourtant des gens arrivent en courant. Dhlakama va à la rencontre de la direction locale. Il y a d'un côté les responsables du parti, que Dhlakama salue en premier, puis, sur la même rangée mais plus loin, les dignitaires religieux. Quelques régulos sont là mais, du moins apparemment, ils n'ont pas de position spéciale dans le meeting. Dhlakama danse un moment avec les femmes. Délire, bien sûr. Une estrade est installée sur un petit camion.

J'adore cette région de Zambézia. Belle foule, typiquement côtière, femmes fières et raffinées... Dhlakama vient m'expliquer que les gens ici vivent très dispersés et qu'ils n'ont pas eu de camions pour aller les chercher. Mais le meeting est très animé.

Discours. Le Frelimo n'a rien fait. Chissano et ses amis sont restés en Tanzanie à boire du whisky ${ }^{80}$. Notre dignité a été attaquée. Des musulmans ont été envoyés en rééducation. La Renamo a ainsi surgi pour la démocratie. Le Frelimo a apporté l'indépendance. Et après ?

«Il a amené les villages communaux, il a amené les ninjas ${ }^{81} \ldots$-Quelqu'un dans la foule : il a amené les arrache-cour ${ }^{82} !-\ldots$ il a envoyé les jeunes en RDA... C'est un bandit celui qui amène la démocratie ? Contraindre le Frelimo a été difficile ! Je suis un homme fort ! Je suis un homme fort! [chants]. Qui en a fini avec le Snasp ? C'est moi ! Mais je ne l'ai pas fait tout seul. Ce sont vos enfants!»

\section{5h. Départ pour la Maganja da Costa.}

15h35. Arrivée à la Maganja. Du monde sur la piste! Trois mille. Tambourins à l'aéroport, un groupe de femmes est en tête, devant la cupula. Juste derrière, les dignitaires religieux. Tout le monde suit vers le stade, où aura lieu le comício. Il y a là rassemblées environ quinze mille personnes, dont il émane une grande ferveur. Toute cette foule chante. Derrière se détache la jolie petite ville, verte, fortement catholique du fait de la grande et ancienne mission. À petite distance, un groupe d'une cinquantaine de personnes du Frelimo cherche à provoquer.

- Já decidiram? », « Avez-vous déjà décidé ? »

- Não!», «Non!»

\footnotetext{
${ }^{79}$ Cette région, en son temps, posséda les plus grandes cocoteraies du monde, propriétés notamment de la Companhia da Zambézia et de la Companhia do Boror.

${ }^{80}$ Allusion à la période de la lutte de libération. La direction du Frelimo était à Dar Es-Salaam, mais la guérilla anticolonialiste n'a jamais vraiment réussi à pénétrer en Zambézia.

${ }^{81}$ Ninjas : police militarisée, troupes de choc.

${ }^{82}$ Tira-coração («arrache-cœur»): la période de la guerre civile a été riche en rumeurs et croyances anomiques, qui avaient commencé à se développer avec la construction de l'appareil d'État du Frelimo en brousse. Les chupa-sangue («suce-sang») venaient, au nom du gouvernement prendre le sang par la tête (interprétation populaire transparente de l'imposition de l' «homme nouveau » du Frelimo); les tira-coração («arrache-cœur») prélevaient le cœur des gens, etc.
} 
- Moçambique precisa de um presidente do povo? », « Le Mozambique a-t-il besoin d'un président du peuple ?»

- Sim! », « Oui !»

Dhlakama développe les mêmes thèmes qu'à Pebane. Mais ensuite un dirigeant local prend la parole et attaque véhémentement les maputenses ${ }^{83}$ qui seuls ont la «liberté » alors que dans le Nord il n'y a rien eu de bien. Alors Dhlakama corrige un peu car « il y a des journalistes ». Des personnes âgées viennent lui offrir un sceptre.

17h. Départ pour Quelimane ${ }^{84}$.

17h30. Arrivée à Quelimane. Pas de meeting ${ }^{85}$, juste deux mille personnes accompagnent triomphalement Dhlakama de l'aéroport à la ville. Peu de temps auparavant, Joaquim Chissano, présent aussi à Quelimane, a été accueilli par une foule qui s'est mélangée à la deuxième... Je demande à un gosse qui court aux côtés de notre Land-Rover :

- Es da Frelimo, tu ? », « Tu es du Frelimo, toi ?»

- Não, sou da Renamo, com a Frelimo não somos nada, são só os machanganes do Sul que vão para a escola! », « Non, je suis de la Renamo, avec le Frelimo nous ne sommes rien, il n'y a que les Machanganes ${ }^{86}$ du Sud qui vont à l'école !»

La foule crie : - Dhlakama, queremos a paz!», «Dhlakama, nous voulons la paix !»

Soir. Manuel Pereira ${ }^{87}$, délégué provincial de Zambézia, est à la Renamo depuis 1987, dans la zone de Ile. Mais sa direction de Quelimane n'a pas réussi à [nous] trouver [un] hébergement. Tous les hôtels sont pleins, car l'équipe de campagne du Frelimo est au grand complet à Quelimane. Les pilotes sont furieux et aboutiront, tard dans la nuit, dans un campement touristique à quatre-vingt kilomètres au nord de la ville. Quant à moi, qui n'ai pas de clause contractuelle à mettre en avant, j'échoue, vers minuit, dans une pension d'une saleté comme j'en ai rarement vue.

\section{$1^{\text {er }}$ octobre, Quelimane}

9h30. Discussion avec Tangos Ussemane Motany, conseiller du délégué provincial, huitième sur la liste des candidats à la députation pour la Zambézia. Il a quarante-sept ans et est né à Inhambane, mais vit ici depuis trente-sept ans. Il est d'une famille métisse indienne et a une petite entreprise de meunerie et pêche semi-industrielle. À l'époque coloniale, il a fait son service militaire dans les comandos. En 1975, il s'est réjoui de l'indépendance, mais a ressenti des désillusions progressives. Il a commencé à avoir des positions contestatrices, puis, en 1982, a été recruté par la délégation de Lisbonne de la Renamo. Adalberto Pereira Satar, un métis indien avait réussi un travail de recrutements et à Quelimane il y eut une cellule Renamo clandestine de sept personnes, la seule alors. Son activité était uniquement civile, sans aucun lien avec les militaires, sans aucun agent de liaison. Le contact se faisait via Lisbonne, d'où ils recevaient tracts et journaux. Mais, le 15 juin 1983, ils furent tous pris par le Snasp. - Polícia terrível, não tem forma de classificar », "Une police terrible, on ne peut pas la décrire ». Il reconnaît que les tortures auxquelles il a été personnellement soumis furent plus psychologiques que physiques. Six ans de cachot permanent, avec quinze autres prisonniers. Au début, personne ne parlait avec

${ }^{83}$ Habitants de Maputo, la capitale.

${ }^{84}$ Capitale de la Zambézia.

${ }^{85}$ Pas de meeting ce jour. Dhlakama avait déjà tenu le premier meeting de sa campagne, précisément à Quelimane, quinze jours avant.

${ }^{86}$ Machanganes, membres de l'ethnie changane accusée de monopoliser le pouvoir (ne pas confondre avec Machanganas, vandau de la région de la Machanga).

${ }^{87} \mathrm{Ne}$ pas confondre avec le dirigeant provincial de Beira, qui s'appelle également Manuel Pereira. 
personne, dans les trente-neuf cachots que comptait le centre. Peu à peu, des liens de solidarité se sont créés. Les autres détenus étaient d'anciens guérilleros [du Frelimo]. Même si beaucoup d'amnisties furent fausses, les gens restant prisonniers, ceux de sa cellule furent effectivement libérés en août 1989, dans le cadre des campagnes que le Frelimo menaient pour tenter [de rallier] certains éléments de la Renamo, et aussi sous pression croissante du Comité international de la Croix rouge.

À Quelimane, les gens commençaient à parler plus ouvertement. La cellule fut reconstituée, avec une meilleure écoute. Elle n'avait toujours pas de relation directe avec les militaires, mais la guérilla se rapprochait. La population ne semblait pas rendre la Renamo responsable de la guerre.

Le contact direct avec la Renamo se fit seulement après les accords de paix, et d'abord à l'échelon politique, à Maputo. Peu à peu les contacts avec les militaires locaux se multiplièrent, notamment avec le brigadeiro Machava, responsable pour toute la Zambézia. Les dirigeants militaires de ce grade avaient le même niveau d'études que les civils de la cellule, ce qui facilita le contact pour construire le parti en temps de paix.

Ici, le fait que Mateus Kathupa ${ }^{88}$ soit directeur de la campagne du Frelimo n'amène guère de sympathie : il est considéré comme de la poudre aux yeux. Soixante-quinze pour cent des membres de toutes les «directions nationales " ${ }^{89}$ de Quelimane sont du Sud. Pourtant à Quelimane, il y a des Macuas-Lómuès formés.

Cependant les Changanes ne sont pas coupables. Si un cadre changane est compétent, pas de problème. Mais si un changane est nommé parce qu'il est changane, ça choque. Surtout s'il dit venir "nos ensinar, a nós Zambézianos, a província mais antiga e mais rica », " nous faire la leçon, à nous Zambéziens, de la province la plus ancienne et la plus riche ». Même si la Zambézia n'est pas homogène ethniquement, il n'y a pas de divisions là-dessus. Mais la pauvreté est telle qu'avec de petits cadeaux le Frelimo peut acheter des consciences.

Le fait que la Renamo soit dirigée par un Ndau ne pose pas de problème, puisque c'est à Quelimane que Dhlakama a ouvert la campagne, et non à Beira. Sur la langue des militaires ? Il ne sait pas s'ils parlent surtout le cindau.

La Renamo a multiplié ses «délégations », qui correspondent aux GDs du Frelimo. Les candidats à l'élection de députés ont été choisis selon le critère de la formation.

10h30. On a découvert une «bombe » dans la maison de Joaquim Chissano à Quelimane ${ }^{90}$. Alors que Dhlakama et Chissano se trouvent, par des hasards de calendriers respectifs, présents en même temps dans la même ville, l'affaire peut devenir délicate. Par chance, il y avait une équipe de la TVM présente auprès de Dhlakama, au moment même où l'on apprit l'incident, et il a réagi en direct en condamnant fermement l'acte. Puis, conférence de presse improvisée :

«J'ai un discours pour chaque région. À Gaza, j’ai un discours spécial. Bien sûr, la majorité de l'élite [du pays] est de Gaza, mais ça n'a pas profité à la région. Le Frelimo a même fait plus de massacres dans cette province. C'est aujourd'hui l'une des provinces les plus pauvres du pays. J'y suis très populaire ${ }^{91}$. »

11h45. Départ pour Morrumbala, zone entièrement dominée par la Renamo mais dont le cheflieu est resté sous contrôle gouvernemental.

\footnotetext{
${ }^{88}$ Ministre de la culture, anthropologue et linguiste de formation, docteur de la School of Oriental and African Studies de Londres, Mateus Kathupa est macua.

${ }^{89}$ C'est-à-dire les directions des grands services ministériels.

${ }^{90}$ On apprit plus tard qu'il ne s'agissait que d'une pile, déposée au fond d'un vase. Mais plus tard seulement... Un moment, je fus même un peu inquiet, car une rumeur circulait selon laquelle il y avait un Blanc, un «SudAfricain », dans l'entourage de Dhlakama, et on faisait le lien avec la « bombe ». Or, ces jours-là, le seul Blanc de l'entourage de Dhlakama, c'était moi ! Cependant, on va le voir, mon inquiétude n'était pas totalement dénuée de fondement...

${ }^{91}$ Néanmoins, il faut noter que sa «popularité », à quelques très locales exceptions près, ne dépassera pas les deux ou trois pour cent dans la province de Gaza.
} 
12h30. Arrivée à Morrumbala, après avoir survolé des régions peu peuplées. Morrumbala est joliment située sur le piémont d'une montagne. Je compte 1200 personnes, un peu plus après, mais pas plus de 2000 . La première file est comme d'habitude constituée des delegados du parti et de l'administrateur des zones Renamo environnant le chef-lieu, André Boaventura.

Né au Alto-Molocué, celui-ci a été administrateur depuis 1986, et jamais militaire. Il a la 9a classe. Ancien professeur de portugais au lycée de Nampula, il a «toujours eu des difficultés avec la politique ». Il affirme être sorti volontairement après avoir eu des contacts avec des militants urbains de Nampula : - Nunca fui preso, mas fui perseguido. A única forma de ficar livre era sair », "Je n'ai jamais été arrêté, mais j'ai été harassé. La seule façon de m'en tirer était de partir ».

La foule en longues files chante : - Nós somos da Renamo, Nós somos », « Nous sommes de la Renamo, nous en sommes!».

Je lie conversation avec trois instituteurs de zones Renamo, jamais soldats ni raptés. Quand la Renamo est arrivée chez eux, elle a cherché des gens avec la $6^{\mathrm{a}}$ ou la $7^{\mathrm{a}}$ classe, pour être instituteurs. Aussi ont-ils été choisis, et ils sont restés.dans la même zone. Ils ont suivi une petite formation pour devenir instituteurs. Au début, un certain Gabriel est venu de Maringué, un militaire, qui a réuni une centaine de «professeurs». Puis des instructeurs de district ont continué. Ils ont beaucoup souffert, beaucoup de professeurs ont été tués, mais ils ont toujours continué. Maintenant, en temps de paix, ils persistent à faire ce métier, en se plaignant de l'absence totale de matériel didactique, et toujours sans salaire, comme pendant la guerre, car le gouvernement ne veut pas les reconnaître et les intégrer.

Dans cette zone, A. Gamito, le gouverneur Nampula, est venu faire un meeting tout près, à Sene (?), le cœur même de la zone Renamo. Et Chissano vient dans quelques jours. La bataille de la Zambézia est âpre !

Dhlakama fait son discours alternativement en portugais et en xisena. Les thèmes sont classiques : démocratie, traditions, droit de choisir ; il y a beaucoup de partis mais la Renamo est unique car c'est elle qui a apporté la démocratie ; elle ne fait pas de promesses matérielles mais une promesse de liberté : chacun pourra aller où il veut, plus d'aldeias comunais ; l'éducation sera sur place. Maintenant, il faut bien « fixer » sa photo ; Dhlakama n'a pas amené de T-Shirts et de capulanas pour le vote : vous n'êtes pas des enfants! Je suis pauvre, et fils du peuple. Vous êtes pauvres, si le Frelimo offre un T-Shirt et une capulana, demandez cinq T-Shirts et vingt capulanas - c'est votre argent !

Des femmes lui offrent un très beau service à café en pau-preto (ébène). Lui-même donne $1500 \mathrm{kwachas}$ malawites à la délégation locale pour qu'elle puisse aller acheter du papier et des crayons au Malawi tout proche.

\section{4h. Départ pour Mopeia.}

14h20. Arrivée à Mopeia, près du fleuve. La Liga da Juventude et la Liga das Mulheres moçambicanas $^{92}$ sont en tête de l'accueil. Une petite estrade a été montée par les militants. Il y a environ mille cinq cents personnes. Le soleil est écrasant. Dans la vila se dresse une espèce de vieille forteresse portugaise, en fait la prison civile. Une grande timbila est amenée, qui produit un son enchanteur. Petits enfants, aux pauvres ventres ballonnés.

Un groupe danse avec une banderole : - Os desmobilizados apoiam a Renamo », "Les démobilisés appuient la Renamo ». Les âges sont divers mais il y a là de jeunes enfants... Je fais un petit tour. Quelques maisons en dur, avec des toits de tôle flambant neufs. Traces de balles sur les murs. Le pilote de l'un des hélicoptères, portugais, qui a rayonné ici avec la Croix-Rouge pendant la guerre, m'indique qu'à Mopeia, il n'y avait presque personne. Les gens vivaient en brousse, presque nus. L'administrateur gouvernemental vivait à Caia, de l'autre côté du Zambèze et venait de temps en temps.

${ }^{92}$ Ligue de la jeunesse, Ligue des femmes mozambicaines (Renamo). 
À un autre bout de la piste, des gens restent en retrait, mais sans hostilité apparente. Un prêtre italien me dit que si Chissano vient, il y aura du monde, mais qu'ici, «c'est la Renamo ». Dhlakama discourt en xisena. Une infinie pauvreté émane de la majorité des gens. Mais toutes les femmes ont un bébé dans le dos.

16h. Départ pour Chinde.

16h30. Arrivée à Chinde. Rapide évaluation, 2250 personnes $^{93}$. Comme d'habitude, la première ligne est celle du parti, avec un détachement féminin. Les régulos sont en deuxième file, sur le côté. Joli paysage côtier, de palmiers. Mais toujours la marque de la pauvreté et de la décadence $^{94}$. Une jeune fille offre une couronne de fleurs à Dhlakama. La petite estrade aussi est bien joliment fleurie.

La Renamo n'a jamais occupé le Posto sede (chef-lieu de district) mais était à cinq kilomètres. Un estivador (docker) me dit :

«La population ne veut pas que la guerre revienne. C'est les politiques, c'est leur affaire.

La population veut la paix, c'est tout. »

Lui-même a été paysan à Ile, puis est venu après la guerre à Chinde. João António Anselme a fait la deuxième classe du lycée ! - Mas não há serviço, tenho que fazer estivador », " Mais il n’y a pas de travail, je dois faire docker ».

Pendant le meeting, plusieurs personnes dans la foule commentaient en rigolant. Visiblement, la population est divisée.

Coucher de soleil derrière les hautes palmeraies...

20h30. Entrevue avec David Alone à Quelimane.

[Je voulais absolument le voir, cadre urbain ayant fait le choix de la Renamo, dirigeant régional potentiellement important pour elle. Je me dirigeai vers sa demeure, belle maison de la Companhia da Zambézia, à la nuit noire. Au moment où j'arrivai devant la porte, un jeune Mozambicain, qui semblait venir en même temps que moi, me dit qu'il était journaliste et allait aussi chez Alone. Nous entrâmes. Évidemment, j'étais bien naïf et mon hôte, lui, avait compris tout de suite. Après quelques banalités d'usage, il réussit à faire sortir le "journaliste » qui $m$ 'avait suivi et venait surveiller notre entretien. Au moins, certaines personnes s'intéressaient à ma présence à Quelimane...]

David Alone est nguni de père et de mère, de la région d'Angónia, qui plus est d'une famille de nobreza tradicional (noblesse traditionnelle) qui avait rayonné en Zambézia. Il est lié à une autre grande famille ${ }^{95}$, les $\mathrm{O}^{\prime}$ da Silva, dont j'ai connu un membre à Paris.

« Depuis l'enfance, j'ai été éduqué à respecter certains principes, et l'un de ces principes est le dialogue. Cela paraît une petite chose mais c'est important. Tout se résoud en dialoguant. »

Il est né le 19 août 1940, d'une famille anglicane relevant de la mission mère du Nyassaland. Bonne stratégie familiale, ses trois frères aînés avaient étudié au Malawi mais son père voulait que les deux plus jeunes étudient dans une école portugaise. Lui-même est le plus jeune. Le Nguni, par tradition, doit être berger et toute une série d'exercices de bergerie furent sa première

${ }^{93}$ Comme, en me perchant le plus haut possible (toit du stade, arbre...), je cherchais toujours à compter le nombre des présents en m'inspirant des méthodes de la police française (comptage par multiplication de surfaces), Dhlakama finit par prendre l'habitude de me demander assez régulièrement mon évaluation. En général, je trouvais un chiffre deux fois inférieur à celui qu'il escomptait, et dix fois supérieur à celui qu'annonçait, quand elle annonçait quelque chose, la presse gouvernementale.

${ }^{94}$ Chinde, à l'embouchure du fleuve Zambèze, fut une jolie petite ville d'ancienne colonisation .

${ }^{95}$ Héritière du système des prazos (concessions semi-féodales supprimées en 1930), la Zambézia est par excellence la région des grandes familles, souvent dominées par des femmes, les Donas da Zambézia. 
éducation. Puis son père réussit à les inscrire à la mission catholique jésuite de Lifidzi (Angónia). Un de ses camarades de classe y fut Manuel Frank ${ }^{96}$. À la fin de la $4^{\text {a }}$ classe (CM 2), il fut envoyé à l'École normale de Boroma qui était un vrai petit centre intellectuel à l'époque. Il y suivit le cours de «professeur ${ }^{97}$.

L’indépendance du Malawi eut de grands effets. Un roi du Malawi, Ngomani Nkhwende, était un parent de sa famille - cette lignée royale existe toujours aujourd'hui, Inkosi Ya Makosi, roi des rois. Une idée de solidarité naquit au point que, durant les vacances, il alla avec son père au premier meeting de Kamuzu Banda ${ }^{98}$ qui revenait d'Angleterre. Cette réunion, en 1958, le marqua, et à partir de ce moment, il sentit qu'il était "anti-colonial ». L'Inkosi Ya Makosi voulait la réunification ${ }^{99}$. Du côté portugais de la frontière, le roi Zintambira d'Angónia fut rapidement arrêté ${ }^{100}$. Des années plus tard, il revint et se fixa aux alentours du Posto sede où il appela sa localité «Folotiya », c'est-à-dire «la frontière », en souvenir de son emprisonnement à Ressano Garcia, à la frontière entre le Mozambique et l'Afrique du Sud.

Pour les jeunes de Boroma, Banda était le sauveur. Les pères portugais s'en aperçurent même si, malgré leur hostilité, les jeunes, avec patience, continuaient à suivre les cours. En 1960 Davide Alone est placé comme «professeur » à la mission de Lifidzi ; sous la pression catholique il avait, en effet, fini par se convertir pour pouvoir poursuivre ses études. Mais pendant cette année de professorat, les missionnaires lui refusèrent l'écoute régulière de la radio... Après un an, il fut envoyé au Portugal pour y devenir missionnaire ${ }^{101}$.

Á Coimbra, il finit le lycée, puis, près de Braga, fréquenta l'Instituto Nuno Alvares, un collège jésuite. Enfin, il étudia la philosophie à l'Université catholique de Lisbonne en 1971.

Il revint alors pour un séjour court au Mozambique et débarqua à Beira. Dès le lendemain, il fut arrêté par la DGS ${ }^{102}$. En effet, au Portugal, il était resté en contact avec le journal malawite The African et avait écrit au courrier des lecteurs en signant de son nom. Mais il ne resta prisonnier que deux jours et partit pour Tete. Il y fut à nouveau détenu par la DGS, et à nouveau libéré... À Angónia, il resta surveillé. Il donna des cours à l'École normale, mais, toujours sous filature, décida de retourner en Europe, au Portugal. Intéressé par la sociologie du développement, il partit ensuite à La Haye, complètement à l'aventure, sans rien en poche. Un ami sud-africain blanc, Michael Wilson, l'aida et il parvint à s'inscrire à l'Université en 1975. Outre la sociologie, il y suivit un cours de «marxisme-léninisme » et de «maoïsme » dont il garda de la sympathie pour Mao...

Revenir, ou rester ${ }^{103}$ ? Il revint en juillet 1975 et resta à Beira ${ }^{104}$ où il avait un frère. Avec un peu de peine, car déjà, son orientation est dite " capitaliste », il réussit à devenir professeur au lycée Pedro de Anaia, et à l'Instituto Comercial e Industrial (1976). En même temps, il travailla comme adjoint de gérance en entreprise. C'est alors qu'il publie à compte d'auteur deux manuscrits écrits précédemment : Estrutura social tradicional negro-africana. Fundo do socialismo africano ? écrit à Braga en 1971, 91 pages, et Ensaio para uma filosofia política da pedagogia, de 1975, 203 pages ${ }^{105}$. C'est tout simplement l'entreprise où il était adjoint de gérance, qui était une typographie, la «Clássica comercial e industrial da Beira »,

${ }^{96}$ Manuel Frank, un Nguni d'Angonia, fera des études de droits et deviendra avocat. Il sera cependant interdit de profession - sans aucune inculpation - et émigrera à Lisbonne, où il rejoindra la Renamo. Il en fut le représentant de 1988 à 1992.

${ }^{97}$ En fait, le cours de moniteur scolaire pour école primaire indigène.

${ }^{98}$ Kamuzu Banda devint le premier chef d'État du Malawi indépendant, puis « Life President » et rapidement dictateur féroce.

${ }^{99}$ Comme bien souvent, la frontière coloniale était passée au beau milieu d'États, chefferies et ethnies.

${ }^{100}$ L'Udenamo (parti antérieur au Frelimo), en pétition à l'Onu, annonça (de manière erronée) qu'il avait été fusillé.

${ }^{101}$ Le début des années soixante constitue en effet le tournant, infiniment tardif, où l'Église catholique du Mozambique pense à africaniser ses cadres et où, plus généralement, la colonisation pense à créer une classe moyenne africaine.

${ }^{102}$ Delegação geral de segurança, la police politique de l'État nouveau salazariste qui succède à la Pide.

${ }^{103}$ L’indépendance du Mozambique est proclamée le 25 juin 1975.

${ }^{104} \mathrm{Je}$ me trouvais alors personnellement à Beira ce même mois, venu en auto-stop de Nairobi... et, de visite au lycée de la ville, j’avais assisté à la dénonciation de quelques professeurs « réactionnaires ».

${ }^{105} \mathrm{Il}$ est par ailleurs auteur de quelques articles dans Portugal em África et dans Igreja e Missão, deux revues catholiques portugaises. 
qui imprima les deux ouvrages. Mais ils furent considérés comme « réactionnaires », et donc lui-même fut désormais un "réactionnaire ». Les exemplaires furent confisqués (même s'il réussit à en faire vendre quelques-uns, envoyés juste avant, à la Livraria Académica, de Maputo). Renvoyé de son poste de professeur, il ne rompit point, par « idéal de dialogue ». Il s'interrogeait cependant sur ce refus de la diversité des pensées. "L'homogénéité de pensée est antagoniste au développement $»$.

À Beira, il y avait trois autres professeurs noirs, qui avaient été formés aux États-Unis. Quatre enseignants noirs, c'était une nouveauté au lycée de Beira, aussi «tivemos muito boa aceitação »(《nous fûmes très bien accueillis »). Mais les quatre furent arrêtés en 1976, sans inculpation formelle. Plus tard, il entendit dire que, pour lui, c'était encore à cause de ses livres. Mais les trois autres ? Ils «transmettaient des idées réactionnaires aux élèves ».

Au lycée et à l'institut, la sympathie qui leur était témoignée inquiétait le Frelimo. Les étudiants se mirent en grève contre les arrestations arbitraires..., ce qui confirmait donc les idées réactionnaires des étudiants. Beira était bien la « ville réactionnaire ».

Ils furent transférés à Quelimane, aux bons soins du gouverneur Bonifácio Gruveta qui ne connaissait pas le motif de leur arrestation, mais savait que l'enseignement leur était interdit. Les trois autres collègues étaient tous passés par Dar Es-Salaam du temps d'Eduardo Mondlane ${ }^{106}$ qui les avait envoyés aux États-Unis pour étudier. "Réactionnaires », ils étaient donc en outre considérés comme «étudiants du Frelimo rebelles ${ }^{107}$. Samora Machel proposa alors qu'ils soient envoyés en rééducation, mais Gruveta obtint de pouvoir les placer en « régime de rééducation» (c'est-à-dire avec le salaire minimum) dans des entreprises publiques - qui manquaient désespérément de cadres. Mais l'un d'entre eux, Gilberto Waya, qui avait eu le malheur d'être ami de Jorge Jardim, fut expédié dans l'un des pires camps du Cabo Delgado. Il en ressortit, vivant, onze ans plus tard.

Un autre fut placé à la Monteiro e Giro ${ }^{108}$, un deuxième à l'Emocha ${ }^{109}$, lui-même à la Companhia de Boror ${ }^{110}$.

Durant cette phase, le Frelimo lui apparaissait seulement comme voulant imposer une «idée unique », donc manquant au respect de la personne.

Á la Boror, il faisait ce qu'on lui demandait. Le président de la commission administrative, l'ancien guérillero Xavier Baptista Sulila, le questionna sur ce qu'il avait pu faire et il répondit : - Não sei $»$, « Je ne sais pas »... mais lui passa un exemplaire de Estrutura social tradicional. Le guérillero lut, et lui dit : - Tem razão, mas cala-se », «Vous avez raison, mais taisez-vous », lui accorda sa confiance et l'envoya dans les bureaux de la filiale à Maputo!

Cependant, le jour même de son arrivée, un télex de la Présidence lui demanda de quitter immédiatement la capitale. Revenu en Zambézia, il fut envoyé à la Mocuba-Sisal pour y couper le sisal, cette fois donc en «vrai rééduqué ». Cependant Sulila à Macusi (le siège de la Boror) se débattait avec d'insurmontables problèmes de cadres : la majorité d'entre eux étaient auparavant composés de Goanais qui avaient pris la nationalité portugaise et avaient dû partir précipitemment. Aussi consulta-t-il le gouverneur Gruveta qui accepta qu'il soit rappelé au siège, sans responsabilité - au passage, David Alone dit que, personnellement, il n'a jamais eu à se plaindre de Gruveta, connu pourtant pour avoir organisé les dernières fusillades publiques.

Á Macusi, Sulila finit par obtenir de Gruveta que David Alone puisse avoir des responsabilités. Le $1^{\text {er }}$ juillet 1977, il fut nommé chef des services administratifs de la Boror. Mais à ses côtés, le GD local savait qu'il était un « réactionnaire »...

\footnotetext{
${ }^{106}$ Premier président du Frelimo, éduqué aux États-Unis, tué par l'explosion d'un colis piégé le 9 février 1969. Le Frelimo connaissait alors des tensions internes importantes et diverses.

${ }^{107}$ Ce qui incitait certains jeunes Mozambicains à rejoindre le Frelimo était la possibilité d'obtenir une bourse pour poursuivre des études à l'étranger, alors que leur situation scolaire était bloquée dans la colonie portugaise. Cependant, surtout après 1969, le Frelimo exigea qu'ils soient aussi formés militairement et participent au combat. Pour cette raison, et aussi du fait des intenses batailles de fraction dans une atmosphère qui était tout sauf démocratique, une bonne partie des étudiants envoyés aux États-Unis entrèrent rapidement en opposition avec la direction (dès avant ou après la mort de Mondlane) et ne revinrent jamais au Mozambique.

${ }^{108}$ Entreprise agricole et commerciale.

${ }^{109}$ Entreprise d'État ayant repris diverses compagnies de thé.

${ }^{110}$ Grande compagnie zambézienne, de capitaux suisses, propriétaire de gigantesques cocoteraies, qui avait été nationalisée après que ses dirigeants aient carrément abandonné l'entreprise, quittant le pays dans un bateau ayant chargé la dernière récolte...
} 
Quand Gruveta fut remplacé à Quelimane par Tazama, qui n'avait suivi qu'une éducation scolaire très rudimentaire, le GD de la Boror en profita pour se plaindre du « réactionnaire ». Mais Tazama prit publiquement sa défense. Il put alors travailler plus tranquillement, avec des résultats positifs. Aussi Tazama le nomma-t-il à la tête d'une entreprise en difficulté, la GERALCO, puis, dix-huit mois plus tard, en 1981, à l'ENACOMO (import-export). L'entreprise n'avait pas de vraie base économique, mais au moins la mit-il en ordre. Dans ces deux entreprises, il chassa quelques travailleurs qui ne respectaient pas les horaires (et qui étaient responsables du GD...) avec le soutien du gouverneur.

Il est resté à l'ENACOMO jusqu'à aujourd'hui, mais dût cumuler de façon croissante diverses responsabilités. En 1984, il fut nommé directeur régional du commerce extérieur, en 1986, délégué de l'Inter-Metal, puis, la même année, gérant de la Companhia da Zambézia !

En 1987, il devint directeur provincial substitut de l'industrie et de l'énergie - sur ordre : - Fiz », «J'ai assumé », dit-il. Il arriva cependant à se défaire peu à peu de responsabilités pour se consacrer à la privatisation de l'ENACOMO, qui se fit de 1989 à novembre 1993 et dont il était devenu actionnaire. En 1993, il laissa la Companhia da Zambézia.

Il reconnaît avoir été utilisé par le Frelimo, mais considère qu'il n'a jamais travaillé avec eux, puisqu'il n'a jamais pu choisir sa profession et ses fonctions.

Au cours de toutes ces circonstances, sa femme, portugaise, l'a toujours accompagné : Uma autêntica heroina! », «Une authentique héroïne! ».

André Matsangaïssa ${ }^{11}$ connaissait le livre Estrutura social..., le livre réactionnaire. Orlando Cristina ${ }^{112}$, Evo Fernandes ${ }^{113}$, le connaissaient aussi. C'est ainsi que, par le biais du mouvement África livre ${ }^{114}$ un premier contact fut établi dès 1977 à Beira. Quand la Renamo commença à agir en Zambézia (1980-1981), il fut de facto "muito ligado à Renamo » (« très lié à la Renamo »), mais reconnaît que c'était « intellectuellement, sans tâche ». La Renamo recrutait aisément car le Frelimo multipliait les désillusions : chicoteadas ${ }^{115}$, fusillades...

L'appui de la République sud-africaine à la Renamo, en plein apartheid, ne l'empêcha pas de lui accorder sa sympathie. Quant aux atrocités, elles furent des deux côtés. Il est même convaincu que certaines furent pratiquées par le Frelimo (ou ses soldats) et attribuées à la Renamo.

En 1981-82, il devait être "rapté ». Mais pour cela, il lui fallait un déplacement en brousse, un viagem de serviço (voyage de service) dont, en semi-liberté, il ne pouvait prendre l'initiative et pour lequel il fallait un objectif. L'opération ne put avoir lieu..

En pratique, il n'est toujours resté que sympathisant (il n'est encore pas formellement membre bien qu'en bonne place sur la liste des candidats aux élections), mais se considère comme ayant été lié à la «philosophie sous-jacente de la Renamo». De plus, ne pas être directement militant lui permet d'être plus libre professionnellement, ce qui reste sa priorité ${ }^{116}$.

Quand les partis se sont formés, il a été invité par plusieurs d'entre eux, même pour être candidtat aux présidentielles. Mais sa réponse fut invariablement:- Qual é a vossa ligação com a Renamo ? », "Quelle est votre relation avec la Renamo ? , - Pensam fazer ou não uma coligação com a Renamo para derrubar o governo ? ", "Pensez-vous faire ou non une coalition avec la Renamo pour battre le gouvernement?». Il souhaitait un «front unique de l'opposition ». Comme il n'y en eut point, il choisit ouvertement la Renamo.

En Zambézia depuis dix-sept ans, il y a constaté la marginalisation politique et économique des Zambéziens : gouverneurs du Sud (sauf Gruveta, de la province, et Tazama, du Niassa), directeurs provinciaux et d'entreprises, administrateurs de districts et même chefs de poste qui ainsi doivent, comme du temps colonial, utiliser un interprète pour parler à leurs administrés ! - É o império de Gaza! », «C'est l'Empire de Gaza ${ }^{117}$ ! »

Comme je lui fais remarquer la mentalité très militaire de la Renamo même devenue « civile », il en convient aisément. À la base comme aux niveaux intermédiaire, on ne prend pas d'initiatives, il n'y a pas d'orientation. Il y a une mauvaise distribution des fonctions. Mais qui les distribue? Jusqu'ici les délégués ne sont pas élus mais nommés par Dhlakama,

\footnotetext{
${ }^{111}$ Premier commandant en chef de la Renamo, ndau, tué en combat en 1979.

${ }^{112}$ Premier secrétaire général de la Renamo, d'origine portugaise, assassiné en 1984.

${ }^{113}$ Deuxième secrétaire général, d'origine goanaise, assassiné à Lisbonne en 1988.

${ }^{114}$ Mouvement avant tout «pied-noir », né indépendamment de la Renamo au départ dans la zone centrale et zambézienne du pays, mais qui s'y fondra.

${ }^{115}$ Samora Machel rétablit légalement la pratique de la chicote (fouet) administrée en public.

${ }^{116}$ David Alone devint, peu de temps après, l'un des principaux dirigeants de la Renamo.

${ }^{117}$ Rappel : la Renamo considère l'État du Frelimo comme la continuation de l'Empire de Gaza, à savoir un État dominé par les élites du Sud.
} 
et les délégués de zone sont nommés par le délégué régional. Cela reste largement une structure de type militaire : - Será preciso um trabalho muito profundo para modificar esta maneira de trabalhar. A entrada de civis deve permitir isso mas às vezes estão à procura de um líder », "Il faudra encore un travail en profondeur pour modifier cette manière de travailler. L'entrée de civils doit permettre cela, mais ces derniers aussi ont tendance à chercher un chef ».

Pronostics électoraux ? Il pense que le Frelimo aura une majorité relative, mais est sûr que la Renamo obtiendra plus que lui en Zambézia. Cependant, il n'a encore reçu aucun argent pour sa campagne électorale, et le parti n'a pas de voitures. »

\section{2 octobre 1994}

Nous n'avons pas été emmenés au meeting d'Inhassunge, qui a eu lieu tôt ce matin.

10h30. Petite discussion à bâtons rompus avec Vitor Guente, délégué de la Ligue de la jeunesse de la Renamo. Il était «clandestin » à Quelimane depuis plusieurs années, et n'a jamais été soldat. Il y a trois mois, à Mocuba, trois militants de la Renamo ont été tués, et d'autres à Inhassunge. À Mocuba, il y a une forte intimidation et c'est pourquoi Dhlakama en a fait une de ses bases de campagne en Zambézia.

\section{1h. Départ pour Milange (hélicoptère)}

12h. Arrivée à Milange, beau paysage de montagnes qui, au loin, sont déjà au Malawi. Il y a beaucoup de monde (selon moi, environ sept mille), avec d'interminables rangées de bicyclettes (la piste d'atterrissage est à $8 \mathrm{Km}$ de la ville, ce qui a sans doute découragé certains). Comme d'habitude, la cupula est en tête et, juste derrière, les régulos. Il y a deux femmes dans la direction locale. Ernesto Michoni Torsida, le délégué de district, est à la Renamo depuis 1983 et n'a jamais été guérillero. Il était infirmier, militant clandestin à Luabo. Il n'a jamais été en brousse. Il a été transféré récemment à Milange, sur ordre du parti. Il n'y a aucun militaire dans la direction locale, sauf quelques-uns parmi les membres.

En attendant le Président, la foule chante en battant des mains. Cent-vingt mille personnes environ se sont fait recenser ici.

12h30. Arrivée de Dhlakama. Longs saluts à la foule, y compris un groupe de jeunes enfants d'une école chantant un hymne (religieux !) à la gloire du «Président Dhlakama ». On lui offre des poules, des bananes, des savons. Une colombe est offerte à la « Première dame ».

Dhlakama a une extinction de voix... De plus, la grande majorité des présents ne comprend visiblement pas le portugais. Le discours est au départ pénible, mais s'anime peu à peu. Mêmes thèmes que d'habitude. Il dénonce les Zimbabwéens et les Tanzaniens qui seraient venus ici. La foule approuve bruyamment.

«Ils ont gagné ? Non, ils n’ont pas gagné, puisque je suis ici ! Nous avons gagné ! [...] Ils ont cherché à me capturer ! Me capturer, moi ?!!! [délire] Dictature du Frelimo, plus jamais ! [...] Je ne suis pas un Président de la Ville ! Je suis votre Président ! Un Président qui ne vous regarde pas de haut ${ }^{118}$ !»

Le thème de la guerre est toujours abordé, mais sous l'angle du soutien apporté par la population malgré les souffrances, de la victoire contre les étrangers, et du résultat: la démocratie. Il aborde très habilement la question de la défaite de Kamuzu Banda, au Malawi voisin, qui pourtant l'avait bien aidé, au moins jusqu'en 1986, en la plaçant sous l'angle de la démocratie :

${ }^{118}$ En portugais : «Um Presidente que para ele não há diferença! », délicieux luso-mozambicanisme, dont le mot-à-mot donne quelque chose du genre : «Un Président que pour lui il n’y a pas de différence » . 
«No País vizinho, governava o Banda. Mas o povo disse : Mmm! vai descansar para o capim! E o Banda está a descansar. Chissano também tem que descansar com a sua Frelimo. », « Dans le pays voisin gouvernait Banda. Mais le peuple a dit : « Hum ! hum ! va t'allonger un peu sur l'herbe! Et Banda maintenant se repose. Chissano aussi doit se reposer, lui et son Frelimo».

Dans les «Vivas», je constate que le lieu où il se trouve est toujours présent («Viva população de Milange! », "Vive la population de Milange!») ou de la province («Viva Zambézia! ») mais jamais «Viva Moçambique! ».

14h. Départ pour Nampula. 


\section{Chapitre 3}

\section{Macuana*}

15h45. Après avoir traversé de vastes régions très peu peuplées mais aux fantastiques paysages d'inselbergs, nous arrivons à l'aéroport de Nampula. Il y a énormément de monde à l'aéroport, des groupes de femmes, d'enfants et de danse en tête. J'essaye d'estimer. Trente mille, ou plus? Des Onumoz présents me disent qu'il y a trois fois plus de monde que pour Joaquim Chissano la semaine précédente.

$\mathrm{Au}$ fur et à mesure qu'on entre dans la ville, la foule de l'aéroport court pour suivre le cortège de voitures, mais une autre foule, compacte, attend sur les trottoirs et s'enthousiasme. Des hommes et des femmes cherchent le visage de Dhlakama dans les Land-Rover découvertes et, le découvrant, pointent le doigt en un grand éclat de rire. Sur les six kilomètres qui séparent l'aérodrome de la résidence de Dhlakama, c'est la même chose et il nous faudra pratiquement deux heures pour les parcourir. La foule crie : - Sem camisola já ganhou! », "Sans chemise, il a déjà gagné ! " ${ }^{119}$ et Dhlakama, accompagné de la « Première dame » salue en faisant le V de la victoire.

Il y a eu au moins cent mille personnes le long du parcours. On a vraiment l'impression que cette grande ville macua, encore sous contrôle du Frelimo la veille, avait gardé secrète sa sympathie et explose tout d'un coup en prenant d'autant plus confiance en elle. Si la province de Nampula bascule... ${ }^{120}$ En tout cas, le sondage de la Vox Populi ${ }^{121}$ qui donnait la Renamo vainqueur en Zambézia mais vaincue à Nampula - évaluation qui m'avait beaucoup étonné - est infirmé : ce n'est tout simplement pas possible, à moins de supposer que la brousse et les petits centres de l'intérieur macua voteraient totalement différemment de la ville de Nampula ? La réponse est pour bientôt.

Je suis toujours le seul observateur indépendant à suivre la campagne de Dhlakama. Même le nombre de journalistes est déséquilibré. La sous-estimation continue, alors que des dizaines de journalistes, mozambicains et internationaux, accourent aux meetings de Chissano.

19h30. Entrevue avec Manuel Pereira, délégué de Zambézia (qui suit Dhlakama à Nampula). Il est né le 10 octobre 1942 à Nauela, dans l'Alto-Molócuè. Il est lómuè, de parents catholiques, agriculteurs traditionnels. Mais son père était aussi cabo da terra ${ }^{122}$ du régulo Komua, et donc échappait au chibalo $^{123}$. C'était une zone de coton, mais, me dit-il, son père ne s'en occupa pas.

\footnotetext{
*Vieux nom colonial et ethnique de cette vaste région intérieure peuplée en grande majorité par les Macuas. Pendant la période plus récente de l'Estado Novo, elle fut nommée « Moçambique » (car incluant l'ancienne capitale, l'île de Moçambique), puis dans l'État indépendant « Província de Nampula », le gouvernement voulant éviter qu'une province ait le même nom que le pays, et refusant évidemment la consonance ethnique de l'ancienne appellation.

${ }^{119}$ Allusion à la distribution massive de T-shirts par le Frelimo. La Renamo avait des moyens beaucoup plus limités et faisait de sa propre non-distribution un argument électoral.

${ }^{120}$ C'est, avec celle de Zambézia, la plus peuplée du pays.

${ }^{121}$ Entreprise brésilienne de communication (celle qui avait fait la campagne du président brésilien Collor), d'une efficacité redoutable, employée par le Frelimo.

${ }^{122}$ Sorte de contremaître au service d'un régulo, le plus souvent pour surveiller le bon accomplissement des cultures forcées exigées par le colonisateur.

${ }^{123}$ Travail forcé dans les plantations européennes, les ports ou chemins de fer de l'État, etc., durant six mois par an.
} 
Il a grandi à Komua. En 1950, il est entré à l'école catholique qui venait d'être créée et qui menait jusqu'à la $3^{\mathrm{e}}$ classe elementar ${ }^{124}$. Il la termine en 1954. Il entra ensuite au séminaire, où il poursuivit jusqu'à la $8^{\mathrm{a}}$ classe. En 1970 , il commença à travailler comme sous-directeur des écoles et de la catéchèse : - «Com os padres cresci, com os padres trabalhei », « Avec les pères j'ai grandi, avec les pères j'ai travaillé ». Il a travaillé comme professeur de pédagogie de la catéchèse et de l'enseignement biblique jusqu'en 1974, à Nauela.

En 1975, le Frelimo ferma la partie religieuse de l'école et il se retrouva sans travail. Il devint instituteur à Komua, dans l'intention de s'y fixer. Il fut directeur de cette école de huit maîtres en 1975 et 1976, puis, fin 1976, directeur d'une «zone pédagogique » couvrant deux régulos, de $45 \mathrm{~km}$ de long et de quinze écoles. Cependant, souvent il ressentait, malgré son travail, un certain mépris de la part du Frelimo qui lui faisait bien comprendre que sa formation missionnaire ne valait rien. Pourtant, il menait $75 \%$ des enfants à la $4^{\mathrm{a}}$ classe, et sa zone était la meilleure! Mais son salaire était maintenu à un niveau très inférieur à celui des élèves qui sortaient du centre de formation des professeurs en deux ans... Il continua cependant, avec le même salaire et les mêmes responsabilités, jusqu'en 1986.

Depuis 1977, il écoutait «Voz da África livre ». En 1983, la Renamo passa le voir, chez lui. Il eut très peur, le Frelimo disait qu'elle tuait tous les professeurs. Mais les guérilleros ne lui demandèrent que de la nourriture, et le chemin. Il sut ensuite que c'était le commandant Metxa qui avait envoyé le groupe depuis la base de Muaquiwa, assez éloignée. Cette incursion les mena jusqu'à l'Empresa Agrícola de Namilepe dont ils chassèrent les miliciens et les coopérants, puis rentrèrent à la base, « sans exaction contre la population ».

Son salaire ne fut plus versé pendant six mois, puis reprit, irrégulièrement, toujours en retard. Mais, même avec le salaire, on ne pouvait rien acheter dans les boutiques, car les lojas estatais exigeaient en troc des produits agricoles ${ }^{125}$. Or, les professeurs ne produisaient pas... Le mécontentement augmentait. Parmi les professeurs, les jeunes formés en deux ans étaient du Frelimo, les plus anciens "gostavam mais do tempo colonial» (« regrettaient la période coloniale»). Dans cette zone d'influence protestante ancienne et qui se considérait comme "avancée », les gens avaient des maisons en tijolos (briques) avec des toits en zinc. Aussi refusèrent-ils absolument de les quitter pour aller se regrouper en aldeias comunais malgré cinq tentatives de l'administration, et ils rejetèrent aussi la coopérative.

Son fils étudiait au collège de Gurué. Or, à l'issue de la $7^{\mathrm{a}}$ classe, il fut envoyé à Cuba sans que ses parents ne soient consultés ni prévenus. Deux ans sans aucune lettre, une grande angoisse. Là-bas, bien qu'il soit parvenu à la 9 $9^{\mathrm{a}}$ classe, on l'en retira pour le placer à l'académie militaire. Il revint au Mozambique en 1982.

En 1986, la Renamo arriva dans sa «zone pédagogique »: $90 \%$ des professeurs la rejoignirent, sous pression. Aussi, ils restèrent tout simplement chez eux. Les $10 \%$ qui partirent n'étaient en fait pas de là. La Renamo cherchait des intellectuels pour avoir des cadres politiques et des administrateurs. Les professeurs du cru préféraient ne pas avoir de salaire, mais pouvoir cultiver et garder leurs maisons.

La Renamo demanda à une partie des professeurs d'aller suivre le cours de delegados et d'administradores de distritos e localidades. Douze d'entre eux allèrent à Morrumbala, à la base centrale de Mongola. Ce cours était fondé surtout sur la politique («Qu'est-ce que la démocratie ?", dénonciation du «communisme », etc.) et des questions administratives. Trois personnes orientaient le cours, sous la direction d'Anselmo Victor. Au total, avec les personnes venues d'autres localités, une trentaine de personnes suivirent ce cours (qui était répété pour d'autres zones).

Les professeurs restés sur place devaient rester professeurs, après un bref recyclage à Mongola pour apprendre les principes de la Renamo. Six membres du groupe des stagiaires

${ }^{124}$ Les écoles missionnaires pour indigènes dispensaient un enseignement rudimentaire de quelques années, après quoi on pouvait éventuellement rentrer dans la $1^{\text {a }}$ classe primaire. Les enfants portugais du Mozambique, sans problème linguistique, entraient directement dans cette classe. Or il ne fallait pas avoir plus de 14 ans lors de l'accès à la $4^{\mathrm{a}}$ classe primaire. Il était donc très difficile pour un enfant « indigène » de réussir à l'atteindre à temps, ayant dû cumuler enseignement rudimentaire missionnaire et enseignement primaire public. Une solution était l'entrée au petit séminaire.

${ }^{125}$ Les lojas estatais (magasins étatiques) refusaient souvent en effet les meticais, l'argent de l'État, en une démarche désespérée pour inciter les paysans à produire plus que pour leurs propres besoins vivriers et à commercialiser le surplus (en chute libre vu la crise du commerce de brousse). Le résultat fut que le produit des récoltes précédentes, payé en meticais par le réseau public, ne pouvait plus leur servir à acheter des biens de première nécessité. Ce refus, par l'État, d'utiliser sa propre monnaie, fut ressenti comme un vol et provoqua une crise de confiance. 
devinrent delegados distritais ${ }^{126}$, c'est-à-dire des permanents politiques. Les six autres, dont lui-même, devinrent administradores de distrito, des gestionnaires. Les administrateurs collaboraient avec les régulos pour la production agricole, l'entretien des picadas (petites pistes), la construction des écoles au plus près des populations (le Frelimo avait placé l'école très loin).

Il y avait des zones où la Renamo faisait du recrutement militaire, mais pas dans la sienne. Cependant, beaucoup de jeunes «voulaient aller à la guerre », eux aussi étaient très mécontents.

En 1987, Manuel Pereira fut nommé administrateur dans le district de Ile, dans la localité de Mulevala qui était totalement Renamo (sa femme restant à Komua). Les professeurs, majoritairement fidèles au Frelimo, avaient fui à Quelimane ou à Luabo. Quelques "formés » avaient cependant été nommés delegados par la Renamo.

En 1989 il fut appelé, au sein d'un groupe d'administrateurs, à la base du Quartier général de Gorongosa, pour une nouvelle évaluation des Zambéziens (chaque province était appelée à son tour). Ils suivirent une série d'examens écrits et oraux. Le séjour se prolongea douze mois, pendant lesquels, à Mulevala, ses quatre adjoints (le chef de secrétariat, un secrétaire et deux contínuos $^{127}$ ) continuèrent le travail.

A Gorongosa, les cours étaient en portugais. Il fit la connaissance de Dhlakama, qui le nomma administrateur régional, avec responsabilité sur six districts : Mocuba, Ile, Maganja, Pebane, Gilé et une partie du Alto-Molócuè, celle de Mutala - le reste de ce district était coupé par une saillie du Frelimo. Son rôle était celui d'inspecteur, et il passait dans chaque district une fois tous les deux mois, toujours à pieds. Chaque administrateur faisait un rapport, et lui-même faisait le rapport régional pour la province ${ }^{128}$. Il y avait quatre régions en Zambézia et le gouverneur Renamo, Joaquim Alface, un ancien militaire, siégeait à Mongola et faisait le rapport provincial pour Gorongosa. Au cours de tous ses déplacements, il n'eut jamais à participer à un seul combat.

Les administrateurs et les délégués récoltaient la nourriture déjà rassemblée par les régulos et l'amenaient à la base militaire une fois par semaine. Chaque famille devait [le contenu] uma tijela (un récipient).

Administrateur régional, il fut appelé à nouveau à Gorongosa par Dhlakama. Il fit le voyage à pied. Le Frelimo avait ses chemins, la Renamo les siens, passant de zone sûre en zone sûre en continu jusqu'à Gorongosa. Il y resta dix mois, avec des administrateurs régionaux de Zambézia, de Sofala et de Manica. En 1992, il revint, cette fois en avion ${ }^{129}$ et devint délégué provincial pour toute la Zambézia. En effet, le gouverneur Alface avait été suspendu: il avait été nommé à Sofala, mais sa famille ne voulait pas et il avait refusé d'obtempérer.

Il cumula la tâche politique de délégué provincial et la tâche administrative de gouverneur. Le siège civil de la Renamo en Zambézia fut Mucubela à partir de 1992. Il y avait quelques bureaux, un hôpital, la direction de l'éducation, de l'administration, du parti... Cette situation dura car le gouverneur (Frelimo) de Zambézia freinait beaucoup la réunification administrative. Elle n'est toujours pas achevée et plusieurs administrateurs de la Renamo sont toujours en place.

En 1994, la Renamo divisa la Zambézia en sud et nord. Il occupa la partie nord, comme délégué provincial à Mocuba, sous administration Frelimo. À Mocuba, pendant son séjour, il n'a pas eu de problème particulier avec le Frelimo. En revanche, dans la Maganja da Costa, à Caboré, la PIR ${ }^{130}$ a assassiné le délégué local.

Quand le cessez-le-feu fut signé, il y eut une grande fête à Mucubela. La population ne rendait pas la Renamo coupable de la longue guerre, car cela correspondait à son sentiment : sous le Frelimo, tout avait beaucoup empiré, tout était cher et rare. Mais elle fuyait à cause des bombardements des Zimbabwéens et des Tanzaniens. Aussi une minorité se rendit-elle en zone Frelimo afin d'être épargnée.

En 1990, quand Manuel António créa les Naparramas ${ }^{131}$, ces derniers attaquaient en fait en tant que soldats du Frelimo, récompensés avec des biens des Calamités ${ }^{132}$. Au Alto-Molócuè,

${ }^{126}$ Équivalent exact des commissaires politiques du Frelimo.

${ }^{127}$ Contínuos : garçons de service.

${ }^{128}$ La Renamo distinguait deux niveaux intermédiaire, «province » et « région » entre les niveaux locaux et le quartier général.

${ }^{129}$ Après le cessez-le feu ?

${ }^{130}$ Police d'intervention rapide, une police militarisée.

${ }^{131}$ Voir note 28 du chapitre précédent. 
les Naparramas étaient vaccinés au siège même du district. Les soldats de la Renamo avaient peur de leur magie et fuyaient en abandonnant leurs armes. Mais bientôt, ils « expérimentèrent » et constatèrent que les Naparramas mourraient aussi.

Après la guerre, beaucoup d'habitants revinrent en zone Renamo. Ainsi, celle-ci a-t-elle gagné beaucoup de gens après le cessez-le-feu.

Au Sofala, cela avait été différent : pendant la guerre, personne ne fuyait, même sous la famine. Mais après le cessez-le-feu, à l'inverse, beaucoup sortirent des zones Renamo pour bénéficier des secours internationaux qui arrivaient en zone gouvernementale.

\section{3 octobre 1994}

\section{8h30. Départ pour Angoche (hélicoptère)}

9h15. Arrivée à Angoche. Une foule bien ordonnée nous attend. Nombreux groupes de femmes aux pagnes éclatants... La direction du parti est bien alignée au premier rang. Des dignitaires religieux musulmans sont à leur gauche. Il y a deux mille personnes à l'aéroport (le meeting aura lieu plus tard, en ville - tant mieux !). On sent le vieux pays. Les femmes sont subtilement habillées, le beige et l'orange sont les couleurs qui dominent dans leurs vêtements. Elles sont noires, mais on devine le vieux fond métissé arabo-indien. Partout, tambourins et danses. Dhlakama prend presque une heure à saluer tous les «corps constitués » de la ville. Enfin, lui et sa femme s'avancent au milieu de la foule, une belle couronne de fleurs autour du cou.

\section{0h30. Nous partons maintenant à l'île de Quiloa}

10h40. Arrivée à Quiloa, pays de marigots, de palétuviers et palmeraies. Pirogues sur la plage, barques à voile triangulaire sur les bras de mer, traces d'un ancien établissement portugais, femmes de la côte aux mêmes pagnes multicolores où l'orange domine, grande élégance, colliers, masques blancs d'argile sur leurs visages.

Une petite estrade est montée à l'abri d'un bâtiment à moitié en ruine. Les tambourins sont très hauts, troncs creusés frappés par de vieilles femmes. La banderole dit : "Dhlakama, amigo, o povo está consigo » («Dhlakama, ami, le peuple est avec vous »)... La pauvreté semble moindre que dans l'intérieur. L'île n'a pas souffert directement de la guerre. On a l'impression que beaucoup de gens ne connaissent pas la figure de Dhlakama, car ils ne réagissent pas quand il s'approche. Il est vrai qu'il y a peu de photos du líder dans la petite foule (cinq cents personnes) qui s'approche de l'estrade, mais beaucoup restent sous les grands arbres. Des gens arrivent des sentiers alentours.

Il y avait une école, qui allait seulement jusqu'à la $2^{\text {a }}$ classe. Ensuite, il fallait aller à Angoche ! Mais aujourd'hui, même cette école est fermée.

Le meeting se déroule sans haut-parleur ni mégaphone. Il n'y a pas d'Onumoz ni de Civpol. Lors des «Vivas », certains lèvent le poing : vieille habitude...

Femmes si jeunes avec des bébés dans le dos...

Des gens sont venus en pirogue des îles voisines, notamment de Namacula (qui dépend déjà du district de Moma). Là, il y a eu la guerre :

« Nous ne savons pas bien qui c'était, ils volaient les enfants. Quelques-uns sont revenus, d'autres se sont perdus. Si Chissano vient ici, les gens ne viendront pas. Ils ont déjà décidé pour qui ils vont voter, sauf qu'ils ne peuvent pas le dire. Pendant la guerre, les gens considéraient la Renamo coupable à cause de ce conflit, mais maintenant le Frelimo parle, la Renamo parle, les gens écoutent et n'accusent déjà plus la Renamo »,

\footnotetext{
132 «Calamités » (Calamidades) : en un raccourci saisissant, il s'agit de l'appellation familière de la DPCCN, le
} Département de combat aux calamités naturelles (voir note 14 du chapitre précédent). 
me dit Ângelo Ussene, un pêcheur de Namacula. À Quiloa, les professeurs nommés repartaient au bout de quelques mois, car ils ne recevaient jamais leur salaire. Mais à Namacula, il y a une école.

Selon Dhlakama, aucun dirigeant d'aucun autre parti n'est venu à Quiloa. Mais l'admiration principale est pour nos hélicoptères.

12h10. Départ pour Angoche.

12h25. Arrivée à Angoche. Le meeting a lieu au stade. L'hélicoptère fait deux fois le tour de la ville pour prévenir les gens. Ils accourent de toutes les rues, des collines, pour venir au rassemblement et entourent l'hélicoptère de Dhlakama.

Un groupe important de jeunes, en grande majorité des garçons, au milieu de l'assistance, crient bruyamment : "Viva Chissano! Viva Chissano!». Le « cirque » dure une demi-heure, puis le service d'ordre de Dhlakama les disperse. Il paraît que ce sont surtout des jeunes du quartier de Horta-Namaripe.

«Des demeurés, ces gas-là, des voleurs ! Nous avons besoin de lui, c'est Dhlakama qui a ramené la paix ! Il n'y a pas de travail ! ».

Il y a selon moi environ cinq mille personnes. Un Onumoz français me dit qu'il y en avait six à sept mille pour Chissano. Naturellement je ne sais pas si nous avons les mêmes méthodes de calcul.

Avec leurs têtes de «mauvais garçons », le groupe de Horta revient. Deux policiers les raisonnent, sans succès. Dhlakama commence à parler et dit :

«Ne vous inquiétez pas de ces jeunots qui viennent ici crier. Nihia ${ }^{133}$, Chissano, viennent ici, ils achètent ces enfants. Nos enfants ont été obligés par le Frelimo à élever et à manger des porcs. Le Frelimo a nationalisé les trois usines de décorticage de la noix [de cajou]. Cinq cents personnes en tiraient leur emploi. Aujourd'hui, aucune ne fonctionne. [...]. Nous sommes contents que ces enfants soient là, car c'est la démocratie, mais le Frelimo nie la démocratie. C'est pourquoi ces garnements ne savent pas ce qu'ils font. [...]. Le Gouverneneur, les administrateurs, seront macuas. On ne les laissera plus amener des personnes pour traiter les Macuas comme des esclaves. [...] Chissano est venu ici coiffé du cofio. Mais il n'est pas musulman. Il trompe le peuple. Moi, je respecte les musulmans, je respecte les catholiques, mais je ne peux pas porter le cofio. C'est une insulte. Chissano a toujours méprisé les musulmans, il les a toujours traités pratiquement de macaques. [...] Nihia est macua, mais qu'est-ce qu'il a apporté aux Macuas ? Nihia est le valet du Frelimo, il n'est pas le représentant du peuple macua. [...]. Ces gosses, si j'étais Samora Machel, je les aurais déjà fait tuer. Si j'étais Chissano, je les aurais déjà fait passer à tabac ${ }^{134}$ »

Dhlakama accuse la Vox Populi d'acheter les cartes des électeurs qui voteront Renamo. Angoche est une vraie ville, mais il n'y a pas un Civpol pour observer le meeting.

14h10. Départ pour Namapanda (Poste administratif du district d'Angoche).

14h30. Arrivée à Namapanda. Nous atterrissons sur le stade. Les gens sont autour, sous les arbres. Pas de «structures» bien définies pour le meeting, pas de groupes de femmes ou d'enfants ici, une foule gentille et désorganisée. Joli petit bourg, dont les maisons en dur sont parfois détruites. Très jolie estrade de fleurs roses et rouges en forme d'enclos. La foule, un millier de personnes, est assise sous les arbres (chaleur !). Quelques bousculades.

${ }^{133}$ Eduardo da Silva Nihia, premier secrétaire du Frelimo de Nampula, ancien militaire.

${ }^{134}$ Le mot employé par Dhlakama, traduit par «passer à tabac » est chamboquear, verbe dérivé en portugais mozambicain du nom chamboco, qui vient sans doute d'un mot de l'Indonésie sous colonisation hollandaise signifiant «bambou » (sjambok), passé ensuite chez les Boers d'Afrique du Sud, puis au Mozambique et signifiant «être frappé » (à coup de bâton) et par extension, passage à tabac. Passer à tabac est donc chamboquear. 
Le Président est allé se rafraîchir. On met de la musique pour attendre. Il revient, danse avec la musique. Le delegado d'Angoche ouvre la séance avec les Vivas habituels. Il introduit ensuite le délégué provincial, Ricardo Sebastião de Oliveira :

"A Frelimo diz aos chefes não falar macua porque macua é língua de quem não estudou, é língua de quem não é gente », - Le Frelimo a dit aux chefs de ne pas parler macua parce que le macua est la langue de celui qui n'a pas étudié, c'est la langue du moins que rien »,

dit ce dernier, en... portugais ! Dhlakama aborde ensuite ses thèmes habituels, mais habilement « islamisés »:

«Si Dhlakama avait accepté l'amnistie ${ }^{135}$, aurions-nous eu les élections ? Vive la démocratie! [...] Je me rappelle très bien, en 1965-1969, de nombreux Macuas étaient recrutés ici pour le Búzi, pour couper la canne ${ }^{136}$. Et le Frelimo en 1975 a fait la même chose $^{137}$ De nombreux musulmans d'Angoche ont été obligés d'élever des cochons, de manger du cochon. Même les Portugais n'ont pas fait ça. Le Frelimo dit: "Macuas, votez pour nous, nous allons rénover". Mais vous n'êtes pas des enfants! Vous conaissez Chissano ! Il veut maintenant se divorcer [sic] du Frelimo, mais ne sait-il pas que le Frelimo n'est rien sans lui ? C'est lui qui commande tout ! [...] Je vais placer un gouverneur macua à Nampula, les administrateurs, et les postes administratifs ${ }^{138}$ aussi seront macuas ! [...] Il y a un parti appelé Pimo ${ }^{139}$, qui veut profiter d'ici. Ce sont des manœuvres, le Pimo n'est pas un parti. Est-ce que ça existe par ici ? Ça n'existe pas le Pimo. Chissano porte le cofio. Est-ce qu'il ne se moquerait pas de nous? N'est-ce pas une insulte? Je ne porte pas le cofio. Mais je reconnais votre religion, la Renamo va protéger les religions. »

\section{6h15. Retour à Nampula.}

17h30. Conférence de presse de Dhlakama, à sa résidence de Nampula. Il déclare qu'on va aller dans beaucoup de très petits endroits où les gens ne connaissent pas sa photo. Il se plaint du boycott des médias : la TVM est correcte, mais pas la Rádio Moçambique qui ne passe rien. Quand Chissano est venu à Nampula, on a fermé les entreprises, envoyé les élèves, on a amené des orchestres, fait un spectacle de sauts en parachutes. Lui n'a rien fait de tout cela, mais l'accueil que la population lui a offert est seulement comparable à celle du pape ${ }^{140}$ ! Il se dit « très préoccupé, il faut que la presse parle de ce qui se passe ! ».

135 Allusion aux amnisties successives que le Frelimo, pendant la guerre, promulgua pour tenter de casser la Renamo.

${ }^{136}$ Le Búzi, district du Sofala, dont est originaire Dhlakama, était le lieu de l'une des plus importantes compagnies latifundaires, la Companhia do Búzi. Elle allait recruter ses travailleurs parfois très loin, notamment dans la région d'Angoche, en régime de travail forcé avant 1961, et en régime progressivement plus libre ensuite, Dhlakama se souvient donc de ces travailleurs macuas venus en Sofala.

${ }^{137}$ Fidèle à son modèle de modernisation autoritaire accélérée, le Frelimo ne rendit jamais aux paysans la terre des compagnies coloniales, ce qui eut pu être la basse d'une agriculture familiale, ou de petits propriétaires, florissante, préférant en faire directement des entreprises publiques, par intervention ou nationalisation. De ce fait, les paysans alentour, ressentant cette continuité, se précipitèrent d'autant moins pour y travailler que la contrainte avait faibli. Cela impliqua donc d'essayer de continuer des recrutements très lointains, dans des zones culturellement différentes - mais rapidement cela ne fut plus possible. Dhlakama d'ailleurs prudemment n'évoque que le début de l'indépendance : « en 1975... ».

${ }^{138}$ Le district, échelon inférieur à la province, est dirigé par un administrateur ; l'échelon administratif le plus bas est le Poste administratif. La Renamo, non sans raison, accuse le gouvernement de nommer partout des gens du Sud.

${ }^{139}$ Pimo, Partido independente de Moçambique, qui se serait appelé parti islamique du Mozambique si la loi ne l'avait pas interdit. Ce parti n'a eu qu'un faible succès auprès des diverses communautés musulmanes. Dhlakama présente ce parti comme une création du Frelimo, d'autant que son principal et jeune dirigeant, Jacob (devenu en cours de campagne Ya-Qub) Sibindy est de la même région que lui.

${ }^{140}$ Jean-Paul II était venu à Nampula en 1988. 
Il est vrai que persiste un extraordinaire déséquilibre médiatique. Je suis toujours le seul observateur étranger indépendant à suivre la totalité de la campagne de Dhlakama. Quelques rares correspondants de presse étrangers font leur apparition quelques jours (trois jours pour le Público de Lisbonne, un jour pour l'Expresso) mais aucun ne suit et ne peut sentir la totalité de la campagne, notamment dans les petites localités de l'intérieur. Quant à moi, je ne suis pas journaliste et je n'envoie pas d'informations quotidiennes à une rédaction. Les journalistes mozambicains font leur travail et envoient leur matériel à Maputo, mais ils ne sont pas maîtres du traitement qui en est fait. Il y a aussi dans la presse des mensonges absolus. Ainsi, dans Notícias du samedi $1^{\text {er }}$ octobre, p. 3 , dans un article dont le titre déjà est partial "Chissano chega à Zambézia e contraria tendência do voto », "Chissano arrive en Zambézie et renverse la tendance du vote »-, est écrit ce qui suit :

«Chissano est descendu du véhicule qui le transportait [...] et se mêla au délire de centaines de milliers de personnes qui criaient : "Chissano, c'est déjà gagné !" »

Centaines de milliers ? Dans une ville moyenne comme Quelimane ? Mais l'article continue :

«Il est curieux qu'environ une demie-heure après l'atterissage de Chissano à Quelimane, le líder de la Renamo, Afonso Dhlakama, a aussi atterri dans le même aéroport et son escorte est passée inaperçue ».

Son escorte est passée inaperçue ? L'auteur de l'article, Jaime Cuambe, peut, en tant que journaliste, s'enorgueillir d'avoir produit un mensonge total, frontal! Je n'étais pas avec Chissano, je ne sais pas combien de personnes étaient avec lui - certainement pas des centaines de milliers parce que dans une ville comme Quelimane cela est mathématiquement impossible. Mais j'étais avec la délégation de Dhlakama, et je sais qu'un cortège qui a besoin d'un heure pour faire deux kilomètres ne peut pas passer inaperçu. À mon avis il y avait deux mille personnes, c'est-à-dire bien moins que quinze jours auparavant, mais la mobilisation avait été différente aussi, il n'y avait aucun meeting prévu. J'ai entendu dire que pour Chissano il y avait dix mille personnes, soit le même type de mobilisation que pour Dhlakama quinze jours auparavant ${ }^{141}$.

Quant à l'accueil à Nampula, cent mille personnes à mon avis, on va voir le traitement fait : hier 2 octobre, la TV a passé des images sans aucune estimation chiffrée. La radio n'a rien dit $d u$ tout...

Quelque chose se passe. Bien ou mal, la population n'ayant pas d'autre alternative, est en train de s'emparer de la Renamo pour exprimer sa volonté de changement. Il est frappant de voir que la population n'accuse nullement la Renamo de la guerre, et quand elle la rend responsable, c'est à égalité avec le Frelimo. La guerre n'est pas, électoralement parlant, un facteur hostile à la Renamo.

Je commence donc à penser possible (pas certain, bien sûr) une victoire de la Renamo. Je découvre aussi un parti, avec des centaines de cadres locaux, presque tous civils (une petite minorité seulement a été militaire) et qui étaient déjà responsables civils pendant la guerre. On a de toute évidence sous-estimé la composante civile, même si, évidemment, la composante militaire dominait. Cette guerre a été très « secrète ». Les gens, peut-être culpabilisés par l'État, ne disent pas ce qu'ils pensent. Mais ça peut «exploser » comme ça a explosé à Nampula le $1^{\text {er }}$ octobre 1994.

\section{Le 4 octobre 1994, départ pour Moma, sud de la province de Nampula}

9h40. Entrevue avec Fernandinho Zacarias (clan Sibindy). [Fernandinho faisait partie de l'équipe de campagne de Dhlakama, en particulier de son atelier vidéo. Nous conversons, assis sur la piste de l'aéroport].

\footnotetext{
${ }^{141}$ Ce paragraphe a été écrit en portugais dans mon carnet, sans doute sous le coup de la colère !
} 
Fernandinho est né à Chibabava, exactement à Mexungué, le 9 septembre 1965. Sa langue maternelle est le cindau, mais il parle aussi cisena. Il a fait l'école primaire jusqu'à la 4a classe à Chibabava, et l'école secondaire jusqu'à la 7ª classe à Dondo :

«Il était en vacances à Chibabava quand la Renamo est arrivée. Ses parents sont paysans, son père aimait bien cultiver le coton parce qu'il avait une machamba grande (une exploitation assez grande) $)^{142}$. Ses parents pratiquent la religion traditionnelle mais lui-même est «zione ${ }^{143}$. Il a été baptisé dans la rivière, à l'âge de onze ans, mais ne sait pas bien par quelle Église. Son père a beaucoup souffert du Frelimo : il haïssait le travail en machamba colectiva $^{144}$, les réunions obligatoires. En 1978, le secrétaire local du Frelimo, Manuel Sitole, envoya un groupe de députés ${ }^{95}$ et ils l'amenèrent au local du parti : - Chamboquearam até ponto que ficou quinze dias no hospital », "Ils l'ont passé à tabac si durement qu'il fit quinze jours d'hôpital ». A partir de là, toute la famille vécut dans un climat d'hostilité. Dans le village, beaucoup de familles connurent des histoires de ce type.

Dans ce district, la Renamo agissait, selon lui, depuis 1979. Elle avait dès cette année attaqué un camp de Zimbabwéens ${ }^{96}$. Mais on la connaissait mal, on savait seulement qu'elle était contre le Frelimo.

La Renamo venait se ravitailler dans son village depuis 1980. Mais lui-même, à l'école à Dondo, ne les avait pas encore vus. Le secrétaire local du parti s'était déjà replié au chef-lieu. La Renamo arriva vers huit heures. Il était là seulement depuis trois jours, pour les vacances de décembre 1981. Il avait seize ans. Les soldats parlèrent avec ses parents : - Precisamos do seu filho », « Nous avons besoin de votre fils ». Ces derniers lui demandèrent son avis : il était d'accord. Il savait que s'il continuait ses études, il serait bientôt appelé aux FPLM. Il préféra cette solution ${ }^{147}$.»

\section{0h15. Départ pour Moma.}

11h15. Arrivée à Moma. En arrivant sur la côte, marigots et palmeraies. Foule assez importante en bordure de la petite piste, environ quatre mille personnes, qui nous attendent depuis huit heures ce matin... La direction du parti local est au premier rang. mais les cheikhs ${ }^{148}$

${ }^{142}$ Après la fin des cultures forcées (1961-62), les compagnies coloniales commencèrent à cultiver directement le coton avec des moyens mécaniques modernes, plutôt que de simplement tenir des concessions sur lesquelles travaillaient des paysans contraints vendant leur produit pour des prix dérisoires. Certains petits colons portugais aussi s'y mirent, le prix d'achat croissant rapidement. Cependant, la plupart des Africains en profitèrent pour arrêter complètement une culture cotonnière honnie : "Jà não batem », «Ils ne nous battent plus ». Cependant, une très petite minorité d'Africains avaient, dès avant 1961, réussi, en général grâce à la protection de l'administration coloniale, à développer une culture cotonnière plus moderne et sur une superficie plus étendue. Ils étaient considérés comme des semi-assimilés par l'administration, bénéficiant du statut d' «agriculteur africain » et n'étaient pas astreints au travail forcé. Ces rares Africains-là continuèrent la culture cotonnière après 1961, et d'aucuns les traitèrent ensuite de «koulaks». Par cette simple précision sur la machamba grande de coton de son père, Fernandinho nous renseigne ainsi sur la trajectoire sociale de sa famille paternelle à la fin de la colonisation. Mais on ne saurait en tirer des conclusions hâtives sur les alignements politiques provoqués par ce type d'évolution sociale : dans d'autres cas, précisément parce qu'ils étaient «modernes», les anciens «agriculteurs africains » furent favorables au Frelimo.

${ }^{143}$ Les églises sionistes se sont répandues rapidement au sud du Mozambique, puis remontant vers le nord. À la différence des autres églises dissidentes (églises protestantes noires ou « éthiopiennes »), elles pratiquent l'apposition des mains et des rites guérisseurs.

${ }^{144}$ Champ collectif, avec ou sans village communal, qui servait à montrer que le peuple soutenait le Frelimo, et aussi à dégager un petit surplus permettant de recevoir les officiels de passage.

${ }^{145}$ Il s'agit ici de « députés » de l'assemblée de localité, en pratique des militants locaux.

${ }^{146}$ Il s'agit donc ici, à cette date (1979) d'un camp de nationalistes, probablement Zapu (Zimbabwe African People's Union). La Renamo jouait le rôle de supplétifs des forces de Ian Smith (le dirigeant de la Rhodésie blanche), à l'intérieur du Mozambique.

${ }^{147}$ L'histoire de Fernandinho continue dans les notes relatives au 7 octobre, $9 \mathrm{~h}$.

148 J'ai noté «cheikhs» sur mon carnet de notes, mais il s'agit de xehes ou chéhés dignitaires religieux musulmans. 
sont, au moment de l'arrivée, en arrière (en fait c'est parce qu'ils sont déjà près de l'estrade). Groupes de femmes. Un long tapis va de la piste à l'estrade, joliment décorée de fleurs et de palmisses. Et toujours ces belles femmes de la côte, aux pagnes où l'orange domine...

Le délégué, João Apacar, est membre de la Renamo depuis 1984, et a toujours été civil, chargé de la mobilisation. Il a été à Monapo, à Nampula (dans la clandestinité en 1989), à Moma (en 1993). Il a la 6e sixième classe de la mission de S. Miguel. Lui-même est catholique, mais la majorité des membres de la cupula sont musulmans. Toute la direction est civile, il n'y a pas de militaires. Les soldats sont seulement membres.

C'est toujours la même chose. Aucun militaire, ou presque, dans les directions locales du parti ! Ça ne peut être que volontaire. Le fait que le parti civil ait été organisé alors que les militaires étaient encore cantonnés a dû aider. Mais à l'inverse, s'il y avait eu ordre d'intégrer un certain nombre de soldats de la guérilla, cela aurait été fait.

11h45. Arrivée de Dhlakama. Le soleil est écrasant. Heureusement, il y a du vent. Aucun Civpol en vue. Un cheikh ${ }^{149}$, Maca, récite une sourate, la foule répond en cœur. C'est une position de la hiérarchie religieuse locale bien nette ! Le délégué provincial commence par un discours uniquement en macua, sauf les Vivas! On lit un «Message des Musulmans au Président Dhlakama » (dont je ne peux savoir la représentativité), qui est strictement identique au discours de la Renamo. Dhlakama fait alors un discours sur son thème du « vosso filho » (« je suis votre fils »), mais brode bien sûr :

«Le district, sur la côte, est oublié, le gouvernement de Nampula ne s'occupe pas d'ici. [...] Aujourd'hui, c'est le deuxième anniversaire de l'Accord général de Paix, deux années de démocratie, deux années sans villages communaux [...]. Ils ne nous obligent plus à élever des cochons [...]. Pourquoi est-ce que le Frelimo n'a pas demandé nos votes en 1975 ? [...] Mon père était chef traditionnel, il n'a jamais été riche, c'est pourquoi voter pour Dhlakama c'est voter pour la démocratie [...].

- Quem é que criou as aldeias comunais?, «Qui est-ce qui a créé les villages communaux? »

- la foule : «Fre-li-mo!»

- Quem é que criou machambas colectivas?, «Qui est-ce qui a créé les champs collectifs ?»

— la foule : «Fre-li-mo!»

- Quem é que criou guias de marcha?, «Qui est-ce qui a créé les laissez-passer ?»

- la foule : «Fre-li-mo!»

- Quem é que aboliu os chefes tradicionais?, «Qui est-ce qui a aboli les chefs traditionnels?»

- la foule : «Fre-li-mo!»

- Quem é que diz que Deus não existe?, «Qui est-ce qui a dit que Dieu n'existe pas ?»

- la foule : «Fre-li-mo!»

- Quem é que criou os Snasp que andava a matar gente?, "Qui est-ce qui a créé le Snasp qui venait tuer les gens?»

— la foule : «Fre-li-mo!»

- Quem é que enviou as vossas crianças para Cuba para cortar a cana de açucar?, «Qui est-ce qui a envoyé vos enfants à Cuba couper la canne à sucre ? »

- la foule : «Fre-li-mo! » [...]

Les administrateurs vont être macuas. Est-ce que des fois vous ne sauriez pas écrire? Mais tous sont venus de Maputo. [...] Dhlakama va établir l'équilibre du pouvoir. [...] Le système d'éducation est marxiste. Nos enfants sont obligés d'apprendre seulement les principes du Frelimo dans les livres. [...] Un parti au pouvoir ne promet pas, il fait. Quand un parti au pouvoir promet, c'est qu'il ment! Pourquoi est-ce qu'il nous lit un nouveau programme ? Pourquoi est-ce qu'il ne l'a pas fait depuis $1977^{150}$ ? Est-ce qu'ils iront le faire après [les élections d'] Octobre ? (la foule : - Não!). C'est un mensonge, c'est un pagne usé jusqu'à la corde. [...] Avec les systèmes marxistes, tous les administrateurs doivent être membres du Frelimo. Même les professeurs, les infirmiers... A Inhassunge, deux directeurs d'école, qui avaient des années d'ancienneté, ont été expulsés quand le Frelimo a su qu'ils avaient adhéré

\footnotetext{
${ }^{149}$ Voir note précédente, pour tout nouvel emploi de « cheikh».

${ }^{150}$ Le Mozambique a acquis son idépendance en 1975, mais le programme de «transition socialiste » a été adopté au $3^{\mathrm{e}}$ congrès en 1977, lequel a transformé le «front » Frelimo en « parti Frelimo ».
} 
à la Renamo. Alors maintenant dans cette campagne électorale ? Le Frelimo continue d'être marxiste !»

À la fin, on lui offre une grande maquette de bateau de l'océan Indien. On lui offre aussi un bonnet de léopard. Il le met, qu'est-ce qu'il ressemble à Mobutu ! Bigre...

13h30. Départ pour Chalaua (hélicoptère).

14h. Arrivée à Chalaua, après avoir cherché la localité pendant dix minutes. C'est un petit poste du district de Moma. Quelques bâtiments en dur au milieu d'un habitat très dispersé. Quelques toits de tuiles aussi, un peu insolites.

La foule se rue sur l'hélicoptère du Président, banderole en tête, puis se dirige en un joyeux désordre vers le lieu de réunion, ombragé de grands arbres. Là, tambourins, danses, chants. Mais l'estrade étant trop basse, on change d'endroit. Le Président parlera de la plate-forme du... poste de police local, un bâtiment quasiment en ruine, mais surélevé. Beaucoup de monde, pour un petit poste administratif (environ 2500 personnes). Pas de Civpol en vue. Grappes d'enfants dans les arbres.

Le délégué appelle les responsables religieux, musulmans, catholiques, Assembleia de Deus, adventistes du $7 \mathrm{e}$ jour, baptistes. Un dignitaire musulman ouvre la réunion avec exhortation et prières. Des camions chargés de coton passent...

Dhlakama fait ici un discours très ethnique :

«[...] Il y a beaucoup de démobilisés ici, il y a eu beaucoup de jeunes Macuas qui sont morts, qui ont perdu les jambes, qui ont accepté la faim, les bombardements [...]. Dhlakama a beaucoup d'appuis parmi les macuas. Dhlakama au pouvoir va respecter le Macua.

- Jà escolheram ?, « Vous avez déjà choisi ?»

- la foule : «Não!»

- Então, após a minha vinda, vão escolher?, «Alors, après ma visite, vous allez choisir?»

- la foule : «Sim!»

- Nos jornais, andam a dizer que os Macuas querem todos Chissano. Será verdade?, «Dans les journaux, ils disent que tous les Macuas veulent Chissano. C'est vrai ? »

- la foule : «Não!»

15h. Départ pour Inluti.

15h20. Arrivée au poste d'Inluti. Vu d'hélicoptère, partout les gens courent pour rejoindre le lieu de réunion, un peu à l'écart du PAdm ${ }^{151}$ lui-même, à savoir une rue de maisons en dur, semble-t-il non détruites par la guerre, au milieu de quelques maisons en banco [argile]. Le terrain est ombragé d'arbres, une banderole affirme : "Dhlakama, defesa da cultura tradicional » («Dhlakama, défense de la culture traditionnelle »). Nous avons beaucoup de retard. Les Vivas habituels. Même le flic à la « kalache » y répond. L'habitude sans doute...

Dhlakama parle d'une voix fatiguée avec un simple mégaphone. Or un groupe de cinquante jeunes du Frelimo (avec des T-shirts qui semblent tout neufs) crient bruyamment. Quelques bagarres, deux policiers interviennent mollement. Le bruit suffit à rendre inaudible le discours parmi une partie du public. Les agitateurs semblent être de jeunes scolarisés. Le service d'ordre de la Renamo n'intervient pas. Le reste du public écoute gentiment. On rigole à propos des jeunes du Frelimo et on se sépare en criant : - Sem camisola, Dhlakama jà ganhou!", "Sans T-shirt, Dhlakama a gagné !».

16h10. Départ pour Nametil (hélicoptère).

16h25. Arrivée à Nametil, chef-lieu du district de Mogóvolas. Large rue bordée de maisons en dur, et les habituels quartiers bancos. La terre est rouge. On se rassemble sur une place, où

${ }^{151}$ Abréviation courante pour Poste administratif, le plus bas échelon de l'État. 
Dhlakama va parler du balcon d'un bâtiment d'école en dur. Banderole et groupes d'hommes, tous coiffés du cófio, dansant et psalmodiant. Dans une salle de classe vidée, un buffet est monté. Dhlakama, sur une chaise, est porté triomphalement par un groupe de femmes, amené devant le buffet et, là, salué par deux dignitaires religieux. Accolades avec deux Indiens, bonjour à la Civpol. Il y a aussi un vieux Portugais, né en Aveiro, qui a eu ses enfants au Mozambique d'une Mozambicaine, est toujours resté et va rester. Sur le plan politique, il me dit simplement : - Sou estrangeiro », «je suis un étranger ».

C'est très impressionnant, il y a énormément de monde, vingt mille personnes sans doute dans ce petit bourg de l'intérieur! Selon un Onumoz français, il y en a eu cinq mille pour Chissano les semaines précédentes. Dhlakama :

«A Frelimo nunca respeitou o Macua... Le Frelimo n'a jamais respecté le Macua. Mas aqui hoje, o Macua é forte... Mais ici, aujourd'hui, le Macua est fort... A Frelimo obrigou os muçulmanos a criar porcos! Ah! Le Frelimo a obligé les musulmans à manger du porc $\mathrm{Ah} ! »$

Appel systématique à la macuanité pour qu'elle soutienne la Renamo qui lui rendra sa dignité. Il s'adresse aux gens en les appelant «Macuas! ». Je suis en pleins travaux pratiques! ${ }^{152}$ Car Dhlakama soulève cette foule, cette foule noire compacte dans la lumière du soir. Il est subversif uniquement parce qu'il s'adresse à elle en l'appelant par son nom, par son identité : « Macuas !", là où le Frelimo ne dit jamais que: "Moçambicanos!". Le reste n'est que pacotille. Au seul nom de «Macuas! » proféré par un grand chef, la foule tressaille et entonne un hymne macua.

Je repère seulement à la fin le petit groupe Frelimo. Les gardes, d'habitude tranquilles, sont nerveux. Le groupe frelimiste lance des pierres sur les hélicoptères. Une grosse pierre frappe «mon » hélicoptère soviétique juste au moment où j'y pénètre en courant. Le colonel Butre sort son arme, sans tirer, mais reste debout devant la porte ouverte, l'arme tendue, pendant que l'appareil s'élève péniblement.

17h25. Départ pour Nampula à la nuit tombante.

17h50. À Nampula. En fait, je n'ai pas vu tous les incidents. L'hélicoptère du Président - un petit appareil britannique - a été sérieusement attaqué, les vitres ont volé en éclats alors qu'il était déjà à l'intérieur. Dhlakama est furibond :

«Chissano n'est plus un chef d'État, c'est un gosse. J'ai mes gardes. Jamais rien n'est arrivé. Dans les pays démocratiques, il n'arrive jamais que le parti au pouvoir crée un groupe pour attaquer le líder de l'opposition. À Mogóvolas, j'estime que nous étions 20000 , et sans congé ${ }^{153}$, sans camions. C'est ce que fait le Frelimo, et maintenant il crée ces groupes. J'ai abandonné la vie militaire, je suis un líder politique. J'aurais déjà pu les faire battre, je n'ai rien fait. La police, avec ses armes, n'a rien fait. Ils doivent savoir que ce sont les deux provinces les plus importantes. Et je vais gagner.

Chaque fois plus, avec ce succès, ils vont créer de ces groupuscules. Je le promets, mes gardes ne vont pas réagir. Ce seront les journalistes qui vont dire : «Les gardes de la Renamo battent ». Je ne vais rien demander. La police est de l'État. La violence vient de l'État, du Frelimo.

Si j'étais à leur place, je ne ferais pas ça, j'organiserais des groupes d'adultes non pas pour des désordres, mais pour dire qu'ils ne veulent pas de Dhlakama.

S'il y a des fraudes [aux élections], nous n'allons pas les reconnaître. Il y aura d'autres élections. Le recours à la guerre est exclu.

Chissano ne doit pas rester enfermé dans son palais. Je voudrais attirer l'attention du Frelimo. Si le Frelimo a déjà perdu, c'est mieux de l'admettre. Si je l'avais demandé, la population de Mogóvolas aurait taillé en pièces ces garnements.

${ }^{152} \mathrm{Je}$ venais de publier mon ouvrage Ethnicité politique. Pour une lecture réaliste de l'identité (Paris, L'Harmattan, 1994, 170 p.) qui cherchait justement à étudier les conditions d'une intégration à la démocratie politique des mouvements sociaux de facture ethnique.

${ }^{153}$ Allusion au jour de congé donné par l'administration et les entreprises quand Chissano vient tenir meeting. 
Mais en tant que politique, je gagne beaucoup plus avec mon attitude. »

À côté de Dhlakama, pour cette conférence de presse organisée, se tient le régulo Nampula qui a été emprisonné par le Frelimo mais qu'ensuite Chissano a voulu regagner en lui offrant des « gratifications » qu'il a refusées ${ }^{154}$.

\section{5 octobre 1994.}

10h45. Départ pour Monapo.

11h20. Arrivée à Monapo, aéroport. Un groupe nous y attend mais le rassemblement est au stade, à environ cinq kilomètres. Le cyclone Nadia a couché beaucoup d'arbres. Au stade, les groupes de femmes sont bien organisés, tambourins, des jeunes hommes dansent.

Le délégué de la Renamo à Monapo, Hilário Lautino, est membre depuis 1991. Il était le seul ici à ce moment. Il a la 7a classe et est instituteur. Il n'a jamais été militaire et il n'y a pas de militaire dans la cupula local: - Os desmobilizados estão a tratar da vida deles. Não são responsáveis », «Les démobilisés s'occupent de leurs vies, ils ne sont pas les responsables dirigeants ».

Les dignitaires musulmans sont d'abord assis sur les gradins du stade au pied de l'estrade, puis certains y montent. À l'entrée, un Civpol.

12h. L'avion du président arrive à l'aéroport. Selon Issufo Momade (cousin du général de la Renamo, du même nom), qui est membre de la Commission électorale du district, il y avait moins de monde pour Chissano le 23 septembre dernier que pour Dhlakama aujourd'hui. Cela dit, d'une part, il est membre de la Renamo et donc porté à l'enthousiasme ; d'autre part, il y a ici 3500 personnes, ce qui peut paraître un gros meeting: à mon avis, pour un district relativement concentré et aussi important démographiquement (environ 120000 habitants) et économiquement que Monapo $^{155}$,j’attendais plus de gens.

12h20. Arrivée du Président au stade de Monapo. Il salue les responsables du parti, puis les dignitaires religieux. Un grand drapeau musulman, noir et orange avec écriture arabe, est brandi dans la foule. Bousculades, des gens vont et viennent.

12h40. Le meeting commence enfin. Insupportable et permanent retard... Les délégués, local et provincial, parlent en emacua, puis Dhlakama lui-même. Il était déjà venu ici en décembre 1993, réaliser un « petit meeting ». Dans ce discours, comme toujours, quand il parle de la guerre, c'est au sujet des «populações que tão sofreram da guerra » (« des populations qui ont tant souffert de la guerre »), mais il ne dit pas que lui-même l'a faite : en ce qui le concerne, il dit avoir mené la lutte.

Ovations quand il dit qu'il ne veut plus ni aldeias comunais, ni guias de marcha, ni campos de reeducação. Et là aussi : - Macuas, jà ganharam a vossa luta! », " Macuas, vous avez déjà gagné la bataille!».

- La PRM ${ }^{156}$ continue à menacer la population ?

- Sim!

- Si la police menace la population, ce n'est pas la police, c'est le Frelimo. Nous n'allons pas supprimer la police. Nous allons organiser des cours, ils n'ont pas de formation, ils respectent des ordres venus d'en haut sinon ils sont tués. Ils ont travaillé dix-neuf ans avec le Frelimo, si Chissano gagne ils vont continuer pareil. »

\footnotetext{
${ }^{154}$ Le régulo Nampula était un fidèle soutien de l'administration portugaise. Il fut même, à la fin de la période coloniale, député à l'Assemblée de l'« État du Mozambique ».

${ }^{155}$ Monapo a été, depuis pratiquement le début du siècle, une zone d'intenses cultures, en cultures forcées (coton) et en grandes plantations (João Ferreira dos Santos, etc.)

${ }^{156}$ Police ordinaire.
} 
La foule est enthousiaste face aux critiques de la police (pourtant fort modérées). De plus, il promet d'augmenter les salaires de la police afin qu'elle ne vole plus le peuple.

« Nous n'allons pas faire comme le Frelimo qui en 1975 a chassé tous les Mozambicains qui travaillaient dans la police, seulement parce qu'ils étaient colonialistes. Le Frelimo comme ça a détruit la police.

Les Sise S157 $^{15}$, ce sont nos frères. Dans tous les pays, il y a des services de sécurité qui protège l'État, qui recueille de l'information utile pour la sécurité de l'État. Une fois Dhlakama au pouvoir, il va promouvoir des cours, de façon à ce que nos frères du Snasp respectent la vie privée, nous n'allons pas écouter les téléphones quand le mari envoie des baisers à sa femme, pour après le poursuivre. »

Il accuse aussi le Frelimo d'avoir volé les dons de la communauté internationale pour le cyclone Nadia qui a détruit Monapo - l'accusation n'est pas neuve. Et il poursuit avec un habile parallèle entre l'Afrique du Sud de l'apartheid et le... Frelimo :

«Les Sud-Africains ont construit des maisons, des routes, mais c'était pour un groupe minoritaire seulement. Si le Frelimo a construit, c'était pour un groupe minoritaire seulement. Le Frelimo ne va jamais faire ce qu'il n'a pas fait pendant vingt ans. La seule alternative, c'est la Renamo, le Frelimo doit prendre sa retraite [...]. »

À la fin du meeting, un dignitaire religieux offre à Dhlakama des tissus aux motifs islamiques.

Tout s'est bien terminé. Pourtant, il semble que des incidents étaient prévus. Nihia, le premier secrétaire du Frelimo pour toute la province de Nampula, était à Monapo hier, et avait organisé un groupe de jeunes. Mais l'administrateur en a eu vent et a tout fait stopper. Le groupe de jeunes a été empêché de se rendre sur les lieux du rassemblement.

Petite conversation avec le régulo Nampula. Il fait partie de la direction du parti à Nampula. Ses premiers contacts, dans la ville même, remontent à 1990.

\section{4h30. Départ pour Nacala.}

14h45. Arrivée à Nacala (aéroport militaire). Des camions nous attendent pour aller à Nacalaa-Nova. « Nadia » laisse encore des traces : partout des anacardiers et des palmiers couchés sur le sol, des toits de chaume visiblement tout neufs, des murs de banco effondrés. Beau soleil, vent frais, lumière méditerranéenne.

15h30. Nous arrivons au grand stade. Foule considérable et bien ordonnée, groupes de femmes organisés. Très nombreuses banderoles, sonorisation déjà installée : visiblement, l'organisation locale a été solide. Les dignitaires religieux ont la coiffe omanite. Les gens sont là depuis 10 heures du matin et il est $16 \mathrm{~h}$. Toujours rien, le Président se repose-t-il ?

La Jeunesse du parti entre dans le stade avec banderoles et drapeaux.

16h10. Le cortège présidentiel arrive enfin, précédé de camions hérissés de drapeaux musulmans et bourrés de gens. Dhlakama entre en apothéose, debout sur une voiture découverte, suivi de cheikhs [xehes], qui entrent à pied avec leurs drapeaux. Offrande de fleurs. Bousculades. Attention les bébés poussés par la foule ! Une jeune femme s'évanouit Il y a trente-cinq mille personnes environ.

16h30. Dhlakama parle. C'est la deuxième fois qu'il est là, depuis décembre 1993. Discours d'appel aux libertés, à la démocratie, contre l'oppression frelimiste.

«As mesquitas foram transformadas em sedes do partido Frelimo.... Les mosquées ont été transformées en sièges du parti Frelimo. Jamais haverá presidente ditador... Plus jamais il n'y aura de président dictateur. »

\footnotetext{
${ }^{157}$ Sise, Serviços de informação e segurança de Estado, les services de renseignements civils, que la Renamo accuse de n'être qu'une nouvelle mouture du Snasp, la police politique.
} 
Il reprend ses thèmes favoris d'écoles primaires aux cycles complets sur place, de la santé budgétairement prioritaire, de la médecine préventive et des brigades mobiles.

Dhlakama : - Pourquoi le Frelimo n'achète pas de médicaments pour l'hôpital ?

La foule : - Faz candonga! », «Il fait la candonga ${ }^{158}$ ! »

Il reprend le thème «Nadia » sur l'aide internationale volée (ovations de la foule), et sur le maïs du Programme alimentaire mondial qui est resté pourrir des semaines avant d'être distribué.

«Le Frelimo, c'est un pagne usé. Dhlakama, c'est un pagne tout neuf » (rires).

Il insiste sur la nécessité de changer les gens du pouvoir.

« Je ne suis pas régionaliste : ils peuvent toujours m'en accuser. Mais tout le monde doit gouverner. Ceux de Nampula, ceux de Maputo, ceux de Nacala, etc. Je vais établir l'équilibre. »

Il fait appel aux fonctionnaires pour qu'ils n'aient pas peur de la Renamo. Elle ne va pas les chasser. Elle ne va pas faire la même chose que le Frelimo en 1975 qui a chassé les fonctionnaires de l'État colonial. De même il fait appel aux agents du Sise (Snasp), de la police. Les coupables sont Manuel António ${ }^{159}$ et Joaquim Chissano.

Dhlakama cherche-t-il, en abordant depuis deux jours, systématiquement, le thème des fonctionnaires et de la sécurité, à éviter un coup d'État, un nettoyage contre lui provoqué par la peur? Ou du moins à prévenir des problèmes futurs? Mais cela signifie qu'il commence vraiment à penser qu'il peut gagner.

La Renamo devient civile, mais l'esprit et la mentalité militaires demeurent. Obéissance et admiration au líder : fascisme ? Mais la mobilisation se fait sur les thèmes de la démocratie, de la liberté individuelle et collective, de l'État de droit, et pas seulement de la tradition. La foule vient pour ces deux registres indissociablement mêlés par l'oppression frelimiste. Même si l'ambiance est d'adulation au líder, ce líder n'a pas un très grand charisme et l'atmosphère n'est vraiment pas celle des rassemblements de masse du fascisme : c'est plutôt la pagaille..., les danses, les bousculades, les rires ! C'est la prise de confiance en elle d'une masse longtemps reléguée au secrétisme individuel, lignager ou clanique, par la répression et la culpabilisation frelimiste.

Il y a une énorme question: de toute évidence la Renamo est déjà un parti, avec des ramifications partout, des structures, des gens qui se connaissent, etc. Comment se fait-il que le Frelimo ne s'en soit pas aperçu après deux ans ? Évidemment, au départ, la Renamo a encore largement agi clandestinement ou semi-clandestinement. Par ailleurs, les services de renseignement de l'État ont été affaiblis par la transformation du Snasp en Sise et étaient de ce fait plus tournés vers la Renamo militaire que civile. Il est quand même frappant de voir que la Renamo a continué à être exclusivement considérée sous l'angle militaire, la démobilisation et l'intégration partielle à la nouvelle armée ayant attiré l'essentiel de l'attention. Par ailleurs, le Frelimo a toujours considéré, sur le fonds, la Renamo comme quelque chose d'apolitique (les « bandits ») et n'a donc, de lui-même, pas porté suffisamment attention au patient tissage de la structure civile des anciens rebelles, regroupant, autour des branches civiles de la lutte, les exclandestins urbains et toute une masse de nouvelles recrues. Cette véritable couche de militants civils, cadres locaux et intermédiaires, est passée largement inaperçue depuis Maputo, avec

${ }^{158}$ Candonga : mot du portugais mozambicain pour mercado negro, marché noir.

${ }^{159}$ Manuel António fut des années durant l'indéracinable ministre de l'Intérieur, obstinément maintenu en place par Joaquim Chissano, malgré la multiplication des scandales (tortures, tranquille reconnaissance publique que des prisonniers étaient morts de faim, etc., pendant que la situation sur le front du banditisme urbain et de grand chemin ne cessait de s'aggraver. - «Daqui, ninguem me tira », « D'ici, personne ne me déloge », disait-il. C'est finalement par une forte pression internationale que le président Chissano consentit enfin à s'en débarrasser, en 1997. Le fait que Manuel António soit un des rares ndaus du régime a-t-il expliqué la protection présidentielle ? Des rumeurs ont également couru sur le fait que ce ministre aurait établi des fiches sur tout le monde, en particulier les dirigeants d'où son pouvoir. 
également le classique phénomène d'auto-intoxication des systèmes de renseignements (hérités) des partis uniques ${ }^{160}$.

On apprend qu'en même temps que se tient le meeting de la Renamo à Nacala-a-Nova, Eduardo da Silva Nihia tient un micro-meeting à Fernão Veloso. Un thème peu abordé jusqu'à présent par Dhlakama : la corruption.

\section{Le 6 octobre 1994.}

10h. Départ pour l'île de Moçambique ${ }^{161}$.

10h25. Arrivée à l'aéroport de Lumbo ${ }^{162}$. Joli petit bâtiment, avec azulejos à l'intérieur. Une petite foule joyeuse nous accueille. La veille, il y avait une multitude, mais le meeting a été repoussé à aujourd'hui à cause du triomphe de Nacala-a-Nova.

10h35. Petite conversation avec l'un des trois assesseurs Renamo du Gouverneur de la province de Nampula ${ }^{163}$. Barros Namouraha est né le 20 juillet 1937. Il travaillait au projet de rénovation du chemin de fer ${ }^{164}$, sortait en brousse parfois même sans «colonne » (convoi militaire) et ne fut jamais attaqué. Son premier contact clandestin avec la Renamo, à NacalaPorto, fut en 1988. Il a été sympathisant du Frelimo jusqu'à l'indépendance. Il a le cours technique moyen et est comptable aux chemins de fer.

11h. Nouveau départ pour l'île de Moçambique, en un saut d'hélicoptère ? Não, avariou! [Non! il est tombé en panne!]

11h10. On part en Land-Rover. Sur la route, on passe devant un siège local du parti, situé près d'une mosquée. Deux cents personnes y sont rassemblées. Femmes en pagnes rouges alignées le long de la route avec petits drapeaux Renamo...

11h25. L'hélicoptère présidentiel survole en un long virage la petite foule, puis se pose. Enthousiasme et désordre. Mais le Président a atterri juste pour saluer. Nous repartons, lui en hélicoptère, nous en Land-Rover, pour l'île.

11h30. Arrivée à Ilha de Moçambique. Paillotes de banco tassées les unes contre les autres ${ }^{165}$, belles demeures historiques incroyablement dégradées. À en pleurer. Maisons aux larges baies sans fenêtres, murs énormes encore debout mais sans portes, sans vitre, vides de toute vie, pièces

${ }^{160}$ Dans le sens de la base au sommet, des services de renseignement qui sont aussi des polices au service d'un parti, ont souvent tendance à dire à l'échelon supérieur que l'échelon inférieur contrôle bien la situation. Le résultat est l'intoxication des niveaux supérieurs par ses propres agents inférieurs. Le même phénomène peut jouer au sein de partis totalitaires : ainsi Jonas Savimbi, chef de l'Unita angolaise, était-il certainement absolument convaincu qu'il allait gagner les élections, et convaincu également de la « fraude du Mpla » quand il les eut perdues.

${ }^{161}$ L'Ile de Moçambique fut, durant des siècles, la capitale du Mozambique. Elle perdit cette position à la fin du $\mathrm{XIX}^{\mathrm{e}}$ siècle, et ronronna dès lors en un bourg provincial et décadent, déclaré patrimoine de l'humanité par l'Unesco mais jamais rénové.

${ }^{162}$ L'aéroport du Lumbo est situé sur le continent, à une vingtaine de kilomètres de l'Ile de Moçambique. C'est une zone de très vieille colonisation portugaise.

${ }^{163}$ Afin de calmer des inquiétudes de la Renamo, l'Onumoz avait obtenu du gouvernement que les gouverneurs de province soient «entourés » de trois assesseurs de la Renamo, sans pouvoir mais devant être consultés.

${ }^{164}$ Le port de Nacala est l'aboutissement du chemin de fer menant au Malawi. Plusieurs projets de rénovation, financés par le Portugal, la France ou l'Italie ont eu lieu et la ville de Nacala est devenue un centre important de techniciens et coopérants techniques expatriés.

${ }^{165}$ L'île n'a jamais souffert directement de la guerre, mais sa population a littéralement explosé, causant de considérables problèmes environnementaux et de salubrité publique. 
dévastées, sans plancher ni carrelages. Elles ont dû être abandonnées en 1975-77 par leurs habitants qui auraient dû pouvoir rester. Visiblement, la défense du patrimoine est passée après tout le reste...

Le meeting est sur la place, l'estrade est le vieux kiosque à musique décoré de pagnes multicolores. Femmes au masque blanc, pagnes et fichus orange, yeux rieurs en amande...

12h. L'hélicoptère présidentiel arrive à l'extrémité de l'île. Hurlements. Un dirigeant local fait les Vivas habituels et ajoute : - Viva a disciplina! ", "Vive la discipline! ». Le vent soulève une intense poussière...

«Frelimo jà não tem tempo aqui !... Le Frelimo est dépassé ici ! Outubro é nosso !... Octobre est à nous ! Frelimo fora !... Dehors le Frelimo! Sem capulana, sem chapéu, sem camisete, Dhlakama jà ganhou!... Sans pagne, sans chapeau, sans T-shirt, Dhlakama a gagné !»

Un petit groupe du Frelimo s'approche et ramasse des pierres. Les militants le signalent à l'unique policier présent.

André Jonas hurle : - «Sem cabrito...», «Sans chevreau... »

La foule répond : - ...»Dhlakama ganhou!», « ...Dhlakama a gagné !»)

Ambiance d'enfer au son saccadé des slogans. Très forte présente des femmes, partout au premier rang.

- "Dhlakama Oyé!»

— «Sem makhúwo... 166

- ...Dhlakama ganhou!»

Il paraît qu'hier, à N'Tocolo, quatre camions pleins de maïs ont tenté de faire des distributions au nom du Frelimo. La population a refusé. Les camions sont revenus aujourd'hui. Une femme du groupe culturel a été sévèrement battue par le parti au pouvoir, à Ilha.

Les Indiens de l'île sont divisés. Nombreux sont ceux qui, ayant des crédits à la banque, etc., ne disent pas leur soutien à la Renamo.

12h25. Le Président arrive enfin. Il y a environ trois mille personnes. Il paraît qu'hier, date initialement prévue, il y avait plus de monde pour l'accueillir. Et l'eau, l'électricité et le téléphone avaient été coupés dans la résidence qui lui avait été réservée...

Les dignitaires musulmans prennent position à la tribune. Le groupe Frelimo revient, mais, immédiatement entouré par la foule, se retire. Un cheikh [xehe] prononce des paroles de bienvenue. Un jeune, au teint presque blanc (est-il omanite ?), chante une longue et austère prière en arabe, dans un silence impressionnant. La « Cadria » est toujours bien là ${ }^{167}$ !

12h40. Le Président parle. Il présente ses excuses pour le raté d'hier.

«Je sais qu'ici on vous menace. Des dames ont été attaquées et leurs pagnes déchirés. Ce comportement c'est celui du Frelimo qui continue comme en 1975. »

Il brandit les lambeaux de la capulana déchirée, applaudissements. Mais il appelle au calme et à ne pas répondre aux provocations qui sont un signe de faiblesse.

«Le Frelimo dit que la Renamo a tout détruit. Mais ici, la Renamo est-elle entrée une seule fois ? Les maisons ici sont détruites ! La Renamo a-t-elle attaqué une fois ? C'est le Frelimo lui-même qui a tout détruit, le gouvernement est incompétent » [ovations].

Il critique ensuite l'absence d'une politique de crédits pour aider les petits pêcheurs à s'équiper. Il reprend le thème du respect que la Renamo est prête à accorder aux fonctionnaires, à la police, au Snasp nommés par le Frelimo.

\footnotetext{
${ }^{166}$ Makhúwo : maïs, toutes allusions (chemises, pagnes, chèvres...) aux cadeaux du Frelimo.

167 «Cadria », ou Qaddyria, l'une des principales confréries musulmanes du monde arabe, implantée depuis un siècle environ dans l'île.
} 
Les groupes de femmes voulaient présenter leurs danses, mais le temps manque...

13h35. Fin du meeting, dans les chants et offrandes des groupes de la Liga das Mulheres. Enthousiasme et cavalcade lors du départ du président.

La dégradation est telle que je n'ai tout simplement pas reconnu l'Ilha que j'ai visitée en 1975. Le fait que toute l'élite luso-coloniale soit partie a évidemment aggravé la situation.

À cause de l'hélicoptère avariado [en panne], on manque de places et je ne peux aller au meeting de Mossuril. Quelle tristesse ${ }^{168}$ !

14h45. Nous sommes toujours en attente à l'aéroport du Lumbo, y compris Dhlakama. Il n'y a pas de transports disponibles. Le petit hélicoptère présidentiel fonctionne, mais aucun autre pour transporter l'équipe de sécurité et les journalistes à Mossuril. Il n'y a pas non plus de piste pour l'atterrissage des petits avions à Mossuril.

Le Président est assis à l'intérieur du petit hall de l'aéroport. Je ne comprends rien. S'il n'y a pas d'hélico, pourquoi ne pas y aller en voiture ? Ce n'est pas si loin ! Peut-être attend-il que l'équipe de sécurité y soit arrivée?

15h30. Le président part à Mossuril, seul, avec le petit hélico. Nous prendrons quant à nous la prochaine avionnette pour Nampula. Demain, tôt (?!) on devrait reprendre le programme.

16h. Une avionnette prend sept d'entre nous pour Nampula. Une autre doit venir chercher les restants, dont moi, vers $17 \mathrm{~h}$.

17h. Enfin l'avionnette vient nous chercher. Aujourd'hui nous avons fait une des cinq localités (deux, avec Mossuril) prévues. Ces problèmes d'organisation ne finissent-ils pas par être un mépris de la base, qui, convoquée tôt le matin, attend des heures, voire des journées entières pour rien?

17h45. Arrivée à Nampula. Petite conversation avec Dhlakama. Selon lui à Mossuril il y a eu un peu moins de gens qu'à Ilha. Alors, environ 2000 ? Il considère qu'il y a encore plus de soutien à Nampula qu'en Zambézia. Au Cabo Delgado et au Niassa, " só basta uma mensagem », «il suffira d'un message », au Manica, Sofala et à Tete, "nem vale a pena », " ce n'est même pas la peine », à Inhambane "sinto-me muito à vontade», "je suis très à l'aise ». Même si à Maputo-capitale et à Gaza "é preciso uma forta luta», « il faut batailler dur », cet optimisme n'est-il pas très dangereux ?...

21h30. Au restaurant Monte-Carlo, petite discussion avec Macoca Martins. Il est membre de la Sécurité présidentielle, chargé du déminage. Avec une sonde, il inspecte le sol et l'estrade avant chaque meeting. Né au Alto-Molócuè de parents sympathisants de la Renamo : - Em 1986, fui levado pela Renamo. Não tive tempo de me despedir», "En 1986, j'ai été emmené par la Renamo. Je n'ai pas eu le temps de dire au revoir ». À la question de savoir s'il aimerait rentrer chez lui, revoir ses parents après ces huit années, il répond avec un sourire triste : - Agora, estou nas mãos deles », « Maintenant, je suis entre leurs mains ».

Mais à la question de savoir s'il n'aurait pas eu envie de profiter de la démobilisation, il précise : - Para um bom elemento como eu, o subsídio não é nada », "Pour un bon élément comme moi, l'indemnisation, ce n'est rien ${ }^{169}$.

\footnotetext{
${ }^{168}$ J'étais par ailleurs en train de mener une étude d'archives sur une importante émeute qui avait eu lieu à Mossuril en 1939 (à paraître). Mais je n'ai jamais été sur place.

${ }^{169}$ Le subsídio (indemnisation) était versé par l'Onu aux soldats démobilisés des deux camps, pendant dix-huit mois. Il s'agissait d'une somme très modeste mais qui, pour de jeunes ruraux, pouvait faciliter leur réintégration en brousse.
} 
Par conséquent il continue à vivre dans la Renamo. Peu de temps après son « recrutement », il a été intégré au service du Président et y est toujours resté. Il a été à l'école jusqu'à la $4^{\mathrm{a}}$ classe. Quand il passe à Maputo, il y trouve quand même des lettres de ses parents. Quand il a été recruté, il n'a pas eu peur - dit-il. Aujourd'hui ses parents sont encore plus partisans de la Renamo qu'auparavant...

Quelle est l'intime mentalité de cet homme jeune, rapté mais acceptant le rapt comme acte normal d'une guerre et que ses parents aussi ont accepté ? Il est parfaitement à l'aise dans la Renamo, son nouveau corps social. Ce sont les forces non contemporaines d'une guerre contemporaine.

Mais même quand il rit, Macoca a une lueur triste au fond des yeux.

\section{7 octobre 1994.}

7h30. Au petit-déjeuner, conversation avec Edgar Ricardo Silva, l'un des assesseurs Renamo du gouverneur de province. Le travail conjoint du gouverneur et des assesseurs ne se fait pas dans une bonne atmosphère : le climat est toujours conflictuel et il n'y a pas de tâches menées en commun.

Il a fait des études de géométrie descriptive à l'Université Eduardo Mondlane (UEM) de Maputo et est actuellement professeur d'enseignement pré-universitaire. Son premier contact avec la Renamo a été à Maputo, en 1986. C'était par l'intermédiaire d'un étudiant de la faculté de droit, qui lui, avait le contact direct. Après la fermeture de cette faculté par Samora Machel ${ }^{170}$, il reprit contact à Nampula. Il devait partir pour la guérilla mais le projet fut découvert. Il y avait des réunions clandestines, qui devinrent carrément courantes à partir de 1990-91, et il avait sa carte de membre, une carte qui ne mentionnait aucun nom, juste un numéro. Peu après l'Accord général de paix, il a été appelé à Maringué, puis est revenu à Nampula en avril 1994 pour assumer la charge d'assesseur du gouverneur. Sa motivation initiale fut ethnique : il était le meilleur étudiant des cours de mathématiques à l'UEM mais il n'obtint jamais de pouvoir faire une licenciatura ${ }^{171}$ ou obtenir une bourse de doctorat: - Havia discriminações, mesmo visíveis », « Il y avait des discriminations, absolument visibles ».

9h30. Je reprends l'entrevue avec Fernandinho Zacarias ${ }^{172}$. Nous sommes assis à l'ombre d'un hangar de l'aéroport, à même la piste, dans l'attente du départ...

Parti pour la Renamo, il fait deux jours de marche jusqu'à la base « Matondo », dans le district de Búzi. Il est la seule recrue de la colonne, mais à la base, il en retrouve d'autres. Il y avait peut-être des raptés, mais : - « ...a gente estava à vontade, sem pensar fugir. Não houve nenhuma fuga », "les gens étaient à l'aise, sans penser à fuir. Il n'y eut aucune fuite ».

L'entraînement préparatoire dura deux mois, surtout physique. La base ne fut pas attaquée pendant toute cette période (elle sera plus tard bombardée par des Migs). Le commandant était João Macia Fumbi Jacata (toujours en vie). Le second entraînement fut militaire. Il y avait de temps en temps des entretiens avec les commissaires politico-militaires pour expliquer les buts du mouvement. Cet entraînement dura six mois. Après l'épreuve finale (champ de tir), le jeune revenait avec son arme personnelle, un AK 47. Il a aussi travaillé avec des RPD (mitrailleuse) et des RPG 7 (lance-grenade anti-tank). Il fut transféré en août 1982 pour la base provinciale Jambé, à Chibabava, commandée par Francisco Jirimoyo.

La base était un périmètre circulaire, aux positions concentriques jusqu'au commandant. Cette base pouvait avoir dans les trois ou quatre kilomètres de diamètre. Il n'y avait pas de civils dans la base, mais des femmes du Destacamento feminino ${ }^{173}$.

${ }^{170}$ Incohérence dans le récit : S. Machel a effectivement fermé la faculté de droit, « foyer réactionnaire », mais en 1983.

${ }^{171}$ Équivalent de la maîtrise française.

${ }^{172}$ Voir 4 octobre, $9 \mathrm{~h} 40$, pour la première partie.

${ }^{173}$ Il est extraordinaire de constater, toujours, à quel point, pour la Renamo, l'ennemi reste le modèle. Dans ce cas précis, la guérilla du Frelimo (1964-74) avait aussi ses troupes féminines, appelées Destacamento feminino (détachement féminin). 
Son premier «contact» eut lieu en octobre 1981. Ils avaient été envoyés en patrouille de reconnaissance, trente hommes, près du chef-lieu du Búzi. Ils faisaient une escale auprès de populations favorables quand apparurent les FPLM. Mais elles s'enfuirent au bout de cinq minutes, sans avoir provoqué de blessés du côté Renamo.

En décembre il fut transféré à Gorongosa, la base centrale, avec neuf cents hommes. Les jeunes sont reçus par Dhlakama, puis répartis en unités. Dans la sienne il y avait 370 hommes. Elle part pour Mudoro, entre Caia et Inhaminga, une base plus petite, d'un kilomètre et demi de diamètre. Elle opère à Cheringoma (attaque d'une localité proche du chef-lieu, sans occupation de ce dernier) pour récupérer de l'armement et libérer la population de l'aldeia comunal [village communal] : - Levávamos a população », "Nous avons emmené la population ». Nombreux sont les présidents de village et les soldats des FPLM qui « changèrent d'idées »...

En juin 1982, ils attaquent le chef-lieu d'Inhaminga. Contact difficile, durant une heure trente $^{\mathrm{r} 74}$. Ils occupent la bourgade 24 heures, remettent en service les batteries anti-aériennes et repoussent l'attaque de l'aviation du gouvernement. Ils se retirent la nuit suivante, emmenant avec eux une partie de la population des villages communaux établis autour de la caserne. Mais l'administrateur réussit à s'enfuir à Beira.

Les opérations se succèdent. par exemple à Chupanga où les quarante hommes de la Renamo attaquent sans succès. Après deux heures de combat et après que le commandant ait été blessé, ils se retirent, à court de munitions. Mais les FPLM ne les poursuivent pas.

Entre eux, les guérilleros parlaient portugais, pour dépasser le clivage des nombreuses langues.

Il reste à Mudoro jusqu'en 1985. Sélectionné pour aller faire un cours de soixante jours en intelligence militaire (IM) et logistique, il part à la Casa Militar. L'IM était très importante pour préparer les attaques. Les professeurs de la Casa étaient des chefs provinciaux : pour la logistique, Juliano Cumbané et pour l'IM, Inácio Faque (aujourd'hui brigadier des FADM, la nouvelle armée unifiée).

Il revint à la même base et commença à travailler au niveau du bataillon (370 hommes) comme agent d'IM. Cela ne lui épargnait pas les combats de tout le bataillon, mais en revanche il n'était pas convoqué pour les petites opérations de patrouille.

Une attaque pour lui «marquante » fut celle de Luabo, par tout le bataillon. Luabo était bien défendue, capitale de la Sena Sugar Estates ${ }^{175}$. En moins d'une heure, ils entrent dans la ville et capturent tout le matériel militaire. Ils y restent deux mois et doivent faire face à plusieurs contre-offensives de parachutistes largués des Antonov. Les bombardements détruisent l'usine et les maisons. Après deux mois, ils se retirent.

En décembre 1982, ils prennent Caia, où ils demeurent également deux mois, partant ensuite attaquer Marromeu. Au cours de nombreux autres combats, il traverse de temps à autre le Zambèze, mais revient toujours sur la rive sud.

Il est ensuite rappelé à Gorongosa, où un deuxième Q.G. avait été établi après la prise du premier par les FPLM et est intégré dans les groupes opérant autour de Vila Paiva de Andrade, restée sous le contrôle du Frelimo. C'est à Vila Paiva qu'était mort André Matsangaïssa. À ce moment, les Zimbabwéens lançaient de dures attaques avec des hélicoptères. On pouvait attaquer de nuit, mais pas de jour. Il resta un an à la base de Chururu près de Vila Paiva, et à celle de Mucoza près d'Inhamapala (également dans l'aire du poste de Vila Paiva, toujours restée Frelimo); Il a fait partie du Batalhão Dragão et du Batalhão Grupo Limpa, qui, selon lui, n'était pas une troupe d'élite ${ }^{176}$.

En 1986, il est nommé major d'IM, un grade entre celui de capitaine et de lieutenantcolonel. En 1987, il part à la base centrale de Gorongosa, appelé à suivre un apprentissage de vidéo. La Renamo voulait produire des «images historiques» du Président, des combats. C'est le département d'Information et Propagande, dont il dépend toujours aujourd'hui. Il suit dès lors les combats pour les filmer, sans y participer directement. Ces vidéos ont été transférées à Maputo, dans la maison du Président (mais l'administration interne est encore à Maringué).

${ }^{174}$ C'est effectivement une durée exceptionnelle. Selon mes sources, la durée moyenne des « contacts » était de l'ordre de quelques minutes. Rien à voir avec la guerre Iran-Irak...

${ }^{175}$ Grande compagnie coloniale, en particulier sucrière, de capitaux majoritairement britanniques, que le Frelimo essaya de ne pas nationaliser. Mais en 1978 il fut découvert que l'endettement de la compagnie était devenu, frauduleusement, pratiquement équivalent à la moitié des avoirs du Banco de Moçambique et l'intervention étatique devint inévitable.

${ }^{176}$ Certaines des opérations les plus sanglantes menées par la Renamo auraient été, selon les sources progouvernementales, le fait des Grupos Limpa («groupes de nettoyage»). 
Il accompagne donc toujours le Président dans ses voyages auprès des unités de guérilla, en motocross (pour Gorongosa ou Tete) ou avionnette (pour le Niassa, le Cabo Delgado ou Maputo). La comitiva (l'escorte) du Président ne fut jamais attaquée.

Il a toujours été formé à l'intérieur, mais parfois par des instructeurs vidéastes sudafricains ou des Portugais du Portugal ${ }^{177}$ (Isabel X, et José Ramos - il ne se rappelle pas des noms des Sud-Africains). Les pilotes des avions étaient mozambicains.

- «Dans la Renamo, je me sens chez moi. Cela ne m'intéresse pas de revenir. Dans ma famille, je me sens plus protégé dans la Renamo, peut-être parce que j'y ai grandi. Peut-être après les élections, je vais leur rendre visite. Ce qui m'intéresse, c'est d'être en un lieu où je puisse étudier pour avoir un métier et survivre. Peut-être ferai-je une formation en télévision ».

Il dit ne pas avoir d'endroit préféré pour s'installer, pas nécessairement dans la zone de ses parents : - «Ce peut être n'importe où ».

Au DEF (Destacamento feminino), il y eut des cas de femmes enceintes. Au début, les relations étaient « muito proibidas » («très interdites »). "Mas de seguida, muito mais para cá, começaram a sair bebés... Mais ensuite, bien après, il a commencé à y avoir des bébés. Alguns casaram no momento do cessar-fogo... Certains se sont mariés au moment du cessezle-feu».

Il nie totalement qu'il y ait eu des femmes jolies sélectionnées pour les commandants : $E$ e, como major, podia amantizar com uma bonita, mas sem ninguém intervir, se eu gostar dela e ela gostar de mim », "Moi, comme major, je pouvais flirter avec une jolie fille, mais sans que personne n'intervienne, si je l'aimais et si elle m'aimait ».

Il a connu des moments de famine, de sécheresse : - «Si la population n'avait plus rien, nous envoyions un groupe à trente kilomètres, dans une zone où la population avait quelque chose». - «Em 1987 e 1990, a população mesmo morria...». En 1987 et 1990, la population mourait littéralement de faim. "Mas nunca houve soldado morrer à fome porque o soldado sai do lugar onde não pode pedir...» "Mais aucun soldat n'est jamais mort de faim parce que le soldat peut sortir de l'endroit où il ne peut plus rien demander ».

10h30. Toujours rien. Discussions autour d'un verre. Dans les zones islamiques, les « camisetes » avec le portrait de Chissano, distribuées par le Frelimo sont contre-productives car on n'a pas le droit d'imprimer la figure humaine ${ }^{178}$. Un officier de la Força Aérea du Frelimo me dit qu'à Nacala, quand Chissano est venu, il y avait trois fois moins de personnes que pour Dhlakama.

La Renamo a quelques craintes pour le meeting de demain, à Nampula. Le Frelimo serait entrain d'organiser des petits groupes dans les quartiers pour faire des désordres. Signe de faiblesse?

12h10. Départ pour Malema (ouest de la province de Nampula).

13h05. Arrivée à Malema, après un survol de très beaux paysages d'inselbergs, et, à l'approche de Malema, de plantations de café.

13h20. Le Président arrive, en retard. Il y a environ deux mille personnes. Il y a une banderole de la Renamo de Cuamba (déjà une localité de la province voisine du Niassa). La foule est attentive, mais assez silencieuse. [Nous sommes ici dans une riche région agricole, avec de petites exploitations africaines "modernes". Il y a eu assez tôt une opposition au Frelimo, notamment à cause des difficultés de commercialisation, mais la guérilla de la Renamo aussi les a évidemment aggravées : cela expliqua-t-il l'attitude attentiste de la foule?] Dhlakama reprend les thèmes de l'éducation, de la santé et le thème fonctionnaires/police/Sise.

La reprise systématique de ces thèmes depuis trois jours est, j'en suis maintenant sûr, le signe sans équivoque qu'au-delà des discours publics où bien sûr il clame victoire, Dhlakama la croit possible. Il réfléchit à la gestion de la contradiction entre un président Renamo et des forces de sécurité Frelimo.

\footnotetext{
${ }^{177}$ La précision « Portugais du Portugal » vise à faire la distinction avec les Portugais d'Afrique du Sud.
}

178 ...mais j'ai vu des « camisetes » avec le portrait de Dhlakama! 
La foule ne s'enthousiasme vraiment que lorsque Dhlakama enlève ses lunettes... : $-O$ Dhlakama é bonito! », « Dhlakama est joli ! », dit... Dhlakama!

Suite au meeting, le Président s'entretient avec un groupe d'agriculteurs (agricultores, machambeiros) de tabac, de maïs et d'autres cultures commerciales.

Sur le chemin du retour qui mène à la petite piste de terre, un groupe assez nombreux et jeune du Frelimo lance des pierres sur la voiture et sur notre camion. La police tire en l'air et les gardes exhibent leurs armes. Des cris de "Chissano» sont lancés auxquels répondent ceux de «Dhlakama». Le départ du Président se fait cependant normalement, pendant que le groupe hostile continue à lancer des slogans sur le bord de la piste, contenu par quelques policiers. Les militants locaux de la Renamo disent que les agitateurs viennent du lieu-dit «Gorongosa » (!), une zone marchande riche en marginaux.

La région de Malema a toujours été la première sur le plan agricole dans la province de Nampula. Tout y pousse, y compris le tabac. C'est aussi le pays natal de Eduardo da Silva Nihia, le premier secrétaire provincial du Frelimo. Mais la police a fait correctement son travail.

14h10. Départ pour Imala. L'hélicoptère suit en fait la ligne de chemin de fer.

14h35. Arrivée à Imala. Une petite foule sur la piste chante l'hymne de la Renamo. Pas de Civpol en vue. Le délégué, Capino da Fonseca Cunaxa, est à la Renamo depuis 1991, toujours resté à Imala sous administration du Frelimo. Il servait comme agent de renseignement civil. Il est secrétaire et a fait la $2^{\text {a }}$ classe du lycée. Comme d'habitude, il y a une ligne de régulos. Il n'y a pas de voitures disponibles : - Proibiram!», «ils ont interdit!», disent les militants locaux, faisant certainement allusion au refus de l'administration de prêter une voiture -, aussi le meeting a-t-il lieu en bordure même de la piste.

Ce district a souffert de la faim. La Renamo y semble peu implantée: pas de groupe de danse féminin, pas de direction bien mise en avant. L'estrade est à peine montée (visiblement, l'absence de voiture a fait changer précipitamment de lieu). La population arrive lentement de la bourgade.

15h. Le Président arrive. Le délégué lance : - «Abaixo a aldeia! » « À bas le village ! » [i.e. le village communal]. L'estrade est complètement envahie de gens, Dhlakama n'y a que son propre espace et deux gardes du corps. Un millier de personnes environ.

«...C'est Dhlakama qui en a fini avec les villages communaux, les laissez-passer, les emprisonnements... [ovations]. Je veux gagner ces élections! [la foule: Vous allez gagner !]...»

16h. Départ pour Ribáuè.

16h10. Arrivée à Ribáuè, gros village avec de belles maisons, dont certaines sont détruites, sans toits, au pied d'un grand massif d'inselbergs.

16h20. Il n'y a presque personne à l'aéroport. Le meeting est convoqué en ville. Deux voitures de l'Onumoz arrivent. Suit un camion archi-bourré de jeunes gens du Frelimo, venus de l'école secondaire de Ribáuè, où ils vivent en pensionnat, éloignés de leurs familles. Mais comme le Président n'arrive pas encore, ils repartent en ville.

16h40. L'avion présidentiel arrive. Pas de voiture pour nous. Flottement. On va à pied ? Je suggère que le petit hélico emmène le Président et que tous les autres (sécurité, journalistes) s'entassent dans le grand hélico russe. C'est OK. 
16h55. Nous arrivons au stade. Des voitures du Frelimo passent et repassent, pendant que le Président commence à parler devant environ deux mille personnes. Une banderole du Frelimo, infiltrée dans le meeting, est saisie et l'intrus fermement éconduit. Le public est agité, attentif, mais visiblement inquiet. Deux policiers expulsent encore un «infiltré » tout près de l'estrade.

«Nous savons que vous êtes intimidés, que vous avez peur. N'ayez pas peur. La démocratie va rester. »

Le soleil se couche et le meeting s'achève dans quelques bousculades. Belle lumière du crépuscule pendant que, déjà, brille une superbe conjonction de la lune et de Jupiter...

17h45. Départ pour Nampula. La nuit est tombée, partout brillent, tout en bas sur la terre invisible, des feux de brousse.

18h30. Petite conférence de presse de Dhlakama à l'aéroport de Nampula.

«Il faut créer les conditions pour que le parti vaincu puisse assumer son opposition, avec un statut de l'opposition. En Afrique, cela concerne les líders et les partis. Celui qui gagne les élections oblige l'opposition à disparaître. Alors, l'alternative est de partir en brousse. Mais pourquoi l'opposition en Europe ne part-elle pas en brousse ? Parce que l'opposition est acceptée dans la démocratie. Ici, on confond démocratie et pouvoir. Je veux que Chissano reconnaisse l'opposition, non au niveau d'une personne, j'ai des milliers et milliers de personnes dans la Renamo, qui ont besoin de la démocratie. Si le président Chissano gagne, il doit le reconnaitre, ce n'est pas seulement donner une maison et un bon salaire au chef de l'opposition. Moi, Dhlakama, je le répète, j'ai la capacité de tout paralyser en 24 heures. C'est un avis. Je ne veux pas châtier, mais je sais châtier. Si c'était une menace, je ne préviendrais pas, je menacerais. Lors de l'affaire de Mogóvolas, le Frelimo était en mauvaise posture, il n'y avait pas moins de 20000 personnes. Cela explique notre réaction [de ne pas répondre alors que nous pouvions facilement les écraser, preuve de notre bonne volonté].

Le tribunal électoral ne fonctionne pas [...]. Je vais continuer à être patient. Mais la population de Malema me demandait : "Monsieur le Président, donnez-nous l'autorisation de battre ces gens". Mais je ne l'ai pas donnée.

Ça, ce n'est rien! J'ai été dans la guerre! Ca, ce n'est rien, je suis habitué. Mais les populations n'aiment pas. Mais, s'il vous plaît, ne réagissez pas. Dhlakama n'appellera jamais les populations à réagir. [...] Il y a des instructions qui viennent de Maputo visant à empêcher ma campagne dans la province de Nampula [...] ».

Alors un journaliste pose une question à sa femme, assise à côté de lui. Mais Dhlakama tout de suite intervient : - Ela não vai responder, não vai comentar », «Elle ne va faire aucune réponse, aucun commentaire ».

22h. Ce soir Dhlakama tient, au cinéma Mozambique, une réunion à portes fermées avec les dignitaires religieux de toutes les confessions, préparée par le général Issufo Momade, un macua musulman chargé des questions religieuses à la Renamo.

\section{Le 8 octobre 1994, à Nampula.}

Aujourd'hui, rien le matin et grand meeting cet après-midi.

15h. Arrivée au stade 25 de Setembro. Joyeux désordre, mais le stade n'est pas plein. Groupes de danses, chants, tambourins, saut à la corde de jeunes filles d'une agilité incroyable... Environ huit mille personnes pour l'instant.

15h30. Ambiance d'enfer, mais toujours seulement dix mille personnes environ. Le journaliste d'Associated Press m'indique que, pour l'instant du moins, il y avait plus de monde pour le meeting de Chissano. 
16h. Le Président arrive. Délire. Problème de micro, on chante pour attendre. On entend à peine les premières allocutions.

C'est réparé, un dignitaire musulman parle. Il y a maintenant peut-être plus de quinze mille personnes, en tout cas moins de vingt mille. «Dhlakama! Dhlakama! », les premiers rangs sont plus enthousiastes qu'au fond.

16h15 Le journaliste d'AP dit que c'est maintenant comparable au meeting de Chissano. Dhlakama parle. Toujours la condamnation du « communisme » et du « marxisme ».

"Jamais haverá ditador, este é o último... », «Il n’y aura plus de dictateur, celui-là c'est le dernier»

Il s'attaque toujours bien trop à des thèmes anciens, qui ne correspondent plus à la réalité vécue. Et il ne dénonce pas assez les affaires, les fortunes rapides, etc., tout ce qui pourrait faire une bonne agitation urbaine.

Au fond du stade s'étend une ancienne inscription de 1985 : "Façamos do $10^{\circ}$ aniversário um momento decisivo da liquidação dos bandidos armados », "Faisons du Dixième anniversaire [de l'indépendance] un moment décisif de liquidation des bandits armés »...

Dhlakama aborde aussi la nécessité de réintroduire la culture africaine dans l'enseignement. Mais en terrain urbain, quelle est l'efficacité de ce discours ? Le discours ethnique peut fonctionner en ville, mais un discours uniquement traditionaliste ?

Cependant il dénonce maintenant les salles spéciales dans les hôpitaux pour ceux qui ont de l'argent :

«Nous ne pouvons pas aller dans ces salles parce que nous n'avons pas d'argent. Nous allons en finir avec ce système, nous allons améliorer le système de santé. »

16h30. Des gens commencent à sortir doucement...

«Nous allons créer l'enseignement supérieur à Nampula afin d'éviter que les jeunes n'aillent à Maputo ${ }^{179}$. C'est pour cela que Dhlakama et la Renamo ont l'intention de créer l'enseignement supérieur dans les grandes régions du pays. »

C'est la première fois qu'il aborde la question universitaire dans un de ses discours.

«Les agriculteurs n'obtiennent pas de crédits [...]. Nous allons donner la priorité à ce secteur [...]. »

Le discours ne retient pas tout le monde, des gens sortent. Du reste, Dhlakama ne semble pas très en forme et parle trop lentement. Il dénonce encore le Frelimo qui a fermé les mosquées :

« Le Frelimo dit qu'il a changé. Quand est-ce qu'il a changé ? [rires] Le Frelimo est au pouvoir. Pourquoi est-il en train de promettre, et non de faire ? Le Frelimo ne va pas changer. Le Frelimo ne sait pas valoriser notre culture. Je ne suis pas tribaliste, je suis nationaliste. Mais, par exemple, le Frelimo dit que le Macua n'a pas la capacité de gouverner. Dhlakama veut en finir avec la discrimination. Dhlakama va faire une juste répartition entre les régions du pays. »

Une personne du public intervient alors pour dénoncer qu'à la direction provinciale des Eaux, tous les Macuas ont été progressivement remplacés par des « laurentinos » ${ }^{180}$. L'assistance vibre. Une autre prend le micro pour raconter d'autres malheurs. Ovations. Dhlakama lui sert la main. Vivas. Le discours s'anime enfin, et reprend le thème fonctionnaires/police/Snasp en lui ajoutant cette fois-ci les médecins du secteur public.

«Viva a reconcilação nacional! », « Vive la réconciliation nationale ! »

\footnotetext{
${ }^{179}$ Les seules universités du pays étaient à Maputo, et aucun projet de décentralisation, même pour les premières années universitaires, n'a jamais été tenté avant la fin de la guerre civile. Aujourd'hui c'est l'université catholique qui s'est installée à Beira et Nampula, ainsi que des annexes de l'Institut supérieur pédagogique.

${ }^{180}$ Laurentinos, laurentins, vieil épithète servant à désigner les habitants de la capitale, Maputo, dont le nom colonial était Lourenço (en français, Laurent) Marques.
} 
Le retour dans les rues est triomphal.

18h45. Petite conférence de presse. À ma question sur la reprise des thèmes anciens ne correspondant plus guère à la réalité d'aujourd'hui (aldeias comunais, etc.), Dhlakama répond :

«Parfois, le Frelimo dit que nous existons sans raison, que nous avons été créé de l'extérieur. C'est pourquoi il est très important de rappeler à la population que la Renamo a existé à cause du système marxiste. Oui, bien sûr, il y a eu la guerre, la Renamo comme le Frelimo ont détruit. Cette guerre justifie [sic : avait pour but] cette période d'élections. Mais il est important également de présenter des alternatives pour l'agriculture, le crédit, des prix bas, toutes choses auxquelles le Frelimo n'a jamais daigné porter attention. Le Frelimo préfère importer du maiis de la République d'Afrique du Sud, du Zimbabwe. Le Frelimo, même après l'indépendance, n'a jamais investi dans la santé ${ }^{181}$. C'est pourquoi les hôpitaux sont dans cet état. [Idem pour l'éducation]. Les jeunes ne connaissent même pas l'histoire du Mozambique, mais savent les noms de Lénine, de Mao... Les jeunes n'étudient pas nos rois, nos régulos. Il n'y a pas de noms nationalistes dans les rues. Cela aurait même eu un sens qu'il y ait une rue Ngungunhana, le fondateur de l'empire de Gaza.

Question : Les chefs traditionnels constituent-ils un pouvoir politique ?

- Les chefs traditionnels ne constituent pas un pouvoir politique. Mais ils pourraient avoir une assemblée représentative, pour discuter des problèmes traditionnels.

Dans ces élections, le plus important, ce n'est pas le programme. Parce que le Frelimo aujourd'hui explique tout de la même manière que la Renamo. C'est pourquoi nous devons rappeler qui a menti, qui n'a pas accompli.

Question : Le Président a-t-il un discours nouveau relatif à la police ?

- Ce discours est le discours d'un nationaliste qui veut la réconciliation nationale. Le Frelimo dit : "Ne soutenez pas la Renamo qui va vous chasser", et parfois ils le croient. Après l'indépendance, le Frelimo en a expulsé beaucoup. Le Frelimo confond les fonctionnaires de l'État et le gouvernement, les membres du Parti et le Governement. »

Après la conférence de presse, je demande out of the record, à Dhlakama :

— «Na cúpula da polícia, vai haver um saneamento ? », " Au sommet de la police, il y aura une épuration ?»

— «Sim, mas não vamos dizer isto agora.», «Oui, mais nous n’allons pas dire ça maintenant. »

Le nombre relativement décevant de personnes au meeting de l'après-midi serait partiellement dû au fait qu' « un bruit a couru » que les Anciens Combattants allaient l'attaquer ${ }^{182}$. La Renamo a dû avertir indirectement Gamito (le gouverneur de province) que si un tel événement se produisait, Dhlakama ferait un appel aux Macuas pour chasser le Frelimo de Nampula. De fait, rien ne s'est passé durant le meeting, mais dans les quartiers il y aurait eu des intimidations. Selon le délégué régional, ceux qui sont venus ne sont qu'une petite minorité de ceux qui auraient dû comparaître. Tous ces derniers jours, les intimidations se sont multipliées et « le meeting a été saboté ${ }^{183}$.

${ }^{181}$ Tous les observateurs s'accordent pour dire que l'un des bilans les moins contestables du Frelimo pendant les « années radicales »(1975-1985) a précisément été celui de la santé, avec un effort considérable et la gratuité des soins. La Renamo a détruit un grand nombre de postes de santé en brousse pendant la guerre civile, et le libéralisme économique ensuite adopté a fait le reste.

${ }^{182}$ Les Antigos Combatentes sont une association du Frelimo regroupant d'anciens guérilleros dotés de maigres avantages. Certains vivent dans des villages spéciaux, les «villages d'anciens combattants », dont l'existence même amène à se poser des questions. Pourquoi ne sont-ils pas retournés chez eux après la guerre de libération ? Auraientils été, eux aussi parfois, «engagés » si jeunes que le Frelimo est devenu leur seul lieu de socialisation ? Aucune étude n'a jamais été menée sur le sujet.

${ }^{183}$ Il est vrai qu'il y a eu un contraste difficilement explicable entre l'accueil triomphal lors de l'arrivée à Nampula le 2 octobre, et la relative modestie du meeting dans cette grande ville le 8 . Il me semble exclu cependant que le Frelimo ait vraiment planifié une attaque par les Antigos Combatentes dont tout le monde sait qu'ils lui sont liés et dans une ville où, contrairement à Mogovolas, de nombreux journalistes étaient présents. Il est beaucoup plus 


\section{Le 9 octobre 1994}

9h45. Départ pour Mecúburi.

10h15. Arrivée à Mecúburi. Étrange, rien ne semble prêt, seuls quelques curieux attirés par l'hélicoptère. Si ! J'aperçois la petite estrade montée près d'un arbre, mais il y a peu de gens. En fait, avec tous les changements de programme, ils ne sont tout simplement pas prêts. C'était prévu pour midi ! On repart pour Lalaua, et on reviendra ici ensuite.

\section{1h25. Départ pour Lalaua.}

11h45. Arrivée à Lalaua. Petit village au pied de grands inselbergs. Il paraît que l'administrateur local a organisé des groupes armés de catanas $^{184}$. La Renamo locale a prévenu la police. La Liga da Juventude chante l'hymne de la Renamo devant Dhlakama et lance des slogans : «Abaixo o marequecismo! » (« À bas le marxisme !»). La Civpol est présente. Youyous. Les maisons en dur sont pour la plupart détruites. Traces de guerre. Celle de la Comissão distrital de eleições a été repeinte de frais. La Civpol m'indique que la situation est calme (mais c'est la PRM qui le lui a dit...) : il y a eu des bagarres avant, mais plus maintenant.

Il y a environ cinq cent personnes, pas d'estrade. Les haut-parleurs sont installés dans deux grands arbres à l'ombre desquels s'entasse la petite foule. Le meeting était convoqué pour vendredi dernier, et la place était alors pleine, soit quelques milliers de personnes : cinq fois cela, me dit quelqu'un se déclarant par ailleurs proche du Frelimo...

Les changements permanents de programme portent évidemment préjudice aux meetings : seuls les gens du village sont venus, au bruit des hélicoptères. Bien sûr le délégué provincial dit que le Frelimo mène une campagne d'intimidation.

Une petite tornade passe, soulevant sa colonne de poussière...

De petits groupes plus éloignés ne s'approchent pas : Frelimo ? D'autres vont et viennent.

Dhlakama dénonce l'administrateur local «que está a dizer que a Renamo vai recomeçar a guerra », « qui se répand à dire que la Renamo va recommencer la guerre ».

12h. Un groupe d'intrus apparaît, suivi par la police. Les gens s'écartent, d'autres viennent voir. Dhlakama continue imperturbablement, mais la foule se divise. Cris, bruits, le groupe s'éloigne.

Selon un petit agriculteur privé, mozambicain, avec qui j'engage la conversation, la population du district est favorable au Frelimo car elle a beaucoup souffert de la guerre. Vendredi les gens étaient venus pour «voir », mais la Renamo est faible ici. Le district a été occupé quarante-cinq jours et la population avait fui pour Ribáuè.

Lui-même, parce qu'il était privé, n'a pas été attaqué "mas a população em geral foi massacrada, sobretudo pela Renamo », « mais la population en général a été massacrée, surtout par la Renamo ». Pourquoi les agitateurs pro-Frelimo sont-ils toujours des jeunes ?

«Ce sont les plus courageux, ils n'ont pas été éduqués à l'époque coloniale où un Africain ne devait pas se mêler de politique. »

Ce Mozambicain a été administrateur de poste à la fin de l'époque coloniale et, à sa propre surprise, pour le gouvernement du Frelimo jusqu'en 1979. Puis il a travaillé pour la João Ferreira dos Santos (JFS) dont il a été gérant à Ribáuè ${ }^{85}$. Quand la JFS a quitté le district à cause de la

efficace de faire courrir le bruit qu'ils vont attaquer, assortis d'attitudes intimidatrices dans les quartiers périphériques.

${ }^{184}$ Catanas : coupe-coupe.

${ }^{185}$ La compagnie João Ferreira dos Santos est une ancienne compagnie coloniale créée à l'Ile de Moçambique à la fin du XIX ${ }^{\mathrm{e}}$ siècle par un commerçant portugais. Elle est peu à peu devenue l'une des principales sociétés agricoles et commerciales du pays et n'a jamais été nationalisée ni n'a donc quitté le Mozambique. Elle a perdu beaucoup de 
guerre, il est resté avec sa propre machamba de tabac. Aujourd'hui, il gère à nouveau le tabac de la JFS qui fournit l'assistance technique auprès des paysans, comme cela se fait au Malawi.

J'ai trouvé intéressante cette vision, « du côté de l'État moderne ». Il est typique de voir comment cet administrateur, mozambicain mais colonial, habitué à travailler avec l'État, s'est naturellement senti plus proche du Frelimo que des rebelles. Mais les gens venus en masse vendredi étaient-ils là seulement pour écouter et voir le «mythique guerrier »? Ce qui est sûr, c'est que, même compte tenu de la petitesse de ce meeting, il n'a pas été très chaleureux. À nombre égal, celui de Quiloa était bien différent...

(Note ultérieure, du 16 octobre : selon Armindo Chavane, reporter à la TVM, il y a eu un grand massacre de la Renamo ici, il parle d'un millier de morts. C'est difficilement imaginable en une seule opération, mais, même en enlevant un zéro, les gens ne doivent pas avoir oublié.)

12h15. Fin du meeting.

12h45. Retour/arrivée à Mecúburi. Ici, le meeting avait été convoqué pour un autre jour... Il n'y a pas beaucoup plus de monde que tout à l'heure : tout le monde réussit à se masser à l'ombre d'un seul (très) grand arbre. Mais d'autres paysans arrivent de partout.

Ni Civpol, ni PRM. Un petit groupe d'enfants chante : "Com Dhlakama, Viva o Povo ». Des dizaines de petits yeux me regardent : les Blancs sont rares ici. En attendant que Dhlakama parle, la foule est silencieuse, massée sous l'arbre. Dhlakama salue les responsables et dignitaires présents. Trois cents personnes?

J'entame une petite discussion avec des desmobilizados du Frelimo.

"Nous avons été engagés, nous sommes comme des chèvres, ça a été le $\mathrm{SMO}^{186}$; du côté de la Renamo, ça a été la même chose. Les gens n'ont pas eu le choix. Qui ne le sait pas ? Vendredi, il y avait plus de monde, mais seulement pour voir, ah ! c'est lui, très bien, merci. Nous n'avons pas de père. Le chevreau, sa place est dans l'enclos [port. : Cabrito está na capoeira].»

Les gens vont et viennent. J'apprends qu'ils ont attendu trois jours, de mercredi à vendredi... Ici, la majorité des desmobilizados sont de la Renamo : - Mas bebemos juntos », « Mais on boit ensemble ».

Dhlakama dénonce l'administrateur :

«...qui se répand en menace et dit qu'il coupera le cou de ceux qui voteront Renamo. C'est faux. Le vote est secret. Il ne va rien arriver. »

14h10. Fin du meeting, Dhlakama salue le régulo et le cheikh.

14h15. Départ pour Murrupula.

15h. Arrivée à Murrupula. L'hélico s'est perdu un bon quart d'heure... Terre rouge, on atterrit sur le stade. Le délégué, Patrício José Ussene, est à la Renamo depuis 1991. Il est toujours resté ici et n'a jamais été militaire. Mais dans la cupula locale de seize membres, il y a l'ancien administrateur de la zone Renamo qui, lui, est un ancien militaire. Chants et danses bien organisés, psalmodie des hommes en cófio, dirigés par un dignitaire musulman. La Civpol et la PRM sont là. Il y a environ trois mille personnes. Une pancarte dit :

«Président Dhlakama, Nous les musulmans t'avons nommé président avant l'Accord de paix. »

camions pendant la guerre mais s'est maintenue et a pu très vite reprendre avec une grande force. Elle possède à Moçambique l'une des très rares anciennes maisons coloniales en parfait état...

${ }^{186}$ Service militaire obligatoire. Le recrutement pour le SMO fut parfois musclé (rafles à la sortie de bars...). 
La session est ouverte par une prière d'un dignitaire musulman. Ici aussi le meeting a été déplacé (il était prévu le 4 octobre !). La foule est bon enfant et s'anime à l'évocation des «camisetes»[T-shirts] et des «chapéus » [casquettes]. Un jeune promène une photo de... C. Jeque (un professeur d'université, dissident de Domingos Arouca ${ }^{187}$ et qui se présente comme candidat indépendant). Quelques jeunes, visiblement Frelimo, font un peu de bruits. Mais cela distrait la foule. L'un d'eux demande la parole...

15h50. Le meeting continue, bon enfant, avec brouhahas de temps à autres. Sur les trois milliers de personnes présentes, on a ici l'impression qu'il y a mille partisans - les plus proches de la tribune, attentifs et approbateurs - et tout le reste sont plus ou moins des curieux.

16h30. Fin du meeting, sous les cris du groupe Frelimo : «Chissano ! Chissano !»

16h55. Arrivée à Nampula.

\section{Le 10 octobre 1994.}

9h30. Départ pour Memba.

10h20. Arrivée à Memba. Petit bourg côtier aux maisons en dur partiellement détruites. Il fut victime d'une sévère famine, à la fin de la guerre, peu avant l'Accord général de paix, pour laquelle l'administration provinciale, malgré les alertes de l'Église catholique, afficha une scandaleuse indifférence. Il est vrai qu'on est ici dans une zone connue pour son adhésion volontaire à la Renamo...

On atterrit dans un champ, le meeting a lieu dans la Vila, près du siège local du parti sur une espèce de place. Soleil écrasant et pas d'ombre ! Le délégué politique Aurélio Domingos Mecota, était militant depuis 1991 à Monapo, et il a été transféré à Memba en mars 1992 (avant les accords de paix). Il n'a jamais été militaire. Parmi les vingt-sept membres de la cúpula locale, un seul est un ex-soldat. Il a la 7e classe et est escrituário [employé aux écritures]. Il me présente quelques delegados de localités voisines.

Avelino Cebola est à la Renamo depuis le 5 juin 1993. C'est un ancien soldat comando de l'armée coloniale. Il a la $6^{\mathrm{e}}$ classe et est actuellement dactylographe pour l'APIE ${ }^{188}$ et pour les Chemins de fer. De 1991 à 1993 il est devenu paysan, quand l'administration l'a chassé, ayant découvert ses sympathies. Il est le delegado de Tropene, une localité voisine.

João Cortes Júnior, délégué de Cava (idem), est à la Renamo depuis 1992 et n'a jamais été militaire à la Renamo. Il a fait l'armée coloniale, mais dans une unité ordinaire, ayant atteint le grade d'alferes (sergent). Il a la $4{ }^{\mathrm{e}}$ classe et n'a pas de travail.

Justino Amade, délégué de Majua, est à la Renamo depuis 1990 même si le poste était resté Frelimo. Lui, a été soldat de la Renamo, il a même été commandant de peloton à Marire ${ }^{189}$. Il a la $4^{\text {a }}$ classe et est paysan.

\footnotetext{
${ }^{187}$ Seul avocat noir du Mozambique pendant la période coloniale, Domingos Arouca avait été élu président du Centro associativo dos Negros de Moçambique, l'association légale des Noirs «assimilés » de Lourenço Marques. Il fut cependant vite arrêté pour appartenance au Frelimo et le Centre définitivement fermé en 1965 ; il passera huit ans en prison. Libéré et assigné à résidence à Inhambane, il fut approché par Jorge Jardim, qui cherchait un « premier ministrable » noir pour son projet de coup d'État. Peu après l'investiture du gouvernement de transition, Arouca, catholique modéré, préféra s'exiler à Lisbonne où il anima un petit parti d'opposition. Sa candidature de 1994 recueillit environ $1 \%$ de voix.

${ }^{188}$ APIE : Administration du patrimoine immobilier de l'État, la structure mise en place pour gérer les immeubles nationalisés à partir de 1976 et qui a été un modèle de bureaucratie, d'incompétence et de corruption . L'APIE ne subsiste aujourd'hui que dans la mesure où les privatisations avancent parfois lentement.

${ }^{189}$ Grande base de la Renamo dans la Macuana. L'étude de Christian Geffray a porté sur cette zone : Mozambique, la cause des armes..., op. cit..
} 
Atumane Omane a été collaborateur de la Renamo depuis 1991 et membre encarté depuis 1992. Il est tailleur et marin, a la $6^{\mathrm{e}}$ classe. Il a fait la troupe coloniale où il a été $1^{\circ}$ cabo (adjudant-chef).

10h40. L'hélicoptère présidentiel atterrit. Pas de Civpol en vue, mais la PRM est là. La foule est bien ordonnée, en plein soleil. Chants, danses, tambourins. Belle vue sur l'océan Indien, en contrebas. Traces de guerre évidentes sur les bâtiments officiels. Et toujours les femmes de la côte vêtues de pagnes jaunes, oranges et rouges, ornées de bijoux dorés. Des élèves quittent le meeting pour retourner à l'école (secondaire ?). Il y a environ deux mille personnes. Mais jeudi, le jour où le meeting devait avoir lieu, toute la ville était remplie de gens. Ils ont attendu trois jours, jusqu'à samedi ! Un bébé est mort (insolation). Le PIMO aussi a fait un meeting et a un siège local.

Vivas habituels, chants, la foule bat des mains en rythme. Le cheikh Malange prononce ses incantations

11h. Dhlakama parle. Insistance sur les thèmes islamiques et discours sur la démocratie.

11h30. Des gens se lassent, mouvements divers, va-et-vient. Le discours de Dhlakama n'est pas très percutant.

« À Memba, il y a la famine. La nourriture arrive, donnée par la Communauté internationale. Mais cette nourriture, quand elle arrive à Memba, est distribuée aux gens qui sont membres du Frelimo. Le gouvernement ne garantit pas le droit à la vie de la population [...]. »

Le directeur de l'école, totalement saoul (en pays musulman), lance une pierre contre le meeting. Ce n'est rien, mais cela provoque un désordre. Il est expulsé et... chamboco $^{190}$.

12h15. Fin du meeting, après reprise du thème fonctionnaires/police/Sise. Le fait que les gens soient restés sous un soleil écrasant est un signe d'intérêt et de soutien, au minimum d'un solide encadrement.

12h35. Départ pour Nacucha, localité du poste administratif de Mossuril.

[Fin du carnet $\left.\mathrm{n}^{\circ} 1\right]$

13h. Arrivée à Nacucha, après avoir survolé la baie de Fernão Veloso. Les gens courent sur la route à l'approche de notre hélicoptère. On se pose dans un champ, en brousse. Un grand groupe nous attend, drapeau musulman en tête et dignitaires en boubous blancs.

13h10. Dhlakama atterrit à son tour. L'enthousiasme n'est pas feint. Le Président danse avec des femmes en chemisier rouge et orange. Pas de Civpol ni de PRM en cette brousse où la seule administration est la Renamo, que l'on surnomme, du reste, « Maringué 2 ». Le cortège se dirige vers le village au son des tambourins. Partout des arbres arrachés par Nadia...

13h30. Le cortège arrive sur le lieu du mitin, déclenchant un grand enthousiasme. La session a lieu sur une petite place, ombragée d'un baobab (c'est-à-dire qu'il n'y a guère d'ombre !) qui a résisté au cyclone. La foule, bien organisée, s'assoit autour de l'estrade. Un agitateur fait sans cesse l'éloge de Dhlakama,

...O nosso pai! o nosso melhor! o lutador que libertou Moçambique!

.... Notre père ! le Meilleur ! le lutteur qui a libéré le Mozambique !

...Olhem bem! ele está a chegar! olhem bem !...

...Regardez bien! il arrive, il arrive ! Regardez bien !...

${ }^{190}$ Chamboco, voir note 16. 
Nouveau chœur de femmes, psalmodies à la saveur presque orientales. Muito carinho popular, evidente... ${ }^{191}$ Des gens sont partout juchés sur les grands troncs effondrés. Vivas, you-yous. Le délégué régional rappelle que la population d'ici a résisté frontalement, totalement, à la villagisation. Aussi le Frelimo avait-il coupé les routes pour isoler la localité. Une vieille femme est appelée à la tribune et s'assoit à la droite de Dona Dhlakama. On l'appelle « Mãe de Dhlakama » [mère de Dhlakama], tant elle a été une militante de choc pro-Renamo au cours de la lutte contre la villagisation et ensuite dans la guerre...

Il y a environ 2500 personnes, ce qui est sûrement considérable pour une petite brousse. Un cheikh prononce l'incantation d'usage. Puis les chants religieux sont repris par la foule.

\section{3h45. Dhlakama parle.}

«...Vous avez résisté ! Les chefs ont été presque tous arrêtés parce qu'ils refusaient les villages communaux, quand ils revinrent ils continuèrent à résister. Vous êtes des combattants de la démocratie. Vous êtes le peuple le plus fort du Mozambique. Vous avez gagné. Vous allez pouvoir choisir votre président librement pour la première fois! Viva Maringué 2.»

La foule est très attentive, il n'y a pas de va-et-vient. Une jeune femme à côté de moi ouvre une vieille boîte en fer toute rouillée et pleine d'eau : elle en emplit le couvercle et donne à boire à son petit. Ici, les femmes ne nouent pas le pan d'étoffe soutenant le bébé dans le dos, sous les seins, mais en diagonale entre les seins.

14h40. Fin du meeting. Plusieurs offrandes, dont une... maquette d'hélicoptère ! La foule reprend le chemin du pré où les hélicoptères ont atterri et, de façon parfaitement disciplinée, se met en bordure.

Nous quittons cette brousse où la Renamo est chez elle, où le soutien populaire, le carinho, sont plus qu'évidents : Maringué 2 !

15h. Départ pour Nacala-a-Velha.

15h10. Arrivée à Nacala-a-Velha. La ville a été dévastée par Nadia. Arbres arrachés, nombreuses maisons encore sans toit... Atterrissage sur le stade. Foule bien ordonnée, drapeaux musulmans au vent. Petits talibés en blancs. Civpol et PRM sont là. La foule est assise sous de grands arbres. Un cheikh pénètre dans la tribune, en représentation des autres. Même chose pour les régulos.

15h20. Chœur des femmes, psalmodies rythmées. Il y a environ trois mille personnes. Le délégué local tout à sa fougue ouvre par un tonitruant «Viva o presidente Joaquim..., Presidente Dhlakama! » Oraison d'un cheikh. Vivas.

15h30. Dhlakama parle.

- «Eu quero prometer a distribuição de poderes políticos...», « Je veux promettre la répartition des pouvoirs politiques...»

[Après tant de meetings, je commençais à avoir du mal à écouter le contenu des discours, ce qui se voit car mes notes se raccourcissent. Avec les journalistes, nous riions à l'idée d'établir un discours type de Dhlakama. Nous étions maintenant parfaitement au point pour parler à sa place, avec les mêmes intonations et expressions !]

Le soutien populaire a l'air plus fort sur la côte et le proche intérieur, parties les plus peuplées de la Macuana, que dans le profond intérieur. Les contradictions historiques entre le littoral et le

${ }^{191}$ En portugais dans le texte : beaucoup de chaleur populaire, évidente... 
proche intérieur semblent avoir disparu ${ }^{192}$. La « côte » doit donc maintenant être comprise comme une bande d'une cinquantaine de kilomètres de large. Les vraies nuances politiques apparaissent encore plus loin dans l'intérieur. Poids des hiérarchies musulmanes ? Identité namarral ${ }^{193}$ maintenue ? La Macuana qui autrefois désignait l'intérieur hostile à la côte va évidemment maintenant jusqu'à elle et l'inclut. L'homogénéisation se serait-elle faite sous hégémonie côtière, en un phénomène de type swahili ?

Dhlakama promet l'enseignement supérieur à Nampula et Beira.

16h. Le meeting se termine. Chants d'enfants.

16h10. Départ pour Meconta/Namialo.

16h30. Arrivée à Meconta/Namialo. Atterrissage sur le stade. Traces de Nadia partout. PRM, Civpol. Le délégué, Anselmo Jacinto Eduardo, a la 9e classe et est technicien. Il est à la Renamo, à Meconta, depuis 1990. Il n’y a aucun militaire dans la cúpula locale.

Chœur de femmes et d'enfants dans le soleil couchant, offrande d'une couronne de fleurs. Il y a environ mille cinq cents personnes sur le lieu du meeting, une place ombragée d'arbres. Petit groupe du Frelimo de l'autre côté de la route, avec boissons à la main. L'administration avait prévu d'organiser des incidents avec jets de pierre, mais le délégué Renamo a obtenu du Commandant de la police que tout se passe bien. Dhlakama :

«...Vous ne devez pas avoir peur des dirigeants du parti Frelimo... »

17h30. Fin du meeting à la nuit tombante. Selon le délégué local, sur 50499 électeurs recensés à Meconta, 42625 ont la carte de la Renamo. Le pire, c'est que c'est possible.

\section{Le 11 octobre 1994.}

13h. Départ pour Pemba, après cinq heures d'attente sans aucune information à l'aéroport de Nampula. Notre hélicoptère est chargé au maximum : trente personnes au lieu de quinze, plus les bagages, les hauts parleurs et de grands sacs de jute fermés, au sein desquels on entend s'entrechoquer les kalachnikovs. Les pilotes russo-ukrainiens ne sont pas contents, quant à moi, je suis vaguement inquiet.

${ }^{192}$ Lorsque les Portugais terminèrent la conquête effective de ces territoires, entre 1910 et 1913 , la côte, organisée en petits sultanats esclavagistes allant se servir dans l'intérieur, opposa une résistance déterminée aux troupes portugaises. C'était les Namarrais, peuples macuas de la côte. Inversement, les Portugais recrutèrent massivement des auxiliaires africains pour leur armée, précisément dans cet intérieur, lesquels ravagèrent ces sultanats dont certains - selon l'historien René Pélissier - perdirent alors la moitié de leur population.

${ }^{193}$ Namarral : singulier de Namarrais, $c f$. note précédente. 


\section{Chapitre 4}

\section{Cabo macua, Cabo maconde*}

\section{Le 11 octobre 1994 (suite)}

14h30. Arrivée à Pemba. Survol du fleuve Lúrio, belle vue sur la baie. Civpol, PRM, aérogare tout neuf le long duquel les dignitaires musulmans sont bien alignés. À l'entrée, groupes de musique, tambourins, psalmodies masculines et féminines, saveur orientale... Groupe de femmes chantant en boubous beiges des louanges au chef - elles sont toutes belles!

15h15. Arrivée du Président. Couronne de fleurs. Deux dignitaires musulmans le portent vers la foule. «Dhlakama Oyé ! », délire. Les chants et youyous redoublent. Femmes aux pieds garnis de grelots, la plus belle a un anneau dans une aile du nez, petite touche d'argent sur un joli visage. Dans le cortège, à côté de moi, un vieux Portugais, badge Renamo à la veste - qui va s'avérer l'un des chauffeurs locaux de Dhlakama. Formules religieuses. Une femme, métisse indienne, prononce un poème de bienvenue. Je pénètre dans le salon VIP. Clim et très jolie décoration.

À l'extérieur, environ deux mille personnes seulement (problème de transport depuis la ville).

16h. On part vers la ville. "O povo está consigo... ». Ici, beaucoup de femmes ont des anneaux ou des perles dans les ailes du nez. Sur les quinze districts du Cabo Delgado, treize sont macuas, Mueda et Muidumbe étant macondes, mais tous les dirigeants [du Frelimo ou de l'État] sont macondes. Les Kimuanes et les Souahilis s'identifient plus aux Macuas qu'aux Macondes, me dit-on.

17h. Au fur et à mesure que l'on s'approche, la foule grossit : 4000 personnes. Partout des imbundeiros (baobabs), soleil couchant. Enthousiasme, les yeux des badauds cherchent le chef : "Quero ver Dhlakama mesmo! », «C'est Dhlakama en personne que je veux voir! ». On me dit que sur les 50000 personnes recensées, environ 30000 sont sur les listes d'adhérents de la Renamo (mais pas forcément munies de cartes), "porque são macuas», "parce qu'elles sont macuas ». Mais comment sont établies les listes? Adhésions individuelles ou indications des chefes de povoação ${ }^{194}$ ? À Mueda, les Macondes pro-Renamo sont souvent des Anciens combattants qui ont souffert des camps de rééducation ou d'autres brimades.

À Pemba, pour le meeting de Chissano du 24 septembre, il y a eu environ 4000 personnes. La foule a encore grossi. Je compte qu'il doit y avoir, dans ce cortège de cinq cents mètres de long sur trente de large, mais peu dense, environ 7500 personnes. L'enthousiasme n'est pas feint.

17h50. Le cortège arrive à la résidence réservée pour Dhlakama. Il fait nuit. Pemba est une jolie ville, surplombant la baie. En plus, elle est assez bien entretenue, maisons et routes, trottoirs et peintures. Fleurs. C'est mignon.

18h. Vicente Ululu, le secrétaire-général de la Renamo et « $\mathrm{n}^{\circ} 2 »$, maconde, lance des Vivas devant la résidence où la foule est encore massée. Il s'agit d'une maison de l'État, louée cinq cents dollars par jour. Le téléphone y a été coupé.

\footnotetext{
* Dans la province du Cabo Delgado (Cap Delgado), la province de l'extrême nord-est frontalière de la Tanzanie, démographiquement, les Macouas (ou Macuas) sont largement majoritaires. Mais les Macondes, fer de lance de la guerre de libération, y ont exercé une nette hégémonie politique. Il y a d'autres groupes ethniques minoritaires, comme les kiMuanes (sing. Muane), les Souahilis (ou Suaílis, ou Swahilis), les Ngunis.

${ }^{194}$ Chefs de hameau, inférieurs aux régulos.
} 
18h45. Conférence de presse de Dhlakama. En décembre précédent, lors de sa venue, cela n'avait pas été ainsi. Aujourd'hui, c'est au-dessus des expectatives. Il dit qu'il ne va pas à Mueda, faute de temps. "Ululu tem mais apoio que Chipande. Nós tinhamos bases em Mueda», «Ululu y a plus d'appui que Chipande, nous avions des bases à Mueda ${ }^{195}$. Je ne suis pas convaincu - ou alors, c'est un simple calcul numérique fondé sur l'idée que Chipande n'aura que les voix des macondes, $2 \%$ de la population. Dhlakama dénonce l'entrée d'étrangers dans le pays, «venus pour voter ».

19h30. Arrivée à l'hôtel «Cabo Delgado ». Il est parfait. Je partage la chambre 117 avec un pilote sud-africain.

\section{2 octobre 1994}

9h. Départ pour Mocimboa da Praia.

9h55. Arrivée à Mocimboa. La foule est massée sur le petit aérodrome. Tambourins, danses et chants des femmes. Ligne des dignitaires musulmans. Direction locale, pas de militaires parmi les six membres. Ils sont tous kimuanes, à une exception. Agira Alumbe est à la Renamo depuis 1993, toujours à Mocimboa, $7^{\mathrm{e}}$ classe, dactylographe. António Cheira est à la Renamo depuis 1992 à Mocimboa, $4^{\mathrm{e}}$ classe, employé de commerce. Fernando Jorge de Moura est à la Renamo depuis 1993, 6 e classe, secrétaire, est l'exception : il est métis portugais/maconde. Bakari Abadri, $3^{\mathrm{e}}$ classe, le delegado, il est à la Renamo depuis 1982, ancien clandestin à Mocimboa, son fondateur isolé au début. La Renamo ne s'est vraiment organisée qu'en 1993. C'est un ancien petit commerçant, dont la boutique a été prise par le Frelimo pour la coopérative. Il est muane, né à Pemba. Il recevait des messages et envoyait les siens à Azizi, un commerçant macua de [Silva] ${ }^{196}$, au croisement Mueda-Montepuez.

Il y a environ 4500 personnes, ce qui est beaucoup pour une petite ville.

10h20. Dhlakama arrive et salue la direction locale, puis les dignitaires. Prière et oraison musulmanes, la foule joint les mains. Mélanges de prières et d'éloges de la Renamo... Carinho popular non feint.

Civpol, PRM. La majeure partie des hommes sont en soutane blanche. Pas de voiture pour nous amener au lieu du meeting, on part à pieds en un joyeux désordre. Ici, les femmes n'ont pas généralement les boubous oranges macuas, c'est un autre pays.

11h20. Après une demi-heure de marche, on arrive sur une grande place ombragée de beaux arbres. Une jolie estrade est montée. Les tambours redoublent, enthousiasme. Groupes de femmes en rouge, en blanc, en vert... J'apprends que Chissano a fait le trajet Pemba/Mueda/Chai sans passer par Mocimboa.

Le delegado métis lit un discours dans lequel il dénonce le fait que la seule université ait été à Maputo, que le Frelimo a développé le «planalto maconde », "esquecendo o litoral afim de nos tornar dependentes do planalto» («oubliant la côte afin de nous rendre dépendant du planalto ») ; il dénonce les « étrangers » qui ont mis la main sur l'économie.

195 Joaquim Chipande est un des dirigeants historiques du Frelimo. Maconde, il aurait été, selon la version officielle, l'auteur du «premier coup de feu », le 25 septembre 1964.

${ }^{196}$ Note sur mon carnet peu compréhensible. Il est probable que ce commerçant africain a repris une ancienne boutique d'un Portugais, du nom de Silva ou Da Silva. Certains commerçants de brousse finissaient par donner leur nom, dans l'usage populaire, aux lieux de leurs cantinas (boutique), au croisement de chemins, par exemple. On peut encore noter aujourd'hui des centaines de cas de ce type. 
11h45. Offrandes. Présentation de Vicente Ululu, originaire de Muidumbe. Ululu présente Dhlakama et sa femme. La foule réclame que Dhlakama monte sur un petit tertre, en dehors de l'estrade. On démonte les haut-parleurs, on les remonte.

12h. Dhlakama parle, thèmes habituels.

«La Renamo ne retournera plus en guerre. La guerre de la Renamo n’a pas été en vain. Si

la Renamo n'avait pas fait la lutte, il n'y aurait pas eu d'élections. »

13h. Fin du meeting.

13h15. Départ pour Palma.

13h40. Arrivée à Palma. Le village est bien ordonné en alignements et maisons perpendiculaires : trace visible d'aldeamento colonial, prolongé par l'aldeia comunal ${ }^{197}$.

Nous atterrissons sur le stade. Civpol avec hélicoptère, comme à Mocimboa: sécurité et observation renforcées? Le meeting a lieu sur une placette ombragée de manguiers immenses. Petit campement de toile Onumoz.

13h45. Arrivée de Dhlakama. Enthousiasme et nuage de poussière. Je revois la statue du Portugais vaincu demandant pardon au Mozambicain qui a brisé ses chaînes, mais elle est toute affaissée $^{198}$ ! L'estrade est spartiate. La foule est mélangée, kimuanes, macondes, swahilis.

14h. Il semble que le lieu prévu n'était pas là. Il y a déjà beaucoup de monde, mais toute une partie est à l'endroit prévu. Or, l'endroit où l'on est celui où Chipande a fait son meeting le 7 octobre. La population n'est pas contente, elle veut aller à l'endroit prévu - pas celui du Frelimo. Nous passons devant la statue (mais elle s'effondre!) et descendons le petit chemin qui va à la palmeraie. Puis nous longeons la plage et la baie de sable blanc. C'est marée basse, les barques à voile arabe sont couchées sur le flanc. Quelques maisons en dur, même un restaurant et un « hôtel ». Un camion réfrigéré attend sa cargaison de gambas.

14h30. Nous arrivons sur une petite place ombragée de grands manguiers. Je demande à la police s'il y avait autant de monde pour Chipande : "Havia muito mais, isso não é nada », "Il y en avait bien plus, ça, ce n'est rien ». Mais l'homme n'a pas l'air content. Un peu plus tard, je lui demande quand Chipande est venu : «Não sei, estava em Nampula », «Je ne sais pas, j'étais à Nampula », me répond-il... En réalité, pour une petite localité comme Palma, il y a du monde, environ 2500 personnes. Oraison musulmane chantée devant la foule silencieuse. Vicente Ululu introduit alors, en swahili.

14h45. Dhlakama parle. Les femmes ont des fichus qui sont ici presque des turbans, de toutes les couleurs, taches vives qui brillent au soleil oblique.

«Le Cabo Delgado a été considéré comme place forte du Frelimo. La population du Cabo Delgado a beaucoup appuyé la lutte pour l'indépendance. Vous avez accepté des sacrifices. Malheureusement, le Frelimo n'a pas reconnu cette province, qui est restée oubliée. À l'inverse, cette province a été transformée en camp de rééducation ${ }^{199}$. (...). Quand le Frelimo vient demander son vote, c'est une offense à la population »

${ }^{197}$ Les aldeamentos (de aldeia, village), littéralement, « envillagements », étaient des villages stratégiques où les Portugais regroupèrent la population pour la soustraire à l'influence de la guérilla. À l'indépendance, le Frelimo demanda aux populations de ne pas les quitter et de ne pas rejoindre l'habitat dispersé en brousse, et de les transformer en aldeia comunal.

${ }^{198}$ Cette statue, que j'avais prise en photo en août 1975 et qui avait alors fière allure, avait servi de couverture à mon ouvrage Mozambique, la révolution implosée. Études sur douze années d'indépendance (1975-1987), Paris, L'Harmattan, 1987, 170p. («Points de vue concrets »).

${ }^{199}$ Plusieurs camps de rééducation ont effectivement été ouverts par le Frelimo dans cette province. 
L'Onumoz me dit que, pour Chipande, il y a eu 2000 personnes. Avec les moyens dont il a dû disposer, ce n'est pas énorme.

15h30. Fin. Heureusement, les hélicoptères se sont rapprochés, posés dans un champ.

16h30. Arrivée à Muidumbe/Nangololo, au cœur du pays maconde. L'hélico s'est perdu [en fait on est passé au-dessus du village de Muidumbe, mais les gens s'étaient rassemblés à Nangololo, la mission proche]. On a survolé longtemps le planalto, entouré de sa falaise, tache verte de prairies et grands arbres contrastant avec la forêt brune et sèche de la plaine. Muidumbe a de toute évidence été un aldeamento et une aldeia comunal. Mais les maisons sont espacées et proprettes. Nous avons atterri dans un pré à l'herbe rase, entouré de palmiers et de manguiers. Jolie lumière du soleil qui, déjà, lorgne vers l'horizon... Ululu.

La petite foule nous attend. Le drapeau de la Renamo flotte au vent - c'est la terre de Vicente

Civpol, PRM.

Nous nous dirigeons vers l'espace du meeting. Pas d'estrade, juste un enclos. Peuple en haillons. Cris et joyeux désordres, femmes scarifiées, vieilles à plateau ${ }^{200}$. Il y a environ 1800 personnes.

16h45. Ululu parle en ximaconde. Des groupes de gens restent à l'écart : Frelimo ? La foule est turbulente. Dhlakama parle, traduit par Ululu.

17h. Un intrus [pro-Frelimo] est expulsé, mouvements dans la foule. Des enfants courent voir l'incident. La foule n'est pas très chaleureuse. Du reste, ni Ululu ni Dhlakama ne lancent de vivas. Ils expliquent la démocratie. Ici, à part le Frelimo, personne n'a encore réussi à faire un meeting, ils ont été empêchés.

17h5. Un intrus de plus est expulsé par la police. La population ici a beaucoup souffert de la guerre de la Renamo, me dit un jeune. La majorité est pro-Frelimo. Mais quand Ululu vient en vacances, "ele tem aceitação, ele não tem problema, porque é daqui. A gente aqui veio para ver quem é Dhlakama» («il est accepté, il n'a pas de problème, parce qu'il est d'ici. Les gens, là, sont venus voir qui est Dhlakama»). Muidumbe a été occupée trois jours et les hameaux alentours ont souffert. Le Frelimo a fait des meetings avec plus de gens.

17h15. Tentative ratée de vivas. Le meeting s'achève, sans vivas ni applaudissements.

17h22. Départ pour Pemba, après qu'une grosse pierre ait atteint l'hélicoptère.

18h10. Arrivée à Pemba.

«-A situação continua difícil no planalto », « La situation reste difficile sur le plateau », disje à V. Ululu.

- Ninguém nunca aproximou essa gente », «Personne n'a jamais approché ce peuple », me répond-il.

Et lui ? Son travail politique local ? En tout cas, l'implantation Renamo en pays maconde a l'air bien ténue. Quel type de guerre a-t-elle fait aux abords du planalto et sur le planalto ? Seulement terroriste ? Ou le vote Frelimo reste-t-il solidement un vote identitaire maconde ? Ce qui renforcerait le vote Renamo des Macuas, Muanes et Swahilis du Cabo Delgado ? La population a pourtant souffert des camps de rééducation, nombreux dans ce district (Rua-Rua, etc.) - mais les gens internés n'étaient bien sûr pas que de là.

[J'apprends ensuite qu'avant le meeting, à Nangololo, il y a eu des bagarres. La police a fait son travail, permettant qu'il se tienne. Muidumbe est le «cœur», encore plus que Mueda, du

\footnotetext{
${ }^{200}$ Le disque de bois introduit horizontalement dans la lèvre supérieure a complètement disparu et ne concerne plus que les personnes âgées. Les scarifications au visage ont persisté une génération de plus mais tendent aussi à disparaître.
} 
pays maconde. Mueda a des commerces, des Indiens, du mouvement et une ouverture à l'extérieur. Muidumbe reste uniquement maconde].

\section{Le 13 octobre 1994}

10h30. Meeting à Pemba, au stade. Oraison musulmane. Un camion citerne distribue de l'eau. La foule attend patiemment sous un soleil écrasant. Environ 4000 personnes. Vicente Ululu introduit. Vivas. Ululu les réclame plus forts. Ils fusent, tonitruants. Applaudissements... Puis il fait un vrai discours - du reste Dhlakama lui laisse toujours une place éminente et ne laisse pas passer une occasion de dire qu'il est le « $\mathrm{n}^{\circ} 2 \mathrm{du}$ parti ». Il parle en portugais, sans traduction. Pourquoi ? Ne sait-il pas l'emacua et a-t-il peur de le montrer ? Mais alors, pourquoi ne parle-t-il pas en kiswahili ?

10h55. Dhlakama parle. Il présente «Ululu, $n^{\circ} 2$ do nosso partido ( «Ululu, le $\mathrm{n}^{\circ} 2$ de notre parti ») et le fait applaudir. Pourquoi avoir choisi un Maconde comme tête de liste ? Est-ce symbolique ? Ce n'est peut-être pas un bon choix.

Dhlakama reprend toujours le thème des gouverneurs et administrateurs du cru, mais jamais il ne propose leur élection, ce qui résoudrait tout sans avoir à faire de considérations ethniques... Thème de l'éducation :

«Un gamin qui quitte l'école avec la $4^{\mathrm{a}}$ classe ne sait rien faire... »

Vifs applaudissements. Visiblement, l'éducation est un thème populaire car le niveau a énormément baissé. Par ailleurs, l'histoire enseignée du pays a été uniquement l'histoire du Frelimo - ce que Dhlakama appelle «a história soviética» («l'histoire soviétique»). Puis il dénonce l'obligation des infirmiers et professeurs d'être membres du Frelimo. Applaudissements.

«Mes frères, j'ai réussi à vaincre le Frelimo [...]. Nombreux sont ceux qui ont quitté le pays, qui se sont réfugiés à l'étranger. Moi, je me suis réfugié en brousse [applaudissements]. Le Cabo Delgado a beaucoup souffert pendant la lutte pour l'indépendance., mais le Frelimo n’a pas remercié, n'a pas su reconnaître. La province est restée oubliée [applaudissements], on vous a donné les camps de rééducation, ce fut la seule récompense. Moi, Dhlakama, je trouve ça triste. Le Frelimo vient demander vos suffrages. Mais le Frelimo a-t-il jamais fait quelque chose pour le Cabo Delgado ? Le Frelimo n'est qu'un pagne usé... [délire]. À Mueda, dans la tribu [sic] maconde, le Frelimo répand des mensonges. Ils disent que la Renamo va évacuer la tribu maconde vers l'Angola, puisqu'il paraît qu'ils sont originaires d'Angola. C'est un mensonge. Celui qui sera évacué, ce sera Chissano lui-même. Comme les Changanes sont d'origine sud-africaine, Chissano sera évacué en Afrique du Sud! [délire] ${ }^{201} \gg$

11h50. Fin du meeting. La ferveur populaire n'est pas feinte.

12h45. Attente pour Montepuez. Le meeting est convoqué sur la piste même, qui est loin de la vila (cinq kilomètres). Attente interminable dans l'hélico chargé à bloc des choses les plus hétéroclites : haut-parleurs, casseroles, biscuits, armes, tracts...

14h. Comment allons-nous pouvoir être à Lichinga avant $17 \mathrm{~h} 45$ ? On téléphone pour que l'aéroport reste ouvert - 125 \$US par demi-heure... Sept personnes sortent de l'appareil, deux entrent.

14h15. Départ pour Montepuez. Vingt-sept personnes à bord (au lieu de quinze), plus les bagages et les réservoirs additionnels remplis... Nous survolons des aldeamentos/aldeias comunais, encore bien alignés. À nouveau des inselbergs, qui annoncent le Niassa. Vestiges d'anciennes concessions de terre coloniale, partiellement envahies par la forêt secondaire...

${ }^{201}$ Cette tirade allait être l'occasion d'une formidable campagne de désinformation du Frelimo dans le Sud. $C f$. infra. 
15h. Nous survolons [en hélicoptère] Montepuez, qui a gardé sa structure d'énorme aldeamento. Il y a du monde au stade, où nous nous posons.

15h02. Arrivée à Montepuez. Confusion : les avions [qui amènent le reste de l'équipe] sont à la piste, à vingt kilomètres... Foule d'enfants et d'adultes, mais pas de drapeaux Renamo ni de banderoles. La réception devait être à l'aérodrome. Nous descendons, pendant que l'hélico repart chercher le pessoal ${ }^{202}$ ! Le meeting a lieu sur la place, à l'ombre des grands arbres. Une grande estrade y a été dressée. Beaucoup de monde (cinq mille), bien organisé. Ni chants, ni tambourins.

Le delegado José Nassir Mamude est clandestin à Montepuez depuis 1991, où il avait le contact avec les zones Renamo. C'est un ancien commerçant, qui a adhéré "por causa da humiliação a que o povo era submetido » («à cause de l'humiliation à laquelle le peuple était soumis »). Il a la $7^{\mathrm{e}}$ classe coloniale. Il y a cinq civils à la direction locale, dont aucun militaire. Il ne veut pas m'en dire la composition ethnique : «São moçambicanos, há variedades », « Ce sont des Mozambicains, c'est varié ».

15h30. Le petit hélicoptère présidentiel est aperçu. Civpol, PRM.

15h35. Dhlakama arrive. Youyous, ovations, Vivas! Bousculades. Personnes perchées sur des toits plats, vraiment grande foule pour un vila. Pagnes oranges des femmes macuas. Devant, la foule est dense, au fond des gens vont et viennent. Des marchands de rue ont placé leurs étals à proximité. Femmes à la cigarette inversée ${ }^{203}$ et perle dans l'aile du nez. À l'arrière du meeting, le son des haut-parleurs arrive brouillé. Dhlakama parle en portugais, la population suit avec difficulté. Enfin, on fait traduire, les applaudissements sont plus nombreux. Un Civpol jordanien m'indique que, quand Chissano est venu, il y avait autant de monde, approximativement. Mais son collègue le coupe et lui dit qu'ils ne doivent répondre à aucune question.

Je suis entouré de curieux.

15h55. Aux derniers rangs du meeting, des gens s'en vont. Décidément, même s'il y a ici soutien, le soutien semble plus fort sur la côte : contradiction non seulement ethnique, mais côte/intérieur? Une femme quitte le meeting en disant (à l'intention de Dhlakama ?) : "Você é macaco... », « Espèce de singe... ».

Dhlakama promet d'augmenter les salaires de tous les fonctionnaires :

«Les prix augmentent tous les jours, mais les salaires augmentent une fois par an. Comment faire avec ça ? »

Le FMI sera-t-il d'accord ?!!! Il reprend ensuite le thème des régulos :

«Ça ne veut pas dire que nous allons mettre un régulo pour gouverneur [de province].

Mais ils ont leur rôle »

16h10. Fin du meeting. Je parle avec deux jeunes mécontents : "O líder falou só trinta minutes. Nós gostámos, é um homem justo, é nosso. Foi muito pouco », "Le Chef a parlé seulement trente minutes. Nous avons aimé, c'est un homme juste, il est des nôtres. Ç'a été bien court ». Désir de maître... À l'inverse du Civpol, ils me disent qu'il y a eu beaucoup moins de monde pour Chissano.

16h20. Départ pour Lichinga. L'hélico décolle avec de grandes difficultés, faisant plusieurs tours sur lui-même et soulevant un formidable nuage de poussière qui surprend et suffoque la foule...

\footnotetext{
${ }^{202}$ En port. dans le texte : le personnel, les collaborateurs.

${ }^{203}$ Il est fréquent, dans tout le nord du Mozambique, de rencontrer des femmes qui fument avec la partie incandescente de la cigarette dans la bouche.
} 
16h25. Atterrissage sur la piste de l'aéroport. L'hélico se vide heureusement un peu dans les deux avionnettes. On repart immédiatement. Encore des aldeamentos/aldeias comunais, nombreux... L'hélico prend de l'altitude. Les inselbergs percent la brume qui s'épaissit au soleil couchant. Immenses étendues de brousse, rivières qui serpentent, moutonnement des forêts sèches.

Les plans d'inselberg se détachent maintenant nombreux dans le lointain. Parsemés de feux de brousse, on dirait des fumeroles de volcans. Le sol est accidenté. On s'approche de la grande faille de la Rift Valley!

17h15. Nous survolons Marrupa et son petit aérodrome. Les gardes du corps dorment, les journalistes écrivent leurs prochains papiers.

18h. Lumière de papaye à l'horizon occidental... 


\section{Chapitre 5}

\section{Niassa}

18h20. Arrivée à Lichinga, capitale du bout du monde, à la nuit tombée.

19h. Peut-être 1500 personnes attendent à l'aéroport, mais dans la nuit, c'est difficile à dire. Ils attendent depuis le matin. Nous sommes hébergés au Conselho cristão de Moçambique ${ }^{204}$. Parfait, mais l'eau de Lichinga est vraiment froide ! La ville est à 1369 mètres d'altitude.

\section{Le 14 octobre 1994}

Comme d'habitude, retard. Il paraît que la programmation va être changée car le Frelimo a loué tous les hôtels de Beira où nous devions être dimanche 16. Il est étrange que Chissano revienne à Beira deux fois la même semaine : insistance pour tenter de récupérer [son retard] ?. Il semble également qu'il va retourner à Nampula.

10h40. Départ pour Mandimba. Mandimba est située à la frontière du Malawi, approximativement à mi-chemin entre Lichinga et Cuamba.

11h15. Arrivée à Mandimba, gros village éparpillé dans la plaine. Civpol, PRM, FADM. Beaucoup de monde ! Chants, danses. Le delegado de Mandimba est Alberto Amissi Baraca, 10 classe coloniale, professeur du secondaire à Cuamba, musulman, membre du Frelimo jusqu'en 1987, puis passé à la Renamo au Poste administratif de Metambe après l'Accord général de paix, puis transféré à Mandimba. C'est un Macua qui parle aussi ajaua, nianja et portugais. Dans la direction locale de seize membres, la majorité sont des Macuas, il n’y a aucun militaire ni régulo. À Catur, le régulo est Renamo : "Passou muito mal com a Frelimo », "Il a beaucoup souffert avec le Frelimo $»^{205}$.

Vitor Anselme ${ }^{206}$, delegado de Ngaúma, venu pour la réception," " a rejoint la Renamo en 1992, après l'Accord de paix. Il travaillait aux Calamités, a la $9^{\mathrm{e}}$ classe de l'indépendance. Il a quinze membres dans sa direction locale (macuas, ajauas, nianjas), dont un militaire (simple soldat) et sept régulos, dont Catur.

Je dis « huit mille personnes » au Civpol, qui me répond « six mille ». Disons sept mille. Pas d'estrade, une simple table en bordure de la petite piste.

11h30. Arrivée de Dhlakama. Mandimba a été occupée plusieurs fois et a été une grand zone de réfugiés et de retour. La Renamo a fait un travail très sérieux parmi les camps au Malawi. Par ailleurs, les Zimbabwéens demandèrent aux FPLM de se retirer de certaines zones et bombardèrent intensivement, mitraillant quiconque avait un uniforme de type militaire, tuant en fait de nombreux civils et occasionnant de grandes vagues de réfugiés ${ }^{207}$. Il y a eu un grand

${ }^{204}$ Conseil chrétien du Mozambique, fédération des principales églises protestantes.

${ }^{205}$ Le régulo Catur, très important chef de la zone frontalière avec le Malawi, avait fui le Mozambique avec l'essentiel de sa population lors du début de la guerre de libération et soutenait le Frelimo. La «base Catur» de ce dernier était d'ailleurs tout à fait stratégique. Mais un habile travail des Portugais avait fini par le regagner, et il était revenu dans la colonie, avec son peuple. Des armes lui avaient été distribuées, pour l' «autodéfense », à savoir la lutte contre le Frelimo.

${ }^{206}$ Pas de relation avec l'homonyme dirigeant national de la Renamo.

${ }^{207}$ Rappelons que la « cause zimbabwéenne » de certaines vagues, au moins, de réfugiés ne fut pas entrevue par R. Gersony dans son célèbre « Report » qui ne pointait que la Renamo ( $c f$. la note 9 de l'introduction). 
massacre à Mocuba aussi, quand Lagos Lídimo, était commandant de la Zambézia - il est aujourd'hui l'un des deux commandants en chef des FADM.

11h50. Le délégué local introduit le meeting :

— «Viva a democracia total! », «Vive la démocratie totale ! »

— « Abaixo os intrigas da Frelimo! », « À bas les intrigues du Frelimo!»

- «Abaixo os que apedrejam os outros! », « À bas ceux qui lancent des pierres sur les autres!»

Soleil écrasant, après le froid de Lichinga !

12h. Joyeux désordre ! Le public ressert le cercle autour du président : - «Nós queremos conhecer! », " Nous voulons le connaître ! » Un camion s'avance, d'où le président va parler.

12h15. Début de la présentation, avec double traduction en emacua et ajaua.

12h30. Dhlakama parle. Le thème «chefs traditionnels » est fortement applaudi, ainsi que celui du crédit rural. Il aborde aussi le thème de la «mulher desgraçada» («la femme infortunée ») et rappelle sa propre mère :

«La femme fait tout, hein ? patron! Tu restes assis. Nous allons évoluer petit à petit. Une femme peut être administrateur de Mandimba ».

13h. Les gens commencent à partir.

13h10. Fin du meeting. En même temps a lieu un petit meeting du Frelimo, à proximité, sans incident.

13h25. Départ pour Cuamba ${ }^{208}$.

13h55. Arrivée à l'aéroport de Cuamba. Belle vue sur les Monts Mituco. Petite foule à l'aéroport (mille personnes). Danses, tambourins, groupes de femmes, Civpol, PRM.

14h10. Dans la section locale, il y a un Portugais, le Senhor Moreno, qui était propriétaire de mines de pierres semi-précieuses et qui, au Portugal, a toujours soutenu la Renamo. Lui et Dhlakama se connaissent, abraço. Le meeting a lieu en ville. On part en voiture au stade, où un petit groupe musical a fait patienter la foule. Je parle avec M. Moreno, qui est marié à une Mozambicaine et a un fils métis :

— «Il y a longtemps que vous êtes rentré au Mozambique?

- Un an, mais je vis au Malawi.

- Avez-vous recommencé votre activité minière ?

- Ces voleurs du Frelimo ne veulent pas me les rendre. Ils m’ont tout volé.

- Mais au Malawi?

- J'y suis aussi dans la recherche minière. Le Frelimo ne veut rien me rendre. Ils ont déjà tenté deux fois de me tuer. Mais c'est mon pays ici !»

L'orchestre reprend. Tout le monde danse, y compris Dhlakama et Moreno le colon. Bousculades indescriptibles, car le seul mouvement de la foule la fait s'avancer et se coller à l'estrade. Il y a 3200 personnes, différentes de celles de l'aéroport. On appelle les régulos à

\footnotetext{
${ }^{208}$ Cuamba, Nova-Freixo du temps colonial, devint un important nœud ferroviaire entre le Mozambique et le Nyassaland (Malawi) quand la ligne Nacala-Blantyre fut achevée. Par ailleurs, le sud du Niassa est une importante zone agricole, densément peuplée, en contraste frappant avec les grandes étendues autour de Lichinga et, encore plus, du nord du Niassa.
} 
l'estrade. La musique repart. Oraison religieuse musulmane. Mais la foule est partagée, tout le monde n'est pas musulman, la majorité cependant semble l'être ${ }^{209}$. Vivas.

— «Abaixo intrigas! », « À bas les intrigues !»

- «Abaixo confusionistas do distrito de Cuamba!», « À bas les semeurs de trouble du district de Cuamba!»

— «Viva o povo!», «Vive le peuple!»

Le délégué provincial du Niassa se présente. Né à Cuamba, ses parents habitent le «bairro mineiro criado pelo Senhor Moreno » (« le quartier minier fondé par Monsieur Moreno »).

— «Abaixo corrupção! », « À bas la corruption!»

- «Abaixo mentira! », « Â bas les mensonges! »

- «Vamos cantar », «Allez, on va chanter ».

15h. Dhlakama parle. Reprise du thème « Fils du peuple » :

«La population de Cuamba va très mal. Il n'y a pas d'eau, mes frères ne vont pas pouvoir se laver après le meeting parce qu'il n'y a pas d'eau. Pourquoi le Frelimo ne donne-t-il pas la priorité à l'eau? »

Thème de l'agriculture. Bousculades, la foule est terriblement comprimée. Thème de la santé :

«Au lieu de transporter un vieux sur trente-cinq kilomètres pour lui donner un comprimé, nous créerons des brigades mobiles qui iront en brousse ».

Thème de la police et des fonctionnaires : ils auront un bon salaire...

«...pour que la police soit à l'aise pour protéger la population. C'est sûr qu'on va changer un peu le fonctionnement, le comportement [de la police] » [rires].

15h25. Mouvement de panique dans la foule, sans cause apparente: une partie du public s'enfuit brusquement... Un calme précaire revient. En fait, il ne s'est agi que d'une tentative de larcin suivi de bagarre.

«...Se pourrait-il que Chissano change ? Ce sont les mêmes personnes! »

15h45. Fin du meeting, le cortège s'ébranle dans un joyeux enthousiasme.

16h45. Départ pour Lichinga. Marrupa est remis à plus tard. Au sud, l'orage gronde. Mon retour s'effectue en avionnette Kinger, petit appareil de six places.

16h50. Nous entrons en plein dans l'orage. Premières pluies sur le Niassa...

17h40. Arrivée à Lichinga au soleil couchant.

\section{Le 15 octobre 1994, à Lichinga.}

8h30. Ce matin le vent souffle sur le planalto de Lichinga. Il fait frais, les nuages sont bas et défilent rapidement, le soleil fait de timides apparitions. La poussière de terre rouge pénètre partout. Au petit-déjeuner, je converse avec le responsable technique de l'équipe de la Renamo, Nhane. Il est né à Sofala et vit à Beira.

Il est membre de la Renamo depuis 1979. Il est toujours resté à Beira, comme technicien rotativiste du Diário de Moçambique. Il y en avait quelques autres, dont certains ont été arrêtés. Mais lui-même n’a jamais été dénoncé. A Beira, même si des gens se doutaient bien qu'il y avait un membre de la Renamo, il n'était pas dénoncé, c'était accepté comme normal. Les militaires de la Renamo venaient «très souvent » à Beira, clandestinement, et il était alors contacté. Il leur remettait de la presse et des informations. Dans le centre du pays (Manica, Sofala, Tete), les gens ne rendait pas la Renamo coupable de la guerre. Au contraire, ils la justifiaient.

${ }^{209}$ Les Ajauas (ou Yaos), sont complètement islamisés, mais pas les autres groupes ethniques du Niassa. 
Son voisin de table [dont j'ai malencontreusement omis de noter le nom] me raconte sa vision du massacre d'Homoïne.

Sa grand-mère y a été blessée. La population d'Homoïne est divisée quant à l'origine du massacre. Les gens de l'élite urbaine croient en la responsabilité de la Renamo, mais les gens des environs, du petit peuple de la ville, n'y croient pas. Les hommes qui ont attaqué avaient des uniformes neufs et, surtout, étaient de solide constitution, visiblement bien nourris unanimité des témoignages là-dessus. Or, les guérilleros Renamo étaient connus pour être des faméliques dépenaillés.

Cela désignerait donc soit une unité d'élite du Frelimo, soit une unité zimbabwéenne. Les gens ont déclaré que les soldats «parlaient cindau ». Mais outre qu'il y a des Vandau ${ }^{210}$ zimbabwéens, au sud du Mozambique, on appelle « ndau » toutes les langues situées à la limite nord, au-delà du fleuve Save. Ce « cindau » peut donc parfaitement être une variante de chona ${ }^{211}$

Autre fait troublant, selon lui. Le jour de l'attaque, ni le commandant du district militaire, ni l'administrateur du district civil, n'étaient présents. La maison du commandant et celle de l'administrateur n'ont pas été touchées par l'attaque.

[Note du 16 octobre : selon Lionel, l'un et l'autre étaient tout simplement invités à un mariage, et si leurs maisons n'ont pas été attaquées, c'est qu'elles étaient les mieux défendues. $C f$. infra]

Ensuite, le Premier ministre est venu, mais seul, sans journaliste. Les journalistes n'ont été autorisés à venir que le quatrième jour. Quant à Chissano, il était en visite à l'étranger. Mais la Renamo n'a pas réussi à prouver son innocence.

On voit mal le bénéfice qu'elle pouvait tirer du massacre. L'interrogation demeure. D'autre part, il aurait pu s'agir d'une tactique contre-terroriste classique, visant à commettre un massacre et à l'attribuer à autrui. En effet, la population du sud et notamment du «nord du sud », de la zone Inhambane-Vilanculos, avait une sympathie croissante pour la Renamo. Il reste à admettre que des gens, au Frelimo, et les Zimbabwéens, étaient capables d'imaginer et d'exécuter une horreur pareille (409 civils tués, selon le bilan officiel, y compris des malades d'hôpital, plus les blessés) ${ }^{212}$.

À noter que c'était le général Fondo qui commandait les forces du Frelimo dans le sud, général connu pour ses trafics en tous genres, qui fut relégué à la réserve lors de la création des FADM.

On apprend qu'une mine a explosé, hier, sur la route où passait Chissano, dans le district de Tete. Le bruit a couru qu'il en avait réchappé de justesse. En fait, la mine a explosé quatre heures après, sous un camion qui n'avait aucun rapport avec l'équipe de campagne de Chissano. Il n'y a pas de blessés. La route avait pourtant été déminée. Bizarre. Comme à Quelimane?

11h. Le meeting est convoqué à 10h. Personne n'est venu nous chercher encore. Des camions passent, bourrés de gens chantant.

11h10. La voiture arrive.

11h20. Arrivée sur le lieu du meeting, place principale de la ville, Praça da liberdade, juste à côté du gouvernement provincial... Les gens sont sagement assis en plein soleil. L'animation fait

\footnotetext{
${ }^{210}$ Mundau (singulier), vandau (pluriel), cindau (la langue ndau).

${ }^{211}$ Les peuples chona représentent la majorité de la population zimbabwéenne et s'étendent jusqu'à la côte de l'océan Indien, au Mozambique (les Vandau, Manica, Mateve...) sont des Chonas.

${ }^{212}$ Un tel terrorisme «pseudo » n'a rien d'exceptionnel. Les Rhodésiens avaient des groupes spécialisés dans la guérilla «pseudo». Cependant, en dehors de toute autre réflexion, cela pose un problème technique gravissime : faire exécuter un massacre civil massif par un groupe de soldats nombreux impose la capacité à leur faire garder le secret au moins des années durant. Qui, au Mozambique, en avfait la possibilité ? Certes, un groupe «pseudo » zimbabwéen pouvait être rapidement renvoyé chez lui : mais ce n'est pas une garantie de secret durable.
} 
de son mieux. Les dignitaires, cheikhs et régulos - pas de prêtres chrétiens -, sont déjà assis à l'ombre de l'estrade. Grappes d'enfants dans les arbres.

11h30. Dhlakama arrive. «Dhlakama Oyé ! ». Chants, applaudissements. Il y a environ sept mille personnes. Un groupe de jeunes chrétiens pro-Renamo s'avance en chantant. Oraison musulmane. [La pratique systématique d'oraisons musulmanes est un peu étonnante dans la mesure où les autres confessions sont importantes aussi. Évidemment la tradition chrétienne est de ne pas s'afficher directement dans des meetings politiques. Mais le déséquilibre n'en est pas moins factuellement patent.]

Civpol, PIR, PRM.

11h45. Vivas! Seule une partie du meeting répond aux vivas, l'arrière répond moins. L'année dernière, Dhlakama est déjà venu. Sur la droite, petit groupe "Chissano », à propos duquel le délégué provincial, le Senhor Náula, fait une mise en garde. Cependant, le groupe s'enfuit, poursuivi par une meute...

11h55. Chissano est venu à Lichinga et le meeting a eu lieu dans un enclos beaucoup plus petit que cette place. Mais un journaliste me dit que l'affluence était comparable. Cependant, il y avait le programme musical en plus. Dhlakama parle, avec traduction en ajaua. Il aborde le thème de la démocratie : pourquoi n'y a-t-il pas eu d'élections en 1975 ?

«Je ne suis pas ici pour parler de la guerre, mais il faut rappeler qu'il a fallu la lutte pour réussir à avoir des élections. Chissano est venu ici pour demander vos suffrages. Mais pourquoi n'est-il pas venu pour ça en 1975 ? [applaudissements]

Le Niassa a beaucoup souffert dans la lutte pour l'indépendance. Mais comment le Frelimo l'at-il récompensé ? Il a fait une seule chose : Samora Machel a décidé de créer la ville d'Unango dans laquelle furent envoyés lesdits improductifs, les soi-disant marginaux, les contre-révolutionnaires, tous ceux qui n'acceptaient pas le communisme ${ }^{213}$. Et il a créé les camps de rééducation. Ce fut une offense, une insulte à la population du Niassa [applaudissements].

La démocratie n'est pas une théorie, elle doit être ressentie. La première chose est que la population puisse voter librement sans intimidation. Le président élu doit reconnaître qu'il a été élu par le peuple, il doit être l'esclave du peuple, ce n'est pas au peuple de servir le président [applaudissements].

Le président Dhlakama au pouvoir va mettre l'accent sur la division du pouvoir. Aujourd'hui au Mozambique, tel n'est pas le cas. Le parlement est constitué par le Frelimo. Lorsqu'une loi y est présentée, tout a déjà été ficelé dans les buraux du Frelimo. Le parlement, c'est seulement pour boire des whiskys, seulement pour la poudre aux yeux [applaudissements].

${ }^{213}$ Dhlakama fait ici allusion à l' «Opération Production » de 1984. Le Frelimo (ou une faction en son sein), sans doute inquiet des conséquences, sur le contrôle des villes, du tournant économique libéral qui pointait dans le rapprochement avec l'Afrique du Sud (les accords de Nkomati seront signés le 16 mars), décida de vider les agglomérations des « improductifs », en clair, tous ceux qui ne pouvaient justifier d'un travail «formel». Inutile de dire qu'une large moitié de la population urbaine pouvait être concernée ! Des rafles incessantes furent lancées et des milliers de malheureux déportés, en avions réquisitionnés quand il s'agissait de zones lointaines, en brousse. Le Niassa reçut ainsi plusieurs milliers de Mozambicains du Sud, censés construire notamment la ville nouvelle d'Unango (aussi spécialisée dans le recyclage des détenus) qui durent bien vite faire face à la plus complète famine. On en vit déambuler, titubant d'anémie, dans les rues de Lichinga, ayant fui Unango et rejoint la capitale provinciale dans l'espoir de pouvoir revenir chez eux. Une partie rejoignit la Renamo. Certains, enfin, y restèrent et survécurent. Lors de la campagne électorale, un appel des «Changanes du Niassa » fut lancé : ils « souhaitaient pouvoir voter Frelimo, leur parti », mais demandaient qu'on les ramènent chez eux... Le principal responsable de 1'«Opération Production » fut Armando Guebuza, qui souhaitait sans aucun doute accroître son pouvoir, et avait été également responsable de la villagisation forcée dans la vallée du Limpopo en 1978. Si quelques règlements de compte eurent évidemment lieu lors des rafles, on ne peut cependant pas dire, à l'inverse de Dhlakama, qu'elles aient globalement suivi un critère politique : en un sens, ce fut bien pire, le critère fut social, l'opération dirigée contre une catégorie entière de la population. 
Quand il y a une affaire au tribunal, l'avocat va d'abord voir le Président, le Ministre, pour connaître leur décision, ce qui signifie qu'il n'y a pas de tribunaux. Ces trois pouvoirs [exécutif, législatif, judiciaire] seront séparés. Le procureur de la République, monsieur Mulembwe, tout le monde le connaît ici, il est du Niassa, a essayé de dénoncer des cas de corruption. Mais il a été prévenu, il a été menacé ${ }^{214}$. »

Il aborde ensuite le thème de l'agriculture, du crédit agricole, de la commercialisation : dénonciation des importations du Zimbabwe et d'Afrique du Sud au détriment de la production locale de maïs. Il faut des bons prix, etc. [qu'en pense le FMI ?] Thème de la santé, de l'éducation, de la police et des fonctionnaires, du SISE, de l'éducation (écoles de proximité). Thème du pouvoir traditionnel (cheikhs et régulos) :

«Le pouvoir traditionnel existe, et n'a aucun rapport avec le pouvoir politique. Aujourd'hui le Frelimo offre des bicyclettes aux régulos. Vous trouvez ça bien ? Le régulo n'est pas président, le régulo peut aider l'administrateur à organiser la population ».

Thème de la religion, thème des femmes :

« Nous allons inclure des femmes parmi les ministres. Jusqu'à aujourd'hui, la seule femme qui a été ministre a été Graça Machel, mais c'est parce qu'elle était l'épouse de Samora Machel. »

Il dénonce le directeur de 1'Escola industrial Gungunhana, né à Marromeu ${ }^{215}$, qui oblige les élèves à soutenir le Frelimo. Il lui conseille d'abandonner "imediatamente este comportamento » («immédiatement ce comportement»). Il dénonce encore le «Frelimo rica» (« le Frelimo riche »), et Chissano qui a dit : «O cabrito come onde está amarado », « Le chevreau broute là où il est attaché », et vend la bière 1500 meticais dans ses meetings alors qu'elle coûte 5000 : «Como que ele fez? », «Comment est-ce qu'il fait?».

13h15. Fin du meeting. Spectacles des groupes culturels, théâtre.

L'après-midi, Dhlakama est en réunion fermée avec deux cents commerçants et dignitaires religieux.

Vent, pluie et nuages bas. Nous prenons une bière dans un bar miteux d'une infinie tristesse.

La «technique » des meetings de la Renamo est plus frustre que celle du Frelimo. Non tant à cause du spectacle offert par ce dernier, le showmício ${ }^{216}$, avec ses groupes musicaux, ses sauts en parachutistes, mais parce que Dhlakama se présente principalement sous le mythe du guérillero qui erra seize ans en brousse et que tout le monde veut voir. Le Frelimo « répète » ses meetings à l'avance, organisant de nombreux groupes de femmes et de jeunes qui, le jour du meeting, « fabriquent » l'enthousiasme, crient, chantent et applaudissent. Cela n'a rien de spontané mais impressionne efficacement les assistants qui sont pris dans l'ambiance.

Dans les meetings Renamo, en dehors de la réception elle-même du Chef, bien organisée, le groupe de militants qui restent actifs durant le meeting est restreint. Les applaudissements sont plus spontanés, mais plus rares et faibles - même si la réaction aux vivas peut, dans une partie des cas, être fervente.

Le rapport [entre personne] assistant à un meeting et électeur restera un mystère jusqu'au jour du vote.

\section{Le 16 octobre 1994}

${ }^{214}$ Mulembwe sera, probablement, le candidat du Frelimo aux élections présidentielles de 2004, le président Chissano ne souhaitant (peut-être) pas se représenter. C'est un «coup politique » habile, que de présenter un Mozambicain du nord pour faire pièce aux accusations contre le pouvoir sudiste du Frelimo.

${ }^{215}$ En Zambézia.

${ }^{216}$ La Vox Populi a produit pour le Frelimo, à l'image des campagnes électorales brésiliennes, des meetings en large partie composés de spectacles musicaux. D'où l'appellation «showmício », jeu de mot entre show et comício (meeting, en portugais). 
9h. Armindo Xavane, de la TVM, n'est pas content. Il avait envoyé un reportage disant que Dhlakama avait été très bien reçu à Mocimboa da Praia, mais mal reçu à Muidumbe. La TVM a refusé le commentaire "très bien reçu » sur Mocimboa, considérant que c'était une opinion et non un fait, mais a passé le «mal reçu » de Muidumbe. Le tout signé par Xavane...

12h. Il semble que nous n'allons plus à Marrupa... Quelle désorganisation et manque de respect des populations qui attendent depuis trois jours !

Notes sur Homoine, sur la base des données de Lionel : en 1979, la Renamo a commencé sa lutte dans le district d'Homoine, dans la localité de Pembe, avec des sagaies. Mais ensuite, le groupe local n'a pas réussi à s'étendre et a reculé vers le nord et le Save. Ensuite la Renamo est redescendue vers le sud. C'est alors que se produit le massacre - dont il ne doute pas que c'est la Renamo.

Mais la «descente» vers le sud date de 1982. Pourquoi un massacre en 1986 ? Et c'est bien dans le district d'Homoine que la Renamo, dans la province d'Inhambane, était la plus forte. Punir la ville restée Frelimo ? Mais il y a eu bien d'autres cas du même type (district Renamo, ville Frelimo) sans massacre de ce genre lors de l'attaque de la ville.

\section{3h15. Conférence de presse de Dhlakama.}

« Nous avons eu, ici dans cette province, des problèmes techniques sérieux [combustible, taxe de stationnement à l'aéroport...]. C'est pourquoi nous ne pourrons aller jusqu'à Lago et Marrupa. Nous devons avancer vers Tete. Les populations de Marrupa ont déjà été prévenues. Nous allons symboliquement y envoyer un dirigeant de Maputo.

Il y a un autre sujet très important: nous avons reçu des informations de Tete selon lesquelles le gouverneur a créé des groupes pour saboter carrément notre campagne à Tete et dans les provinces du centre. Les administrateurs ont déjà reçu des instructions. On va dépenser beaucoup d'argent pour acheter des jeunes afin de dénigrer l'image de Dhlakama. Il y a un ordre du Comité central du Frelimo pour essayer d'acheter les scrutateurs des bureaux de vote. Le Frelimo se prépare à gagner par la fraude. Des milliers de dollars seront offerts à nos membres, en particulier les plus proches du président Dhlakama. Ce plan a été défini après ma victoire dans le nord.

Autre chose, l'entrée de Zimbabwéens à Manica : ils arrivent en autocars avec des cartes d'électeurs.

L'impression de six millions de T-shirt et de millions de pagnes a coûté plus de vingt millions de dollars.

Â Vanduzi ${ }^{217}, 4000$ Zimbabwéens sont entrés dans le pays la semaine dernière ${ }^{218}$. Chissano, quand il s'y est rendu [à Vanduzi] a été reçu par des responsables zimbabwéens. Une différence de dix mille suffrages peut au total peser lourd. Ils sont actuellement répartis dans les postes et les bureaux de vote. $\mathrm{Ca}$ a été un plan sophistiqué : vol des registres de recensement là-bas, mais les noms sont déjà sur les listes ici ! Rául Domingos ${ }^{219}$ a été à New York pour discuter de cela au Conseil de sécurité [...].

Quand j'ai dit que le Frelimo a fait entraîner 9000 hommes en Tanzanie, personne n'a fait attention. Un Macua qui a fui et est revenu à Nampula [a tout raconté]. Mais ensuite, il a été capturé et a disparu.

Je ne vais pas retourner en brousse, mais jamais je n'accepterai ce genre de plaisanteries. »

\footnotetext{
${ }^{217}$ Localité de l'ouest du Manica.

${ }^{218}$ Cette accusation insistante de Dhlakama n'a jamais pu être étayée de témoignages crédibles. Qui lui répétait cette « information », dont le résultat objectif était de le persuader qu'une fraude massive était en route ?

219 Dirigeant politique national, ancien chef militaire, négociateur de l'Accord général de paix de Rome, en pratique le vrai $n^{\circ} 2$, même si Dhlakama a voulu fabriquer un « $n^{\circ} 2$ civil», Vicente Ululu (qui n'a jamais été militaire). On a dit aussi que ce voyage à New York de l'ancien chef militaire avait été le moyen de le tenir éloigné, précisément à cause de tensions avec Ululu. Note du 10 janvier 2001 : Raul Domingos finit, après de fortes tensions, par être expulsé de la Renamo.
} 
On m'informe que ce sont les cheikhs qui ont demandé les oraisons. Si des catholiques avaient demandé, il y en aurait eu. "Mas, no Norte, foram os muçulmanos a pedir », " Mais dans le nord, ce sont les musulmans qui ont demandé ».

14h40. Départ pour Tete dans le Kinger de six places, piloté par Paul le Sud-Africain. En contrebas de la piste de Lichinga, il y a une ruine d'avion, un Boeing qui a raté l'atterrissage...

Nous survolons le lac Niassa, coupant à travers le Malawi. Vue sur Monkey Bay...

15h30. Nous pénétrons à nouveau au Mozambique. Le ciel est totalement couvert.

15h50. Il pleut à verse !

16h. Nous amorçons la descente. Terres brunes et brûlées de Tete. Zambèze à moitié sec, parsemé de bancs de sable. Baobabs. 


\section{Chapitre 6}

\section{Zambèze}

\section{6 octobre (suite)}

16h10. Arrivée à l'aéroport de Tete. Pluie intense. Malgré cela, environ trois mille personnes sont là, depuis plusieurs heures, à attendre le líder. Le meeting aurait dû avoir lieu immédiatement. Dhlakama «faz questão » («met son point d'honneur ») à parler quelques minutes, sans parapluie puisque le peuple n'en a pas...

17h. Le cortège s'ébranle. La voiture des journalistes se met en tête et arrive la première à l'hôtel Zambèze. Nous sommes intégralement trempés (c'était une Toyota de caixa aberta, à benne ouverte!). Dhlakama suit, également dans une voiture découverte, avec à ses côtés Madame, impassible comme toujours...

17h15. Le cortège de camions arrive, criant des «Dhlakama! », auxquels répondent ici et là sur les trottoirs des « Chissano».

Mon sac à dos a pris la pluie déjà dans la soute à bagage de l'avionnette ! Le carnet $\mathrm{n}^{\circ} 1$ est trempé !

Jorge Correia est déçu de la réception à l'aéroport. Quand Dhlakama était venu la première fois durant la pré-campagne, cela avait été grandiose. Aujourd'hui, seulement trois mille personnes que la pluie lui semble insuffisante à expliquer.

[Alors que j'ignorais tout de sa présence ici, je tombe, au bar de l'hôtel au dernier étage, sur João Gomes Cravinho, un ami du Centro de estudos sobre África de Lisbonne, dont nous avions publié, dans Lusotopie, l'étude politique pionnière sur la communauté portugaise d'Afrique du Sud. Nous bavardons, et puis...]

19h. João Gomes Cravinho, qui est responsable provincial pour Tete des observateurs européens de l'Awepa ${ }^{220}$, m'apprend qu'à Maputo, dans les milieux de l'Université E. Mondlane, « on » dit que je suis un assesseur de la Renamo, payé par la Renamo... Joe Hanlon ${ }^{221}$ l'aurait entendu et le répèterait... Tanta pequenez! ["Quelle médiocrité !»].

[C'est la seule mention de l'incident dans mon carnet $n^{\circ} 2$. Mais je me souviens très bien que cette «nouvelle »' m'avait mis dans tous mes états pour plusieurs heures.]

23h. J'assiste à une conversation passionnée entre Jorge Correia et José Eduardo Rebelo (du magazine Visão), sur Evo Fernandes ${ }^{222}$, Orlando Cristina ${ }^{223}$, les Russes, etc. [Rebelo avait fait une

\footnotetext{
${ }^{220}$ Association of Western Parliamantaries on Africa. L'Awepa a été, au sein du Parlement européen, un actif groupe de pression en faveur de la lutte anti-apartheid - de ce fait souvent très pro-Frelimo.

${ }^{221}$ Joe Hanlon fut un militant très actif de la cause du Frelimo à l' «époque révolutionnaire », mais, à la différence de certains autres, jamais aveugle. On lui doit des travaux contondants sur l'activité des organisations non gouvernementales au Mozambique, et sur les méfaits du FMI, cette «Peace without Profit ». J. Hanlon animait dernièrement le très utile Peace Process Bulletin financé par l'Awepa, qui donne de nombreuses informations sur la démocratisation.

${ }^{222}$ Mozambicain de Beira, d'origine goanaise, un moment secrétaire général de la Renamo, assassiné en 1988.

${ }^{223}$ Exemple typique du Portugais profondément enraciné au Mozambique, broussard, chasseur, aventurier, autoinfiltré dans le Frelimo au cours des années soixante (il avait déserté l'armée portugaise de sa propre initiative pour rejoindre Dar Es-Salaam, en prévenant seulement la Pide - ce qui lui valut d'être emprisonné à son retour !),
} 
enquête qui tendait à montrer qu'Evo Fernandes serait devenu, les tout derniers mois de sa vie, un agent soviétique, d'où son assassinat. Jorge Correia démentait vivement, nourrissant son argumentation de toute une série d'informations sur la culpabilité du Snasp ${ }^{224}$.]

\section{Le 17 octobre 1994}

Il pleut sans vent mais de manière continue.

10h10. Conférence de presse de Dhlakama. Il dénonce le sabotage du téléphone partout où il arrive : «Comportamento anti-democrático ».

«Depuis le jour de la signature de l'Accord général de paix, j’ai cherché à assurer l'avenir de la démocratie au Mozambique. Parfois, dans les pays africains, l'opposition tend à disparaître. Qu'en sera-t-il après les élections ? Comment se comporteront ceux qui vont gagner? Ceux qui vont perdre ? C'est pour cela que nous avons fait une étude pour assurer le statut de l'opposition et la réconciliation nationale. Dans le document que nous présentons à Chissano, je propose la création du statut du Chef de l'Opposition. Dhlakama au pouvoir travaillerait avec lui, je devrais les [sic] tranquilliser pour qu'ils ne sabotent pas. Je n'ai pas encore eu de réponse [...]

Le gouvernement laisse entendre à la communauté internationale qu'il va gagner, parce qu'évidemment il se prépare à frauder. [...]

Je ne suis pas entré en brousse comme un simple militaire. J'y suis entré comme líder politique ${ }^{225}$ parce que je n'aimais pas le marxisme. Il était impossible de faire de l'opposition pacifique. L'alternative, ça a été de partir en brousse. Nous y avons été obligés... Évidemment le Frelimo a beaucoup résisté. Si la Renamo avait fait la guerre contre les civils, nous ne pourrions gagner les élections. La guérilla n'est pas une armée, c'est le peuple qui se rassemble. Si les gens avaient été raptés, il aurait fallu les attacher, ç'aurait été impossible de combattre seize ans. Il est évident que, sous le feu, des femmes et des enfants sont morts, mais je me refuse à assumer que la Renamo aurait fait la guerre pour tuer des femmes et des enfants. »

Il commente ensuite la défection du responsable de la Liga da Juventude de la Renamo pour la province de Maputo ${ }^{226}$ :

« S'ils ont fait ça avec cet enfant, c'est une défaite pour eux, parce que cela signifie qu'ils

n'ont pas réussi à acheter des chefs de département.

[...] La brousse est pleine d'armes [du Frelimo]... ».

Je lui pose une question sur l'élection des gouverneurs et administrateurs : «ce sera discuté après ». Je lui demande son avis sur l'alphabétisation en langues africaines : il ne répond pas nettement - « les détails seront vus après les élections ».

Après-midi. Il a plu toute la journée. Dans la basse ville, les rues ne sont qu'un immense cloaque.

Discussion avec Jorge Correia sur l'histoire de la Renamo, la nature de la guerre, etc. C'est le colonel Sakala, du département de la LCB (Luta Contra-Bandidos) du Snasp qui a tué Joana Simeão, Lázaro N'Kavandamne et Uria Simango ${ }^{227}$ sur ordre du Bureau politique. Selon Jorge

collaborateur de Jorge Jardim et premier organisateur militaire de la Renamo en Rhodésie puis en Afrique du Sud. Assassiné en Afrique du Sud en 1984.

${ }^{224}$ L'hypothèse Snasp est évidemment possible. Personnellement, j'avais également émis l'hypothèse d'une responsabilité sud-africaine, le régime d'apartheid tuant, dans les années quatre-vingt, les cadres politiques qui auraient pu donner une vraie autonomie à la Renamo - c'est pratiquement avéré pour O. Cristina, bien que des rivalités entre Portugais d'Afrique du Sud soient probablement aussi en jeu.

${ }^{225}$ Souligné par moi dans mes notes.

${ }^{226}$ Ce responsable, accompagné d'un petit groupe des jeunesses de la Renamo, venait publiquement de rompre avec cette dernière.

${ }^{227}$ Joana Simeão était l'une des rares femmes macuas de formation universitaire. À la fin de la période coloniale, elle fut promue et instrumentalisée par Jorge Jardim pour créer un parti noir et alternatif au Frelimo - 
Correia, la LCB aurait aussi injecté le virus de la blénorragie à des centaines de femmes, en zones disputées, sous couvert de vaccinations anti-cholériques. Ce serait elle, avec la ContraInteligência militar, qui aurait perpétré le massacre d'Homoine. Il s'agit de gens très bien entraînés, qui ne parlent pas, et que, du point de vue matériel, le Frelimo n’a jamais laissé tombé, même aujourd'hui.

comme par hasard dirigé par un líder macua - le Gumo (Grupo unido de Moçambique). Elle fit des réunions au Mozambique dès avant le 25 avril réclamant l'indépendance, fut reçue à Lisbonne par le président du Conseil... Jorge Jardim l'abandonna pratiquement ensuite, quand il comprit que le seul interlocuteur ne pouvait être que le Frelimo.

Lázaro N'Kavandame était un agriculteur maconde particulièrement dynamique, émigré au Tanganyika, un «moderne » (il n'était nullement, comme on le voit parfois écrit, un chef traditionnel). Il rentra au Mozambique pour y développer le même activisme économique. D'abord soutenu, puis étroitement surveillé, par les autorités coloniales, il fut poussé par l'impossibilité d'y développer un entrepreneuriat noir, dans les bras du Frelimo qu'il rejoignit en 1963. D’une popularité considérable, il fut nommé responsable de la région du Cabo Delgado. Cependant, sa volonté de continuer, grâce à la guérilla, les activités économiques et commerciales que les Portugais l'avaient empêché de mener, l'opposa de plus en plus souvent à la stratégie militaire de la guerre populaire prolongée - il souhaitait qu'on expulse vite les Portugais de la seule région du Cabo Delgado, pour ensuite seulement étendre la guerre, au lieu d'en relativiser l'importance dans la marche vers le Sud. Dans le contexte d'absence de démocratie interne au sein du Frelimo, ces divergences politiques et économiques se doublèrent d'une rivalité entre les chairmen (chefs civils, et souvent chefs traditionnels, des branches du Frelimo) et les militaires. Il tenta dès lors de détacher sa province de la hiérarchie militaire du Frelimo. Après l'assassinat d'Eduardo Mondlane le 9 février 1969, et suite à de graves incidents à la frontière entre ses milices et le dirigeant militaire régional fidèle à la direction du Frelimo (qui fut tué), il se livra aux autorités portugaises, ayant été mené à croire que ces dernières donneraient une espèce d'autonomie - notamment en matière économique et commerciale - au Cabo Delgado. L'opération fut un échec : rompant avec la guerre, N'Kavandame fut lâché par les Macondes. Comprenant ensuite que l'autonomie, même partielle, du Cabo Delgado n'était pas du tout dans les intentions portugaises, il prépara alors, vers juillet 1970, sa deuxième fuite au Tanganyika, avec ses chairmen, pour rallier à nouveau le Frelimo. Mais la Pide, parfaitement au courant, l'arrêta et l'assigna à résidence surveillée à Pemba (alors Porto Amélia), ne le faisant réapparaître publiquement, et spectaculairement, qu'en 1972, après que Le Monde Diplomatique ait annoncé, sous la plume de Virgílio de Lemos, qu'il avait été tué par les Portugais. (Par ailleurs, la complicité de L. N'Kavandame dans la mort de Mondlane n'est absolument pas prouvée et semble avoir été avancée dans la plus pure tradition stalinienne afin de mieux « démontrer», a posteriori, la « trahison » du dissident.)

Uria Simango, originaire de la Machanga (Sofala), fils de Uria Timoteo Simango (arrêté lors de l'émeute de 1953 dans ce village), était pasteur de l'Igreja do Cristo em Manica e Sofala (une branche du congrégationnalisme américain par ailleurs lié aux presbytérianisme suisse). Il avait émigré en Rhodésie du Sud où il avait créé la Portuguese East African Society, comme couverture mutualiste pour les activités du Partido da Convenção nacional, rebaptisé ensuite Udenamo (União democrática nacional de Moçambique) lorsque le petit groupe fusionna avec celui d'Adelino Gwambe (originaire d'Inhambane), puis dut passer au Tanganyika. Mais à la différence de Gwambe, Simango défendit la création du Frelimo le 25 juin 1962 et fut dès lors un proche collaborateur de Mondlane, même s'il était parfois taxé de «maoïste » face aux autres cadres « pro-soviétiques ». Après la mort de Mondlane (1969), il devint brièvement vice-président du Frelimo, solidement encadré au sein d'un «triumvirat» par Marcelino dos Santos et Samora Machel, avant de rompre et d'être exclu suite à la publication d'un texte dénonçant les violences internes au Frelimo. À la différence d'autres dissidents du Frelimo, il ne se rendit jamais aux Portugais. Mais, rentré au Mozambique après le 25 avril 1974 et y animant à nouveau son petit PCN, il commit l'erreur de se montrer lors des émeutes pieds-noirs du 7 septembre. Il s'enfuit alors au Malawi, dont la police le livra au Frelimo. Son fils Lutero Simango a, en 1993, repris le sigle et recréé de toute pièce un PCN.

Joana Simeão, Lázaro Kavandame et Uria Simango (ainsi que le père Gwenjere et Paulo Gumane, deux autres dissidents), furent envoyés en camp de rééducation et fusillés sans procès en 1979 (et leurs femmes en 1982), sans doute quand le Frelimo eut peur qu'un coup de main de la Renamo ne puisse les libérer et ainsi donner à la rébellion naissante des dirigeants politiques de premier ordre. Sérgio Vieira, dirigeant du Frelimo et un temps ministre de la sécurité, devait encore, en 1995, justifier, en pleine assemblée nationale, ces fusillades... 
La LCB a essayé de tuer Dhlakama via un... casque de moto ${ }^{228}$. Le casque avait été offert par un « sympathisant » à un groupe de guérilleros pour acheminement jusqu'au Président. L'un de ceux-ci, las de le porter à la main, l'aurait alors mis et... serait tombé mort quelques instants après. Le groupe reprit sa marche après l'incident, et un deuxième guérillero, las à son tour, l'aurait mis et serait tombé raide mort. Le casque était piégé : des pastilles d'un gaz mortel avaient été insérées dans la mentonnière.

\section{Le 18 octobre 1994}

Un timide soleil dégage du sol une moiteur étouffante.

\section{9h30. Brève discussion avec Lutero Simango, du $\mathrm{PCN}^{229}$.}

On dit que « Dhlakama a amené la pluie ».

11h40. Départ pour Mutarara. Dhlakama part, la pluie cesse... Nous survolons le fleuve Zambèze sur la rive gauche.

12h. On traverse la ligne haute tension de Cahora-Bassa ${ }^{230}$.

12h50. Arrivée à Mutarara. Nous atterrissons en bordure du terrain de foot où la foule est déjà massée. Le délégué local est Pedro Hole. Responsable des Armazéns das lojas do povo [Entrepôts des magasins du peuple] à Beira, il rejoint la Renamo dès 1978. Arrêté une première fois, il sort de prison en 1979. Arrêté à nouveau, il échappe à la fusillade et est libéré le 10 août 1986. Il part alors en zone Renamo dans les montagnes près de Mutarara. Jamais militaire, $4^{\mathrm{e}}$ classe coloniale. Dans la direction locale de 9 membres, il y a trois anciens soldats. Ils sont tous sena, sauf un Macua zambézien et un de Nampula.

Le délégué provincial de Tete est António Mafuta Banda [je ne l'avais pas rencontré dans cette ville, et je commis la gaffe d'interroger d'abord le délégué local. Je devais comprendre par la suite qu'il était extrêmement susceptible sur sa reconnaissance...]. Auparavant membre du Frelimo, il rejoint la Renamo le 18 janvier 1982, engagé dans la zone d'influence pédagogique de Matenje-Macanga, au nord de Tete, dont il était responsable - en tant qu'ancien instituteur [ayant suivi les] études coloniales. Il quitta sa maison sans même qu'il y ait eu une attaque ${ }^{231}$ et partit directement pour Gorongosa ${ }^{232}$. Il y reste de 1982 à 1986. Il fut militaire et coordinateur pour l'éducation et la culture dans la zone Centre. En 1986, il est nommé cadre politique en Zambézia (Luabo, Baixa Zambézia) jusqu'en 1988. En janvier de cette année, il repart à Gorongosa, puis ouvre le «front administratif et politique » de toute la province de Nampula. Il vit à Murrupula, en zone Renamo, jusqu'à 1989, puis ensuite à Muecate. Il est donc « gouverneur provincial » jusqu'à l'Accord général de paix. Il reste jusqu'en février 1994 à Nampula, puis est

${ }^{228}$ Dhlakama voyageait souvent, dans l'intérieur du Mozambique, en moto-cross.

${ }^{229}$ Lutero Simango (voir note 8 ci-dessus) est le fils d'Uria Simango ; il animait en 1994 un petit parti resté sans représentation parlementaire, le Partido da Convenção nacional. Ce parti est connu pour être l'un des rares à mener une vraie réflexion intellectuelle (voir note 20 du chapitre «Madjermane »). Aux élections de 1999, il a intégré une coalition avec la Renamo.

${ }^{230}$ Le barrage de Cahora-Bassa, l'un des plus grands du monde, sur le Zambèze, fut une initiative controversée jusqu'au sein du régime salazariste, car elle impliquait une entrée massive de capitaux sud-africains au Mozambique. L'électricité ne devait initialement pas profiter au Mozambique mais être vendue à l'Afrique du Sud, via une gigantesque ligne à très haute tension et à fil unique (la terre représente le pôle opposé). Durant la guerre civile, la Renamo fit sauter jusqu'à 900 pylônes...

${ }^{231}$ Cette insistance, un peu douteuse, sur les circonstances de l'« engagement », peut couvrir un rapt - dont, comme il arriva souvent, il se serait senti finalement content.

${ }^{232}$ Chaîne de montagne abritant le QG de la Renamo. 
appelé à Maputo pour complément de formation. Enfin, il est nommé délégué provincial de Tete. Il est sena.

(Il paraît que 80 membres de la Renamo de Montepuez ont rendu leurs cartes.)

13h. Dhlakama arrive. Civpol, PRM. Les cases sont couvertes de bâches plastiques de l'UNCHR ${ }^{233}$, récupérées dans les camps de réfugiés du Malawi, dont les habitants se réinstallent. Enthousiasme, chants, curiosité rieuse. 4000 personnes environ.

13h10. Vivas repris largement et interminables! La «population» dénonce le fait que le Frelimo a mis des troncs sur la piste pour empêcher l'atterrissage. Mafuta Banda, excellent orateur :

«Le Frelimo devient de plus en plus un analphabète politique. Mais nous avons atterri, ici, à Mutarara ».

Je me renseigne, la Civpol dément : la piste était libre, hormis des enfants jouant au ballon... Le meeting a été annoncé seulement hier. Les povoações éloignées n’ont pu venir.

13h20. Ovation à Mamãe Dhlakama. La foule est terriblement dense. Dhlakama parle en portugais et en cisena. Il est déjà passé en juillet dernier.

«Gorongosa ${ }^{234}$, ce n'est pas loin d'ici, je connais bien vos problèmes... Il y a des personnes qui viennent de revenir du Malawi [applaudissements], qui n'ont pas de nourriture [applaudissements], qui souffrent de discrimination. Celui qui est à la Renamo, rien pour lui, celui qui est au Frelimo, il reçoit de l'aide... Il y a même des personnes qui veulent retourner au Malawi [applaudissements]. Dhlakama au pouvoir garantira la sécurité alimentaire... »

Une partie du public n'a pas été recensée, car il s'agit de réfugiés rentrés du Malawi après la fin du recensement.

«C'est Dhlakama qui a libéré Chissano. Sans notre lutte, Chissano serait-il en chemin pour demander les suffrages de la population ?... Qui n'a pas tué ? Avant la guerre, le Frelimo tuait déjà ! N'est-ce pas Chissano qui a envoyé les Zimbabwéens bombarder Mutarara et tuer des enfants ?»

Il paraît qu'à Angónia, c’est plein de gens qui attendaient Dhlakama. À Domué aussi.

14h10. Fin du meeting. Vivas! Chants. Pas de photos du Président et d'emblème du parti ici. Ils ne sont pas arrivés?

Chissano aussi est venu, et il y a eu du monde - un peu moins, malgré les moyens [mis en place], selon le correspondant de l'agence Lusa.

14h20. Départ pour Tete.

15h35. Arrivée et transfert au stade.

16h20. Arrivée au stade, Vivas bien répondus. Environ 4200 personnes. Dhlakama parle en portugais.

«Le Frelimo a mis ses tireurs de bazooka pour gérer des entreprises. Alors, celui qui sait tirer sait gérer une entreprise ? Nous n'allons pas faire cela ${ }^{235}$.

16h55. Fin du meeting.

${ }^{233}$ Haut Comité des Nations unies pour les réfugiés.

${ }^{234}$ Ancien quartier général de la Renamo pendant la guerre.

${ }^{235}$ Dans cette vieille cité de métissage, Dhlakama essayait de toute évidence de jouer sur le ressentiment de l'élite locale face à la nomination d'anciens guérilleros du Frelimo aux meilleures places. 
17h20. Départ pour Chimoio, l'hélicoptère plein de valises et d'armes - des chargeurs se répandent à mes pieds...

18h55. Arrivée à l'aéroport de Chimoio : 1000 personnes environ.

23h00/01h. Entrevue avec Chale, le correspondant mozambicain de l'agence Lusa, sur mon analyse de la situation ${ }^{236}$.

${ }^{236}$ Sauf erreur, cette entrevue n'a jamais été publiée. 


\section{Chapitre 7}

\section{Manica, terra dos Matsangaissas ${ }^{*}$}

\section{Le 19 octobre 1994}

Chimoio est une jolie ville. Non pas tant par le site ou les monuments, mais par le bon état surprenant où elle se trouve, par la coquetterie des maisons, la propreté des trottoirs. Les champs alentour sont parfois alignés comme des jardins.

\section{1h25. Départ pour Catandica (nord-Manica) et Barué ${ }^{237}$.}

12h10. Arrivée à Catandica, après avoir longé la ligne de montagnes qui fait la frontière avec le Zimbabwe ${ }^{238}$. La montagne et son piémont sont verdoyants, donnant à tout ce paysage une impression de quiétude.

Atterrissage sur la piste qui jouxte la vila. Chants, danse, tambourins. Civpol, PRM. Le meeting a été convoqué seulement hier soir. Au pied des collines verdoyantes, Catandica a un air méditerranéen, avec ses arbres mêlés à des palmiers et plantes fleuries. Mais des tentes de réfugiés récemment rentrés sont éparpillées. Un camion «Chissano » passe et repasse. La sono est très mauvaise, mais le public semble plus curieux que sympathisant (environ mille personnes). Des gens vont et viennent, ou s'en vont. Quelques-uns applaudissent. Le groupe Chissano est descendu de son camion et fait une petite contre-manifestation. Il s'agit surtout d'enfants et de jeunes : «Vota! Vota Chi-ssa-no! ». Le meeting continue, entrecoupé de pannes de sono.

13h25. Fin du meeting. Chants. La population du Barué est faible, mais la Renamo y a eu des bases. Si Catandica-Vila n'a jamais été occupée, les environs étaient Renamo.

\section{3h30. Départ pour Gondola.}

14h05. Arrivée à Gondola. Nous atterrissons sur un stade en bordure du chemin de fer ${ }^{239}$. Le public est installé sur les gradins. Tambourins, chants, danses, vivas! L'orateur parlera du stade. Civpol, PRM.

14h10. Arrivée de Dhlakama. Ovation et carinho [ferveur]. Dhlakama danse. Il y a environ 3500 personnes, ce qui n'est pas mal pour un meeting convoqué seulement la veille au soir.

14h30. Une chèvre... perturbe le meeting... Dhlakama est déjà venu en juillet. Il parle, sans traduction, en ximanica. Il est toujours, visiblement, plus à l'aise en langue africaine qu'en portugais.

\footnotetext{
* «Manica, terre des Matsangaissas ». Matsangaissas, ou Matsangas, nom populaire donné aux soldats de la Renamo (voir note 4 ci-dessous).

${ }^{237}$ Le Barué a toujours été une zone politiquement sensible. Lieu de la très grande révolte de 1917-1922, elle fut aussi une des premières régions d'implantation du Frelimo dans l'ancienne province coloniale du Manica e Sofala. Ensuite, la Renamo s'y implanta solidement. Les chefferies traditionnelles y ont encore d'importantes et légitimes implantations.

${ }^{238} \mathrm{La}$ frontière entre le Mozambique et le Zimbabwe est constituée notamment de l'escarpement montagneux qui appartient au Rift.

${ }^{239}$ Il s'agit de la ligne vitale du vital chemin de fer de Beira au Zimbabwe, le « corridor de Beira ».
} 
«Le président est Frelimo, les ministres sont Frelimo, les gouverneurs sont Frelimo, ce sont jusqu'aux administrateurs de localité qui sont Frelimo. Ça, ce n'est pas la démocratie. Dhlakama au pouvoir, lui, ne gouvernera pas seul, il appellera des gens d'autres partis. »

Il reprend ensuite les thèmes de l'éducation, de la santé, de la police et des fonctionnaires.

«Ce pays de Manica était le pays des Matsangaissas ${ }^{240}$, n'est-ce pas ? Les Matsangaissas ont réussi à vaincre le Frelimo. Et le Frelimo vient quémander les suffrages des Matsangaissas ?»

C'est la première fois qu'il parle ouvertement des Matsangaissas.

15h10. Fin du meeting. Ici, les gens entourent les paillotes familiale d'une rangée de buissons, qui délimitent ainsi coquettement l'espace [de l'airial].

15h35. Nous partons en cortège automobile pour Manica. À travers les plantations de pins et d'eucalyptus, cette région est comme une petite Europe du Mozambique ${ }^{241}$.

16h25. Tempête de grêle. Le cortège est stoppé. Les grêlons frappent comme des balles de plus en plus grosses et impressionnantes. Le bruit est considérable dans la Land Rover. Nous sommes blottis, nous attendant à ce que les vitres volent en éclat. La route est couverte de glace. Les policiers de la voiture de tête sont réfugiés sous leur voiture. Enfin, la grêle faiblit.

16h35. Arrivée à Manica. Le pire, c'est que les gens ont attendu ! Les rues sont pleines, un cortège s'improvise jusqu'au lieu du meeting. La Vila de Manica a de jolies maisons rhodésiennes, une placette coquette, des fleurs, le tout entouré de montagnes...

Dhlakama amène la pluie!

17h. Vivas habituels, mais aussi : "Viva o herói inesquecível André Matsangaissa! », «Vive le héros inoubliable André Matsangaissa ! ». Le délégué se plaint des intimidations, des magasins des sympathisants détruits, des menaces. Il y a environ deux mille personnes. Dhlakama est déjà venu en juillet et il y avait eu environ mille personnes, selon Jorge Correia. Dhlakama parle en portugais et en ximanica. En même temps, un peu en retrait, se tient une petite réunion du PCN, avec des enfants qui chantent. Ils attendent la fin du meeting Renamo pour faire le leur [Lutero Simango me racontera plus tard que, la Renamo partie, le PCN a fait son meeting au même endroit, avec les mêmes installations et les mêmes personnes, et que tout s'est très bien passé. Cependant le score du PCN à Manica sera dérisoire].

Plus loin, il y a un concert du Frelimo, donné du balcon de la sede distrital [siège du district] du Frelimo. Ce devait être un meeting, mais le gouverneur du Manica, Artur Canana, a reculé face au danger de «confusão » [désordre]. Deux cents personnes environ y assistent.

Étrange meeting. L'élite de la ville n'est pas là, les métis et les Indiens sont restés chez eux. Seuls les descamisados sont venus.

«Ce pays a été aux Matsangaissas! Les Matsangaissas étaient des bandits ? Et maintenant, le Frelimo vient demander les suffrages des Matsangaissas ? Comment est-ce possible? (...) Aniceto dos Muchangos ${ }^{242}$ et Manuel Tomé ${ }^{243}$ sont des enfants de la région. Ils mangent bien à Maputo, mais leurs parents ici ne mangent rien. »

240 «Matsangaissa » est 1'appellation populaire pour du soldat de la Renamo, à cause du nom du premier chef militaire, André Matsangaissa. Une forme voisine est « matsanga ».

${ }^{241}$ La région du planalto de Manica a d'ailleurs été, du temps de la colonisation, une zone importante de petits planteurs portugais, producteurs en particulier de maïs. Les zones plus élevées sont couvertes de plantation d'arbres. C'est d'ailleurs ici que fut implanté le «complexe Ifloma», une importante entreprise publique de plantations d'arbres, en même temps fleuron de la coopération scandinave. Ifloma a fortement souffert de la guerre.

${ }^{242}$ Universitaire et géographe, longtemps ministre de l'Éducation.

${ }^{243}$ Secrétaire général du Frelimo. 
17h40. Fin du meeting. Sur le chemin du retour, le cortège s'arrête. Dhlakama ramasse quelques grêlons. Qui mange la grêle est immunisé... Il a grêlé à Vumba, la terre où a commencé la guerre et où est né André Matsangaissa. Il a grêlé le jour anniversaire de la mort de Samora Machel. Il avait plu à Tete, le jour du meeting de Dhlakama, jour anniversaire de la mort de Matsangaissa...

\section{Le 20 octobre 1994. Chimoio}

Ce matin le ciel est clair, lumineux, bleu comme à Lisbonne en janvier. Le vent est délicieux. Un groupe de démobilisés attend devant le BPD [Banque populaire de développement] le subsídio ${ }^{244}$. Passe un cortège du Pimo ${ }^{245}$.

Le meeting a été convoqué à dix heures. Il est onze heures, nous attendons depuis deux heures la voiture qui doit venir nous chercher et nous y conduire.

11h20. La voiture arrive. Le meeting vient de commencer au stade. Civpol, PRM. Dhlakama parle en ximanica. Il y a environ 4500 personnes, cela aurait pu être plus important. En juillet, il y avait eu plus de gens, selon Jorge Correia, mais le meeting avait été préparé plus longtemps à l'avance.

Dhlakama attaque Momboya, du Pacode ${ }^{246}$ - et c'est la première fois qu'il critique un parti d'opposition dans un meeting :

«Ce Monsieur dit que tant le Frelimo que la Renamo ont les mains sales. Mais il fait erreur. Premièrement, il a créé son parti grâce à la Renamo, grâce à notre victoire. Il fait fausse route. Si Dhlakama n'avait pas fait la guerre, n'avait pas résisté, il n'y aurait pas eu de Pacode. Nous sommes dans la campagne électorale, les partis sont libres. Mais la population doit bien écouter les messages des líders. Pourquoi n'y a-t-il pas eu d'élections en 1975, 1976, 1977, 1978, 1979, 1980, 1981, 1982 ? [Applaudissemnts] Où était le Frelimo ? Qui estce qui a rejeté la démocratie ? Qui est-ce qui a fait pression sur le Frelimo ? La guerre est mauvaise dans n'importe quel pays, mais quand il ne reste que la voie de la résistance, la guerre est nécessaire. Et il est important de rappeler à la population que ce fut difficile. Le Frelimo ne voulait pas. Ce n'est pas Chissano qui a amené la paix. Il promet un «Futur meilleur ${ }^{247}$. Comment cela ? Est-ce que des fois il aurait changé ? [rires] C'est vrai, il a déjà changé un petit peu. Vous voulez savoir comment?

- Oui!

- Il a amené les parachutistes ${ }^{248}$ ! Vous voulez en savoir plus ?

- Oui!

- Il vend dans les meetings la bière à 1500 meticais ! C'est pas bien, ça ? ! Je trouve ça

bien ! Il a apporté des pagnes et des T-shirts [bruits divers]. Ça n'a pas été bien aussi ?

- Non!

- Vous n'avez pas eu de T-shirts?

- Non!

- Mais ces T-shirts viennent de votre argent, c'est l'argent des impôts, l'argent qui a été pris pour acheter des T-shirts! Prenez ces T-shirts, parce que cet argent est à vous [applaudissements] »

Il reprend ensuite le thème santé, notamment les salles spéciales et payantes des hôpitaux publics. Des gens critiquent Maputo que « está a acabar com o nosso milho » (« qui accapare notre maiis »). Dhlakama réagit :

«Écoutez, mes frères! Moi je vis à Maputo, je ne défends pas Maputo mais je parle en tant que Mozambicain ! Le peuple à Maputo n'a rien! Ils n'ont rien! Les ministres, ça oui !

${ }^{244}$ Le Banco popular de desenvolvimento distribue les primes de démobilisation de l'Onu.

${ }^{245}$ Pimo, Partido independente de Moçambique, cf. note 21 du chapitre 3.

${ }^{246}$ Pacode, Partido da convergência democrática, petit parti considérant Frelimo et Renamo comme « deux monstres ». Son dirigeant, Momboya, a eu une évolution politique complexe : dissident du Frelimo dans les années soixante, il l'a ensuite rejoint, puis en est à nouveau sorti.

${ }^{247}$ Futuro melhor (« un futur meilleur ») était le slogan central de la campagne du Frelimo.

${ }^{248}$ Les meetings du Frelimo incluaient presque toujours un spectacle de parachutisme. 
On dit que tout le pouvoir est de Gaza! Mais regardons la population de Gaza! Ils n'ont rien! La population de Maputo souffre, la population de Gaza souffre, la population d'Inhambane souffre! Les ministres, eux, ils ont tout! Quel est le ministre qui n'a pas d'entreprises ?

- Aucun!

- Quel est le ministre qui n'a pas de voiture de luxe?

- Aucun!

- Quel est le ministre qui n'a pas un haut salaire ?

- Aucun!

- Mes frères, nous voulons changer la situation dans toutes les régions ! »

Il reprend le thème évoqué à Manica, de la «terra de Matsangaissa » auxquels maintenant le Frelimo demande leurs votes, et interpelle Aniceto dos Muchangos et Manuel Tomé :

«Hier nous étions des bandits. Et aujourd'hui, on vient vous demander de voter Frelimo. Acceptez-vous cela?»

Il évoque ensuite les Zimbabwéens qui entrent pour voter et appelle la population de Manica à se mobiliser pour les repérer et les reconduire à la frontière. Alors un militant prend la parole qui dénonce «l'invasion» des produits zimbabwéens, et la répression du Snasp, dont il a souffert sans preuve. Un autre dénonce la répression : - "Frelimo, segurança, matadores! », « Frelimo, flics, massacreurs » et lance : - «Problemas de Moçambique, não são os Zimbabueanos que resolvem, somos nós! », "Les problèmes du Mozambique, ce ne sont pas les Zimbabwéens qui vont les résoudre, c'est nous !». Le suivant dénonce les fosses communes où le Snasp a enterré ses victimes. Lui-même a été prisonnier, lui-même peut témoigner de ces enterrements et peut montrer où c'est. Un homme âgé dénonce encore la répression, et voudrait que se vident les prisons. Il aimerait que la perdriz sorte non seulement la tête, mais tout le corps ! Un professeur se plaint de la marginalisation des professeurs, un autre encore se plaint d'avoir été traité comme un esclave au Zimbabwe. Dhlakama reprend ensuite la parole.

12h30. Vivas très bien repris. Carinho.

12h40. Fin du meeting. André Jonas me dit que le Frelimo a distribué des capulanas dans les quartiers en disant que le meeting était à $14 \mathrm{~h}$ - alors qu'il était à 10 heures.

15h. Nous arrivons à l'aéroport et y apprenons que l'Antonov qui doit nous ramener à Maputo est encore à Tete et ne sera là que vers $17 \mathrm{~h}$. Retour en ville.

16h30. Nous patientons à la Feira de Chimoio [Foire], buvant des bières du Zimbabwe et écoutant les Tubarões du Cap-Vert ${ }^{249}$.

17h15. La pluie s'abat, soudaine et violente, presque à l'horizontal. La grêle, à nouveau ! Nous sommes réfugiés dans une petite hutte sans mur, frêle abri. Grêle et soleil en même temps, avec le vent qui tourne brusquement à 180 degrés, inondant l'abri... Je tente une petite discussion avec le général Mário Frank qui, après avoir été à Espungaberra en 1979, puis sur 1'Estrada Nacional $n^{\circ} 1$ [Route nationale $\mathrm{n}^{\circ}$ 1] dans le district de Chibabava, est venu ouvrir le front de Gaza en 1982, puis développer le front de la province de Maputo en 1984, qui n'existait alors qu'en sa partie nord. À 21 ans, Mário Frank fut secrétaire d'un GD du Frelimo à Sussundenga, de 1974 (avant l'indépendance) à 1977. Il rejoint alors volontairement une Renamo qui n'a encore que soixante membres, dans les monts Chimanimani. Il déclare n'avoir pas eu de motif individuel, mais «avoir assisté à la résistance du peuple à la villagisation ». Général depuis 1983, il a été démobilisé le 19 septembre 1994.

\footnotetext{
${ }^{249}$ Les Tubarões (les « Requins ») furent des années durant l'un des principaux groupes musicaux du Cap-Vert, jouant autant des coladeras (danses rapides) que des mornas (mélodies lentes et tristes).
} 
18h30. On est toujours là ! Les pitas $^{250}$ apparaissent, car elles savent que la Renamo vient boire et danser tous les soirs : - «Só querem bébés », "Elles ne cherchent qu'à tomber enceintes », interprète la militante de choc qui conduit toujours la voiture de Dhlakama. Armindo Xavane, le Zoulou, de la TVM, mange la viande à même le feu, selon la tradition.

19h. Soudain, violente altercation entre André Jonas et Jorge Correia.

Le jour de l'arrivée à Tete, Jorge Correia avait réuni à ses frais une tablée des pilotes et d'invités qui, à une exception (Chale, de l'agence Lusa), étaient tous blancs (dont moi). Je pense qu'il s'agissait d'un hasard, puisque ce n'étaient pas les gens qui étaient invités personnellement, mais la tablée, qui se remplissait au fur et à mesure des arrivées dans le restaurant, qui était payée par J. Correia. Comme J. Correia avait déjà eu une petite altercation avec le délégué provincial, Mafuta Banda, André Jonas comprit que l'on se plaignait du fait que « les Blancs » avaient été invités à dîner par Correia alors que « les Noirs » avaient dû manger à une autre tablée du même restaurant. Pour éviter la confusão, il avait reporté le cas au Président, et m'en avait parlé au mata-bicho [petit-déjeuner], à Chimoio, deux jours après.

Jorge Correia, qui était allé parler au téléphone avec le Président, revient tout d'un coup, fou de rage, et immédiatement lance je ne sais quelle insulte à André Jonas qui se retourne furieux vers moi en disant :

- "Você é a única pessoa com quem eu falei do assunto », "Vous êtes la seule personne à qui j'en ai parlé », il oublie qu'il en a parlé au Président et ne sait pas que Correia vient de parler à celui-ci, et je suis donc le coupable, j'ai tout rapporté à Jorge Correia puisque nous sommes blancs tous les deux... Bien sûr, je nie de façon véhémente et je ne sais plus quel cadre de la Renamo me défend :

- «Aquele homem, não!», « Non, pas lui !».

Jonas et Correia s'insultent un long moment :

- «Você é puto, só copitos e putas! », «Tu n'es qu'un gosse, toujours à boire et avec les putes !» hurle Correia

- "Nunca aceitarei insultos de um branco de Lisboa. Eu sou do Gabinete da presidência, ouve? Eu sou Adido de imprensa do Presidente! », "Jamais je n'accepterai d'insultes venant d'un Blanc de Lisbonne. Je suis du cabinet de la présidence, tu entends ! Je suis attaché de presse du Président! », éructe Jonas

Les autres ont toutes les peines à les empêcher d'en venir aux mains, alors que Correia, hurlant, cherche à sauter du bus par la fenêtre pour se jeter sur Jonas.

- "Isso é vergonha nossa, os jornalistas vão dizer que isso é a Renamo », " Honte à nous, les journalistes vont dire que la Renamo, c'est cela ${ }^{251}$.

19h15. Nous sommes à l'aéroport. L'Antonov a déchargé du matériel de la CNE. Il paraitt qu'on va passer par Beira.

La lune regarde les hélicoptères de l'Onu et l'Antonov, immobiles dans l'obscurité.

19h30. Départ pour Beira.

20h. Dans l'avion du retour, je mets les choses au point avec Jonas. Il admet sans plaisir. Visiblement, le moindre faux pas fait ressurgir immédiatement de vieilles rancœurs dans les relations entre Blancs et Noirs. On a ici les mêmes problèmes à la Renamo qu'au Frelimo...

20h05. Arrivée à Beira. Moiteur épouvantable. Nous déchargeons du matériel STAE de l'avion, que personne n'est venu chercher...

\footnotetext{
${ }^{250}$ Pitas, terme très péjoratif, presque synonyme de prostituées, en tout cas femmes de mauvaise vie, jeunes et à la mode.

${ }^{251}$ Je n'ai pas eu connaissance qu'aucun des journalistes présents aient rapporté l'incident.
} 
20h45. Départ pour Maputo. Nous ruisselons de sueur dans l'air épais.

21h30. Maintenant, dans l'Antonov, gardes du corps et journalistes dorment au milieu du fatras de matériel sono, d'armes et d'autres objets indéterminés. João et Mulhovo sont recroquevillés sur leurs caméras TV. 


\section{Chapitre 8}

\section{Inhambane, terra da Boa Gente*}

\section{Le 21 octobre 1994 [à Maputo]}

8h. Fernando Manuel ${ }^{252}$ et moi sommes à la résidence [de Dhlakama], évidemment rien n'est prêt. Il y a un avion de cinq places, seulement pour les journalistes. Mais le Président souhaite que je vienne. Visiblement, il m'aime bien : prudence !

10h30. À l'aéroport. Environ cinq cent personnes.

(Il semble que Dhlakama ait abandonné l'idée de faire un meeting à Xai-Xai. Le travail «sujo» [sale] sur «l'expulsion des Changanes » semble avoir été intense et avoir rendu le meeting impossible. Sur la base d'un mensonge absolu, certains développent une campagne ouvertement tribaliste parmi les Changanes afin de les souder contre les populations du Nord).

(Dhlakama est rentré hier à Maputo bien plus tôt que nous. Quelques centaines de personnes à l'aéroport, et des curieux le long du chemin, mais sans l'aspect «manifestation » de Nampula, donc non comptabilisable. Il semble que Dhlakama est venu à Maputo aussi «para arrumar $a$ casa » [pour faire le ménage] après la sortie de la direction de la Liga da Juventude de Maputo (qui a attendu la semaine précédant les élections pour découvrir que la Renamo n'était pas démocratique...), après des rumeurs persistantes sur une dissidence de Raúl Domingos qui, il est vrai, ne joue pratiquement aucun rôle dans la campagne.)

12h. Départ pour Inhambane, dans le Kinger piloté par Paul, le Sud-Africain. Nous avons attendu seulement quatre heures, sans information...

12h40. Nous survolons Xai-Xai.

13h20. Nous approchons. La région est densément peuplée, partout de petites exploitations parsemées de palmiers, orangers et anacardiers. Plus loin, des rizières, en bordure de la baie sillonnée de voiles arabes.

13h25. Arrivée à l'aéroport d'Inhambane.

Un quadrimoteur des Nations Unies vient juste de débarquer des dizaines d'observateurs de la Communauté européenne, avec leurs sacs à dos, comme au Club Med... Christine ${ }^{253}$ n'y est pas. Cela aurait été un hasard! Le quadriréacteur repart immédiatement, avec quatre hélicoptères.

Une petite foule est massée devant la banderole "Dhlakama presidente » accrochée à l'aéroclub d'Inhambane. Cinq cent personnes, pas plus. Le meeting a lieu en ville.

Terrifiante moiteur.

Je profite d'une boleia [trajet offert] Civpol pour aller en ville. Il y a du monde partout qui attend. Nous sommes dans la Terra da Boa Gente. Fernando Manuel, le BiTonga de Maxixe, est content [d'être presque chez lui]. Bien sûr, partout, on trouve des mestiços de Inhambane ${ }^{254}$.

\footnotetext{
* Terra da Boa Gente, Terre de Gentilshommes, appellation donnée à Inhambane lors de son exploration par les Portugais, au début du XVI ${ }^{\mathrm{e}}$ siècle. L'appellation peut, encore aujourd'hui, être assez fondée, pour décrire la vieille société créole de la ville.

${ }^{252}$ De l'hebdomadaire indépendant Savana.

${ }^{253}$ Christine Messiant, de l'École des hautes études en sciences sociales, était observateur de la Communauté européenne ( $c f$. introduction).

${ }^{254}$ Métis d'Inhambane. Cette ville est une enclave d'ancien métissage et, plus généralement, de créolité.
} 
Partout aussi les bicyclettes neuves distribuées (tardivement) par la Renamo !

14h30. Le cortège présidentiel arrive en ville. Les curieux sont nombreux, mais rien à voir avec Nampula. Les Indiens et Métis saluent le cortège qui parade dans la ville, au milieu des vieilles maisons de la ville assoupie. Les femmes ici le plus souvent ont des jupes et non des pagnes. Vieille cité !

L'organisation est bonne, mais le public clairsemé.

15h. Nous arrivons au stade de sable rouge, près du dépôt ferroviaire où fument encore des locos à vapeur alimentées au bois.

Dhlakama est assis, coiffé de la casquette «Dhlakama é nice! ». Maningue nice, oyée $e^{255}$, mais vraiment il n'y a personne dans ce meeting ! D'ailleurs, le Président, qui discute à voix basse avec le chef national de l'information, Murrial, n'a pas l'air content. Où est la popularité clamée parmi les BiTongas?

"Kanimambo Dhlakama », chantent les femmes de la Liga. Mais le reste du public est silencieux. Les gens vont et viennent, plus curieux que sympathisants.

15h15. Vivas. La moitié du meeting répond. Le premier orateur, délégué provincial, dit que

«nous avons été surpris par l'annonce de ce meeting, c'est pourquoi la population

d'Inhambane n'est pas représentée ici dans sa totalité [certes !], parce que nous avons dû faire

face à diverses difficultés techniques » .

Mais si la cité elle-même participait, sans parler des localités avoisinantes, il y aurait plus de monde. Huit cents personnes?

Le chef national de l'Information reconnaît qu'il y a peu de monde, mais dit que cela ne signifie pas que la population ne soit pas avec Dhlakama :

« Tous les districts, depuis Inharrime jusqu'au Rio Save, sont pour la Renamo».

Pas évident du tout.

- «Abaixo o marequecismo! », « À bas le marxisme!»

- «Abaixo candonga! », « À bas le marché noir!»

15h20. Dhlakama parle (il a déjà été ici en décembre 1993 et en juillet 1994).

«Pour moi, ce n'est pas grave [i.e. le peu de monde], car je connais la population, je suis enfant de cette région ${ }^{256}$. Quand on a toute confiance, on ne perd pas son temps à faire campagne. J'ai été à Chimoio seulement un jour, je suis ici seulement un jour ! En revanche je suis resté neuf jours en Zambézie et à Nampula. Cela voudrait-il dire que j'aime mieux ces provinces quemon Sofala natal ? Non. Mais il n'y a pas beaucoup de travail à mener dans votre province. Ma présence ici est symbolique. Le travail est fait.

Dhlakama aurait-il de l'appui à Gaza ? à Inhambane ? alors qu'il est du Centre du pays ? Mais des fois, le Frelimo aurait-il bien gouverné le Sud? [Ovation]

Je ne me suis pas battu pour les Ndaus - je suis ndau - j'ai combattu pour libérer le Mozambique. Pendant seize ans, j'ai combattu dans dix provinces ${ }^{257}$ ! C'est important de le rappeler, parce que parfois le Frelimo veut prendre l'avantage. Mais le Frelimo a déjà perdu. Comme il a déjà perdu, dernièrement il a voulu se servir des médias qu'il contrôle! Les

255 «Maningue nice, oyé ! , approximativement « super génial, oyé !»...

${ }^{256}$ Dhlakama est en réalité de Chibabava, bien plus au nord et dans une autre province (Sofala). Mais, présent à Inhambane, ville ancienne à l'incontestable localisme frondeur vis-à-vis de la capitale et, en quelque sorte « Nord du Sud », il essaie visiblement de l'inclure dans un grand «Centre du pays » hostile au Sud. Ce propos peut avoir un certain sens à Inhambane même, ainsi qu'aux environs immédiats (populations BiTonga et Chopi ayant souffert et résisté déséspérément aux invasions ngunies - les Changanes de Gaza étant ressentis comme leurs descendants), mais certes pas dans tout le reste de la province d'Inhambane, peuplée majoritairement de VaTsua, ethniquement très proches des Rongas et Changanes.

${ }^{257}$ Le Mozambique en compte onze, compte tenu de la capitale elle-même, qui a un statut de province. 
journalistes ne peuvent écrire librement ! Malheureusement, ils ne peuvent écrire la vérité. Chissano a été à Gaza, et il dit partout que la Renamo va évacuer les Changanes vers l'Afrique du Sud ! C'est de la propagande ! Il dit que Dhlakama n'aime pas les Changanes !, Mes frères, je suis un nationaliste j'ai lutté parmi les Changanes, parmi les Ndaus, les Macuas, les Lómuès, etc. Chipande ${ }^{258}$ dit à Mueda que la Renamo va évacuer les Macondes vers l'Angola! [rires]. Ce n'est pas vrai. Je suis un nationaliste! Je déments cela, j'ai dit que Chissano, lui, lui qui est d'origine sud-africaine, que c'est lui qui serait évacué en Afrique du Sud ! [rires]. Mais même encore aujourd'hui, Chissano est à Gaza pour dire partout que j'ai des plans pour évacuer les Changanes. Mais les Changanes me connaissent, j'ai été en brousse, j'ai mangé le manioc avec eux !

D'ailleurs, le Frelimo a-t-il jamais fait quelque chose pour Gaza?

- Non!

Nous, nous voulons la démocratie, un Président capable de servir les intérêts du peuple! Un Président capable d'accepter les conseils, les critiques! Un Président qui rétablira nos traditions ! C'est cela que le peuple veut, du Rovuma au Maputo ${ }^{259}$. »

Le peuple écoute attentivement les explications sur les «évacuations ». Il émaille son discours de phrases en xitsua. Applaudissements. Reprise des thèmes agricultures, éducation, salaires des fonctionnaires, santé, police.

Ensuite, le frère (frère ? en quel sens ?) du ministre de l'Agriculture prend la parole et dénonce le «million six cent mille » [meticais] à payer à l'entrée de l'hôpital, et dit qu'il soutient la Renamo :

«Le Frelimo a été jusqu'à planifier des opérations cruelles contre les Changanes pour dire ensuite que la Renamo est du Nord ${ }^{260}$. Mais les Changanes n'ont rien !»

16h10. Fin. Curieux meeting, présences peu nombreuses mais devenu plus chaleureux au fur et à mesure du discours. Plus de gens au retour qu'à l'aller. Carinho.

Mais il a parlé des Tsuas plus que des BiTongas, et a parlé en xitsua. C'est une erreur ${ }^{261}$.

[On le voit, le meeting d'Inhambane avait été conçu non point comme un meeting local, pour Inhambane, mais comme un meeting pour tout le Sud : d'où l'insistance des thèmes relatifs aux Changanes, et la langue xitsua parlée par les orateurs. Erreur tactique évidente : les assistants étaient inhambanenses, principalement BiTongas, et n'allaient pas faire le compte rendu du meeting à toutes les populations du Sud. Mais cela exprimait la démission de Dhlakama, «traitant » tout le Sud en un seul meeting (à l'exception de la parade du lendemain à Maputo même). Démission délibérée, ou parce que ses conseillers, pour lui cacher la vraie situation dans le Sud, lui répétait que ce n'était "même pas la peine » de venir y faire campagne ? Un mélange des deux certainement, mais le résultat fut chèrement payé...]

16h45. Départ pour Maputo. Ciel bas, humidité considérable.

(Quand Chissano est venu à Inhambane, il y a eu beaucoup plus de monde. Il est vrai que ce fut avec orchestre, parachutes et une organisation puissante ratissant les alentours, et un appel aux Églises d'Inhambane ${ }^{262}$ ).

Jonas n'est pas venu avec nous aujourd'hui... ${ }^{263}$

${ }^{258}$ Dirigeant maconde du Frelimo. Voir aussi note 2, chap. 4.

259 «... du Rovuma au Maputo», Dhlakama reprend ici une des expressions favorites du discours politique du Frelimo, se réclamant toujours de la totalité du Mozambique, de la frontière nord (le fleuve Rovuma) à celle du sud (le fleuve Maputo), pour en nier les spécificités locales et les ethnicités. Dhlakama reprend l'antitribalisme du Frelimo pour mieux l'accuser d'être tribaliste.

${ }^{260} \mathrm{Il}$ fait ici probablement référence au massacre d'Homoine, non loin d'Inhambane. La Renamo a toujours nié en être l'auteur et avance ce type d'explication.

${ }^{261}$ Les Tsuas sont le plus grand groupe ethnique de la province d'Inhambane, mais le groupe ethnique d'Inhambane est BiTonga

${ }^{262}$ Il s'agit en particulier d'Églises protestantes (notamment méthodistes), qui ont soutenu le Frelimo pendant la lutte pour l'indépendance. 
(Note du 23 octobre : selon Domingo, il y a eu 4000 personnes au meeting de Dhlakama à Inhambane, venues surtout de Jangamo, où la Renamo est forte. Ils doivent compter de la même manière, ou avec plus d'inflation encore, pour le Frelimo !) ${ }^{264}$.

${ }^{263}$ Voir l'incident relaté au chapitre précédent.

${ }^{264}$ Domingo est un hebdomadaire lié au Notícias contrôlé par le pouvoir. Ce «bon compte rendu » du meeting de Dhlakama dans le Sud, à ce moment précis de la campagne électorale, avait-il pour fonction de l'aider à s’illusionner sur la situation réelle? 


\section{Chapitre 9}

\section{À Maputo}

\section{Le 22 octobre 1994}

10h. La colonne de propagande se prépare près de la résidence présidentielle. Capulanas, chapeaux, bicyclettes, voitures sonorisées...

(Il semble que les Senas du Sofala, travaillés par la Sotemaza ${ }^{265}$, peuvent être ramenés à la fidélité au Frelimo. Les villages senas ont été plus durement attaqués durant la guerre que les villages ndaus. En 1972 [avant l'indépendance], il y avait déjà eu de graves heurts - avec nombreuses victimes mortes - entre Ndaus et Senas à Beira. La situation peut être différente parmi les Senas de Zambézie, qui ne sont pas confrontés aux Ndaus. Cela induirait donc une division politique des Senas. La réception de Chissano à Beira - environ 30000 personnes - a ainsi été meilleure que prévue ${ }^{266}$.)

11h15. Toujours l'attente, face à la résidence. Dhlakama s'entretient avec l'Ambassadeur de Grande-Bretagne. Problème des manœuvres de la Vox Populi ${ }^{267}$ révélées par Savana le 21 octobre $^{268}$ ? Caches d'armes?

(Il y a eu une conférence de presse de Dhlakama, que nous avons manquée, à propos du document Vox Populi et de directives du STAE ${ }^{269}$ validant des cartes d'électeurs non conformes. Ajello a déclaré que le document Vox Populi devait être faux, et ne pas croire que Chissano

${ }^{265}$ La Sotemaza est une association formée notamment à l'initiative d'Armando Guebuza, souvent considéré comme le $n^{\circ} 2$ du Frelimo, dont l'acronyme reprend les diverses provinces de peuplement sena - So(fala)-Te(te)Ma(nica)-Za(mbézia). Il s'agissait notamment de dynamiser les rivalités entre les Senas et les Ndaus à l'intérieur de la ville de Beira, la capitale du centre et deuxième ville du pays. En effet, si la région de Beira est, historiquement, incontestablement ndau, le massif exode rural, combiné à la plus grande densité de population des régions d'origine des Senas, ont fait que dans cette ville, le nombre de locuteurs cisena est très légèrement supérieur à celui du cindau. Cela a entraîné des difficultés, y compris au sein de l'Église catholique dont l'archevêque est ndau.

${ }^{266}$ En pratique cependant, cette tentative du Frelimo d'attiser les ressentiments ethniques dans un sens hostile à la Renamo, n'allait pas fonctionner: la conscience régionale l'a emporté sur la conscience ethnique, et le centre (Manica, Sofala, Tete, Zambézia), quels qu'en soient les groupes ethniques, allait, plus ou moins massivement mais toujours nettement, voter en faveur de la Renamo aux élections d'octobre 1994.

267 Vox Populi, la compagnie de communication brésilienne, d'une redoutable efficacité, qui avait assuré l'élection du président Fernando Collor au Brésil, et qui menait la campagne du Frelimo.

${ }^{268}$ Le 21 octobre, l'hebdomadaire indépendant Savana occupa toute sa dernière page par la reproduction intégrale d'un document interne et confidentiel de la Vox Populi expliquant comment des manœuvres massives allaient être engagées pour tromper la vigilance de la Renamo face à la fraude, et étalant des considérations peu élogieuses sur Brazão Mazula (le président de la CNE), «bien trop honnête » pour se rendre compte de quoi que ce soit. Tant le Frelimo que la Vox Populi nièrent véhémentement l'authenticité de ce document qui révélait leurs intentions frauduleuses, et firent remarquer que les locaux de l'agence de communication avaient été cambriolés deux fois peu de temps auparavant, permettant de recueillir les éléments nécessaires à la fabrication d'un faux. L'historien, qui n'est pas, en règle général, un politicien même s'il est spécialiste de l'histoire immédiate, est mal armé pour décrypter ce genre d'incident... Aussi me fallut-il bien trop de temps pour comprendre...

269 STAE, Secrétariat technique d'administration électorale. À la différence de la Commission nationale électorale (CNE), paritaire, le STAE, comme administration technique, dépendait uniquement du gouvernement. Il venait de déclarer valides des procédures dans lesquelles les requérants n'avaient pas présenté les pièces nécessaires. 
pouvait être mêlé à de tels tripatouillages. Mais ses services allaient faire des recherches, et si la préparation de la fraude était prouvée, les élections seraient retardées]

Pendant l'attente, A. Xavane me donne sa version sur le massacre d'Homoïne, selon un médecin qui avait un fils à la Renamo...

[C'est bien la Renamo qui aurait attaqué la vila. Mais les Anciens Combattants d'un quartier proche, auraient contre-attaqué maladroitement, en bombardant, certes la Renamo, mais la Renamo dans la ville, faisant de nombreuses victimes civiles.]

12h. Départ de la colonne de propagande, avec Dhlakama en tête.

12h30. Un piquet de propagande Frelimo est détruit sur le passage. Dhlakama appelle au calme et condamne les agresseurs de l'avenue Kaunda.

12h40. Maintenant, tous les T-shirts Frelimo s'enfuient à l'approche du cortège. Nous sommes à Polana Caniço. Foule gentille sur les trottoirs :

— Estamos a pedir capulanas », « Nous voulons des pagnes », réclament des femmes.

13h. Les flics poussent leur Land Rover en panne, en tête du cortège !

- «Dá capulana, dá!», «Des pagnes! donnez-nous des pagnes!»

- «Nós queremos camisetes! », « Nous voulons des T-shirts!»

Quelle est la productivité politique d'un tel défilé ? Bien faible ! Et la Renamo n'a que des photos de son líder à distribuer. Sur le front des T-shirts, elle est largement battue...

13h15. Nous arrivons au Dumba Nengue ${ }^{270}$ de la Praça dos Combatentes. Muita confusão ! [quel désordre!] Beaucoup de gens aux sentiments mélangés! "Chi-ssa-no! Chi-ssa-no!» Dhlakama passe, impassible, escorté de ses camions bourrés de supporters et hérissés des drapeaux à la perdrix.

13h30. La police intervient, la Civpol s'approche pour voir. Dhlakama converse avec des journalistes, arrêté au milieu de la foule incertaine. En haut du Dumba Nengue, un très fort groupe crie «Chi-ssa-no». Dhlakama improvise un meeting. Une voiture Frelimo passe. Mouvements dans la foule...

13h45. Le cortège, bloqué, reprend enfin. Avenida das $\mathrm{FPLM}^{271}$, «É nice ${ }^{272}$, Dhlakama! » («Il est super, Dhlakama!»), crachent les porte-voix. Passe une avionnette Chissano. Sur l'avenue des FPLM, à double chaussée, le cortège de la Renamo sur la gauche, est suivie sur la droite d'un cortège Frelimo de jeunes et d'enfants. Porradas ${ }^{273} \ldots$

$\grave{A}$ un carrefour, de jeunes enfants (envoyés par qui ?) crient "Chissano ». Deux adultes sont derrière. Le groupe recule précipitamment mais revient. Bagarre. La police intervient. L'avionnette Chissano repasse au-dessu de l'avenue.

13h50. Face à l'Empresa Comercial do Índico, fort groupe Frelimo.

${ }^{270}$ Dumba nengue, que l'on peut traduire approximativement par «Cours pour ta vie », signifie en pratique les lieux du marché noir (candonga). Par extension, marché informel.

${ }^{271}$ Avenida das FPLM : avenue des Forces populaires de libération du Mozambique (nom officiel de l'armée avant son unification avec la guérilla Renamo sous l'égide de l'Onumoz).

${ }^{272}$ Prononcez «naillessi » (il s'agit bien du mot anglais nice, très utilisé dans le Sud du Mozambique).

${ }^{273}$ Porrada : castagne. 
14h. Plus loin, un autre groupe. Cris contre cris. Une voiture Frelimo attend carrément le cortège. Au lieu d'accélérer le mouvement, Dhlakama continue à avancer au pas. Pour prouver qu'il peut se promener tranquillement dans Maputo ?

14h10. Praça dos Herois ${ }^{274}$.

14h20. Encore des enfants «Chissano»? Pourquoi aller si lentement dans des zones peu peuplées ? Les supporters sont fatigués et marchent (ils courent depuis trois heures !).

14h30. Aéroport, puis Escola nacional de Aeronaútica, on longe maintenant le chemin de fer. Une voiture Frelimo s'enfuit.

(Le journaliste de la RM me dit que, à l'accent de la majeure partie des supporters Renamo, on voit qu'ils sont originaires du Nord du pays).

15h. Rua Vulcano, Bairro do Jardim [Quartier du Jardin].

— «Dá camisetes ! Dá camisetes! », « Donne des T-shirts, donne des T-shirts!»

Pauvres gens.

15h10. Meeting sur une place de terre. Mais il n'y a que les gens du cortège, et bien sûr des curieux. Dhlakama parle :

«La première chose que je vais faire, c'est nettoyer ces ordures. Parce que de l'argent, il y en a.»

Environ cinq cents personnes. Dans la capitale...

15h25. Bairro Chamanculo ${ }^{275}$. Un camion Frelimo qui vient en sens contraire est bloqué, puis poussé sur le côté, sans cesser de crier. Mais maintenant, les ardeurs Renamo sont mieux contrôlées.

(Va-t-on profiter du fait que le quartier de Mafalala est surtout peuplé de gens originaires de Nampula ? Il y a aussi d'autres noyaux nampulenses éparpillés).

15h30. Bagarre, car un téméraire supporter du Frelimo insultait le cortège. La police intervient. Plus loin, des cris «Abaixo Renamo! » (« À bas la Renamo !»).

Jusqu'à présent, je ne peux que noter qu'il n'y a aucun soutien populaire - à quelques exceptions près - mais pas non plus d'hostilité spontanée (pour ne point parler, donc des groupes organisés du Frelimo qui nous suivent pas à pas). Curiosité et espoir - déçu - de recevoir des capulanas (pagnes) et camisetes (T-shirts).

15h40. Bairro do Jardim. Les rues sont animées, les gens massés sur les trottoirs. Mais ces gens n'ont rien à voir avec ceux de Nampula. Ils sont là, mais ne sont pas venus pour ça.

15h50. Un groupe de populares $^{276}$ crient « Renamo ! ». Nous sommes au Bairro Inhagoia où la Renamo a réussi une certaine implantation parmi les gens du Sud, et une délégation du quartier vient à notre rencontre.

16h. Les militants Renamo sifflent pour écarter les gens porteurs de camisetes Frelimo. L'intolérance est partout présente.

${ }^{274}$ Place des Héros (la construction d'une mythologie des héros a tenu une grande place dans le nationalisme du Frelimo. La Renamo a revendiqué que certains de ses chefs militaires, comme A. Matsangaissa, accèdent aussi au statut de héros, au grand scandale du Frelimo).

${ }^{275}$ Quartier de Chamanculo.

${ }^{276}$ Gens du peuple. 
16h10. Bairro 25 de Junho ${ }^{277}$, zone du commerce informel, zone violente.

Bagarre. Police. Que confusão! (Quel désordre!) Le cortège est mêlé à la circulation dense des camionnettes commerciales et des chapas $100^{278}$.

16h30. Bairro de Bagamoyo.

16h45. Bairro Benfica ${ }^{279}$, foules du Dumba Nengue et celle du marché officiel mêlées, pour voir, et dans l'espoir des ofertas! Désordres et rires quand les gens réussissent à apercevoir le líder, dans la lumière du soir qui vient.

Pauvres, pauvres maisons, mais joliment bordées de haies et parsemées d'arbres fruitiers. Dans les chapas 100 paralysées par le cortège, des centaines d'yeux cherchent le líder.

17h. Missão Roque ${ }^{280}$

- «Dhlakama é homem, Dhlakama!» (en portugais), «Dhlakama c'est quelqu'un, Dhlakama!»

- Dhlakama Iwa Núna! » (en tsonga)

Cabanes de réfugiés, serrées les unes contre les autres, en roseaux. Les nouveaux $\operatorname{caniços}^{281}$ !

— «Já não há capulanas? », « Il n'y a plus de pagnes ? »

17h15. Les cabannes de roseaux sont maintenant parsemées de maisonnettes de parpaings. On s'installe!

17h20. Bairro comunal Mahlazine, ou Madhlazine. Petites boutiques de ciment, couleurs ocres et pastels. Voitures aux plaques sud-africaines : volées, importées, là et ici ?

17h45. Les journalistes partent, pour rejoindre leurs rédactions. Je dois donc quitter la voiture de la RM dans laquelle j'étais depuis le début, pour continuer à pied.

17h50. Dhlakama s'arrête. Petit meeting impromptu pour parler aux gens massés sur les trottoirs - assez sympathiques envers lui :

- «Kanimambo! Kanimambo! Eu conheço os vossos problemas! O povo quer mudanças! Vamos dar camisetes! Vamos caminhar! », « Bonjour! bonjour! Je connais vos problèmes ! Le peuple veut des changements ! Nous allons donner des T-shirts ! Nous allons de l'avant!».

Plus un seul journaliste ou photographe. Ceux des gardes du corps qui ne me connaissent pas me regardent avec des yeux soupçonneux.

- «Jacamo! Jacamo!», les gens montrent du doigt Dhlakama (Jacamo) quand ils l'aperçoivent, et rient.

Le cortège a au moins le mérite de «montrer » le líder à des gens de la capitale qui ne le connaissaient pas, et donc de l'humaniser.

${ }^{277}$ Le 25 Juin est la date decréation du Frelimo (en 1962) et de l'indépendance (en 1975).

${ }^{278}$ Les «Chapa 100 », à savoir les «camions bennes à 100 meticais » suppléèrent la crise complète des transports urbains, entassant dans leurs bennes les gens partant au travail, pour cent meticais. Il y a longtemps que leur prix a atteint les mille meticais, mais l'appellation reste. Bien qu'en principe interdits, ils sont souvent la propriété, en sous-main, de hauts dignitaires du régime, voire de ministres.

${ }^{279}$ La décolonisation ayant ses limites, il ne saurait être question de toucher aux noms des quartiers rappelant des équipes de football portugaises.

${ }^{280}$ Quartier de la mission Roque (on est déjà dans les zones vraiment suburbaines).

${ }^{281}$ Le caniço, ou roseau, désigne les bidonvilles des périphéries urbaines. Ce sont les équivalents des muceques (quartiers du sable) de Luanda. 
- Viva Democracia!».

18h15. Bairro de Uhulene. Ici les gens semblent plus sympathisants, répondant mieux aux bords de la route.

— «Maputo é da Renamo! Maputo é Dhlakama! Já confirmado!», « Maputo est à la Renamo ! Maputo est à Dhlakama! C'est confirmé ! »

Pas évident du tout...

18h30. Bairro da Lixeira ${ }^{282}$. La nuit est tombée. Les ordures enflammées illuminent le sinistre terrain. Dhlakama m'invite à monter dans sa voiture. J'accepte et suis donc désormais aux premières loges. Le groupe qui suit le cortège est toujours assez important, et les gens sortent des cabanes pour le regarder passer.

Le speaker s'égosille en ronga et en portugais. Le public rit. Après une telle guerre ! Que les gens sont gentils ! Réconciliation nationale...

— «Aujourd'hui, il n’y a plus d'Opération-Production ${ }^{283}$ ! Il n’y a plus de Guebuza ! Ils mentent pour voler le peuple!»

18h40. Des trottoirs, on crie «Chissano ». Mais point de bagarres. Le haut-parleur recouvre par «Dhlakama é nice » («Dhlakama est super »).

«La Renamo ne veut pas gouverner seule. Notre capitale est belle, mais notre capitale est abandonnée, nous allons changer ça!

Nos frères sont encore au Niassa, à Unango, sans inculpation. Ils n'arrivent pas à rentrer. Nous allons changer cela ! ${ }^{284}$

Le cortège court maintenant dans la nuit du Bairro Ferroviário.

«Le Frelimo marequeciste [marxiste] a fait de la terre une chose de l'État ! Mais la terre n'est plus aux seuls Matolas, aux seuls Mpfumos ${ }^{285}$ ! »

19h. Bairro Xiquelene, Dumba-Nengue. La foule salue gentiment. Tout le cortège court ! On se rapproche de la ville.

19h10. Polana-Caniço, à nouveau.

« Nous sommes de Maputo, de Chamanculo, de Maxaquene, nous ne sommes pas venus du Niassa !»

19h30. Sommerschield. Le cortège est exténué ! Nous arrivons à la résidence, la voiture y pénètre. Dhlakama prononce une petite allocution du haut de la terrasse. Le public ici est formé uniquement d'activistes.

«Comment avez-vous trouvé notre tournée ? Nous avons prouvé que nous avons le soutien de Maputo. Ça a été plus qu'un meeting! Nous avons parlé dans les quartiers à plus de 50000 personnes [sic] et tout a été bien compris. Nous avons démontré que la population respecte la Renamo, nous avons discuté avec les mamans et les papas! Aujourd'hui, ça a été extra [port.: Hoje foi de mais!] Des journalistes étrangers ont pu constaté l'appui que Dhlakama a à Maputo [sic], De cela, je les remercie. »

Il appelle à continuer le porte-à-porte, pour expliquer qu'il faut un président jeune. Cinq cents personnes environ l'écoutent.

\footnotetext{
${ }^{282}$ Quartier de la décharge.

${ }^{283}$ Voir note 8 du chapitre « Niassa ».

${ }^{284}$ Dhlakama fait ici habilement référence à l'Opération Production et au collectif des « Changanes du Niassa ». Voir note 9, chapitre 5.

${ }^{285}$ Matola et Mpfumo sont deux grands clans du Sud, bien représentés dans l'appareil d'État.
} 
19h45. «Dhlakama é nice, é bonito! », «Dhlakama est super, il est joli ! », dit... Dhlakama! «Tudo estava bonito, tudo! Isto signifique que a Renamo ganhou», « Tout était joli, tout! Cela veut dire que la Renamo a gagné ».

19h50. Je discute avec Dhlakama. Il est sincèrement ravi. Face à ma moue dubitative, étonné, il me fait remarquer que ce n'est pas Nampula, que l'on n'a pas appelé les gens à venir, qu'on est simplement aller à leur rencontre dans les quartiers. Certes. Mais justement, pourquoi pas un grand meeting dans la capitale? Il s'auto-enthousiasme trop, c'est dangereux parce qu'un échec aux élections peut être ressenti par lui comme une fraude du Frelimo - il est vraiment persuadé qu'il va gagner.

[Et moi, je commençais à être assez inquiet de ce qui allait suivre. Que le fiasco dans le SudInhambane, Maputo, abandon de Gaza - ne l'alarme absolument pas, cela montrait qu'il perdait pied avec la réalité. Entouré de cadres lui répétant sans cesse, pour lui plaire, que le peuple le soutenait - et parmi eux, forcément, des membres des services du Frelimo -, et jouissant d'un réel soutien dans le Centre et le Nord, il ne pouvait que se convaincre qu'une défaite ne viendrait que d'une fraude de l'adversaire.] 


\section{Chapitre 10 «A Beira é da Renamo!"*}

\section{Le 23 octobre 1994}

10h30. Départ pour Beira, en Antonov.

12h30. Arrivée à l'aéroport de Beira.

Foule à l'aéroport, classiques tambourins. Petits spectacles de la Liga da Juventude [Ligue de la Jeunesse]. Un responsable râle pour mettre les gens en ordre. Mais rien de notable. Dhlakama est annoncé pour 15 ou16 heures.

(Dans l'avion, petite conversation avec Jorge Correia. Je lui donne mon analyse de la parade d'hier à Maputo. Il opine. Dhlakama est entouré de gens serviles et mauvais organisateurs. J. Correia me dit qu'il a écrit une lettre à Dhlakama pour que celui-ci la lise dans l'avion qui le ramenait de Chimoio à Maputo, «carta violentíssima » (« lettre extrêmement violente »), où il lui dit, «antes das eleições » («avant les élections »), qu'il peut (ou va ?) perdre à cause de telle ou telle chose ; que lui, Dhlakama n'a pas réussi à imposer son modèle d'humilité et d'organisation, que le travail n'est pas fait, que le département des Affaires politiques ne fonctionne pas ${ }^{286}$, etc. Lettre « secrète »- «Ninguém sabe...» (« Personne ne le sait ») (?). Le lendemain, Dhlakama l'a appelé et l'a remercié.

Lui, Jorge Correia, est totalement conscient que sa place dans la Renamo dépend uniquement du statut que Dhlakama lui accorde : - «Um branco nunca poderia ser outra coisa senão um assessor », «Un Blanc ne pourra jamais être autre chose qu'un conseiller ». Du reste, pour lui, la Renamo n'existe pas sans Dhlakama, la Renamo est Dhlakama).

Si le meeting à Beira n'est pas gigantesque, de façon à compenser la non-réalisation d'un travail sérieux dans le Sud et l'insuffisance relative à Tete, Manica et dans le Nord du Cabo Delgado, la Renamo perdra les élections. À Inhambane, le travail n'a tout simplement pas été fait. Seul le lien avec les régulos peut sauver la Renamo, car les régulos, eux, font le travail.

13h30. Départ en ville. Visiblement, partout des gens attendent le líder. Arrivés à un marché, c'est le délire, les gens croient que c'est lui...

16h. En face du siège de la Renamo, d'énormes camions-benne viennent charger les gens pour aller à l'aéroport. Nous entrons dans l'un d'eux pour regagner l'aéroport.

17h. Le Président est arrivé. Foule énorme de «Dhlakama!». Quelques groupes de «Frelimo!» cependant. Mais la ville, elle, est Renamo. De partout sortent des gens, qui courent en même temps qu'avancent les voitures. Je suis maintenant dans la voiture RM qui se défend d'être prise d'assaut au long des dix kilomètres qui nous séparent de la ville! Une vraie loucura $^{287}$ !

17h30. Nous passons les rizières noires de gens. Un peuple en haillons, pieds nus, court maintenant sur les huit voies des deux travées de l'autoroute, totalement envahie...

\footnotetext{
* Beira est à la Renamo !

${ }^{286}$ Le Departamento dos Negócios políticos était à ce moment dirigé par Raúl Domingos.

${ }^{287}$ Loucura : folie.
} 
17h50. Le cortège est à nouveau paralysé - sur l'autoroute! Aussi loin que je puisse voir devant (le terrain est plat, je suis juché sur une voiture), il y a du monde. Derrière nous, ce sont les énormes camions, bourrés à mort - 300 personnes par camion ! - qui reviennent de l'aéroport.

Quoi qu'on en pense, il n'y a qu'une alternative dans ce pays : le Frelimo ou la Renamo.

— «Fora Chissano! Filho da puta...», «Dehors Chissano, fils de...».

18h. On n'avance vraiment plus. On quitte l'autoroute pour l'entrée en ville. Un pneu de camion éclate sous la surcharge. Quelqu'un tombe d'un autre camion. Combien va-t-il y avoir de blessés dans cette cohue?

18h30. Dumba-Nengue de Tchungamoyo, puis...

19h... Bairro Popular Espangara. Les seguranças qui courent, de part et d'autre de la voiture présidentielle depuis dix kilomètres, sont épuisés. Nous faisons un grand détour dans la ville, dans la puanteur des gaz d'échappement, car la route qui passe par le gouvernement provincial est barrée.

19h30. Nous arrivons enfin à la résidence, près du minigolf. La foule a bien diminué, mais les activistes sont encore là.

Au total, plus de gens qu'à Nampula. Si, sur les quinze kilomètres du parcours, on peut dire qu'il y avait marée humaine sur cinq, soit 5000 mètres et 5000 personnes « linéaires » (une par mètre), multipliées par trente par rangée, cela ferait 150000 personnes. La vérité se situe certainement entre 100 et 150000 , disons $130000 \ldots$

\section{Le 24 octobre 1994}

7h45. À l'aéroport. Nous devons partir à la Machanga! Je vais pouvoir voir à quoi ressemble «ma $»$ zone $^{288}$.

9h10. Départ pour la Machanga.

Paysages de palétuviers, bras du fleuve, bancs de sable. Zone peu peuplée, au point que les quelques maisons de la Machanga apparaissent soudain comme incongrues. Nous atterrissons sur le lieu même des événements de 1953, la petite piste de terre sableuse. Foule habituelle, chants, tambourins. Le régulo Chiteve arbore son arc et ses flèches.

Le délégué de la Machanga est Domingos Fereira. Il est membre depuis 1987, après un premier contact à Beira. Il est chauffeur routier et, dans la Renamo, de l'intelligence civile. Il est toujours resté à Beira, venu à la Machanga seulement en 1992. Mais il est né ici. Il a la $7^{\mathrm{e}}$ classe coloniale. Sa direction locale est formée de 36 personnes, dont dix anciens soldats. Tous vandau.

Je parle avec les fils des régulos Maropanhe et Chiteve de 1953. Ils se souviennent:

- "Aqui foi sempre zona de reacionários. O diabo parou aqui e nunca foi-se embora », "Ici, ça a toujours été un coin de réactionnaires. Le diable s'est arrêté chez nous et n'est jamais reparti ».

Ce qui me frappe est que le souvenir de ces événements d'il y a près de quarante ans est encore très vif : c'était le 18 octobre 1953. Le chef de poste avait vendu à son profit les secours envoyés depuis Beira après la crue du Save. Mille hommes montèrent depuis Inhambane "Foram de casas em casas prender as pessoas », "Ils passèrent de maison en maison arrêter les gens », et cinquante huit personnes furent déportées à São Tomé e Príncipe. Certains - peu,

288 J'avais, en 1991-92, fait un important travail d'archive sur un mouvement associatif (et une émeute) qui s'était développé dans l'estuaire du Rio Save de la fin des années trente à 1953, mais ne m'étais jamais rendu dans ce lieu. Voir le paragraphe «Mambone et Machanga » de l'introduction et la note 13, puis le chapitre « Mambone». 
disent-ils - en revinrent, dont Gabriel Tivane et Timoteo et Brito Maganja Simango, encore en vie et vivant à Mambone ${ }^{289}$.

Le délégué de Mambone, Inocêncio António de Faria est, lui, à la Renamo depuis... 1977 ! Il a travaillé avec Matsangaissa, qu'il rencontra plusieurs fois. Il communiquait avec une radio de son frère Vasco Joaquim Leitão (aujourd'hui au Portugal), donnée par Matsangaissa. Il est toujours resté à Mambone. Le Snasp a cherché à l'arrêter trois fois, sans y réussir. Il avait une cellule de six membres. Le chef s'appelait «Brilhante»-c'était lui -, et il y avait aussi « Cofre », «Brande » (maintenant au Portugal), « Rizota » (décédé). Ils cherchaient à recruter des jeunes de dix-huit ans pour les envoyer à la Renamo, mais c'était très difficile. En 1953, il était enfant, mais se souvient. Il a été membre du Frelimo de 1974 à 1977 et secrétaire de GD. Il a la $4^{\mathrm{e}}$ classe coloniale et a été chaudronnier (bate-chapa soldador) et cantonnier. Maintenant, il est commerçant. Sa direction locale de la Renamo est formée de douze personnes, qui sont toutes toujours restées ici, toutes vandau et lui-même métis mundau/portugais. Il y a aussi la Liga das Mulheres, la Juventude. Il y a 3000 adhérents et encore 30000 « candidats »: - Não temos cartões », « Nous n'avons pas de cartes d'adhérent». Ceux qui, ici, restent encore au Frelimo, sont souvent matsua. La Renamo a aussi des Matsuas, mais pas à la direction.

Eduardo Mondlane était très populaire ici, à cause de Uria Simango ${ }^{290}$. Aussi, Mondlane disparu, la rupture du Frelimo avec Simango fut aussi la rupture de sa génération locale avec le Frelimo. Du reste, si le Frelimo a ensuite réussi à «envillager » ${ }^{291}$ les Vatsua, il n'a pas réussi avec les Vandau. Quand Samora Machel est venu visiter les salines de la Machanga, en 1982, seuls les Vatsua sont venus le saluer.

Le meeting avait été annoncé pour samedi dernier, et il y avait alors plus de monde à attendre qu'aujourd'hui ! Il n'y a pas de combustible pour les camions.

Dhlakama n'est encore jamais venu ici.

11h. Dhlakama arrive. Enthousiasme ! Non, ce n'est pas lui, c'est Raúl Domingos... PRM, Civpol.

11h15. L'avion de Paul le Sud-Af arrive. À nouveau l'enthousiasme. Non, ce n'est pas encore lui, mais l'hélicoptère est en vue. Maintenant il est là. Couronne de fleurs. Quel désordre ! Une femme, vêtue du T-shirt du PCN, brandit le portrait de Dhlakama. Délire et carinho.

Dhlakama monte sur un char tiré par deux grands bœufs aux longues cornes, effrayés par la foule. Dans le nuage suffoquant de poussière que soulève la foule qui piétine la terre, nous arrivons à l'habituelle place ombragée de manguiers. Pas d'estrade, une simple table. Mais la foule s'assoit gentiment, en une ovation qui ne finit jamais. Il y a environ 2500 personnes massées sous les arbres, ce qui est beaucoup pour une zone peu peuplée. Plus loin, un groupe reste un peu à l'écart, des femmes surtout, sous d'autres arbres.

Finalement une estrade de fortune est montée sur le char à bœufs. Le vent, délicieux, se lève. Comme souvent ailleurs, dans la foule, debout et badgé Renamo, il y a un pauvre et vieux Portugais, resté ici. Manuel Pereira, le délégué provincial de Sofala, prend la parole :

« Vous vous lamentiez. Papa Dhlakama est venu à Beira et ne va pas venir ici ? »

Problème de sono. Il reprend :

\footnotetext{
${ }^{289}$ Vraie petite bourgade de l'autre côté du fleuve (mais dépendant déjà de la province d'Inhambane, alors que la Machanga est rattachée à celle de Beira. C'est une «poche » ethnique ndau dans cette province au Sud du rio Save, limite stratégique entre le Sud et le Nord.

${ }^{290}$ Sur Uria Simango, voir la note 8 du chapitre « Zambèze ».

291 ... c'est-à-dire, les regrouper en villages communaux (aldeias comunais), dont les objectifs étaient d'abord politiques, puis militaires à l'image des aldeamentos portugais.
} 
«Raúl Domingos est également ici, qui a lutté deux ans à Rome ${ }^{292}$ pour obtenir l'Accord général de paix.»

Mais Dhlakama monte sur le char... Ovations. Vivas, auxquels la foule répond massivement-:

— «Bom dia, bom dia, como que estão de saúde? », «Bonjour, bonjour, la santé est-elle bonne?»

Il parle, alternant portugais et cindau. Le vieux Portugais rit, qui comprend le cindau. Ovations d'un discours que je ne suis plus...

— «Eu quero ganhar as eleições...», « Je veux gagner les élections... »

Une branche s'effondre avec ses grappes d'enfants... Le discours est habituel, aux thèmes simples et démogogiques, mais portant sur des préoccupations réelles :

«Pas de confusion, mes pères, mes mères ${ }^{293}$ ! Je ne suis pas ici pour critiquer le Frelimo. Mais quand un pagne est usé, n'en achète-t-on pas un nouveau? Le Frelimo est un pagne usagé... [rires et ovation].

Si Dhlakama gagne, il va pouvoir gouverner cinq ans. S'il échoue, vous pourrez en choisir un autre. Mais le Frelimo a failli et a gouverné dix-neuf ans. Si le Frelimo a écrit un nouveau programme, c'est qu'il reconnaît avoir mal gouverné ces dix-neuf ans. Et maintenant le Frelimo promet de gouverner avec des gens bien. Il admet donc que les ministres sont mauvais ».

12h50. Fin du meeting. Raúl Domingos, tête de liste à Sofala, n'a pas parlé... Le régulo Chiteve offre l'arc et les flèches. D'autres présents sont offerts en série - peaux, calebasses, poteries.

(La population locale est mécontente, car les produits de l'aide internationale sont vendus, et non donnés ou échangés contre du travail, seulement vendus contre de l'argent que la population n'a pas. Or il n'y a pas ici de travail rémunérateur.)

J'apprends que, cette nuit, Dhlakama doit rencontrer Mugabe pour discuter des «problemas da linha da Frente » («des problèmes des pays de la Ligne de front ») ${ }^{294}$. On repart, cette fois à pied sur la piste, entourés des youyous des femmes et des huuuum-huuuum des hommes.

13h20. Départ pour Nhamatanda (ex-Vila Machado). Nous sommes 31 dans l'hélicoptère (au lieu de quinze maximum), serrés comme des sardines et couverts de poussière. Cette terre est tellement aride.

14h20. Arrivée à Nhamatanda. Banderolles «O marxismo e o leninismo é [sic] inimigo do povo » («Le marxisme et le léninisme est [sic] l'ennemi du peuple»), et «Irmão Dhlakama, $a$ Liga da Juventude chora emprego » («Frère Dhlakama, la Ligue de la jeunesse pleure pour des emplois »). Foule, beaucoup d'enfants, et de femmes.

14h25. Arrivée de Dhlakama. Estrade ombragée de bâches de l'UNHCR... Belle cohue, les gens rient en voyant le líder. Bousculade habituelles de la foule comprimée. Environ deux mille personnes.

- «Vota Dhlakama! Vota»

Les vivas fusent, [auxquels répondent] assez bien [ceux de la foule], mais pas unanimement. Comme d'habitude, la sono crachotte.

${ }^{292} \mathrm{R}$. Domingos avait dirigé la délégation de la Renamo à Rome, durant les pourpalers de paix.

293 «Meus pais, minhas mães », «mes pères et mes mères », expression fréquente au Mozambique qui exprime on ne peut plus nettement le concept de famille élargie. La mère biologique, par exemple, n'est pas forcément la mère principale pour l'enfant qui, de ce fait, a «plusieurs mères » (et plusieurs pères).

${ }^{294}$ Il y avait un sommet des pays de la ligne de front, à Harare, et Dhlakama nourrissait l'espoir d'y être reçu quasi officiellement. 
«Le programme de la Renamo n'a pas été écrit il y a un an, comme les autres. Notre programme a été écrit quand nous avons rejeté le communisme, il y a dix-sept ans. »

Les vivas sont maintenant très bien repris.

«Je vais promettre seulement deux choses. Premièrement, Dhlakama va en finir avec le chômage. Deuxièmement, les prix sont trop élevés. Dhlakama va prendre des mesures pour que les prix ne soient pas si hauts [ovations] ».

Après avoir promis «seulement» ces deux choses, Dhlakama reprend les thèmes des fonctionnaires et de la santé. Puis, pour la première fois, il ajoute à propos des autres oppositions :

«Certains d'entre vous peuvent voter pour d'autres partis, à l'exception du Frelimo, parce que pendant dix-neuf ans il n'a rien fait. Celui qui vote Frelimo n'a pas de cour. Ceux qui n'aiment pas Dhlakama peuvent voter pour d'autres partis et pas pour Dhlakama ».

15h30. Le meeting se termine sous les ovations.

16h10. Arrivée à Beira, au stade Ferroviário da Manga, pour le meeting de clôture de campagne. Il y a énormément de monde. Dhlakama a le malheur de monter sur une moto. Délire dangereux des mouvements de la foule dense. Le líder lui-même est bousculé et vient dans notre Land Rover découverte - je l'aide à monter. Le délire est ensuite indescriptible. On risque cinquante fois d'écraser dix gamins.

16h30. Dhlakama enfin à la tribune. Une banderolle dit "Dhlakama semente » [ Dhlakama graine »] ([le dessin le montre] la tête sortant d'une fleur...). Une autre montre la perdrix sortant du drapeau... Du haut du stade, je calcule tant bien que mal : deux cents lignes de profondeur sur trois cents lignes de largeur, 60000 personnes.

- «Vota Renamo! Vota!»

- «Vota Dhlakama! Vota!»

Raúl Domingos parle. Les vivas sont repris sans retenue, les gens ne sont pas des curieux mais bien des sympathisants.

16h50. Civpol, PRM. Dhlakama parle sur ses thèmes habituels constamment interrompus par les ovations de la foule...

«Pourquoi est-ce que le Frelimo a caché la démocratie? [rires] Nous voulons en finir avec la misère et avec le chômage... »

Il parle en portugais, en cindau, en cisena. Un journaliste zimbabwéen qui comprend le cindau me confie que son discours, alors, « is very poetic and powerful ». Mais il n'est pas modeste :

«Dhlakama est déjà entré dans l'histoire du peuple du Mozambique! Chissano lit maintenant un programme qui n'a rien à voir avec la philosophie du Frelimo. C'est pour tromper. Notre programme, à nous, a été écrit en 1977. »

Il fait ensuite compter en chœur la foule jusqu'à six (Dhlakama est en sixième position sur le bulletin de vote des présidentielles) et jusqu'à huit (pour les législatives, en cindau et en cisena.

- «Vamos combater fraudes », « Nous allons combattre les fraudes ».

17h35. Le meeting se termine avec la mention que Dhlakama va rendre visite à l'Amodeg ${ }^{295}$ et il fait don d'une moto au secrétaire local de l'association. La Suzuki est montrée au public, ainsi que deux bicyclettes. Une bicyclette va au régulo Luis.

295 Amodeg : association mozambicaine des démobilisés de guerre, puissante association, au départ formée surtout d'anciens soldats du Frelimo mais rapidement ouverte à ceux de la Renamo. 
Tiens, le grand «journaliste cameraman », à côté de Dhlakama, c'est un membre du CIO zimbabwéen et tout le monde le sait ${ }^{296}$. Ce qui se passe à Beira intéresse toujours Mugabe ! Mais l'arrivée de cet envoyé technique, suite au meeting grandiose du Ferrovário da Manga, donne à la viste de Dhlakama à Harare un aspect quasi présidentiel! Dhlakama va discuter des équilibres régionaux et de la sécurité mutuelle !

La campagne électorale s'achève donc sans pratiquement aucune présence dans le Sud. L'organisation y est faible, et cette extériorité de la Renamo y est probablement en rapport avec la nature de la guerre au Sud, bien plus uniquement militaire et «privée » que la vraie guerre civile du Nord.

\section{Tableau récapitulatif des réunions publiques de A. Dlakhama, avec mes estimations, septembre et octobre 1994*}

\begin{tabular}{|c|c|c|}
\hline Localités & Dates & Assistance estimée \\
\hline Zambézia & 12 septembre au 2 octobre & 52300 \\
\hline (Quelimane) & $(12 / 09 / 94)$ & $(10000)^{\mathrm{a}}$ \\
\hline Mocuba & $27 / 09 / 94$ & 6000 \\
\hline Lugela & $29 / 09 / 94$ & 1000 \\
\hline Ile & 29/09/94 & 2000 \\
\hline Gurué & $29 / 09 / 94$ & 1000 \\
\hline Gile & $30 / 09 / 94$ & 1000 \\
\hline Pebane & $30 / 09 / 94$ & 800 \\
\hline Maganja da Costa & $30 / 09 / 94$ & 15000 \\
\hline Quelimane (aéroport) & $31 / 09 / 94$ & 2000 \\
\hline Morrumbala & $01 / 10 / 94$ & 1800 \\
\hline Mopeia & $01 / 10 / 94$ & 1500 \\
\hline Chinde & $01 / 10 / 94$ & 2200 \\
\hline Inhassunge & $01 / 10 / 94$ & 1000 \\
\hline Milange & $02 / 10 / 94$ & 7000 \\
\hline Nampula & 2 au 10 octobre & 211800 \\
\hline Nampula (arrivée) & $02 / 10 / 94$ & +100000 \\
\hline Angoche & $03 / 10 / 94$ & 5000 \\
\hline Ilha de Quiloa & 03/10/94 & 500 \\
\hline Namaponda & 03/10/94 & 1000 \\
\hline Moma & $04 / 10 / 94$ & 4000 \\
\hline Chalaua & $04 / 10 / 94$ & 2500 \\
\hline Iuluti & $04 / 10 / 94$ & 2000 \\
\hline Nametil-Mogóvolas & $04 / 10 / 94$ & 20000 \\
\hline Monapo & $05 / 10 / 94$ & 3500 \\
\hline Nacala-Porto & $05 / 10 / 94$ & 35000 \\
\hline Lumbo (vers l'Ilha) & $06 / 10 / 94$ & 500 \\
\hline Ilha de Moçambique & $06 / 10 / 94$ & 3000 \\
\hline Mossuril & $06 / 10 / 94$ & 2000 \\
\hline Malema & $07 / 10 / 94$ & 2000 \\
\hline Ialapa & 07/10/94 & 1000 \\
\hline Ribáuè & 07/10/94 & 2000 \\
\hline Nampula (meeting) & 08/10/94 & 15000 \\
\hline Laáua & $09 / 10 / 94$ & $500^{\mathrm{b}}$ \\
\hline Mecúburi & $09 / 10 / 94$ & $300^{c}$ \\
\hline Murrupula & $09 / 10 / 94$ & $3000^{\mathrm{d}}$ \\
\hline Meconta & $10 / 10 / 94$ & $2000^{e}$ \\
\hline
\end{tabular}

${ }^{296}$ Central Intelligence Office, les services secrets zimbabwéens, créés par la Rhodésie au temps de l'apartheid et, sous Ken Flower, quasi-fondateurs de la Renamo... 


\begin{tabular}{|c|c|c|}
\hline Macuja (Mossuril) & $10 / 10 / 94$ & $2500^{\mathrm{f}}$ \\
\hline Nacala-a-Velha & $10 / 10 / 94$ & $3000^{\mathrm{g}}$ \\
\hline Meconta-Namialo & $10 / 10 / 94$ & $1500^{\mathrm{h}}$ \\
\hline Cabo Delgado & 11 au 13 octobre & 25300 \\
\hline Pemba (arrivée) & $11 / 10 / 94$ & 7500 \\
\hline Mocimboa da Praia & $12 / 10 / 94$ & 4500 \\
\hline Palma & $12 / 10 / 94$ & 2500 \\
\hline Muidumbe-Nhangololo & $12 / 10 / 94$ & 1800 \\
\hline Pemba (meeting) & $13 / 10 / 94$ & 4000 \\
\hline Montepuez & $13 / 10 / 94$ & 5000 \\
\hline Niassa & 13 au 15 octobre & 19500 \\
\hline Lichinga (aéroport) & $13 / 10 / 94$ & 1500 \\
\hline Mandimba & $14 / 10 / 94$ & 7000 \\
\hline Cuamba (aéroport + ville) & $14 / 10 / 94$ & 4000 \\
\hline Lichinga (meeting) & $15 / 10 / 94$ & 7000 \\
\hline Tete & 16 au 18 octobre & 11200 \\
\hline Tete (aéroport) & $16 / 10 / 94$ & 3000 \\
\hline Mutarara & $18 / 10 / 94$ & 4000 \\
\hline Tete (meeting) & $18 / 10 / 94$ & 4200 \\
\hline Manica & 18 au 20 octobre & 12500 \\
\hline Chimoio (aéroport) & $18 / 10 / 94$ & 1000 \\
\hline Catandica-Barué & $19 / 10 / 94$ & 1000 \\
\hline Gondola & $19 / 10 / 94$ & 3500 \\
\hline Vila de Manica & $19 / 10 / 94$ & 2000 \\
\hline Chimoio & $20 / 10 / 94$ & 5000 \\
\hline Provinces du Sud & 20 au 22 octobre & 3300 \\
\hline Maputo (aéroport) & 20/10/94 & 500 \\
\hline Inhambane (aéroport + meeting) & $21 / 10 / 94$ & 1300 \\
\hline Maputo (Praça dos Combatentes) & $22 / 10 / 94$ & 1000 \\
\hline Maputo (Vulcano) & $22 / 10 / 94$ & 500 \\
\hline Sofala & 23 et 24 octobre & 214500 \\
\hline Beira (aéroport + ville) & $23 / 10 / 94$ & 150000 \\
\hline Machanga & $24 / 10 / 94$ & 2500 \\
\hline Nhamatanda & $24 / 10 / 94$ & 2000 \\
\hline Beira (Ferroviário da Manga) & $24 / 10 / 94$ & 60000 \\
\hline Total estimé & Septembre et octobre & 550400 \\
\hline \multicolumn{3}{|c|}{$\begin{array}{l}\text { * À noter que mes estimations ont systématiquement été nettement inférieures à celles de la Renamo. } \\
\text { a . Meeting d'ouverture de la campagne, auquel je n'ai pas assisté (estimation la plus courante). } \\
\text { b. Ce meeting avait été convoqué le } 7 \text { octobre et a lieu avec deux jours de retard. } \\
\text { c. Ce meeting avait été convoqué le } 7 \text { octobre et a lieu avec deux jours de retard. } \\
\text { d. Ce meeting avait été convoqué le } 4 \text { octobre et a lieu avec cinq jours de retard (les gens ont attendu trois jours, } \\
\text { puis la grande majorité s'est dispersée). } \\
\text { e. Ce meeting avait été convoqué le } 6 \text { octobre et a lieu avec quatre jours de retard (les gens ont attendu trois jours, } \\
\text { puis la grande majorité s'est dispersée). } \\
\text { f. Idem. } \\
\text { g. Idem. } \\
\text { h. Idem. }\end{array}$} \\
\hline
\end{tabular}

[Fin du carnet $n^{\circ}$ 2]

\section{"Mozambique : une situation plus ouverte que prévue sur fond de fraude?"}

[J'avais prévu d'envoyer un article d'analyse politique de conjoncture à la revue française La Lettre de l'Océan Indien (LOI, Paris, Indigo Publications), à laquelle je collabore de temps à autre. Pour des raisons dont je ne me souviens pas, cet article n'a pas été envoyé - peut-être tout simplement n'avais-je pas trouvé d'ordinateur, ou même de machine à écrire, pour le saisir et l'envoyer -, et il est donc resté inédit et manuscrit, occupant les premières pages de mon troisième carnet de route. Je le reproduis ci-dessous, inchangé, car il synthétisait ce que je 
ressentais à ce moment précis, à la fin de la campagne électorale, impressionné que j’étais - trop impressionné certainement, puisque je n'excluais pas complètement une victoire de la Renamopar la campagne que j'avais suivie dans son intégralité du côté des anciens rebelles (sans qu'aucun collègue du Groupement de recherche "Afrique australe » du CNRS n'ait pu, comme il avait initialement été prévu, la suivre du côté du Frelimo), - anciens rebelles dont la réalité sociale était infiniment plus complexe que ce que les commentateurs écrivaient habituellement au sujet des "bandits pro-apartheid». Les lignes qui suivent constituent un écrit de circonstance et je n'en partage plus certains aspects, manifestement erronés, même si l'analyse d'ensemble me semble avoir gardé de sa pertinence. Il a été écrit le dimanche 25 octobre, certains paragraphes y ont été rajoutés le 26.]

« La campagne électorale pour l'élection simultanée du nouveau Président de la république et du premier Parlement pluraliste de l'histoire du pays, s'est achevée lundi 24 octobre, après avoir officiellement commencé le 27 septembre.

Le mois qui vient de s'écouler a révélé une situation probablement différente de celle qui était généralement attendue par les analystes. Ceux-ci, tout en admettant que la Renamo aurait un score qui eût paru inimaginable il y a deux ans, lors de l'Accord général de paix du 4 octobre 1992 à Rome, se disaient persuadés que le Frelimo et le président Chissano remporteraient le scrutin, à cause des profondes divisions engendrées par la guerre, à cause d'une machine électorale incomparablement supérieure à celle de la Renamo, à cause de la propriété d'État (gouverneurs, administrateurs, voitures, équipement, essentiel des médias, etc.) qui a été systématiquement utilisée à des fins partisanes.

Le sondage de l'entreprise brésilienne Vox Populi, réalisé l'été dernier, renforçait cette impression. Il reconnaissait la victoire de la Renamo dans les provinces centrales de Manica et Sofala - berceau de la rébellion - et dans la populeuse province de Zambézia. Mais il donnait une nette victoire au Frelimo, non seulement dans le Sud (dont ont été originaires les trois présidents successifs du Frelimo), mais aussi dans la province de Nampula, la plus peuplée du pays, et dans les deux provinces de l'extrême-nord (Cabo Delgado et Niassa).

Si le Frelimo a fait une bonne campagne, parfaitement orchestrée par les Brésiliens (distribution de six millions de T-shirts et autant de pagnes, chapeaux, foulards, bicyclettes) avec la réalisation de nombreux «showmicios » (show + comício, meeting en portugais) réunissant les meilleurs groupes musicaux du pays et des spectacles de parachutisme, cela ne saurait cacher une situation politique en réalité ouverte.

Déjà, les historiens avaient été étonnés de la différence annoncée entre la Zambézia, le Nampula et le Cabo Delgado, trois provinces majoritairement (et totalement pour Nampula) peuplées de Macuas. Les Macuas sont le plus grand groupe ethnique du pays (environ quatre millions d'habitants) et leur relation avec le Frelimo, de 1964 à nos jours, a toujours été médiocre. Un seul ministre, Mateus Kathupa (portefeuille de la culture), est macua - et a été habilement nommé directeur de campagne. Au Cabo Delgado, la base fidèle du Frelimo est restreinte au planalto maconde (deux districts sur dix-sept), alors que Muanes et Swahilis semblent plus proches des Macuas.

Or si le déroulement de la campagne électorale a réservé un accueil favorable à Afonso Dhlakama en Zambézia, il fut parfois triomphal dans la province de Nampula. Sans musiciens ni parachutistes, sans T-shirts ni pagnes, Dhlakama a réuni des foules considérables. Les points forts ont été Mogóvolas (20 000 personnes pour un petit bourg rural), Nacala-port (35 000 personnes encadrées par les cheiks musulmans), et surtout dans la capitale provinciale Nampula, où une foule seulement comparable à celle de la visite du pape en 1990 - sans doute 100000 personnes - est venue attendre l'ancien chef guérillero.

Plusieurs gros meetings ont également été réalisés au Cabo Delgado, notamment à Mocimboa da Praia, terre des Muanes. À Muidumbe, terre maconde, l'échec a en revanche été patant. L'implantation de la Renamo semble particulièrement réussie sur la bande côtière qui va de la Maganja da Costa, en Zambézia, à Pemba près de la frontière tanzanienne, à l'exception 
d'Angoche. Selon la LOI, présente dans la totalité des meetings de Dhlakama ${ }^{297}$, ce dernier a réuni près de 700000 personnes au cours du mois de campagne, ce qui, pour un pays de quatorze millions d'habitants (dont 6390061 électeurs) est considérable. Cela n'est que très partiellement apparu dans la presse, la couverture journalistique, mozambicaine et internationale, de la campagne du líder de la Renamo étant bien inférieure à celle de Joaquim Chissano.

La désorganisation proverbiale de la campagne de Dhlakama a néanmoins eu des effets négatifs. Parfois, la population, venue à pied des localités, attendait trois jours sans que le líder apparaisse. Les retards ont écourté la campagne au Niassa, des pluies torrentielles l'ont gênée à Tete et Manica. De plus, Dhlakama n'a pratiquement pas fait campagne dans le Sud, un très modeste meeting à Inhambane et un défilé sans grand écho à Maputo montrant la marginalité de la Renamo chez les Changanes, les Vatsuas et les BiTongas.

En fin de campagne, le Frelimo a déclenché une puissante opération de désinformation, accusant, sur la base d'une phrase de Dhlakama tronquée et dont le sens a pratiquement été inversé, la Renamo de vouloir «évacuer» les Macondes vers l'Angola (dont ils [seraient] historiquement originaires) et les Changanes vers l'Afrique du Sud. Aussi grotesque que puisse paraître l'accusation, elle a été martelée et a parfaitement fonctionné, paralysant la campagne de la Renamo dans la province de Gaza. L'objectif du Frelimo est naturellement de provoquer parmi les Changanes et les Macondes un réflexe tribaliste hostile aux ethnies du Centre et aux Macuas, afin de s'y assurer $90 \%$ des voix, contrebalançant les difficultés dans tout le Centre et le Centre Nord du pays. Joaquim Chissano n'est ainsi pas retourné à Beira et Nampula comme il l'avait annoncé, préférant sillonner sa terre natale de Gaza. Le Frelimo a achevé sa campagne à Maputo, où un immense "showmicio » a réuni de 70 à 100000 personnes durant une journée entière.

A. Dhlakama a terminé la sienne à Beira, seconde ville du pays et capitale du Centre, de manière triomphale : plus de 100000 personnes massées tout le long du parcours de l'aéroport à sa résidence (dix kilomètres) le 23 octobre, et 60000 personnes venues au meeting du stade Ferroviário (à sept kilomètres de la ville).

Tous les partis ont eu un discours très démagogique, multipliant les promesses. Outre la défense du pouvoir traditionnel et des valeurs africaines, Afonso Dhlakama a promis d'en finir avec rien moins que le chômage et la misère... Sa voix en revanche a porté quand il a affirmé être en faveur d'un juste partage du pouvoir. Cela concernait non seulement la séparation entre exécutif, législatif et judiciaire, cheval de bataille du plus important des petits partis de la troisième force, le PCN (Partido da convenção nacional) de Lutero Simango, mais aussi une meilleure représentation des groupes ethniques au sein de l'appareil d'État. Il a promis qu'administrateurs de district et gouverneurs de provinces seraient systématiquement originaires de leur lieu de nomination - rompant avec la situation actuelle où les cadres du Sud dominent l'administration.

Selon l'historien français Michel Cahen, du Centre d'étude d'Afrique noire de Bordeaux ${ }^{298}$, qui étudie actuellement la transformation de la Renamo de groupe guerrier en parti politique, la Renamo souffre d'une profonde contradiction entre le discours démocratique de Dhlakama et son fonctionnement quotidien.

Si la composante civile de la Renamo (anciens civils des zones Renamo, clandestins des villes et nouvelles recrues depuis 1992) domine aujourd'hui complètement le parti après la démobilisation des militaires, la psychologie des militants reste militaire : personne ne prend la plus petite initiative, tout le monde attend les ordres de Dhlakama lui-même. Rares sont les dirigeants qui osent critiquer une appréciation ou émettre des doutes sur l'analyse de la situation. Dhlakama est un homme seul, entouré de cadres obéissants qui lui répètent que tout va bien. Lors d'une récente réunion nationale, cette situation a largement indisposé le líder, qui s'est montré caustique envers eux : un seul dirigeant sur douze avait osé déclaré qu'il n'était pas sûr de la victoire.

${ }^{297}$ N'oublions pas que cet article était rédigé pour être publié dans cette revue, dans laquelle les articles ne sont jamais signés.

${ }^{298}$ Voir note ci-dessus. Pour indiquer que j'étais en réalité l'«inspirateur » de l'article, je ne pouvais que me citer moi-même. 
Néanmoins, il est évident que Dhlakama s'est, en cours de campagne, convaincu de la possibilité de sa victoire. Il a multiplié les appels aux fonctionnaires, à la police et au SISE (les services secrets), garantissant qu'il travaillerait avec eux et augmenterait les salaires. Cela a été l'indice qu'il pensait désormais devoir gérer une situation de Présidence Renamo avec un appareil d'État restant largement Frelimo.

Dhlakama a clairement indiqué qu'il n'accepterait jamais des résultats entachés de fraude, comme la publication, issue d'une fuite, d'un document de la Vox Populi, semble pouvoir l'annoncer ${ }^{299}$. Aldo Ajello, l'envoyé spécial des Nations Unies, s'est dit persuadé que le document était un faux, mais n'en a pas moins tenu une réunion d'urgence avec Dhlakama le samedi 22 octobre. Ce dernier a également rencontré plusieurs ambassadeurs occidentaux. Or le 24 octobre au soir, Dhlakama s'est envolé de Beira pour Harare où, en marge du Sommet des Pays de la ligne de front, il a rencontré Mugabe et Keith Mazire. Mugabe a dit en privé à Dhlakama avoir la confirmation que le document était vrai. Les ambassades américaine et italienne ont confirmé ${ }^{300}$. Il est vrai que 8,3 millions de bulletins de vote et de cartes d'électeurs avaient été imprimés, alors que 6,4 millions de personnes avaient été recensées. Or, on n'a pas retrouvé les 1,9 millions de bulletins et cartes supplémentaires. Par ailleurs, le STAE, contrôlé totalement par le gouvernement à la différence de la CNE, a donné l'ordre de considérer comme valable le vote d'un citoyen porteur d'une carte mentionnant un nom ne correspondant pas au numéro, ou n'apparaissant pas sur la liste de recensement... La possibilité technique existe donc de citoyens votant plusieurs fois sous diverses identités. Naturellement, le président Chissano a dit aux Chefs d'État ne pas avoir eu connaissance d'un tel document [de la Vox Populi] et s'en tenir à la version d'Ajello. Tous les partis d'opposition ont décidé, le mercredi 26, de demander l'ajournement des élections et le président de la CNE, Brazão Mazula, se sentant trahi, a mis en jeu sa démission. Techniquement, il est cependant très difficile d'ajourner les élections la veille même du scrutin. Elles risquent d'avoir commencé avant même que la nouvelle ne soit transmise aux bureaux reculés. Par ailleurs, la CNE fonctionne à l'unanimité. Afonso Dhlakama a décidé de ne faire aucune déclaration et de rester à Beira un jour de plus afin de ne pouvoir être accusé de mettre de l'huile sur le feu.

Que les élections soient ajournées ou non, deux choses sont certaines : en deux ans, le chef de guerre a réussi à transformer profondément son image, apparaissant comme le champion de la démocratie et des sans-chemise, et la Renamo, partie d'une structure militaire, a réussi sa transcroissance en parti auprès de larges secteurs fatigués de l'extériorité d'un gouvernement de l'extrême Sud. Elle surgit ainsi comme grand mouvement conservateur-populiste.

Il est impossible de faire un pronostic sur les élections des 27-28 octobre (sauf ajournement), dont les résultats devraient être proclamés de sept à dix jours plus tard. La guerre civile a inclus une forte dose de «secrétisme » parmi les populations. Elles accourent aux meetings, mais dans ce pays qui n'a jamais voté, personne ne peut mesurer leur implication politique.

Or, l'impossibilité d'établir un pronostic semble précisément le fait nouveau, et majeur, de la situation. »

\section{Le 26 octobre 1994}

Hier 25, journée entière d'attente, sans information, à ne rien faire.

10h45. Et ce matin, nous sommes depuis $8 \mathrm{~h} 45$ devant la résidence du Président à attendre l'autorisation de partir. Mais personne n'ose prévenir le Président. C'est ridicule.

11h. Nous avons décidé de partir à l'aéroport sans rien dire. Je vais rentrer à Maputo, comme seul passager dans le petit hélicoptère de Dias, l'ancien commando de la $7^{\mathrm{a}}$ Companhia (celle de

\footnotetext{
${ }^{299}$ Voir la note 4 du chapitre précédent.

${ }^{300}$ Je ne me souviens plus qui m'a donné ces informations sur le déroulement du Sommet, probablement Jorge Correia. Ni Mugabe, sûrement informé par les autorités mozambicaines, ni les ambassades, ne mentaient ! Le document était vrai et c'était là, justement, que résidait la falsification...
} 
Wyriamu $\left.^{301}\right)$. Quatre heures trente de vol, le petit hélico est plus lent que le grand russe et que l'Antonov, mais au moins je sais quand il part.

11h45. Dias veut aller directement à Maputo, sans faire escale à Inhambane. Aussi lui faut-il des jerricanes supplémentaires. Mais la BP n'a pas le droit de remplir les jerricanes... Alors on syphone le réservoir, déjà plein, pour remplir les jerricanes, et on fait à nouveau le plein du réservoir... Ce n'est qu'un retard de plus.

12h30. Sauf que le camion BP qui, entre temps a ravitaillé de gros hélicoptères russes, est maintenant vide... Dias va devoir attendre je ne sais combien de temps.

12h40. J. Correia, arrivé entre temps à l'aéroport, m'informe de la situation et de la demande d'ajournement des élections (voir article LOI).

13h05. Départ pour Maputo dans l'avionnette du Commandant James. Belle vue sur l'estuaire du Pungué.

13h50. Nous passons le Save, pratiquement à sec ! Au loin à l'est, Machanga et Mambone.

${ }^{301}$ Wyriamu, dans la province de Tete, fut le lieu, en 1972, de l'un des plus abominables massacres de la guerre coloniale, qui put être connu et internationalement dénoncé grâce aux témoignages de religieux. Le Times publia un article sur le sujet la veille de l'arrivée à Londres de Marcelo Caetano, président du Conseil portugais, venu rendre visite au vieil allié britannique... 


\section{Chapitre 11}

\section{Au bord de l'abîme}

\section{Le 27 octobre 1994, à Maputo}

10h. La Renamo aurait dû donner une conférence de presse au complexe Kaya Kwanga. Dhlakama est toujours à Beira et, à Maputo, Rahil Khan, qui représente sans doute le clan Raúl Domingos, a déclaré la veille que les conditions d'élections libres et justes n'existaient pas et que la fraude était en cours. Dhlakama, obsédé par la volonté de ne pas être un nouveau Jonas Savimbi ${ }^{302}$, veut dénoncer la fraude avant et laisse déclarer, puis confirmer, que la Renamo ne participe pas aux élections. Mais c'est infiniment tard pour dire ça, c'est techniquement impossible et c'est un suicide! Si la Renamo ne participe pas, il n'y aura pas de fraude et l'ONU sera obligée de déclarer les élections libres et justes. Dhlakama perdra tout son crédit et Raúl Domingos pourra prendre le pouvoir, mais un pouvoir vide car la Renamo n'existe pas sans Dhlakama!

[Je ne sais pas, aujourd'hui, si cette vision d'une rivalité Dhlakama/Raúl Domingos, était juste. La rumeur en courait. Diffusée par qui ? Parler de rivalités, c'est aussi en créer, distillant mutuellement la suspicion auprès des dirigeants concernés].

De fait, la conférence de presse n'a pas lieu ${ }^{303}$.

12h30. Déjeûner à la résidence d'Aldo Ajello, avec ce dernier, sa femme et Éric Lubin. Tour de la situation, définition de l'idée : cueillir Dhlakama, préalablement prévenu par Jorge Correia $^{304}$, à son arrivée à l'aéroport, l'isoler de ses mauvais conseillers, le convaincre d'aller voter demain à sept heures devant toutes les caméras, faisant une déclaration pour demander des garanties et le prolongement d'un jour des élections.

C'est encore rattrapable, car l'ébulition maputense n'est pas encore arrivée en brousse. Les nouvelles montrent que ça se passe bien, que les gens votent, que les scrutateurs de la Renamo n'ont pas quitté les bureaux de vote.

17h. Rádio Moçambique et la TVM continuent à marteler que la Renamo ne participe pas... Rahil Khan l'a confirmé à 16h à la CNE. Mais Dhlakama est dans l'avion. Éric Lubin doit déjà être à l'aéroport, avec la confiance d'Aldo Ajello. Une conférence de presse était prévue à $17 \mathrm{~h}$. Elle n'aura pas lieu. J'en saurais peut-être plus à $18 \mathrm{~h}$, au coktail de l'Ambassade de France, ou ce soir au dîner.

Dhlakama paye : il a dérapé. Persuadé de gagner, il se persuade qu'il ne peut perdre que par fraude et dénonce par avance des moulins à vent. Des gens autour de lui ne cessent de lui dire qu'il est génial et qu'il ne doit pas se laisser faire. En fait, ils le poussent au suicide car ils

\footnotetext{
302 Jonas Savimbi, chef de l'Unita, avait dénoncé pour «fraude massive » les élections de 1991 en Angola seulement après que la publication des résultats aient sanctionné sa défaite.

${ }^{303}$ Cela était capital : compte tenu des caractéristiques de la Renamo, tant que ce n'était pas Dhlakama luimême qui déclarait le boycott des élections, les militants de base participeraient. Quant à moi, je commençais enfin à comprendre... La meilleure dissimulation n'est-elle pas la manœuvre la plus visible, la plus éclatante, à l'image de la fameuse lettre d'Edgar Poe ? Le document de la Vox Populi annonçait des fraudes, et décrivait des fraudes si habiles que personne ne les découvrirait. Effectivement : la fraude, c'était ce document lui-même et rien d'autre, tout entier conçu pour convaincre Dhlakama que le Frelimo allait frauder et le pousser ainsi à l'erreur et au boycott. Les mauvais cadres l'entourant, craignant le verdict des urnes, alors qu'ils n'avaient cesser de clamer victoire, et parmi eux inévitablement des agents infiltrés du Frelimo, ne pouvaient que le pousser dans le même sens, finement calculé par les experts en manipulation psychologique de la Vox Populi...

${ }^{304}$ Je n'ai pas su l'opinion personnelle de Jorge Correia sur cette question du boycott de dernière minute. Mais contacté par Éric Lubin, il ne pouvait pas lui refuser ce service, refus qui par ailleurs l'aurait rendu directement responsable du boycott.
} 
veulent juste que la vie dorée continue $\mathrm{e}^{305}$ : être député (1 $000 \mathrm{FF}$ par mois) ne les intéresse pas et ils préfèrent tenter leur va-tout pour obtenir encore des avantages. Aberrant.

\section{8 octobre 1994}

1h30. Après avoir dîné chez Francis Heude (premier conseiller de l'Ambassade), je suis à la résidence de Dhlakama à attendre Lubin et des nouvelles. La réunion s'éternise, ce qui est bon signe.

2h. Lubin sort en trombe. Je saute dans la voiture qui démarre sous les flashes des caméras. Lubin ne dit rien et je ne lui demande rien. L'information principale, je l'ai déjà, à le regarder. Ouf. Les détails, on les aura demain.

2h10. Lubin me glisse: Dhlakama vote demain à 8 h30 après avoir rencontré les ambassadeurs des pays de la CSCE. Je rentre dormir.

8h30. Forêts de caméras et foule de journalistes à la résidence.

9h10. Dhlakama et les ambassadeurs sortent, tout sourire.

9h45. Poignée de main Dhlakama-Ajello, dans le crépitement des flashes. Dhlakama me fait un signe de la main, souriant. Il semble que les élections soient prolongées de deux jours. C'est bon. final.

10h20. Attente. Ils doivent être en train de rédiger et discuter mot à mot un communiqué

10h45. Lubin entre dans la salle où les «homens grandes ${ }^{306}$ sont réunis.

11h. La conférence de presse s'organise, les journalistes sont aussi serrés que les militants des meetings, se bousculent et certains s'insultent. Il y a plus de gens, me dit la correspondante du Figaro, que pour les élections en Afrique du Sud.

11h20. Ajello et Dhlakama, entourés des ambassadeurs, arrivent.

11h25. Dhlakama parle. Il a obtenu des «garanties » que les recherches sur les plaintes de la Renamo vont être faites (bien que la CNE et Mazula n'aient pas réagi). Un documentprotocole va «valoriser» le processus. Dhlakama va voter. La "Communauté internationale », même après les élections, fera les recherches nécessaires. Les élections seront prolongées, le nombre de jours nécessaires, « jusqu'à trois ou quatre ».

- "Nunca tivemos a vontade de sabotar as eleições. A festa é do povo. Haverá uma lista de todas as garantias que a comunidade internacional vai dar », " Nous n'avons jamais voulu saboter les élections. La fête appartient au peuple. Il y aura une liste de toutes les garanties que la Communauté internationale va donner ».

11h30. Distribution d'un communiqué des ambassadeurs de la CSCE, y compris Ajello, qui veut formellement plaire à la Renamo en reconnaissant que la CNE «não foi capaz de satisfazer a Renamo », "n'a pas réussi à donner satisfaction à la Renamo » - formule qui ne veut pas dire que la CNE n'a pas fait son boulot! Ajello confirme en anglais : "Now, everything is $O K »$.

12h. Je pars à l'Onumoz préparer mon retour à Machanga et Mambone $\mathrm{e}^{307}$. Discussion avec José Luis Cabaço $^{308}$. Une enquête de l'ARPAC sur les rapports entre les régulos et les

${ }^{305}$ Tant que coulait l'argent de l'ONU, certains cadres supérieurs de la Renamo étaient très bien rémunérés.

${ }^{306}$ Les hommes importants.

307 Ces deux localités étaient idéales pour moi: non seulement je pourrais y poursuivre l'enquête commencée dans les archives sur les événements de 1953 (voir note 4 du chapitre précédent), mais il s'agissait de zones de forte implantation Renamo qui, pourtant, étaient toujours restées sous l'administration du 
élections, indiquent qu'ils sont ennuyés : - «Isso não é bem o nosso trabalho. É a cidade que deve escolher o Presidente, e depois é o Presidente para nós o respeitar », « Ce n'est pas notre boulot. C'est la ville qui doit choisir le Président, à lui ensuite de faire en sorte que nous le respections ». D'autres disent que "para saber para quem votar, estamos à espera de orientações do governo », "pour savoir pour qui voter, nous attendons les directives du gouvernement»! Bien sûr, «governo» («le gouvernement») veut parfois aussi dire Renamo. Dans plusieurs localités, il est clair que les régulos organisent leurs populations de manière à ce qu'une moitié vote Frelimo et une moitié Renamo. C'est le vote pour la paix, pour qu'ils s'entendent. Bien des gens ont exprimé leur désir de voter à la fois pour la Renamo et pour le frelimo. Dans une localité du Cabo Delgado, les observateurs ont eu la surprise de voir, en arrivant, deux files de gens sagement alignés. A leur question du pourquoi de ces deux files, on leur répondit que la première était la file de la Renamo et la seconde celle du Frelimo... Derrière l'anecdote gentille, il y a en fait la volonté profonde de la paix, et que ça se passe bien, que Frelimo et Renamo soient désormais des choses habituelles.

17h. Discussion avec Heumin (du ministère de la Défense) et Garcin (l'attaché militaire). Intéressant, mais ils ne m'apprennent rien.

\section{Le 29 octobre 1994.}

C'est le troisième jour des élections, peu d'électeurs se présentent. Mais le taux de participation globale pour ces trois jours semble très élevé $( \pm 85 \%)$.

\section{Le 30 octobre 1994}

Je devais partir demain pour Vilanculos via Inhambane, en Antonov puis hélicoptère ONU. Le vol est annulé.

\section{Le 31 octobre 1994}

Quelques estimations ont commencé à tomber. Mieux vaut attendre plutôt que de s'énerver à raisonner sur des résultats ultra-partiels.

Le vol a bien été supprimé, mais il y en avait un autre, celui qui allait chercher, à vide, les observateurs internationaux pour les ramener à Joburg. Sauf que, comme ce n'était pas le même service, le service ordinaire de l'Onumoz n'a pas été averti... Rageant.

Je pars demain en Antonov pour Inhambane. Après, je dois me débrouiller, par route.

\section{1"r novembre 1994}

5h30. Onumoz Air Base. Les soldats japonais ${ }^{309}$ organisent l'enregistrement des passagers. Je suis le seul pour Inhambane, l'avion pour Beira y faisant escale seulement pour moi.

(Hier soir, j'ai discuté avec Pascal Torres, un des responsables de Handicap International, qui a séjourné cinq ans à Inhambane, au début en pleine guerre, et y a vu la cruauté de la Renamo dans le sud. Le lieutenant-colonel de la base de Neves lui a dit, après de nombreuses

gouvernement du Frelimo. Cela me permettrait donc d'approcher la réalité non seulement de la « Renamo civile », mais de la Renamo en zone étatique.

308 José Luis Cabaço, vieux militant blanc du Frelimo s'était, à ce moment-là, mis en congé de parti et agissait comme consultant. Fidèle de Samora Machel, il avait néanmoins toujours eu une attitude libérale et ouverte à la recherche. Sans son intervention, il est infiniment probable, par exemple, que Christian Geffray n'aurait pas obtenu les autorisations nécessaires de l'état-major pour aller enquêter en zone de guerre, en 1988, dans la province de Nampula, sur la base sociale de la Renamo, qui devait aboutir à son ouvrage de référence $L a$ cause des armes au Mozambique. Anthropologie d'une guerre civile (Paris, Karthala, 1990).

${ }^{309}$ La présence d'un contingent japonais dans les troupes de l'Onumoz était symboliquement importante pour Tokyo : non seulement elle démontrait l'intérêt de ce pays pour l'Afrique, mais cette participation d'un contingent japonais constituait en même temps la première intervention de cette armée à l'extérieur de l'archipel depuis la Seconde Guerre mondiale. 
bières $^{310}$ sanctionnant la redécouverte d'un corps - qu'ils avaient torturé (un coopérant italien) - afin de le rendre à la famille, que c'était lui qui avait fait l'attaque d'Homoïne. Et il est maintenant, semble-t-il, à Homoïne).

Le long de la voie de chemin de fer où ne passe aucun train, des centaines de gens attendent dans l'aube des chapas, ou s'organisent en petits dumba-nengue.

Ni même un café ! ${ }^{311}$

7h10. Départ pour Inhambane.

${ }^{310}$ On n'insistera jamais assez sur le rôle de la bière dans les enquêtes ! Mon expérience avec les anciens comandos portugais de l'armée coloniale est que «cela» devenait intéressant vers la septième. Le seul problème, dans cette observation participante, est qu'il faut tenir le coup, si possible mieux que l'interlocuteur !

${ }^{311}$ Lusitanisme volontaire : «Nem uma bica ! » doit naturellement être traduit par « Pas même un café !» mais signifie littéralement « Ni un café ! ». 


\section{Chapitre 12}

\section{Mambone}

\section{Le 1' novembre (suite)}

\section{8h15. Arrivée à Inhambane.}

9h15. Les recommendations [de Michelle de Rosset, du Public Information Office de l'Onumoz de Maputo, que j'exhibe] auprès du Force Commander [d'Inhambane, Major General Mohammad Abdus Salam] sont lues, mais toutes les voitures ont été réquisitionnées pour les opérations de vote, et sont encore en brousse, ou, en tout cas, n'ont pas encore été rendues. Mauro, l'Italien de l'Unohac, s'occupe gentiment de moi. Un capitaine va arriver, alors...

Petit tour sur le front de mer de la ville, encore bien jolie, avec les barques à voile arabe.

9h45. Le capitaine uruguayen de la Civpol va me conduire à un Espagnol de la Civpol, qui va à Vilanculos, peut-être même jusqu'à Inhassoro.

(Le délégué de la Renamo à Inhambane est le Senhor Pires, un commerçant dont le frère est au Frelimo. Bonne stratégie familiale! Mais ici, la Renamo est marginale.)

10h15. Arrivée à la base militaire Onu. On cherche l'Espagnol. Je prends un pot au bar de l'état-major, sous tente et bambous.

10h45. Retour en ville à l'Onumoz. Le capitaine uruguayen m'amène à l'Espagnol qui est en fait Anglais. Départ pour Inhassoro quand la voiture sera réparée, et demain pour Mambone. Le mécanicien a dit que la voiture était prête « já ${ }^{312}, \ldots$ c'est-à-dire dans quelques heures.

12h. Interminable attente. Heureusement le temps est délicieux, presque méditerranéen. Avec un vent frais. Vue sur la baie, à marée basse. Au loin, quelques voiles arabes.

$\mathrm{Si}$ au moins j'avais une indication claire du moment du départ, je pourrais aller me promener, aller au siège Renamo. Mais... há de vir ! ${ }^{313}$

Un enfant dort à même le ciment, en plein soleil. Pourquoi n'est-il pas à l'école ?

13h. L'Anglais, Paul, a décidé que trop, c'est trop, après moult conflits bureaucratiques au sein de l'Onumoz, et il vient de résilier son contrat. Aussi, va-t-il rester ici quelques jours. M...!

16h30. Enfin, départ dans une autre voiture Civpol. Non ! elle est pleine. Ça devient fou. Il paraît que Paul, finalement, va venir. J'ai tellement hâte d'arriver pour enfin quitter ces petits problèmes Onumoz!

21h. Arrivée à Inhassoro, après un voyage sans autre problème que celui de voyager sans phare plusieurs centaines de kilomètres en pleine nuit, ce qui n'est pas très pratique.

Je suis au «Complexo Turístico », occupé par l'Onumoz. Paul et Liz O'Grady, le couple anglais, vont peut-être demain à Mambone. Mais j'apprends que Farias habite en fait très loin de Mambone, à 20 kilomètres. Vamos lá ver... ${ }^{314}$

\section{Mercredi 2 novembre}

\footnotetext{
312 «á »: déjà, tout de suite.

313 «Há de vir ! » : ça va venir, c'est pour bientôt - c'est-à-dire, comparé à «Já ! », un futur indéterminé.

314 «On va bien voir».
} 
8h. Le campement baigne dans la lumière du matin clair, face à la mer argentée. Au loin dans la brume, 1'île de Santa Carolina ${ }^{315}$. Bref, le paysage colonial classique tel que je l'aime, mais sans les cocotiers, car ici ce sont les longues plages débouchant directement sur une brousse de savane...

9h. La malchance continue. Le commandant Jambeck m'apprend qu'une voiture Civpol est partie ce matin, à $8 \mathrm{~h}$, pour Mambone, et qu'il n'y en a que rarement. Il ne savait pas que je voulais y aller, et Paul m'avait dit d'aller le voir ce matin... Shit !

9h30. Inhassoro est un village étendu en bordure de mer. Immense plage de sable blanc, mais très étroite à marée haute. On aperçoit maintenant l'île de Bazaruto avec ses dunes claires. Quelques barques arabes sont échouées. Gamins. L'école est dans un bâtiment en dur, mais si endommagé que les enfants sont réunis dans une hutte rectangulaire où, sans aucun matériel, ils répètent en chœur ce que dit le maître.

Peut-être un jour toute la zone dorée qui va de Vilanculos à Bartolomeu Dias, sur la côte, avec les îles Macarugune, Bazaruto, Santa Carolina au large, sera couverte d'hôtels. Les fonds sous-marins sont beaux, on peut naviguer ; l'hinterland, une fois déminé, est aussi intéressant. Si cela peut rapporter un peu aux pêcheurs, ce sera bien...

Inhassoro a été attaquée plusieurs fois pendant la guerre. De nombreuses personnes ont été abattues sur la plage par la Renamo.

11h20. Départ pour Pande. S'il y a de l'essence à Pande, Paul va à Mambone, sinon, il revient.

12h. Arrêt à Pande, petit village sur la route ${ }^{316}$. Brève discussion avec le frère de Farias. On fait le plein. Farias vient à Pande, il faut le croiser sur le chemin. On prend la première piste sur la droite.

12h30. On croise effectivement Farias avec son camion bleu détraqué. Il revient demain après-midi.

13h. L'approche du nord du Govuro est intéressante. Les maisons changent, elles s'ornent de peintures. On quitte le monde tsua pour entrer dans l'enclave ndau du Sud du Save.

Nous nous arrêtons à la Mission, à sept kilomètres de Mambone. Le padre Amadeu (Giovanni Amandio en italien) Marchiol nous reçoit ${ }^{317}$. Je vais le revoir mais de suite il raconte sa vie ici (depuis 1956), les attaques de la Renamo : la première, le 19 octobre 1982, qui respecta bien la localité ; puis la seconde, du 20 novembre 1982 au cours de laquelle la mission fut attaquée et le padre Marchiol faillit être enlevé, attaque que la population ne comprit pas du tout - population qui soutenait de tout cœur les rebelles. Alors que les grands groupes Renamo respectaient la population, il y eut ensuite beaucoup d'autres attaques de groupes isolés dont la population ne savait pas si c'était ou non la Renamo. Une fois un groupe de miliciens du Frelimo fut pris en train de tuer des femmes à la machette (six victimes) tout en affirmant qu'il s'agissait de la Renamo. On peut croire que des groupes locaux Renamo ont aussi fait des sacs. Lors de l'attaque de la mission, le padre a reconnu certains de ses anciens élèves dans les soldats rebelles. Mais les massacres individuels ne sont pas attribués à la Renamo par la population. Cependant le vol de trois cents têtes de bétail en 1982 (au cours de la deuxième attaque) n'est pas «passé » facilement. La population a été confuse : - «Quem afinal vai poder vir salvar-nos? », «Qui finalement va pouvoir venir nous sauver?». Globalement, elle est cependant restée pro-Renamo, comme les élections le montrent bien.

\footnotetext{
${ }^{315}$ Déjà très prisée du temps des Portugais, l'île de Santa Carolina est toujours restée, même en pleine guerre civile, un Eldorado touristique (plongée sous-marine, etc.) pour Sud-Africains argentés.

${ }^{316}$ Il s'agit de la route nationale $\mathrm{n}^{\circ} 1$. Pande pourrait devenir, dans quelques années, un centre de production de gaz naturel.

${ }^{317}$ Je lui avais écrit, en 1991 ou 1992 et le plus étonnant est que la lettre était arrivée. Même s'il ne m'avait pas répondu, il se souvenait de moi.
} 
Après-midi. Petite discussion avec l'administrateur-adjoint. Il est d'Homoïne, et ici depuis trois mois. Mambone est remplie de chemisettes, pagnes et foulards Frelimo - ce qui n'a pas empêché tout le monde de voter Renamo.

Petite ballade. Je suis vraiment regardé comme un zombie. Un peu gênant, mais il faut bien être le Blanc.

19h15 à Mambone. Francisco Madeira, membre de la délégation locale de la Renamo et dont... l'électricité a été coupée, est né en 1948. Son père, du même nom, était le premier infirmier noir de Mambone et faisait même des opérations, il était «muito famoso » («très connu »). Lui-même a fait ses études à partir de 1956 à Beira/Inhamudima (un quartier près de Palmeira), à l'école de la Mission S. João Bosco. Il est catholique. Il a été jusqu'à la $4^{\mathrm{e}}$ classe [coloniale] en 1964 et, en 1965, a été admis à l'Escola de Arte e Ofícios de Beira ${ }^{318}$ qui n'a duré qu'un an. À seize ans, il travaille à la pharmacie Beira, dirigée par un Grec. Puis, six mois après, à la nouvelle agence de la banque Pinto \& Sotto Mayor. En 1970, il fait son service : préparation militaire à Boane, puis Hospital Militar de Maputo où il passe par divers services. Il est ensuite infirmier à Lichinga, Valadim ${ }^{319}$. Il termine la guerre avec le grade de furriel infermeiro ${ }^{320}$, en 1973, année où il est mis en disponibilité. Il entre alors dans la PSP ${ }^{321}$, « $6^{\mathrm{e}}$ esquadron, guarde de $2^{\mathrm{e}}$ classe », à Beira/Palmeira.

\section{Jeudi 3 novembre 1994}

8h, suite de l'entretien [avec Francisco Madeira]. En 1974, il se trouve à Beira quand éclate le 25 Avril. Il assiste aux troubles contre les petits partis (Gumo, Fumo, Manu ${ }^{322}$ ), les voitures brûlées, etc. : - «A população só queria a Frelimo porque os outros partidos não tinham feito nada », «La population ne voulait que le Frelimo, parce que les autrs partis n'avaient rien fait ». Lui-même est alors responsable de l'information et de la propagande du Groupe dynamiseur de Palmeira/ $6^{\mathrm{e}}$ Localité $\mathrm{e}^{323}$ et ouvre une « machamba colectiva » ${ }^{324}$.

Il travaille avec le Dr Dias Coelho, responsable à la santé pour tout Beira, un «Portugais du Frelimo ». Puis, le 31 octobre 1975, comme le camp de rééducation de Sakuzu, à Gorongosa, avait ouvert, il y part d'urgence, avec quelques médicaments, sur ordre, sa femme restant à Beira.

Il y avait là des gens arrêtés dans les provinces de Tete et de Zambézia qui venaient d'arriver - prisonniers et encadrement arrivèrent en même temps. Il n'y avait aucune installation, "só capim ${ }^{325}$ à hauteur d'hommes! Pour diriger le camp, il y avait le commandant guérillero Sumaíl Chingo, un Maconde qui ne savait ni ne voulait apprendre le portugais. Il en resta le commandant. L'adjoint Ernesto était de Tete, le responsable de la production était Daniel Catchumba, d'Angónia. Lui-même était, en tant que policier, le chef de la santé. Le radio, Tamango, fut, en 1976, tué par un crocodile.

La majeure partie des prisonniers ne savaient pas pourquoi ils étaient là. Dès les premiers jours, «algumas brancas» («quelques femmes blanches») des cabarets, considérées prostituées et d'autres réactionnaires, s'évanouissaient par manque de nourriture - ils

\footnotetext{
${ }^{318}$ Les Écoles d'arts et métiers étaient, à l'époque coloniale, une sorte d'enseignement professionnel.

${ }^{319}$ Localités de la province nordique du Niassa.

${ }^{320}$ Sergent infirmier.

${ }^{321}$ Police de sécurité publique.

322 Le Frelimo, fort de sa légitimité guerillera et nationaliste, organisait systématiquement des manifestations contre les autres partis, dont certains avaient été manipulés par l'administration coloniale de la toute dernière période mais pouvaient cependant avoir une certaine représentativité. Mais le Frelimo préparait le passage au parti unique. Gumo, Grupo unido de Moçambique, Fumo, Frente unida de Moçambique, Manu, Mozambique African National Union.

${ }^{323}$ Palmeira $/ 6^{\mathrm{e}}$ quartier.

${ }^{324}$ Champ collectif. Les champs collectifs avaient une importance plus symbolique que productive. Souvent, leurs maigres récoltes servaient uniquement à financer les repas lors du passage de responsables

325 «Seulement des hautes herbes».
} politiques. 
n'arrivaient pas à manger la fuba [farine]. Madeira évacue ainsi certains prisonniers pour leur sauver la vie et leur permettre, en s'appuyant sur leurs relations, de revenir à Maputo certains réussirent.

Lui-même se pose alors des problèmes : le camp ne rééduquait personne et fonctionnait seulement comme «torture idéologique ». Fuir ? Tout autour, lions et brousses...

Il y avait aussi des policiers et soldats amenés, pour être rééduqués.

En décembre 1975 y arrive André Matsangaissa ${ }^{326}$. Quand il cherche à fuir pour la première fois, en janvier 1976, la punition est la suivante : allongé sur le ventre, un prisonnier assis sur la tête, un autre sur les pieds, et un troisième le battant à coup de bâton sur le dos et le postérieur, jusqu'à ce que le bâton soit complètement cassé. Ensuite, infailliblement, ce traitement menait à l'infirmerie. Les prisonniers récalcitrants étaient nus, vêtus d'un sac de maïs.

À la caserne, bataillon $n^{\circ} 16$ de Matacuane à Beira, Matsangaissa s'était fait mal voir et avait été accusé de desvio ${ }^{327}$ - ce qu'il niait.

La deuxième fois, à la fin février, il est repris et subit la même punition. Dès lors, il est Xiconhoca ${ }^{328}$.

La troisième fois, fin mars, André Matsangaissa sort par la route nord, direction Maringué, puis gagne le Zimbabwe ${ }^{329}$. Lui et d'autres, environ cinquante, partent de nuit.

Chaque groupe de prisonniers du camp de rééducation avait un nom : coelho, bufalo, tigre, elefante, crocodile, gazela, galo, etc. ${ }^{330}$. Le groupe de André était bufalo. André disait que

- «atitude deste governo é massacrar o povo, o homem tem medo de falar, tudo é fechado, Estou contra », "l'attitude de ce gouvernement est de massacrer le peuple, on a peur de parler, tout est fermé. Je suis contre ».

Il avait déjà l'idée de former un "grupo de reacção contra o centro [de reeducação]" (« un groupe de réaction contre le centre [de rééducation]»). Son groupe est d'abord détenu par Ian Smith, qui ne savait pas de quoi il s'agissait. Mais après : - «Smith deu tudo », « Smith a tout donné ».

André revient le 31 août 1976, à 9h du matin et intercepte le groupe nouveau, envoyé le plus loin pour défricher (les groupes récents étaient envoyés le plus loin, les anciens travaillaient les champs déjà ouverts). Il explique sa lutte à ce groupe de Machanganes ${ }^{331}$ et de quelques Blancs et métis. La majorité le suit, six revenant au camp.

En novembre 1976, il revient de nuit et brûle le camp, sans tirer. Il fait de même du camp de Kanda (à Gorongosa, lieu-dit Casa Banana).

Francisco Madeira quitte le camp en janvier 1977 et revient à Beira. La guerre commençait à se développer. Il travaille à la $\mathrm{PIC}^{332}$ comme «agente de investigação criminal » («agent d'investigation criminelle ») et y reste un an avec l'inspecteur Pinto de Almeida (un Blanc mozambicain). Mais en 1979, Samora Machel demanda l'expulsion de tous les anciens membres de l'appareil répressif colonial. L'expulsion était pire que la démission, car elle ne permettait aucune indemnité. Comme ancien agent de la PSP ayant porté l'uniforme

326 ... qui deviendra le premier commandant de la Renamo.

${ }^{327}$ Desvio, détournement de fonds ou de marchandises - accusation, avérée ou non, quasi-habituelle pour se débarrasser d'un gêneur.

328 «Xiconhoca» est une appellation infâmante forgée à partir de Xico (ou Chico, pour Francisco), l'indicateur de la Pide, et de nhoca, serpent venimeux. «Xiconhoca » est le symbole de l'ennemi, dans tous les domaines, qui doit être dénoncé et détruit par tous les moyens.

${ }^{329}$ À savoir, à ce moment, encore la Rhodésie.

${ }^{330}$ Lapin, bufle, tigre, éléphant, crocodile, gazelle, coq. Il est intéressant de noter que la Renamo reprendra ensuite systématiquement cette pratique d'appellation animalière venue du camp de Sakuzu (ou Sacusi) pour désigner ses bataillons, exprimant par là sa conscience d'être les « rééduqués, les «marginaux » façonnés par le Frelimo lui-même.

${ }^{331}$ Étant donné les confusions fréquentes, j’ignore si, ici, le terme « Machanganes » noté dans mon carnet désigne des Changanes (ethnie du sud) ou des Machangas, groupe ndau côtier. Je penche, sans certitude, pour la première hypothèse.

${ }^{332}$ Police d'investigation criminelle. 
portugais, il est expulsé sans aucun droit. Même l'argent donné par le Portugal à ses anciens agents, comme subside, fut confisqué.

Il « réfléchit à sa vie, à ce qu'il a fait » et ouvre un petit bar à Beira. En même temps, il entre à la Renamo, grâce à Ndachata («John », aujourd'hui locuteur à la VORE ${ }^{333}$ ), qui était en contact avec des intermédiaires de Matsangaissa. Il y reste jusqu'en août 1983, date à laquelle il revient à Mambone.

À Beira, son travail était seulement de « angariar pessoas ${ }^{334}$.

[L'entretien se poursuivit le 4 novembre, à 20h30. J'avais rendez-vous avec le padre Marchiol.]

9h20. Le padre Amadeu aurait dû venir me chercher à Mambone. Comme il ne vient pas, je prends une boleia ${ }^{335}$ pour la Mission. Naturellement, j'y apprends qu'il est allé à l'hôpital, à Mambone, hôpital où pourtant nous nous sommes arrêtés sur le trajet! Attente - comme toujours.

10h, puis toutle reste de la journée. Entrevue avec le padre Amadeu Giovanni Marchiol.

Le père commence, répondant à ma question, par me citer certains des membres du Núcleo negrófilo de Manica e Sofala, de 1953, de Mambone ou de la Machanga, ou de leurs familles que je pourrais interroger. Outre la famille Simango, il y a Gimo Tomas, conseiller de la Renamo, qui vit à Matasse ${ }^{336}$, il y a Jó, un catholique qui vit près de l'aéroport de même que Petreque Chamussa, et encore Alexandre Nova, un catholique «au courant de tout», également à Matasse ; André Machava, lui, est décédé ; Madenga Zingoma vit près de Jó, il est protestant; Gabriel Castigo Tivane vit entre Genga ${ }^{337}$ et Mussassa ; Denis Matibe vit à Matasse ; Sipumburo Mukove est à Jeque (Machanga), il fut arrêté en 1953 et déporté ; Fernando Chogogolo vit près du fleuve. Il y a aussi le fils Matique ${ }^{338}$ qui a repris la chefferie en l'absence d'oncle ou de neveu ${ }^{339}$. En revanche, il n'y a pas encore de successeur à Genga, car le fils, qui vit à Beira ou Maputo, n'est pas très chaud pour revenir.

Selon le padre Amadeu, le regulado d'origine est Machacane, qui est à quarante kilomètres à l'ouest, sur le fleuve Save. Mais suite à un conflit - la mort d'un enfant dont Machacane fut déclaré coupable - il dut donner à la famille plaignante la partie maintenant Genga, alors presque vide. Les chefferies locales (Maave, Massassa, etc.) viennent toutes de Genga et de sa famille. Le premier Matique fut, lui, un marin noir d'Angola, laissé là par les Portugais pour établir des contacts avec la population locale encore très traditionnelle. Le nom Matique vient de kutika (carregar, charger, transporter), Ma-Tika étant donc le carregador, le porte-faix. Mais Matique, chef pour les Portugais, laissé là comme leur représentant, réussit également à devenir chef traditionnel ${ }^{340}$. Il resta avec la petite enclave de Matique, qui n'inclut même pas Mambone. Machacane est entré en désuétude et $\mathrm{il}^{341}$ serait mort alcoolique.

Les deux chefferies [Genga et Matique] sont assez artificielles, à l'inverse de celles de Liudo, Singarrel, Mabote, Chichanga, Magumbere (à l'ouest), Jofane (partie de Chichanga). Chichanga est le principal régulo de la zone de Mabote, mais ne vit pas à Mabote même. Côté

${ }^{333}$ VORE, Voz da Renamo, radio de la Renamo.

${ }^{334}$ Recruter des gens.

335 Trajet offert, éventuellement en auto-stop.

${ }^{336}$ Lieu-dit près de Mambone.

${ }^{337}$ L'une des chefferies, $c f$. infra.

${ }^{338}$ Chefferie locale qui fut impliquée dans les événements de 1953.

${ }^{339}$ Règle normale de dévolution en terre matrilinéaire.

${ }^{340}$ Il est important de noter que le problème principal dans les chefferies n'a jamais été leur aspect traditionnel ou non, mais leur légitimité reconnue ou non. Un élément non traditionnel avait certainement plus de difficulté à devenir légitime, ou se voyait plus facilement reprocher ses défauts, mais ce n'était pas un obstacle infranchissable. S'il convenait, la population et les Anciens pouvaient tout à fait le soutenir, quitte à déclencher une interminable guerre dynastique avec les descendants de la famille évincée...

${ }^{341}$ C'est-à-dire probablement un de ses descendants (les chefs successifs prennent le nom de la chefferie). 
Machanga [i.e. au nord du fleuve], Chiteve et Maropanhe datent d'avant Ngungunhana qui n'est pas vraiment arrivé jusque lá, et sont donc originels ${ }^{342}$.

À Mambone, les communautés chrétiennes furent pratiquement détruites par les menaces du Frelimo - par exemple, l'église de la Mission était cadenassée, une église ne pouvait fonctionner à proximité d'un «centro educacional ${ }^{343}$. Mais elles reprirent vie en 1984 : au début, douze personnes se réunissent dans la maison d'une secrétaire de l'Éducation. Cette démarche se multiplia localement, puis à Machanga même, à Maropanhe, etc. Tous les baptisés se réunirent à nouveau, tous des responsables, impossibles de les arrêter tous. Les « communautés » étaient illégales. Les protestants, au départ mieux disposés envers le Frelimo, qui pensaient que c'était à l'Église catholique de souffrir, souffrirent cependant aussi et se réorganisèrent plus tard - à l'exception de Jaime Maconhera, de l'Igreja do Cristo de Moçambique $^{344}$, qui, à cent ans, évangélisait encore et qui, un jour, traversa le fleuve en disant qu'il allait mourir ce jour, et, le retraversant le soir, se coucha à l'ombre d'un arbre et mourut.

Maintenant, les contacts des protestants avec leurs structures supérieures ont repris.

Le 4 octobre 1994, l'Église catholique invita toutes les Églises et la population pour remercier Dieu et aborder avec force les élections. "Um mar de gente " ( une mer de gens »). Les protestants furent très contents.

Les Ziones cependant restèrent à l'écart, car ils ne sont pas vraiment considérés comme une Église mais plutôt curandeiros [guérisseurs] et l'ensemble des Chrétiens ne veulent pas d'eux ${ }^{345}$.

La création des communautés de base fit, pour la première fois, apparaître l'Église catholique comme Église mozambicaine et non plus portugaise : elle avait tout perdu, mais pas les biens spirituels. C'est la répression du Frelimo fit comprendre cela, alors que l'Église avait eu bien du mal à l'expliquer ! La population ne considérait pas la Mission comme exploiteuse - le padre avait construit des maisons en ciment, ouvert une rizière collective pour le peuple, mené une action sociale plus forte que l'action évangélisatrice elle-même.

Pourtant, au début, les esprits n'aimaient pas les maisons en ciment, car ils ne pouvaient pas y entrer et donc allaient se venger. Cependant, construire une maison traditionnelle améliorée coûtait cher - et les maisons ordinaires ne durent pas plus de dix ans, après quoi il faut les refaire, ce qui empêche d'économiser. Aussi, certains acceptèrent et les esprits ne se vengèrent pas, notamment grâce à des cérémonies nhamussoros ${ }^{346}$ — « quelle est la cause du mal ? » demandait-on. Mais les nhamussoros ne transmirent pas d'ordre des esprits de quitter les maisons en dur. Au cours des années soixante, on en construisit un grand nombre.

${ }^{342}$ C'est-à-dire que ces regulados n'ont pas été remaniés par l'empire de Ngungunhana. Ce dernier fut l'un des principaux rois ngunis, dont le premier empire était situé au centre du pays et contenait la zone ndau. Les Ndaus furent massivement recrutés dans son armée, y constituant, juste après le petit noyau nguni promement dit, l'avant-garde. Ngungunhana déplaça ensuite le centre de gravité de son État dans le sud (d'où le nom d'«Empire de Gaza») afin d'échapper à l'avancée de la colonisation luso-britannique, mais fut finalement vaincu par les Portugais et déporté aux Açores. Les esprits des nombreux soldats ndaus morts sans sépulture au cours des batailles sont pour cela même des esprits vengeurs très craints dans tout le sud du Mozambique. La Renamo, dont la direction militaire originelle est ndau, a pu être vue, au sud, comme leur envoyé.

${ }^{343}$ À l'indépendance, le Frelimo nationalisa les écoles et les services de santé privés et des Missions, tout en reconnaissant officiellement la liberté de culte. Mais évidemment, dans les Missions, l'école et l'église étaient nécessairement proches : la nationalisation des écoles, doublée de l'invocation interdisant l'activité d'une église trop proche d'une école afin de ne pouvoir l'influencer, servit donc en pratique à fermer un grand nombre de lieux de culte.

${ }^{344}$ Branche du congrégationnalisme américain, dont Uria Simango avait été l'un des principaux pasteurs.

${ }^{345}$ Il va sans dire que c'est toujours le padre Amadeu Marchiol qui s'exprime ici. Les Églises sionistes (ou zionistes) fondent effectivement une grande partie de leur pratique sur la «cure », qui soigne de tous les maux et maladies, signes du Malin. Cependant, ils mènent une guerre sans merci aux curandeiros traditionnels ou alors, cherchent à les gagner à leur cause. Il y a une farouche rivalité entre les courants protestants classiques, mêmes dissidents, et ces courants synchrétiques.

${ }^{346}$ Les cérémonies nhamussoros permettent de transmettre la parole des esprits, par l'intermédiaire de femmes habitées par un esprit tiers. Ces femmes, appelées en raccourci, elles-mêmes nhamussoros, peuvent donc aussi exorciser. 
À l'inverse des Vatsua qui doivent abandonner la maison à la mort de quelqu'un et qui n'accumulent pas, les Vandau de Mambone, à partir des années soixante, commencèrent à rester dans les mêmes maisons - seulement purifiées -, les mêmes champs, etc.

Ces Vandau de Mambone (à la différence de ceux de Chibabava ${ }^{347}$ ) sont très unis. Quand ils vont en Afrique du Sud ou en Rhodésie, ils ne vont pas dans les mines mais travaillent dans les fermes où ils constituent un personnel de confiance.

Le padre João Vespertini, italien et deuxième supérieur de la Mission, avait insulté le colonel portugais venu d'Inhambane réprimer le motim $^{348}$ de 1954 (ou 1955) à propos du ruralato $^{349}$ :

- Tira lá a bandeira portuguesa que vou por ali as minhas cuecas ! », « Enlève le drapeau portugais [du mat] que j'y mette mon slip ! » ${ }^{50}$. Il n'avait pas la langue dans sa poche.

La Mission avait été ouverte par Gabriel Cuaglia, le supérieur italien de l'Institut [de la Consolata] pour tout le Sud du Save, le 26 juin 1946. Le premier supérieur [de la Mission] vint du Niassa, João Tolosano, avec G. Cuaglia qui s'installa à Mapinhane. Ils ouvrirent aussi les installations de Massinga et Maïmelane, quatre établissements au départ.

Quand Tolosano fut transféré au Brésil quelques mois plus tard, il fut remplacé par Giuseppe Bottacin qui resta de la fin 1946 à 1950. Ce furent des années très difficiles, Bottacin était épuisé - il est aujourd'hui à Fátima, au Séminaire de la Consolata, toujours bien vivant. Puis vint João Vespertini, de 1950 à 1956, mal vu de l’Église [portugaise] et du Gouvernement mais dont tout le monde [i.e. : dans le microcosme colonial] avait peur. Le caractère italien, et non portugais, de la Mission, lui donnait évidemment une plus grande autonomie envers l'État dans sa relation avec la population indígena. Le régulo Genga ne l'aimait pas et refusait que les enfants aillent à l'école. Genga était très accroché au drapeau portugais et ne voulait pas de cet Italien. La communauté catholique restait petite. Son attitude en 1953 resta identique : si le régulo Chiteve participa aux événements, ni Genga, ni Matique, étrangers et donc plus arrimés au Portugal, n'y participèrent.

João Vespertini, parti en vacances, fut opportunément muté en Colombie (où il est mort).

Lui-même, padre Marchiol, arriva le 6 décembre 1956, avec un camion acheté à Maputo. Il y avait des Portugais : ceux de la MCT ${ }^{351}$, dont le chef José Marques da Silva (peut-être communiste, ou ancien communiste mais resté libéral ${ }^{352}$ ), et ceux de l'administration. Mais au début les commerçants étaient trois familles chinoises. Ensuite un ancien employé de la MCT, Albano Nunes, devint aussi commerçant; puis deux métis, João Lisboa Abrantes, un contestataire, et Cesarilo ; et deux ou trois Indiens, Cassamo Cara, musulman et Portugal [sic], hindouiste.

${ }^{347}$ District originaire d'A. Dhlakama.

${ }^{348}$ Motim, émeute, mais en pratique, sous la colonisation, toute manifestation, même tout à fait pacifique, non autorisée.

${ }^{349}$ Après la répression des motins de 1953, l'administration avait engagé de vigoureux plans de développement, notamment un ruralato, espèce de remembrement modernisateur impliquant évidemment des remises en cause de droits sur la terre et les pâtures (ne pas confondre avec les colonatos, qui impliquaient prioritairement des colons blancs venus de métropole). Cf. M. CAHEN, Les "mutineries" de la Machanga et de Mambone (1953)..., op. cit.

${ }^{350}$ Au-delà de l'anecdote, cela permet de souligner une contradiction : si le rôle officiel de l'Église catholique était de christianiser les indigènes, il était tout autant de les portugaliser ; or la pratique d'une partie du clergé de base fut souvent autre, notammnt quand il s'agissait de prêtres non portugais - christianisation oui, portugalisation, non. Or la proportion de ceux-ci atteint jusqu'à 53\% au début des années cinquante. Voir mon article «L'État Nouveau et la diversification religieuse au Mozambique, 1930-1974. I. Le résistible essor de la portugalisation catholique (1930-1961). II. La portugalisation desespérée (1959-1974)», Cahiers d'études africaines (Paris, École des hautes études en sciences sociales), XL (2),158, juin 2000 : 309-349, rés. fr. et angl. p. 349, et XL (3),159, septembre 2000 : 551-592, rés. fr. et angl. p. 592.

${ }^{351}$ Missão de combate às tripanosomiases, Mission de combat aux Trypanosomiases (maladie du sommeil).

${ }^{352}$ Note en marge du carnet : «à vérifier». Quoi qu'il en soit sur le «communisme » de José Marques da Silva, le rapport qu'il publia par la suite dans les Anais de medicina tropical (Annales de médecine tropicale) de Lisbonne contient, noyées dans une tonalité médicale apte à écarter la censure, une analyse sociale de la région des plus intéressantes. Cf. M. CAHEN, Les "mutineries"..., op. cit. 
Il y avait un médecin et un infirmier, venus respectivement du Portugal et de Macao, un cabo do mar $^{353}$, un mécaninien, l'administrateur et le secrétaire. Avec les cinq ou six familles de la MCT, telle était la communauté portugaise de Mambone. Certains de la MCT vivaient dans leurs campements de chasse ${ }^{354}$.

Mais dans les années quarante, il n'y avait que Xavier, l'administrateur, et le chasseur Lourenço Lopes Bulha qui a laissé une descendance métisse après s'être cafrealizado $^{355}$.

La Companhia de Búzi ${ }^{356}$ avait une plantation de canne à sucre qui allait de l'ouest de Maave jusqu'à Mataúla (près de la Mission) et, à partir de la Mission, continuait encore sur trois kilomètres en direction de Mambone. Lors de l'attribution de cette concession, tout le monde fut expulsé, ou réintégré comme travailleur. Les gens s'entassèrent alors plus à l'est ${ }^{357}$, à tel point que la Mission eut du mal au début à trouver une terre. Un petit chemin de $\mathrm{fer}^{358^{\circ}}$ allait de Maave à la côte en face de Bartolomeu Dias.

La plantation cessa de fonctionner au début de la Deuxième Guerre mondiale, le responsable local et le matériel étant allemands. La cheminée du four, qui, seule, demeura, fut détruite en 1966 pour en récupérer les briques au profit de la Mission.

Mais comme la Compagnie y avait mis des bêtes sélectionnées, les gens ne purent récupérer les terres. Pourtant, ce bétail attrapa la tuberculose et l'exploitation du terrain fut totalement abandonnée vers 1954-1956, dès lors ouvert à l'expansion de la mouche tsé-tsé. La MCT voulut alors créer un ruralato - base d'une occupation saine des terres -, mais au sud de la concession de la Búzi car elle voulait édifier pour elle-même sa « Búzi » [son exploitationmodèle]. Les femmes de Mambone, anciennement expulsées par la Búzi, furent appelées, en 1954 ou 1955, à aller y occuper des lopins, par l'administrateur Chambino et le médecin Marques da Silva. La réunion (banja) eut lieu au régulo Genga (entre la Mission et Mambone). Les femmes - les hommes, déjà réprimés en 1953, ne vinrent pas - se présentèrent avec leurs houes et se mirent à crier en voulant attaquer Marques da Silva : "Queremos as nossas terras!», « Nous voulons nos terres!». Les cipayes intervinrent et permirent l'évacuation de Marques da Silva et de sa voiture, hors du lieu ${ }^{359}$. Une semaine

${ }^{353}$ Équivalent local et modeste du capitaine du port - le port consistant en l'accostage de rares barges le long du fleuve, sans aucun équipement.

${ }^{354}$ La première mesure contre la glossine était toujours l'abattage du gibier, vecteur naturel de la mouche.

${ }^{355}$ Cafrealizado, «câfréalisé », devenu «câfre », c'est-à-dire africanisé ou indigénisé, au sens péjoratif (colonial) de ces mots. Même si les «broussards » eurent une large place dans l'idéologie coloniale portugaise, en réalité, les rares Portugais qui vivaient en brousse avec une (ou des) femme(s) africaine(s), en reconnaissant parfois les enfants, étaient tout à fait méprisés par ceux venus de métropole. Tout à la fin de la période, l'armée et les services de renseignement cherchèrent à s'en servir et, alors, les exaltèrent. Éthymologiquement, câfre vient de l'arabo-swahili kaffir, l'infidèle (et par extension les Noirs de la côte de l'océan Indien).

${ }^{356} \mathrm{La}$ Compagnie du Búzi était une des principales compagnies de plantations coloniales. Cependant, à la différence de la Compagnie du Mozambique sur les terres de laquelle elle avait acquis ses concessions, elle n'avait pas de «charte » et n'était donc pas une «compagnie majestique » dotée de pouvoirs para-étatiques. La Compagnie du Mozambique, contrôlée par des capitaux principalement britanniques, fut un véritable État dans l'État, dotée d'une monnaie, d'une police, etc., jusqu'en 1942. La zone située au sud du fleuve Save et une large bande à la frontière de la Rhodésie (Mossurize, Espungaberra), qui aujourd'hui font partie des provinces d'Inhambane, voire de Gaza, au sud, faisaient partie du «Territoire de Manica e Sofala » attribué à la Compagnie du Mozambique. Mambone relevait donc de ce sous-pouvoir colonial situé à Beira, au nord, bien plus que de la plus proche vraie ville relevant de l'administration directe de l'État, à savoir Inhambane, des centaines de kilomètres au sud. Le territoire ethniquement ndau était, de ce fait, administrativement plus unifié qu'il ne fut par la suite, après 1942 et à l'Indépendance - aujourd'hui la zone d'extension de l'ethnie ndau dans son ensemble relève de trois provinces mozambicaines, Sofala, Manica et Inhambane, et de l'est du Zimbabwe.

${ }^{357}$ Donc plus près de l'océan.

358 Il s'agit des petites lignes Decauville (de $60 \mathrm{~cm}$ d'espacement) que les plantations installaient fréquemment.

${ }^{359}$ L'ironie de l'histoire est que ce motim ait éclaté contre la MCT dirigée par un médecin certainement acquis à l'opposition. Avec nos mots d'aujourd'hui, nous dirions que la conception purement technocratique du projet de développement de la MCT, ignorante des réalités sociales, lignagères et ethniques, provoqua la mobilisation hostile de la population en faveur de laquelle, pourtant, on établissait officiellement un projet modernisateur. Le Frelimo aura exactement le même genre de problème avec ses «villages communaux ». 
après, un contingent de deux cents soldats vint d'Inhambane, mais seulement en mission d'intimidation, sans répression [à la différence de 1953$]^{360}$.

La MCT abandonna alors l'enrôlement des Ndaus et alla chercher des VaTsua - seuls quelques Ndaus y allèrent -, en tout trois cents familles. (La guerre civile a pratiquement fait disparaître le ruralato, mais quelques personnes reviennent aujourd'hui sur les meilleures terres). Certains, puissamment aidés par la MCT, s'en tirèrent bien. Mais le départ de la MCT entraîna illico le déclin, la Junta de algodão ${ }^{361}$ et la Direction de l'Agriculture n'apportant pas de soutien équivalent.

Même du temps colonial, l'administrateur Chambino n'aimait guère la MCT. Celle-ci avait des crédits et ne dépendait pas de l'administration. Chambino essayait de faire un colonato $^{362}$. Après le motim [de 1953, ou celui de 1954 ?], le gouvernement obligea la Búzi à abandonner les terres en échange d'une forêt près de Chibabava (circonscription du Búzi). L'administration fit des parcelles de trois hectares non irriguées, mieux acceptées car les gens pouvaient occuper plus ou moins les portions correspondant à leurs anciens champs. Le colonato fonctionne toujours...

Quand vint l'administrateur Mário Rodrigues Praça, un de l'École coloniale - le premier à venir à Mambone avec le cours ${ }^{363}$-, le colonato progressa et la Mission y délimita aussi son terrain pour y élever des vaches à lait et y pratiquer l'agriculture irriguée. Ce terrain fonctionna comme une coopérative : ceux qui y travaillaient avaient le droit à la terre, chacun sa sous-parcelle, et une parcelle collective pour les dépenses communes. Cette règle acceptée, quiconque pouvait venir, mais la majorité était des catholiques - soixante familles avec parcelles, qui pouvaient bien sûr avoir des parcelles ailleurs dans le colonato. En 1975, le terrain et les moyens attenants furent nationalisés. La pompe, par manque d'entretien, fut emportée par le fleuve, le tracteur utilisé comme moyen de transport et le bulldozer emmené à Homoïne. La machamba colectiva dos obscurantistas (le «champ collectif des obscurantistes $\left.^{364} \gg\right)$ reste un souvenir quasi mythique parmi la population...

La majeure partie des gens de la zone de la Mission résidèrent vraiment au colonato. Les familles venues de Matique, Mambone, Matasse, eurent deux résidences, car elles ne voulaient pas abandonner la pêche. Les chars à bœufs se multiplièrent, avec des roues en bois dur d'Afrique du Sud, puis des pneus. Praça [l'administrateur] créa des puits avec pompe manuelle, des lavoirs et abreuvoirs, un centre de sélection de semences et de plants. Il distribua des milliers de plans de cocotiers, d'orangers, tangeriniers, caféiers et anacardiers (la MCT avait aussi planté beaucoup d'anacardiers, le long des routes). Mais cela heurta les croyances locales : si certains avaient des arbres et pas d'autres, les attaques en sorcelleries allaient survenir et la plupart des gens ne plantèrent pas. Seuls les bananiers, considérés plantes ordinaires, furent plantés. La coqueraie de la Mission catholique fut aussi suspectée : mais comme le Père mangeait les noix sans mourir, le doute s'installa. Cependant, les propres

\footnotetext{
${ }^{360}$ Note en marge du carnet: «Voir les archives de la Consolata à Rome, les diários (journaux) des missionnaires y ont été recueillis ».

361 Junte du coton, organisme para-étatique corporatif chargé de la sélection des semences et de la commercialisation du coton, notamment après la suppression du travail forcé en 1962.

${ }^{362}$ Il s'agit ici d'un colonato local, s'adressant aux Africains, à la différence du sens général de ce mot (voir note 38 supra). Le terme ruralato fut sans doute évité, simplement afin de bien montrer à la population la différence avec le projet précédent de la MCT.

363 L' «Escola colonial», puis «Escola superior colonial», ensuite «Instituto superior de estudos ultramarinos » et enfin «Instituto superior de ciências sociais e política ultramarina », fondée en 1903, devait en principe former tous les cadres de l'administration civile coloniale. En pratique, elle en fut loin, mais coexistèrent ainsi toujours, avec force rivalité corporative, les deux catégories : d'une part, les administrateurs ayant suivi le cours «de l'École» («da Escola»), à savoir les reinois (ceux du royaume, de métropole), diplômés et accédant directement au grade d'administrateur, mais peu connaisseurs du terrain ; d'autre part, les tarimbeiros (de la tarimba, couchette spartiate), souvent Blancs nés en Afrique, connaisseurs du terrain mais peu formés et devant gravir tous les échelons depuis l'aspirant, le chef de poste... Naturellement cette opposition ne fut pas systématique et certains da Escola eurent une excellente pratique de terrain pendant que certains tarimbeiros devinrent d'authentiques anthropologues.

${ }^{364}$ Obscurantistes : croyants, dans le discours politique du Frelimo de la phase radicale (1977-1988), en l'occurrence ici les catholiques.
} 
ouvriers de la coqueraie encouragés par le Père à emmener certaines noix de coco à la maison, refusèrent, car c'était des noix à planter :

- «Na minha casa não dá, não quero morrer», " Pas dans ma maison, je ne veux pas mourir ».

Un autre facteur nuisible à la production était (est) la libre circulation du bétail, qui mange tout. Au début seuls les régulos avaient du bétail, vaches et chèvres, et ainsi personne ne se plaignait, malgré les dégâts. C'est seulement en 1993 que l'administrateur a interdit la libre circulation sous peine de devoir imposer des dédommagements. Mais la peur des attaques en sorcellerie limite fortement cette réglementation : en pratique les dédommagements ne sont réclamés qu'aux métis et aux Indiens...

Quand Praça partit (en 1964 ou 1965), arriva Mário Baptista, assez libéral, anti-salazariste et qui resta ensuite [au Mozambique] sous le Frelimo quelques années. Baptista respectait les gens et les traditions. Le colonato fonctionnait bien. Quand il partit pour Inhambane, déjà en 1974, arriva un "colonialiste » administrateur (nom oublié), et un médecin encore plus colonialiste, le Senhor Oscar, qui voulaient mettre tout le monde dans la ligne portugaise. Ils entrèrent en conflit avec la Mission, dont l'hôpital vendait les médicaments alors que la loi prévoyait l'assistance médicale gratuite - mais elle n'existait pas ${ }^{365}$ ! Leur campagne de vaccinations ne marchait pas - les gens pensaient qu'il s'agissait de les stériliser [pour laisser la place aux Portugais]. Mais quand la Mission convoqua la population, une multitude de gens se présenta...

En 1974, quand l'administration lui proposa des armes - la peur de l'Angola 1961 s'était répandue -, il les refusa ${ }^{366}$.

En cette terre d'Uria Simango, les gens savaient donc bien ce dernier était au Frelimo. [Par ailleurs] António Hama Thai ${ }^{367}$ avait été élève de la Mission, puis avait travaillé à la serração (la scierie) à la Machanga, de l'autre côté du fleuve, puis, de là était parti à Beira et au Frelimo. Mais c'était peu et les gens, même en 1970, attendaient surtout Banda ${ }^{368}$. Le Frelimo était un mystère. Contre le gouvernement, les gens disaient : - «Há de vir Banda para $a q u i$ », «Il faut que Banda vienne par ici ». Même la «disparition » de Hama Thaï ne fut pas liée, dans l'esprit des gens, au Frelimo : on ne savait pas pourquoi il avait disparu.

Le Frelimo arriva depuis Beira, avec le Comandante Jeremias, à Mabote ; à Mambone, ce fut un Vitorino, un guérillero avec des marques de blessure sur toute la figure. Plusieurs banjas furent organisées. Après la sortie du dernier administrateur colonial, il y eut quelques mois avec seulement le secrétaire. Le premier administrateur du Frelimo, Senhor Dengo, vint du sud et ne parlait pas le cindau. Il respecta la Mission et ne mena pas, durant la période de

${ }^{365}$ Situation typique du torrent législatif de la colonisation portugaise tardive, qui décrétait moult mesures favorables aux Africains (sauf l'Indépendance), sans aucun moyen de les appliquer.

${ }^{366}$ En 1961 éclata dans le Nord de l'Angola la grande révolte menée par le FNLA (Front national de libération de l'Angola). Rapidement, non seulement les administrations furent attaquées, mais également la population civile blanche et métisse, femmes et enfants compris. Ces meurtres, souvent horribles, furent naturellement mis au compte de la sauvagerie indigène, en oubliant que la région avait vu, toute la décennie précédente, se multiplier les expropriations de terres africaines à l'occasion du boom du café, accumulant silencieusement la haine. C'est d'ailleurs pourquoi - mais l'administration coloniale fut plus discrète sur ce plan - les travailleurs forcés venus du Sud, ovimbundus pour la plupart, furent souvent aussi massacrés, tout Noirs qu'ils fussent, ressentis par les populations du Nord, en général Bacongo, comme partie prenante de l'économie caféière qui les avait expulsés. Au Mozambique, rien de tel ne s'était produit en 1964 quand commença la lutte armée du Frelimo, et, pour les principaux noyaux de population coloniale, la guerre restait loin dans le nord. Cependant dès 1970 le Frelimo avait ouvert le front de Manica e Sofala et, au début de 1974, la mort d'un fermier blanc lors de l'attaque de son exploitation avait provoqué de vifs incidents à Beira (la population blanche manifestant violemment contre l'armée incapable de la protéger - événement grave qui accéléra le passage de ladite armée à l'opposition). L'administration appela alors les colons à former ou financer eux-mêmes des milices locales, et à s'armer.

${ }^{367}$ Il rejoignit le Frelimo et devint chef d'état-major général de l'armée mozambicaine.

368 À savoir Hasting Kamuzu Banda, président (et dictateur) du Malawi. Banda avait des rêves d'annexion d'une partie du Mozambique, mais il s'agissait plutôt de la Zambézia et du sud du Niassa jusqu'à Nacala. L'ironie de l'histoire est qu'à ce moment, il collaborait ouvertement avec le pouvoir portugais. Mais le simple fait qu'un pays voisin - les autres étaient la Rhodésie et l'Afrique du Sud blanches - était dirigé par un Noir gardait sa puissance de séduction. 
transition, de lutte anti-religieuse. Cela commença à se gâter quand Samora devint président $^{369}$, mais l'administration de Dengo resta modérée. Cependant, c'est le Parti qui dominait, bien que, des gens nés à Mambone, seuls certains professeurs ${ }^{370}$ y aient participé. Tous les autres membres du Frelimo étaient vaTsua ou, en tout cas, du sud. Ils dominèrent totalement tous les postes à responsabilité dans l'administration. Même le directeur de la Direction de district à l'Éducation, José Julaï, qui avait été éduqué à la Mission mais été né à Mabote $^{371}$, devint le pire ennemi. Les gens se sentirent colonisés, incapables d'être dirigeants. Calamidades $^{372}$, Agriculture, Parti, furent toujours des gens de l'extérieur, s'organisant entre eux, au détriment de la population. La première fois qu'un administrateur ndau fut nommé à Mambone, ce fut Joaquim Meque en 1990, mais il était alcoolique et ne fit rien - il fut ensuite envoyé, à titre de punition, à Funhaloro ${ }^{373}$. Le deuxième fut António Domingos Mapure, meilleur, né à la Machanga, éduqué à la Mission et ouvert au dialogue. Mais les vaTsua du Frelimo sont contre lui.

Le 29 novembre 1989 eut lieu un incident grave. Le Frelimo recrutait les soldats par rusgas (râfles), car personne ne se présentait aux appels ordinaires annoncés par editais (affichettes officielles). Aussi cherchait-il les jeunes gens par surprise.

Le jour de l'OJM ${ }^{374}$, un dimanche, une levée de drapeau, près de l'Église de Mambone [pas celle de la Mission], réunit aussi les chrétiens venus pour la messe. Ensuite, ils furent emmenés au meeting. Les miliciens voulaient déjà agir. Mais à la fin du meeting, tout le monde se rendit à l'Eglise. Un groupe de jeunes célébraient la cérémonie des catéchumènes, pour baptêmes tardifs. Après la cérémonie, Farias vit les miliciens s'approcher pour entrer. Il leur dit - Amadeu était à Beira - que ce n'était pas ici qu'ils devraient recruter. Postés à la sortie, ils commencèrent à tirer en l'air. Les jeunes cherchèrent alors à sortir par les portes latérales et du fond. Quand un jeune chercha à s'enfuir, il fut abattu par le garde du corps de l'administrateur Dengo. Les femmes désarmèrent alors les miliciens et voulurent les tuer. Farias et les autres hommes adultes les calmèrent. Le blessé mourut sur le chemin de l'hôpital. Les autres jeunes s'enfuirent. Le garde du corps s'enfuit aussi, et n'a pas été puni. On sait qu'il est ailleurs.

Les recrutements continuèrent et, avec ou sans mort, souvent avec blessés (balle dans la jambe, etc.). Un jeune venu de Beira en 1991 voir sa mère fut tué aussi, par des miliciens ivres venus demander à boire. La mère n'a jamais obtenu justice.

Hama Thaï, à qui Amadeu avait transmis le rapport relatif au catéchumène - rapport également donné à tous les évêques - envoya deux enquêteurs qui conclurent que tout était normal $^{375}$. Mais à Mambone, tout le monde était révolté.

En 1977, le padre Marchiol alla, via le Botswana, à Salisbury en Rhodésie [pour raison religieuse]. Mais il y rencontra Orlando Cristina ${ }^{376}$, qui lui demanda sa collaboration pour le

${ }^{369}$ Le jour de l'Indépendance, le 25 juin 1975.

370 «Professeurs» en portugais (au Mozambique comme au Portugal), désigne l'ensemble du corps enseignant. Ici, il s'agit évidemment d'instituteurs, voire de simples moniteurs scolaires.

${ }^{371}$ Il était donc matsua.

372 Rappelons que les Calamidades (Calamités) désignent, dans le langage courant, le Département de combat aux calamités naturelles, à savoir l'organisme public chargé de distribuer les secours en cas de famine, qu'elles soient dues à la sècheresse ou à des crues, ou à la guerre. Le groupe tenant les Calamités locales était ainsi assuré d'être à la source des rares - et donc précieux - secours.

${ }^{373}$ Petit poste très isolé de l'intérieur des terres.

374 Organização da Juventude moçambicana, Organisation de la Jeunesse mozambicaine, structure d'encadrement du parti unique pour la jeunesse.

${ }^{375}$ Tout dépend de la «normalité » et les enquêteurs n'avaient pas nécessairement tort de leur point de vue : des jeunes gens refusant la guerre du Frelimo contre la Renamo et donc, ipso facto, le service militaire. Si la Renamo a évidemment recruté très souvent par rapt, le recrutement au SMO (Service militaire obligatoire) a lui aussi très souvent eu les aspects décrits ci-dessus (en ville, râfles à la sortie des cinémas, etc.).

${ }^{376}$ Premier secrétaire-général de la Renamo. Cristina était le prototype même de l'aventurier portugais broussard ayant fait du Mozambique sa terre d'adoption (il avait même, feignant une désertion, infiltré le Frelimo en 1965 et, à son retour, avait été arrêté par l'armée non tenue au courant de la manœuvre...). Ancien collaborateur de Jorge Jardim dans les services très spéciaux de ce dernier, il passa en Afrique du Sud à l'indépendance du Zimbabwe. Il y est mort assassiné dans des circonstances non éclaircies, mais probablement 
recrutement de jeunes Mozambicains. Naturellement, il refusa, répondant seulement que si un tel jeune lui demandait conseil, il pourrait lui indiquer le chemin. Ce fut son seul contact avec la Renamo, jusqu'aux attaques de la Mission.

[Suite de l'entretien le 4 novembre à 12h30.]

\section{Vendredi 4 novembre}

6h30. Je suis au bar de Madeira, qui m'y a donné rendez-vous à cette heure. Naturellement, il n'y est pas.

[Les fils de Madeira comprennent, mais ne parlent pas le cindau. Leurs parents leur ont toujours parlé portugais...].

8h. Il paraît que Francisco Madeira est allé chercher Alexandre Nova, de Matasse (à trois kilomètres à l'Est de Mambone). Le fils Madeira amène une bicyclette bleue de la Renamo, qui me sera prêtée pour mes déplacements. Il suffit de retrouver la personne qui a pris la pompe, pour regonfler les pneux complètement à plat.

Un char à bœufs passe, encore avec les vieilles roues en bois, type "Grand Treck», importées d'Afrique du Sud.

8h10. Le vélo a dix jours, mais la pédale est dévissée et le pneu arrière est en fait crevé. On répare.

Passe le camion du Majonejone ${ }^{377}$.

9h. Visite au $\operatorname{STAE}^{378}$. Copie du résultat des élections pour le Govuro ${ }^{379}$.

Élections présidentielles [résultats globaux]

Les candidats sont dans l'ordre du bulletin de vote

\begin{tabular}{|c|c|c|}
\hline Catégories & Suffrages & Pourcentages [**] \\
\hline Total recensés & {$[13593 *]$} & 100,00 \\
\hline Abstentions & 1070 & 7,87 \\
\hline Total votants & {$[12523 *]$} & 92,12 \\
\hline Votes nuls & 624 & 4,98 \\
\hline Votes blancs & 906 & 7,23 \\
\hline Votes exprimés & 10993 & $\begin{array}{r}87,78 \\
100,00\end{array}$ \\
\hline Maximo Dias & 166 & 1,51 \\
\hline Carlos Jeque & 47 & 0,44 \\
\hline Casimiro Nhamitambo & 57 & 0,52 \\
\hline Mário Machele & 42 & 0,38 \\
\hline Carlos Reis (lunettes) ${ }^{380}$ & 263 & 2,39 \\
\hline
\end{tabular}

liées aux tentatives de donner à la Renamo une direction politique plus autonome - ce qui pouvait déplaire tant aux services sud-africains qu'à certaines composantes de la communauté portugaise d'Afrique du Sud.

377 Majonejone (prononcer «Madjonidjoni ») : Ma- est la marque du singulier, et jonejone, à savoir «JohnJohn », est relatif à l'émigré mozambicain revenu d'Afrique du Sud (pays appelé en langage populaire « John ») avec quelque argent, dans ce cas investi dans l'achat d'un camion.

${ }^{378}$ STAE : secrétariat technique d'administration électorale. À la différence de la Commission nationale électorale chargée d'organiser politiquement et juridiquement les élections, et qui était paritaire et présidée par un indépendant, le STAE, chargé de la logistique, était entièrement contrôlé par le gouvernement.

${ }^{379}$ Le Govuro est le district, situé au nord de la province d'Inhambane, dans lequel est située Mambone et la « poche ethnique » ndau au sud du fleuve Save, minoritaire dans la population globale de ce district.

${ }^{380}$ J'ai porté sur mon carnet, en face des noms de ces candidats, la mention «lunettes », pour la raison suivante : pour ces premières élections pluralistes, le vote par erreur a été assez important. Il y avait douze candidats aux présidentielles, et quatorze partis aux législatives, dans un ordre différent sur les bulletins de vote. La photographie des candidats était un critère de reconnaissance important, mais pouvaient prêter à confusion. 
\begin{tabular}{lrr} 
Afonso Dhlakama & 4407 & 40,09 \\
Jacob Sibindy & 117 & 1,06 \\
Padimbe Kamati & 70 & 0,64 \\
Domingos Arouca & 90 & 0,82 \\
Vasco Momboya Alfazama & 341 & 3,10 \\
${\text { Wehia Monokacho Ripua(lunettes })^{69}}^{6}$ & 422 & 3,84 \\
Joaquim A. Chissano & 4974 & 45,25 \\
\hline
\end{tabular}

[* Calculés par moi.Le total des inscrits (recensés) ne figurait pas sur le registre recopié

** Pourcentages calculés de retour en France, le relevé du STAE local ne comportant que des valeurs absolues.]

Élections législatives [résultats globaux]

Les listes sont dans l'ordre du bulletin de vote

\begin{tabular}{lrr}
\hline Catégories & Suffrages & Pourcentages [**] \\
\hline Total recensés & {$\left[13583^{*}\right]$} & 100,00 \\
Abstentions & 1065 & 7,84 \\
Total votants & $12530\left[12518^{*}\right]$ & 92,16 \\
Votes nuls & 1094 & 100,00 \\
Votes blancs & 1157 & 8,74 \\
Votes exprimés & $10274\left[12267^{*}\right]$ & 9,24 \\
& & 82,02 \\
AP & 123 & 100,00 \\
Unamo & 47 & 1,20 \\
PT & 53 & 0,46 \\
Fumo-PCD & 116 & 0,52 \\
Frelimo & 3571 & 1,13 \\
Sol & 170 & 34,78 \\
Pimo & 127 & 1,66 \\
Renamo & 4781 & 1,24 \\
PRD & 122 & 46,57 \\
Pacode & 229 & 1,19 \\
Pademo & 95 & 2,23 \\
PPPM & 182 & 0,92 \\
PCN & 152 & 1,77 \\
UD (Frelimo) ${ }^{381}$ & 499 & 1,48 \\
\hline
\end{tabular}

Or, systématiquement, on remarqua que deux candats parfaitement inconnus dans certaines zones, Carlos Reis et Wehia Ripua, avaient néanmoins un nombre surprenant de voix : ils avaient des lunettes sur la photo, comme Afonso Dhlakama. La proximité du nom à côté des deux candidats les plus connus (Dhlakama et Chissano), a aussi engendré des «votes» par mauvais positionnement de l'empreinte digitale : ainsi Carlos Reis, déjà « lunetté », et Jacob Sibindy, de part et d'autre de Dhlakama, et Wehia Ripua, juste avant Chissano. Voir aussi note suivante.

${ }^{381} \mathrm{~J}$ 'ai porté sur mon carnet, en face du sigle UD, la mention « Frelimo », pour la raison suivante. L'União democrática, groupuscule totalement inconnu, eut un nombre surprenant de voix... C'est que le Frelimo avait donné la priorité aux élections présidentielles, et le message le plus martelé avait été, vu la position du nom de Joaquim Chissano tout en bas du bulletin, de « voter pour le dernier ». Mais aux législatives l'ordre n'était pas le même sur le bulletin, ce que ne remarqua pas une partie de l'electorat qui, désirant voter pour le Frelimo, le parti de Joaquim Chissano, vota pour le sigle situé en dernier. Ce groupuscule passa ainsi la barre des 5\% et eut une repésentation parlementaire, ce à quoi aucun autre petit parti ne parvint... Au Govuro, le Frelimo y perdit sa première place, passant en dessous du score de la Renamo. On pourra du reste constater, dans le tableau des résultats détaillés ci-après, que là où le Frelimo n'a pas de bons résultats, l'UD n'en a aucun, et que là où il est majoritaire, l'UD a des scores consistants. À l'échelle nationale, étant donné les circonstances, on peut se poser des questions sur la réalité des électorats de toutes les formations ayant eu moins de 5\% des voix. Il n'est pas absurde de penser que, le vote par erreur ayant certainement atteint $10 \%$ du total des suffrages, de telles 
[* Entre crochets, les valeurs recalculées par moi. les pourcentages (cf. ci-après), sont calculés en conséquence. ** calculés de retour en France, le relevé du STAE local ne comportant que des valeurs absolues.]

[Abréviations: AP : Aliança patriótica; Unamo : União nacional de Moçambique ; PT : Partido trabalhista ; Fumo-PCD : Frente unida de Moçambique-Partido da convergência democrática ; Frelimo : Frente de libertação de Moçambique; Sol: Social-democracia de Moçambique; Pimo: Partido independante de Moçambique ; Renamo : Resistência nacional de Moçambique ; PRD : Partido da renovaàão democrática ; Pacode : Partido de convergência democrática ; Pademo : Partido democrático de Moçambique ; PPPM : Partido dos problemas dos povos de Moçambique ; PCN : Partido da convenção nacional ; UD : União democrática]

Résultats détaillés du district

Bureaux de votes et prédominances ethniques

\begin{tabular}{lcc}
\hline Brigades et bureaux de vote & $\mathrm{n}^{\circ}$ officiel d'enregistrement & Prédominance(s) ethnique(s) \\
\hline Brigada da Sede/Mambone : & & vaNdau \\
- Bairro J. Machel/Escola EP1 & 5585 & vaNdau \\
- Bairro J. Machel/Garagem & 5586 & vaNdau \\
- Bairro J. Machel/EP1 & 5587 & vaNdau \\
- Sede/Veranda & $7176^{382}$ & vaNdau \\
\hline Brigada de Genga : & & vaNdau \\
- Genga & 5955 & \\
- Genga & 5956 & \\
- Brigada do colonato : & & vaNdau et minorité vaTsua \\
- Colonato & 5951 & vaNdau et minorité vaTsua \\
- Escola do colonato & 5952 & Équilibre vaTsua/vaNdau \\
\hline Brigada de Mahave : & & Équilibre vaTsua/vaNdau \\
- Mahave & 5579 & \\
- Mahave & 5580 & vaTsua \\
\hline Brigada de Pande & & vaTsua \\
- Escola primária 1 & 5732 & vaTsua \\
- Escola primária 2 & 5733 & vaTsua \\
- Escola primária 3 (Bartolomeu Dias) & 5734 & vaTsua \\
Brigada do Luido & 5582 & vaTsua \\
Brigada de Jofane & 5959 & vaTsua \\
Brigada de Machacame & 5776 & 5729 \\
Brigada do Save & &
\end{tabular}

Ceux de Bartolomeu Dias ont dû voter à Pande! Ils ont dû quitter l'île ${ }^{383}$ en bateau, puis marcher à pieds environ quarante kilomètres jusqu'à Pande. D'ailleurs, on peut constater que l'abstentionnisme y est nettement plus fort qu'ailleurs: aux présidentielles, 86 pour 530 votants, et 86 pour 529 aux législatives (il y a donc une erreur sur le total des votants).

Un jeune de la CNE :

- «Não sei se isto é democracia, tribalismo ou engano. Mas eu gostei deste povo, tudo foi calma, a gente andou a pé tudo na ordem. Perceberam que era importante ", «Je ne sais pas si c'est de la démocratie, du tribalisme, ou si je me trompe. Mais j'ai aimé ce peuple, tout a été calme, les gens ont fait le chemin à pieds. Ils ont compris que c'était important».

représentativités n'existent tout simplement pas. Voir aussi le $\S$ « Jeudi 10 novembre » du chapitre « Retour à la nation ».

${ }^{382}$ La rupture dans la numérotation officielle des bureaux de vote vient de ce que celui-ci a été créé après coup, par démembrement du précédent, au vu du trop grand nombre d'inscrits.

${ }^{383}$ Bartolomeu Dias était une mince presqu' ̂̂le délimitant une belle baie qui faillit devenir un grand port au début du $\mathrm{XX}^{\mathrm{e}}$ siècle, mais fut marginalisée par l'essor de Beira. Sans lutte contre les courants, la presqu'île est devenue île côtière, restant un petit port de pêche prospère. Elle est progressivement détruite par les courants marins. Il est probable qu'elle va complètement disparaitre. 
Mambone est remplie de gens avec les chemisettes Frelimo. Ça ne les a pas empêchés de voter Renamo.

[Voir tableau des résultats détaillés des élections présidentielles et législatives dans le district du Govuro à la fin de ce chapitre]

11h15. Paul, de passage ici, m'apprend la raison pour laquelle Bartolomeu Dias a été recensé avec Pande, obligeant les habitants à aller voter si loin : tout simplement, le président de la CNE à Inhambane était ivre et s'énervait des remarques de l'observateur du PNUD, et s'enferra en disant qu'il avait décidé, point final... Le bureaucrate alcoolique a obligé toute la population de l'île à un effort disproportionné, et empêché certains de voter.

11h30. Sur mon insistance, le fils Madeira est parti en vélo - mon vélo - chercher le fils d'Alexandre Novas, à Matasse, dont le père a dit qu'il passerait me voir. Quant à Madeirapère, il paraît qu'il est parti à la Machanga, sans rien dire - le chien ! Farias y est peut-être aussi. Bref, je perds mon temps. Mais qu'est-ce que le temps?

12h30. Mambone est naturellement copié, politiquement, sur Maputo. Il y a une place de l'OMM ${ }^{384}$, une place de l'OJM $^{385}$, une place des Héros mozambicains, une avenue Samora Machel. La maison de l'administrateur s'appelle le Palácio ${ }^{386}$.

Une partie des maisons en dur sont abandonnées. Sans toit, ni portes, ni fenêtres. Et là, ce n'est pas la guerre, la Renamo n'a rien détruit à Mambone.

[J'ai retranscrit ce 4 novembre certains éléments de l'entrevue précédente du père Marchiol.]

(Amadeu m'a aussi dit qu'en 1983, la moitié de la population mourrait de faim. Lui, pendant cinq ans, n'habitait plus à Mambone, replié sur Beira, mais il faisait des aller-retour. Lors de l'un d'eux, il trouva la population dans un état lamentable. Pas de commerce, aucun secours, des familles entières mouraient en silence à la maison :- "Sobre quatorze pessoas, talvez dez morriam, quatro sobreviviam », "Sur quatorze personnes, peut-être dix mouraient, quatre survivaient ». Un père hollandais de Beira - connu sous le nom portugais de João Mateus - fit demander des secours mais ils arrivèrent d'Europe seulement quatre ou cinq mois après.

Le Parti, lui, avait toujours des secours : - «É preciso ajudar os membros », «Il faut aider les membres ». Aussi, les «membres » avaient droit à deux sacs et les autres à deux litres seulement par famille et par semaine. C'était la différence entre le povo (le " peuple », c'est-à-dire le « peuple organisé et conscient », à savoir, le Frelimo) et la massa (la « masse » informe, sans organisation, les elementos da população, les « éléments de la population »).

Nomenklatura locale d'autant plus haïe qu'essentiellement ethnique ${ }^{387}$. Ce sont des choses qu'on n'oublie pas.

« Au début, la Renamo, pour les gens, c'était... Dieu! Un mythe! Les sauveurs! Après les attaques [des groupes du Sud, toujours plus dévastateurs que les groupes venant du Nord], la population fut découragée. Qui allait pouvoir la sauver? Cependant, le doute resta, la population disait: "Ce ne sont pas eux", et pensait que c'était un troisième groupe, inconu. Elle continua donc à soutenir. Je ne sais quel diable les avait possédés pour qu'ils fassent de telles destructions et barbaries ».

À Mambone proprement dit, il n’y a pas eu de barbaries cependant : des boutiques pillées, des rapts peu fréquents, la Mission attaquée.

384 OMM : Organização da mulher moçambicana, Organisation de la femme mozambicaine (liée au Frelimo).

${ }^{385}$ OJM : Organização da juventude moçambicana, Organisation de la jeunesse mozambicaine (liée au Frelimo).

${ }^{386}$ Le «Palácio », le Palais, à savoir, la résidence présidentielle à Maputo, ancien palais du gouverneur colonial...

${ }^{387}$ A savoir un « peuple » ethniquement tsua, pendant que la « masse » était ndau. 
Un groupe de miliciens Frelimo fit de son côté un massacre dans les environs (six ou sept femmes tuées à la catana ${ }^{388}$ ) pour les attribuer à la Renamo. Mais les gens savaient. Massacre aussi dans les environs de Mabote ${ }^{389}$, car l'armée disait que la population était Renamo puisqu'elle était restée dans une zone Renamo.

15h30, à Matasse. Entrevue avec Gimo Miguel Tomás, 63 ans, neveu de Sixpence Simango $^{390}$, avec Denis Matibe, 71 ans et avec Alexandre Nova, 57 ans, cousin maternel de Tomás.

Ils ont seulement entendu parler de Kamba Simango ${ }^{391}$. Bed Simango ${ }^{392}$ était mieux connu, car il était de Mambone. Mais il était parti étudier alors qu'il était jeune, et n'était jamais revenu. L'American Board avait éclaté 393 entre l'Igreja do Cristo, d'Uria Simango, [et les fidèles de] Sixpence Simango restant à l'American Board. L'Igreja do Cristo resta l'héritière locale de l'American Board mais, comme ils n'avaient pas de prêtres, ils en empruntaient aux méthodistes et aux baptistes. Le Núcleo n'était pas une Église, mais l'American Board [dont il était quand même issu], dirigé par Sixpence, se réunissait normalement à son siège. [La réalité était pluri-religieuse :] le frère de Nova était, par exemple catholique, et également membre du Núcleo. Ceux qui n'étaient pas à l'American Board acceptaient [la présence de celui-ci au sein du Núcleo].

En revanche, l'Igreja do Cristo « expulsa les Américains ». Les Portugais faisaient pression pour les chasser, disant que " a Igreja devia ser própria dos naturais, não dos Américanos », «l'Église devait être celle des Africains eux-mêmes, pas des Américains » ${ }^{394}$.

Gimo. $_{\text {- }}$ «n 1952, il plut beaucoup, avec une grande crue et la Machanga fut atteinte $^{395}$, les maisons et les champs furent inondés. Les gens n'avaient plus rien ».

Novas. - «L'administrateur envoya un télégamme à Beira. Les premiers colis, il les distribua, les seconds, il les cacha et les vendit et mit l'argent dans sa poche ».

Sixpence, à Beira, reçut une lettre de la Machanga et écrivit à Maputo au gouverneur général, qui transmit au gouverneur du district ${ }^{396}$ (ou l'inverse, ils ne savent plus).

«La population commença à réclamer, enfin, à murmurer. Mais le chef de poste avait ses amis, Francisco Junja et Inchimbane, deux commerçants africains ambulants de la Machanga. Ils étaient considérés presque assimilés ${ }^{397}$, parce qu'ils étaient ds proches de l'administrateur. Ils dénoncèrent les gens.

Le chef de poste envoya les cipayes arrêter Gimo Macanguisse, Niacha, Manuel Manjena et de nombreux autres, tous du Núcleo negrófilo.

Les gens allèrent réclamer le matin de bonne heure, toute la population (mais pas les régulos Chiteve et Maropanhe) se réunit devant la résidence de l'administrateur, avant même son réveil, avec des coupe-coupe et des pioches. Quand il se réveilla et se rendit au Poste, le Chef l'interrogea, et les gens dirent qu'ils voulaient qu'ils [les prisonniers]

${ }^{388}$ Catana : machette.

${ }^{389}$ Dans l'intérieur du district de Govuro, zone sèche et peu peuplée.

390 Ancien dirigeant de 1'Associação cristã evangélica (Association chrétienne évangélique, American Board of Foreign Missions).

${ }^{391}$ Fondateur du Núcleo negrófilo de Manica e Sofala et l'un des tout premiers Mozambicains à avoir fait des études supérieurs, avec l'aide de l'American Board of Missions, avec lequel il devait ensuite rompre. Voir aussi note 243.

${ }^{392}$ Bed Simango fut très longtemps professeur à la station scolaire congrégationnaliste de Gogoi et, à la différence de Kamba Simango, ne rompit jamais avec l'American Board.

${ }^{393}$ Il s'agit d'une coupure ultérieure à celle entre l'Associação cristã et le Núcleo negrófilo. Cependant, à la différence de cette première scission qui était non seulement religieuse, mais politico-sociale (le Núcleo étant devenu largement une association civile), l'Igreja do Cristo fut une semi-dissidence africaine d'une mission occidentale, et établit des liens avec d'autres branches protestantes, sans renier pour autant sa filiation « américaine » (congrégationnelle) et «suisse » (presbytérienne).

${ }^{394}$ Contrairement à ce que l'on pourrait penser, il y eut plusieurs cas où l'administration portugaise favorisa la création d'Églises purement africaines, en scission des missions blanches - quand bien sûr il ne s'agissait pas de missions catholiques portugaises. Il s'agissait, en «mozambicanisant» les communautés religieuses créées par les protestants étrangers, de les soustraire à l'influence étrangère et asinsi de les portugaliser,

${ }^{395}$ Mambone est sur un site un peu plus élevé, et souffre moins des crues du fleuve.

${ }^{396}$ Les districts coloniaux sont aujourd'hui les provinces.

${ }^{397}$ Rappel : les « assimilés » sont les Africains considérés comme «portugalisés » et faits citoyens. 
sortent. Francisco Junjo et Inchimbane demandèrent: "Mais enfin, que veulent ces personnes ?" Les gens commencèrent à crier et à les battre très dur, à démolir leurs bicyclettes. Le Chef du Poste administratif entra dans sa maison - les gens ne le suivirent pas - et il envoya un cipaye à Mambone dire qu'il y avait la guerre ici à Machanga. Mais il libéra les prisonniers. »

Après l'affaire de Mambone [cf. entrevue de G. Tivane infra], la troupe venue d'Inhambane alla aussi à la Machanga. Les soldats arrêtèrent Macanguisse, Nhumba et son fils Manuel Manjena, Júlio Magone, Madivase et d'autres, qui furent envoyés à Ibo ${ }^{398}$. Tomas Simango, le frère de Sixpence, de Mambone, fut aussi inclus dans les arrestations, [et envoyé] à Ibo, pour dix ans. Ils rejoignirent Sixpence, qui y fut professeur et y mourut. Tomas revint et mourut à Mambone en 1972.

Alexandre.- «Au temps du Núcleo, les gens parlaient déjà de l'indépendance, les gens parlaient de Kamba Simango ».

Gimo. - «Kamba Simango fut arrêté à Beira à son retour de l'Amérique, il alla en prison $»$.

Denis. - «Le gouvernement le menaça ».

Alexandre.- «Après, le Núcleo continua à exister, mais clandestinement ${ }^{399}$. Aujourd'hui encore, le siège existe, il y a une école à Espungaberra/Goto [aujourd'hui école de l'Etat]. Mais petit à petit, il s'arrêta. Quand le Frelimo entra, il y eut un groupe qui voulut recommencer: Afonso Henrique (il est mort 1985 ou 1986), Pedro Camacho (frère d'Alexandre Nova), Eduardo Nolongwe (il est mort), João Sixpence Simango (le fils de Sixpence, il est mort en 1992) et Daniel Tomas, frère de Gimo Miguel Tomas. Ils vivaient à Beira. Le Frelimo les empêcha, ils ne furent pas arrêtés, mais le Frelimo empêcha. C'était vraiment le souvenir du Núcleo, ils voulaient recommencer. »

[Comme je leur fais remarquer qu'exactement la même chose s'est passé à Maputo, quand le Centro associativo dos Negros, dirigé par Domingos Arouca, interdit en 1965, tenta de recommencer ses activités en 1974 et en fut empêché par le Frelimo, ils m'apprennent justement que] Domingos Arouca (qui est d'Inhambane) a été infirmier à Mambone, et secrétaire du «Ciclone de Mambone » ${ }^{400}$, en référence au vrai cyclone de 1948, puis est parti à Vilanculos et a repris ses études ${ }^{401}$.

Alexandre.- « Les gens qui ont été du Núcleo, aujourd'hui ils sont du côté de la Renamo. Ceux qui avaient une religion, avec le Frelimo, ils n'avaient pas de place. Il voulait en finir avec Matasse pour faire un village communal à Matique. Mais même Matique n'était pas d'accord ${ }^{42} \gg$.

Denis. - «D'ailleurs, ils n'avaient plus besoin de religion. Personne n'accepta. Cela s'est passé en 1976 : le champ collectif, la pêche collective. La Maison des pêcheurs était

398 Île de la côte du Cabo Delgado, dont l'ancienne forteresse servait de prison. Mais l'île servait aussi de lieu de déportation, les exilés pouvaint y vivre en semi-liberté, sans la quitter.

${ }^{399}$ Alexandre Nova confond ici visiblement les périodes, entre l'arrestation de Kamba, au début des années trente, et la répression du Núcleo en 1953-56. Pendant des années, le Núcleo fut une association parfaitement légale.

${ }^{400}$ C'est-à-dire le groupe de football local.

${ }^{401}$ Il devait devenir le premier avocat noir du Mozambique. Arrêté en 1965 pour appartenance au Frelimo, il fut emprisonné huit ans au Portugal - maintenant le contact avec les nationalistes grâce à un gardien de prison membre du Parti communiste - puis mis en résidence surveillée au Mozambique. Jorge Jardim, qui le savait non marxiste, tenta de le récupérer, l'imaginant en président noir modéré d'un Mozambique multiracial où la communauté blanche aurait gardé son pouvoir économique. Il rouvrit brièvement le Centro associativo en 1974, avant que le Frelimo ne l'interdise. D. Arouca entra rapidement dans l'opposition et créa, à Lisbonne, le Fumo, qu'il rêva de temps à autre de transformer en une branche civile de la Renamo - ce que cette dernière lui refusa toujours. Il faillit être tué dans un attentat (sa voiture avait été piégée) attribué aux services secrets du Frelimo. De retour d'un long exil et candidat aux présidentielles de 1994, il obtint de piètres résultats, malgré l'estime que certains continuent à porter au Doutor.

${ }^{402}$ C'est-à-dire que le Frelimo voulait concentrer les populations de Matasse et de Matique sur les terres de Matique. Ce genre de projet posait des problèmes agronomiques (épuisement rapide des terres autour du village, en l'absence d'engrais) et politico-culturels, la population déplacée sur une terre qui n'était pas celle de ses ancêtres et des esprits, tombant dans la dépendance de la population du lieu. 
une association, mais chacun pêchait pour son compte $e^{403}$. Elle avait été créée en 1954, à l'intiative du Mkuchwani ${ }^{404}$, et ensuite du Chambica ${ }^{405}$. C'était de la commercialisation collective. Joaquim Alves et Albanao ${ }^{406}$ recevaient le poisson de la Maison. La Maison s'occupait des dépenses communes. Le Frelimo ne s'en occupa pas, il voulait la pêche collective. Aujourd'hui, il n'y a plus que le réfrigérateur, mais c'est un bandit du Frelimo qui l'a et ne paye même pas son loyer ».

Gimo. - «Il y avait de l'argent qui venait d'Afrique du Sud pour le Núcleo ${ }^{407}$. Et il y avait un Portugais, João António Paulo, qui avait deux terrains, 23 hectares à Matasse et 200 ha à Lunde-Matique. Un jour, un bœuf est passé sur le champ de 23 ha et João Paulo a tué le bœuf. Le peuple était fâché et alla se plaindre au Caneco ${ }^{408}$. L'administrateur appela le Senhor Paulo devant le peuple. Celui-ci dit que si le peuple avait l'argent pour lui payer son terrain, il s'en irait. Le peuple dit : «C'est combien ? », il dit 80 contos, à l'époque, c'était de l'argent. Le peuple dit : «On va payer». Au bout de deux semaines, le peuple paya, ils durent vendre du bétail, des chèvres, pour réunir cet argent. Les gens se partagèrent le terrain, qui est resté cultivé jusqu'à aujourd'hui. João Paulo partit pour Beira mais n'eut pas de chance, il y mourut».

Denis.- « En 1954, le gouverneur et l'archevêque vinrent, après les bruits qu'il y avait la guerre à la Machanga et à Mambone. Matique fut arrêté avec Gabriel Tivane, emmenés à Lourenço Marques.

Matique était régulo pour les Portugais et Matibe, grand-père de l'actuel, était chef traditionnel, ensuite ça été Gimo Matibe, père de Denis Matibe ${ }^{409}$. Denis Matibe, Genga, Silas Tunzine (un auxiliaire du régulo), et Frank Chovane furent emmenés visiter le colonato du Limpopo par [l'administrateur] Landerset Simões, afin d'inciter à faire le colonato et le ruralato. Les gens eurent deux maisons, une à Matasse, l'autre au colonato 410 .

Quand il y eut le premier Séminaire national d'Agriculture à Marrupa ${ }^{411}$, des personnes de Mambone y allèrent. Samora Machel parlait des villages communaux. Dans les réunions, je me suis levé et j'ai demandé :

- Aquele que tem uma boa casa tem que sair para a aldeia comunal ?, "Celui qui a une bonne maison doit en sortir et aller au village communal ? »,

- Sim, senhor, porque aquele que não sai não tem direito à escola da aldeia comunal para os seus filhos, na loja não pode comprar, no hospital não pode ir, "Oui bien sûr, parce que celui qui ne quitte pas sa maison n'a pas droit à l'école du village communal pour ses enfants, à la boutique pour acheter, il ne peut pas aller à l'hopital ».

Je suis resté silencieux, le cœur battant, et j'ai commencé à réfléchir.

${ }^{403}$ La Maison des pêcheurs avait été créée avec l'aide de l'autorité coloniale après les événements de 1953, dans la foulée des plans de « développement communautaire » de l'époque.

${ }^{404}$ Mkuchwani, « Celui qui tousse », surnom donné à Landerset Simões, l'administrateur portugais.

${ }^{405}$ Chambica, surnom donné à Chambino, qui succéda à L. Simões.

${ }^{406}$ Deux importants commerçants portugais du Govuro.

${ }^{407}$ Le Núcleo avait une section en Afrique du Sud, formée par des émigrés. L'administration portugaise s'acharna à détruire cette section, située à l'étranger, lorsque le Núcleo fut interdit au Mozambique en 19531956.

${ }^{408}$ « Caneco », le Goanais, surnom donné à l’administrateur António de Jesus Colaço (années quarante).

409 Il y avait une pratique fréquente dans la population africaine, celle des «doubles chefferies». Les Portugais reconnaissait un régulo, et la population, en leur présence, faisait comme si c'était le vrai chef. En réalité, le vrai chef traditionnel, chef de terre et chef religieux, restait dans l'ombre et les Portugais n'avaient parfois même pas connaissance de son existence. Mais le chef officiel, qui subissait donc toutes les humiliations coloniales, ne pouvait rien faire sans l'accord du chef de l'ombre. Il arriva cependant, et de manière de plus en plus fréquente, que les Portugais fassent très attention aux lignages traditionnels et investissent le véritable chef.

${ }^{410}$ Il se produisit exactement la même chose avec les villages communaux du Frelimo. Contraints de s'installer auprès du village officiel, les familles n'en gardèrent pas moins leur maison sur la terre traditionnelle.

${ }^{411}$ Il s'agit de la réunion au cours de laquelle le nouveau régime du Frelimo lança la politique de regroupement forcé dans les villages comunaux (aldeias comunais). Marrupa est une localité isolée du Niassa, dans l'extrême nord. Ce lieu ne fut pas choisi au hasard, le Niassa représentant, dans la geste développementaliste du nouveau pouvoir, le symbole de la colonisation interne, de la frontière, des grands plans (jamais appliqués), comme s'il s'agissait d'une terre vierge sans population locale et dont on pouvait disposer par décret. C'est au Niassa que l'Opération-production, en 1983, envoya des milliers de déportés râflés en ville en tant qu' «improductifs », dont une partie mourut de faim (voir la note 9 du chapitre « Niassa »). Aujourd'hui, la Mosagrius y a acquis des droits pour y installer des fermes de Boers sud-africains qui supportent mal la fin de l'apartheid. 
Alexandre.- En 1976, moi, Farias, Arturo Dique (il est mort), nous avons eu une corrspondance avec le cousin de Farias qui avait fui de Maputo en Afrique du Sud, et ensuite au Portugal. Il était de la Renamo. Nous avons toujours continé à correspondre. Mais des contacts avec les zones de la Renamo, ça non, il n'y en a pas eu.

À Mambone, le Frelimo aussi était très présent. La Renamo a attaqué la caserne, mais n'est jamais arrivée jusqu'à Matasse. La Renamo a rapté pour les portages. Les gens se sont fâchés, mais ensuite la Renamo a expliqué. Le Frelimo attrappait les garçons, même les filles, pour l'entraînement [militaire]. Le fils de Denis est mort au combat dans les rangs des FPLM ${ }^{412}$ après avoir été rapté à l'école, les livres à la main, sans avoir pu même dire au revoir à ses parents.

Ici, la Renamo n'a pas rapté, mais à Maave, elle a enlevé un garçon de Matasse, un Ndau, Brito, qui y faisait son champ. Quand il a vu les Matsangas ${ }^{413}$, il a voulu fuir, mais ils l'ont attrapé et emmené. Jusqu'à aujourd'hui, il n'est pas revenu.

Mambone est une des zones les plus oubliées. Il n'y a pas assez de places [à l'école], ils vont à Inhambane après la $7^{\mathrm{e}}$ classe, mais après la $9^{\mathrm{e}}$ classe, il n'y a plus de places. Pour Beira, c'est diffile, parce que nous sommes [de la province] d'Inhambane. Jadis, au temps de la Compagnie du Mozambique, ce n'était pas comme ça, nous étions du côté de Sofala, il y avait le commerce, tout ${ }^{414}$. Nous avons besoin d'une école jusqu'à la $1 \mathrm{Oe}$ classe, avec la $10^{\mathrm{e}}$ classe, après on se débrouille. L'université, c'est seulement pour les gens du Sud. Nous en avons assez, ça fait dix-neuf ans que ça dure ».

20h30, suite de l'entretien avec Francisco Madeira [suite du 3 novembre à 8h30].

À Manga (quartier à sept kilomètres de Beira), il y avait aussi une implantation de la Renamo, mais pas de cellule, seulement des réunions à deux. Il y avait toutefois des estafettes qui venaient une ou deux fois par mois, et à la fin, plus souvent. Les estafettes allaient toujours chez Ndachata. Il ne fut jamais découvert. Il y avait aussi Bavá, un commerçant noir musulman. En 1983, F. Madeira arrive à Mambone. Les affaires n'allaient pas très bien. Son fils, à ce moment-là, étudiait au Swaziland, il faisait déjà la $10^{\mathrm{e}}$ classe, avec une bourse du gouvernement [swazi]. À Mambone, en octobre, il y avait une famine terrible. Les jeunes tombaient [d'anémie], même au bourg et surtout autour. Il allait chercher la farine, le riz, le sucre et le thé par la gasolina ${ }^{415}$, et faisait des repas bon marché. Le restaurant était plein, dix tables, il y avait la guerre à deux cents mètres, même l'administration venait manger, les familles depuis Beira et Maputo envoyaient l'argent. Ce fut le seul restaurant. Il avait des contacts personnels, à Beira, pour trouver où acheter. Cela dura jusqu'en juillet 1984. La Mission distribuait aussi des secours de la Caritas. L'administrateur, Lourenço, de Massinga, ne fit rien, seulement attendre les Calamités ${ }^{416}$, qui étaient distribuées surtout aux membres [du Frelimo]. Même l'armée venait manger.

En 1988-90, la guerre s'intensifia beaucoup. En 1983, le magasin du China ${ }^{417}$ fut incendié par la Renamo car il avait des photos de Samora. Une autre boutique fut atteinte par une roquette de l'armée, tirée depuis la Machanga ${ }^{418}$.

La population se cachait la nuit. Lui-même et le délégue [de la Renamo] faisaient de même pour ne pas attirer l'attention, mais expliquaient que la Renamo venait pour attaquer l'armée.

Le 25 avril 1990, la Renamo vint la nuit et occupa le cimetière. Ils s'assirent et firent une cérémonie traditionnelle pour que les esprits de la zone soient favorables. Le commandant luimême officiait. Puis ils vinrent frapper aux portes des maisons demander des personnes pour

${ }^{412}$ FPLM, Forces populaires de libération du Mozambique, armée du Frelimo.

${ }^{413}$ Rappel : Matasangas, ou Matsangaissas, désignation des guérilleros de la Renamo.

${ }^{414}$ Avant la réintégration du territoire de la Companhia de Moçambique dans l'administration étatique, la marge sud du fleuve Save, qui en faisait partie, relevait donc de la ville de Beira, bien plus proche, au nord, que celle d'Inhambane, très loin au sud. Le Frelimo a ensuite maintenu le fleuve Save comme « frontière naturelle » entre le sud et le centre du Mozambique, au mépris des réalités ethniques locales.

${ }^{415} \mathrm{La}$ «gasolina » est, depuis l'époque coloniale, le nom donné par les gens de Mambone et de la Machanga au petit bateau à moteur qui fait la liaison entre l'estuaire du Save et la ville de Beira.

${ }^{416}$ Voir note 61.

${ }^{417}$ Du nord au sud du Mozambique, l'appellation «China» peut désigner un commerçant chinois, mais également indien. À Mambone, il s'agissait effectivement d'un Chinois.

${ }^{418}$ La guerre civile mozambicaine, extrêmement meurtrière pour les civils, a cependant rarement été une guerre d'engagements directs et encore moins de corps à corps. La scène ici décrite est très classique : la Renamo a attaqué Mambone (au sud du fleuve Save) et l'armée du Frelimo, sans se déplacer, tire quelques roquettes sur la bourgade, depuis la Machanga, au nord du fleuve... 
porter ce qui avait été volé à la boutique du Mussa Caro, l'indien musulman, qui était Frelimo (aujourd'hui, il est Renamo). Sa boutique à lui [i.e. Madeira] a eu quelques pains volés, c'est tout. Les personnes qui chargeaient les marchandises étaient renvoyées chez elles. Mais les jeunes étaient appelés à rester :

«C'est pas vraiment qu'ils ont été raptés. Ils [les gens de la Renamo] ont expliqué et sont allés parler aux familles. Bon, mais ils sont partis. Quand le Frelimo est revenu, il a tout nettoyé, tout, dans les boutiques. Ensuite, ils ont dit que c'était la Renamo. La population se réfugiait à Matique. La Renamo ne s'intéressait pas à Matique, ils voulaient la confrontation avec les militaires. Quand ils entraient, ils tiraient en l'air ».

Je lui dis qu'à Inhassoro, la Renamo a tué beaucoup de gens sur la plage. Il hoche la tête :

« J'ai été à Inhassoro, je savais que la population se réfugiait sur la plage, mais ça, tuer les gens, c'est le Frelimo qui donne cette information.

En 1991, ils sont revenus, la Renamo a pénétré juste pour se montrer. Personne ne dormait ici! Quand la population partait dans ses cabanes [refuges en brousse] de Matasse, Matique et des berges du fleuves, elle y trouvait déjà les soldats de l'armée [i.e. du Frelimo] dans ses cachettes.

Ça a été comme ça jusqu'au 4 octobre ${ }^{419}$. Tout de suite, nous nous sommes réunis chez Inocêncio Faria, avec Chico Maave et quelques autres. Ensuite, on a fait des réunions dehors. Le siège [de la Renamo] fut ouvert, avec le drapeau, en avril 1994. Á Inhassoro, aujourd'hui encore, il n'y a pas de siège. Nous avons fait de la mobilisation, des réunions avec la population au régulo Matique, au chef Matasse, au chef Massaruge, chef M'Sassa, chef Nasso, chef Batata, régulo Genga, chef Magurure, chef Chicoreque, chef Mataúla, chef Mucumbudje, chef Maave, chef Maluane, chef Pande (la réunion y a été petite), chef Chindautane (près de Maluane), chef Muchacane, chef Save (presque personne), Luido (une grande réunion) $)^{420}$.

Les VaTsua misent très fort sur Chissano président toujours, à vie, comme Banda ${ }^{421}$, ils sont très tribalistes. La Renamo n'est pas tribaliste, la Zambèzie, Tete, ne sont pas ndau, Dhlakama est national. Le $1^{\text {er }}$ juillet 1994 est arrivée ici la première brigade provincial de la Renamo, avec le délégué provinciale, Pires. J'ai demandé à faire une photographie, mais Pinto a aussi photographié le marché, où il y avait six soldats. Ceux-là ont confisqué l'appareil et m'ont battu jusqu'à l'évanouissement. La police n'a pas voulu recevoir ma plainte. L'Onumoz non plus, ils ont dressé un procès-verbal et mais tout est resté pareil. Donc, ça va empirer demain.

Aujourd'hui ils ont été démobilisés, ils ne sont pas d'ici, Mais personne n'est rentré chez soi, ils sont restés ici. Je suppose qu'ils ont gardé leurs armes à la maison. La police aussi, elle a un peu d'armes.

Le président de la CNE de Mambone, qui est Frelimo, est allé chercher, comme délégué de liste [de la Renamo], une personne de Pande, qui est de la Renamo mais en qui nous n'avons pas confiance. La délégation n'a pas été d'accord, mais la CNE ne l'a pas changée. À Pande, c'est l'administrateur qui a été le président du bureau de vote, ce qui n'est pas admissible.

Il n'y a pas eu d'enquête sur la mort de notre délégué de liste du colonato, tué par un débile mental, qui a aussi blessé son propre fils, qui a la carte du Frelimo. Il est resté là sans être arrêté. Il est fou, mais il va tuer d'autres gens, il a déjà blessé son fils. Il est chez lui, à Matasse. L'hopital devrait s'en coccuper. Ou alors, comme dans la tradition, il faut l'amarrer à un tronc, pour l'empêcher de marcher ».

(On coupe un gros rondin et on y met une chaine reliée au pied du dément qui peut ainsi bouger, mais pas se déplacer).

\section{Le 5 novembre 1994}

8h45. Entrevue avec Gabriel Castigo Tivane.

Il est né à Metinha, après Matique, presque sur la mer, le 22 avril 1929. Son père était le cuisinier de l'administrateur, sa mère restant à la maison. Il alla à l'école de Metinha [qui dépendait] de la mission Nossa Senhora do Rosário da Cidade da Beira, puis à la Machanga où son oncle Jorge Baptista Mutapate était professeur [i.e. moniteur scolaire, instituteur auxiliaire].

${ }^{419} 4$ octobre 1992, date de signature de l'Accord général de paix, à Rome.

${ }^{420}$ On voit nettement se dessiner ici l'implantation ethnique de la Renamo dans la zone : les réunions sont ratées là où la population, majoritairement, n'est pas ndau.

${ }^{421}$ Hastings Kamuzu Banda, président-à-vie du Malawi depuis 1965, la «vie » ayant quand même fini par être écourtée lors des élections libres du début des années 1990, qu'il perdit. 
«À cette époque, Machanga n'était même pas un poste, c'était seulement le régulo Chiteve. Dans les années trente (1931 ?), il y eut une modification de l'impôt de paillotte qui passa de 155 à 200 escudos, décidée par le gouvernement du Territoire de Manica e Sofala ${ }^{422}$. A Beira, il y eut des désordres : ils [les manifestants] allèrent voir l'Intendant qui représentait le gouvernement portugais. Comment est-ce qu'on va pouvoir payer ? À Beira, ils envoyèrent les cipayes pour frapper les gens, sans savoir qu'ici à Mambone les gens faisaient de même. Les gens ont même renversé la voiture de l'administrateur, celle aux roues de bicyclettes, de ces modèles anciens. Les douze cipayes ne purent rien faire. Le gouvernement du Territoire rabaissa les impôts (c'était le contre-amiral José de Magalhães Correia).Ça ne bougea plus jusqu'en 1942. Ce fut la population - les régulos avaint peur - à Mambone, mais aussi avec des gens de Machanga ${ }^{223}$.

L'administrateur, c'était « Champador », ca veut dire « Ne leur donnez pas à boire », il était contre l'alcoolisme, pas de nipa ${ }^{424}$, pas de surra ${ }^{425}$. Mais le Gouverneur du Territoire, J. Malgalhães Correia, envoya son propre chef de cabinet, José da Costa Xavier, comme administrateur de la circonscription du Govuro à Nova Mambone ${ }^{426}$.

(« Nova Mambone », c'est parce que, quand les Portugais sont arrivés ici par la mer, il y avait un petit port du côté de Metulha ${ }^{427}$. On trouve encore des morceaux de faïence là où ils mangeaient. Les gens d'ici leur disaient que ce n'étaient pas eux les chefs, c'est-àdire : - "Mambo, ne », "Vous n'êtes pas chefs » ${ }^{428}$. les Portugais pensaient que c'était le nom du lieu, et quand ils ont construit le poste, ils l'ont appelé Nova Mambone).

Après quelques années, en 1938, Xavier est parti en vacances au Portugal. Le secrétaire Chovane est resté comme substitut. Cette année-là, il y a eu beaucoup à manger, il a bien plu. Les gens disaient que le substitut avait la bonne étoile.

(La production de canne à sucre de la Búzi s'est arrêtée en 1935-36 [il y a ici contradiction de date avec ce que dit le père Marchiol] parce que la terre était salée. Le chemin de fer de la fabrique fut démantelé et emmené par le bateau «Féfé », de la compagnie du Búzi, au siège de la compagnie [on voit encore à l'entrée de Mambone un vieux rail qui sert de balustrade] $)^{429}$.

Quand Xavier revint après deux ans de congé, il reprit ses fonctions jusqu'en juillet 1942 , date du passage à l'État ${ }^{430}$. Le nouvel administrateur fut Joaquim António de Jesus Colaço, qui était secrétaire de Chemba ${ }^{431}$. Il resta jusqu'en 1951. C'était un caneco (un

${ }^{422}$ C'est-à-dire le gouvernement privé de la Compagnie du Mozambique (compagnie à charte).

${ }^{423}$ Les deux localités relevaient, alors, de la même administration. Dès le début de l'entrevue, Gabriel Castigo Tivane devait m'impressionner avec son invraisemblable mémoire et sa culture politique et historique : l'incident dont il parle ici a eu lieu en 1932, à Beira. La Compagnie du Mozambique, pour renflouer ses pertes dues à la baisse des cours mondiaux suite à la crise de 1929, n'avait rien trouvé de mieux que d'augmenter l'impôt indigène, alors même que le chômage sévissait, ce qui ôtait aux indigènes les moyens d'obtenir l'argent nécessaire à l'impôt, et que de surcroît, classiquement, le chômage avait entraîné la baisse des salaires déjà misérables. Une très importante foule d'Africains, dont nombre étaient originaires de Machanga et Mambone, organisèrent (possiblement à l'initiative de membres des missions congrégationnalistes) une manifestation qui traversa toute la ville et se dirigea non point vers le gouvernement de la Compagnie du Mozambique, mais vers le siège de l'Intendance (espèce d'ambassade du gouvernement portugais dans le territoire donné en charte à la Compagnie), afin de demander son aide. S'il y a des documents dans les Archives sur la manifestation de Beira, en revanche, le journal du chef de poste de Machanga-Mambone ne fait que «démentir », auprès de ses supérieurs, la rumeur de la manifestation aussi chez lui : il les assure que règne le calme le plus absolu....

${ }^{424}$ Sorte de rhum tiré de la canne à sucre locale.

${ }^{425}$ Vin de palme.

${ }^{426}$ La première installation de l'administration de la compagnie, à Mambone, avait été emportée par la forte érosion du fleuve lors des crues successives. C'est pourquoi le poste fut reconstruit plus en retrait et en amont.

${ }^{427}$ Dès l'époque du Monomotapa, Machanga et Mambone étaient l'un des débouchés du commerce de l'hinterland vers l'océan Indien.

${ }^{428}$ Dans les langues chona (dont le cindau fait partie), mambo signifie effectivement chef. Mais la négation en ne supposerait donc que les gens parlaient déjà un sabir portugais. Ce n'est pas impossible, mais il y a d'autres hypothèses sur l'éthymologie du lieu.

${ }^{429}$ Je rappelle que, même si ces entrevues ne sont pas des enregistrements, mais le fruit de notes prises au cours d'entretien, j'en respecte scrupuleusement le déroulement et si possible le vocabulaire et les tournures, d'où des retours en arrière, des parenthèses, etc., mélangés au thème principal, et des expressions populaires pas forcément «correctes » grammaticalement. Les ajouts entre crochets, mais pas en italiques, ont été portés par moi, au cours même de l'entretien, en marge du carnet.

${ }^{430}$ Il était administrateur pour le compte de la Compagnie du Mozambique, dont la concession s'acheva en 1942.

${ }^{431}$ Circonscription au nord-est de Beira. 
Goanais). Colaço fut substitué en août 1951 par Sebastião Chambino (surnommé « chambica »). C'est lui qui a eu des problèmes.

Le Núcleo a été fondé à Beira par des gens surtout d'ici. La majorité, c'était des Ndaus. À Lourenço Marques, le Brado Africano aussi publiait des articles du Núcleo (1937, 1938...). Le Núcleo avait une délégation à Mambone et à la Machanga, peut-être au Búzi, et, avec le groupe de Kamba Simango, à Gogoï [où enseignait Bed Simango ; Gabriel Tivane est son neveu]. Bed est mort à Mount Silind ${ }^{432}$ le 19 septembre 1993.

Le Núcleo n'était pas une religion, mais en son sein, il y avait une école de religion de l'American Board. Les Portugais le savaient. Mais Raúl Domingos Mucacho était catholique et c'était le secrétaire de Sixpence, et il n'y avait pas de problème (il est maintenant à Nampula, marié à une femme de là).

Bed Simango est resté à l'American Board ${ }^{43}$, mais il correspondait avec l'Igreja do Cristo em Moçambique [Église du Christ au Mozambique] du pasteur Nkomo (ou Como $)^{434}$. À Beira, on parle encore aujourd'hui de l' «Église de Como ».

Le problème commence en 1951. Comme les maris travaillaient en Afrique du Sud ou à Beira ${ }^{435}$, et que c'était le régulo qui devait voyager pour couvrir [l'impôt de paillote] et qu'il n'y réussisait pas auprès de tous, alors Chambino a arrêté les femmes de ceux qui n'avaient pas payé l'impôt, beaucoup de gens, [et les a mises] à travailler aux routes, à dormir au bourg près de l'ancien cachot, dehors. L'administrateur a dit aux femmes d'écrire à leurs maris pour envoyer l'argent et chaque vendredi, si l'argent ne venait pas, envoyait les cipayes donner des coups de férules sur les mains, douze ou quatorze coups! Ce Chambino, ça a été l'un des pires.

Alors, de nuit, il surveillait les femmes, une bengala ${ }^{436}$ à la main. Le jour, il les battait avec cette bengala.

Cette année-là, j'étais déjà en Afrique du Sud, clandestinement (j'ai quitté Beira le 8 mai 1951) $)^{437}$. Je suis parti par le chemin de fer, avec les papiers d'un Mozambicain qui vivait en Rhodésie, à Salisbury et qui était venu en vacances. Cet António m'a donné son sauf-conduit, et je suis parti. J'ai renvoyé les papiers par retour du courrier. Le jour suivant, j'ai été à la frontière de Plumtree, du Bechuanaland, où j'ai dit que j'allais jusqu'à Lourenço Marques! Je suis entré en Afrique du Sud clandestinement, le 13 mai.

J'ai été chez un oncle, Daniel Simango, qui vivait là depuis 1932 sans être jamais revenu. Il vivait au quartier Orlando West Cliff de Soweto. Il travaillait dans une laverie. Les premiers mois, j'ai travaillé à Morningside comme employé domestique. Ensuite, j'ai réussi à avoir les papiers pour travailler en ville : il faut remettre une photographie à un avocat, qui sait bien que c'est pour un faux, on paye neuf livres, et il s'occupe de donner un nom sud-africain. Moi, j'ai été Lewis Tibane! J'ai travaillé dans une laverie. Je vivais au Denver Mens Hostel. On y parlait un peu zoulou, mais il y avait beaucoup de gens [originaires] de Mambone, déjà nés en Afrique du Sud.

C'est à cette époque, en septembre 1951, que nous recevons des lettres de nos familles d'ici, nous disant que ça allait mal. Nous nous sommes réunis pour discuter quoi faire. Seulement entre amis de Mambone, un dimanche, au Village Minde de Johannesbourg. Et là, on est arrivé à un consensus : il y avait un avoué portugais, Paiva Raposo, que nous avons contacté et c'est lui qui rédigea une requête à Son Excellence le Gouverneur général du Mozambique ${ }^{438}$. Nous connaissions déjà la position du Gouverneur d'Inhambane, favorable à l'administrateur, c'est pourquoi nous avons écrit au capitaine

${ }^{432}$ Mount Silind est une localité située au Zimbabwe, proche de la frontière du Mozambique, non loin d'Espungaberra. C'est lá que l'American Board of Foreign Missions, abandonnant le sud du Mozambique et Inhambane en particulier, avait installé sa «capitale», non seulement pour la Rhodésie, mais aussi pour le Mozambique. La station de Gogoi était ainsi en contact direct avec Mount Silind, qui rayonnait jusqu'à Beira et l'estuaire du Save et qui forma une précoce génération de cadres mozambicains qui, à la différence de la suivante, n'était donc pas principalement sudiste. Il faut noter que Mount Silind appartient à la petite région zimbabwéenne ethniquement ndau.

${ }^{433}$... à la différence de Kamba Simango qui, rappelons-le, rompit.

${ }^{434}$ Nkomo (nom de clan très répandu dans le centre du Mozambique et au Zimbabwe) désigne ici Guilherme Tapera Nkomo.

${ }^{435}$ L'exode rural à Beira était légal, mais l'émigration en Afrique du Sud était interdite, car Machanga et Mambone sont au nord du $22^{\mathrm{e}}$ parallèle, limite nord des accords sur la main-d'œuvre avec Prétoria : on émigrait donc en large échelle, mais clandestinement.

${ }^{436}$ Morceau de bois lisse et effilé, parfois sculpté, qui est symbole de pouvoir mais peut servir aussi à frapper.

${ }^{437}$ Les émigrés clandestins, par conséquent considérés comme présents au Mozambique, devaient donc payer l'impôt, en pratique réclamé à leurs femmes...

${ }^{438}$ Dans la tradition bureaucratique portugaise, toute requête à un officiel devait être rédigée sur papier timbré et authentifiée, d'où le recours à un avoué. 
de la marine de guerre, Gabriel Maúricio Teixeira ${ }^{439}$. Une lettre signée par quatre personnes en représentation de tous, ceux qui savaient bien écrire: Gabriel Castigo Tivane, Daniel da Rocha Chicamba (il est mort), Jobe Tundo Maïneque et Obadias Mulenda Senguayo, tous de Mambone. Cette requête fut envoyée en recommandé à Lourenço Marques. Nous y racontions tout ce que l'administrateur faisait.

Une fois reçue la requête, le Gouverneur général nomma un inspecteur administratif, Oscar Ruas, qui vint à Mambone en avril 1952. Quand il arriva là, il demanda aux familles de ceux qui avaient signé la requête de venir lui parler. Il était dans la maison qui sert aujourd'hui de siège au parti Frelimo. À l'époque, je n'avais pas de femme, alors ils appelèrent ma mère, et les femmes des trois autres. Même à ce moment, quand l'inspecteur était là, des gens étaient encore arrêtés.

Il prit contact avec l'administrateur seulement après avoir tout confirmé. L'administrateur nia. Quand l'inspecteur partit, l'administrateur demanda aux régulos et aux chefs de hameaux de lui présenter ceux qui avaient signé la requête. Et il continua à arrêter des gens.

Alors, ils nous écrivirent, en mai 1952. En octobre, je me décidai à rentrer chez moi.

Quand je revins, même chemin, mais cette fois avec le laissez-passer en règle, je rencontrai le régulo Armando Matique à Beira, qui était venu là recouvrir les impôts. Il me dit:

- "Você não pode ir para Mambone, o administrador está à espera de você para ajustar as contas », " Il ne faut pas aller à Mambone, l'administrateur vous attend pour régler les comptes ».

J'ai répondu :

- "Tenho que ir, não há alternativa», «Je dois y aller, il n'y a pas d'autre solution $\gg$.

Je suis parti. Quand je suis arrivé, le 23 octobre 1952, par le bateau, les policiers prenaient les laissez-passer des passagers pour l'administrateur. Le jour suivant, on allait se présenter. Mais dès l'après-midi de ce jour-là, arrive à ma maison de Metinha le chef de hameau João Mabingo Metinha, à dire que je devais l'accompagner le jour suivant à l'administration. L'administrateur voulait parler avec moi. Je n'avais pas peur, je n'ai jamais eu peur quand j'ai raison.

Le jour suivant, à six heures, on est parti, on arrive là au bourg et alors que je remettais l'argent de ceux qui travaillaient en Afrique du Sud pour payer les dettes à la boutique d'Abrantes - les choses que les femmes y prenaient -, le chef déjà me fait appeler.

Dès que j'arrive, moi, alors, il me dit :

- "Anda cá, anda cá», "Viens ici, viens ici », avec l'interprète Angelo Guerra Tomas.

L'administrateur commence à m'interpeller :

- "Você conhece quem sou eu? ?, «Vous savez qui je suis ?».

Je ne l'avais jamais vu, mais je savais [qui il était] parce qu'il avait les devises [sic, insignes], les feuilles d'olivier en platine.

- "O que é que você dizia na Exposição?", "Qu'est-ce que vous disiez dans la requête?»

- "Diziamos o que o administrador andava a fazer cá às mulheres indefesas", « Nous disions ce que l'administrateur faisait aux femmes sans défense d'ici ».

- "Como é que você conheceu se você nunca me viu ? ", "Comment l'avez-vous su si vous ne m'avez jamais vu? »

Je lui ai raconté tout ce qu'il faisait. L'administrateur me demanda mes témoins. J'ai répondu que, de par la loi, il ne pouvait pas demander à mes témoins de se présenter, mais s'il y avait un jugement, alors là je présenterais mes témoins. L'administrateur me donna quinze jours pour que je présente mes témoins, sinon il me châtierait. Et dire que c'était un Administrateur de première classe ${ }^{440}$ !

Il tappait sur la table, je tappais aussi sur la table. À l'époque, j'étais considéré $100 \%$ indigène ${ }^{441}$. Angelo Guerra [l'interprète] ne savait plus où se fourrer. L'administrateur était l'accusé et non le plaignant.

Dehors, plein de gens parlaient à voix basse. Il est rentré à son domicile. Cette première semaine passée, je fis une nouvelle requête au Gouverneur général, disant que l'administrateur était l'accusé et que je n'avais pas à produire quelque témoin que ce soit parce qu'il pouvait les châtier. J'envoyai la lettre à Daniel da Richa Chicamba en Afrique du Sud et seulement après un réunion avec les autres, il envoya la lettre à Lourenço Marques.

Les quinze jours passés, le délai était expiré mais je ne suis pas allé à l'administration. J'étais à une fête à Genga. Il envoya un policier à la maison, et ensuite il vint me chercher

${ }^{439}$ Tel était bien le grade exact, à ce moment du gouverneur général G. Teixeira !

${ }^{440}$ Le grade d'administrateur de circonscription comprenait trois classes hiérarchiques.

${ }^{441}$ C'est-à-dire qu'il n'avait pas le statut d'assimilé lui donnant les droits d'un citoyen, et notamment de parler d'égal à égal avec un Portugais. 
à Genga. J'avais bu, mais bon, on part. Mais arrivés là, lui était à la maison, c'était samedi après-midi, au palais.

- "Porque é que você não apresentou as testemunhas?", «Pourquoi n'avez-vous pas présenté vos témoins? ». J'ai répété ce que j'avais dit.

- «Na segunda-feira às oito horas tem que apresentar os testemunhas », «lundi à huit heures, vous devez présenter vos témoins ».

Il pouvait me faire battre, mais c'était un crime induit, les choses se présentaient mal pour lui. Le lundi, je crois que c'était le 11 novembre 1952 , je me présentai à l'administration. Tout de suite il dit à l'aspirant ${ }^{442}$ de dresser le procès-verbal à la machine à écrire. Il me le donne pour signer, je prends le papier et je le déchire en plein de petits morceaux. Il se mit à crier. Ils durent faire un autre papier, mais je n'ai pas signé. L'administrateur demanda aux trois chefs de hameaux, celui de Metinha, João Mabingo, celui de Matasse, Serafim Guacho (frère de Denis Matibe) et Matade Macharuge, de Genga, comme témoins pour lui, de dire que les accusations étaient fausses. Il demanda aussi au commerçant chinois, Chopak, et au Goanais, Álvaro de Souza Cezerilo [ou Cesarilho]. Ils acceptèrent. Ils envoyèrent le procès-verbal à Inhambane et à Lourenço Marques.

Mais ce qui arrive, c'est que je fais encore une autre requête, également via l'Afrique du Sud, pour justifier pourquoi je n'avais pas signé et pourquoi je n'avais pas présenté mes témoins.

Quand ils ont reçu ma requête, ils ont appelé l'administrateur à Inhambane. Le 9 décembre 1952. Quand il est arrivé à Inhambane, ils lui ont parlé de la requête. Quatre jours après, il était de retour à Mambone, mais ce même jour, il reçut un autre message lui demandant de repartir immédiatement à Inhambane et Lourenço Marques. Je ne sais pas ce qui s'est passé là-bas. Puis il est revenu le 22, à la nuit, et dès le 23 de bon matin, j'avais deux cipayes devant ma maison.

Mais le secrétaire de l'administration, Sacadura Cabral, s'entendait bien avec moi et m'informa que l'administrateur avait été réprimandé.

J'étais déjà arrivé en bicyclette à la boutique d'Abrantes. Une personne me dit alors que deux cipayes étaient partis [chez moi] pour m'arrêter. Alors je suis reparti en vélo pour Genga.

Mais, avant tout ça [il faut que je dise que] notre groupe de Johannesbourg [c'est-àdire ceux qui étaient revenus d'Afrique du Sud ${ }^{443}$ ] avait formé un Núcleo dos Naturais de Mambone [Groupe des natifs de Mambone], qui avait été créé à cause des mauvaises relations avec l'administrateur. Il était clandestin. Nous faisions nos réunions en brousse, le jour, avec les madodas - les Anciens -, à Matasse mais en brousse, ou du côté de Genga, sur le chemin des berges du fleuve, avant le carrefour du chemin pour la mission. Ces personnes, quand elles ont su que deux cipayes étaient venus m'arrêter, prévinrent tous les autres après que j'aie moi-même prévenu les gens importants (Simango, ce sont les maîtres de la terre ${ }^{444}$, ensuite arrivent les Tivane, et il y a très peu de Dhlakama, de Muchanga, de Ncomo).

Je suis revenu et j'ai été parlé avec le responsable du Núcleo dos Naturais à Matasse, Zebedias Simango. Il savait déjà tout (Ceux du Núcleo negrófilo de Mambone faisait aussi partie du Núcleo dos Naturais. Mais personnllement, je n'ai jamais fait partie du Negrófilo parce que j'ai toujours travaillé à l'extérieur. La création du Núcleo dos Naturais avait été décidée au cours d'une réunion en Afrique du Sud. En Afrique du Sud non plus, il n'était pas légal. Le président était Sr. Lore Mavida Dgenga, le frère du régulo Genga, qui était en Afrique du Sud depuis très longtemps.)

J'ai trouvé un des deux cipayes chez moi. Je leur dis:

- "Tá bem, mas já é noite. Não há lei de prender as pessoas à noite. Temos que ir amanhã ", "D'accord, mais là, c'est déjà la nuit. Ce n'est pas légal d'arrêter les gens la nuit. On devra y aller demain $\gg$.

Mais les deux cipayes ont insisté, et nous sommes arrivés à 21 heures, le 23. L'administrateur était fâché contre les cipayes qu'il avait envoyés depuis le matin. Il ordonna qu'on me mette au cachot. Alors j'ai dit:

- «Não posso andar para o calabouço sem ordem da Sua Exa. o Governdador geral. Mostra lá a ordem », "Je ne peux pas être mis au cachot sans ordre de Son Excellence le Gouverneur général. Montrez-moi l'ordre ».

On s'est mis à discuter, pendant une demi-heure. Il commença à insulter les cipayes pour qu'ils me mettent au cachot.

\footnotetext{
${ }^{442}$ Grade inférieur de l'administration.

${ }^{443}$ Les émigrés de retour font souvent figure de notables.

${ }^{444} \mathrm{C}$ 'est-à-dire le clan reconnu comme le plus ancien sur cette terre.
} 
Le père de Salema ${ }^{445}$, Mabote, était l'un des deux cipayes. Ils ont mis deux heures et demie pour m'emmener, cinq cent mètres !

Un troisième cipaye est arrivé, qui amenait deux femmes qui marchaient du côté de l'administration après neuf heures du soir, heure du couvre-feu ${ }^{46}$. Une de ces femmes étaient la femme du pasteur André Machava (il est mort), qui plus tard allait être emprisonné avec nous. Alors, pour qu'on ne soit pas dans la même salle, ils ont laissé les femmes partir. Quand j'y suis entré, dès le lendemain matin une personne est venue me parler par la fenêtre dire que les gens du Núcleo de Genga allaient se réunir à l'abreuvoir anti-tés-tsé $^{447}$ à l'entrée du bourg, et ceux de Matique à l'entrée de l'autre côté. Les deux groupes devaient former un seul groupe pour aller trouver l'administrateur. C'était le 24 décembre 1952.

Il fut décidé qu'il n'y aurait pas de fête de Noël tant que Gabriel serait emprisonné. [On célébrerait] seulement à la maison, sans batuque. Ainsi, ils vinrent me donner toutes les informations. Le 25 , la population vint manifester en face du bureau de l'administrateur. En ce temps-là, à Noël, les régulos venaient dire leur «Baiete », une espèce d'allégeance ${ }^{448}$. Mais ils ne vinrent pas, parce qu'ils savaient qu'il y aurait des problèmes. Matique était déjà revenu de Beira, mais ne comparut point, ni Genga.

En revanche, la population se rassembla là, environ deux mille personnes, il n'y avait plus de places dans le bourg !Quand ils ont vu qu' [au bureau] il n'y avait personne, ils allèrent à la résidence de l'administrateur. Avec grand vacarme!

- «Nós queremos falar com o administrador!», « Nous voulons parler avec l'administrateur!»

Le gars était en pyjama et demanda :

- "Faz favor, que é que vocês querem? ", "S'il vous plaît, qu'est-ce qu vous voulez ?»

- "Nós queremos saber porquê é que o Gabriel está preso », "Nous voulons savoir pourquoi Gabriel est emprisonné »

- "Está preso porque ele mentiu para mim, escreveu ao Governador geral para queixar-se de mim que eu fazia isto e aquilo - toda aquela história », «Il est prisonnier parce qu'il m'a menti, à écrit au Gouverneur général pour se plaindre de moi, que je faisais ceci et cela - toute cette salade ».

La population a dit :

- «Isto você fazia, somos nós! », « Si, vous le faisiez, on en sait quelque chose !»

- "Ah! eu pensava que era o Gabriel que fazia isso da sua cabeça, então vou tirar o Gabriel. Vocês deixam um homem para acompanhar o Gabriel e vocês todos vão para a casa », «Ah ! bon, je pensais que c'était Gabriel qui sortait tout ça de sa tête, bon, je vais libérer Gabriel. Vous laissez une personne pour accompagner Gabriel et tout le monde rentre à la maison ».

- «Não, nós todos vamos acompanhar o Gabriel para casa, senão você vai prender as duas pessoas », "Non! nous allons tous accompagner Gabriel à la maison, sinon, vous allez arrêter les deux personnes ».

Alors il a ordonné au gardien de me libérer. La population à commencé à me porter en triomphe ! J'ai été à la maison, en passant par chez le régulo Matique. Il a fait tirer des feux d'artifice, il a dit que j'avais raison. Ça lui en coûté plus tard, parce qu'ainsi il se mettait du côté de Gabriel. Dès ce moment, il y a eu des batuques partout, dans la nuit du 25 au 26.

Tout ça, le fait d'être porté en triomphe, le Senhor José Marques da Silva, de la MCT, avait assisté à la scène (c'est le père de Manuel Aranda da Silva, ex-ministre mozambicain du commerce $\left.{ }^{449}\right)$. En janvier 1953, il va à Lourenço Marques et raconte tout ce qui s'est passé, et c'est arrivé aux oreilles du Gouverneur général. Alors le gouverneur général envoie le gouverneur du district d'Inhambane pour enquêter là-dessus. Le Gouverneur général voulait parler avec l'administrateur à Lourenço Marques.

- "Porquê é que você tirou, se é assassino ? ", "Pourquoi l'avez-vous libéré, s’il est un assassin? »

C'était en janvier 1953. Quand il est revenu, il est resté seulement deux jours, le temps de recevoir un télégramme lui ordonnant de remettre l'administration au substitut

${ }^{445}$ Salema, membre du Frelimo, est l'ancien directeur des Salines de l'État. Il chercha par tous les moyens à faire nationaliser aussi les Salines de la Mission catholique. Il est aujourd'hui le patron de ces mêmes Salines, privatisées à son profit.

${ }^{446}$ La population indigène n'avait pas le droit de se promener sans sauf-conduit, passé neuf heures, dans les zones relevant directement de l'administration européenne.

${ }^{447}$ Abreuvoir anti-tsé-tsé installé par la MCT.

448 «Baiete» était le cri de reconnaissance de la souveraineté du chef, notamment au temps de Ngungunhana. L'administration portugaise avait tourné à son profit la coutume.

${ }^{449}$ Aranda da Silva a été ministre du commerce dans le gouvernement du Frelimo. On l'a vu précédemment, J. Marques da Silva était de l'opposition. 
Sacadura Cabral. Il est suspendu pour trente jours. Sacadura Cabral me l'a montré, dans le Bulletin officiel.

Quand tout cela arrive, c'est le moment même où il y avait des problèmes à la Machanga aussi, parce qu'il y avait eu une crue à la fin de 1952. Alors, de Beira, ils ont envoyé des secours par la gazolina. Quand le chef de poste les a reçus, il a pris les produits et les a mis en vente dans les boutiques. Le Núcleo negrófilo a fait une requête au gouvernement. Comme ça, quand nous, nous faisions du bruit, la Machanga aussi faisait du bruit!

Février se termina. À la fin février, Chambino reprit son poste, jusqu'au 31 mars. C'est là qu'arriva un autre télégramme, pour dire: «L'administrateur de $1^{\mathrm{e}}$ classe Chambino est versé à la retraite ». Sacadura Cabral recommença à être le substitut, jusqu'à l'arrivée du nouvel administrateur. Sacadura Cabral me dit:

- "Olha, isto vai ser muito duro para você. Compra-là uma bicicleta e vai para África do Sul. Depois na África do Sul, reembolsa a bicicleta », «Écoutez, ça va devenir très dur pour vous. Achetez donc une bicyclette et partez en Afrique du Sud. Après, en Afrique du Sud, vous remboursez la bicyclette ».

Les gens vont d'abord à Mabote, Massengena, Pafuri et ensuite, c'est déjà la frontière, le National Kruger Park, dix jours ça y est, on est arrivé. Il y avait des gens qui allaient à pied, arrivés à un endroit, ils aidaient aux champs, ils mangeaient ce jour-là, et comme ça jusqu'à la fin. J'ai répondu que je ne voyais pas de raison pour fuir, je n'étais pas coupable.

Mais le nouvel administrateur est arrivé, venu de Pafuri, Armando de Landerset Simões, il contacta les madodas, les régulos et quand il arrive à Matique, il dit :

- "Vocês são todos bem, mas há aqui pessoas que são cobras, são contra o governo português, nós vamos pisar nas cabeças dessas cobras ", "Vous êtes tous très bien, mais il y a ici des gens qui sont des serpents, qui sont contre le gouvernement portugais, et nous allons piétiner les têtes de ces serpents ».

Les madodas étaient inquiets. Quand je l'ai su, je me suis dit que ça sentait mauvais.

Un jour plus tard, l'interprète Angelo Torres Guerra me dit :

- «O administrador recebeu um telegrama do Governo de Inhambane a perguntar o paradeiro do Gabriel Castigo Tivane, se estava lá e se não, onde se encontra", «L'administrateur a reçu un télégramme du gouvernement d'Inhambane, qui demandait les coordonnées de Gabriel Castigo Tivane, s'il était là, et si non, où se trouvait-il ».

C'était à la fin de 1953. Alors, je me suis allé me présenter à l'administration, demander un laissez-passer pour aller travailler à Beira. L'administrateur me dit qu'il ne pouvait pas pour l'instant, que j'attende quelques jours. Je suis resté tout le mois de mai, et en juin, je suis revenu à l'administration. Il me dit qu'il ne puvait toujours pas. Mais pendant ce temps, le gouvernement de province [c'est-à-dire du district colonial d'Inhambane] préparait les moyens de m'inculper. Il n'était pas d'accord avec le gouvernement général. Simões cherchait à savoir si nous parlions d'indépendance et si nous étions dirigés par la Russie! Non, nous étions contre les mauvais traitements, ce sont eux qui nous ont appris cette idée d'indépendance!

En juin, je suis appelé par l'administrateur:

- «Você quer ir para a Beira, então deixe aqui a caderneta para nós ficarmos a tratar do seu assunto », "Vous voulez aller à Beira, alors laissez ici votre livret indigène pour que nous traitions votre dossier ».

Mais il y avait déjà là trois policiers blancs venus d'Inhambane. Je ne fus pas arrêté, mais sans livret je ne pouvais pas partir. Ensuite, ils m'ont dit qu'ils allaient me donner un laissez-passer pour Beira, mais je ne devais pas partir pour l'Afrique du Sud. Ça sentait mauvais. J'écrivis tout au Núcleo en Afrique du Sud.

$\mathrm{Au}$ même moment, il y avait des arrestations à la Machanga, plein de gens, Jeque Sipumburo, etc.

Mais quatre jours avant de signer la requête (du 11 novembre 1952), le chef Matade Macharuge s'était pendu dans sa maison. Il avait promis que sa population était d'accord pour être transférée dans la zone du ruralato, et quand il vit que la population ne voulait pas, l'administrateur se retourna alors contre lui. Ainsi, il arriva à la conclusion qu'il devait se pendre pour retrouver sa liberté.

Quelques semaines après, le chef de groupe $e^{450}$, Serafim Guacha, qui avait aussi signé [en faveur de l'administrateur], tomba subitement malade et mourut ${ }^{451}$. Le groupe de Chambino commençait à diminuer. Et en juillet 1954, déjà longtemps après, João Mabingo de Metinha se pendit aussi chez lui, après avoir fui de l'endroit où il avait passé la nuit; il avait été battu et menacé d'être battu encore s'il ne disait pas la vérité, pendant

${ }^{450}$ Dans la hiérarchie des chefs reconnus par les Portugais, les « chefs de groupe » sont intermédiaires entre les régulos et les chefes de povoação (chef de hameau).

${ }^{451}$ Militant historique du Frelimo, Gabriel Castigo Tivane ne pouvait me le présenter ouvertement, mais son propos décrit, de manière limpide, un cycle d'attaques en sorcellerie. 
une enquête d'Afonso Henrique Ivens Ferraz de Freitas ${ }^{452}$. C'est lui-même qui ordonna de le battre ! Moi-même, il ordonna que je sois battu, par les cipayes Luis Machava, qui vit aujourd'hui à la Machanga $a^{453}$ (il était surnommé Satana ${ }^{454}$, parce que son nom complet est Luis Santana Machava), et Candieiro.

Le commerçant Cesarillo était malade, à Beira, et Chopak je ne sais pas. Mais les témoins de Chambino étaient réduits presque à zéro.

Mais alors, j'étais déjà en prison.

Le 5 juillet 1953, je revins à l'administration pour dire que je serais là demain pour chercher mon laissez-passer pour Beira. Mais ils avaient déjà combiné, Simões et le gouverneur Otávio Ferreira Gonçalves, d'Inhambane, la venue de troupes de Lourenço Marques, demandées au général Orto de Vale, commandant militaire du Mozambique.

Quand je suis revenu le 6, je ne trouve pas l'administrateur. A onze heures, j'allais m'asseoir pour l'attendre l'après-midi. Tout d'un coup, je vois une jeep stopper en face de moi et ils me mettent dans la voiture. J'ai été mis au cachot. Une heure après, je vois arriver le régulo Matique également prisonnier, le père d'Alexandre Nova, André Machava, Rodrigo Muguio (du Núcleo dos Naturais), et bien d'autres personnes. Vers quinze heures, il y avait plus de vingt personnes prisonnières.

À ce moment, je vois l'avion militaire survoler Mambone et atterrir, amenant le gouverneueur d'Inhambane. Une heure et demie plus tard, il était presque 17 heures, arrivèrent quinze camions et jeeps militaires, 150 hommes, venues de Lourenço Marques. Toute la nuit ils fouinèrent parce qu'ils croyaient qu'il y avait des armes cachées en brousse.

Le 7, le gouverneur fit une banja avec toute la population. Mais ils avaient une liste et arrêtèrent d'autres personnes. Il y avait une mitrailleuse sous la véranda et des soldats autour. Nous avons été présentés comme ça :

- "Estes são bandidos, mas vocês são boa gente, não há problemas, vocês voltam para as machambas. Mas esses revoltosos o governo sabe o que vai fazer com eles », «Ceux-là sont des bandits, mais vous êtes de braves gens, il n'y a pas de problème, vous allez retourneur aux champs. Mais ces révoltés, le gouvernement sait bien ce qu'il va en faire ».

Alors, Raúl Martinho, le frère du catéchiste de Metinha, Chigalo, demanda qu'est-ce qu'ils auraient fait. La réponse fut: «Le gouvernement sait». Le gouverneur d'Inhambane demanda qui il était et il répondit :

- "Sou daqui, já esteve em São Tomé », "Je suis d'ici, j’ai déjà été à São Tomé ».

(Il avait eu, vrai ou faux, un problème à Beira. Or, le curateur des indigènes à São Tomé était à cette époque Otávio Ferreira Gonçalves, à présent gouverneur d'Inhambane !)

Nous ne parvînmes pas à entrer tous dans le cachot, plus de cent personnes !

L'après-midi du 7 ont commencé pour moi les passages à tabac. Le capitaine Maia, de l'armée, un lieutenant, un adjudant noir appelé Novidade, coups de bâtons, coups de férules :

- «Vocês comunistas, têm ligação com a Russia », "Vous êtes des communistes, vous avez des liens avec la Russie ».

Je ne savais même pas ce qu'était le communisme. Des réflexions comme ça, on ne devrait même pas les faire à des enfants. J'ai perdu connaissance.

Le jour suivant, encore des passages à tabac. Ils m'ont battu quatre jours. Ensuite, ils ont arrêté deux jours et ensuite ils ont commencé le procès. Nous sommes restés là tout le mois d'août. Nous avons fait des travaux forcés jusqu'au 19 août. Alors, ils ont choisi seize personnes, considérées comme chefs de file, pour être envoyées à Inhambane. Nous y sommes arrivés à minuit. Le cachot d'Inhambane, c'est quelque chose de sérieux. Tout le monde, entassés comme des sardines, à dormir sur le côté. Celui qui va aux toilettes ne

452 Les «autorités traditionnelles» reconnues par les Portugais étaient souvent dans une situation impossible, en dépit de leurs menus privilèges : elles devaient servir les Portugais mais, n'y parvenant pas, étaient parfois maltraitées et, de ce fait, déconsidérées aux yeux de la population. Afonso Henrique Ivens Ferraz de Freitas fut administrateur du conseil de Lourenço Marques. Il est l'auteur d'enquêtes dont l'objectif était évidemment policier, mais que l'on pourrait appeler d'anthropologie appliquée au colonialisme, et qui restent des sources précieuses. Il mena en particulier la première enquête sur les « sectes païennes » (Églises africaines dissidentes), puis enquêta longuement sur la radicalisation des Macondes (à l'extrême nord du Mozambique). Il est le fondateur des Serviços de centralização e coordenação de informações de Moçambique (SCCIM), un service de renseignements civil créé aussi en Angola et en Guinée-Bissau en 1961, mais qui exista au Mozambique dès 1959 sous la forme de la «Central de informação », sous la dépendance directe du Gouverneur général (c'est-à-dire non contrôlée par la Pide).

453 ... et militant local de la Renamo ( $c f$. infra).

${ }^{454}$ Comme en français, Satana désigne le diable en portugais. 
trouve plus de place pour dormir [quand il revient]. On ne pouvait dormir bien que le jour, pendant que les autres allaient travailler dehors.

Le 24 août, nous avons été envoyés à Lourenço Marques, parce qu'au moment de notre arrestation le gouverneur général était en Rhodésie et c'est lầ qu'il avait reçu un message du secrétaire général (Carvalho ?) l'informant que les indigènes de Mambone s'étaient rebellés et que le commandant militaire avait envoyé une troupe pour les mater. Il représentait le Portugal lors de la visite de la reine Isabelle II d'Angleterre. Il fut obligé d'annoncer en public qu'il repartait immédiatement parce que dans sa province il y avait des indigènes révoltés. Les quotidiens rhodésiens l'ont publié !

Quand nous sommes arrivés à Maputo, dans la nuit du 24 au 25, nous y avons trouvé ceux de la Machanga, mais déjà mis dans un autre endroit. Ils avaient été interrogés à Nova Sofala, puis à Beira, par António Craveiro Lopes (frère du Président du Portugal), et après à Lourenço Marques au siège de l'administration du conseil, par Afonso Henrique Ivens Ferraz Freita, pendant que nous, nous étions dans une des cellules du commissariat du Corps de police (PSP).

Du 25 août à la fin janvier 1954, nous restâmes prisonniers. Un de nos collègues, Lote Chicamba, ça lui a coûté très cher, parce qu'il avait écrit un billet qu'il avait remis à une des personnes qui nous rendaient visite, quelqu'un l'a vu et le billet est arrivé aux mains de la Pide. La Pide à cette époque agissait déjà à Lourenço Marques ${ }^{45}$. Luis «Santana » Machava avait été envoyé en Afriqe du Sud pour une recherche secrète et les gens d'Afrique du Sud ne savaient pas qui il était. Dans le billet pour son frère Daniel Chicamba, Lote dénonçait la venue de Santana à ses collègues de Johannesbourg. Mais le billet n'est pas arrivé. Çependant, ils avaient déjà su par d'autres voies.

La Pide ${ }^{456}$ alors nous a appelé, chacun à notre tour, pour que tout le monde fasse sa signature. Ils ont repéré ainsi Lote, ils l'ont battu quatre jours. Quand il est revenu, il n'arrivait plus à marcher et ne voulait même pas raconter. Fin janvier 1954, nous avons été enmmenés au conseil, de Ferraz Freitas. Dès que nous sommes arrivés, la première personne à être appelée ce fut moi. Le chef de poste de la Munhuana ${ }^{457}$ se mit à la machine à écrire, mais Ferraz Freitas lui dit :

- "Para o quê, aquele é duro, não vai dizer nada, que é que vai escrever aí?", «Arrêtez ça, celui-là est un dur, il ne vient dire du tout, qu'est-ce que vous allez écrire?».

Alors il a demandé :

- "Nós queremos saber a verdade, nós temos a certeza que vocês têm ligação com a Russia e os comunistas de Portugal », "Nous voulons savoir la vérité, nous avons la certitude que vous êtes liés à la Russie et aux communistes du Portugal ».

Je répondais que non, que nous protestions contre les mauvais traitements.

- "Nada disso, isto é conversa vossa, você é comunista. Cheiram-te as roças de São Tomé! », «Arrêtez ça, c' est du baratin, vous êtes communiste. Pour toi, ça sent très fort les roças de São Tomét ${ }^{458} \gg$.

Nous sommes restés à parler jusqu'à environ deux heures. Le jour suivant, ils ont commencé à battre, questionner, battre, questionner :

- «Vocês querem ser independentes, vocês têm ligação com a Russia», "Vous voulez être indépendants, vous êtes liés à la Russie ».

Ils restaient deux ou trois jours sans m'appeler, ils appelaient les autres, puis ils me rappelaient :

- "Você tinha combinado com o régulo Matique, era satisfeito », "Vous aviez tout bien combiné avec le régulo Matique, vous étiez content ».

J'étais battu jusqu'à deux heures du matin. Un jour, j'en ai eu assez d'être battu, j'ai arraché le bambou des mains de l'administrateur Ferraz Freitas, qui battait personnellement, et je lui ai donné aussi quatre ou cinq coups ! Il était dans une colère ! Ils me renvoyèrent dans ma cellule et je suis resté plusieurs jours sans être interrogé. Plus jamais ils ne m'ont battu. Mais Ferraz Freitas ne sut jamais que Matique avait fait les feux d'artifice ${ }^{459}$.

En juillet 1954, Ferraz Freitas revint à Mambone, pour enquêter auprès de ceux qui étaient restés. Et il arrêta encore d'autres gens. C'est à cette époque que le chef João Mabingo, de Metinha, se pendit : l'ex-administrateur Chambino avait ouvert une scierie à

${ }^{455}$ Ce n'est pas exact, la Pide fut étendue à l'outre-mer seulement en 1960. Mais elle avait une organisation embryonnaire au Mozambique par le biais d'agents intégrés au corps de la PSP.

${ }^{456}$ Il est très probable que Tivane fait ici confusion et qualifie de «Pide » des agents de la PSP.

${ }^{457} \mathrm{La}$ Munhuana était (à l'époque) un poste de la périphérie urbaine dépendant du conseil de Lourenço Marques.

${ }^{458}$ Les plantations de cacao (roças) de São Tomé étaient la destination principale des déportés de longue durée.

${ }^{459}$ Allusion à la joie populaire lors de la libération de Tivane, le 25 décembre précédent, quand le chef Matique avait effectivement lancé des feux d'artifice pour ouvrir le batuque ( $c f$. supra). 
Divinhe, au nord de la Machanga, et fut appelé [par Ferraz Freitas] pour savoir comment c'était avec lui. Chambino dit que c'était Mabingo qui orientait tout ça. Alors, il se pendit pour ne plus être passé à tabac.

C'est cette même semaine que le gouverneur général, Gabriel Maurício Teixeira, vint pour voir de près ce problème de la Machanga et du Govuro. Il resta deux ou trois jours et repartit. Freitas avait été envoyé par le gouverneur général pour faire ces enquêtes. Freitas est le gendre de Gabriel M. Teixeira, sa femme madéroise est la fille de Gabriel Teixeira.

Ferraz Freitas me dit, une fois revenu de ses enquêtes, d'où il ramena plus de prisonniers :

- «Sabe que o seu tio Mabingo enforcou-se?», «Tu sais que ton oncle Mabingo s'est pendu? »

Et je répondis :

- "Não, não se enforcou, é você que o enforcou, a batê-lo!", «Non, il ne s'est pas pendu, c'est vous qui l'avez pendu, à le battre! »

- "Não, não sou eu! São eles o Chambino e o Mabingo a fazer as suas asneiras!", «Non, ce n'est pas moi ! Ce sont eux, Chambino et Mabingo, avec leurs âneries!»

Ils ont continué les recherches, mais sans jamais réussir à découvrir la Russie. Pendant ce temps, je suis resté seul, à l'isolement. J'étais le chef de file. En décembre 1954 arriva ma sentence : neuf ans de déportation à São Tomé e Príncipe.

Fin du carnet $n^{\circ} 3$

Gabriel Castigo Tivane (suite)

Également déportés furent André Machava, six ans, Jeque Mavuma, trois ans (Jeque Mavuma était le lieutenant du régulo Matique, et quand Matique était à Beira pour percevoir les impôts, le lieutenant recouvrait l'impôt dans la zone de Matique. C'est pourquoi il fut accusé d'être au courant des réunions du Núcleo dos Naturais, et de n'avoir rien dit. Il fut déporté au Mossuril ${ }^{460}$ ).

La femme du pasteur Machava fut autorisée à partir avec son mari, à Ibo. Je fus le seul, de Mambone, à partir pour São Tomé e Príncipe, où je retrouvais ceux de la Machanga : : José Tacaisana, João Mudeco, Jeque Sipumburo Mukove. Tacaisana mourut à son retour à la Machanga, mais João Mudeco mourut après six mois à São Tomé à cause de la nourriture à l'huile de palme crue, qu'il ne supportait pas. Sipumburo est toujours en vie.

Nous sommes sortis du conseil [de Lourenço Marques], pour attendre le bateau, au poste de police, le 15 jnvier 1955. Les autres qui avaient déjà fait deux années de préventive, furent libérés. De la Machanga, il y eut aussi d'autres déportés, mais à l'intérieur de la colonie: Ibo, Mossuril, Muecate (c'est là qu'a été Raúl Domingo Mucacho).

A Mambone, tout resta calme.

Quand j'ai fini les neuf ans, en 1964, ils dirent que non, que c'étaient douze ans, et je suis revenu seulement en 1967.

Je suis parti le 7 avril 1955 de Maputo et je suis arrivé le 17 avril, dans le navire «Luanda », voyageant dans la cale. Il y avait plus de cinq cents personnes déportées, venues de tous les coins du Mozambique. Le jour de l'embarquement, Joaquim António de Jesus Colaço me vit parce qu'il faisait partie des commissaires de bord qui accompagnaient les déportés. Alors il dit :

- Não sei que é que ele fez. Trabalhei com ele muito bem. Veja lá se arranja uma posição um bocadinho de destaque, porque ele vai lá para muitos anos », "Je ne sais pas ce qu'il a fait. J'ai très bien travaillé avec lui. Voyez si vous pouvez lui trouver une place un peu meilleure, parce qu'il va là pour de nombreuses années ».

Alors, déjà dans le bateau, dès qu'on eût passé l'île d'Inhaca ${ }^{461}$, ils viennent me chercher et me disent :

- "Você vai ser o encarregado dos desterrados", "Vous allez être le chargé d'affaires des déportés ».

Je m'occupais de la nourriture, des problèmes, je devais informer. Quand je suis arrivé à São Tomé, ils m'ont payé 75 escudos pour dix jours. Ce n'était pas beaucoup, mais mieux que rien. À São Tomé, c'était 120 escudos par mois, dont 70 à la caisse (à recevoir au retour) et 50 dans la poche. Mais ils donnaient la nourriture. Les chibalos ${ }^{462}$ avaient le même traitement, les Capverdiens ${ }^{463}$ également.

${ }^{460}$ Localité en face de l'île de Moçambique, dans la province de Nampula.

${ }^{461}$ L'île d'Inhaca ferme la baie de Maputo (ou Delagoa Bay).

${ }^{462}$ Chibalos : appellation des travailleurs forcés dans les langues du sud du Mozambique (il ne s'agit pas ici des condamnés aux travaux forcés (trabalho correcional), mais des indigènes astreints, légalement et «normalement», au travail obligatoire, en portugais désignés sous l'euphémisme de contratados («sous contrat »). La grande majorité venaient d'Angola, mais certains, en contrats de trois ans, du Mozambique.

${ }^{463}$ Les grandes famines aux îles du Cap-Vert (notamment dans les années quarante) avaient contraint de nombreux Capverdiens, pourtant non-indigènes et « semi-citoyens », à émigrer à São Tomé. Certains, mais pas 
J'ai été envoyé à la Roça ${ }^{464}$ Porto Alegre, dans le sud de l'île, là où il pleut beaucoup ${ }^{465}$. J'y ai été comme contremaître de mes compagnons de bateau. Ils avaient fait de petites choses : trois ans, six ans, etc. La majeure partie, c'était six ans. Je suis resté à Porto Alegre d'avril 1955 jusqu'en juillet 1959, et ensuite, j'ai eu un problème : j'ai refusé de signer ce qu'ils nous demandaient pour feindre que nous n'étions pas déportés, comme si on renouvelait le contrat. Alors l'administrateur de l'entreprise, Braúlio Esteves, ne voulut plus de moi. J'ai dû quitter cette compagnie et je suis venu à la ville de São Tomé. Braúlio Esteves déposa une plainte auprès de l'inspecteur administratif Mendes Serra, le chef du service du Travail, de la Prévoyance et de l'Action sociale qui, du fait que j'avais abandonné l'entreprise, me condamna à quatre-vingt-dix jours de travail correctionnel : creuser des trous, sur les routes. Dans l'édifice même de l'Institut du travail, il y avait des terrasses et je devais creuser des trous pour y planter deux grands arbres, pour l'ombre. Je refusai. L'inspecteur m'appela dans son bureau. Quand j'y entre, il me donne deux claques. Je les lui rends et je pousse le bureau contre lui, mais la chaise avait des bras, qui ont bloqué le meuble! Je sortais quand la police est arrivé. Ils m’ont demandé pourquoi ils avaient été appelés. J'ai répondu qu'ils devaient demander à l'intérieur. Ils m'ont dit d'entrer. J'ai refusé. Je voulais savoir pourquoi il m'avait battu. L'adjoint du directeur, un métis de Timor, me dit :

- "Você vai lá, você tem toda a razão, mas a razão é isto, a pele », "Vous devez y aller, vous avez tout à fait raison, mais la raison c'est ça, c'est la peau ».

Alors, j'ai été mis au cachot, où il y avait le Capverdien Luis Lopes da Costa, un voleur de première classe. Il avait des amis dehors, qui venaient par derrière les barreaux de fer et lui amenaient des scies métalliques. Ainsi, durant la nuit, le gars sciait les barreaux pendant les premières heures de mon sommeil! Il arrive qu'un de ces jours, je sens le fer qui tombe et je vois le gars qui sort ! Je dis : «Luis s'évade!» pour ne pas être battu. Mais Luis était déjà loin quand le garde est arrivé. On m'a mis dans une autre cellule.

A cette époque, j'avais des contacts avec le mouvement de libération. Parce que pendant que nous avions nos problèmes à Mambone et à la Machanga en 1953, eux [de São Tomé] aussi avaient des problèmes, en février et mars, avec le gouverneur Carlos de Sousa Gorgulho ${ }^{466}$. Aussi, quand ils ont su la raison de mon emprisonnement, ils m'ont aidé. Ils me donnaient du pain, etc.

La famille dont j'étais le plus ami était celle de Hipólito Afonso Jordão et son fils Ivo Sosthenes de Vera Cruz Jordão, originaires de São Tomé. Pendant mon emprisonnement, ils avaient déjà organisé un groupe d'entraide entre les travailleurs santoméens de l'Institut du travail, qui rassemblait un peu d'argent pour acheter du pain. Dans un des pains, ils mettaient un crayon et un papier, pour que j'écrive tout ce que je vivais. Venaient des directives. Je devais me plaindre des oreilles pour pouvoir aller voir l'infirmier de service, qui faisait partie de notre groupe! Ainsi, je donnais la réponse. Après, ils faisaient une rédaction meilleure et ils dactylographiaient. Lors d'une autre visite, je signais la requête, qui était envoyée à António de Oliveira Salazar, pour dénoncer les irrégularités ! Il y eut deux lettres.

La première racontait l'histoire depuis l'arrestation à Mambone, résumée, jusqu'à ce que je vivais à São Tomé.

On portait les lettres à Mário Santos, un communiste, qui était chef de la station de téléphone. Au moment précis de la fermeture des malles postales, à 11h30, il glissait les lettres dans le sac. On ne pouvait déjà plus voir à qui elles étaient adressés !

Salazar a lu les lettres et les a envoyées au ministre de l'Outre-mer. Alors, une semaine après, arrive le gouverneur de São Tomé, le Dr Manuel Marques de Abrantes Amaral, qui

tous, y occupèrent des positions intermédiaires : contremaîtres de plantation, etc. Il y a toujours, aujourd'hui, une communauté capverdienne à São Tomé. Le thème du départ pour São Tomé, le «long chemin » (« esse caminho longe »), reste très vivant dans la chanson capverdienne d'aujourd'hui.

${ }^{464}$ Les roças de São Tomé sont des plantations cacaoières très typiques du colonialisme du XIX ${ }^{\mathrm{e}}$ siècle : au centre il y a la maison du maître, souvent en haut d'une colline, autour les installations et les maisons des serviçais, et enfin, les plantations propement dites.

${ }^{465}$ L'île de São Tomé a une hydrographie équatoriale extrêmement humide, mais il y a des micro-climats très marqués du fait du relief : le nord, où se situe la capitale a ainsi une hydrométrie presque «française », cependant que le sud et le sud-ouest sont pires qu'« himalayens»!

${ }^{466}$ Gabriel Tivane fait ici référence à la «Guerre du Batepá», épisode fondateur du nationalisme santoméen. Dans le cadre de la difficulté croissante à recruter de la main-d'œuvre pour les roças et les travaux d'agrandissement du port, le gouverneur tenta d'imposer le travail forcé aux forros, les «fils de la terre » de São Tomé, qui n'étaient pas indigènes et par conséquent se refusaient «identitairement» à travailler dans l'agriculture ou au port. Des incidents éclatèrent, réprimés sauvagement par l'administration. Mais elle ne parvint pas à imposer le travail forcé aux forros. 
fut ensuite secrétaire général du Mozambique, et plus tard encore juge d'appel au Tribunal correctionnel de Lourenço Marques.

Quand il arrive, j'avais déjà rêvé à l'aube qu'il devait venir. Je dis à Luis - c'était avant sa fuite - que le gouverneur allait venir ce jour-là. À trois heures de l'après-midi arrive le gouverneur, qui avait reçu la requête, reçue du ministre de l'Outre-mer.

En premier, arrivèrent sur place le lieutenant Pinho, adjoint au commissaire de la Police de São Tomé, et ensuite le capitaine Rafael, le commissaire. Et quelques minutes plus tard, arrive la voiture du gouverneur ! Un garde vint me chercher, me dirigea vers la salle des sergents. On me demande de m'asseoir, moi, un prisonnier! Alors le gouverneur tire sa chaise pour s'approcher plus près de moi et converser comme si nous étions des amis ! Il me questionne sur la requête que j'aurais envoyée à Son Excellence. Oui, je l'ai envoyée, parce que quand j'ai eu des problèmes, j'ai présenté mes plaintes mais personne ne les a reçues, on m'a seulement mis au cachot.

- "Então você não sabe que sou eu o governador, que devo resolver questões da província? », "Alors, vous ne savez pas que c'est moi le gouverneur, qui dois résoudre les questions de la province? »

- "Sim, eu apresentei uma exposição mas Sua Exa não atendeu », «Si, j' ai présenté ma requête, mais Votre Excellence ne l'a pas reçue »

- "Como? Você nunca apresentou!", "Comment cela? Vous ne m'avez jamais rien présenté !»

(Mais avant d'être prisonnier, alors que je quittais la roça, j'avais croisé, au Morto de Trindade où il avait sa résidence de campagne, sa voiture qui venait au palais, et je lui avais fait signe de s'arrêter ! Et il s'était arrêté et avait demandé ce que je voulais. Alors, j'avais commencé à expliquer que j'avais été expulsé parce que je ne voulais pas signer, etc. Il avait répondu :- «Não! Você volta para a roça! », " Non, vous retournez à la roça !». Mais je n'y étais pas retourné et c'est alors qu'était intervenu l'Institut du travail.)

Il se rappela. Et quand je m'étais battu avec l'inspecteur Mendes Serra, le gouverneur était présent. Parce qu'à cette époque, pendant les réparations au Palais, le gouverneur était au premier étage de l'édifice de l'Institut du travail. Et le chef de cabinet du gouverneur était venu à la fenêtre pour voir ce qui se passait et avait informé le gouverneur.

Il se rappela. Alors, il dit :

- "A partir de agora, quando tiver problema, vem ter comigo, e quando eu não resolver, escreva à sua Excelência », "Â partir de maintenant, quand vous aurez des problèmes, venez me voir et seulement si je ne les résouds pas, vous écrirez à Son Excellence ».

Ensuite, je suis resté dans l'enceinte de la prison, mais déjà plus en cellule. Le jour suivant, on me plaça à ramasser les feuilles tombées des amandiers. Je refusai, parce que j'étais prisonnier, j'étais un détenu. Alors on m'a remis en cellule. Le jour suivant, je fus libéré et ils me donnèrent le laissez-passer pour me présenter de nouveau à l'Institut du travail. C'est alors, sans que je le sache, qu'apparaît un agent de la Pide : j'étais en train d'être salué par des gens qui me connaissaient et il y avait ce gars assistant à la scène, sans intervenir, sans montrer qu'il était un agent de la Pide. Seulement quand apparut un Angolais, qui venait me présenter ses compliments, cet agent de la Pide menaça l'Angolais : - "Se você falar com este Senhor, eu ponho-te na prisão », « Si vous parlez à ce Monsieur, je te mets en prison ». Alors j'ai compris qu'il était de la Pide.

Le secrétariat m'appela :

- "Onde é que você quer trabalhar? », « Où voulez-vous travailler? »

- "Qualquer roça eu aceito, mas para assinar o contrato, não, um prisoneiro não assina contrato », «Dans n'importe quelle roça, ça me va, du moment qu'on ne me fais pas signer de contrat, un prisonnier ne signe pas de contrat »

Alors, j'ai été à la roça Aragão. Mais ils n'avaient pas de place. Je suis revenu. Il se trouve que, quand je revins, ça tombait un 12 octobre à la nuit, j'allais à l'Église de l'évêché pour assister à une procession de cierges, de l'église du Bon Jésus à l'église de l'évêché.

J'y rencontre le père António Rodrigues Alves qui me connaissait déjà de la roça Porto Alegre et qui m'avait protégé pour que je sois professeur à la mission, mais j'avais été refusé par l'Institut du travail, ce même Mendes Serra! Le père dit :

- "Oiça lá! Tem que ter muito cuidade!", "Écoutez! Vous devez être très prudent! La Pide est à vos basques. Vous n'avez pas vu cette homme en chemise à manches longues, kaki, il vous surveille (ce n'était pas le même). Quand vous allez quelque part, regardez derrière pour voir si une personne vous suit à distance. Je vais trouver un endroit à l'école de la roça Boa Entrada. Viens [sic] demain matin à l'église de Santo Amaro, après la messe, je vais parler au Dr Mendonça (le patron de la roça), je donnerai la réponse.

Après avoir assisté à la procession, je rencontre Manuel Guadalupe de Assunção, secrétaire à l'Institut du travail, qui me fait cette question :

- "Então você também anda com Deus? Por que você teve problema com Braúlio Esteves, e aquele logo tive problema com um Caboverdeano que lhe esfaqueou, e morreu. 
Então, anda com Deus ou anda com feitiço? », «Alors, vous frayez aussi avec Dieu ? Parce que vous avez eu ce problème avec Brandão Esteves, et il a de suite eu un problème avec un Capverdien qui l'a poignardé, et il est mort. Alors, vous frayez avec Dieu ou avec la sorcellerie ?»

Et juste derrière venait le gars de la Pide. Sûr qu'il venait pour me provoquer. Alors j'ai répondu :

- "Ninguém deseja a morte do Pecador, mas que ele se converta e vive », "Nul ne souhaite la mort du pêcheur, mais au contraire qu'il se convertisse et vive. ».

Le jour suivant j'eus la réponse, c'était oui. C'était le 14 octobre 1959, je me présente au Dr Mendonça. Il fut d'accord que je pouvais travailler. C'était déjà 500 escudos par mois. Je devais commencer le 16. J'ai commencé à travailler, du 16 octobre 1959 au 31 décembre 1966. Ce fut une période calme, je fus professeur et secrétaire.

J'avais déjà entendu parler des guerres de libération.

Quand Ivo Sosthenes de Vera Cruz Jordão se maria, il m'invita à aider à l'organisation du mariage, en 1963. Comme il appartenait au Clube Desportivo, ils louèrent le Club pour faire la cérémonie. J'avais une femme, qui aidait aussi. Alors, l'inspecteur adjoint de la Pide, Nogueira Branco, également invitée $e^{467}$, s'approcha de ma femme et dansa avec elle. À minuit, je demandai donc à Mário Santos (des téléphones) de m'emmener avec ma femme à la roça. Le gars de la Pide ne réussit rien du tout, mais ça me montra que la Pide était toujours à mes basques.

En 1964 arriva un de mes cousins de Mambone, marin sur le navire Beira, qui chercha où j'étais. Je quittais la roça pour aller le trouver. Mais, pour pénétrer dans le bateau, je devais avoir un laissez-passer de la Pide. Parce que le bateau reste au large. J'ai donc été à la Pide, j'avais déjà réussi à avoir la carte d'identité (pas seulement le carnet d'identité qui avait substituté le livret indigène en $1961^{468}$ ).

Ils me délivrent le laissez-passer, mais Nogueira Branco n'était pas là. Quand il revint, il se fâcha, mais j'étais déjà à bord ! Je pouvais y rester jusqu'à 17 heures.

Le bateau devait lever l'ancre à $17 \mathrm{~h} 30$, mais j'y suis resté pour bavarder! Un gars de la Pide vint me chercher, mais je fus le dernier à sortir !

Je revins dans le petit cannot, avec le gars de la Pide. Mais il eut une panne. Le cannot ne pouvait plus démarrer! Nogueira Branco était inquiet. Quand je suis arrivé, Nogueira dit que j'avais voulu fuir. Fuir, après neuf ans? J'étais déjà citoyen portugais, libre ${ }^{469}$ !

Le 31 décembre 1966, je préparai mes bagages et attendit le cargo «Índia ». Il arriva le 26 janvier. Je me séparais de mes collègues, je fus le dernier à embarquer. Le bateau leva l'ancre...

Mais il se trouve que le commissaire du bord était un de mes amis de l'Institut du travail!

- "Você já não é prisoneiro, passa a adjunto de comissário! », «Vous n’êtes plus prisonnier, vous passez adjoint du commissaire!»

$\mathrm{J}$ 'eus droit à la nourriture de $1^{\mathrm{e}}$ classe.

Nous sommes arrivés à Lourenço Marques le 8 février. J'avais un oncle à Lourenço Marques. Quand j'arrivai, il y eut une pluie torrentielle qui inonda toute la ville! Nous dûmes attendre un jour de plus pour débarquer, le 9 .

Je préférai ne pas aller à Mambone, parce que là-bas, la famille de João Mabingo qui s'était pendu soutenait que si nous n'avions pas eu de problèmes avec Sebastião Chambino, leur parent ne se serait pas pendu. Ma maison était en face de la leur, et je ne voulais pas d'autre problème ${ }^{470}$.

${ }^{467}$ On ne peut savoir quelle est la motivation précise de Sosthenes ici, mais c'était une tactique classique des milieux nationalistes que d'inviter, à chaque réunion un peu importante (que ce soit une assemblée associative ou une fête), un officiel de la Pide. Cela «innocentait» la réunion et on savait au moins l'identité de l'(un des) indicateur(s)!

${ }^{468}$ Cette précision est importante : quand l'indigénat fut officiellement supprimé en 1961-62, demeura la distinction entre «droit coutumier » et «droit écrit», ou entre le « rural» et l'« urbain ». Les anciens indigènes reçurent donc un cartão à la place de l'ancien livret indigène (caderneta indígena), mais s'ils optaient pour le droit écrit (et rompaient ainsi avec la «ruralité»), ils recevaient la vraie carte d'identité portugaise (bilhete de identidade). Malgré le maintien de cette distinction stigmatisante, la différence avec l'ancien système était néanmoins que le passage d'un état à l'autre était désormais bien plus facile (presque automatique lors de la demande, sauf veto de l'administration) et que le travail forcé n'était plus associé à la situation «rurale». Gabriel Tivane est donc devenu, en 1964, ce que l'on appelait un assimilado (assimilé) avant 1961, jouissant, en principe, de la citoyenneté portugaise de plein droit.

${ }^{469}$ Voir note ci-dessus.

${ }^{470}$ Très probablement, il ne fait pas référence à de simples querelles de voisins, mais plutôt à la crainte d'une attaque en sorcellerie. 
En attendant, je trouvai un travail à Lourenço Marques. Je visitai la famille seulement deux années plus tard. À ce moment, j'allai voir Afonso Henrique Ivens Ferraz Freitas qui travaillait dans une entreprise privée depuis sa sortie de l'administration. Mendes Serra aussi était à Maputo. Il avait reconnu son erreur ${ }^{471}$ et avait donné de moi de bonnes informations pour l'obtention de la carte d'identité, quand j'étais encore à São Tomé.

Je suis entré à la Gulf Oil comme téléphoniste auxiliaire. Mais quand fut ouvert le concours d'agents de recensement, Mendes Serra me fit dire de me présenter. Nous nous présentèrent aux épreuves, j'obtins la deuxième place et j'entrai comme agent de recensement de l'impôt domicilaire ${ }^{472}$. Mais c'était un travail à l'année, et je dus me soumettre aux épreuves pour la deuxième année. Ensuite, j'ai arrêté et j'ai travaillé dans un entrepôt, puis dans la Companhia de transportes de Moçambique qui exploitait une ligne d'autocar pour Mabote, ensuite dans la Foto portuguesa, enfin à la Maquil.

Au temps de São Tomé, j'étais le chef des Mozambicains, ils venaient me demander conseil. Aussi, à Lourenço Marques, j'eus des amis aussi bien de Mambone que de tout le Mozambique. Je suis très connu à Gaza.

A mon retour, je ne rejoignis pas le Centre associatif ${ }^{473}$ ou l'Association africaine. La Pide continuait à me poursuivre. Celui qui me protégea fut Mendes Serra, l'homme des claques à São Tomé ! Il était inspecteur administratif, proche de la retraite. Il resta résident et ne partit qu'à l'indépendance du Mozambique. Il ne passa pas plus de deux ans au Portugal où il mourut ${ }^{47}$.

Ensuite, j'ai été à Xai-Xai, à l'entreprise A.J. da Costa, dans la construction, le 16 septembre 1974. Je suis resté à Xai-Xai jusqu'en août 1977. Ma sympathie pour le Frelimo [avant l'indépendance] était de la curiosité. Je n'ai jamais eu l'idée de vouloir aller en Tanzanie. J'avais déjà assez souffert, j'avais fait l'équivalent de ceux qui étaient partis en Tanzanie. Je ne voulus pas m'attirer d'autres problèmes.

Quand le Frelimo a pris le pouvoir, je fus secrétaire du Groupe dynamiseur ${ }^{475}$ de l'entreprise A.J. da Costa, et secrétaire aux questions sociales du GD du quartier $n^{\circ} 1 \mathrm{de}$ Xai-Xai. J'ai assumé.

En 1977, je suis retourné à Maputo, comme comptable à la FACIM $^{476}$ et responsable des ressources humaines, comme simple militant du Frelimo. En 1981, j'ai été transféré à la Pescom Internacional ${ }^{477}$, comme comptable, et toujours militant du Frelimo.

En juillet 1982, j'ai demandé ma démisssion pour entrer aux Salines de Nova Mambone comme comptable. Je suis resté militant du Frelimo, bien que je n'aie pas eu de carte d'adhérent parce que, même si j'étais catholique, j'avais deux femmes ${ }^{478}$.

J'ai été contre cette idée de supprimer les chefferies. Le Frelimo disaient qu'ils avaient été des collaborateurs du colonialisme. Mais ce n'était pas vrai. C'était toujours le «Abaixo ${ }^{479}$. Mais les régulos qui collaboraient ne le faisaient pas par libre choix. Au cours d'une réunion, j'ai demandé la raison, pour laquelle on ne versait plus un subside aux régulos et chefs de hameau ${ }^{480}$. C'était au cours d'une réunion en 1975 . Je n'étais pas à Mambone, mais je venais chaque mois.

J'ai travaillé aux Salines jusqu'en septembre 1985. Je suis sorti parce que je trouvais que ça ne marchait pas, les travailleurs étaient indisciplinés, l'entreprise sombrait. Cela est allé presque jusqu'à la faillite, les horaires n'étaient pas respectés. J'ai arrêté. J'ai

${ }^{471}$ Mendes Serra se fit connaître par un rapport retentissant démontrant la réalité du travail forcé en Angola.

${ }^{472}$ Nouvelle désignation de l'impôt indigène, pour ceux qui restaient soumis au « droit rural ».

${ }^{473}$ L'eût-il voulu, il ne l'aurait pas pu, puisque le Centro associativo dos Negros de Moçambique fut interdit en 1965 et ne réapparut, de façon éphémère, qu'en 1974 (voir note 90).

${ }^{474}$ L'information de Gabriel Tivane est tout à fait erronée. Mendes Serra continua à vivre très bien, je l'interrogeais en 1980. Il était alors à Lisbonne l'un des responsables du Centro démocratico e social (un parti chrétien de droite).

${ }^{475}$ Les Groupes dynamiseurs (ou GD) étaient, à la base, à la fois des structures du parti (pré-cellule) et des institutions d'entreprise ou municipales de quartier.

${ }^{476}$ FACIM, Foire agricole, commerciale et industrielle du Mozambique, la Foire annuelle internationale de Maputo.

${ }^{477}$ Entreprise publique de pêcheries.

${ }^{478}$ À partir de 1977, le Frelimo entreprit une épuration de ses rangs de tous ceux accusés de pratiques « féodales », « obscurantistes », etc., dont la polygamie. Mais à la base, la souplesse prévalut souvent, comme l'indique la situation étrange de Gabriel Tivane, « militant non membre », catholique et polygame, du Frelimo !

${ }^{479}$ Tivane fait référence aux mots d'ordre du Frelimo qui commençaient invariablement par «Abaixo... » (« À bas... ») le colonialisme, le régionalisme, le tribalisme, l'obscurantisme, le féodalisme, etc. Ses militants étaient donc appelés les Abaixo.

${ }^{480}$ Les régulos et chefs de hameaux percevaient une modeste allocation de l'État colonial, en pourcentage des impôts qu'ils percevaient pour celui-ci. Le Frelimo la supprima évidemment. 
commencé à travailler avec le grossiste Inocêncio Farias, l'actuel délégué de la Renamo. En 1989, j'ai arrêté aussi parce qu'il sombrait, pour des raisons familiales.

Je suis resté comptable à mon compte mais cette région n'a pas beaucoup d'entreprises. Je suis aussi assistant juridique de l'INAJ ${ }^{481}$.

Je suis toujours resté au Frelimo. Ceux du Núcleo negrófilo ${ }^{482}$ sont à la Renamo, parce qu'ils y ont leur dirigeant ndau. Dans mon idée, je pense que je ne dois pas forcément être de la Renamo parce que je suis ndau. Je me considère père et fondateur du Frelimo, parce qu l'idée du Frelimo de déclencher la guerre de libération est venue de nous, ici, de revendiquer, etc.

Cette guerre [civile], je ne sais pas bien l'expliquer. Quand la Renamo a commencé la guerre contre le Frelimo, c'était juste. Personne n'aimait le communisme, je n'aimais pas les directives. Mais je ne pouvais rien dire. Mais la Renamo, en faisant la guerre, au lieu d'attaquer le Frelimo lui-même et les dirigeants ou les administrateurs, s'est mise à attaquer la population. La population aimait bien la Renamo. Mais quand ils attaquaient le bourg, après avoir pillé les gros, sur le chemin du retour ils volaient aussi et même tuaient la population. Au lieu d'attaquer la police et les soldats.

Moi, population ${ }^{483}$, bien que je sois adepte du Frelimo, je n'étais pas responsable pas leurs mauvaises actions et donc je ne devais pas non plus être attaqué.

Le 25 août 1991, ils ont attaqué le bourg [de Mambone], ils ont volé les boutiques de Mussa Caro, d'Abdula, etc. C'est bon, ils venaient lutter contre ceux qui étaient sur le trône. Mais ensuite, ils commencent à casser les maisons, une femme qui vivait dans la maison de son oncle a perdu tous ses biens: mais maintenant, avec l'actuelle réconciliation, elle est devenue membre de la Renamo, quand même elle aurait pu rester neutre.

Alors j'ai demandé les raisons : les gens répondaient que si on ne votait pas pour elle, la Renamo allait retourner en brousse. Mais je sais que la Renamo ne va jamais retourner en brousse. Elle doit servir à modérer le Frelimo. C'est maintenant l'époque où la Renamo doit étudier, adopter des comportements civiques. La population l'aimera mieux, parce que, encore aujourd'hui, la réconciliation est assez faible : - «Não vou votar naquele que matou o meu primo », "Je ne vais pas voter pour celui qui a tué mon cousin », mais la Renamo va abandonner ses attitudes grossières. Je crois que d'ici cinq ans, la Renamo va gagner les prochaines élections.

Maintenant j'ai ma carte du Frelimo, parce qu'il n'y a plus ségrégation pour polygamie.

Si le Portugal avait eu une bonne administration, l'indépendance aurait été graduelle, comme une école. Mais il n'y a pas eu cette volonté de travailler en commun, d'accepter que le Noir puisse gouverner aussi.

De fait, le Frelimo a amené des gens qui n'avaient jamais gouverné auparavant. Les techniciens ont fui et le pays est allé de pire en pire. En 1975, le Mozambique était déjà développé. Peut-être qu'il n'y aurait pas eu le communisme [si le Portugal avait eu une bonne administration].

Maintenant, nous sommes en 1950, nous recommençons les années soixante, les années soixante-dix. Ça mettra peut-être vingt ans. »

Gabriel Tivane s'est vu reconnaître la qualité d'ancien combattant [de la guerre de libération] et est membre de l'association. Il touche une petite pension de 300 contos par mois $^{484}$. Son rêve est de développer une petite entreprise de pêche artisanale : - «Eu gosto

\footnotetext{
${ }^{481}$ Sigle non élucidé (Instituto nacional de apoio à juventude ?)

${ }^{482}$ C'est-à-dire le Núcleo negrófilo de Manica e Sofala. Voir notes 80 à 83 supra, ainsi que le paragraphe «Mambone et Machanga » de l'introduction, et la note 13 attenante.

${ }^{483}$ «Eu, população...» («Moi, population... »), expression typique du vocabulaire politique populaire au Mozambique, dérivé du discours politique du Frelimo lui-même. Ce dernier en effet n'a jamais considéré pertinentes les sociétés africaines en tant que telles. Dans son vocabulaire politique, il ne daignait considérer que, d'une part, les estruturas et le povo organizado (les «structures » et le «peuple organisé », c'est-à-dire les organes du parti-État et les personnes qu'elles encadraient: fonctionnaires et adhérents) et,d'autre part, les elementos da população («éléments de la population»), les habitants en général,bien distincts du concept de «peuple», censés n'avoir nulle «organisation» puisque ethnie, tribu, lignage, clan, religion ne pouvaient en tenir lieu, et devant donc être organisés ex-nihilo, comme simples individus, par le nouveau pouvoir. «Eu, população... » est donc la contraction populaire de «Eu, elemento da população » et signifie: «Moi, simple

${ }^{484} 300$ contos, soit 300000 meticais, environ 300 francs français ou 10000 escudos portugais.
} habitant...». 
muito da pesca », "J'aime beaucoup, la pêche ». [Pour finir, nous évoquons rapidement] le rôle important de l'Escola de Artes e Óficios de Gogoi, créée par Bed Simango ${ }^{485}$.

17h. Fin de l'entrevue. Je retourne à la Vila pour trouver Inocêncio Faria. Il m'attendait chez Madeira depuis 16 heures. Nous combinons de nous rencontrer demain dimanche à 11 heures, après la messe.

18h. Je devais aller dormir à la Mission, j'en ai assez de la Casa de hóspede de l'administration ${ }^{486}$. Mais il n'y a plus de boleia ${ }^{487}$. Alors je reprends le vélo bleu de la Renamo, avec la pédale gauche qui tombe tout le temps, pour faire les $7,5 \mathrm{~km}$ jusqu'à la Mission, sur cette mauvaise piste de sable.

C'est déjà l'obscurité, avec un fin croissant de lune et des milliards d'étoiles, une Voie lactée fantastique! Mais pédaler dans le noir avec un vélo sans phare, ça fait une drôle d'impression.

De surcroît, à chaque fois que je croise des gens, je suis le spectacle! Un muzungu ${ }^{488}$ en vélo, on a rarement vu ça. [D'ailleurs, j'ai oublié de noter qu'hier, avant d'aller à Matasse, j'ai essayé d'aller à Machanga. Mais la marée était basse, donc il n'y avait plus la barque, il fallait traverser à pied, avec de l'eau jusqu'au slip. J'ai renoncé, non à cause de l'eau, mais pour ne pas être le muzungu en slip à traverser la rivière ! N'est pas Blanc qui veut.]

18h45. Arrivée à la Mission. Dîner avec le Padre et un frère. Amadeu dit :

- "O grande erro da Renamo foi de, para esfomear o leão, ter morto as gazelas. Se a luta tinha continuado como até 1982, com este comportamento impar, a libertação teria chegado muito mais cedo », "La grande erreur de la Renamo fut, pour affamer le lion, d'avoir tué les gazelles. Si la lutte avait continué comme jusqu'en 1982, avec ce comportement modèle, la libération serait arrivée bien plus vite ».

\section{Dimanche 6 novembre 1994}

10h. Départ de la Mission, en vélo bleu de la Renamo, pédale réparée, pour la maison de Inocêncio Faria, délégué Renamo : 7,5 km de sable, oyé !

10h30. J'arrive chez Faria, qui est encore à la messe. Évidemment, la pédale s'est à nouveau déboitée juste après mon départ, et j'ai dû la remettre toutes les cinq minutes...

À Mambone, il y a un grave problème agronomique. À cause des famines dues aux sécheresses et à la guerre, les gens ont pris l'habitude de donner la priorité aux chèvres, car les chèvres survivent toujours : - «O cabrito salvou-me a vida! », "La chèvre m'a sauvé la vie ! », cela veut dire que, quand on n'a plus rien, on vend la chèvre aux commerçants et on achète un sac de riz ou de maïs. Pendant la grave crise de 1983, les chèvres ont été vendues jusqu'à la somme dérisoire de 500 meticais ${ }^{489}$. Aujourd'hui, c'est 70000 meticais.

En conséquence, les chèvres sont laissées en liberté au milieu des cultures, à proximité des maisons, et, en période sèche, avides de feuilles vertes, elles saccagent systématiquement les cultures. Seuls ceux qui peuvent cloturer sont protégés. La Mission, elle, envoie son troupeau de soixante-dix bêtes loin en brousse, sur le planície ${ }^{490}$.

485 L'École des arts et métiers de Gogoi fut typique de l'activité des Africains protestants congrégationnalistes, cherchant à dignifier l'homme noir. Gogoï était, dans l'intérieur du Manica, la station missionnaire mozambicaine la plus importante liée à la «capitale régionale » du congrégationnalisme américain, située à Mount Selinda, en Rhodésie.

${ }^{486}$ Maison d'hôte louée par l'administration, ou servant à des officiels de passage. Celle-là était en piètre état.

\footnotetext{
${ }^{487}$ Boleia : transport en auto-stop.

${ }^{488}$ Muzungu : Blanc.

${ }^{489}$ Environ cinquante centimes français, ou quinze centavos portugais.

${ }^{490}$ Planície, plateau bas.
} 
Par ailleurs, même si à l'inverse du mouton qui arrache la racine, la chèvre mange «seulement» les feuilles et tiges tendres, sa salive étant très acide, presque vénéneuse, la plante amputée traverse une crise aiguë et ne peut repousser à l'endroit de la morsure.

L'an passé, l'administrateur a fait un edita ${ }^{491}$ interdisant ces pâtures sauvages et autorisant les demandes [d'indemnisation]. Au début les gens ont eu peur, habitués à la forte administration du Frelimo. Les indemnisations (voir carnet $n^{\circ} 3$ ) n'ont guère été demandées, sauf aux métis, par peur du feitiço, du mauvais sort. Mais ils ont fait attention.

Mais comme l'administrateur n'a rien fait - «a Frelimo deixou de governar », "Le Frelimo ne gouverne plus », dit Amadeu -, cette année ça a recommencé de plus belle.

La maison de Faria est, comme de coutume, un vrai airial landais ${ }^{492}$, avec trois maisons en ciment plus une cuisine et plusieurs petites cases en banco (matope). Il aurait pu être riche, avec un grand armazém (entrepôt) et sa propre boutique. Mais il s'est laissé volé par un neveu, il a été grugé par divers autres commerçants liés au Frelimo et a souffert de la guerre. Son vieux camion Mercedes avance aos soluços, par soubresauts, au pas.

Son airial est rempli de personnes métisses, habillées à l'africaine, parfaitement ndaus, et de personnes noires. De vieux filets de pêche, des carcasses de voiture. Un puits. Quelques papaiers et de vieux anacardiers. On a parfois l'impression d'être dans un coin paumé du Mexique - je n'ai jamais été au Mexique, mais j'imagine. Poules, canards, dindes, cochon.

11h30. Entrevue avec Inocêncio Faria, délégué de la Renamo à Nova Mambone.

« Je suis né au cap de Bartolomeu Dias, en 1935, en novembre, le 12. À l'époque, B. Dias n'était pas encore une île, c'était un cap ${ }^{493}$. Mes parents arrivèrent là en 1890 , mais étaient nés à Mambone. Mon père était interprète, il parlait cindau, xitsua, anglais, indien $\left[\mathrm{sic}^{494}\right]$. Il travaillait sur les boats [sic], France, Portugal, Angleterre, Amérique. Il était métis. Mon grand-père était portugais. Après le métier d'interprète, il était resté là. Quand le territoire est passé à l'État ${ }^{495}$, l'administration fut transférée de Bartolomeu Dias à Nova Mambone.

Le mot «Mambone », ça veut dire «bibelots ». Parce que les premiers qui arrivèrent n'ont pas été les Portugais, mais les Indiens. Dans leur langue, « Mambones », ce sont les bibelots, que les gens voulaient. Ils demandaient : «Mambone, Mambone » et le nom est resté.

Mais mon père est resté à Bartolomeu Dias comme chef du Poste administratif et capitaine du port. Il fut un des premiers chefs de poste métis. Mais il y avait plus de population à Inhassoro, et le Poste administratif fut transféré à Inhassoro ${ }^{496}$. Le Govuro de cette époque était très grand, Inhassoro était dans le Govuro.

Mon père se déplaçait en maxila ${ }^{497}$ pour recouvrir l'impôt. Arrivé dans une chefferie, le régulo désignait quatre hommes pour porter la maxila. Arrivé à une autre chefferie, les hommes revenaient, et le régulo de là désignait de nouveau quatre hommes. Quatre cipayes marchaient aussi avec lui.

Nous nous sommes installés à Batata-Nachingalala, un petit port avec des salines, en face de B. Dias, en 1943 ou 1944. Il continua à travailler pour l'administration, comme interprète, en dessous des autres. Quand il revint à B. Dias, le gouvernement lui donna un terrain. Il défricha, marqua le terrain, fit un petite maison de bois et rosaux. Lors du cyclone de 1948, tout fut détruit et il perdit ses économies en livres ${ }^{498}$.

${ }^{491}$ Edital, arrêté local.

${ }^{492}$ Dans les Landes de Gascogne, l'airial est un espace sur lequel, autour de la belle maison du maître, on trouve la maison du métayer, l'étable, la grange. La structure architecturale épouse fidèlement la relation sociale paternaliste.

${ }^{493}$ La côte évolue très rapidement en cet endroit. Voir note 72.

${ }^{494}$ Probablement gujerate, car il n'y a pas de Goanais (parlant konkani) dans la région.

495 Il s'agit du territoire de Manica e Sofala, attribuée en concession à la Compagnie du Mozambique en 1891 (compagnie à charte), et repassé sous administration directe de l'État seulement en 1942. Contrairement à la division territoriale postérieure à 1942 (toujours en vigueur aujourd'hui), le territoire de la Compagnie embrassait une large bordure au sud du fleuve Save, incluant notamment le Govuro.

${ }^{496}$ Plus au sud, sur la route de Vilanculos.

${ }^{497}$ Maxila, sorte de hamac suspendu à une forte branche et portée par deux hommes devant et deux hommes derrière.

498 Une monnaie dénommée livre et copiée sur celle de la Rhodésie circulait dans le territoire de la Compagnie jusqu'en 1942, et ne disparut que peu à peu ensuite. 
Il faisait les lettres de la révolution de Gabriel Tivane, du Núcleo dos naturais, pour l'Afrique du Sud. Il faisait aussi partie du Negrófilo. Après 1953-54 ${ }^{499}$, il remit sa démisssion et resta comme pêcheur. L'atmosphère dans l'administration était mauvaise, ils [la police] voulaient découvrir quelque chose sur lui, alors il feignit la maladie. Il partit pour Lourenço Marques pour être examiné par les médecins. Il ne voulait plus.

Il resta comme pêcheur, avec son propre personnel. Moi, il m'envoya en 1949 à l'école de Mossurize ${ }^{500}$. Ici, à l'École publique Pery de Lind, il disait que je ne faisais que jouer. J'ai donc été vivre chez mon oncle Pinto et ma tante. L'oncle était l'interprète de Mossurize. J'y suis resté deux ans. C'était à Espungaberra. J'allais faire mon entraînement de boxe à Mount Silind, en Rhodésie. Gogoi, je l'ai visté, parce qu'il y avait beaucoup de gens de la Machanga et de Mambone à l'École des Arts et métiers de Bed Simango.

En 1952, avec mon oncle, nous nous sommes installés à Vila Pery ${ }^{501}$. Mon oncle avait cessé d'être interprète. J'allais à l'école de la mission Catedra de V. Pery. Après 1955, je fus transféré à la misssion des Amatongas. Aux Amatongas, il y avait beaucoup de travail scolaire, de travail aux champs, de chargement et déchargement des camions, de récolte des fruits. Il n'y avait presque pas de temps pour étudier. Nous nous levions à 4 heures du matin, pour la cueillette des fruits. Ensuite, toilette, de l'eau, la bouillie [petit-déjeuner] et, à $7 \mathrm{~h} 30$, école.

Après la $4^{\mathrm{e}}$ classe aux Amatongas, j'ai décidé que ça ne valait pas la peine d'étudier. L'argent que mon père envoyait, mon cousin [i.e. l'oncle] mangeait tout. Quand je revins, douze ans après sans jamais être retourné [à la Machanga], j'ai été à Beira avec une qualification de soudeur-chaudronier. J'étais aussi cantonnier. J'étais joueur de football du Cyclône. Le président en était Maimisse Mafalala, et Domingos Arouca ${ }^{502}$ était sympathisant [supporteur]. On a remporté de nombreuses victoires.

Quand j'arrivai à Beira, le Centro africano, qui était pour les métis, vint me chercher pour le football. Je suis resté à Beira jusqu'en 1956, et je suis revenu à Mambone pour me reposer. Mais j'ai travaillé à la boutique de Cassamo Kara. Après deux ans, j'ai changé pour la boutique d'Ibraimo Hassan, qui payait plus, sur les terres de Malanguene, un poste commercial près de Pande. J'ai travaillé là six ans. Ici, c'était 300 escudos, là 600 . De là, j'ai été avec mon beau-frère José Alves, frère de Joaquim Alves, un commerçant portugais de Vilanculos qui avait quarante boutiques et des lignes [de camionage]. J'ai ouvert sa boutique de Mambone, avec un salaire de 3500 escudos comme gérant en 1964. J'y ai travaillé jusqu'en 1968. Le Blanc Albano Nunes de Carvalho est alors venu me chercher, pour ouvrir sa boutique à Pande. Il avait laissé la Mission de combat aux trypanossomiase $^{503}$. Là, je recevais déjà 15000 , plus qu'un chef de poste. J'ai travaillé avec lui très longtemps. Je parcourais la brousse pour vendre. Je connais toute la zone de Mabote - qui faisait encore partie du Govuro. En 1972, je suis revenu à Mambone. Ma première femme, la fille de José Alves, était enceinte et nous sommes allés à Beira. Le bébé est mort-né. Je n'ai pas repris le service. J'ai acheté un camion et j'ai mené ma vie particulière.

En 1962, j'ai fait l'armée coloniale, dans les commandos - les premiers commandos ${ }^{504}$. Mon frère Paulo António Faria à Vila Pery sympathisait avec le Frelimo et avait donné les immatriculations de mes camions pour qu'ils ne soient pas attaqués, en $1973^{505}$. Je venais toujours d'Inchope sous le feu, en voyant des camions brûler. Après être arrivé, la DGS demandait :

- "Como há de passar, você ? ", «Comment réussissez-vous à passer, vous ?»

- "Não sei, um dia hei de ficar! ", « Je ne sais pas, un jour j’y resterai !»

Ils venaient toujours me voir, ils achetaient aussi ce que je rapportais.

\footnotetext{
${ }^{499}$ C'est-à-dire au moment des émeutes de Machanga et Mambone et de leur répression.

${ }^{500}$ District proche de la frontière rhodésienne, dont le chef-lieu est Espungaberra.

${ }^{501}$ Nom colonial de l'actuelle Chimoio.

${ }^{502}$ Il s'agit bien du même Domingos Arouca, brièvement en poste à Mambone. Voir note 90, supra.

${ }^{503}$ Rappel : la MCT était l'une des principales stations de lutte contre la mouche tsé-tsé au Mozambique.

${ }^{504}$ L'armée coloniale n'avait pas de troupes d'élites jusqu'à cette date. Leur formation fut décidée après les événements d'Angola (1961). Mais les comandos étaient encore copiés sur l'armée portugaise métropolitaine. Ensuite apprurent les «Grupos especiais» (Groupes spéciaux), les «Grupos especiais paraquedistas » (parachutistes), et les «Grupos de pisteiros de combate» (pisteurs de combat), troupes d'élites noires de contre-

${ }^{505}$ L'année 1973 est celle d'une forte croissance de l'activité du Frelimo, toujours plus au sud, qui affectait en particulier la circulation routière.
} guérilla. 
Quad le Mozambique a été livré [au Frelimo], nous aussi étions frelimistes parce que nous voulions voir cette terre libre. Quand Machel est venu du nord pour Maputo ${ }^{506}$, avec la flamme en tête, nous avons retrouvé la flamme au [fleuve] Save. Nous avons porté la flamme jusqu'aux limites de Vilanculos, pour ceux de Vilanculos et nous sommes revenus à la maison pour faire la fête. En 1975 et 1976, j'ai été secrétaire du Front à Mambone. Il y avait beaucoup de gens. Mon camion était utilisé pour le service, pour amener les nouveaux secrétaires dans les localités, à la place des régulos. Toutes les dépenses, les transports, l'huile, le riz, les courriers, pour la fête de l'indépendance, ils ne m'ont jamais payé.

En 1977, le Parti me demanda d'aller faire une perquisition chez deux Blancs, José Maria Lourenço (patron d'une boutique à Pande), et Carvalho (patron des pompes à essence de Vila Franca do Save), qui étaient mes amis, pour voir s'ils avaient des armes. Je leur dis :

- «Não sou eu, primeiro secretário, a fazer isso. Vocês é que vão », «Ce n'est pas moi, premier secrétaire, qui vais faire ca. C'est vous qui y allez »

Ils voulaient me tester. Ils y allèrent et ne trouvèrent rien. Au retour, ils me demandèrent d'aller perquisitionner chez Manejo, le guérisseur ${ }^{507}$. Ils disaient :

- «O Manejo recebe muitas pessoas de fora, da África do Sul, e tem muitos trabalhadores em casa, isto não pode ser, isto é exploração do homem pelo homem ", «Manejo reçoit plein de gens de l'extérieur, d'Afrique du Sud, et a de nombreux travailleurs chez lui, ce n'est pas possible, c'est de l'exploitation de l'homme par l'homme.».

Ils pensaient que lui aussi avaient des armes ou quelque chose de ce genre. J'ai dit :

- «Não vou, vocês estão a insistir, vou desistir », «Je n'y vais pas, si vous insistez, je démissionne ».

Or mon cousin, Vasco Joaquim Leitão, était père [i.e. religieux], mais un père seulement en couverture, il allait et venait ainsi, il était déjà de la Renamo, il faisait des réunions comme s'il était père. Je ne sais pas comment il a connu André Matsangaissa, parce qu'il n'avait jamais été mis en camp de rééducation. C'était en 1978 ou 1979. Mais il avait une radio et parlait avec André sous le nom de code de Velito. Il vivait dans le quartier de l'Alto-Maé, à Maputo, et venait en Volkswagen. Il vivait au deuxième étage mais avait loué un garage en sous-sol où il avait sa radio et son bureau. Quand arrivait l'heure, il allait en bas. Il ne fut jamais découvert à ce moment, même pas par sa femme.

Très souvent, il me disait :

- «Vamos embora, voltamos para o mato. Vamos pôr a família a seguro, os seus carros também, e nós vamos para o mato », "Allons-nous en, retournons en brousse. On va mettre la famille en sécurité, les voitures aussi, et nous nous partons en brousse. »

J'ai parlé à ma vieille $e^{508}$ et elle me dit qu'elle ne pouvait pas y aller, qu'elle ne supporterait pas le climat ${ }^{509}$. Alors, je ne suis pas parti. Mais j'ai dit que je restais ici pour faire localement le travail de la Renamo.

Quelque temps après, le Snasp $p^{510}$ l'a découvert, parce que sa femme était la maîtresse d'un homme de la direction du Snasp. À la femme, il disait :

- «Espera para ver bem quem entra, quem vem, para fazer tudo bem », « Regarde bien qui entre, qui vient, pour tout bien noter $»^{511}$.

Alors, le jour où il [mon cousin] m'avait appelé pour emmener sa radio et d'autres choses, ils m'ont dit quand je suis arrivé que mon frère ${ }^{512}$ était parti avant-hier pour le Swaziland, accompagné par deux majors du Frelimo, des amis à lui, qui collaboraient avec nous. La mère $e^{13}$ et les enfants étaient restés. J'ai pris la clé, j'ai été dans le compartiment en bas, j'ai ouvert, je me suis enfermé dedans et j'ai tout détruit: les papiers, la radio. Il y avait une fosse avec de l'eau. J'ai tout brûlé et j'ai mis la cendre dans l'eau. J'ai mis la chappe de nouveau par-dessus. J'ai vérifié qu'il n'y avait plus aucun vestige qui pourrait nous mettre en péril. J'ai pris la clé et l'ai rendue à ma tante. Je lui ai dit :

${ }^{506}$ Samora Moisés Machel, président du Frelimo, mit puissamment en scène son arrivée à Maputo, la faisant précéder d'un voyage terrestre aux multiples étapes, depuis le nord du Mozambique jusqu'à la capitale dans l'extrême-sud. Son escorte était devancée par la flamme, en un symbole quasi olympien.

${ }^{507}$ Manejo est un guérisseur (curandeiro) très célèbre. Sa clientèle, en 1975 comme en 1994, s'étendait jusqu'à l'Afrique du Sud.

${ }^{508}$ Il n'y a rien de péjoratif, au contraire, dans cette expression ( $a$ velha), qui désigne affectueusement sa mère.

${ }^{509}$ Sa mère pensait certainement à un exil au Portugal ou en Afrique du Sud.

${ }^{510}$ Snasp, Serviço nacional de acção e segurança popular, la toute puissante police politique.

${ }^{511}$ Il n'est pas du tout certain que le cadre du Snasp ait eu, alors, des doutes sur le mari. Mais il profitait classiquement de sa position pour chercher à se débarrasser de lui.

512 « Frère », c'est-à-dire son cousin au sens européen.

${ }^{513}$ C'est-à-dire la mère de son cousin, sa tante. 
- "Ponha a chave no lugar onde ele costumava pô-la, e diga se eles perguntam: "Não sei, não costumava mexer nesta chave" ", "Mets la clé à l'endroit où il avait l'habitude de la mettre, et s'ils te demandent, dis leur: "Je ne sais pas, je n'avais pas l'habitude d'utiliser cette clé" ».

Alors elle m'a dit :

- «Daqui a nada hão-de chegar e você não pode fazer barulho, comprimento só, não perguntam quem são eles », "Ils vont arriver dans un instant, il ne faut pas faire de bêtise, seulement les saluer sans leur demander qui ils sont. »

Dix minutes après, trois personnes arrivent, elle, lui (le nouveau mari) et un autre. Nous buvons, nous parlons, mais ils ont pris la clé. Ils sont allés voir ces choses. Mais ma tante dit :

- «O primo chega agora mesmo, não foi ainda à casa de banho », « Le cousin vient d'arriver, il n'a même pas été aux toilettes ».

Alors, je vais aux toilettes et ils vont en bas. Mais ils avaient laissé un magnétophone. Alors, on a parlé de choses et d'autres pour le magnétophone !

Mais ils ont pensé que Vasco Leitão était encore là, que c'était lui qui avait tout emmené, puisque je venais juste d'arriver. Ils sont partis. La tante me dit en cachette :

- "Eu também deve haver um carro a vir buscar-me. Não sei a que horas. Vamos a sete pessoas. É um major que vem me levar para o Suazilândia, num carro da tropa, que não é revistada», "Moi aussi une voiture doit venir me chercher. Je ne sais pas à quelle heure. Nous partons à sept personnes. C'est un major qui vient me chercher pour le Swaziland, dans une voiture de l'armée qui n'est pas fouillée. »

Vers dix heures du soir, ils revinrent et nous avons parlé. Je demandai : "Qu'est-ce qui s'est passé ? ». Je dis que je repartais pour Mambone, mais que je reviendrais pour savoir. Ils sortirent, mais j'avais repéré un micro ! Il ne devait pas y en avoir seulement un, mais du moins j'en ai vu un. Aussi, nous avons parlé dans la véranda.

À onze heures du soir sont arrivés les deux majors de l'armée ! Ils partirent et je suis resté seul. Je ne dormis pas. A l'aube, je suis parti.

De retour à Mambone, trois semaines après, le Snasp de Maputo arrive chez moi : « Nous sommes venus chercher ton frère s'il est arrivé ici ». J'ai dit qu'il n'était pas arrivé. Ils m'ont dit que quand il arriverait, ce serait mieux de prévenir l'administration. Ils sont partis.

Alors, quinze jours plus tard encore, apparaît le Snasp d'Inhambane, vers onze heures du matin. Il y avait un des gars que je connaissais. Ils m'ont questionné une fois de plus, mais à mon tour je demandai ce qu'ils avaient fai de lui, à la fin, l'avaient-ils tué ? Quinze jours plus tard encore, d'autres Snasp sont venus d'Inhambane, Vilanculos, des personnes que je connaissais. Encore une fois !

Mon frère [c'est-à-dire, mon cousin] était ami de Marcelino dos Santos, mais il pensait que c'était lui qui avait tué Mondlane et était révolté ${ }^{514}$. Comme je connaissais ces personnes du Snasp, je leur dis que mon cousin était déjà hors du pays. Alors, j'ai été à Maputo contacter un Blanc qui m'avait été indiqué par mon cousin. Il n'était pas là, mais sa femme et les enfants étaient là. Je leur dis de communiquer à Velito de partir immédiatement pour l'Afrique du Sud parce que je savais par mes amis du temps de l'armée qu'ils avaient déjà envoyé un groupe au Swaziland.

Comme ce Blanc faisait le transport de Maputo à la Zambézia, je dis que je laisserais mon courrier à Pande, chez José Maria Lourenço. Vasco est alors parti à Lisbonne. Il y est encore aujourd'hui, il est devenu docteur ${ }^{515}$, je ne sais pas pourquoi il ne revient pas.

En 1978, il n'y avait que moi qui savait ce qu'était la Renamo. Jusqu'en 1980, je suis resté seul. Ensuite, j'ai parlé avec les amis du service, on avait des noms de code, Cofre, Risata, Lanco e Brand (le gendre de José Maria Lourenço). Brilhante ${ }^{516}$ était le chef, c'était moi.

La première attaque, ce fut en août ou septembre 1981. Ils sont venus à cinquante-cinq - je n'ai pas fui, j'ai compté -, chacun avec trois armes, à cinq heures du matin, il ssont partis à neuf heures. En entrant, ils ont tiré en l'air un coup de bazooka de $80 \mathrm{~mm}$. Ils sont entrés dans les boutiques, ont pris les choses. Mais de l'autre côté, de la Machanga, ils ont tiré à volonté [c'est-à-dire les soldats du Frelimo], les maisons du côté du fleuve étaient en feu. Les soldats de Mambone s'enfuirent.

${ }^{514}$ Eduardo Mondlane, le premier président du Frelimo, fut assassiné par un colis piégé, à Dar es-Salaam, début 1969. Bien que la Pide portugaise fût le suspect $n^{\circ} 1$ dans l'affaire (ce qui me semble personnellement, avec les sources dont je dispose, le plus probable), des bruits coururent (et courent toujours) sur des complicités internes au Frelimo, liées aux guerres de clans alors très violentes et recoupant non seulement des divergences d'orientation politiques, mais aussi de milieux sociaux et sensibilités ethniques. Bien que Mondlane fût changane (du sud), il était accepté par nombre de militants du centre et du nord du fait de sa position modérée et... de la couleur noire de sa peau, alors que Marcelino dos Santos, « marxiste », était métis.

${ }^{515}$ C'est-à-dire qu'il a passé une thèse ou un mestrado.

${ }^{516}$ Brilhante, c'est-à-dire, le Brillant... 
Ils sont venus dans ma maison. Je ne pouvais pas parler, sinon les autres me tueraient. Six d'entre eux ont avancé, avec un major. J'avais déjà écrit à la base pour dire :

- "Não pode matar quando entrar, não pode violar, só estragar da Frelimo. Quando vocês querem bois, levam, coisas das lojas, levam », "Ne tuez pas quand vous entrez, ne violez pas, abîmez seulement le Frelimo. Quand vous voulez des bœufs, prenez-les, des choses dans les boutiques, emportez-les ».

Derrière eux arrivait un soldat en courant, il disait :

- «Não, não se pode vir nesta casa, aquela carta é esse homem que escreveu, é nosso, é bom fingir que não é nosso, vamos embora», "Non, ne venez pas dans cette maison, la lettre, c'est lui, il est des nôtres, c'est mieux de faire comme s'il n'était pas des nôtres, allons-nous en ».

J'en ai réchappé ainsi. Ils n'ont emmené personne d'ici pour porter, ils avaient des sacs à dos très grands, et les femmes de leur groupe aussi portaient. C'est comme ça que fut la première attaque.

En février 1982, la deuxième attaque fut plus violente, parce qu'il y eut des morts de part et d'autre, de cinq à dix heures du matin, ceux de la Machanga [le Frelimo] tirant sans traverser le fleuve. Même les chèvres fuyaient. Je suis resté dans ma maison avec mon arc. J'avais prévenu la troupe : personne n'entre, de quelque côté que ce soit, il prend une flèche. La flèche ne fait pas de bruit. Arme silencieuse. C'est la guerre, on ne peut pas marcher de nuit.

Ensuite, ils sont revenus en juillet 1982, même genre d'attaque, en respectant toujours le peuple. Ils se promenaient de-ci, de-là, sans problème, la troupe leur tirait dessus de loin.

En 1983, en septembre ou octobre, il y eut une grande attaque. Ils ont emmené des choses, l'armée s'enfuyait toujours. Ils ont pris aussi les bœufs. Le peuple allait trouver l'armée, pour lui dire qu'ils feraient bien d'aller voir. La troupe disait: "Ir lá para morrer, vocês é que vão », "Y aller pour mourir, c'est vous qui y allez ». Le peuple aimait la Renamo mais la Renamo n'avait rien à manger. Je préférais qu'on me prenne mes bœufs mais qu'on me laisse, moi. Et les entrepôts des Calamités ${ }^{517}$ étaient pleins. En 1983 , il y avait une forte famine, une forte guerre.

Ensuite, ça a été tous les ans. Ils brûlèrent le village communal de Chemundo, l'ancien ruralato de la MCT, Machacame, de tous les côtés où il y avait des villages communaux pour libérer les gens et qu'ils puissent revenir dans leurs maisons. Il y avait des jeunes qui voulaient partir [à la Renamo], d'autres ont été pris. C'est la guerre. Là où il y a la guerre, il n'y a pas de choix.

Ils vinrent se promener presque tous les jours, tout près, sans que la troupe ne sorte. La Renamo attrapait quelqu'un, lui donnait une lettre à donner à l'armée, qui disait :

- "Venham aí onde estamos para não lutar onde há população. Vamos lutar ali. Quem está com sede pode beber ali, depois vamos lutar. Mas nós não podemos esperar muito », "Venez là où nous sommes, pour qu'on ne se batte pas là où il y a de la population. On va combattre ici. Il y a de l'eau ici pour ceux qui ont soif, après on va combattre. Mais nous ne pouvons pas vous attendre longtemps ».

Ils attendaient quelques heures, des fois ils dormaient, après ils repartaient pour leurs grandes bases.

Je voyageais toujours sans être pris. J'avais ma piste. Aussi, un jour, j'ai sauté sur une mine, ici même, juste après la mission, je suis sûr que c'est le Frelimo. Je suis resté un peu sourd. Cinq personnes sont mortes, mais mon auxiliaire et moi-même ne sommes pas morts. Un miracle.

Depuis ce jour, j'ai cessé de voyager loin. J'ai vécu seulement de l'élevage d'animaux, de la pêche et du commerce à Mambone.

Notre groupe avait déjà vingt personnes. Vasco nous envoya des armes, pour que les gens se défendent, des pistolets 33 d'Afrique du Sud. Mais je n'en ai pas eu besoin. De 1983 à 1990, ça a été dur, on ne peut pas imaginer! À partir de 1991, les gens parlaient déjà à voix basse.

A Nova Mambone, le Frelimo voulut faire un village communal en 1983: «para a Renamo não vos matar», "Pour que la Renamo ne vous tue pas $»^{518}$. Le peuple ne voulait pas, nous n'allons pas aller là comme des chèvres dans une étable. Vous allez donner du zinc et des parpaings pour faire de bonnes maisons? Nous avons déjà de bonnes maisons ! Il y eut des coups de poing et des disputes !

${ }^{517}$ Rappel : dans le langage courant, les Calamidades (Calamités) désignent la « Direction nationale de lutte contre les calamités naturelles », organisme d'État approvisionné par l'aide internationale et chargé de secourir les populations victimes de la sécheresse ou des crues. Bien vite son action fut étendue aux zones affectées par la guerre. Elle fut accusée de nombreuses fois de détournements de vivres et de corruption.

${ }^{518}$ En effet, très vite, l'objectif de «transformation socialiste de la campagne » à l'origine des villages communaux, passa à celui de simples villages stratégiques du regroupement plus ou moins forcé de populations, afin de les garder sous le contrôle du pouvoir bien plus facilement que dans le cas de l'habitat dispersé traditionnel. 
Quand le père Amadeu s'est réfugié à Beira, le Frelimo, en 1984, voulut nationaliser les salines ! Le père Amadeu me remit la gestion. Je ne voulus pas de la nationalisation. Le Frelimo disait :

- "Você não vê que o Italiano anda a explorar? », "Vous ne voyez donc pas que l'Italien fait de l'exploitation ?»

Je disais que les salines n'étaient pas au Père, mais à la Mission, et je suis catholique ! Ils furent fâchés avec moi, ils ont dit que j'avais été acheté, ou que j'avais déjà acheté les salines ! Moi, acheter les salines ? Je suis resté comme directeur, avec Sebastião Nhamulo comme comptable. J'ai dû tuer des bœufs à moi pour les ouvriers des salines, parce que le Frelimo, quand ils savaient que c'était pour les salines, ils coupaient le ravitaillement. Ils disaient que nous avions des subsides du Père. Mais d'où venait ce subside? Rien du tout!

La dernière attaque fut en 1991, en octobre. Même type d'attaque, ils ont pris des bœufs du côté de Chemundo pour la base de Ziombe.

Ensuite, c'est le Frelimo [qui a attaqué], un major qui est venu de la Machanga voler les bœufs et les emmener au Búzi, disant ensuite que c'était la Renamo.

Je sortais pas loin avec la voiture, sous prétexte d'aller faire du bois. Et ensuite, je contactais la Renamo, parce que je connaissais les endroits où ils attrapaient la surra ${ }^{519}$ :

- "Vocês não podem entrar e matar, evitam roubar os pobres, podem roubar a minha loja, levar uns cabritos », "Vous ne devez pas venir tuer, évitez de voler les pauvres, vous pouvez voler ma boutique, emmener quelques chèvres ».

J'avais peur qu'ils se comportent mal, parce que sinon il n'y aurait plus cet appui des gens. J'expliquais aux gens que les guerilleros, quand ils attaquaient sans avoir mangé, étaient un peu fêlés. C'est la guerre.

En 1990, quand ont commencé les conversations ${ }^{520}$, le peuple a été content parce qu'il voulait se reposer. C'était encore à voix basse, des réunions en cachette. Le premier jour, le 4 octobre [de 1992$]^{521}$, nous sommes sortis tout de suite, j'ai couru auprès des régulos, chez les missionnaires, chez les guérisseurs, chez les sociétés privées, pour expliquer :

- "Não tenham medo, chegou a hora da verdade! », "N'ayez pas peur, l'heure de la liberté est arrivée! Que ceux qui le veulent pardonnent. Vous, commencez déjà à travailler avec les régulos, comme au temps colonial. C'est seulement quand ils ne résolvent pas les différends que vous allez voir la police. Vous, catholiques, faites ce que vous avez à faire. C'est la liberté. »

Le premier meeting a été dès le mois d'octobre, le 25, au régulo Matique, le fils. Il y eut beaucoup de monde. Nous avons été au Genga, plein de monde. Mataúla, plein de monde, Mocumbuge, plein de monde. Maave, plein de monde. Machacane, peu de monde. Chindotane - moitié Ndau et Vatsua -, plein de monde ${ }^{522}$.

Nous avons été les premiers. Mais ensuite, le Frelimo, ils ont récupéré. Ils sont venus plus de cinq fois, avec des hauts-parleurs, des boissons et tout. Une fois à Jofane, le Frelimo est venu le premier. Ils ont appelé les personnes à l'hôpital pour être vaccinées, au même moment où ils organisaient le meeting. Mais j'ai attendu. Nous avons fait des meetings à la chefferie Chigamane. Mais le Frelimo a récupéré. L'éducation civique, tous les gens de notre bord le savent, et j'ai déjà écrit à la direction provinciale de la Renamo et au STAE ${ }^{523}$ provincial, ils expliquent seulement comment voter Chissano, «o gajo de barba em baixo do boletim », «le gars barbu en bas du bulletin $»^{524}$.

Le président du STAE local de Mambone est Pascoal, fonctionnaire de l'Agriculture, membre du Frelimo. Le directeur du STAE est Mutombo, professeur, membre du Frelimo. Nous avions choisi une personne en qui nous avions confiance, mais ils ont refusé parce que cette personne, Chimbueja, de Pande, était professeur et devait enseigner. Mais Mutombo aussi est professeur et il a arrêté d'enseigner. Un autre est Fernandes Massinga, pour le STAE, ils ont refusé aussi. Nous avons proposé Madeira, et Xico. Après, Pascoal a dit qu'ils pouvaient, il a manœuvré, il a accepté sans me prévenir. Mais c'était moi, le délégué, qui devait choisir, et je n'avais déjà plus confiance. Ensuite il y en a eu d'autres qui ont fait des bêtises, qui ont volé des papiers. D'autres encore qui ont enfoncé la porte du STAE, de la CNE, et la RM [Rádio Moçambique] a dit que c'était

${ }^{519}$ Rappel : amande du palmier utilisée pour le vin de palme.

${ }^{520}$ A savoir, les négociations de Rome entre le Frelimo et la Renamo.

${ }^{521}$ Date de la signature de l'Accord général de paix, à Rome.

${ }^{522}$ On le voit, tous les lieux où il y a «beaucoup de monde » sont en réalité des zones de peuplement ndau. Dès que l'on passe chez les Vatsua, la sympathie pour la Renamo est bien moindre.

${ }^{523}$ Rappel : le STAE est le secrétariat technique à l'administration électorale. À l'inverse de la Commission nationale électorale (CNE), paritaire et présidée par un indépendant, le STAE restait dans les mains exclusives de l'État.

${ }^{524}$ Le tirage au sort des positions des candidats sur le bulletin de vote présidentiel avait placé Joaquim Chissano, le candidat du Frelimo et président sortant, en dernière position du bulletin. 
la Renamo! Nous, nous n'avons eu aucun civique ${ }^{525}$, tous sont venus du STAE. Mais jusqu'à aujourd'hui, ils n'ont pas été payés! Nous ne savons pas où la bombe va exploser.

Lors du meeting de la Machanga, avec Dhlakama ${ }^{526}$, quand nous sortions pour y aller, le Frelimo était en train de nous provoquer, à dire que Dhlakama n'avait rien, même pas de T-shirts, et que eux, ils avaient tout. Au retour, nous nous sentions forts et le peuple voulait en finir une fois pour toutes avec ces Vatsua. J'ai dû dire :

- <Vocês não podem fazer mal aos Vatsua, não somos tribalistas », "Vous ne devez pas faire de mal aux Vatsua, nous ne sommes pas tribalistes ».

Alors, simplement, on a fait une marche dans le bourg.

Nous sommes en train de former le parti. Seulement ensuite, on pourra organiser des discussions, pour discuter les lois. Quand j'ai entendu à la radio l'ordre de boycott de Dhlakama, j'étais prêt à obéir. Mais pas seulement avec la radio, parce que la radio faisait de la propagande. Sans recevoir d'ordre, je ne divulguais rien. Moi, délégué, je n'ai pas dit aux gens de boycotter.

Dhlakama n'en pouvait plus ${ }^{527}$, et comme tout ne s'est pas bien passé, c'était en permanence du boycott [de la radio] à Dhlakama. Mais sans ordre, je ne divulguais rien, et nous n'avons rien fait.

Si nous perdons ${ }^{528}$, la Renamo ne va pas retourner en guerre. Il y a des confusions, le Frelimo dit que c'est nous qui avons tué, mais c'est le Frelimo qui a le plus tué. Si nous perdons, nous restons avec notre parti et notre líder, en attendant les élections suivantes ».

17h15. Chez Jó Zabicuo près de l'aéroport, pour organiser une réunion avec lui, avec Patreque Chamussa et Mandenga Zingoma. Les trois sont ex-Negrófilo et sont aujourd'hui Renamo. Rendez-vous pris à 9 heures du matin.

17h30. Retour à la Mission, 7,5 km de sable.

— "Ché-hé! Muzungu pa basikola! », « Hé ! un Blanc à vélo!»

C'est vrai, cela ne doit pas être fréquent.

— «É da Onumoz! », «Il est de l'Onumoz!»

— « Não, é do padre! », « Non, il est du père ! » [i.e. de la misssion]

Tout cela est un peu vrai, après tout.

19h. Dîner à la Mission. Je raconte à Amadeu ce que Faria m'a dit sur les (non-)massacres de la Renamo. Il me dit que Faria ne sait pas parce qu'il ne veut pas savoir.

Même ici il y a eu des massacres : une femme enceinte et son enfant ont été les témoins du massacre de porteurs réquisitionnés, à coups de machette. Peut-être avaient-ils protesté ? Ellemême a eu le ventre piétiné. Son enfant a été traumatisé pendant deux ans, ne pouvait parler qu'à sa mère. Elle a sauvé elle ne sait comment l'enfant qu'elle attendait, et elle-même en a réchappé par miracle.

Mais Amadeu confirme que les pires barbaries ici ont été le fait des miliciens du Frelimo, quand ils ont découpé à la machette six ou sept femmes, et blessé quelques autres, en disant ensuite que c'était la Renamo. La population le sait et dit que c'est la « Renamo 2 ».

[Au cours de la conversation à bâtons rompus, nous revenons à la question de l'étymologie de Mambone.] Selon le padre, l'étymologie m'bone (brincos, petits objets) est de loin la plus vraisemblable. Mais le mot $m$ 'bone est ndau, et non indien, et désigne les objets de pacotille du commerce triangulaire.

\section{Lundi 7 novembre 1994}

La Mission va fermer car ils vont à une réunion de trois jours à Vilanculos. Retour à la Vila, cette fois par la picada (piste) qui longe le fleuve, un peu moins sabloneuse.

9h45. Traversée du fleuve.

${ }^{525}$ C'est-à-dire aucune personne de la Renamo employée dans le service d'éducation civique.

${ }^{526}$ Voir chapitre 10, supra.

${ }^{527}$ Port. : «Dhlakama estava saturado » (littéralement : «Dhlakama était saturé »). Inocêncio Faria indique certainement à mots couverts que Dhlakama a fait une grave erreur en appelant, quoique pas très clairement, au boycott.

${ }^{528}$ Rappel : les résultats définitifs n'étaient pas encore proclamés. 
De la boue à mi-cuisse pour arriver jusqu'aux pirogues. Jolie traversée. Chemin sablonneux jusqu'au village. La CNE locale m'apprend que la CNE de la province, en toute illégalité, a emmené la totalité des editais (procès-verbaux) des résultats locaux. Ainsi, il n'y a plus aucune documentation pour contredire d'éventuels tripatouillages à Beira...

Je vais au local de la Renamo, à un kilomètre. Ils ont leurs propres résultats, que voici mais qui n'ont pas de valeur officielle.

Bureaux de votes (mesas)

\begin{tabular}{|c|c|c|}
\hline $\begin{array}{l}\text { Localités : } \\
\text { chefs-lieux, quartier et localités }\end{array}$ & Bureaux de vote & $\begin{array}{l}\text { Nombre de } \\
\text { recensés }\end{array}$ \\
\hline \multirow[t]{6}{*}{ Chef-lieu Mavinga-Chigogovo } & Bureau n ${ }^{\circ} 5522$ & 1000 \\
\hline & Bureau n 5523 & 1000 \\
\hline & Bureau nº 7075 & 1000 \\
\hline & Bureau n 3639 & 1000 \\
\hline & Bureau n ${ }^{\circ} 5524$ & 1000 \\
\hline & Bureau n 3640 & 539 \\
\hline \multirow{2}{*}{$\begin{array}{l}\text { Quartier Mavinga/Malalanhe } \\
\text { (à l'Est) }\end{array}$} & Bureau $\mathrm{n}^{\circ} 5525$ & 1000 \\
\hline & Bureau n ${ }^{\circ} 5526$ & 747 \\
\hline Quartier Mavionga/Zimuala & Bureau n $^{\circ} 5527$ & 418 \\
\hline Quartier Manguese & Bureau n 5528 & 397 \\
\hline Localité Javane & Bureau n $^{\circ} 3641$ & 275 \\
\hline Localité Matongua e Riomar & Bureau n ${ }^{\circ} 5529$ & $?^{530}$ \\
\hline \multirow[t]{3}{*}{ Localité de Inharingue } & Bureau n ${ }^{\circ} 5541$ & 1000 \\
\hline & Bureau n 5540 & 1000 \\
\hline & Bureau n $^{\circ} 5542$ & 146 \\
\hline \multirow[t]{2}{*}{ Localité de Divinhe } & Bureau n ${ }^{\circ} 5532$ & 890 \\
\hline & Bureau n ${ }^{\circ} 5531$ & 936 \\
\hline Localité de Maropanhe & Bureau n 5533 & 511 \\
\hline \multirow[t]{3}{*}{ Île de Chiloane } & Bureau nº 5537 & 1000 \\
\hline & Bureau n $^{\circ} 5538$ & 1000 \\
\hline & Bureau n 5539 & 91 \\
\hline \multirow{2}{*}{ Localité de Inhagosse } & Bureau n 5536 & 1000 \\
\hline & Bureau n 3684 & 435 \\
\hline Localité de Buene & Bureau n ${ }^{\circ} 5534$ & 1000 \\
\hline Localité de Mutambanhe & Bureau n ${ }^{\circ} 3645$ & 103 \\
\hline
\end{tabular}

\section{Élections présidentielles. Résultats détaillés}

Un grand nombre de votes nuls sont des gens qui ont mis la marque sur la photo. Ils furent considérés - ici - nuls. Le Président de la CNE est Frelimo, le vice-président est Renamo. La $\mathrm{CNE}$ nationale réétudie. Ces résultats sont donc avant éventuelle modification ${ }^{531}$.

[Voir Résultats détaillés des élections législatives et présidentielles dans le district de la Machanga (non officiels, selon la Renamo) à la fin de ce chapitre]

[Discussion avec le groupe local de la Renamo]

\footnotetext{
${ }^{529}$ Le nombre de 1000 en face de nombreux bureaux s'explique simplement par le fait qu'une fois arrivés au millier de recensés, on établit un bureau de vote supplémentaire.

${ }^{530}$ Riomar est très éloigné. Le recensement n'y a, semble-t-il, pas été effectué dans des conditions correctes.

${ }^{531}$ Au niveau national, la CNE devait revalider une grande partie de ces votes nuls : il fut considéré qu'une marque apposée sur la photo du candidat (au lieu du petit cadre réservé à cet effet) indiquait clairement la volonté de l'électeur.
} 
De 1983 à 1992, il y eut la pratique de la «busca de lenha $»^{532}$. Selon Fernando Vitorino Castigo (oncle de Gabriel Tivane), l'armée (la troupe et la milice) attrapait des personnes dans des localités, des personnes qui cueillaient de la surra, elle les emmenait au rio, près de la caserne $n^{\circ} 519$. Même dans les localités, s'il y avait suspicion, la personne était appelée par Caetano (agent du Snasp-Sise). Les personnes étaient ensuite fusillées. Il y en a eu onze dans cet endroit.

Selon Fernando Dacamudine, quand le major Fernando Nampulala, un Maconde, était commandant du Bataillon Matola, à la caserne de Divinhe, lorsque la Renamo était passée par une maison (sans en tuer les occupants), l'armée repérait les traces et venait dans la maison prendre le père et le fusillait au lieu-dit Deuitiue (la «petite forêt»). Le peuple a récupéré les ossements pour pouvoir faire les cérémonies. Toute personne qui provoquait n'importe quel problème subissait le même sort au même endroit. Les miliciens sont ndaus, mais du Frelimo. Un milicien qui refusait de donner un coup de baïonnette à une personne reçut lui-même un coup de baïonnette d'un soldat, à Mutambanhe (localité de Divinhe).

- "Não era uma brincadeira, era mais do que o terror», "Ce n'était pas une plaisanterie, c'était plus que de la terreur ».

Témoignages de Luisa Chanduque (secrétaire) et de Angelina Chiliro (Liga das Mulheres). Luisa :

«Ça s'est passé aujourd'hui, j'ai été à la Direction départementale de l'Agriculture pour demander du riz de semence. Tout le monde y a droit. António Muculu, des services de la Poste et membre du comité de district du Frelimo, a dit :

— "Onde você vai ? », " Où allez-vous ? »

- «Vou na agricultura, diz», «Je vais à l'Agriculture, j'ai dit»

- «Efazer o quê ? », «Et pour quoi faire ?»

- "Vou pedir sementes de arroz », « Je vais demander du riz de semence »

Il a donné sa réponse :

- "Você não vale a pena ir na agricultura porque você votou perdriz ", «Vous, ce

n'est pas la peine d'aller à l'Agriculture, parce que vous avez voté perdrix ${ }^{533} »$.

J'ai demandé :

- "Como é que o senhor conhece que eu votei chikuale", "Comment se fait-il que Monsieur sait que j'ai voté chikuale ? $?^{534} »$.

Il a répondu :

- «Todas as pessoas da Machanga têm grande brutalidade, porque não conhecem quem está no poder? ", "Tous les gens de la Machanga, sont vraiment des brutes ${ }^{535}$, ils ne savent donc pas qui est au pouvoir?»

J'ai demandé :

- "O Senhor quando a Frelimo ganhou em 1975, trouxe tudo? ", «Vous, quand le

Frelimo a gagné en 1975, c'est vous qui avez tout amené ?»

Il ne m'a pas répondu

J'ai été à la DDA, mais il allait aussi à la DDA et il a dit qu'on ne me donne pas. Il a dit :

- "Você é bom o que fizeram, votar chikuale? Você tem que receber agora sementes da Renamo », "Vous croyez que c'est bien ce que vous avez fait, de voter chikuale ?

Maintenant, vous devrez recevoir vos semences de la Renamo ».

Angelina confirme. Le vendredi précédent, même chose. Ils ont vendu les sacs de semences 70 contos aux gens de la Renamo, alors qu'ils les ont donnés aux structures Frelimo $^{536}$.

Entrevue de Alberto Gimo et Luis Santana (secrétaire du district de la Renamo).

Alberto Gimo._- " Je suis né en 1947 à Inhagosse, district de la Machanga. Je n'ai jamais fait l'armée [coloniale] parce que quand mon nom est sorti, ça a déjà été le coup d'État ${ }^{537}$. J'étais sympathisant du Frelimo, mais j'ai connu Ngwenha de l'hôtel Estorial

${ }^{532}$ Corvée de bois.

${ }^{533}$ C'est-à-dire Renamo (la perdrix est le symbole de la Renamo).

${ }^{534}$ Perdrix, en cindau.

${ }^{535}$ Brutalidade, au sens de boçal, personne primaire.

536 «Structures Frelimo », c'est-à-dire les gens ayant une responsabilité au sein de ce parti.

${ }^{537}$ C'est-à-dire la Révolution des Eillets à Lisbonne, le 25 avril 1974, qui mit fin à la dictature et aux guerres coloniales. 
avant son départ, pour la Tanzanie ${ }^{538}$. C'est arrivé en 1975, j'ai été accusé d'être membre de la «Voz de África livre ${ }^{539}$. C'était vrai. Une réunion avait été organisée par Manuel Ngwenha à Beira (il a été fusillé, c'était un combattant déserteur du Frelimo qui avait fui de Tanzanie en 1969 parce qu'il craignait d'être assassiné. Il a été au Malawi, y est resté. Il a contacté le consul du Portugal et est revenu au Mozambique. Mais il n'a pas combattu dans l'armée portugaise. Il nous a dit que cela ne valait pas la peine, qu'au sein du Frelimo ils étaient en train de se tuer les uns les autres, qu'ils avaient tué Mondlane et avait expulsé Uria Simango ${ }^{540}$ ). [La réunion de Beira, c'était] pour parler : ça ne va pas bien, nous sommes coincés. Il disait qu'était en train d'arriver ce qu'il avait prévu lors de sa fuite. Mais dans le groupe, il y avait un espion (qui est déjà mort de maladie, peut-être de sorcellerie, parce que nous l'avons suspecté). Tous les sept, nous avons été pris. Ngwenha a disparu dans la caserne. Nous avons été envoyés à Sacusi, le camp de rééducation, en juin 1976. Avant, nous n'avions pas été battus, seulement des questions et des menaces. À Sacusi, il y avait déjà André Matsangaissa. Lui, André, était commandant du génie à Matacuane (Beira), il était malade. Il était accusé de détournements. Je ne sais pas si c'est vrai. Nous étions tous contre le gouvernement, mais nous ne savions pas qu'il avait l'intention de partir et de créer son propre groupe. Ensuite, toujours en 1976, il a réussi à fuir. En 1977, il est revenu, et s'est montré, déjà armé, dans le plus grand champ de Sacusi, celui qui est le plus loin du camp. Il a réussi à emmener 150 hommes, sans tirer une seule fois. Quelques autres sont revenus au camp. Je n'étais pas, ce jour-là, dans ce champ. Alors, on est resté dans ce camp qui avait 1350 prisonniers.

Nous avons été transférés au camp de Canda-Gorongosa, au site du régulo Canda. Nous étions entraînés pour avoir une nouvelle vie parce qu'ils disaient, "vocês têm $o$ espírito do colonialismo », «vous avez la mentalité du colonialisme ». Nous travaillions et il y avait des réunions politiques. Ensuite, en 1977, il y a u les avions de la Rhodésie qui venaient la nuit pour amener le matériel de la Renamo.

Alors, nous avons été évacués à Beira, trois jours en caserne, pour être ensuite conduits au camp de Nhamaze (aux sources de Cheringoma). La vie au camp était très dure et j'ai personnellement souffert de châtiments [corporels], puisque j'étais xiconhoca ${ }^{541}$.

À Nhamaze, il y eut des problèmes lors d'une confrontation, c'était déjà avec la Renamo, mais à l'époque ils disaient les xiconhoca. Certains ont été transférés au Niassa, au camp de Biribiza. Nous, nous avons été évacués à Beira. J'ai été libéré, sans avoir été entendu ni rien, en novembre 1979.

Je suis retourné dans la cellule ${ }^{5 \dot{4} 2}$ d'Inhagosse, à vivre de la pêche. Ma femme pensait que j'étais mort et elle avait pris un autre mari. Elle a fait une nouvelle famille. Alors ensuite, il y a eu en 1983 l'entrée des hommes de la Renamo dans la zone, un petit groupe, sans uniforme, seulement les commandants. Ils ne faisaient pas de mal, je leur ai parlé, ils voulaient un appui, de la nourriture. Ils n'emmenèrent personne. La population portait le chargement, puis revenait. J'ai demandé à partir avec eux, au commandant Tanonoca. Ce nom, en cindau, veut dire : « Nous sommes pressés »

Ce commandant dit :

- «Você nem vale a pena sair nesta zona, você fique para informar », "Vous, il vaut mieux que vous ne sortiez pas de cette zone, vous restez pour nous informer ».

Je suis resté au service de la Renamo depuis ce moment. Le chef Mankhamba, du régulo d'Inhagosse, aimait bien la Renamo. Toute la population apportait de la nourriture dans sa maison. Toute ! Le peuple était faché, personne n’appuyait le Frelimo.

À la nuit, nous sortions jusqu'à une zone appelée Chiconde, en canot, sur la côte du Búzi, et nous laissions la nourriture. Ensuite, la population de cette zone, qui était sous le contrôle de la Renamo, la portait.

Le major Fernando Nampulala [de l'armée gouvernementale] est sorti de la Machanga pour entrer à Inhagosse. Il y avait là six soldats de la Renamo, en visite. Ils l'ont su. Il y eut un feu intense, des tirs de mortier, de bazooka. [Comme la] Renamo n'avait pas de base ici, ils ont attaqué la population, brûlé trente-trois maisons. Ils ont tué une femme qui était folle, parce que tous les autres ont fui. Ils ont brûlé les chatas [petites embarcations] et ont pris le moteur, ils ont tout volé à la population. C'est le Frelimo qui a volé. Le Frelimo a essayé d'entrer, mais les soldats de la Renamo ont fait leur boulot très bien, ont tiré. Mais les soldats de la Renamo ne pouvaient pas résister, en face il y avait cinq cents hommes. Ils nous ont dit de fuir. Alors nous avons fui vers la zone des palétuviers, au bord de la mer. Nous y sommes restés trois jours, nous venions la nuit

${ }^{538}$ Allusion au départ de ce Ngwenha pour le Frelimo, dont le siège était à Dar es-Salaam, sans doute au début des années soixante.

539 «La Voix de l'Afrique libre », une radio animée notamment par des colons portugais à partir du Malawi et hostile au Frelimo.

${ }^{540}$ Référence aux graves crises internes du Frelimo de 1968 à 1970.

${ }^{541}$ Rappel : Xiconhoca est l'agent du colonialisme et de l'impérialisme.

${ }^{542}$ Dans le cadre de la fusion du parti et de l'État, les gens eux-mêmes confondent les structures. Ainsi, la « cellule » est en réalité la localité. 
chercher de la nourriture dans les maisons qui étaient restées debout. Puis nous sommes revenus et nous avons reconstruit les maisons.

Le Frelimo est revenu de nouveau occuper cette zone d'Inhagosse. À partir de ce moment, nous sommes restés sous le contrôle du gouvernement du Frelimo, le Frelimo a dit à tout le monde de revenir, y compris ceux qui avaient des armes, parce qu'il n'y avait plus de guerre, c'était Nkomati ${ }^{53}$. Personne de la Renamo n'est revenu, mais le Frelimo a occupé. Ils ont commencé à demander qui appuyait la Renamo. Ces années 1983-1984, il y a eu une grande famine, mais le Frelimo n'a rien amené, de nombreuses personnes sont mortes.

J'ai continué à maintenir les contacts, mais nous ne pouvions plus approvisionner. Je faisais les contacts à Beira, avec Ricardo Massambo, de la Machanga, plusieurs fois. Il avait des gens à lui qui allaient à Maringués ${ }^{544}$. Il travaillait dans une compagnie d'assurance maritime internationale.

Mais le Frelimo recrutait des jeunes pour le service militaire obligatoire, frappait à la porte de toutes les maisons. Quand ils arrivèrent à la maison de Massambo, il y avait chez lui deux soldats de la Renamo, venus de la base de Maguacua, de la localité Inhangalo, du district de Beira, mais sans armes, qui fumaient de la surruma ${ }^{545}$. Le Frelimo a senti l'odeur, est entré dans la maison et a pris les deux jeunes. Massamba et Paulo Simango, de la Machanga, ont eu peur que les deux jeunes ne parlent et sont partis de suite à Maringué, en voiture. Mais les deux jeunes en ont réchappé.

Après, le contact fut établi avec Senhor Machava, de la Machanga, qui vivait à Beira. Ce dernier a recruté beaucoup de jeunes de Beira pour rejoindre la lutte. Il avait le contact avec cette base de Maguacua.

Le contact fut maintenu jusqu'à la fin, et je suis resté à Inhagosse, ensuite je suis parti à Beira mais ma famille est restee. Jusqu'en 1989, la Renamo a multiplié les contacts, mais n'est pas entrée.

En 1990, ils sont entrés à Buene, près d'Inhagosse. Il n'y a pas eu de combat, ils sont seulement passés. Je suis resté à Beira, je viens juste de revenir. »

Luis Santana Machava ${ }^{546} \cdot$ - «En juillet 1986, à quatre heures du matin, le bourg de la Machanga a été attaqué. C'était les matsangaissas. Ils ont attaqué l'administration et l'hôpital, pour prendre des médicaments. Ils ont cassé les boutiques de Campos, un métis musulman, et du commerçant Abdula. Le Frelimo cachait des armes dans les entrepôts d'Abdula. Ils sont revenus, mais les soldats avaient fui, et ils ont tué le garde-du-corps de l'administrateur, Matemede (l'administrateur était à Beira). Ils ont brûlê la maison d'une personne, Domingos Madaire, un guérisseur, qui protestait qu'ils étaient des voleurs. Il a été tué.

Ils ont attaqué deux fois en 1986, une fois en 1987. Une fois, le Frelimo est venu avec des Migs, en 1986, ils ont bombardé le bateau «Estrela do Mar », la gazolina, qui vient de Beira. Les gens en ont réchappé. Les Migs ont survolé la population, en menaçant et en tirant.

Je suis à la Renamo depuis 1978, j'ai eu le contact pour la première fois à Maputo, avec quelqu'un qui était un commandant du Frelimo, Francisco Chanzeze, qui travaillait clandestinement pour la Renamo. J'étais alors prisonnier parce que j'avais mal répondu au Président Machel.

C'était au cours d'une réunion des compromis ${ }^{547}$ et il m'envoya chercher. Machel me demanda :

- «Agora eu já sou presidente. O que é que você diz? ", "Maintenant je suis le Président, qu'est-ce que vous avez à en dire ? »

- «Não tenho nada que dizer mas o que é certo é que os 500 anos que os Portugueses viveram em Moçambique, em cinco anos a Frelimo estragou tudo, só andou fotografias sem motivo nenhum, Snasp. Afinal o que é isso? ", "Je n'ai rien à dire, mais ce qui est certain, c'est que, ce que les Portugais ont fait au Mozambique en 500 ans, en cinq ans le

${ }^{543}$ Le 16 mars 1984, le gouvernement mozambicain signe à Incomati (ou Nkomati) avec le gouvernement sud-africain, un accord stipulant que le premier cesse de soutenir l'ANC et le second la Renamo. La Renamo devait être intégrée au gouvernement. En réalité, l'accord ne fut pas appliqué par les Sud-Africains, mais compliqua quelque peu l'approvisionnement en armes de la Renamo.

${ }^{544}$ Q.G. de la Renamo.

${ }^{545}$ Surruma : sorte de marijuana très prisée au Mozambique.

${ }^{546}$ Voir l'entrevue de Gabriel Castigo Tivane, supra. Il s'agit bien du même « Satana », l'ancien cipaye de l'administration coloniale lors de la répression de 1953, devenu responsable de la Renamo !

${ }^{547}$ Os Comprometidos, les compromis, étaient souvent d'anciens prisonniers qui avaient été retournés par le colonisateur dans le cadre de l'action psychologique au centre pénitenciaire de Machava. Mais ils pouvaient être de simples collaborateurs ou fonctionnaires africains de l'ancien régime. Le Frelimo organisa quelques réunions publiques d'autocritique et récupération. 
Frelimo a tout abîmé, il a juste pris [les gens] en photo sans aucun motif, avec le Snasp. Qu'est-ce que ça veut dire?»

Machel a dit que j'étais de la Pide : «Vai para a cadeia », «Va en prison », et j'ai été arrêté le jour même. J'y suis resté deux ans.

C'est en prison que j'ai eu le contact avec Chanzeze, parce qu'il était un commandant de la prison. Il n'a jamais été découvert.

Je suis revenu ici en 1981. Je suis resté tranquille; seulement un peu dans les conversations, je dévoilais.

J'ai aimé l'indépendance, mais aujourd'hui encore j'aime le Portugal, j'aime servir le Portugal, tout le monde ici a des choses grâce au Portugal, rien du Frelimo et il ne réussira rien. Ce sont des promesses et ils ne font rien. J'ai bien aimé le colonialisme. Je suis fatigué. »

Alberto Gimo. - «Le peuple a plus souffert de l'indépendance que du Portugal. Des gens sont morts...»

Luis Santana. - «J'ai vu des gens brûler des voitures de Portugais avec les gens dedans, et le Frelimo seulement à regarder, je l'ai vu de mes yeux ${ }^{548}$. »

Alberto Gimo.- Si Monsieur le Journaliste ${ }^{549}$ reste ici plus longtemps, il pourrait aller en brousse et y entendre des choses terribles.

Luis Santana.- Je suis né ici mais j'ai été à Lourenço Marques en 1949. J'étais cuisinier du chef de poste administratif de la Machanga, Francisco Dias Veredas, le «Trovoada " ${ }^{550}$. Il m'a envoyé dans sa famille à Lourenço Marques, comme cuisinier. Mais il arriva que son fils est tombé dans les escaliers et s'est cassé une dent. Ils dirent que c'était de ma faute et m'envoyèrent à la police où j'ai été gardé prisonnier et j'y ai pris vingt-cinq coups de férule ${ }^{551}$. Et ensuite, ils m'ont envoyé travailler sur la ligne de chemin de fer, à creuser, à nettoyer. Alors que j'étais couché la nuit, au poste de police, j'ai rêvé d'une voiture qui avait tué des gens, et de sa plaque d'immatriculation. Et de fait, sur la ligne, au petit matin, on a trouvé une personne noire, étendue morte, sans qu'on sache la raison. J'ai parlé au chef de la police, Jacinto, que cette personne, j'en avais rêvé, qu'elle avait été heurtée par la voiture d'un Anglais, qui ensuite avait suivi la route de la plage. Jacinto a enquêté et on a trouvé cette voiture, avec la même immatriculation que celle dont j'avais rêvé. Il a arrêté cet Anglais, qui a confessé qu'il avait senti juste un choc, sans savoir ce que c'était.

Alors ils m'ont appelé et m'ont donné un service dans la police comme cipaye enquêteur criminel. J'ai travaillé très bien, très souvent à l'aide des rêves. J'ai un don. Mais en ce qui concerne le Negrófilo, ça n'a pas été avec des rêves ${ }^{552}$.

Du temps colonial, je vivais donc à Lourenço Marques comme cipaye et $1^{\text {er }}$ enquêteur criminel, sous la direction d'Afonso Henrique Ferraz Freitas ${ }^{553}$. Alors, il a décidé que j'irais à Beira, pour enquêter au sujet du Negrófilo qui faisait du bruit, à cause des mauvais traitements de l'administrateur Chambino [de Mambone] et du chef de poste de la Machanga, «Massute ${ }^{554}$. Le Negrófilo avait raison, mais ils ne s'y sont pas bien pris. Massute reçut des biens alimentaires, qu'on appelait ndodge, sorte de haricots, petitspois. Tout d'abord, il les donna gratuitement. Mais ensuite, il les a vendus pour sa poche à lui, et il envoyait les chasseurs récolter l'ivoire et il vendait l'ivoire et la viande au Senhor Coelho, un commerçant portugais qui vivait à Mossurize.

Et alors, le Negrófilo voyait tout ça. Il a commencé à écrire, et Massute a entendu dire qu'ils sont en train de se plaindre de lui.

${ }^{548}$ Luis Santana fait ici référence aux dramatiques incidents d'octobre 1974, à Lourenço Marques (Maputo), quand, après une provocation d'une compagnie de comandos portugais, des éléments africains incontrôlés montèrent des opérations punitives contre les Portugais, qui firent des centaines de morts, accélérant l'exode des Blancs du Mozambique vers l'Afrique du Sud. Ces incidents avaient été précédés, le 7 septembre, d'incidents beaucoup moins meurtriers mais plus politiques, quand des pieds-noirs avaient refusé la constitution du gouvernement intérimaire Portugal-Frelimo, sur laquelle ils n'avaient pas été consultés.

${ }^{549}$ C'est-à-dire moi-même, perçu comme journaliste.

550 «La Tempête », surnom du chef de poste.

${ }^{551}$ Jusqu'au début des années soixante, il était très fréquent que, lorsqu'il y avait un problème, dans une famille portugaise, avec un employé africain, celle-ci l'envoyait à la police qui se chargait de châtier ledit coupable, même pour des motifs purement domestiques...

${ }^{552}$ Il fait référence à l'enquête dont il fut chargé sur le Núcleo negrófilo, $c f$. entrevue de Gabriel Tivane, supra.

${ }^{553}$ Rappel : administrateur du Conseil de Lourenço Marques, qui fut chargé de l'enquête sur le Negrófilo en 1953.

554 « Massute », le « nerveux, le « mauvais ». 
Il a pris l'un d'eux, un religieux, Francisco Chambave, un commerçant et protestant de l'Église de Como ${ }^{555}$. Chimbave, c'était un ami à lui, il n'était pas pour le Negrófilo. Les gens de Como, c'est-à-dire l'Église du Christ du Mozambique, n'aimaient pas Massute, mais lui, il l'aimait bien [i.e. Chambave aimait bien l'administrateur]. Mais Massute a été méfiant, il l'a fait appeler. Il [Chambave] a voulu venir en vélo, mais la population l'a vu et ils ont crevé les pneus, et ça, c'était déjà quelque chose, c'était déjà la grève, la révolution.

Beira a communiqué avec Lourenço Marques, parce qu'à Beira, il se passait la même chose $^{556}$, et à Mambone aussi. Ils ont vu qu'il se passait vraiment quelque chose.

On m'a envoyé pour enquêter. Je servais, je défendais le colon, c'est vrai! M'en détourner, je n'ai pas pu.

Quand Tivane a été arrêté, parce qu'à Mambone c'était la même chose, j'ai dû traverser la rivière pour voir comment c'était. Je suis entré dans la cellule de Tivane. Tivane a demandé pourquoi et j'ai dit que c'était à cause d'affaires à la Poste, feignant que j'étais prisonnier aussi. Mais lui, c'est un malin, lui, ce n'est pas une plaisanterie. Tivane n'a rien expliqué, mais d'autres ont parlé. L'administrateur me fit appeler et je lui dis que je n'avais rien trouvé mais que le coupable était le Negrófilo, j'ai dit ça pour me défaire de l'administrateur et parler [seulement] à Freitas. Le coupable, c'était l'administrateur Chambino. Comment pouvais-je continuer les recherches dans ces conditions? Quand on a découvert qu'ils [ceux de la Machanga et de Mambone] n'étaient pas coupables parce que la faute était [surtout] à ceux de Beira, je devais demander à parler directement avec le Senhor. Freitas. J'ai parlé avec Inhambane, et demandé à parler secrètement avec Freitas.

Freitas m'a rappelé à Maputo. Il avait d'autres documents qui venaient de Beira, et alors nous sommes retournés à Beira. Nous avons commencé le procès. En ce temps colonial, personne ne pouvait critiquer et écrire des lettres contre le colonialisme. J'étais mandaté seulement pour chercher, je ne pouvais rien dire. Le Negrófilo n'était pas coupable. Massute a été expulsé [de l'administration] et Chambica ${ }^{557}$ aussi. Je pense que ceux qui ont été déportés n'étaient pas coupables, ils avaient raison. Mais ce n'était pas une époque à demander ses droits. Tuer une poule, c'était six mois !

Au moment de l'indépendance, j'étais déjà fonctionnaire de service, toujours à Maputo ».

15 h. Avec Elidja Chimbirombiro Simango (frère de Uria Simango).

À nouveau une bicyclette bleue à la pédale défoncée. Je vais chez Dandoga Chivaca, pasteur de l'Igreja do Cristo Unida em Moçambique ${ }^{558}$, dans la zone de Magerete, de Machanga.

[Chez Dandoga, plusieurs personnes m'attendaient, toutes chargées d'histoire. Et moi, mal éduqué au possible, courant d'un rendez-vous l'un autre, je vins les mêmes vides, sans même avoir pris le temps d'acheter un paquet de sucre et du thé. Elidja me le fit bien remarquer : "Aquele homem não sabe viver», "Cet homme ne sait pas vivre ». Il avait entièrement raison. Heureusement, Dandoga m'excusa et cette maladresse de ma part ne porta pas à conséquence sur les entrevues que je fis.]

Dandoga Chivaca est né en 1956, à Búzi. Il est ndau. Il est à la Machanga depuis deux ans. La capitale de l'Église est à Beira, le responsable change tous les quatre ans. Le responsable de l'actuelle commission est Jonathan Ernesto Simango.

Dandoga Chivaca. - «L'American Board, c'est une mission venue dans les années 1880 et ils se sont installés dans la région du Manica e Sofala. En ce temps, il y avait des persécutions, à cause du chibalo ${ }^{559}$ pour la construction du chemin de fer vers la Rhodésie.

Les missionnaires blancs ont porté cette préoccupation auprès du Conseil mondial des Églises. Le Conseil a fait pression sur le gouvernement portugais ${ }^{560}$ et alors celui-ci fit fermer toutes les chapelles qui agissaient au nom de la mission de l'American Board. Alors, comment sauver l'Église? On chercha un nouveau nom et le premier nom fut Associação cristã evangélica portuguesa (Association chrétienne évangélique

${ }^{555}$ Rappel : Igreja do Como - Église de (Tapera) Nkomo - est le nom populaire local de l'Église issue du congrégationnalisme américain, l'Igreja do Cristo em Manica e Sofala.

${ }^{556}$ Alertée de ce qui se passait à Mambone et à la Machanga, la direction du Negrófilo à Beira avait envoyé une protestation - légale, papier timbré, etc - au gouverneur.

${ }^{557}$ Surnom de Chambino, l'administrateur de Mambone.

${ }^{558}$ Nom officiel du congrégationnalisme lié à l'American Board.

${ }^{559}$ Chibalo : travail forcé des indigènes, six mois par an (jusqu'en 1962).

${ }^{560}$ Il s'agit certainement du gouvernement de la Compagnie du Mozambique, qui administrait alors le territoire du Manica e Sofala en tant que compagnie à charte. 
portugaise $)^{561}$. C'est de cette association qu'est sorti ensuite le Núcleo [negrófilo] ${ }^{562}$. Mais il y a eu un problème, parce que des gens ont dit qu'une Église ne pouvait pas être [i.e. : avoir la même activité qu'] une association. Un groupe est donc sorti de l'Associação, pour former une autre association, le Negrófilo ${ }^{563}$.

L'Associação evangélica rechercha encore un autre nom : en 1947, ce fut donc l'Igreja do Cristo em Moçambique, branche du Manica e Sofala. Comme il y avait des églises abandonnées à cause de la politique portugaise, le Conseil Chrétien (protestant) a décidé d'attribuer un nom qui pouvait recouvrir toutes les missions abandonnées ${ }^{564}$. La nouvelle Église a continué avec cette dénomination jusqu'en 1993. L'an passé, nous nous sommes réunis pour revenir au nom originel, Igreja do Cristo Unida em Moçambique, exAmerican Board, parce qu'en Amérique, ils disent eux-mêmes United Church of America, ex-American Board.

Nous sommes restés congrégationnalistes, mais avec l'aide de la Mission suisse, indirectement ${ }^{565}$. Le changement de nom ${ }^{566}$ a signifié aussi que c'était nous les Africains qui commandions ici, avec l'appui des missions acceptées du Sud ${ }^{567}$. Nous sommes toujours restés en contact avec Mount Silinda ${ }^{568}$, mais on ne pouvait pas dire que c'était l'American Board. Il n'y a pas eu de vrai changement, seulement le nom. Mais les missionnaires blancs [américains] ne pouvaient plus venir, et les Portugais ont été contents. Nous ne recevions que les visites des missionnaires blancs des Églises du Sud. Nascimento Jesus Freire, de 1942 à 1949, un Portugais de l'Igreja Associação de Deus, résidait à Beira, et aidait. Ensuite est venu Georges Andrié, un autre Suisse.

Ils ne sont jamais venu pour changer la doctrine congrégationnaliste,qu'ils ont toujours respectée, ils ont seulement aidé.

Guilherme Tapera, Ncomo ou Como, fut l'un des premiers pasteurs à être formé par l'American Board. Son nom est resté.

Mais nous, nous n'utilisons jamais l'appellation «Église de Como », ce sont les gens qui disent comme ça. Il a travaillé à Beira, ensuite à Maxemedje, du temps de Kamba [Simango]. Ensuite, il a été à Mount Selinda. Il est resté là jusqu'en 1976. Il est revenu au Mozambique, déjà vieux, pour rendre visite à sa famille à la Machanga. Il est retourné à Beira, et y est mort en 1977.

${ }^{561}$ En réalité, l'administration du territoire facilita la relégalisation sous ce nouveau nom, qui dissociait légalement le congrégationnalisme africain de ses maîtres américains: le «mozambicanisant», elle le «portugalisait» aussi - même si le statut associatif octroyé n'était pas fait, dans l'esprit de la loi portugaise, pour une église relevant d'une confession internationnalement reconnue (ce fut d'ailleurs la raison de sa non relégalisation en tant qu'association en 1942, cf. infra note 252).

${ }^{562}$ Ce n'est pas tout à fait exact : si l'Associação et le Negrófilo viennent effectivement de la même matrice, à savoir l'American Board, les deux structures furent formées simultanément, avec des directions rivales (même si les adhérents de l'un(e) pouvaient aussi participer à l'autre). L'Associação représentait la fidélité au congrégationnalisme américain dans le contexte légal portugais de la Compagnie à charte, alors que le Núcleo était en rupture partielle avec lui. Voir aussi note suivante.

${ }^{563}$ Ce débat recouvrait une véritable question politique. Kamba Simango, le fondateur du Negrófilo, véritable Eduardo Mondlane avant la lettre, bien que chrétien congrégationnaliste lui-même, mais en rupture avec les missionnaires blancs, souhaitait laïciser partiellement l'activité afin de créer des écoles de métier, des cours en cindau, etc., en un authentique protonationalisme ndau. L'administration de la Compagnie légalisa toutefois simultanément les deux structures, y voyant un certain partage des tâches (activité religieuse/activité associative) et aussi une division toujours utile. Quand le Territoire du Manica e Sofala repassa sous administration directe de l'État portugais (1942), l'Associação fut dissoute en tant qu'association mais survécut en tant qu'Église (comme l'indique la suite du récit), alors que le Núcleo fut relégalisé (1944).

564 Il s'agissait principalement de trouver une structure commune aux groupes relevant du congrégationnalisme américain et du presbytérianisme suisse, ainsi que de quelques autres dénominations plus réduites.

${ }^{565}$ Mission suisse, nom populaire de l'Église presbytérienne du Mozambique. Cette Église a directement aidé la branche sud de l'American Board, et aussi le rameau du Manica e Sofala.

${ }^{566}$ Il s'agit ici du changement de nom de 1934 et de 1947 (de American Board à Associação cristão evangélica portuguesa, puis Igreja do Cristo).

567 Il est tout à fait exact qu'avec le chapeau légal de l'Église presbytérienne du Mozambique (Mission suisse), on eut ici une église noire dissidente légale, en plein indigénat (lequel dure jusqu'en 1961).

${ }^{568}$ Mount Selinda, capitale du congrégationnalisme américain dans la région, situé sur la frontière orientale de la Rhodésie du Sud, en zone ndau. 
Tapera Ncomo est resté pasteur dirigeant de l'Igreja do Cristo depuis la fondation de l'Associação cristã, jusqu'à sa retraite à Mount Selinda ${ }^{569}$ ».

\section{6 h. Entrevue de Elidja Chimbirombiro Simango ${ }^{570}$}

«Je suis né en 1930, à la Machanga/Magerete, fils de Timoteo Chimbirombiro Simango. Mon père était peintre à Beira, mais était né ici. Il a arrêté ce travail quand il est revenu sur sa terre ici. Il achetait des poules, il était commerçant. Son père, mon grandpère, Mpébo Simango, était de religion traditionnelle. Il [i.e. Timoteo] fut pris par Tapera Ncomo. Timoteo ne fut pas pasteur, il était seulement croyant, et Ancien. Il faisait partie de l'Associação cristã.

En 1954, à cause des grèves de 1953, mon père fut déporté. Mon père ne faisait pas partie du Negrófilo, mais quand il y avait des problèmes, il y avait de l'entraide, des unifications.

Au sein du Negrófilo, il y avait des gens du gouvernement, des espions, comme Pepswe et Chimbave ${ }^{571}$. Ils ont fait une liste et $y$ ont mis le nom de mon père.

Mon père a été à Marrupa ${ }^{572}$, dix ans tout seul, sans sa femme. Nous sommes restés cing ans sans savoir où il était. Ensuite, on a reçu une lettre. Il fut peintre.

Il est revenu en 1963. Ils étaient deux, un autre avec lui, je ne me rappelle pas.

Chipumburo Jeque Mukove fut déporté, dix ans aussi, je ne sais pas où. J. Mudeco est mort après six mois à São Tomé e Príncipe ${ }^{573}$. Macanguisse, dix ans aussi, il est revenu et est mort ici. Matacole, il est mort déjà, je ne sais plus [où il a été déporté].

J'ai été bouvier quand j'étais enfant. Après, j'ai commencé l'école catholique Santa Teresinha de Zivava, à la Machanga, jusqu'à la $2^{\mathrm{e}}$ classe. Mais pour la $4^{\mathrm{e}}$ classe, il fallait être catholique et assimilé, alors mon père m'a envoyé à Beira pour continuer mes études dans l'école de l'Associação cristã. Mais quand j'y suis arrivé, l'école venait juste d'être fermée par les Portugais. Alors, je n'ai jamais étudié, j'en suis resté à la $2^{\mathrm{e}}$ classe. J'ai travaille à la capitainerie de marine. En ce temps, elle était aux Anglais ${ }^{574}$, alors que le port était déjà nationalisé. Aussi, comme je ne voulais pas travailler avec les Portugais, je suis parti en Afrique du Sud en 1949. On avait des combines, [au Mozambique] on disait qu'on allait étudier à Mount Selinda. C'est en Rhodésie, et on sortait de là pour l'Afrique du Sud, il n'y avait pas de passeport, seulement des livrets indigènes. [À la frontière entre la Rhodésie et l'Afrique du Sud, ils] ne demandaient rien, seulement nos papiers et où on va. On dit qu'on va â Lourenço Marques, qu'on ne reste pas [en Afrique du Sud]. Ouste, je suis passé et je suis resté.

Je suis resté à Gemisten, près de Johannesbourg. J'y avais un parent, Mateus Simango, frère de mon père. Je suis resté quinze ans.

Mon frère aîné, pasteur de notre Église, qui est ensuite parti pour la Tanzanie, Uria Simango, nous écrivait ce qui se passait. Au moment des événements de 1953-1954, il se trouvait à Beira. En 1962, comme la Pide était à ses trousses, il a demandé à la direction, à Mount Selinda, son transfert et ils lui ont donné une province à Salisbury. Les Portugais envoyèrent des gens pour l'attraper. Alors, il est parti en Tanzanie 575

J'étais à l'époque encore en Afrique du Sud. Je suis retourné à la Machanga en 1963, en mai et mon père est rentré en décembre. Il était déjà vieux, et il est resté là. Il est mort en 1989. Il n'a plus voulu faire de la politique. Mais il a aimé l'indépendance, comme tout le monde ici.

Après sa sortie du Frelimo - nous, nous ne savions rien ${ }^{576}$-, il est parti en Égypte. En 1974 , il est revenu à Beira, sans intention de refaire de la politique ${ }^{577}$ ni même d'être pasteur. Seulement pour voir ce que ça allait donner. Il n'a pas été Gumo ${ }^{578}$.

${ }^{569}$ Dandoga Chivaca me donna ensuite la référence du livre ronéoté de Pegissanhe Fernando SimANGO, Breve histórico da Igreja do Cristo, Beira (il y a aussi une édition en cindau).

${ }^{570}$ Simango parle tantôt portugais, tantôt cindau, Dandoga traduit.

${ }^{571}$ Voir entrevue de Luis Santana, supra.

${ }^{572}$ Marrupa, localité extrêmement isolée de la province du Niassa, au nord.

${ }^{573}$ Voir entrevue de Gabriel Tivane, supra.

${ }^{574} \mathrm{C}$ 'est-à-dire à la Compagnie du Mozambique, de capitaux majoritairement britanniques.

575 Rappel: Uria Simango, outre son travail de pasteur, animait une association d'entraide mutuelle d'émigrés mozambicains en Rhodésie, la Portuguese East African Association, qui servait de couverture à son organisation politique, le PCN (Partido da Convenção nacional), devenue l'Udenamo (União democrática nacional de Moçambique) lors de l'arrivée de Adelino Gwambe. L'Udenamo passa rapidement en Tanzanie, où existaient déjà diverses organisations macondes, notamment la MAA (Mozambique African Association) et la MANU (Mozambique African national Union).

${ }^{576}$ Rappel : Suite à l'assassinat du premier président du Frelimo, Eduardo Mondlane, Uria Simango, viceprésident en titre, aurait dû devenir président, mais en fait fut mis en place un triumvirat au sein duquel il était solidement encadré par deux dirigeants de la tendance politico-militaire, Marcelino dos Santos et Samora Moisès 
Après l'indépendance, il laissa ses trois enfants - Lútero $^{579}$, Davis-Mpébo et Maúca - à la maison de son beau-frère au Búzi. Il est retourné à Beira et, laissant sa femme, est parti à Nairobi. Le Frelimo a pris sa femme. Alors il est rentré au Malawi. Arrivé au Malawi, la police du Frelimo était là à l'attendre et il fut pris ${ }^{500}$. Lui et sa femme, ils furent envoyés à Nashingwea ${ }^{581}$. Il écrivit une lettre pour dire : "Não fiquem preocupados, hei-de vir", "Ne vous inquiétez pas, je vais revenir"'s82. Il fut transféré au Niassa. Il a écrit pour nous dire de lui écrire là, mais, depuis, nous n'avons plus rien reçu.

Joana Simango ${ }^{583}$ était malade, et mourut. Nkavandame ${ }^{584}$ était malade, et mourut. Dr Unhai, il était en bonne santé, on ne sait pas. Uria aussi, on ne sait pas où il est ${ }^{585}$.

En 1963, je ne me suis pas remis dans la politique. Mais maintenant, je suis au PCN. Le PCN était d'Uria Simango, mais c'est son fils qui l'a ramené. Lútero dit que ce parti ne date pas d'aujourd'hui.

Il n'y a pas de différence entre le PCN et la Renamo. La politique du PCN et de la Renamo, c'est la même, mais le PCN n'a pas fait la guerre ».

17h30. Domingos Pereira Jeque Chitale, délégué du district de la Machanga pour la Renamo. Il est né en 1957, à la Machanga.

« J'ai été un militaire du Frelimo de 1978 à 1982, à combattre contre la Renamo. J'ai combattu du côté de Chibabava, Machaze (à l'intérieur du Búzi), Estaquinha, Bândua, au bataillon de défense anti-aérienne. J'étais chauffeur.

C'était dans la zone de Bândua, qui était une zone contrôlée par la Renamo. La Renamo disait à la population :

- "Vocês, se verem a Frelimo, dar sinal de pilão", "Vous, si vous voyez le Frelimo, faites le signal du pilon".

Machel. Peu de temps après, Uria Simango rompit avec le Frelimo, publiant (en anglais et en Tanzanie) un document retentissant sur les luttes de factions et les crimes au sein du Frelimo (Gloomy Situation within Frelimo). Dès lors, il ne fut plus membre que de groupuscules se déchirant mutuellement en permanence, mais ne passa jamais du côté portugais. On peut noter que le document Gloomy Situation..., est resté pratiquement inconnu au Mozambique jusqu'à sa republication, à la fin de l'année 2000, par l'hebdomadaire Savana.

${ }^{577}$ Ce n'est pas exact, $c f$. note suivante.

${ }^{578}$ Gumo, Grupo unido de Moçambique, parti politique mis sur pied dès avant le 25 avril 1974 par l'homme d'affaire portugais et intime de Salazar, Jorge Pereira Jardim, alors gagné à l'idée d'une indépendance à la brésilienne. Il cherchait à faire émerger des courants africains alternatifs au Frelimo, tout en prônant, dès 1973, des négociations avec lui. Joana Simeão, une femme macua formée à l'université, en fut l'animatrice principale. Le Frelimo accusa ce parti d'être une pure création policière et tribaliste, d'autant que le Gumo participa aux événements du 7 septembre 1974. Uria Simango n'en fut effectivement jamais membre, ayant recréé son propre groupe d'avant l'Udenamo, le PCN, mais il commit l'erreur de se montrer lors desdits événements, ce qui donna un argument de plus au Frelimo pour le considérer comme traître et contre-révolutionnaire.

${ }^{579}$ Devenu ingénieur, Lutero Simango est l'actuel animateur du Partido da Convenção nacional.

${ }^{580} \mathrm{Ce}$ récit n'est pas tout à fait exact, mais Elidja parle selon sa mémoire. Bien des éléments sur la disparition d'Uria Simango sortirent peu de temps après dans la presse mozambicaine. Après les événements de septembre 1974, Uria Simango se réfugia au Malawi, dont le président-dictateur, Hastings Kamuzu Banda, avait collaboré avec les Portugais, pourchassant au besoin le Frelimo sur son sol. Mais le vent ayant tourné et cherchant à établir des relations avec le nouveau régime d'un pays dont les chemins de fer étaient pour lui d'une importance vitale, Banda ordonna à sa police secrète de livrer Simango à celle du Frelimo.

${ }^{581}$ L'un des principaux camps militaires du Frelimo en Tanzanie pendant la guerre.

${ }^{582}$ On ne pourra évidemment jamais savoir si cette lettre était sincère, Simango n'ayant pas pris conscience du sort qui l'attendait, ou si, à l'inverse, c'est la seule lettre qu'il pouvait écrire sous la surveillance de ses geôliers, ou encore si cette étrange insistance à rassurer alors qu'il était dans un camp militaire, ne signifiait pas exactement, en filigrane, le contraire - ce que ses familiers de la Machanga n'auraient pas compris.

${ }^{583}$ Il s'agit évidemment de Joana Semeão. Voir note 8 du chapitre « Zambèze ».

${ }^{584}$ Sur Lázaro N'Kavandame, voir la note 8 du chapitre « Zambèze ».

${ }^{585}$ Rappel ( $c f$. note 8 du chap. 6 «Zambèze ») : quand la Renamo commença à agir, le Frelimo craignit qu'un coup de main ne libérât ces personnes du camp de rééducation, ce qui aurait donné une direction politique au groupe rebelle alors uniquement militaire. Ils furent de ce fait exécutés sans procès, dans des conditions encore mal éclaircies, en 1977. Il s'agit certainement de l'une des pages les plus sombres de l'histoire du Frelimo. Le chef du groupe parlementaire du Frelimo lors de la première législature pluraliste, le colonel Sergio Vieira, devait cependant, en pleine assemblée, justifier ces meurtres officiels, puisque «c'était la révolution » et que « c'étaient des traîtres ». Ces personnes n'ont toujours pas été réhabilitées. 
C'est-à-dire, le pilon, mais sans rien dedans. Ça fait tou-tou, deux fois. Un autre répondait tou-tou, jusqu'à arriver à la base de la Renamo, la base Matondo et d'autres bases de ce côté-là.

Le Frelimo attrapait la population, ils disaient que c'étaient des Matsangaissas sans même avoir atteint la base. Ils tuaient les hommes par fusillades et ceux qui n'étaient pas morts, à la baïonnette. Ils laissaient [en vie] les femmes et les enfants, mais les emmenaient dans un endroit pour les récupérés ${ }^{56}$, à Inhamatanda. Ils étaient emmenés en camion, et j'étais le chauffeur d'un de ces camions ZIL et GAZ, des camions lourds russes. Tous les hommes de la population étaient fusillés, sans même arriver [i.e. que le Frelimo n'arrive] à la base [de la Renamo].

Une fois, j'ai été témoin [d'une chose], en 1980. C'était dans cette zone de Bândua. Le Frelimo a découvert, il s'est approché pour voir, et a vu que dans le pilon il n'y avait rien. Alors il a demandé à la dame :

- "Então você está a pilar o quê ?", "Alors, vous êtes en train de plier quoi ?"

- "Não, não estou a pilar, só a brincar!", "Je ne pile pas, je m’amuse juste !"

Mais le Frelimo savait déjà :

- "Então como você gosta de pilar, meter o seu filho no pilão e pilá-lo", "Alors, comme vous aimez piler, mettez l'enfant dans le pilon et pilez-le".

C'était un bébé, un garçon, il avait à peu près deux ans. Autour de la mère, il y avait des soldats de la $5^{\mathrm{e}}$ brigade du bataillon d'Infanterie motorisée. La femme n'a pas voulu mais sous les menaces, en tremblant, elle a commencé, doucement. Ensuite, elle a vraiment pilé. La femme a été emmenée dans la zone de Tico, près d'Inhamatanda. Aucun soldat n'a bougé, ni moi. Comme j'étais le chauffeur, je suis resté dans le véhicule.

Ensuite, ils parlaient un peu, ils me disaient que j'étais matsangaissa, ils me disaient : "a sua família está toda no mato com a Renamo ", "Ta famille est toute entière en brousse avec la Renamo", et je disais "sim, toda", "oui, toute entière", alors qu'ils étaient à la Machanga.

Je n'ai pas déserté, mais mon cœur était avec la Renamo, et j'ai été sur le point de fuir pour l'autre camp.

Après ma sortie [de l'infanterie], je suis allé à Beira, comme agent d'information de la Renamo. Je n'ai jamais été découvert. Je donnais des informations à Judo Chipedja, qui les donnait au commandant Nongo qui était à la base "Praia da Cidade", qui se trouvait d'aire même du district de Beira.

Je suis resté comme ça jusqu'à Rome ${ }^{587}$. Ensuite, je suis rentré à la Machanga. J'ai été choisi par Manuel Pereira ${ }^{588}$ comme délégué de district. C'est pour tout ça que je dis que ça, le fait de piler, c'est le Frelimo qui a commencé ${ }^{599} »$.

17h30. Je dois partir pour attraper le dernier canot à la nuit tombante. Je n'ai pas eu le temps d'écouter Fernando Dacamudine, qui a des choses horribles à raconter sur la guerre à Divinhe. Il me promet d'écrire dès demain matin et de transmettre [ce qu'il aura écrit] à F. Madeira pour que je l'ai avant de partir.

18h. Traversée du fleuve, dans la fantastique lumière du soleil couchant. Pas de nuages, des rayons fusants et - est-ce une impression ? - je crois bien voir le rayon vert.

- «Ä̈e, maningue corrente! », «Aïe ! beaucoup de courant ! , dit le piroguier.

On s'échoue dans la vase à dix mètres du rivage.

\section{Mardi 8 novembre 1994}

8h15. Pas de bicyclette aujourd'hui. Je vais à pied chez Jó Zabicua. Soleil écrasant, air poisseux.

Patreque Chamussa, aveugle, n'est pas là car il est allé dans la famille de Joaquim Gonda, délégué de liste de la Renamo. Il a 64 ans, est né à Mambone. Il a été frappé à coup de houe par Augusto Chipumbulo Mandima, le malade mental, ancien membre du Frelimo ${ }^{590}$.

586 «Récupéré » (recuperado), dans le vocabulaire politique de la guerre civile mozambicaine, désignait les personnes raptées par le Frelimo dans les zones de la Renamo, par conséquent bien distinctes des refugiados (réfugiés) à l'extérieur et des deslocados (déplacés) à l'intérieur qui, qu'ils aient été favorables au Frelimo ou aient simplement fui les zones de combat, avaient du moins quitté les zones Renamo (ou attaquées par la Renamo) de leur propre initiative. Bien entendu, la Renamo aussi raptait de la population - pas seulement de jeunes hommes - pour l'envoyer vivre dans ses zones.

${ }^{587}$ C'est-à-dire la signature de l'Accord général de paix, à Rome, le 4 octobre 1992.

${ }^{588}$ Dirigeant de la Renamo de la province de Sofala.

${ }^{589}$ Mon interlocuteur fait ici référence au fait que la Renamo a été souvent accusée de ce genre d'atrocité. Il s'en défend sans le nier, simplement pour lui, «c'est le Frelimo qui a commencé ». 
[Jó Moisès Zabicua me reçoit. Comme il ne parle pas portugais, Leonardo Chamusso Patreque, fils de Patreque Chamussa, fait la traduction.]

Jó Zabicua._ « Je suis né en 1911, mais sur le registre c'est 1912, 20 juin, à Mambone. Mon père était charpentier et ferrailleur. J'ai étudié très peu, jusqu'à la $2^{\mathrm{e}}$ classe, ici, et dans une école catholique à Beira, jusqu'à mes quinze ans. J'étudiais à la nuit, à l'école des Arts et métiers. Après, j'ai travaillé à la compagnie Allen Work Shipping, une agence, durant quinze ans. Quand Carmona est arrivê ici en 1939, le Negrófilo existait déja ${ }^{591}$. Un groupe du Negrófilo s'est porté au devant de Carmona pour l'accueillir, et fut bien reçu. Carmona nous a beaucoup fait d'éloges, beaucoup, et a accepté les status du Núcleo negrófilo. Sixpence Simango était le président, avec Kamba Simango. J'ai très bien connu Kamba, j'ai travaillé avec lui. Il était le premier pasteur de Gogoi ${ }^{92}$ avec Bed Simango. Il n'y a pas eu de lutte, nous avons bien collaboréés3. Kamba était très bon, aujourd'hui encore nous le pleurons. Mais il est parti, il a dit qu'il reviendrait, mais il n'est jamais revenu ».

Alors je les informe de la triste fin de Kamba Simango au Ghana ${ }^{594}$.

Jó Zabicua - «Il a encore de la famille à Chiloane, Maropanhe. Le Negrófilo et l'Église de Como ${ }^{595}$ ont été fondés la même année, mais étaient séparés. Le Negrófilo a commencé à Munhava et ensuite a acheté une maison à Espangara, quartiers suburbains de Beira. L'Église de Como était à Esturru [Estoril ?], elle y est encore.

Le Negrófilo était une espèce de gouvernement, c'était politique. L’Église de Como était seulement une église. Ils ne travaillaient pas ensemble. L'Église faisait seulement la messe pendant que le Negrófilo se consacrait à l'éducation politique. Pour la mesee, c'était la même chose ${ }^{596}$. Mais le Núcleo avait une école primaire - pour les premières classes, en cindau, ensuite en portugais -, des activités récréatives (le football du Grupo desportivo Unido, le chant choral Macuaiera, c'est-à-dire un chant choral très libre, il n'y avait pas d'instruments). Chaque mois, tout le monde payait dix escudos, c'était de l'argent!

Au sein du Negrófilo, j'étais protestant. C'est seulement quand je suis revenu ici, et comme le père Amadeu aidait, je suis redevenu catholique puisque le Negrófilo n'existait plus.

${ }^{590}$ Cet homme malade avait déjà tué un autre militant de la Renamo, mais n'avait toujours pas été interné (voir supra l'entretien avec Francisco Madeira).

${ }^{591}$ C'est tout à fait exact. Lors de son voyage à Beira, le président de la République, le général Carmona, reçut en personne la direction du Negrófilo.

${ }^{592}$ Rappel : Gogoï, dans l'intérieur du Manica e Sofala, station la plus importante de l'American Board au Mozambique, dépendant directement de Mount Selinda.

${ }^{593}$ Kamba Simango rompit avec l'American Board, accusant les missionnaires blancs de comportement raciste. Cependant, cette scission, matérialisée par la co-existence de l'Associação cristã et du Núcleo, ne fut souvent pas ressentie, à la base, comme une rivalité, mais plutôt un partage des tâches.

594 Kamba Simango s'était installé au Ghana après avoir constaté l'impossibilité de développer son université noire dans le Mozambique colonial et s'était lié à l'équipe de N'Krumah. Son fils était devenu un important médecin à l'hôpital d'Accra. Kamba, déjà âgé, fut renversé par une voiture alors qu'il traversait la rue. Le responsable, à ma connaissance, ne fut pas retrouvé. Quand on s'aperçut qui il était, on lui prodigua les meilleurs traitements... Mais c'était trop tard. J'ai, personnnellement un doute (je dis bien : un doute). En effet on trouve, dans les archives de la Pide à Lisbonne, trace de contacts entre Adelino Gwambe, le jeune leader de l'Udenamo et Kamba (dans une correspondance à un tiers, Ndabaningi Sithole, de la ZANU zimbabwéenne, qui ignorait la plus élémentaire prudence, se réjouit que « le Vieux » ait décidé de revenir à la politique suite à la démarche d'A. Gwambe). Cela n'a rien d'étonnant, du reste, étant donné les séjours de Gwambe au Ghana. N'Krumah, qui soutenait Gwambe mais ne pouvait qu'être inquiet de sa grande jeunesse, avait-il fait pression sur Kamba en ce sens ? Son entrée à l'Udenamo aurait était un renfort considérable, au moins en terme de légitimité et de prestige, et aurait assis par la même occasion l'influence ghanéenne sur le mouvement de libération mozambicain - ce qui ne pouvait qu'inquiéter les Américains, les Tanzaniens et... les Portugais. Quelques jours plus tard, Kamba est renversé par une voiture dont le propriétaire disparaît. (Je ne connaissais pas ces derniers éléments en 1994).

${ }^{595}$ Sous la forme de 1'Associação cristã.

${ }^{596}$ Bien que le Negrófilo fût «politique », il y avait aussi des offices religieux congrégationnalistes en son sein, mais comme une activité parmi d'autres.. 
Je suis revenu [à la Machanga] en $1940^{597}$, pour ne plus jamais en partir. Je me suis consacré aussi à la charpenterie. Au cours des années cinquante, j'ai été à Maïmelane, près d'Inhassoro, dans l'entreprise de Jorge Cabrito ${ }^{598}$. Je suis revenu à Mambone en 1980 .

À Mambone, le Núcleo faisait la messe, avait une école dans une maison à lui, à Embatanhe (près de la piste d'atterrissage). C'était une école protestante. Patreque Chamussa en fut le professeur provisoire, il alphabétisait les femmes, il leur faisait faire les premières lettres. À la Machanga aussi, il y avait une école à Djimbawe (régulo Chiteve). Chireve faisait partie du Negrófilo.

On est venu m'arrêter à Maïmelane, parce que j'étais du Negrófilo. Ils ont pris Gavasa, qui travaillait dans la même entreprise. J'ai eu de la chance, j'ai été relâché. Gavasa a été arrêté mais ensuite, il est sorti, à Mambone.

Gabriel Tivane, Patreque Chamussa, le régulo Matique, beaucoup d'autres, ont été prisonniers à Lourenço Marques, dans la prison civile près de l'église Santo António. Quand le Negrófilo a disparu, certains ont été à l'Église catholique, d'autres chez Como, les Églises qui n'ont pas eu de problèmes.

Timoteu Simango a été déporté et Samuel Simango a été libéré et est mort ici. »

Leonardo Chamussa Patreque.- «Je suis catholique. Je suis né en 1931, à Mambone, le 25 octobre. La première école, je l'ai faite au Núcleo negrófilo, en 1942, à Beira. C'était une école très grande. Le premier livre était en cindau, "Matapayawa », ce qui veut dire carril ${ }^{599}$ de feuille de manioc. Le deuxième livre était déjà en portugais. Les noms des professeurs, il y avait Eduardo Ndongwe, et puis João Simango, fils de Chovane Simango. J'ai eu ce dernier de 1942 à 1946. En 1946 je suis revenu à Mambone, avec le second degré colonial, et j'ai gardé le bétail.

A Beira, j'ai été un des fondateurs de l'équipe de football du Negrófilo, la « Unido ». Ici à Mambone, j'ai seulement participé.

Je suis revenu à Beira en 1949, j'ai commencé à travailler le 4 septembre, avec les sœurs de l'hôpital. En juin 1950, j'ai été employé à la J.M. Barnett C Ltd, jusqu'en 1986. En 1986 j'ai été renvoyé, seulement avec des indemnités pour trois mois par an, ce qui faisait en tout huit ans, mais sur la base d'un salaire très bas.

Quand nous avons appris qu'il y avait un mouvement qui luttait pour le Mozambique, nous avons été contents. Mais c'était seulement par des bruits. Quand la guerre est arrivé en 1973 , nous avons vu que c'était vrai ${ }^{600}$. L'indépendance, c'était super, tout le peuple mozambicain a reçu des deux mains cette organisation. Le peuple a été très étonné avec le deuxième mouvement. Le peuple ne savait pas quel était l'objectif de la Renamo, il fallut une explication. C'est seulement quand il y a eu les accords de Rome que le peuple a compris que c'était pour la démocratie. La démocratie, c'est ce qui a été rejetée pendant l'indépendance. Le peuple aimait la démocratie, puisque et comme nous étions indépendants il n'y avait plus de raison d'embêter le commerce ${ }^{601}$ et aussi la vie de toute la nation. »

Jó Zabicua. - « La Renamo n'a tué personne ici, ils n'ont pas fait de mal, nous fuyions du côté de Matasse, mais ensuite, ils ne faisaient pas de mal. Ils nous ont menacé, ils sont venus très souvent, mais pour ce qui est de tuer à coups de feu, non. Ils ont emmené quelques personnes, certaines sont revenues, d'autres sont en train de revenir. »

Leonardo Chamussa Patreque.- « Après que la Renamo a expliqué, tout le peuple est déjà avec eux. Les enfants de ceux du Núcleo [negrófilo] ont suivi la Renamo, parce que leur politique est celle du Núcleo. Le Frelimo a été très différent du Núcleo. Le Frelimo a

${ }^{597}$ Qu'il s'agisse d'une erreur de ma part ou de l'auteur, cette date de 1940 ne coïncide pas avec la phrase précédente : la mention « le Negrófilo n'existait plus » date son retour à 1953 au plus tôt.

${ }^{598}$ Ce colon portugais, complètement désillusionné par la petite société coloniale, avait prévu d'écrire un livre au vitriol de souvenirs sur la présence portugaise au Mozambique. Survint le 25 avril 1974. J'ignore si le livre fut finalement publié.

${ }^{599}$ Carril (curry en anglais et français) a, dans le contexte africain, un sens beaucoup plus large qu'en Europe ou en Inde : il n'y a pas forcément de « curry » dans un carril (mais il peut y en avoir) : c'est une sauce dont les ingrédients peuvent grandement varier.

${ }^{600}$ Rappel : la lutte armée de libération a commencé, dans le nord, en 1964, mais les premiers combats près de Beira ont débuté en 1973.

${ }^{601}$ Sans même y penser - ce qui est intéressant -, Leonardo Chamussa identifie ici l'interdiction de commercer que les Portugais faisaient peser sur les indigènes (jusqu'en 1962 officiellement, et souvent plus tard aussi), et les tracasseries du Frelimo, en sa phase radicale, contre le secteur privé même quand il s'agissait de simples commerçants de brousse. 
été plus comme l'Associação dos naturais de Moçambique, là, à Lourenço Marques ${ }^{602}$. Mais ici, non [on n'a pas suivi].

Ici, il y a les catholiques en premier, ensuite les méthodistes ${ }^{603}$, et les zionistes qui sont nombreux du côté de Maave. Et il y a les bezes ${ }^{604}$, les nhamussoros ${ }^{605}$, qui sont des femmes, et les nhangas, des hommes qui devinent avec les pierres. Chez Manejo, personne d'ici ne va chez lui, parce qu'il est cher et il y aussi des personnes qui ne croient pas en lui. C'est seulement des gens qui viennent de loin, d'Afrique du Sud. Il ne travaille pas pour soigner une personne malade, mais pour donner de la chance. »

Zingoma Mandenga (traduit du cindau en portugais par Leonardo). - «Je suis né je ne sais pas quelle année, mais il y a très longtemps. Je suis né à Mambone. Je n'ai jamais été à l'école, j'ai seulement assisté à la messe catholique. Mais avant de passer catholique, $\mathrm{j}$ 'assistais aux messes du Gerémio ${ }^{606}$. Je n'ai jamais été membre, seulement les messes.

En 1937, je suis parti au Transvaal, j'ai été clandestinement, via Paúri [Pafuri ?], à pied jusqu'à Mapai, et de là pour arriver à Djone $e^{607}$, en voiture.

Il y avait des façons d'y entrer. La frontière n'était pas aussi rigoureuse qu'aujourd'hui. Quand je suis arrivé à Chirinze, près de Zucamacala, qui est en Afrique du Sud, on pouvait déjà entrer [plus avant]. J'ai été à Johannesbourg, j'avais de la famille. J'y allais et revenais, pendant quarante ans, à travailler en ville comme domestique. Je suis rentré définitivement en 1976.

Nous en avons assez de la guerre, nous en avons assez du mandat de Chissano, ce ne doit pas être tout le temps le même gars, nous voulons d'autres personnes. C'est vrai, nous sommes en faveur de l'opposition. Nous allons avoir une nouvelle vie, personne n'a peur de la Renamo. Ni du Frelimo. Mais le peuple veut voir le changement. Les autres pays ont déjà changé les présidents, c'est seulement le Mozambique qui n'a jamais changé. »

15h40. Fernando Dacamudine Damanga. Il m'a cherché toute la journée à Mambone et environs... (il préfère me parler plutôt que d'écrire ce qu'il m'avait promis).

« Je suis né en 1935, à Chingune, quartier de Chiloane. Je n'ai pas été à l'école pendant mon enfance.

En 1949, je suis allé à Beira. J'ai travaillé comme domestique chez quelqu'un, puis j'ai été travailler à la Manica Trading, comme employé. Après, à l' Empresa Estivadores en 1953. La nuit, je fréquentais l'école de l'Amercian Board. Maintenant, l'American Board est l'Igreja do Cristo Unido de Moçambique, qui s'est séparée de l'Igreja do Cristo de Moçambique en $1983^{608}$. À Beira nous avons maintenant une grande chapelle. À Divinhe, zone de Maomga, une petite chapelle.

Mais ma femme est restée à Divinhe jusqu'en 1981. À cette date, elle est venue à Beira. Je suis resté docker jusqu'en 1984, ça a fait 31 ans. Aux débuts [du gouvernement]

${ }^{602}$ L'Associação dos naturais de Moçambique (Association des natifs du Mozambique) était, au début uniquement le regroupement des Blancs nés sur place. Peu à peu certains métis «de première classe » (nés directement d'un père blanc) y entrèrent, et peu à peu elle s'élargit aussi aux autres métis et à quelques Noirs assimilés. Au début des années soixante, un processus d'unité (non d'unification) apparut entre elle, l'Associação africana (métisse) et le Centro associativo dos Negros (assimilés noirs), en un objectif directement politique. Pour Leonardo, le Frelimo est donc l'héritier de cette tradition mozambicaine blanche et métisse du Sud.

${ }^{603}$ Il y a effectivement des méthodistes, mais Leonardo confond évidemment ici l'ensemble des protestants de grandes confessions internationales (presbytériens, congrégationnalistes, etc.).

${ }^{604}$ Bezes (en cindau) : guérisseurs (curandeiros, en portugais).

${ }^{605}$ Voir note 35.

606 «Gerémio », c'est-à-dire grémio (les bantouphones ont souvent du mal à prononcer deux consonnes consécutives et intercallent une voyelle). Grémio, c'est-à-dire le Núcleo negrófilo. L'appellation de grémio («groupement »), très courante dans les associations, fut interdite par l'autorité coloniale quand la législation corporative métropolitaine fut, pour la «population civilisée », étendue à l'Outre-mer en 1937 et dès lors réservée aux structures corporatives patronales (donc blanches). Toutes les associations légales (non corporatives ou corporatives non patronales) durent alors changer de nom. Cela signifia faire approuver à nouveau leurs statuts, ce qui permit aussi un certain «nettoyage» de la part de l'autorité. Le Grémio negrófilo devint alors le Núcleo, mais l'ancienne appellation ne disparut pas pour autant dans le langage courant.

${ }^{607}$ Rappel : Djone (= John), Afrique du Sud.

${ }^{608}$ Sur mon carnet, j'ai noté 1983, mais il s'agit certainement de 1993 (voir entrevue de Dandoga Chivaca, supra). C'est en 1993 que les congrégationnalistes reprirent leur indépendance organisationnelle, cessant de participer à la structure unique mise en place avec les méthodistes et les presbytériens sous la colonisation portugaise pour faire face aux difficultés matérielles et aux tracasseries. 
du Frelimo, il y eut une grève dans les chemins de fer. Je n'ai pas participé à cause des turras $^{609}$, j'étais sur les bateaux. Beaucoup de gens ont été arrêtés. Ils sont restés prisonniers deux ans, ils ont été au camp de rééducation de Sacusi. La grève était pour le salaire. Il n'y eut plus jamais de grève. C'était Tomé Eduardo le gouverneur de Sofala.

En 1985, j'ai fait commerçant à mon compte. Je voyais que le Frelimo n'était pas ce que les gens voulaient. Le pasteur Uria Simango est venu. C'est lui qui m'a enseigné la religion. Quand Simango est revenu, le Frelimo l'a attrapé et il a disparu. Alors le Frelimo automatiquement est sorti de ma tête. C'est pourquoi je devais aimer la Renamo. À cette époque, c'était Africa livre ${ }^{610}$. J'écoutais la radio, tout seul ou avec un ami. Je suis devenu membre.

Mais en 1985, je me suis engagé carrément à travailler dans la politique de la Renamo. Je voulais partir pour la brousse, malgré mon âge. En 1981, il y avait un secrétaire du Frelimo, Tinga, de la zone de Maomga, qui poursuivait ma femme pour qu'elle soit secrétaire de l'OMM ${ }^{611}$. Ni ma femme, ni moi-même, ne voulions. Alors, j'ai emmené ma femme et mon fils à Beira.

Mais je revenais à Divinhe, où j'ai une meunerie que j'ai commencée en 1971, un commerce (une boutique depuis 1982) et en plus j'avais mon tracteur et ma carriole. Alors le Frelimo a commencé à regarder mon tracteur, à s'en servir pour emmener les gens aux meetings ou d'autres choses. Je ne pouvais rien dire: parler, c'est être battu ${ }^{612} \mathrm{de}$ suite. Alors j'ai emmené le tracteur à Beira, il était déjà tout abîmé.

Je suis entré à la Renamo, mon contact était avec Castigo Tchuncha et avec Salomão. Salomão a été prisonnier six ans à la prison de Beira. Il est vivant. Tchuncha n'a jamais été découvert, mais moi j'ai été découvert. J'étais délégué pour le niveau du district de toute la Machanga : je faisais de l'intelligence pour Tchuncha et Salomão, et ces derniers transmettaient à la base de Magoacua, de la pointe de Savane, dans le district de Beira. On part à sept heures du soir et on arrive à cinq heures du matin, à pieds. Le Frelimo ne savait pas. C'était près !

J'ai été découvert. Je suis parti de Beira en 1982 pour l'île de Chiloane, où j'avais mon séchage [de poisson]. Ensuite j'ai fait un voyage par Inhagosse. Quand je suis arrivé, j'ai trouvé un groupe de soldats de la Renamo dans la zone de Ngosso. Ils m'ont rapté sans savoir. Ils ne m'ont pas fait de mal. Mais j'avais des documents de la Renamo : j'avais ma carte d'adhérent avec le $\mathrm{n}^{\circ} \mathrm{A}-0038$. Le groupe m'a amené au commandant Joaquim Mapuia. Il se préparait à aller attaquer l'île de Chiloane, il y a pénétré deux fois. Il a demandé pour qu'on y aille ensemble, avec ma chata ${ }^{613}$. J'ai refusé parce que les gens de là me connaissent et ça allait faire du vilain. Le commandant a compris. Ils y sont allés avec une autre chata, mais avec mon moteur. Ils ont attaqué les boutiques, et cette fois-là ils n'ont emmené personne, seulement pour charger jusqu'à Inhagosse. Ils m'ont rendu mon moteur.

Or l'administrateur de Divinhe avait fui sur l'île de Chiloane. Comme j'étais venu de ce côté, il s'est méfié et a fait son rapport. Le Frelimo a tout de suite monté sa brigade pour aller me chercher. Quand je sortis de Ngosso, quand la Renamo m'a laissé, je me suis dirigé vers Divinhe, pour me présenter et dire que j'avais été rapté. Mais ils m’ont ordonné de me dévêtir et ont commencé à me battre, et à battre aussi les employés de la chata, avec un bâton. À 16 heures, ils m'ont emmené pour la fusillade. Mais un autre soldat a parlé au commandant Jorge, du Frelimo :

- "Em primeiro lugar, vamos tirar prova onde está a chata dele", "D’abord, on va tirer au clair où se trouve sa chata".

Ils ont été là où la chata était cachée, ils ont questionné la population. La population a dit que la chata n'avait pas été à Chiloane, ni qu'elle était venue de Chiloane. Le commandant a dit :

- "Você ali já escapou", "Ce coup-là, vous vous en tirez".

Le commandant m'a envoyé au district. Je suis arrivé là, à la Machanga, et ils m'ont de nouveau mis en prison, c'était le major Sefo, sans que je puisse faire une déclaration. Ils m'ont dit :

- "Você para escapar tem que dar dinheiro, e para receber documento", "Vous pour sortir, il faut payer, et aussi pour les papiers".

${ }^{609}$ Turras, terroristes, nom donné par les autorités coloniales aux combattants du Frelimo, repris ici par Dacamudine, qui les craint visiblement.

${ }^{610}$ Voir note 228.

${ }^{611}$ OMM, Organização da Mulher moçambicana, Organisation de la femme mozambicaine, c'est-à-dire l'« organisation de masse » féminine du parti unique, la seule légale jusqu'en 1990.

612 J'ai traduit ici par «battu», mais le mot luso-mozambicain utilisé est «chamboqueado». Rappel: chamboquear, en portugais mozambicain, est un verbe dérivé du substantif chamboco, mot issu de l'afrikaans sjambok, venu de l'Indonésie hollandaise, pour « bambou». Le chamboco est le fait de se faire battre à coup de bambou ou autre objet : passage à tabac.

${ }^{613}$ Chata, petit bateau. 
J'ai dû payer, aller à Divinhe chercher l'argent, revenir pour avoir mes papiers (déclarations de libération et carte d'identité).

Le commandant Jorge de Divinhe a reçu les 500 contos, et ceux de la Machanga ont reçu 3500 contos. C'était beaucoup, beaucoup d'argent! Mon commerce a été en dégringolant. La Renamo a attaqué quatre fois ma boutique, mais je ne me suis pas fâché, je ne l'ai pas quittée. Le Frelimo faisait sa manœuvre : ils demandaient des marchandises et comme c'était la crise à ce moment, c'étaient eux qui venaient les premiers, je ne pouvais pas vendre avant l'arrivée du Senhor Secrétaire, ils divisaient entre les membres, et seulement ce qui restait était pour la population. Il y avait des membres qui payaient, et d'autres qui ne payaient pas ${ }^{614}$.

Des fusillés de Deuitiue ${ }^{615}$, je connais Mauwane, natif de Inharigue mais amené à Divinhe, qui a été dénoncé. Il ne faisait pas partie de la Renamo, il avait seulement dit le nom à un ami. Une autre personne est Gomate, natif de Divinhe, accusé de collaborer avec la Renamo, seulement une méfiance. Mais il y eut beaucoup d'autres fusillés pendant que j'étais à Beira.

À Divinhe, la Renamo attaquait, mais n'a jamais brûlé les maisons, elle pillait seulement les boutiques. À Divinhe, ils n'ont pris personne pour la lutte, seulement des gens pour les chargements qui après revenaient. C'est seulement dans la forêt, du côté d'Inhangwena, près de Divinhe, qu'ils ont pris Malangue et un autre. Ceux-là ont été raptés, mais ils sont déjà revenus aujurd'hui.

À Mutambanhe, certains sont partis volontairement et d'autres ont été raptés, trois ou quatre. A Chelinda, quatre personnes ont été raptées, peut-être plus? Et d'autres, volontairement.

C'est la même chose que pour l'armée, personne ne choisit, c'est seulement quand il arrive là [i.e. à la base rebelle ou à la caserne de l'armée], on lui explique et il va faire du bon boulot [i.e. il devient un bon guérillero rebelle ou un bon soldat gouvernemental].

Je continue à être commerçant. Le Frelimo ne vient plus m'embêter. Mais il n'y a pas beaucoup d'argnt.

Je suis délégué pour Divinhe, mais je ne voulais venir à la Machanga pour être délégué de district. Alors comme délégué j'ai proposé Domingos Pereira Jeque Chitale qui venait d'arriver de Beira, mais qui est né à la Machanga.

Avant le cessez-le-feu, à Divinhe, il y avait cinq éléments, avec moi six. Quand il y a eu le cessez-le-feu, j'ai commencé à faire des meetings à Buene, Inhajungue, Inhagosse, Ngosso, Chiloane, Inharringue, Maropanhe. À la Machanga, c'était Domingos Pereira.

Au début, les gens aimaient bien le Frelimo, parce que c'était le gouvernement de notre couleur. Mais tout de suite, il a autorisé les exécutions, après les villages communaux, après, pour aller de Divinhe à la Machanga, de la Machanga à Mambone, il fallait des laissez-passer, cinquante meticais ${ }^{616}$ pour chaque laissez-passer . Ils se sont appropriés des activités des personnes, ils ont nationalisé les maisons des quartiers suburbains ${ }^{617}$. Personne ne pouvait réclamer, c'était arrêté ou... fusillé.

Ce que m'a fait le Frelimo, ça me crève le cour. Je le hais.

À l'hôpital, dans la salle normale ${ }^{618}$, pour avoir le traitement, il faut donner des pourboires. Pour un petit filet de pêche aux crevettes, juste pour le carril de la maison, il faut une licence, quarante contos par an. Pour chaque pirogue, et chacun a une pirogue, 110 contos par an!

Pour inscrire mon fils en $11^{\mathrm{e}}$ classe, c'est 2000 contos.

Le crédit: par exemple je suis commerçant, je n'ai plus d'argent, je veux faire un emprunt. Mais il n'est pas donné. Ils disent :

- "Sim, senhor! ", "Bien sûr !"

Mais après, ils exigent plein de choses : extrait de compte, patrimoine, un témoin, etc. jusqu'à vous enlever l'envie. C'est seulement les ministres et les sécurités [i.e. les membres des services de sécurité] qui n'ont pas de problème. Et les monhés [indiens]. Peut-être parce qu'ils ont déjà de l'argent. J'ai de l'orgueil pour ce que j'ai fait. Parce que j'ai donné de la nourriture, des tissus, des sandales à la Renamo, parce que je voulais bien. Et quand est arrivé le moment des garçons, j'ai envoyé des garçons : un à Divinhe, quatre à Beira. Ils le désiraient, ils voulaient y aller, ils m'ont demandé comment. J'accompagnais personnellement le garçon jusqu'à la base, ou en chata. Je suis à la Renamo, ce que j'ai fait, c'est presque soldat, moi aussi je suis un soldat ».

Il termine en me disant, pour lui écrire, d'envoyer le courrier via Manuel Pereira, Delegação de Beira, à l'attention de la localité de Divinhe.

${ }^{614}$ Rappel : dans le vocabulaire populaire, les «membres» sont les adhérents du Frelimo et les fonctionnaires de l'État, la «population » est le reste.

${ }^{615}$ Voir le premier témoignage de Dacamudine, supra.

${ }^{616}$ Rappel : le metical (plur. meticais) est la monnaie mozambicaine.

${ }^{617}$ Il fait probablement référence à la nationalisation des immeubles locatifs en 1976.

618 «Salle normale », en contraste avec les salles chères et correctement équipées. 

dit :

17h30. Au moment de partir reprendre la pirogue, Fernando Dacamudine Damanga me

«Ce que vous faites est une grande aide, une grande aide. Parce que l'Africain n'a pas la biographie, n'a pas l'histoire. Le Frelimo n'a pas fait l'histoire du Mozambique, seulement la leur. C'est très important. »

\section{Mercredi 9 novembre 1994}

6h. Départ de Mambone. Attente d'une boleia pour aller au moins à Pande (route nationale $\mathrm{n}^{\circ} 1$ ) ou Inhambane pour essayer d'attraper l'avion de l'Onumoz à $15 \mathrm{~h}$.

7h20. En face, les enfants chantent l'hymne national, dont les thèmes sont tous à la gloire du Frelimo et de sa vision de l'histoire. Les gens disent que la pluie n'est pas loin. Hier, on a été envahi de bestioles qui sautent. Le vent est du nord, chargé d'humidité. Il serait temps, tout le monde est inquiet.

8h20. Pas de voiture. Même celle du curandeiro Manejo, qui vient tous les matins à $8 \mathrm{~h}$, ne vient pas.

Je raconte à quelques membres du STAE la bizarrerie de la Machanga, où l'Unamo n'apparaît pas. Réaction :

"Normalmente, o boletim que vem da Nação, vem depois na Nação de Inhambane, é verificado antes de chegar aqui.", "Normalement, le bulletin qui vient de la nation va ensuite à la nation d'Inhambane, il est vérifié avant de venir ici.

La «Nation », c'est bien la manière dont est ressenti le gouvernement du Sud. Cette expression est très utilisée. Un envoyé du gouvernement est désigné comme " aquele que vem da Nação », « celui qui vient de la nation ».

Il est vrai que le Frelimo, non seulement a proclamé la nation, mais l'a imposée. Il est la Nation.

9h15. [Je profitai de l'attente pour faire encore une petite entrevue]. Zacarias Chambueja. Né à Mambone, vice-président de la CNE locale, il est celui-là même qui est contesté par Faria et Madeira. Il dit qu'il est membre de la Renamo depuis un an. Il est professeur à Pande. Il se porte candidat à Pande, pour la $\mathrm{CNE}$, et est contacté par des membres de la délégation de la Renamo d'Inhambane. Il est refusé deux fois par les services d'éducation, mais on lui dit que s'il trouve un remplaçant, c'est $\mathrm{OK}$. La troisième fois, il est donc accepté - son nom était déjà apparu au bulletin officiel. Aussi prend-il sa charge et est nommé ensuite vice-président au titre de la Renamo.

Mais la délégation de Mambone, finalement non consultée, n'est pas contente. Il n'a rien à voir avec la porte enfoncée. Ce sont des membres du bureau, mécontents de ne pas être payés, de ne pas avoir l'augmentation du troisième jour ${ }^{619}$.

De même il n'a rien à voir avec les capulanas qui ont disparu, et ont déjà été rendues.

Petite lutte intestine. Je lui conseille d'aller parler directement avec Faria et Madeira.

"Madeira quer estar aqui à força, foi várias vezes à província, mas lá foi sempre rejeitado. Somos aqui quatro membros da Renamo », "Madeira veut être ici à toute force, il a déjà été plusieurs fois à la province, mais a été toujours rejeté. Nous sommes ici quatre membres de la Renamo.»

Madeira est un vieux militant, qui a ressenti amèrement la nomination d'un membre de la Renamo d'une ancienneté d'un an seulement.

${ }^{619}$ Suite à l'affaire du boycott des élections par la Renamo, lors du retour de celle-ci, il avait été décidé que le scrutin serait allongé d'une troisième journée. Et elle devait être payée, comme tous les actes des jours précédents. L'image de la démocratie donnée par l'aide de la communauté internationale n'est-elle pas que l'on paye grassement? Tous mes interlocuteurs étaient très étonnés d'apprendre qu'en France, les scrutateurs et délégués de liste étaient des militants bénévoles... 
10h30. Aucune voiture. Chaleur écrasante. Un groupe de femmes passent, cigarette ao contrário $^{620}$.

11h30. Sortie de l'école. Comme toujours, il y a deux écoles en une, une du matin et une de l'après-midi. Tout le monde se plaint du niveau qui a incroyablement baissé. Les personnes plus âgées précisent bien qu'elles ont " a $4^{a}$ classe colonial, o que não era a mesma coisa do que hoje », « le CM2 colonial, ce qui n'était pas la même chose qu'aujourd'hui ».

12h. Somnolence. La chaleur m'assomme. Il ne se passe plus rien.

14h30. Je démarre dans une vieille Usuzi, immatriculée en Afrique du Sud, au réservoir d'essence percé. Dans la benne à côté de moi, quelques grossos («bourrés », ivres) de surra. Devant, une mère avec son bébé. On perd encore du temps à chercher les affaires de je ne sais qui je ne sais où. La voiture s'arrête en plein soleil. Le conducteur aussi est saoul.

"O White passa à frente! O White atrás? Fodes! O White é dono desta terra que descobriu esta merda! O White à frente! », « Le White passe devant! Le White dans la benne? Putain! Le White est maître de cette terre, il a découvert cette merde ! Le White devant ! »

Le White a envie de fuir. Mais c'est la seule voiture.

15h20. On passe au croisement de la Mission. Je prétexte que c'est maintenant trop tard pour moi et que je vais dormir là. Si aucun autre camion non ivrogne ne passe, ça sera peutêtre vrai! L'alcoolisme, ici comme ailleurs au Mozambique, est un problème majeur. La surra est à un prix accessible. La faim épouse l'alcool.

Assis à l'ombre d'un grand robinier. Fraicheur du vent. Devant, un paysan ouvre la terre à la houe, en plein soleil. Il place ses plants de palmeraie. On attend la pluie.

16h. Arrive une Land Rover normale où je peux monter, derrière. Mais cela n'a rien à voir avec la Toyota Onumoz de l'aller.

18h15. J'arrive à Inhassoro couvert de poussière et de sueur. Le boulot, quoi !

20h. Le soir, un militant Frelimo d'Inhassoro :

«Em Moçambique, só há três etnias que andam a chatear os outros, a quererem mandar : os Machanganas, os Vandau e os Macondes », "Au Mozambique, il y a seulement trois ethnies qui n'arrêtent pas d'embêter les autres, à vouloir commander : les Machanganas ${ }^{621}$, les Vandau et les Macondes »

Une femme brésilienne Onumoz m'informe que, dans le district d'Inhassoro, la Renamo n'a absolument pas fait campagne. Elle n'y a d'ailleurs encore même pas de vrai siège.

${ }^{620}$ «À l'envers » : au Mozambique, nombre de femmes fument la cigarette la partie enflammée dans la bouche.

${ }^{621}$ C'est-à-dire les Changanes, ne pas confondre avec le terme parfois employé de Machangas pour désigner les gens d'ethnie ndau de la Machanga. 
Résultats détaillés des élections dans le district du Govuro

\begin{tabular}{|c|c|c|c|c|c|c|c|c|c|c|c|c|c|c|c|c|c|}
\hline Catégories/Bureaux $n^{\circ}$ & 5585 & 5586 & 5587 & 7176 & 5955 & 5956 & 5951 & 5952 & 5579 & 5580 & 5732 & 5733 & 5734 & 5582 & 5959 & 5776 & 5729 \\
\hline \multicolumn{18}{|c|}{ Élections présidentielles } \\
\hline Total votants & 944 & 946 & 903 & 311 & 755 & 939 & 962 & 413 & 948 & 363 & 917 & 932 & 530 & 220 & 910 & 869 & 740 \\
\hline Abstentions & 67 & 75 & 106 & 50 & 53 & 70 & 58 & 43 & 61 & 33 & 63 & 71 & 86 & 16 & 41 & 96 & 81 \\
\hline Votes nuls & 55 & 27 & 45 & 22 & 28 & 32 & 41 & 7 & 67 & 9 & 78 & 58 & 22 & 22 & 41 & 23 & 47 \\
\hline Votes blancs & 80 & 63 & 109 & 31 & 50 & 60 & 97 & 49 & 61 & 21 & 34 & 32 & 80 & 16 & 46 & 51 & 26 \\
\hline Votes exprimés & 809 & 856 & 748 & 258 & 677 & 847 & 824 & 357 & 818 & 333 & 739 & 743 & 428 & 182 & 822 & 795 & 667 \\
\hline Maximo Dias & 7 & 14 & 5 & 2 & 7 & 12 & 15 & 4 & 14 & 4 & 15 & 12 & 12 & 2 & 4 & 22 & 15 \\
\hline Carlos Jeque & 1 & 2 & 2 & 2 & 1 & 6 & 7 & 1 & 7 & 1 & 2 & 0 & 4 & 0 & 1 & 9 & 1 \\
\hline Casimiro Nhamitambo & 6 & 5 & 3 & 0 & 6 & 7 & 4 & 0 & 12 & 1 & 2 & 1 & 0 & 0 & 0 & 10 & 0 \\
\hline Mário Machele & 1 & 3 & 0 & 0 & 0 & 7 & 6 & 0 & 7 & 0 & 1 & 1 & 4 & 1 & 4 & 5 & 2 \\
\hline Carlos Reis & 22 & 17 & 9 & 4 & 25 & 31 & 26 & 10 & 50 & 6 & 12 & 15 & 10 & 2 & 7 & 15 & 2 \\
\hline Afonso Dhlakama & 587 & 529 & 556 & 172 & 477 & 601 & 590 & 269 & 313 & 116 & 13 & 19 & 25 & 16 & 22 & 84 & 18 \\
\hline Jacob Sibindy & 17 & 12 & 11 & 1 & 7 & 22 & 17 & 5 & 7 & 2 & 8 & 4 & 3 & 0 & 2 & 4 & 0 \\
\hline Padimbe Kamati & 7 & 6 & 4 & 2 & 4 & 10 & 11 & 5 & 4 & 1 & 1 & 7 & 2 & 0 & 0 & 6 & 0 \\
\hline Domingos Arouca & 5 & 8 & 5 & 2 & 6 & 11 & 10 & 2 & 11 & 4 & 5 & 4 & 0 & 3 & 0 & 12 & 2 \\
\hline Vasco Momboya Alfazama & 41 & 30 & 9 & 3 & 30 & 34 & 29 & 3 & 37 & 8 & 6 & 3 & 3 & 8 & 4 & 89 & 4 \\
\hline Wehia Ripua & 34 & 23 & 18 & 1 & 38 & 36 & 40 & 16 & 51 & 21 & 13 & 26 & 8 & 10 & 10 & 64 & 13 \\
\hline Joaquim A. Chissano & 81 & 207 & 126 & 69 & 76 & 70 & 69 & 42 & 305 & 170 & 666 & 743 & 357 & 140 & 768 & 475 & 610 \\
\hline \multicolumn{18}{|c|}{ Élections législatives } \\
\hline Total votants & 944 & 946 & 903 & 311 & 755 & 939 & 956 & 413 & 946 & 363 & 917 & 937 & 529 & 220 & 910 & 869 & 742 \\
\hline Abstentions & 67 & 75 & 106 & 50 & 53 & 70 & 58 & 43 & 63 & 33 & 63 & 66 & 86 & 16 & 41 & 96 & 79 \\
\hline Votes nuls & 81 & 53 & 93 & 31 & 25 & 43 & 73 & 18 & 98 & 15 & 136 & 120 & 67 & 24 & 103 & 37 & 82 \\
\hline Votes blancs & 81 & 80 & 107 & 43 & 69 & 74 & 112 & 61 & 79 & 38 & 57 & 51 & 83 & 24 & 68 & 80 & 50 \\
\hline Votes exprimés & 782 & 813 & 700 & 237 & 661 & 822 & 771 & 334 & 768 & 310 & 659 & 764 & 379 & 172 & 740 & 752 & 610 \\
\hline AP & 3 & 4 & 7 & 0 & 2 & 10 & 5 & 1 & 6 & 4 & 10 & 19 & 9 & 4 & 19 & 11 & 9 \\
\hline Unamo & 2 & 5 & 0 & 1 & 1 & 3 & 6 & 0 & 3 & 0 & 8 & 4 & 3 & 1 & 3 & 2 & 4 \\
\hline PT & 3 & 7 & 2 & 0 & 3 & 4 & 4 & 1 & 6 & 0 & 7 & 5 & 5 & 1 & 3 & 2 & 2 \\
\hline Fumo/PCD & 2 & 7 & 2 & 0 & 9 & 4 & 6 & 1 & 10 & 3 & 11 & 10 & 10 & 1 & 23 & 5 & 12 \\
\hline Frelimo & 61 & 166 & 103 & 58 & 61 & 45 & 42 & 39 & 226 & 116 & 421 & 488 & 264 & 95 & 551 & 390 & 445 \\
\hline Sol & 10 & 10 & 8 & 1 & 12 & 9 & 14 & 7 & 10 & 7 & 15 & 26 & 5 & 10 & 13 & 10 & 3 \\
\hline Pimo & 13 & 12 & 5 & 2 & 10 & 19 & 21 & 4 & 7 & 3 & 5 & 8 & 1 & 1 & 5 & 10 & 1 \\
\hline Renamo & 620 & 544 & 542 & 164 & 517 & 654 & 601 & 271 & 393 & 123 & 24 & 28 & 26 & 26 & 28 & 195 & 25 \\
\hline PRD & 17 & 9 & 10 & 0 & 4 & 19 & 16 & 4 & 10 & 5 & 11 & 5 & 1 & 2 & 2 & 7 & 0 \\
\hline Pacode & 10 & 10 & 4 & 3 & 11 & 12 & 10 & 1 & 17 & 15 & 35 & 45 & 8 & 5 & 7 & 24 & 12 \\
\hline Pademo & 6 & 8 & 2 & 0 & 8 & 9 & 10 & 1 & 13 & 1 & 5 & 10 & 6 & 2 & 3 & 10 & 1 \\
\hline РPPM & 19 & 10 & 9 & 3 & 12 & 13 & 18 & 0 & 16 & 7 & 15 & 18 & 10 & 4 & 7 & 21 & 8 \\
\hline PCN & 7 & 5 & 1 & 3 & 6 & 7 & 7 & 2 & 13 & 6 & 15 & 23 & 8 & 7 & 7 & 15 & 20 \\
\hline UD & 9 & 16 & 5 & 2 & 5 & 14 & 13 & 2 & 38 & 20 & 77 & 75 & 23 & 13 & 69 & 50 & 68 \\
\hline Groupes ethniques* & $\mathrm{N}$ & $\mathrm{N}$ & $\mathrm{N}$ & $\mathrm{N}$ & $\mathrm{N}$ & $\mathrm{N}$ & $\mathrm{Nt}$ & $\mathrm{Nt}$ & NT & NT & $\mathrm{T}$ & $\mathrm{T}$ & $\mathrm{T}$ & $\mathrm{T}$ & $\mathrm{T}$ & $\mathrm{T}$ & $\mathrm{T}$ \\
\hline
\end{tabular}


* $\mathrm{N}=$ forte majorité vaNdau, $\mathrm{T}=$ forte majorité vaTsua, $\mathrm{Nt}=$ majorité vaNdau/minorité vaTsua, $\mathrm{NT}=$ équilibre vaNdau/vaTsua. 
Résultats détaillés des élections présidentielles dans le district de la Machanga (non officiels, selon la Renamo)

\begin{tabular}{|c|c|c|c|c|c|c|c|c|c|c|c|c|c|c|c|c|c|c|c|c|c|c|c|c|c|}
\hline Catégories/Bureaux $n^{\circ}$ & 5522 & 5523 & 7075 & 3639 & 5524 & 3640 & 5525 & 5526 & 5527 & 5528 & 3641 & 5529 & 5541 & 5540 & 5542 & 5532 & 5531 & 5533 & 5537 & 5538 & 5539 & 5536 & 3684 & 5534 & 3645 \\
\hline Recensés & 1000 & 1000 & 1000 & 1000 & 1000 & 539 & 1000 & 747 & 418 & 397 & 275 & 402 & 1000 & 1000 & 146 & 890 & 936 & 511 & 1000 & 1000 & 91 & 1000 & 435 & 1000 & 103 \\
\hline Abstentions & 95 & 66 & 47 & $87 ?$ & 70 & 88 & 82 & 95 & 33 & 5 & 9 & 169 & 89 & $89 ?$ & 6 & 89 & 76 & 4 & 74 & 100 & 19 & 52 & 17 & 165 & 14 \\
\hline Total votants & 918 & 934 & 953 & 912 & 930 & 451 & 918 & 651 & 402 & 392 & 280 & 263 & 924 & 717 & 140 & 801 & 803 & 507 & 926 & 916 & 72 & 953 & 418 & 835 & 89? \\
\hline Votes blancs & 80 & 73 & 95 & 112 & 101 & 49 & 176 & 82 & 78 & 24 & 14 & 51 & 125 & $125 ?$ & 16 & 103 & 76 & 52 & 94 & 140 & 6 & 71 & 39 & & 13 \\
\hline Votes nuls & 108 & 32 & 36 & 102 & 82 & 11 & 67 & 26 & 53 & 27 & 11 & 12 & 82 & $82 ?$ & 9 & 16 & & 14 & 77 & 93 & 6 & 44 & 23 & & 15 \\
\hline Votes exprimés & 730 & 837 & 822 & 685 & 747 & 389 & 675 & 546 & 270 & 339 & 255 & 212 & 698 & 832 & 115 & 682 & 727 & 441 & 776 & 681 & 60 & 844 & 356 & & 73 \\
\hline Maximo Dias & 9 & 19 & 14 & 14 & 24 & 4 & 18 & 13 & 17 & 9 & 11 & 8 & 9 & 15 & 0 & 32 & 15 & 7 & 18 & 4 & 0 & 13 & 7 & & 3 \\
\hline Carlos Jeque & 1 & 2 & 5 & 2 & 4 & 7 & 1 & 0 & 1 & 2 & 0 & 0 & 0 & 2 & 0 & 7 & 5 & 1 & 3 & 1 & 0 & 9 & 0 & & 1 \\
\hline Casimiro Nhamitambo & 0 & 3 & 2 & 2 & 0 & 0 & 3 & 5 & 2 & 1 & 1 & 2 & 0 & 1 & 1 & 6 & 3 & 1 & 0 & 2 & 1 & 0 & 0 & & 0 \\
\hline Mário Machele & 4 & 2 & 3 & 0 & 2 & 1 & 1 & 0 & 2 & 0 & 0 & 3 & 1 & 0 & 0 & 5 & 5 & 2 & 2 & 1 & 0 & 2 & 1 & & 0 \\
\hline Carlos Reis & 4 & 10 & 7 & 9 & 8 & 1 & 17 & 8 & 8 & 11 & 7 & 13 & 14 & 18 & 1 & 37 & 29 & 8 & 10 & 11 & 1 & 26 & 10 & & 0 \\
\hline Afonso Dhlakama & 599 & 712 & 722 & 594 & 655 & 305 & 565 & 429 & 74 & 203 & 125 & 139 & 618 & 740 & 99 & 465 & 533 & 328 & 650 & 578 & 48 & 711 & 309 & 637 & 57 \\
\hline Jacob Sibindy & 19 & 22 & 23 & 6 & 6 & 10 & 15 & 18 & 5 & 3 & 1 & 9 & 10 & 6 & 2 & 23 & 22 & 7 & 9 & 9 & 0 & 39 & 11 & & 2 \\
\hline Padimbe Kamati & 0 & 2 & 0 & 1 & 2 & 1 & 5 & 3 & 0 & 2 & 2 & 2 & 2 & 2 & 0 & 7 & 11 & 2 & 1 & 2 & 0 & 9 & 2 & & 1 \\
\hline Domingos Arouca & 4 & 1 & 0 & 0 & 1 & 2 & 3 & 4 & 3 & 3 & 3 & 6 & 1 & 1 & 0 & 6 & 9 & 2 & 0 & 1 & 0 & 3 & 2 & & 0 \\
\hline Vasco Momboya Alfazama & 0 & 4 & 1 & 2 & 0 & 1 & 4 & 1 & 5 & 8 & 8 & 11 & 3 & 2 & 0 & 12 & 4 & 1 & 1 & 1 & 0 & 2 & 1 & & 0 \\
\hline Wehia Ripua & 7 & 15 & 7 & 16 & 15 & 7 & 23 & 21 & 30 & 20 & 9 & 7 & 14 & 8 & 1 & 27 & 71 & 10 & 3 & 9 & 0 & 9 & 4 & & 3 \\
\hline Joaquim A. Chissano & 83 & 45 & 38 & 66 & 30 & 50 & 20 & 44 & 123 & 77 & 88 & 12 & 35 & 37 & 11 & 55 & 20 & 72 & 79 & 62 & 10 & 21 & 9 & 18 & 6 \\
\hline
\end{tabular}


Résultats détaillés des élections législatives dans le district de la Machanga (non officiels, selon la Renamo)

\begin{tabular}{|c|c|c|c|c|c|c|c|c|c|c|c|c|c|c|c|c|c|c|c|c|c|c|c|c|c|}
\hline Abstentions & 95 & 64 & 47 & $87 ?$ & 68 & 80 & 82 & 90 & 33 & 5 & 9 & 169 & 89 & $?$ & 4 & 86 & 76 & 26 & 74 & 84 & 19 & 52 & 24 & 165 & 14 \\
\hline Total votants & 919 & 936 & 953 & 1088 & 932 & 449 & 918 & 657 & 402 & 392 & $?$ & 263 & 924 & $?$ & 142 & 804 & 860 & 485 & 801 & 916 & 72 & 953 & 411 & 835 & 89 \\
\hline Votes blancs & 80 & 83 & 115 & 122 & 109 & 21 & 206 & 108 & 120 & 34 & 9 & 62 & 137 & ? & 21 & 135 & 182 & 40 & 106 & 144 & 7 & 80 & 29 & & 14 \\
\hline Votes nuls & 137 & 53 & 51 & 135 & 122 & 69 & 63 & 50 & 57 & 46 & 10 & 9 & 97 & $?$ & 8 & 31 & & 15 & 103 & 126 & 5 & 52 & 30 & & \\
\hline Votes exprimés & 702 & 793 & 922 & 831 & 701 & 359 & 648 & 499 & 225 & 313 & 289 & 205 & 690 & 799 & 113 & 638 & 678 & 430 & 727 & 645 & 58 & 820 & 352 & & 75 \\
\hline AP & 8 & 5 & 4 & 7 & 7 & 3 & 5 & 7 & 19 & 4 & 8 & 2 & 9 & 15 & 2 & 14 & 5 & 6 & 2 & 2 & 0 & 6 & 2 & & 0 \\
\hline Unamo & \multicolumn{25}{|c|}{ Le sigle Unamo n'est pas apparu sur les bulletins de vote distribués à la Machanga ! } \\
\hline PT & 2 & 4 & 1 & 9 & 2 & 1 & 2 & 2 & 2 & 0 & 2 & 4 & 0 & 0 & 0 & 6 & 3 & 1 & 1 & 0 & 0 & 1 & 0 & & 0 \\
\hline Fumo/PCD & 1 & 1 & 2 & 0 & 0 & 0 & 1 & 0 & 1 & 4 & 5 & 1 & 2 & 1 & 0 & 7 & 4 & 1 & 0 & 2 & 0 & 1 & 0 & & 0 \\
\hline Frelimo & 56 & 35 & 24 & 60 & 13 & 40 & 6 & 20 & 71 & 59 & 56 & 9 & 21 & 26 & 10 & 47 & 58 & 59 & 68 & 55 & 9 & 5 & 5 & 11 & 2 \\
\hline Sol & 2 & 0 & 1 & 5 & 1 & 1 & 4 & 2 & 5 & 3 & 1 & 4 & 2 & 2 & 0 & 6 & 4 & 1 & 1 & 1 & 0 & 2 & 0 & & 0 \\
\hline Pimo & 6 & 0 & 15 & 5 & 4 & 3 & 8 & 9 & 2 & 5 & 56 & 8 & 4 & 2 & 0 & 20 & 15 & 9 & 0 & 1 & 1 & 13 & 4 & & 2 \\
\hline Renamo & 552 & 707 & 680 & 550 & 621 & 280 & 576 & 429 & 89 & 215 & 138 & 153 & 629 & 731 & 99 & 495 & 536 & 327 & 641 & 573 & 47 & 760 & 324 & 734 & 67 \\
\hline PRD & 17 & 11 & 19 & 14 & 5 & 7 & 9 & 9 & 2 & 4 & 1 & 11 & 5 & 9 & 0 & 16 & 10 & 3 & 4 & 4 & 0 & 15 & 10 & & 1 \\
\hline Pacode & 3 & 2 & 2 & 2 & 4 & 0 & 8 & 2 & 3 & 1 & 2 & 4 & 5 & 2 & 0 & 6 & 8 & 7 & 3 & 0 & 0 & 6 & 1 & & 0 \\
\hline Pademo & 1 & 0 & 3 & 0 & 0 & 0 & 1 & 1 & 3 & 1 & 0 & 1 & 0 & 2 & 1 & 2 & 12 & 2 & 1 & 1 & 0 & 3 & 1 & & 0 \\
\hline PPPM & 1 & 0 & 3 & 1 & 4 & 3 & 5 & 0 & 2 & 0 & 2 & 2 & 0 & 5 & 0 & 3 & 7 & 2 & 2 & 1 & 0 & 3 & 1 & & 2 \\
\hline PCN & 46 & 21 & 26 & 22 & 30 & 18 & 13 & 8 & 7 & 4 & 5 & 4 & 6 & 0 & 1 & 4 & 4 & 8 & 0 & 1 & 1 & 1 & 0 & & 1 \\
\hline UD & 7 & 7 & 7 & 1 & 10 & 3 & 10 & 10 & 19 & 13 & 13 & 2 & 7 & 4 & 0 & 12 & 12 & 4 & 4 & 6 & 0 & 4 & 4 & & 0 \\
\hline
\end{tabular}

[Note ultérieure: les valeurs en italiques ne figuraient pas sur les relevés de la Renamo et ont été recalculées ensuite. Si les voix des candidats semblent à peu près comptées, les absentions, nuls et blancs sont parfois manifestement erronés (leur total avec celui des candidats dépassant le nombre de votants).] 


\section{Chapitre 13}

\section{Retour à la nation}

\section{Jeudi 10 novembre, à Inhassoro}

10h30. Par chance, Paul, dont le contrat se termine - l'Onumoz commence à plier bagage - va à Inhambane. Il y a un avion vers $16 \mathrm{~h}$.

À partir de Vilanculos, la brousse est beaucoup plus verte. Il a plu ici. À Maxixe, c'est presque une Normandie! Mambone en comparaison est un désert de plantes séchées.

14h30. Onumoz Headquarters d'Inhambane. Évidemment, le calendrier des lignes régulières a été changé. Le dernier avion, c'était hier et le prochain, c'est samedi.

On essaye de me trouver un hélicoptère. Attente, car l'Air Force Commander fait la sieste.

15h30. À l'aéroport. Il est possible qu'il y ait demain un avion à 8 heures, pas confirmé. On essaye d'envoyer un fax à Maputo via la section de communication de l'UruBat, le bataillon uruguayen, stationné aux environs d'Inhambane. Mon chauffeur est un Madjermane qui a essayé de se réintégrer à Inhambane en montant un groupe musical, avec tout l'appareillage acheté. Le groupe a eu du succès, avec l'appui d'un gouverneur qui aimait la musique. Mais lorsque ce dernier a changé, le groupe a été assailli de demandes d'aides financières. Il a tout vendu, et vit de l'Onumoz. Après l'Onumoz, il espère l'Unavem ${ }^{622}$.

17h30. Hospitalité chez Philippe et Caroline, de Handicap International. On passe à la CNE d'Inhambane, qui vient de publier ses résultats officiels, et déjà contestés.

Comme ailleurs, Wehia Ripua et Carlos Reis « apanharam a boleia do Dhlakama» («ont profité du vote Dhlakama») à cause des lunettes. Et l'UD (União democrática), qui a l'incroyable score de $9,36 \%$ des votes exprimés «apanhou a boleia da Frelimo » ( «a profité du vote Frelimo ») ${ }^{623}$.

La campagne présidentielle a tellement écrasé le reste que le Frelimo en paye les effets pervers. Ses cívicos ont expliqué qu'il fallait voter pour le dernier (Chissano est en dernier sur le bulletin des présidentielles) et les gens ont aussi voté pour le dernier aux législatives, alors que le Frelimo y était en cinqième position!

Si on ajoute, par rapport au nombre de votants, les $10,71 \%$ de blancs (le «blanc politique » doit être infinitésimal), les $9,14 \%$ de nuls (dont certains seront sans doute rattrapés, ceux qui ont posé la marque sur la photo du candidat et non dans le petit carré), et par rapport aux exprimés, les 9,36\% de l'UD, soit environ $7 \%$ des votants, cela fait $26 \%$ des électeurs de la province d'Inhambane qui n'ont pas réussi à voter dans les normes législatives. C'est peut-être même un peu plus, car les décalages entre le candidat Nhamitando $(0,68 \%)$ et son parti Sol $(1,28 \%)$, et entre Domingos Arouca $(0,72 \%)$ et son parti Fumo $(1,56 \%)$, suggèrent que ces deux partis, situés respectivement juste après et juste avant le Frelimo, ont bénéficié aussi d'un petit vote par erreur. On est déjà du côté des $27 \%$.

\section{Résultats officiels des élections dans la province d'Inhambane}

$$
\text { Total des électeurs inscrits sur les registres du recensement : } 467522 \text { (100\%) }
$$

\footnotetext{
${ }^{622}$ Unavem, United Nations Verification Mission, la mission de vérification de l'Onu en Angola qui, après le fiasco des élections dans ce pays, était prolongée et devait être considérablement renforcée.

${ }^{623}$ Rappel : il s'agit de l'important vote par erreur. Wehia Ripua et Carlos Reis, candidats mineurs, avaient, comme Dhlakama, des lunettes et certains électeurs de Dhlakama se sont trompés. Par ailleurs, ils étaient, sur le bulletin de vote des présidentielles, respectivement juste avant Chissano et juste avant Dhlakama, certains électeurs maladroits n'ont pas coché au bon endroit. Enfin, en ce qui concerne 1'UD, sa position sur le bulletin de vote des législatives était la dernière, tout en bas..., soit la même position que Joaquim Chissano sur le bulletin des présidentielles. Nombre d'électeurs du Frelimo ont pensé que les positions étaient les mêmes, et ont voté aux législatives pour un groupuscule totalement inconnu.
} 


\begin{tabular}{lrrlrr}
\hline Élections présidentielles & Nombre & $\%^{*}$ & Élections législatives & Nombre & $\%^{*}$ \\
\hline Abstentions & 59422 & 12,71 & Abstentions & 59470 & 12,72 \\
\hline Bulletins dans l'urne & 408 & 100 & Bulletins dans l'urne & 408052 \\
\hline Votes exprimés valides & 350100 & 85,79 & Votes exprimés valides & 327045 & 80,15 \\
Votes blancs & 25362 & 6,21 & Votes blancs & 43703 & 10,71 \\
Votes nuls & 32638 & 8,00 & Votes nuls & 37304 & 9,14 \\
\hline Nom du candidat & \multicolumn{1}{c}{ Votes } & $\%^{*}$ & Sigle du parti ou coalition & Votes & $\%^{*}$ \\
\hline Máximo Diogo José Dias & 7290 & 1,79 & AP & 7213 & 1,77 \\
Carlos José Maria Jeque & 2375 & 0,58 & Unamo & 2542 & 0,62 \\
Casimiro Miguel Nhamitambo & 2761 & 0,68 & PT & 2308 & 0,57 \\
Mário Carlos Machele & 1703 & 0,42 & Fumo/PCD & 6385 & 1,56 \\
Carlos Alexandre dos Reis & 5069 & 1,24 & Frelimo & 195295 & 47,86 \\
Afonso M. Marceta Dhlakama & 36525 & 8,95 & SOL & 5204 & 1,28 \\
Jacob Neves Salomão Sibindy & 1786 & 0,44 & Pimo & 2547 & 0,62 \\
Padimbe Mahose Kamati Andrea & 1478 & 0,36 & Renamo & 42490 & 10,41 \\
Domingos A.M. Arouca & 2934 & 0,72 & PRD & 2491 & 0,61 \\
Vasco Campira M. Alfazema & 3211 & 0,79 & Pacode & 5339 & 1,31 \\
Wehia Monokacho Ripua & 10146 & 2,49 & Pademo & 3811 & 0,93 \\
Joaquim Alberto Chissano & 274822 & 67,34 & PPPM & 5755 & 1,41 \\
& & & PCN & 748 & 1,83 \\
& & & UD & 38183 & 9,36 \\
\hline
\end{tabular}

[*Pourcentages du total des inscrits].

Source: CNE/STAE Inhambane, Edital provincial, Eleições gerais 1994, 10 de Novembro de 1994, 1 p. multigr.

\section{Vendredi 11 novembre 1994}

7h45. Aéroport d'Inhambane. Un avion cargo est censé arriver à $8 \mathrm{~h}-$ «Há de vir »- en route pour Maputo. Vamos lá a ver...

Entre une jeune femme avec un bébé de deux mois. Mais ce n'est pas la mère. La mère, une jeune fille de 19 ans, est morte à l'accouchement, hémorragie interne due à l'incapacité de retirer le placenta. La jeune femme est la tante qui a adopté immédiatement l'enfant.

La salle d'attente est remplie d'abeilles, pas agressives. Juste le zum-zum inquiétant.

Ici comme ailleurs, les gens de la CNE, y compris les Onumoz de la Technical Unit, me stupéfient : pour eux, il est évident qu'il n'y aura pas de second tour aux présidentielles. Rien n'est prévu, ils ont déjà fait leurs bagages. Cela me semble terriblement léger. Ils font totalement confiance à leur sondage post-électoral ${ }^{624}$.

8h10. L'avion arrive. Sauf qu'il ne va pas à Maputo, mais à Vilanculos. Il repassera à $14 \mathrm{~h}$. Retour en ville avec mon madjermane.

9h. Chez Jamu, para matabichar ${ }^{625}$. C'est une petite esplanade en bordure de la baie. J'imagine cette baie, véritable bassin d'Arcachon, remplie de parcs à huitres ! Il y en a déjà quelques-unes du reste, sauvages, dans les palétuviers et les rochers.

Les deux bacs qui font la liaison avec Maxixe, en face sur l'Estrada nacional $n^{\circ} 1$, sont en panne. Ce n'est pas une mauvaise affaire pour les petits passeurs des barques à voiles arabes, qui suppléent la carence de l'État moderne.

L'échelle des valeurs n'a plus aucun sens. Matabichar un thé, un œuf, une salade, c'est environ 3000 meticais, soit $35 \mathrm{FF}$, c'est-à-dire $40 \%$ du salaire minimal (7500 mt.). Ce n'est plus la lutte des classes, ce sont des mondes distincts.

${ }^{624}$ On le voit, fortement impressionné par les épisodes de la campagne électorale que j'avais vécus du côté de la Renamo, j'envisageais sérieusement la possibilité d'un second tour. Mais je n'avais que peu voyagé dans le sud, et je sous-estimais donc le vote écrasant - et ethnique - en faveur du Frelimo dans les trois provinces du Sud. Même le petit pourcentage Dhlakama-Renamo de la province d'Inhambane ne venait, en fait, pratiquement que du Govuro, et plus exactement de la Machanga.

${ }^{625}$ Matabichar, portugais mozambicain, pour tomar o pequeno almoço, « petit-déjeuner ». Ce verbe est très probablement dérivé de l'expression matar o bicho, «tuer le ver», venue, comme parfois aux Antilles françaises, de l'image de «tuer la faim » qui, telle un ver, se tortille au fond de l'estomac le matin. 
Jamu se fait construire une chata. La coque prend forme, en joli bois rouge. Deux scieurs de long préparent les poutres, ils scient pendant une minute, et s'arrêtent dix, pour bavarder et rire à l'ombre des résineux plantés en bordure de mer du temps des Portugais, pendant que le thé bouillonne sur trois pierres.

Dans tout le Sud, le Frelimo domine, de façon écrasante à Gaza et de façon très nette à Inhambane. La Renamo n'y est pas cette «coalition des marginalités » qu'elle a réussi à construire ailleurs, elle reste un petit appareil de marginaux. Néanmoins, il y a eu une évolution. Par exemple, l'employée de Philippe et Caroline a certes voté Frelimo et Chissano, mais à un moment de la campagne, elle a pris conscience de quelque chose de parfaitement étonnant:

- «Mas então, tenho o direito de votar na Renamo ? », «Mais alors, j'ai le droit de voter pour la Renamo ? », a-t-elle constaté devant ses patrons. La prochaine fois, peut-être ?

$12 \mathrm{~h}$. J'attends depuis plus d'une heure à l'aéroport. Toujours rien. Si j'avais su, j'aurais pris le machimbombo ${ }^{626}$ qui passe à Maxixe, vers dix heures, en direction de Maputo.

12h15. On apprend que l'avion ne sera pas là avant 14h30. Retour en ville.

14h30. L'Antonov est là. Chargements de l'Onumoz qui commence à démonter. On attend deux Civpol qui doivent arriver d'Inhassorro.

15h10. L'ordre vient de ne plus attendre. Até que enfim! [Finalement!] Mais les pilotes russes n'ont pas fini leur thé. Je suis le seul passager au milieu des caisses.

15h15. Départ.

16h25. Arrivée à Maputo.

Fin du carnet $n^{\circ} 4$

[À mon arrivée chez Luis et Adélaïde de Brito, mes amis de Maputo, j'appris avec étonnement qu'ils avaient été très inquiets de ne pas avoir de mes nouvelles. Ils avaient même déposé une demande de recherche auprès de la Civpol, qui leur avait répondu que la zone de la Machanga était «très dangereuse ». Je n'y avais rencontré aucun Civpol, mais ainsi naissent les rumeurs...]

\section{Lundi 14 novembre 1994}

17h45. Onumoz. Conférence de presse de Aldo Ajello et des ambassadeurs de la CSCE. Ajello commente le document de Domingo, du 13 novembre ${ }^{627}$. Il dénonce une certaine stratégie de tension, que l'Onumoz refuse totalement, alors que l'évolution a été bonne. Production de rumeurs et documents faux : celui de la Vox Populi, puis celui qui dénonçait le Premier ministre donnant des ordres pour placer des bombes chez Dhlakama, puis celui du Domingo.

«Ce dernier document produit des informations tellement confuses qu'elles ne peuvent provenir de milieux militaires, et contredit toutes les informations en notre possession. Ce document est faux. »

Mais il estime que quelque chose est plus important: le document insinue que des ambassadeurs seraient compromis dans ces manœuvres de déstabilisation : c'est inacceptable et intolérable. Quand un directeur de journal reçoit ce type de document, il devrait vérifier très prudemment. C'est une diffamation contre les ambassadeurs, et une provocation pour instaurer la panique dans le pays. "Nous sommes en présence d'un comportement non professionnel et non éthique » dit Ajello. «Prix Nobel de la stupidité », selon l'ambassadeur

${ }^{626}$ Machimbombo (parfois Maxibombo), portugais mozambicain pour camioneta, autocar. Ce mot vient peut-être des Maxi-Bombers, les premiers bus britanniques en service à Lourenço Marques au début du siècle.

${ }^{627}$ Un «document » publié par l'hebdomadaire pro-gouvernemental Domingo « révélait » que la Renamo préparait sa remilitarisation et commençait à remobiliser. $C f$. infra. 
américain Denis Jett: «Je ne sais pas qui est responsable». Puis l'ambassadeur anglais donne lecture d'une lettre au directeur du Domingo, et remercie Pascoal Mocumbi pour sa déclaration disculpant la communauté internationale.

Selon moi, la fonction de ce document est évidente : faire croire à la Renamo que le Frelimo est en train de créer les conditions psychologiques d'un nettoyage complet, et donc pousser la Renamo à la faute. Qui ?

Prennent ensuite la parole les ambassadeurs du Portugal et d'Allemagne.

Paul Fauvet, de l'Agence d'information du Mozambique, demande à Ajello ce qu'il pense alors des «vraies caches d'armes » découvertes dans le pays. Ajello répond qu'ils sont allés voir dans tous les endroits dénoncés et qu'ils n'ont rien trouvé - sauf dans le cas du camion bourré d'explosifs dans lequel sont entrés 21 policiers qui ont sauté avec le tout. Mais on ne sait pas à qui étaient ces explosifs, car ce n'est pas l'Onu qui est allée voir ${ }^{628}$.

\section{Mardi 15 novembre 1994}

12h30. Déjeuner à la Feira Popular - frango à zambeziana [poulet à la zambézienne] avec l'équipe de Savana: Fernando Lima, Lourenço Jossias et Kok Nam, le célèbre photographe de l'école Cartier-Bresson.

18h30. Au complexe sud-africain de la Costa do Sol, réception en l'honneur du départ d'Éric Lubin. Je devise gentiment avec Aldo Ajello et Armando Guebuza, avec Rahil Khan et Mascarenhas (Renamo) et, surtout, j'obtiens un rendez-vous avec Bob Chalton, le légendaire, l'homme des sabotages, le responsable des opérations de la Renamo à l'intérieur du Zimbabwe ${ }^{629}$.

\section{Mercredi 16 novembre 1994}

11h. Visite de l'émetteur-récepteur de la Renamo. Un sympathisant (blanc) de la Renamo, responsable de la VORE ( Voz da Renamo) me dit tout le dépit qu'il ressent à voir l'incapacité, la corruption et le racisme anti-blanc de certains cadres de la Renamo.

$\mathrm{Si}$ les capulanas ne sont pas arrivées à temps, c'est aussi parce que de très hauts responsables voulaient toucher une commission sur la commande et, ne l'ayant pas obtenue, ont saboté les contrats...

14h. Déjeuner chez Jorge Correia. La discussion fait rage, dans des cercles très restreints de la Renamo, pour savoir s'il faut ou non demander des ministères. Demander des gouverneurs, tout le monde est d'accord : en demander cinq (les cinq provinces majoritaires) pour en obtenir trois. Mais des ministères ? La politique du ventre y pousse. Raúl Domingos voudrait être ministre. L'intérêt du Frelimo va évidemment dans le même sens. L'intérêt de la Renamo serait de profiter de ce délai supplémentaire pour créer une solide opposition.

${ }^{628}$ J'avais mis du temps à comprendre qui était l'auteur du vrai-faux document de Savana. Cette fois-là un cynique averti en vaut deux - j'émis rapidement une hypothèse. Ce document, transmis à un journal progouvernemental et dénonçant la remilitarisation de la Renamo, aurait été produit par un secteur d'un service secret favorable à la Renamo. Réponse du berger à la bergère : celui de Savana, accusant le Frelimo de préparer des fraudes électorales, voulait pousser la Renamo à la faute et à se retirer du jeu électoral - ce qui, on s'en souvient, faillit réussir. Mais Dhlakama, acceptant finalement la tenue des élections, continuait à dire qu'elles n'avaient pas été démocratiques. Alors comment en accepter maintenant les résultats ? Un document accusant la Renamo de remilitariser, provoquant un regain de tension, lui permettait de faire une déclaration solennelle et, sur l'autel de la paix, d'en accepter le résultat - c'est exactement ce qui se produisit - et de signifier aux « autres » que l'on avait bien compris la manipulation précédente. Je doute fort, en revanche, que la Renamo ait été capable de produire elle-même ce type de document, même s'il semble bien qu'il fut transmis à Domingo par un de ses responsables. Certains services secrets ont ainsi dû dialoguer entre eux de la sorte. Je pense notamment aux services de renseignement militaire d'un pays occidental...

${ }^{629}$ Pour punir Robert Mugabe de soutenir puissamment le gouvernement mozambicain, la Renamo décida d'y mener quelques opérations militaires. Bob Chalton en fut le responsable. 
Dhlakama a aimé mon article de $\operatorname{Savana}^{630}$. Quand il a appris que j'étais marxiste, il a alors dit : - «Marxista? Mas aquele é um marxista bom...», « Marxiste ? Mais celui-là est un marxiste bon ».

\section{Jeudi 17 novembre 1994}

11h. Brève visite au Conselho Cristão de Moçambique, je suis reçu par le secrétaire général, Lucas Amosse Tivane, lui-même congrégationnaliste et très intéressé par l'histoire religieuse du Manica e Sofala.

\section{2h30. Déjeûner avec Dominique Buff, du Comité international de la Croix rouge ${ }^{631}$.}

15h. Entrevue avec Hermínio Morais, alias Bob Chalton.

[Il était étonnant de se retrouver face à «Bob Chalton », cet homme timide et réservé, qu'une circonstance de la vie fit basculer vers seize ans de guérilla, ainsi devenu cette redoutable machine de guerre mais qu'une chose intéressait plus que tout, le football - d'où son pseudonyme ! Cependant, dans cette trop brève entrevue, H. Morais ne me dit pas tout, loin de là, et en particulier rien sur ses propres difficultés au sein de la Renamo, les punitions et la surveillance sévères qui lui furent infligées, dont je savais le détail par d'autres sources mais dont je ne soufflais mot - entrevues non directives obligent !]

Le Frelimo ne découvrit jamais, durant le conflit, la véritable identité de ce guerrier. Il est né à Maputo, Mafalala - «o bairro dos melhores atletas de Moçambique » (le quartier des meilleurs athlètes du Mozambique) -, le 15 septembre 1960. Son père était

« caissier ambulant, un Blanc venu [au Mozambique] à 14 ans. La mère était employée d'une entreprise. Catholique, née ici mais d'ascendence macua de l'Ile de Moçambique. J'ai fait ma première communion, et l'École de l'État ${ }^{632}$. J'ai parlé seulement portugais pendant mon enfance. J'ai appris les langues [africaines] plus tard. J'ai étudié jusqu'à la $2^{\mathrm{e}}$ année du cycle industriel. Allors, j’ai été désigné pour aller à Cuba, mon nom est sorti avec ceux de trois de mes collègues. Nous avons été concentrés au camping. Avec mes

${ }^{630}$ Dès mon retour de la campagne électorale, j'avais envoyé à l'hebdomadaire indépendant Savana un article analysant à chaud ce que j'avais vu. Le journal le publia quelques jours après : «Renamo, o grande partido conservador-populista» («Renamo, le grand parti conservateur-populiste») in Savana, Maputo, 4 novembre 1994 : 7. J'y défendais l'idée qu'à l'inverse de l'Unita angolaise, ce groupe guerrier avait réussi une étonnante transformation en parti civil. Mais il souffrait encore d'une psychologie militaire contradictoire aux aspirations démocratiques de son électorat. Cet article provoqua une véhémente réaction de Paul Fauvet, de l'Agence d'information du Mozambique et membre du parti communiste britannique, m'accusant de flagornerie envers la Renamo, reconnue comme vrai mouvement politique : «Um marxista francês na hostes da Renamo » («Un marxiste français aux bons soins de la Renamo »), Savana, 11 novembre 1994 : 7 . Du coup, la Renamo était mise au courant de mes opinions politiques marxistes ! Je répondis, bien sûr : «A verdadeira vitória da Renamo. Resposta ao camarada Paul Fauvet » («La véritable victoire de la Renamo. Réponse au camarade Paul Fauvet »), Savana, Maputo, 18 novembre 1994 : 7. Au-delà de la polémique, je traçai un bref historique des phénomènes de marginalisation sociale au Mozambique, qui furent le fondement du soutien à la Renamo et soulignais la victoire de légitimation que constituait un score approchant les $40 \%$ pour les anciens «bandits armés ». P. Fauvet répondit encore, in Savana, 2 décembre 1994 : 9 : «Fontes (primárias e secondárias), e o respeito pela História ». J'eus encore l'occasion de préciser tout cela dans une entrevue conduite par Fernando Manuel le 15 novembre et publiée après mon départ : «Um olhar problematizador sobre Moçambique », Savana, Maputo, 2 décembre 1994 : 16-17 (la nouvelle géopolitique interne ; le mythe de l'Império de Gaza; le phénomène du vote par erreur ; parti unique et transition socialiste ; les conditions du développement ; pays sans nation et État légitime ; les chances de stabilisation de la Renamo civile ; le problème des cadres ; la nécessaire réorientation des études historiques au Mozambique ; le recentrage du Mozambique sur son centre de gravité traditionnelle, la Zambézia).

${ }^{631}$ Pendant des années, le CICR fut la seule organisation non gouvernementale à tenter d'aider aussi bien les zones sous contrôle gouvernemental que rebelle. Les autres ONG ne se posèrent pas trop de questions sur le fait, qu'agissant uniquement en zone étatique, elles aidaient seulement l'un des deux camps en guerre.

${ }^{632}$ Avant 1962, les métis reconnus par leur père blanc, et donc considéré « civilisés », pouvaient suivre l'école publique (de l'État) alors que les indigènes devaient obligatoirement suivre l'école missionnaire. Après les réformes de 1961-62, cette séparation légale n'eut plus cours, mais les écoles de l'État restèrent principalement urbaines, et donc bien plus blanches et métisses ou indiennes que celles, missionnaires, de brousse. 
trois collègues, j'ai fui, fin 1977. J'écoutais déjà Rádio África Livre. Nous pensions que les jeunes ne partaient pas pour étudier, mais, tous, pour travailler dans les plantations de canne à sucre. Nous avons pris le machimbombo [autocar] jusqu'à Beira et nous avons suivi les indications de la Rádio Africa Livre, nous sommes allés à Maxipanda, près de la frontière.

Nous avons rencontré un premier groupe de huit personnes. Nous n'avions pas d'idée politique. Nous pensions que la Renamo était capable de nous donner des bourses d'études ${ }^{633}$. Nous avons compris [ensuite] que la Renamo ne pouvait pas nous donner des bourses et que nous devions être militaires, toujours avec l'espoir de recommencer un jour nos études ${ }^{634}$. Maintenant, j'aimerais faire des études de droit et de relations internationales, étant donné que j'ai accompagné le processus électoral. Je vais être député, puisque je suis deuxième de liste à Maputo.

Jamais je n'aurais imaginé que la chose irait si loin. Les histoires de la guérilla du Frelimo restant dix années en brousse me paraissaient impossibles. Finalement, j'y suis resté seize ans !

J'ai fait mon entrainement militaire au Mozambique, parce que mon groupe restait en opération au Mozambique. Sept mois plus tard, j'ai participé à mon premier combat, une embuscade sur une route, une voiture militaire. Nous fumes poursuivis, [subissant] divers accrochages. À l'époque, les soldats du Frelimo ne fuyaient pas et nous méprisaient ${ }^{635}$.

Le chef du petit groupe de huit personnes était Dhlakama lui-même, encore seulement "Chefe Dhlakama». Mais j'ai eu l'opportunité de voir André Matsangaissa ${ }^{636}$. Notre groupe, de Dhlakama, avait plus de possibilités de recrutement, nous opérions au Sofala, près de Beira, alors qu'André Matsangaïssa opérait au Manica ${ }^{637}$.

Petit à petit, nous nous sommes divisés en groupes plus nombreux, et j'ai été commandant du groupe «Leopardo », et nous changions de nom quand l'ennemi le savait.

Quand le président Matsangaissa est mort, j'opérais sur le corridor de Beira, dans la zone de Motocoma, près de Chimoio. Juste après la mort de Matsangaïssa, le Frelimo a créé ses groupes «Limpa », mélange de Snasp et d'armée ${ }^{638}$. Mais très vite nous avons reçu l'information que Dhlakama était le nouveau Commandant. Je suis resté diriger un petit groupe, les petits groupes étaient divisés afin de mener la contre-offensive. Chaque groupe avait une mission de deux mois. À cette époque, nous n'avions pas de radio, seulement des estafettes. L'actuel général Vareia était aussi l'un des chefs [de petits groupes]. Il y avait les Rhodésiens dans leurs camps pour lutter contre les Zimbabués ${ }^{639}$, mais nous essayions de ne pas entrer en contact avec eux.

J'avais un bon contact avec les hommes, j'étais toujours bien obéi. Je n'ai pas, en tant que métis, eu de problème, il y avait beaucoup de métis. J'ai retrouvé y compris mon propre cousin, qui était à Sacusi ${ }^{640}$ parce qu'il avait fui le service militaire obligatoire. Les gens à Sacusi étaient surtout originaires de Maputo.

${ }^{633}$ L'ironie de l'histoire est que nombre de jeunes étudiants avaient voulu, au cours des années soixante, rejoindre le Frelimo exactement pour la même raison, et non pour devenir guérilleros.

${ }^{634}$ «...Et que nous devions être militaires...» : on le constate, H. Morais reste très discret sur la manière dont on «expliqua » aux fugitifs qu'ils « devaient» être militaires. Il est évident qu'ayant fui le Frelimo et se trouvant très probablement au Malawi ou en Rhodésie, ils n'avaient plus aucun choix.

${ }^{635}$ Les premières années de la guerre civile furent assumées, côté Frelimo, par une armée qui était encore partiellement celle de la lutte armée de libération, avec des guérilleros (ou au moins un encadrement d'anciens guérilleros) endurcis. La situation devait, progressivement, changer radicalement.

${ }^{636}$ Rappel : A. Matsangaissa, fut le premier commandant militaire de la Renamo, tué au combat en 1979.

${ }^{637} \mathrm{La}$ région de Sofala est majoritairement ndau, d'une population historiquement rétive à la domination du Sud. La population du Manica, bien que relevant également du grand groupe chona, est plus hétérogène ethniquement et dans ses trajectoires historiques.

${ }^{638}$ «Grupo Limpa», groupe de nettoyage. H. Morais fait probablement référence aux groupes spéciaux, relevant de la police politique (Snasp) bien qu'ayant des tâches militaires, de la structure secrète LCB, Luta Contra-Bandidos ( «utte Anti-Bandits»). D'une certaine manière, le Frelimo reprenait ainsi l'exemple des Flechas («Flèches »), les groupes spéciaux de contre-guérilla de la Pide portugaise.

${ }^{639}$ «Zimbabaués», à savoir les combattants zimbabwéens en lutte contre le régime de Ian Smith. La Rhodésie, outre ses raids d'aviation meurtriers et les opérations spéciales de ses Selous Scouts, maintenait également au Mozambique des «groupes pseudo». Les «groupes pseudo » étaient des groupes de contreguérilla, d'apparence guerillera, chargés de traquer la guérilla zimbabwéenne en Rhodésie comme au Mozambique même, et parfois composés d'anciens guérilleros nationalistes retournés. La simultanéité d'existence de la Renamo et de ces « groupes pseudo » a très souvent, propagande du Frelimo à l'appui, permis la confusion de la première avec les seconds.

${ }^{640}$ Rappel : l'un des camps de rééducation. 
Mais la majorité des hommes [de la Renamo] étaient, eux, de Manica et de Sofala. À partir de 1983, la majorité fut de Nampula et de Zambézia ${ }^{641}$.

En 1981, nous avions déjà des groupes en Zambézie, dans la Maganja da Costa, commandés par Abel Sequete. Calisto Meque allait en même temps à Tete. Sequete est aujourd'hui démobilisé. Quand Sequete a été à Nampula où il y avait un fort appui de la population et où on avait besoin d'un bon général, Calisto est parti pour la Zambézia et Issufo Momade et Antóni Pedro sont allés à Nampula, dans des zones différentes. Quand ceux-ci se sont rendus à Gorongosa ${ }^{642}$ et qu'on a monté les états-majors régionaux, Calisto est devenu commandant régional.

En 1983, je suis revenu à Gorongosa, en opération autour de Vila Paiva, j'ai opéré aussi à Inhaminga, où nous avons commencé à intervenir en bataillon (850 hommes), le premier fut le bataillon «Limpa». Nous étions trois compagnies dans ce bataillon, sous le commandement d'António Watch, les deux autres étaient moi-même et Avelino Samuel. Nous avons été à Marromeu, Mopeia, affrontant déjà les Zimbabweens et leurs hélicoptères.

La décision d'intervenir à l'intérieur du Zimbabwe a été prise en 1987. À partir de $1985^{643}$, les Zimbabweens opéraient en Zambézie. Alors nous avons décidé de mener des actions au Zimbabwe même.

Il y avait beaucoup de réfugiés mozambicains qui avaient fui les opérations des Zimbabweens, et qui nous donnaient des informations ${ }^{644}$. On ne différenciait pas bien qui étaient les Mozambicains et les Zimbabweens dans cette zone ${ }^{645}$.

Nous attaquions de petites escadres, des casernes, des patrouilles sur la frontière. Mais nous avons été poursuivis par huit hélicoptères dans une zone découverte, sans arbres. Nous avons donc dû retraverser la frontière. Au total, nous avons fait pénétrer au Zimbabwe 270 hommes. Nous avons eu quelques pertes. C'était en septembre 1987 et nous avions commencé en juillet.

Nous sommes retournés au Zimbabwe quinze jours plus tard, nous divisant en trois régions : Mucumbura, Merry Mountains, et la zone de la frontière Coachman (la route pour le Malawi). J'étais déjà général. Ça a été meilleur. Même type d'attaques. Nous avons mieux tenu le coup. Nous n'attaquions jamais les bourgades pour ne pas perdre l'appui de la population. Nous n'attaquions pas la population, à l'inverse des Zimbabweens au Mozambique, qui brûlaient tout. Nous sommes restés jusqu'au début de 1989 , jusqu'au cessez-le-feu partiel ${ }^{646}$.

Je suis resté un an et demi à l'intérieur du Zimbabwe. Nous n'y avons jamais eu de contacts avec l'opposition. Le groupe Sithole ${ }^{647}$ ? Il semble qu'il intervenait plus au sud.

J'opérais surtout comme saboteur. J'ai commencé tout seul à me perfectionner en sabotages. Le commandant Chigomba était aussi saboteur.

${ }^{641}$ En 1983, la Renamo fusionne avec le Partido revolucionário de Moçambique, qui opérait en Zambézie, et traverse ainsi le fleuve Zambèze. Le PRM était un petit groupe militaire dirigé par Gimo Phiri, issu de l'Unar (União nacional da Rombezia) de l'époque coloniale, elle-même issue d'une scission de l'Unami (União nacional de Moçambique independante de Baltazar da Costa Chaconga), sous influence de Jorge Jardim et du Malawi, pour revendiquer l'indépendance du seul Nord du Mozambique. Il s'agissait en réalité d'une manœuvre pour séparer le «Mozambique utile », au centre et au sud, du Nord affecté par la guérilla du Frelimo, mais elle s'appuyait aussi sur des sensibilités régionales et ethniques totalement ignorées dans le discours politique nationaliste et jacobin des indépendantistes. Ces sensibilités continuèrent du reste à exister, ce qui permit aux services secrets du Frelimo de provoquer une scission au sein de la Renamo, sans affecter pour autant son implantation d'ores et déjà assurée dans le nord sous la direction du général Calisto Meque. Cette scission, entraînant une partie de l'ancien PRM, apparut sous le nom d'Unamo (União nacional de Moçambique) et fut elle-même l'objet d'une scission. Sa branche militaire, toujours dirigée par Gimo Phiri, un temps connue sous le nom de Udemo (União democrática de Moçambique) se rallia au Frelimo, tandis que sa branche politique, dirigée par Carlos Reis, restait plus utile au Frelimo en maintenant son activité comme «parti d'opposition », pour gêner l'implantation politique de la Renamo en Zambézie. C'est cette branche qui s'est présentée aux élections en 1994 sur un programme fédéraliste.

${ }^{642}$ Quartier général de la Renamo, à la Casa Banana, avant Maringué.

${ }^{643}$ Prise de la Casa Banana par les troupes du gouvernement et du Zimbabwe.

${ }^{644}$ Il s'agit des Mozambicains qui avaient fui au Zimbabwe pour échapper aux bombardements aériens zimbabwéens au Mozambique.

${ }^{645}$ De part et d'autre de la frontière, il s'agit de la même ethnie ndau. Par ailleurs, l'armée zimbabwéenne pourchassait une fantômatique guérilla dans cette région (voir note 26), ce qui provoquait des violences arbitraires contre la population, et fournissait donc un minimum d'appui à la Renamo.

${ }^{646}$ En 1989, la Renamo accepte un cessez-le-feu sur le corridor de Beira, en échange d'un arrêt des opérations militaires zimbabwéennes.

${ }^{647}$ Il s'agit de la ZANU-Ndanga, de N. Sithole, petit groupe sorti des années auparavant de la ZANU de R. Mugabe et notoirement ndau. 
Ensuite, je suis revenu au Gorongosa, agissant dans les alentours de Vila Paiva. Je n'ai jamais été envoyé dans le Sud.

Quand nous occupions une zone, nous cherchions à recruter des jeunes. Ceux qui ne voulaient pas fuyaient. Nous expliquions [ce qu'était] le communisme, la situation du pays, et la volonté de la Renamo de changer ça. La première question des jeunes recrutés étaient: - "Quando é que a guerra acaba, quando tempo vamos ficar no mato?", «Quand est-ce que la guerre va finir, combien de temps allons-nous rester en brousse ?». Nous avions l'espoir d'une guerre courte. D'année en année, nous alimentions cette espérance.

Il y a eu des désertions, notamment quand les Zimbabweens attaquaient fortement et quand le Frelimo a fait la loi d'aministie. C'est dans le Sud qu'il y a eu le plus de désertions. Mais dans le Centre et le Nord, nous n'avons pas eu ce type de problème. La propagande de l'ennemi était la plus forte dans le Sud.

Les femmes restaient dans les bases centrales.

Je suis resté toujours avec la même femme, depuis le temps de Maputo. J'avais déjà un fils. Je l'ai informée de ma fuite. Nous sommes restés sept ans séparés, jusqu'en 1983. Elle a été jusqu'à Beira (elle recevait mes messages), et ensuite à Gorongosa.

Le Président lui-même se réunissait avec nous pour les explications politiques. Seulement lui. »

\section{Vendredi 18 novembre 1994}

11h. Retour au Conselho cristão de Moçambique. Le pasteur Tivane me donne des textes introuvables sur l'histoire de l'Igreja do Cristo em Manica e Sofala. Nous décidons de rester en contact.

13h. Déjeûner avec Miguéis Lopes Júnior, l'éditeur de Imparcial Fax. ${ }^{648}$. Selon lui la Renamo va demander cinq ministères, dont ceux de l'Agriculture, de la Santé, de l'Intérieur (la police ! le même coup que pour Buthelezi ${ }^{649}$ ?).

16h. J'arrive au palais des Congrès pour la cérémonie de proclamation officielle des résultats. Les délais légaux n'ont pas été respectés puisque le délai maximal de quinze jours après le scrutin s'achevait dimanche dernier.

Je rencontre Armindo Xavane, mon compagnon de campagne Renamo et journaliste TV. Il est encore fou furieux de cette histoire d' «évacuation des Changanes ». Car, bien involontairement, c'est de lui qu'est venu le scandale ! Il a professionnellement transmis la fameuse phrase, et ensuite la TVM a fait mousser en manipulant l'information... Il s'en est expliqué lors de l'émission «Linha Directa », et aussi dans MediaFax..

Bon, la cérémonie est repoussée à 19 heures...

19h. Ambassadeurs et journalistes emplissent le hall. Ya-Koob Sibindy, genre Hollywood, trône en grand boubou bleu turquoise et, bien sûr [coiffé d'un] turban que même un taliban n'oserait porter ${ }^{650}$.

Sauf que la cérémonie est remise à 23 heures.

Luis Pedro de l'Expresso, m'amène chez Jean-Claude et Maryse Legrand, chez qui je dîne.

${ }^{648}$ Imparcial Fax, comme son nom ne l'indique pas, est une publication favorable à la Renamo. Miguéis Lopes Júnior (frère de Mota Lopes, un chercheur «historique » du Centro de estudos africanos de 1'Université Mondlane, émigré ensuite à la State University of New-York at Binghamton grâce à l'appui d'Immanuel Wallerstein) était lui-même plutôt de la faction radicale, très marxiste-léniniste, du Frelimo, qui dénonçait les atermoiements des moins radicaux. Ce type de position fut assez courant parmi les Mozambicains blancs proFrelimo. Il changea ensuite radicalement d'opinion et créa l'Imparcial à l'image de MediaFax de Carlos Cardoso, politiquement indépendant mais « sociologiquement » plus proche du monde du Frelimo.

${ }^{649}$ Buthelezi, on le sait, dirige l'Inkhata Freedom Party, parti ouvertement tribaliste zoulou, qui mena une quasi-guérilla urbaine contre les bases zouloues de l'ANC pendant le processus de transition. Suite à la formation du gouvernement d'unité nationale, Nelson Mandelson prit le risque habile de le nommer ministre de l'Intérieur. Depuis, les relations semblent s'être améliorées entre l'Inkhata et l'ANC, à tel point que certains parmi les plus radicaux anti-ANC ont scissionné. Sauf que Miguéis Lopes Junior se trompait : le Frelimo n'avait aucunement l'intention de répondre favorablement à une demande de la Renamo en ce sens, à supposer que celle-ci fût effectivement faite.

${ }^{650}$ Rappel : il s’agit du dirigeant du seul parti se réclamant ouvertement de l'islam. 
23h. Le palais des Congrès est fermé. La cérémonie est remise à demain 10 heures. Toujours le fameux problème du recomptage des bulletins nuls. Tensions de dernière minute, énervement, épuisement.

Rafael da Conceição ${ }^{651}$ n'est pas venu, hier, manger chez José Alves ${ }^{652}$, alors qu'il avait confirmé. Signe que des réunions interminables se succèdent à la CNE.

\section{Samedi 19 novembre 1994}

10h. La cérémonie est convoquée pour 10 heures. Bien sûr, elle est en retard. Aucune sécurité visible.

11h45. Calane da Silva lit un poème évoquant les Droits de l'Homme, de Tiago de Melo, poète brésilien.

11h50. Le directeur du STAE ouvre la cérémonie et donne la parole à Brazão Mazula, président de la CNE.

11h55. Mazula lit le rapport. Il souligne l'apparition d'une «culture électorale » dans le pays. Le processus a été « transparent» et les élections ont rendu manifeste un degré élevé de civisme des citoyens. Certaines «alegadas irregularidades » (allégations d'irrégularités) ont été étudiées, mais en général elles se sont avérées sans fondement. D’un point de vue légal elles n'étaient pas recevables. Cependant, la CNE y a réfléchi et ainsi les réclamations ont eu un rôle pédagogique. La CNE a conclu qu'elles ne mettaient pas en doute les résultats des élections «tranquilles, transparentes et justes ». Et libres ? Il n'a pas prononcé le «free and fair » habituel de l'Onu, «libres et loyales »! Chaque mot de ce rapport a dû être soupesé ! "Todos saímos vencedores », « Nous en sortons tous vainqueurs ».

13h. Déjeûner chez l'ambassadeur de l'OUA.

15h20. Conférence de presse de Dhlakama.

« À partir de maintenant, le peuple sera représenté au parlement, garantie qu'il n’y aura plus jamais de dictature au Mozambique. C'est pourquoi il y a de la joie. Cependant, il y a eu des moments difficiles, de par l'existence d'irrégularités, la discrimination contre la Renamo. Ces élections n'ont pas été justes. Cependant nous savons qu'elles furent les seules possibles. Le processus a été nouveau pour nous tous. La démocratie devra se construire jour après jour. La Renamo accepte les résultats comme base de l'exercice de la démocratie. »

[Très politique et très habile appréciation. C'était aussi, presque mot pour mot, ce que Jorge Correia m'avait présenté, le mercredi précédent, comme l'analyse qu'il allait présenter au Président...]

«Il reste la promesse qu'au cours des prochaines élections, nous saurons éviter les irrégularités, les failles. La Renamo est renforcée par l'appui populaire, surtout dans les cinq provinces du pays dans le Centre et le Nord ${ }^{653}$. La Renamo utilisera sa grande force en tant que parti d'opposition pour critiquer, contrôler, le gouvernement. Il faut de la maturité pour faire avancer la démocratie. L'opposition devra être respectée. Au peuple du Mozambique, le grand vainqueur de ces élections, je veux témoigner ma reconnaissance pour avoir voté pour moi et pour la Renamo, pour avoir légitimé notre présence [...]. La victoire de ces élections est la nôtre et celle du peuple du Mozambique.

- «Vai a Renamo pedir ministérios...», «La Renamo va-t-elle demander des ministères...»

_ «Não posso dizer que sim ou não, mas há muito tempo que falamos de reconciliação nacional e isso signifique trabalharmos juntos », « Je ne peux dire ni oui ni non, mais il y a longtemps qu'on parle de réconciliation nationale et ceci signifie travailler ensembles »

_...e Governos de províncias ?», « ... et des gouvernements de province ?»

${ }^{651}$ Anthropologue mozambicain, docteur de l'Université de Paris 8, membre du Groupement de recherche « Afrique australe» du CNRS et de l'association Lusotopie, Rafael da Conceição siégeait à la CNE au titre des indépendants.

${ }^{652}$ Attaché culturel à la Mission française de coopération.

${ }^{653}$ La Renamo obtint la majortié des voix au Sofala, au Manica, à Tete, en Zambézia et au Nampula. 
- «Não posso dizer ainda. Falando de reconciliação nacional, seria possível misturar a Frelimo e a Renamo. A Renamo conseguiu as províncias mais ricas, as mais povoadas $[. .$.$] ., « Je ne peux rien dire. Au nom de la réconciliation nationale, on pourrait$ mélanger Frelimo et Renamo. La Renamo a gagné les provinces les plus roches et les plus peuplées $[\ldots] \gg$.

16h. Je vais dire au revoir à Dhlakama. Il me reçoit en tête à tête, une vingtaine de minutes. Il a aimé mon article dans Savana. Je discute un peu du désastre dans le Sud. Bien sûr, il ne pouvait pas gagner, mais il est, lui, certain que la fraude y a été « très forte » et me dit comme preuve qu'il y a plus d'adhérents que de voix dans certains districts. Ce n'est pas une raison - bien des gens ont les deux cartes. Il ajoute que la Renamo n'était pas présente dans tous les bureaux, que la nuit le Frelimo y restait seul, qu'on retrouve aujourd'hui un peu partout des bulletins favorables à Dhlakama qui ont été jetés...

Il me dit cependant qu'à Maputo, ils se sont « laissés tromper par la ville », en recrutant des jeunes et des «doutores » qui n'ont pas été solides et se sont laissé acheter, ou n'ont pas su construire le parti. Il me dit que, même à Sofala, si on avait envoyé en brousse les « doutores » de Beira, la Renamo aurait perdu. Mais là, ce sont les civils du temps de la lutte qui ont contrôlé la situation.

C'est là, sans doute, une vision plus réaliste [que celle de la «fraude-du-Frelimo »].

Il termine en me disant que de temps en temps, quand ils auront une difficulté, ils me téléphoneront pour demander conseils... Toujours la tendance à transformer des « observadores » en « assessores » ${ }^{654} \ldots$

16h20. Sortant, je salue David Hoile ${ }^{655}$, qui m'affirme ne pas être David Lean, l'auteur de l'article d'Imparcial Fax qui annonçait la possibilité d'une assemblée sans majorité absolue, et d'une victoire de Dhlakama au deuxième tour. Je ne suis pas absolument convaincu, mais après tout c'est sans importance ${ }^{656}$.

Raúl Domingos m'interpelle :

_ «Michel! O artigo foi bom! Paul Fauvet é um comunista!», « Michel! L'article était bon! Paul Fauvet est un communiste!».

Certes, certes... Comment lui expliquer que ce n'est pas cela qui me gêne ?

Ivete Fernandes est là, je ne l'avais pas immédiatement reconnue. Cela me fait vraiment plaisir de la voir. La dernière fois, c'était à Cascais (Portugal) en 1988. Après Carmo Jardim en 1986 -, elle avait été la deuxième personne liée à la Renamo que j'avais osé rencontrer. Ce n'était pas facile alors ! La réprobation morale était terrible ${ }^{657}$ !

Elle revient au Mozambique définitivement, non à Beira, «sa»ville, mais à Maputo, pour la scolarisation de son fils - le fils de Evo Fernandes qui n'aura connu son pèreque jusqu'à ses quatre ans.

${ }^{654}$ Mais jusqu'à ce jour, on ne m'a pas téléphoné !

${ }^{655}$ Animateur du lobby anglais pro-Renamo.

${ }^{656}$ Ce qui est sûr est que la Renamo a commis une gravissime erreur politique en réclamant une barrière à hauteur de $5 \%$ des votes pour obtenir des députés à la proportionnelle. Elle pensait sans doute obliger les petites formations à se rallier à elle, mais cela ne se produisit pas. Le résultat est que le total des voix de la Renamo et des petits partis d'opposition a été supérieur à celui du Frelimo - fait rarement signalé - mais tous, sauf 1'UD, n’ont eu aucun élu, donnant la majorité absolue des députés au Frelimo.

${ }^{657}$ Nous autres, intellectuels de gauche ou d'extrême-gauche, mais hostiles au parti unique, restâmes des années dans une position délicate sur le plan, je dirais, moral. Le soutien de l'apartheid à la Renamo avait un puissant effet de légitimation pour le Frelimo. Seuls des journalistes marqués à droite avaient alors le contact avec la Renamo. Carmo Jardim (célèbre fille de Jorge Jardim) et Ivete Fernandes, veuve de Evo Fernandes, secrétaire général de la Renamo assassiné au Portugal probablement par le Snasp, n'étaient pas (ou plus) liées directement au mouvement rebelle. Il m'avait donc été plus facile de faire ce pas, avant d'aller plus loin, à savoir, de rencontrer Daniel Frank, le représentant officiel, à Lisbonne, puis Dhlakama lui-même, à l'hôtel Lutetia à Paris quelques mois avant le cessez-le-feu. Voir dans l'introduction, le paragraphe « Faut-il fréquenter Satan?». 
Ces «créoles» de la Renamo eux aussi n'ont pas d'autre patrie que le Mozambique. Revenir à Maputo après dix-huit ans d'absence n'est pas facile. Cela prouve au moins que la motivation est forte et qu'il ne s'agissait pas de la «composante portugaise » de la Renamo ${ }^{658}$.

17h. Au SARDEC, une ONG de documentation présente au Mozambique et au Zimbabwe, on essaie désespérément d'envoyer par fax mon article au journal Le Monde. J'abandonne alors que la note est déjà de soixante dollars. Tant pis, je faxerai lundi matin de Paris - se Deus assim quiser ${ }^{659}$ !

J'ai une angyne, typique chez moi, de fin de mission. La fatigue qui s'abat brusquement, la dépression et démobilisation dues au départ, et cela suffit pour attraper le premier microbe qui passe.

\section{Dimanche 20 novembre 1994}

Ce matin, le rendez-vous avec le colonel Bute, de la Sécurité de Dhlakama, a été manqué [il m'avait dit "oui » et je le croyais car nous avions sympathisé durant la campagne. Mais dit-on «non » à un hôte étranger?] Personne n'a répondu au numéro qu'il m'avait laissé.

20h30. Voilà, départ. Je suis tremblant de fièvre dans l'air frais de l'orage. Le ciel est zébré d'éclairs. Le courant a bien sûr sauté dans Maputo plongé dans le noir.

Luis et Adelaïde vont devoir, une fois de plus, remonter leurs neuf étages à pied et dans l'obscurité.

${ }^{658}$... Argument systématique du Frelimo et de ses compagnons de route occidentaux pour désigner les quelques Blancs (ou Indiens) de la Renamo. Pourtant, parlait-on de la «composante portugaise » du Frelimo pour désigner les Blancs mozambicains soutenant le Frelimo ? Il est juste, cependant, de souligner que la Renamo désignait ainsi ces derniers !

${ }^{659}$ «Si Dieu en décide ainsi ». Tel ne fut pas le cas et l'article ne fut jamais envoyé. 


\section{Table des matières}

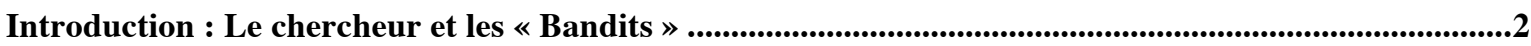

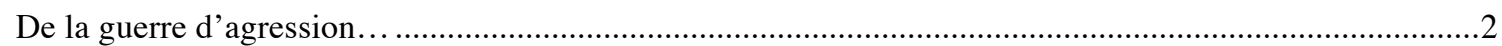

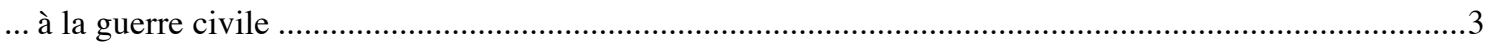

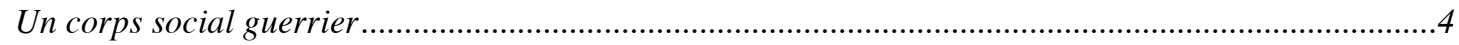

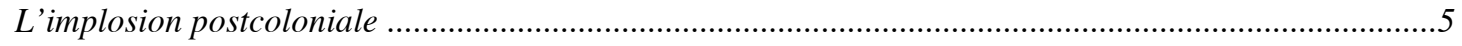

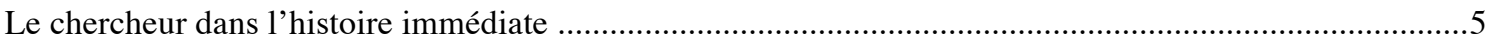

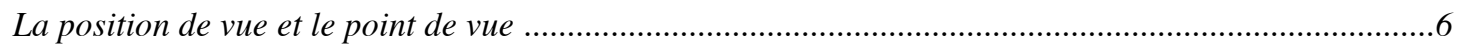

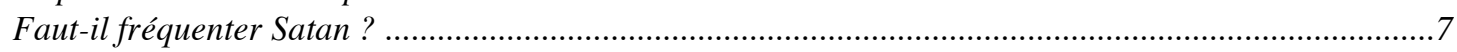

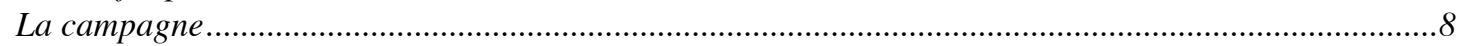

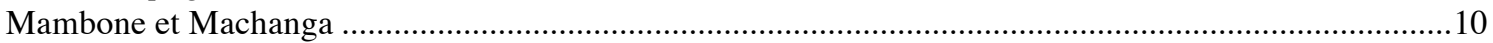

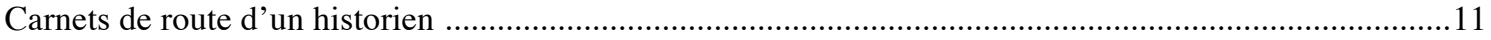

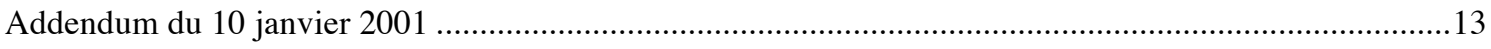

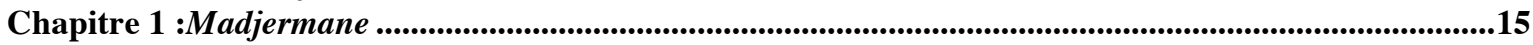

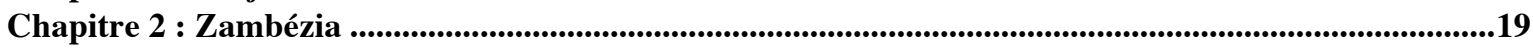

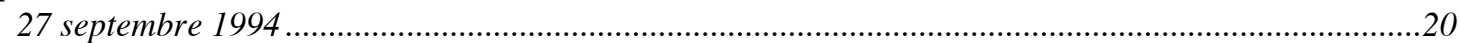

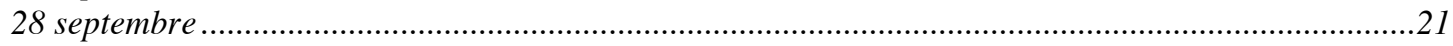

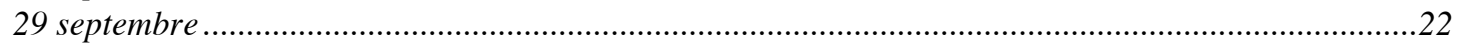

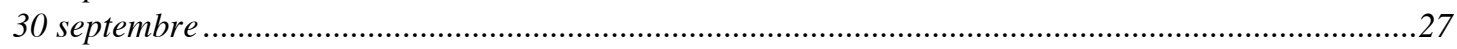

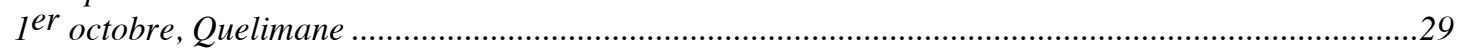

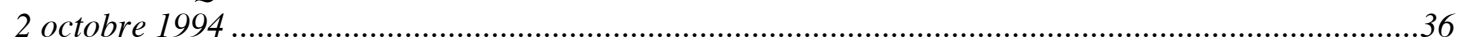

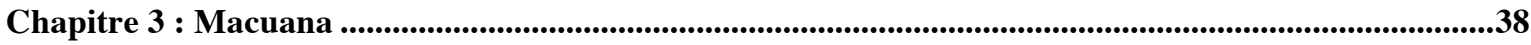

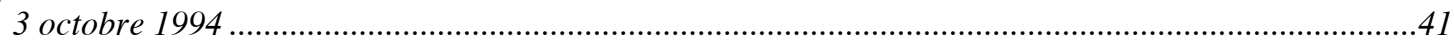

Le 4 octobre 1994, départ pour Moma, sud de la province de Nampula .............................................44

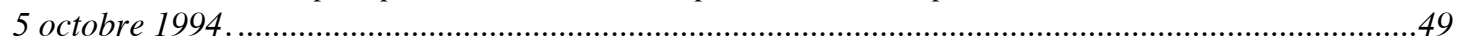

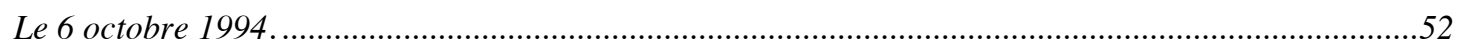

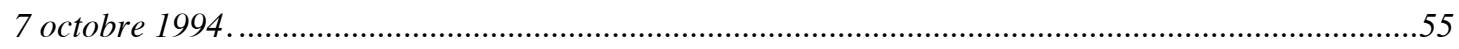

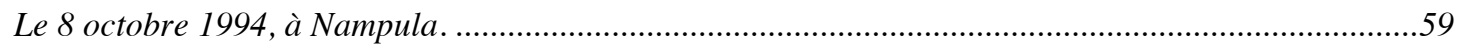

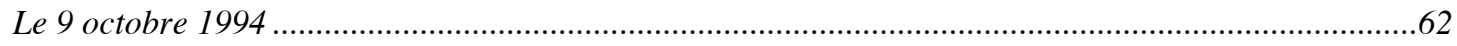

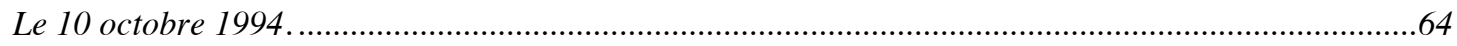

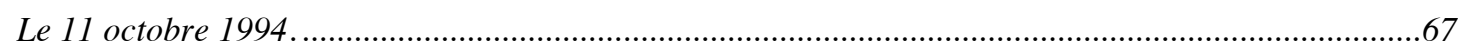

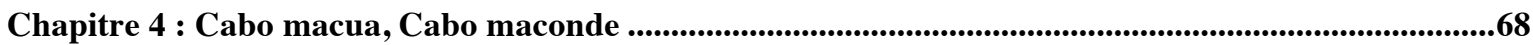

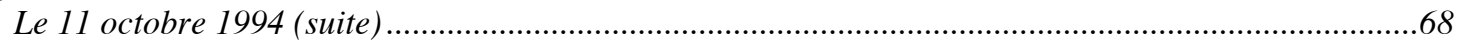

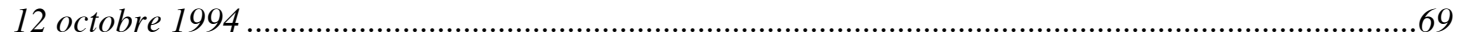

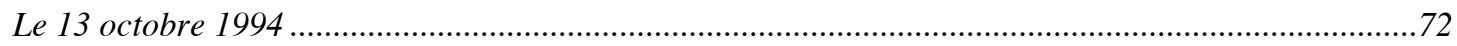

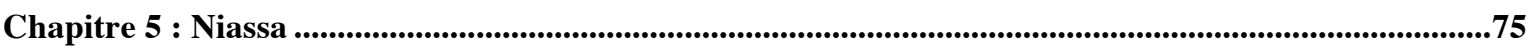

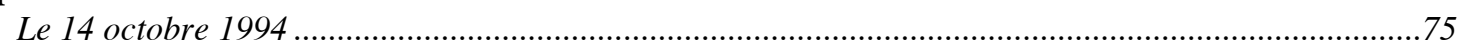

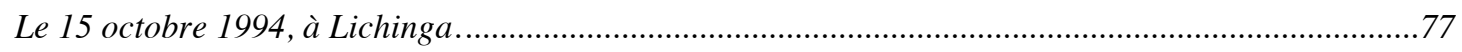

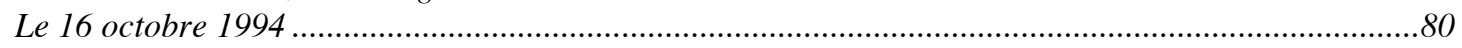

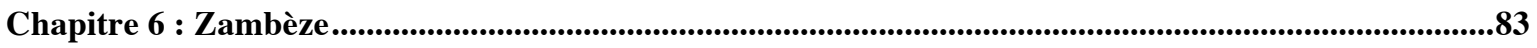

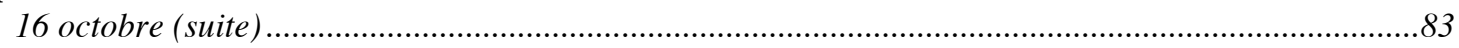

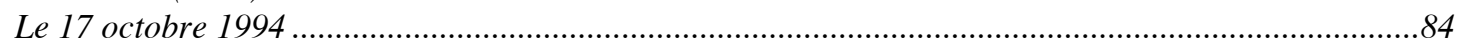

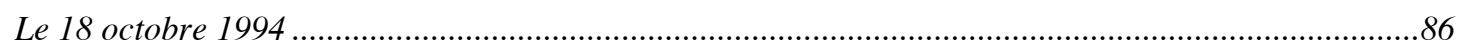

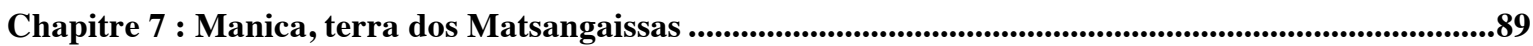

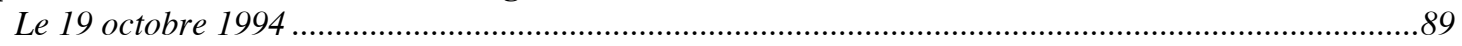

Le 20 octobre 1994. Chimoio ..............................................................................................................91

Chapitre 8 : Inhambane, terra da Boa Gente ..................................................................................................95

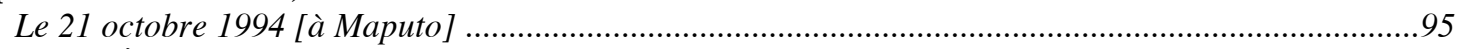

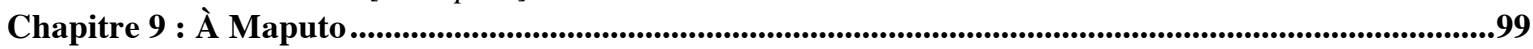

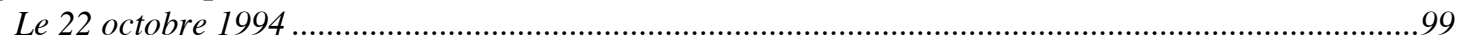

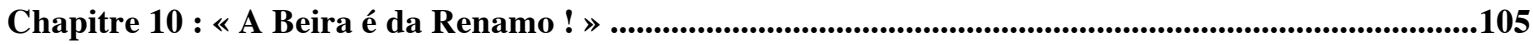

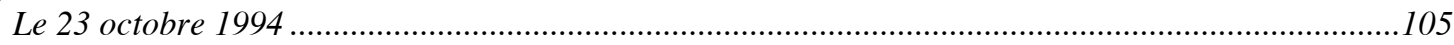

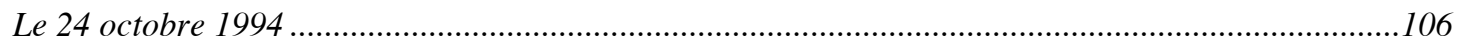

« Mozambique : une situation plus ouverte que prévue sur fond de fraude ? » ..................................111

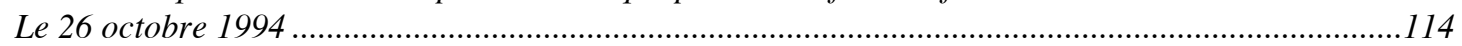


Chapitre 11 : Au bord de l'abîme .................................................................................................................116

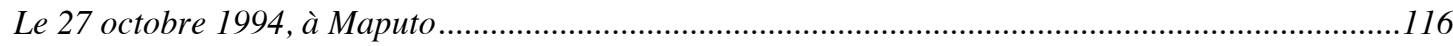

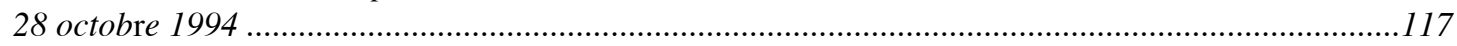

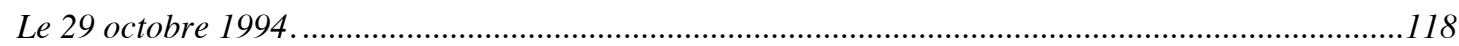

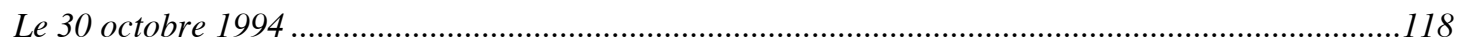

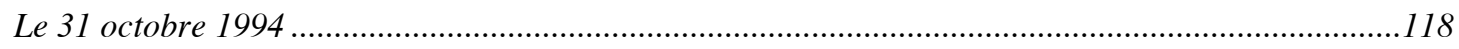

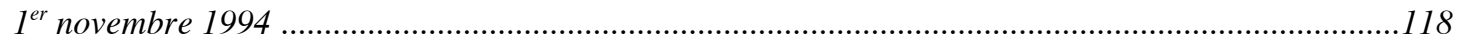

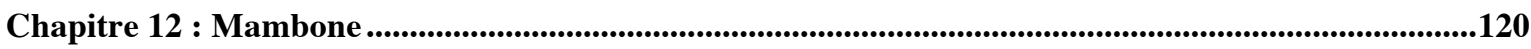

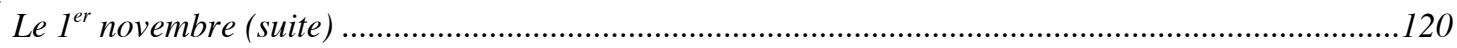

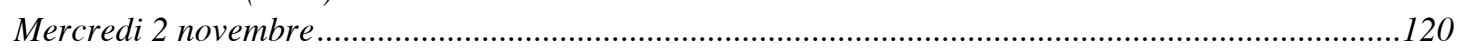

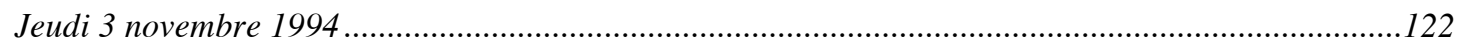

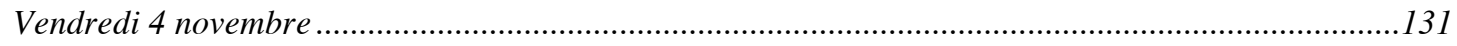

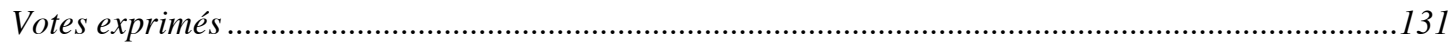

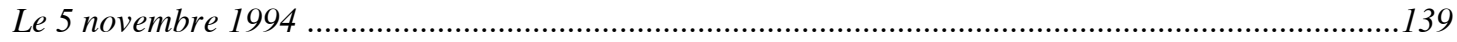

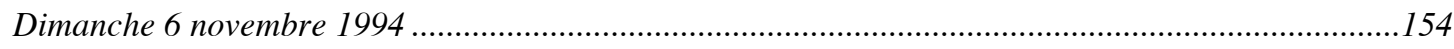

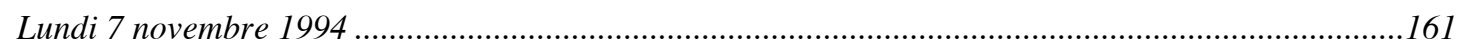

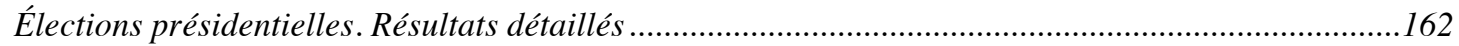

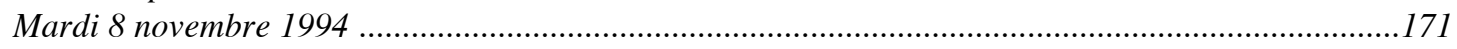

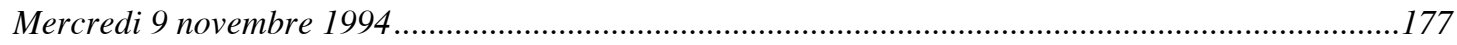

Résultats détaillés des élections dans le district du Govuro ...............................................................179

Résultats détaillés des élections présidentielles dans le district de la Machanga ...............................181

Résultats détaillés des élections législatives dans le district de la Machanga .....................................182

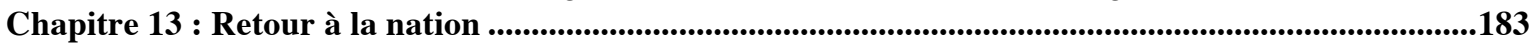

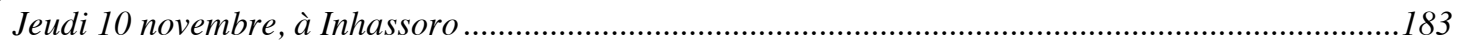

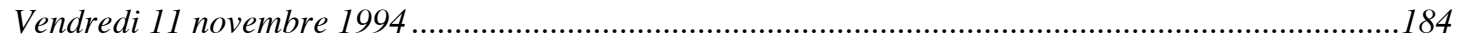

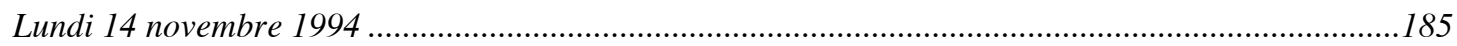

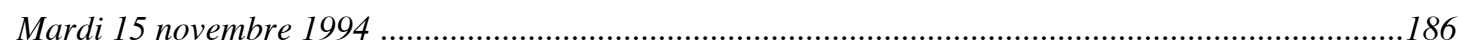

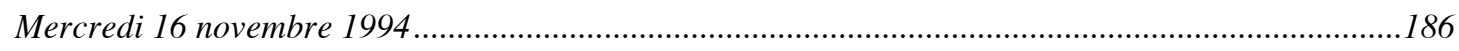

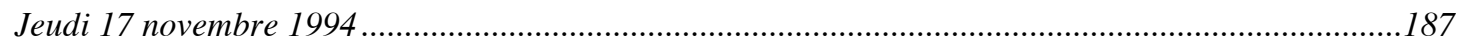

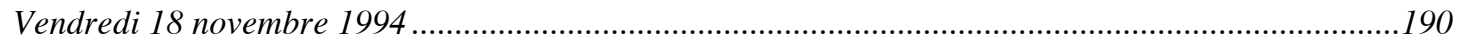

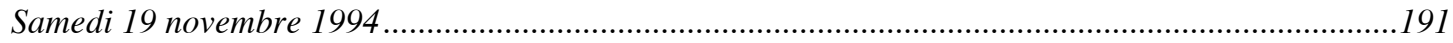

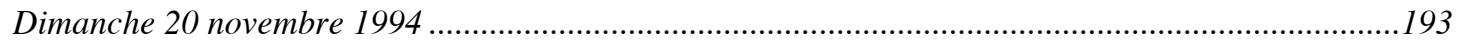




\section{$4^{\mathrm{e}}$ de couverture}

\section{Les Bandits \\ Un historien au Mozambique, 1994}

En 1994, dans le cadre du Groupement de recherche sur l'Afrique australe du CNRS, Michel Cahen partit suivre les premières élections pluripartisanes de l'histoire du Mozambique. Le pays sortait d'une terrible guerre civile qui, loin des médias, fit peut-être un million de morts sur environ quinze millions d'habitants. La rébellion de la Renamo (Résistance nationale du Mozambique) luttait contre le régime «marxiste-léniniste » du Frelimo, le Front de libération du Mozambique qui avait arraché l'indépendance aux Portugais en 1975. Et elle le combattait avec le soutien, d'abord, de la Rhodésie de Ian Smith, puis de l'Afrique du Sud alors en plein apartheid.

Classique guerre Est-Ouest par acteurs locaux interposés ? Contre-révolutionnaires au service des racistes blancs ? Sans doute, mais... Comment comprendre l'incapacité du gouvernement «populaire » à les vaincre ? Comment comprendre l'expansion des activités de guérilla à presque $80 \%$ du territoire ? Et comment se faisait-il que plus d'un tiers des Mozambicains, en cet automne 1994, s'apprêtaient à voter pour elle ?

Michel Cahen, de formation marxiste revendiquée, n'avait aucune sympathie pour la Renamo. Mais il fallait, en historien, comprendre le phénomène. C'est pourquoi il s'intégra à l'équipe de campagne d'Afonso Dhlakama, le chef rebelle candidat aux élections présidentielles, puis visita des zones de vieille implantation « réactionnaire ».

Ainsi sont nés ces carnets de route, issus de la visite de près d'une centaine de villes, bourgs, villages et localités de brousse, au cœur de l'actualité mais avec, en permanence, l'histoire du siècle colonial et de ses marginalités qui ressurgit.

Ce n'est pas un roman, mais on y découvre des histoires de vie, et les efforts du régime pour repousser des rebelles en mal d'intégration vers la marginalité...

Michel Cahen est chercheur du CNRS au Centre d'étude d'Afrique noire de l'Institut d'études politiques de Bordeaux, Il est spécialisé dans l'histoire contemporaine de l'Afrique d'ancienne colonisation portugaise et est l'auteur de nombreux travaux sur la politique coloniale, les nouveaux États et la question ethnique. Il a fondé en 1994 la revue de recherche politique Lusotopie. Enjeux contemporains dans les espaces lusophones (Paris, Karthala) et anime toujours l'association du même nom. 